\title{
Addendum for - Groundwater Flow Model of Corrective Action Units 101 and 102: Central and Western Pahute Mesa, Nevada Test Site, \\ Nye County, Nevada
}

Addendum - May 2007

Appendix D

$$
\begin{aligned}
& \text { D.3.1 } \\
& \text { D.3.2 } \\
& \text { D.3.3 }
\end{aligned}
$$

Plates

Plate 1 


\section{Preface}

An Addendum to the Groundwater Flow Model of Corrective Action Units 101 and 102: Central and Western Pahute Mesa, Nevada Test Site, Nye County, Nevada, S-N/99205--076, Revision 0 (June 2006) was prepared to address review comments of this final document by the Nevada Division of Environmental Protection (NDEP) in a letter dated July 19, 2006. The Addendum includes revised pages that address NDEP review comments and comments from other document users. Change bars are included on these pages to identify where the text was revised.

In addition to the revised pages incorporated in the Addendum, the following clarifications are made:

- On Plate 1 (inserted in the back of the document), the ET Unit legend has been revised. The revised Plate 1 is included with the Addendum and replaces the original Plate 1.

- Some of the Appendix D perturbation sensitivity analysis plots included on the CD for Sections D.3.1 and D.3.2 were not properly aligned. A revised CD is provided with all plots properly aligned. Please replace the original CD with the revised CD included with the Addendum. 
decay with no anisotropy was investigated briefly, but completely neglecting anisotropy was deemed unreasonable, and it was discarded. The application of anisotropy and depth decay to selected HSUs and to all HSUs cases was carried to final calibrations. Both models could represent the flow system reasonably well, as defined by matching the head and flow calibration targets.

The selected HSU depth-decay and anisotropy parameterization approach began by assessing the effect of permeability depth decay only, and its effects were found to be quite pronounced in terms of not requiring consistently low permeabilities as in the case described in the no-depth-decay, no-anisotropy case. Depth decay applied to regionally contiguous units existing at a wide variety of depths along with horizontal-to-vertical anisotropy of 10:1 in selected units provided reasonable results.

SCCC HFM Flow Model Calibration. This model has fewer HSUs than the base HFM, and does not have as deep or extensive of a fault system. In particular, the Calico Hills formation is reduced from four separate HSUs to one that is several hundred meters thick. The calibration of the SCCC alternative began with the calibrated parameters from the selected HSU depth decay and anisotropy base HFM for both HSUs (where still present) and faults (where still present). However, because of the lumped nature of the Calico Hills unit, its anisotropy was increased to 50:1 because many dissimilar types of units were combined. In addition, the Benham Aquifer (BA) also incorporates the Lower Paintbrush Confining Unit in the SCCC HFM. The BA was assigned anisotropy of 20:1. The units selected to have permeability depth decay and anisotropy are the same as presented for base HFM selected depth decay and anisotropy. The SCCC HFM did not calibrate as well as the SDA and ADA models using the base HFM.

Calibration Summary. Three calibrations for the base and SCCC HFMs were carried to completion: base HFM with selected HSU depth decay and anisotropy with MME recharge, base HFM with all HSU depth decay and anisotropy with MME recharge, and SCCC HFM with selected HSU depth decay and anisotropy with MME recharge. Key behaviors and observations of the model calibrations are summarized below:

1. Purse Fault Behavior. A striking difference between the base and SCCC HFMs is the area along the Purse Fault. An area of "hydraulic discontinuity" exists coincident with the Purse Fault that shows about 100-m head difference (west to east) across the fault with flow directed sub-parallel to the fault (e.g., the fault may act as an approximate no-flow barrier). In order to 
match the head in Wells PM-3, PM-2, UE-20p, UE-20j, and U-20m in the base HFM on the western side of the Purse Fault and wells in southwestern Area 20, the Purse Fault permeability had to be reduced by a factor of 10,000 relative to the surrounding HSUs in order to maintain the $100 \mathrm{~m}$ or so difference between the two areas. In contrast, the SCCC HFM does not have a Purse Fault geometry that allowed fault continuity along its length or goes as deep (the base HFM has faults projected to the bottom of the model). Thus, simulated head at PM-3 was too low and head in southwestern Area 20 too high because the fault did not separate the two areas sufficiently. The SCCC does incorporate juxtaposition across the caldera margins, so HSU juxtaposition alone seems insufficient to replicate the observed behavior. Whether or not the Purse Fault alone is the source of the observed discontinuity is unclear, but its configuration in the base HFM does allow the observed head to be reproduced, whereas HSU juxtaposition alone does not.

2. Comparison of Model and Estimated HSU Permeabilities. Estimates of mean hydraulic properties and their uncertainty were made before beginning model calibration. These estimates were used as a guideline during calibration. The model-calibrated permeabilities were compared to the estimated values for all HSUs. The comparisons suggest that the flow model has been reasonably parameterized for the three calibrated models with respect to the expected values of HSU permeability.

3. Water-Balance Summary. An additional check on the CAU water balance is the comparison of flow along the northern edge of the Yucca Mountain saturated zone model, which lies entirely within the Pahute Mesa CAU flow model. The YMP saturated zone model (DOE/ORD, 2004) gives a value of 196 kilograms per second (kg/s) inflow. The BN-MME-SDA, BN-MME-ADA, and SCCC-MME-SDA cases give values of 250, 300 and $218 \mathrm{~kg} / \mathrm{s}$ along the YMP model northern boundary, respectively. The DVRFM (Belcher et al., 2004) boundary flows were also estimated for the Pahute Mesa CAU flow model boundaries, and found to be in reasonable agreement with estimates developed from the UGTA regional model (DOE/NV, 1997). Thus, the Pahute Mesa CAU model is in reasonable agreement with other independent water-balance analyses in the area.

4. Data Components of Calibration. Four categories of data, representing two types (head and flow), were used to calibrate the Pahute Mesa CAU flow model: observation well head, spring head, Oasis Valley ET discharge, and net model boundary flow. An evaluation of the contribution of each data type to the model goodness of fit shows that observation well heads comprised the bulk (between about 50 to 60 percent) of the objective function, followed by Oasis Valley discharge (about 25 percent), estimated regional boundary flow (about 15 percent), and spring head (5 to 10 percent). Clearly, observation well data must be given strong consideration in model calibration because they define the direction and magnitude of the hydraulic gradient, which is directly related to the velocity field that will be used to simulate radionuclide transport. Oasis Valley discharge is the only internal flow constraint for the model, and as such is a major control on the effective permeability. Oasis Valley is also the nearest access point for radionuclides that might leave Pahute Mesa, and matching its discharge ensures that the potential for such migration is properly captured in the flow model. In addition, matching the spring data also helps ensure that the heads in Oasis 


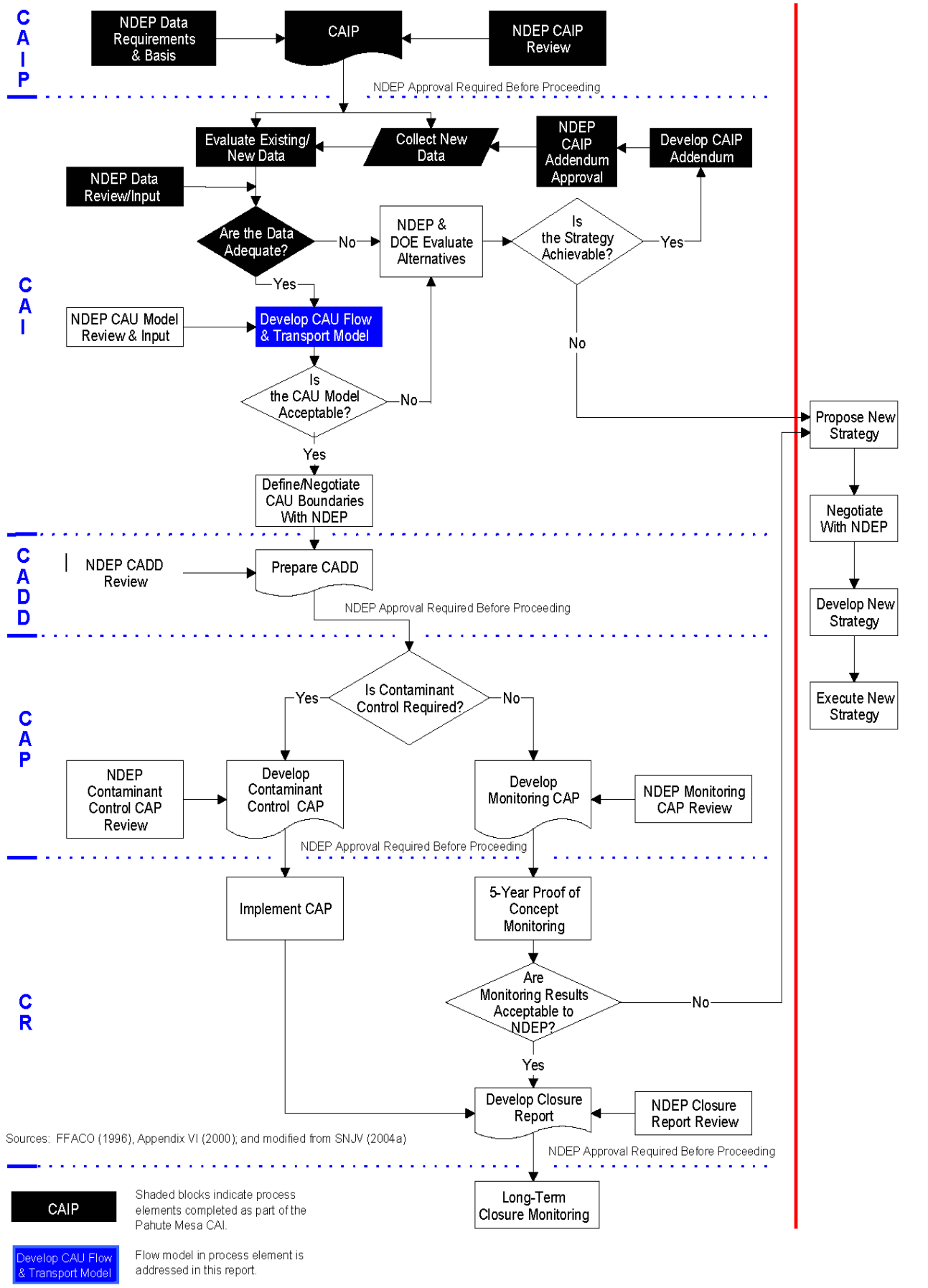

Figure 1-3 


\subsection{Framework for GroundWater Flow Modeling of Central and Western Pahute Mesa - Data, INFORMATION, AND CONCEPTUAL MODELS}

The development of a CAU-scale groundwater flow model for Central and Western Pahute Mesa is a key element of the FFACO corrective action strategy. The framework for this flow model incorporates data and information related to multiple component models of the Pahute Mesa hydrogeologic system. Each of these component models is characterized by uncertainties in both the data and information that characterize the processes described by the component model, and in the conceptual models that incorporate the data and information.

Figure 2-1 summarizes the regional and site-specific elements that are integrated into the Pahute Mesa flow model. These elements include:

- Regional data and information that provide the hydrogeologic context for the CAU-specific flow model.

- CAU-specific geologic data and information that establish the local hydrostratigraphic framework within which groundwater flows.

- Component models that integrate the regional hydrogeology into the CAU-specific hydrogeology.

- Alternative CAU-specific models to address uncertainty in hydrostratigraphy, lateral boundary flux and heads, and recharge.

- $\quad$ CAU-specific hydrologic parameters (including their uncertainty).

This section provides an overview of the data, information, and conceptual models that are incorporated into the Pahute Mesa flow model. The data, information, and conceptual models presented in this overview represent a large body of work (Table 1-1) and are described in more detail in the integrating report Hydrologic Data for the Groundwater Flow and Contaminant Transport 


\subsection{Hydraulic Heads}

Observed hydraulic heads are derived from depth-to-water measurements and well information. Hydraulic heads may also be approximated by the land surface elevations of regional springs. This section provides a summary of the evaluation of hydraulic head data in the Pahute Mesa area. A more detailed description of this evaluation is provided in SNJV (2004a, Section 8.0).

The results of the water-level data analysis were used to identify hydraulic head values that are most representative of steady-state, predevelopment conditions at specific boreholes and well locations. Each temporal subset of measurements that represents steady-state conditions was reduced statistically to a mean, standard deviation, and variance of the mean. The hydraulic head data derived from the water-level data were supplemented with land surface elevations of the selected regional springs.

The uncertainty associated with each of the hydraulic head values was estimated in several different ways depending on the case. The uncertainty associated with hydraulic heads derived from multiple water-level measurements is represented by the total variance. In this case, a given steady-state hydraulic head variance was calculated as the sum of the variance of the mean hydraulic head and the variance of the land surface elevation derived from the measurement accuracy estimates provided in SNJV (2004a). The uncertainty associated with hydraulic heads derived from land surface elevations at spring locations was equated to the variance of the land surface elevation derived from the measurement accuracy estimates also provided in SNJV (2004a). It was not possible to quantify the measurement variance for many of the wells due to a lack of information. No estimates of uncertainty have been made for these cases. As part of the modeling analysis, weights will be derived and assigned to the hydraulic heads as described in Section 5.2.

A potentiometric contour map was prepared using composite water-level data to provide a general understanding of the hydraulic gradient and direction of groundwater flow. Figure 2-16 shows the potentiometric surface and the HSUs at the water table. The wells and hydraulic heads used in the calibration of the Pahute Mesa flow model are summarized in Table 5-2.

Vertical flow analysis was performed with the aid of the EV software program (Version 5.1 by Dynamic Graphics, 2002) to produce an isocontour model. The amount of information available on 
the vertical distribution of hydraulic heads in the region is sparse. The EV model was, therefore, only used to evaluate regions with sufficient data. In wells with multiple screened intervals, the vertical gradient was calculated as the difference in hydraulic heads divided by the difference in vertical distance between open intervals. The vertical gradient was then applied to the midpoint between effective open intervals.

An analysis of vertical flows (SNJV, 2004a) indicated:

- A strong downward vertical gradient occurs near the water table in the Rainier Mesa region with a slight upward gradient at depth.

- A moderate downward gradient occurs in the area of Beatty Wash.

- There is a slight upward gradient at intermediate depths throughout the central portions of NTS Area 19 and Area 20.

- The Oasis Valley region contains a mixture of vertical gradients. Near the surface, there is a very weak upward gradient as well as areas of localized downward gradients.

As described in Section 2.4, 10 pumping wells have been historically used to withdraw groundwater from the Pahute Mesa area; eight of them are NTS water supply wells located in Pahute Mesa. The two other wells are Beatty Well No. 1 and Gexa Well 4, located outside of the NTS. In 1989, the maximum volume of $1,154,700 \mathrm{~m}^{3}$ was pumped. This volume represents only 15 percent of the ET estimate. The three largest producing wells are WW 8, UE-19c WW, and U-20 WW. The effects of pumping at U-20 WW were observed as drawdown at several wells located up to $5.9 \mathrm{~km}$ away (Fenelon, 2000). As reported by Fenelon (2000), the correlation of monthly withdrawal rates and drawdown is hindered because of relatively long periods of no pumping interspersed with periods of pumping. In conclusion, transient well-related effects are very localized and likely not representative of conditions over a majority of the model area.

\subsection{Hydraulic Parameters}

Hydraulic parameters are required to simulate groundwater movement. The following sections summarize the assessment of hydraulic parameter data presented in SNJV (2004a). 


\subsubsection{Hydraulic Conductivity Data}

Analysis of hydraulic conductivity data included evaluations of measurement scale (laboratoryscale data, slug-test-scale data, constant-rate-scale data), scaling and spatial variability, vertical anisotropy, and the alteration of hydraulic conductivity in test cavities (SNJV 2004a). Hydraulic conductivity parameters for each HSU are presented at the end of this section. All hydraulic conductivities are in m/d. Figure 2-17 shows the locations where the hydraulic conductivity data were obtained.

Approximately 1,200 laboratory-scale data measurements are available for 44 locations, nearly all of which are outside the Pahute Mesa model boundary. Laboratory data have been subdivided on the basis of the regional model HSUs including the AA, LCA, LCCU, VCU, VA, and VU. Table 2-16 provides the statistics of laboratory-scale hydraulic conductivity data.

More than 200 hydraulic conductivity values were obtained by methods that have been lumped into the general category of slug tests. The types of tests in this category include bailing recovery, drill-stem test, falling-head slug test, packer-injection test, pressure-injection test, slug-injection test, slug-withdrawal test, and swabbing-recovery test. Each of these test types are of relatively short duration, involving the movement of smaller volumes of water through the formation than would be typical for a constant-rate test. Therefore, hydraulic conductivity values derived from slug tests represent a smaller volume of the tested formation than either single-well or multi-well constant-rate aquifer tests. Table 2-17 provides the statistics of the slug-test-scale hydraulic conductivity data. Plots of slug-test hydraulic conductivity versus depth from SNJV (2004a, Section 5.5.4, Figures 5-9 and 5-10) suggest that there is a trend of decreasing hydraulic conductivity with increasing depth.

Approximately 300 hydraulic conductivity values were obtained from analyses of constant-rate test data. The data classified as constant-rate-scale represent tests in which water was injected or withdrawn at a constant rate for several hours to several days. As a result, these tests sampled a larger volume of the tested formation than either laboratory-scale or slug-scale tests. This group of data contains results from both single- and multi-well aquifer tests. Table 2-18 summarizes the statistics for these analyses. 


\section{0 flow model Calibration}

The Pahute Mesa CAIP (DOE/NV, 1999) and modeling approach/strategy (SNJV, 2004b) indicate that model calibration will be conducted after flow model construction. These documents describe model calibration as "the process of matching historical data" and "calibration consists of determining model parameter values such that simulated heads and fluxes are consistent with observed or target values.” In addition, ASTM Standard Guide D 5490-93 (ASTM, 1993b) defines calibration as, “ $\ldots$ the process of refining the model representation of the hydrogeologic framework, hydraulic properties, and boundary conditions to achieve a desired degree of correspondence between the model simulations and observations of the groundwater flow system.” The purpose of the Pahute Mesa CAU-model calibration is to use observed head data, discharge estimates from Oasis Valley, boundary flow estimates from the regional model, and estimated hydraulic properties for HSUs to develop a numerical model representation of the groundwater flow system in the Pahute Mesa CAU area. This will be used to assess underground-test related radionuclide migration.

This section describes the flow model calibration approach, and the calibration results for the base HFM and the major alternative HFM, the SCCC. These HFMs, presented in Section 2.2.1, are described in detail by BN (2002). Other HFMs are considered in Section 6.3. In addition, the calibrations described in this section are with the MME recharge model; other recharge models are investigated in Section 6.4.

The flow model sensitivity and uncertainty analysis are presented in Section 6.0. Geochemical verification is presented in Section 7.0, and thermal sensitivity and verification is shown in Section 8.0.

The Pahute Mesa CAU flow model considered seven HFMs and five recharge models. In the interest of brevity, the following shorthand is used. The first part of the name is the HFM and the second is the water-balance condition. Two other modifications are applied only to the base model: SDA for selected HSU depth decay and anisotropy, and ADA for all HSU depth decay and anisotropy. 
Examples of the naming conventions are as follows:

- BN-MME - Bechtel Nevada (or base) HFM with the MME recharge model and boundary flows.

- BN-DRIA - Bechtel Nevada (or base) HFM with the DRI alluvial recharge model and boundary flows.

- BN-USGSD - Bechtel Nevada (or base) HFM with the USGS redistribution recharge model and boundary flows.

- BN-USGSND - Bechtel Nevada (or base) HFM with the USGS no redistribution recharge model and boundary flows.

The other HFMs are:

- SCCC - Silent Canyon Caldera Complex

- PZUP - Raised Pre-Tertiary/Surface

- DRT - Deeply Rooted Belted Range Thrust Fault

- $\quad$ RIDGE - Basement Ridge

- TCL - Thirsty Canyon Lineament

- SEPZ - Contiguous Imbricate Thrust Sheet

Thus, SEPZ-MME is the contiguous southeast LCA HFM with the MME recharge model and boundary flows.

The five recharge models are:

- MME - Modified Maxey-Eakin

- USGSD - USGS recharge with redistribution

- USGSND - USGS recharge without redistribution

- DRIA - DRI recharge with alluvial mask

- DRIAE - DRI recharge with alluvial and elevation mask

\subsection{Calibration Approach}

The ASTM Standard Guide D 5981-96 (ASTM, 1996) (also Anderson and Woessner, 1992) describes a general protocol for model calibration. In this protocol, each cycle of parameter adjustment should begin with sensitivity and error analysis (Figure 5-1). The sensitive parameters to be adjusted should be considered in light of the data certainty. Conceptually, the process is not much different than if an automated parameter estimation technique is used (Poeter and Hill, 1997). The general protocol, as 


\subsection{Parameter Assignment}

Each node in the FEHM mesh has an associated material property index that is used to assign hydraulic properties. Faults are also specified by material zones, and are specified after the HSUs are defined. However, the material properties associated with the HSU nodes remain assigned to the fault nodes pending another property assignment. The approach in parameterizing the faults was to assign a permeability factor that multiplies the existing fault node properties (still derived from an HSU). Thus, the difficulty that could be encountered in directly assigning a fault permeability that is reconciled with each HSU that it crosses is avoided. For instance, if a vertical fault crosses both aquifers and confining units (which most do), and a uniform fault permeability of $10^{-16} \mathrm{~m}^{2}$ is assigned, the aquifer (with a permeability of $10^{-12} \mathrm{~m}^{2}$ ) would see the fault as a barrier, but a confining unit with a permeability of $10^{-16} \mathrm{~m}^{2}$ would see the fault as neutral. This approach tacitly assumes that a fault acts the same in each HSU that it encounters. Depth decay was computed in the depth-integrated manner described in the UGTA regional model (DOE/NV, 1997). Because FEHM determines its control volumes from node locations (unlike the block-centered code used in the regional model), which also may not necessarily be rectangles or squares, the bounding control volume coordinates were used in the depth-decay calculation. In the case of non-rectangular control volumes, the computed depth decay is approximate because the height of the control volume may not be constant. This was deemed a reasonable approximation in light of the overall uncertainty surrounding the depth-decay process.

\subsection{Base Hydrostratigraphic Framework Model Flow Model Calibration}

Bechtel Nevada (2002) presents a best estimate, or what will be referred to hereafter as the "base," HFM of Pahute Mesa and the surrounding area, as well as several alternative interpretations. The following sections document the evaluation of four different approaches (two in Section 5.6.2) to assigning model parameters in the base model. The same calibration data and model structure were used in each case; only the approach to assigning parameters was changed. These approaches include:

- No depth decay, no anisotropy

- $\quad$ Selected HSU depth decay

- Selected HSU depth decay and anisotropy

- All HSU depth decay and anisotropy 


\subsubsection{No-Depth-Decay, No-Anisotropy Case}

The Pahute Mesa CAU model discretizes each HSU with multiple nodes in the horizontal and vertical dimensions. It was thought that this level of discretization might not require horizontal-tovertical anisotropy because the arrangement of the HSUs would naturally produce the stratification of flow, and the approach described in this section was designed to test this hypothesis. In addition, the necessity of permeability depth decay was also tested by using a single permeability for each HSU estimated from characterization data as described in the Pahute Mesa hydrologic data document (SNJV, 2004a).

This case was not as extensively examined as the others described in Section 5.6 for reasons that are explained in the following text. It also was set aside before other changes were made to the model, but this section describes the process and results used in developing the Pahute Mesa CAU flow model.

Figures 5-10 through 5-13 show the observed (or estimated in the case of boundary flows) and unweighted simulated values for the calibration wells, springs, Oasis Valley discharge, and boundary flows, respectively. On Figures 5-10 and 5-11, the line of perfect agreement is shown, and ideally the data would plot exactly onto this line. The agreement in Figure 5-13 between the regional and CAU models is generally good, and in general, the simulated boundary flows from the regional and CAU models are comparable. The scatter around the line of perfect agreement is generally random in Figure 5-10, although there are some large errors at around 1,450 $\mathrm{m}$ and a bias toward undersimulation above 1,300 m. Figure 5-14 shows a histogram of weighted observation well residuals. The bulk of the weighted errors are less than 20. The errors are approximately symmetrically distributed around zero, with a single large undersimulated (positive sign) PM-2, and single large oversimulated UE-19b \#1 WW.

The Oasis Valley discharge and boundary flow components provide the water-balance constraint on the model. The total estimated Oasis Valley discharge, divided among seven zones numbered 1-6 and 8, is $227 \mathrm{~kg} / \mathrm{s}$. The simulated discharge, shown in Figure 5-12, is $128 \mathrm{~kg} / \mathrm{s}$. The model captures the northernmost two discharge zones well, but performs poorly for the rest of Oasis Valley. This suggests that the head in the southern part of Oasis Valley needs to rise in order to produce the observed discharge. The boundary flows, estimated from regional model analysis, do not trend the same way on the western edge, although the north, south, and east flows reasonably agree with the regional model. 


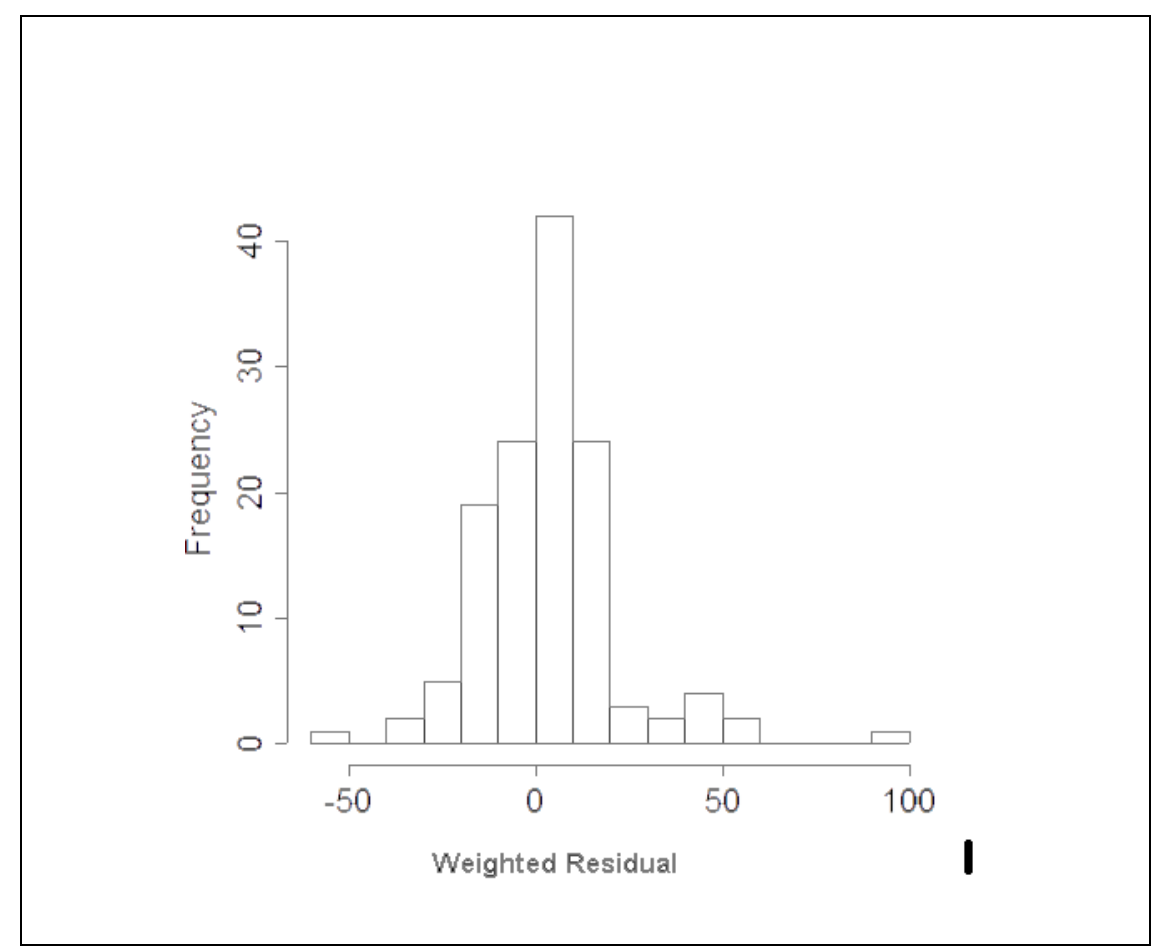

Figure 5-14

\section{Histogram of Weighted Head Residuals - Base HFM, No Depth Decay, No Anisotropy}

The weighted head and spring errors (or residuals), defined as observed minus simulated heads, are shown on Figure 5-15, color-coded by value and sign. Only locations with weights greater than 0.01 $\left(\mathrm{m}^{-1}\right)$ are shown in order not to bias the display (low weight observations will give an erroneously favorable impression because almost any error times the low weight will be low). There is a pattern of undersimulated wells west of the Purse Fault and in Oasis Valley. The low simulated water levels in Oasis Valley result in the undersimulation of observed discharge in the valley. There is an area of high bias in northeastern Area 19.

The quantitative measures of the model calibration are given by summary statistics shown in Table 5-6. There is a noticeable low bias in the spring heads, resulting in the undersimulation of Oasis Valley discharge. The standard deviation is wider than the other cases described in Section 5.6, reflecting the overall poorer fit of this case. Table 5-7 shows the contribution to model goodness of fit from each data type. 


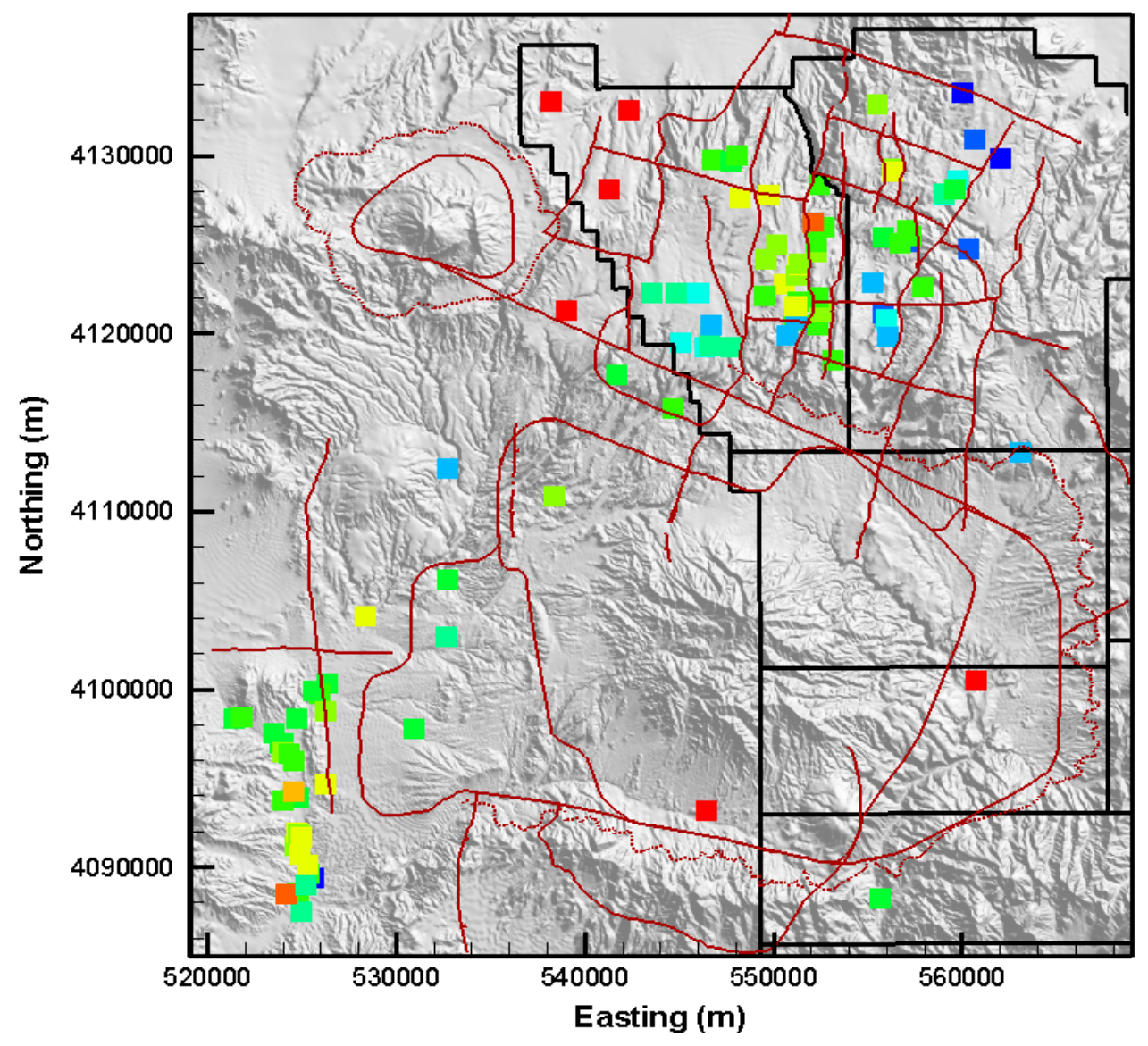

Weighted Residual

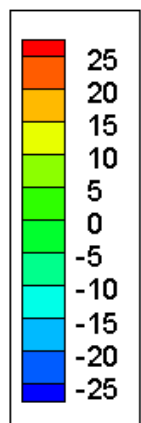

Figure 5-15

Post Plot of Weighted Well and Spring Head Residuals - Base HFM, No Depth Decay, No Anisotropy

Figure 5-16 shows the simulated water table for this model case. In the western part of Area 20, the influence of the Purse Fault is absent except along the northern part of the fault. Head in southern Area 20 is very similar to that on the other side of the Purse Fault, which is the incorrect representation and results in the low heads at PM-2, PM-3, UE-20j WW, U-20m, and UE-20p (the area of low bias in Figure 5-15). The misfit at PM-2 is particularly large and, as described in Section 5.3, is directly caused by regional model misfit just north of the CAU-model boundary. This result led to the revision of boundary head (also described in Section 5.3) on the northern CAU-model edge. A mound is not simulated under Timber Mountain; this interpretive feature was added after this case was no longer being investigated. If implemented, it may raise head and discharge in Oasis 
Table 5-6

Calibration Summary Statistics - Base HFM, No Depth Decay, No Anisotropy

\begin{tabular}{||c|c|c|c|c|c|}
\hline $\begin{array}{c}\text { Calibration } \\
\text { Data }\end{array}$ & $\begin{array}{c}\text { Number of } \\
\text { Data }\end{array}$ & $\begin{array}{c}\text { Mean } \\
\text { Weighted } \\
\text { Errora }\end{array}$ & $\begin{array}{c}\text { Maximum } \\
\text { Weighted } \\
\text { Residual }\end{array}$ & $\begin{array}{c}\text { Minimum } \\
\text { Weighted } \\
\text { Residual }\end{array}$ & $\begin{array}{c}\text { Error } \\
\text { Standard } \\
\text { Deviation }\end{array}$ \\
\hline \hline Well Head & 152 & 1.6 & $96(\mathrm{PM}-2)$ & $\begin{array}{c}-52(\mathrm{UE}-19 \mathrm{~b} \# 1 \\
\text { WW) }\end{array}$ & 16 \\
\hline Spring Head & 28 & 5.8 & $24($ Spring id & -6.5 (Spring id & 9.2 \\
\hline $\begin{array}{c}\text { Oasis Valley } \\
\text { Discharge }\end{array}$ & 7 & 28 & 74 (Zone 3) & -33 (Zone 1) & 45 \\
\hline Boundary Flow & 4 & -15 & 50 (North) & -91 (West) & 53 \\
\hline
\end{tabular}

apositive sign is undersimulation of target data, negative is oversimulation.

Table 5-7

Contribution to Model Goodness of Fit by Data Type for Base HFM Selected HSU Depth Decay and Anisotropy

\begin{tabular}{|c|c|c|}
\hline Data Type & Value (-) & \% of Total \\
\hline \hline Well Head & 42,531 & 61 \\
\hline Spring Head & 2,387 & 3 \\
\hline Oasis Valley Discharge & 14,029 & 20 \\
\hline Boundary Flow & 11,156 & 16 \\
\hline Total & 70,103 & 100 \\
\hline
\end{tabular}

Valley by diverting water to the west. Oasis Valley discharge is apparent, but not as pronounced as in other cases because it only is about half of the observed flow (the other cases capture the flow much better).

Particle tracking (Figure 5-17) from each of the NTS wells used in model calibration shows generally the same noted flow paths as shown by SNJV (2004a) and as shown in Appendix A of the Pahute Mesa hydrologic data document (SNJV, 2004a). However, very few of the particles discharge in Oasis Valley, and as previously noted, this model greatly undersimulates Oasis Valley discharge. The broad flow path through the Timber Mountain area is not known to exist. However, data do not exist to rule it out. The flow paths shown are consistent with the boundary conditions applied to the model. However, as a matter of first principles, an area of higher elevation and commensurate recharge should have higher hydraulic head underlying it. Thus, the flat potentiometric surface and associated flow paths through Timber Mountain shown in Figure 5-17 are not thought to be realistic. In southern Area 20, the flow paths look reasonable, but the heads are not correct along the Purse Fault. Finally, 


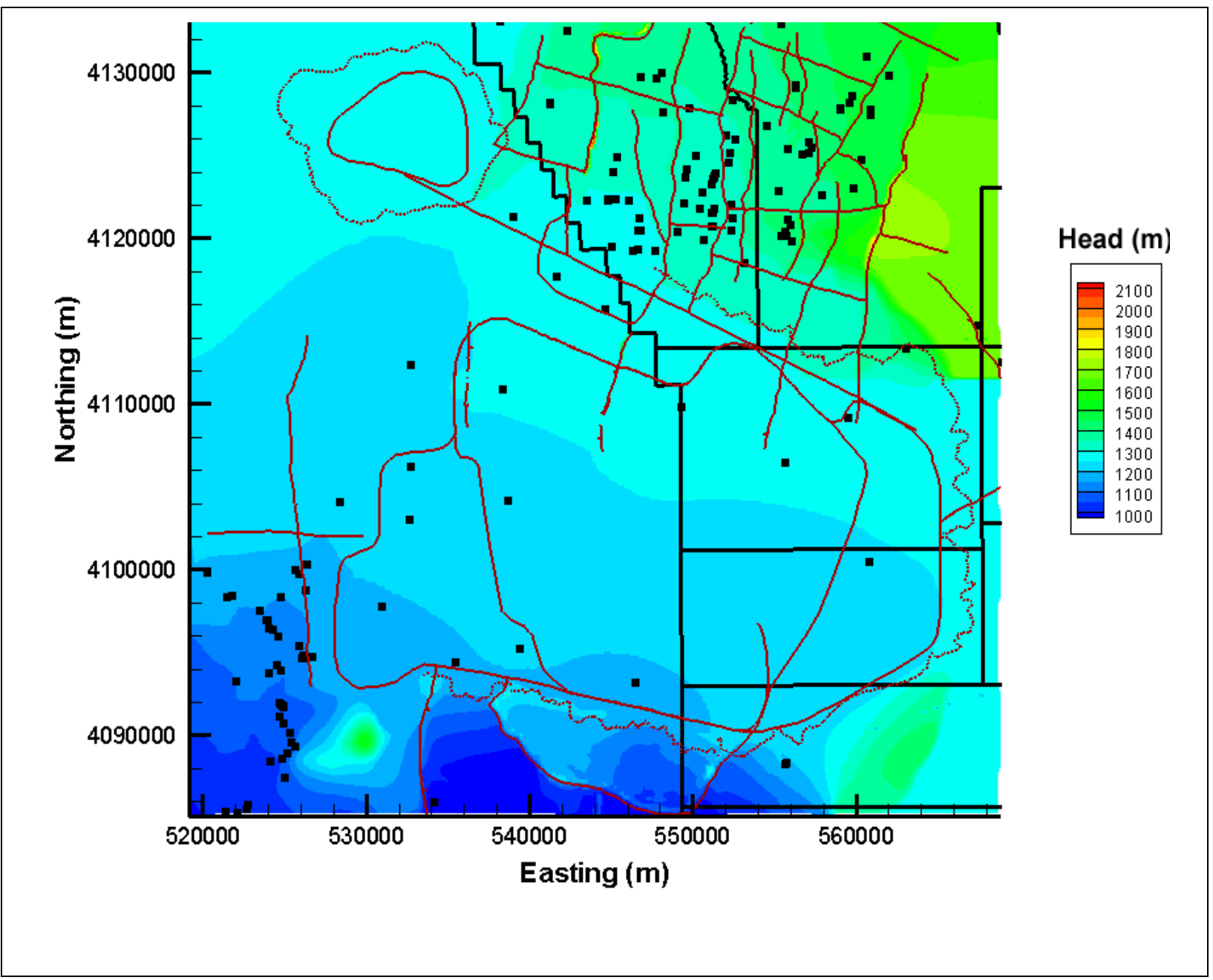

Figure 5-16

Simulated Water Table - Base HFM, No Depth Decay, No Anisotropy

a large number of flow paths exit the model deep (elevation of $-1,000 \mathrm{~m}$ or more) in the LCA underlying Oasis Valley, which is unsupported by the analysis of SNJV (2004a). This was one of the key observations that lead to this parameterization of the base HFM not being investigated further.

This parameterization approach, no depth decay and no anisotropy, produced flow paths that were judged unrealistically deep and represented Oasis Valley discharge poorly. It also required systematically low permeabilities relative to the expected values and ranges as described in the Pahute Mesa hydrologic data document (SNJV, 2004a). Figure 5-18 shows the estimated versus calibrated permeabilities; the estimated standard deviation is published in SNJV (2004a), but for practical purposes can be considered to be one order of magnitude. Nearly all the values are multiple 


\subsubsection{Selected HSU Depth Decay and Anisotropy (SDA)}

The SDA parameterization approach began by assessing the effect of permeability depth decay only, and its effects were found to be quite pronounced in terms of not requiring consistently low permeabilities as in the case described in Section 5.6.1. The depth-decay-only case was used to establish the insight into the need for permeability depth decay and was not extensively investigated.

In the UGTA regional model (DOE/NV, 1997), depth decay and horizontal-to-vertical anisotropy were assigned to every HSU. An alternate parameterization of the base HFM was designed to test whether depth decay applied to regionally contiguous units existing at a wide variety of depths along with anisotropy in selected units could give a reasonable result. Table 5-8 shows the units selected for depth decay and anisotropy. The rationale for selectively applying depth decay is that units that are contiguous over the CAU and that exist over a great range of depths (such as the LCA and PBRCM) would have large variation in permeability, which is conceptually best addressed via depth decay rather than, for instance, subdividing HSUs by burial depth and assigning individual permeabilities based on depth. The depth-decay coefficients are the mean values presented in the UGTA regional model report (DOE/NV, 1997). The vertical-to-horizontal anisotropy value is derived from the YMP site-scale saturated zone model (DOE/ORD, 2004).

Horizontal-to-vertical anisotropy, typically associated with granular media, may not be a meaningful concept in fractured rock. Pawloski et al. (2001) did not use horizontal-to-vertical anisotropy in the analysis of the CHESHIRE HST. They showed that it was reasonable to have permeability along the main flow direction be the same through the vertical extent of fractured HSUs. The composite units in the CAU HFM model are, by definition, an amalgamation of HGUs that could not be extensively mapped. Thus, internally a layer-cake arrangement of massive fractured units with bedded tuffs, for example, would tend to impart horizontal-to-vertical anisotropy over the scale of a CAU-model element. If the geologic description were detailed enough, and if the computational mesh could accommodate such detail, such anisotropy would result naturally. However, as described in Section 5.6.1 it appears that the HFM model and FEHM mesh are not fine enough for this to occur.

Figures 5-19 through 5-22 show the observed (or otherwise estimated) and unweighted simulated values for wells, springs, Oasis Valley discharge, and boundary flows, respectively. On Figures 5-19 and 5-20, the line of perfect agreement is shown, and ideally the data would plot exactly onto this 
Table 5-8

Hydrostratigraphic Units with Depth Decay and Anisotropy

\begin{tabular}{|c|c|c||}
\hline HSU & Depth Decay $\lambda$ & Anisotropy \\
\hline \hline TMCM & 0.0026 & 0.1 \\
\hline YMCFCM & 0.0026 & N/A \\
\hline LCA & 0.001 & 0.1 \\
\hline PBRCM & 0.0026 & N/A \\
\hline BRA & 0.0026 & N/A \\
\hline PCM & 0.0026 & N/A \\
\hline TCVA & 0.0026 & N/A \\
\hline TMA & 0.0026 & 0.1 \\
\hline CFCM & N/A & 0.1 \\
\hline N/A & 0.1 \\
\hline FCCM & N/A & 0.1 \\
\hline YVCM & N/A & 0.1 \\
\hline AA & N/A & CHVCM, CHVTA \\
\hline
\end{tabular}

See Table 2-6 for HSU descriptions.

line. However, in practice, there is always some model misfit. The scatter around the line of perfect agreement is generally random in Figure 5-19, until an observed head of 1,450 $\mathrm{m}$ is exceeded. At the very highest-observed observation well water levels, the model has a tendency towards undersimulation. The largest error is associated with the ER-19-1 deep completion. The remaining errors above 1,450 $\mathrm{m}$ are all in far eastern Area 19, where data become very sparse and uncertainty increases. Figure 5-23 shows a histogram of weighted observation well residuals. The bulk of the weighted errors are less than \pm 10 . The errors are not symmetrically distributed around zero, with larger oversimulated (negative sign) wells. Total number of errors above +10 and below -10 appear to be about the same. 


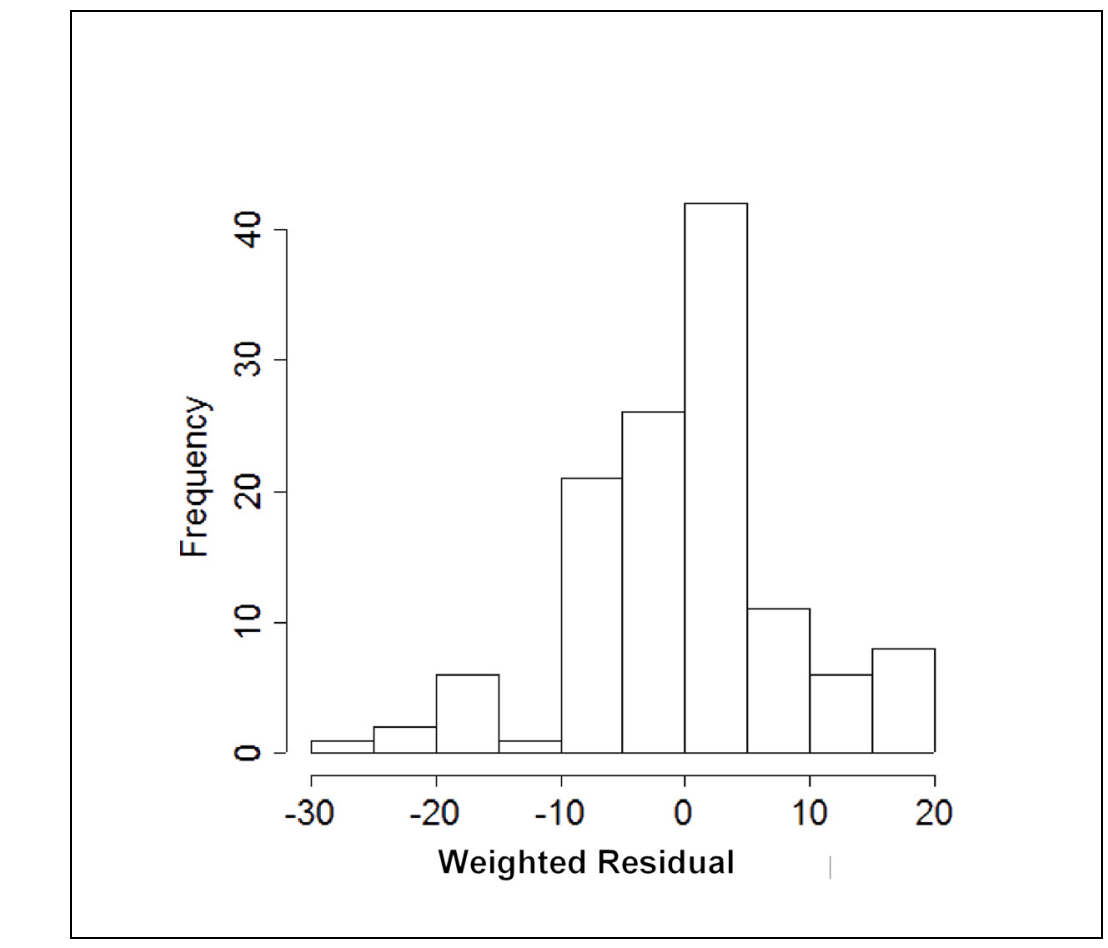

Figure 5-23

Histogram of Weighted Head Residuals for BN-MME-SDA

The weighted head and spring errors are shown on Figure 5-24, color coded by value and sign. The two lowest, or undersimulated, wells were ER-OV-06a and ER-OV-01. The single highest well was UE-20a \#1 in northern Area 19. In general, the errors are randomly distributed, although there is a slight low bias in northern Area 20 at easting and northing of about 547,500 and 4,130,000 m, which includes wells U-20i, UE-20e \#1, U-20e, and U-20ar \#1.

The two springs with the largest errors are Goss Spring, which has an uncertain location, and Oleo Road Spring in an area of very high topographic gradient that the model is unlikely to represent in sufficient detail. Goss Spring was incorrectly located in the Pahute Mesa hydrologic data document (SNJV, 2004a), and locations were re-estimated based on USGS 1:24,000 maps. These two springs were assigned low weights because of their questionable representativeness.

However, springs at similar and higher elevations were matched well, and this misfit appears to be a local issue.

The Oasis Valley discharge and UGTA regional model (DOE/NV, 1997) boundary flows provide the water-balance constraint on the model. The total estimated Oasis Valley discharge is $227 \mathrm{~kg} / \mathrm{s}$. The simulated discharge, shown in Figure 5-21, is $209 \mathrm{~kg} / \mathrm{s}$. The total error is within one standard 


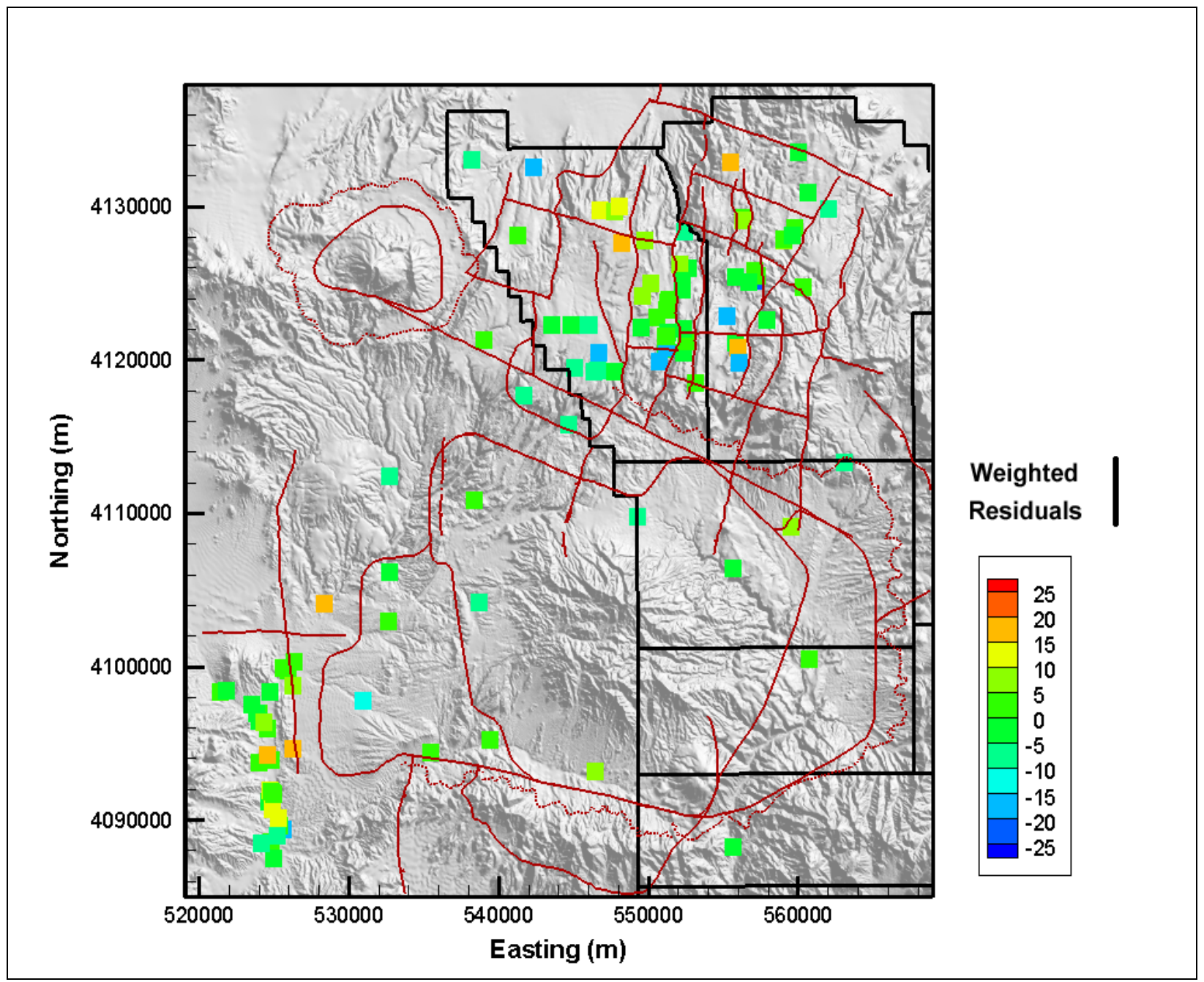

Figure 5-24

Post Plot of Weighted Well and Spring Head Residuals - Base HFM,
No Depth Decay, No Anisotropy

deviation (30 kg/s) as reported by Laczniak et al. (2001). The model trends the same as the data with some scatter, showing that the general representation of Oasis Valley is correct. The northernmost (and closest to the NTS) zone is matched well. The boundary flows (Figure 5-22), estimated from regional model analysis, all trend the correct way (e.g., have the proper sign), with the largest relative misfit on the western edge.

The quantitative measures of the model calibration are given by summary statistics shown in Table 5-9. These statistics alone are not used to judge model calibration; they are used in conjunction with the graphical approaches shown previously. There is a slight dry bias in the spring heads, with a slight overprediction bias for the flows. The total model objective function was 16,651. Table 5-10 shows the contribution of each data type to the total model goodness of fit. The strongest contributors are observation well heads and Oasis Valley flow, which are also the two key pieces of calibration data. 
Table 5-9

Calibration Summary Statistics for BN-MME-SDA

\begin{tabular}{||l|c|c|c|c|c||}
\hline $\begin{array}{c}\text { Calibration } \\
\text { Data }\end{array}$ & $\begin{array}{c}\text { Number } \\
\text { of Data }\end{array}$ & $\begin{array}{c}\text { Mean } \\
\text { Weighted } \\
\text { Error }^{2}\end{array}$ & $\begin{array}{c}\text { Maximum } \\
\text { Weighted } \\
\text { Residual }\end{array}$ & $\begin{array}{c}\text { Minimum } \\
\text { Weighted } \\
\text { Residual }\end{array}$ & $\begin{array}{c}\text { Error } \\
\text { Standard } \\
\text { Deviation }\end{array}$ \\
\hline \hline Well Head & 152 & -0.46 & $\begin{array}{c}18 \\
\text { (ER-OV-06a) }\end{array}$ & $\begin{array}{c}-27 \\
(\text { UE-20n \#1) }\end{array}$ & 7.4 \\
\hline Spring Head & 28 & 2.7 & $\begin{array}{c}19 \\
\text { (Torrance } \\
\text { Spring) }\end{array}$ & $\begin{array}{c}-5.5 \\
(\text { Spring id 159) }\end{array}$ & 6.7 \\
\hline $\begin{array}{l}\text { Oasis Valley } \\
\text { Discharge }\end{array}$ & 7 & 4.8 & $\begin{array}{c}41 \\
\text { (Zone 3) }\end{array}$ & $\begin{array}{c}-26 \\
(\text { Zone 4) }\end{array}$ & 23 \\
\hline Boundary Flow & 4 & -13 & $\begin{array}{c}26 \\
\text { (West) }\end{array}$ & $\begin{array}{c}-35 \\
\text { (South) }\end{array}$ & 27 \\
\hline
\end{tabular}

apositive sign is undersimulation of target data, negative is oversimulation.

Table 5-10

Contribution to Model Goodness of Fit by Data Type for BN-MME-SDA

\begin{tabular}{|l|c|c|}
\hline \multicolumn{1}{|c|}{ Data Type } & Value (-) & \% of Total \\
\hline \hline Well Head & 8,487 & 51 \\
\hline Spring Head & 1,283 & 8 \\
\hline Oasis Valley Discharge & 3,883 & 23 \\
\hline Boundary Flow & 2,997 & 18 \\
\hline Total & 16,651 & 100 \\
\hline
\end{tabular}

Figure 5-25 shows the simulated water table for this model case. In the western part of Area 20, the influence of the Purse Fault (Figure 4-7) is evident by nearly $100 \mathrm{~m}$ offset in water levels across it, with more subdued effects also present at West Boxcar Fault. Water flows from Areas 19 and 20 towards the southwest and Oasis Valley. A mound is simulated under Timber Mountain. It is unknown whether such a feature exists, but from first principles, a higher elevation area where recharge occurs should have a higher groundwater potential. This assumption tends to focus flow between the northern part of the Timber Mountain Caldera and the southern Silent Canyon Caldera. Ubiquitous discharge in Oasis Valley, including flow from Sarcobatus Flat to the west, is also evident by the simulated low trough-shaped potentiometric surface. Finally, flow occurs out across the southern boundary towards Yucca Mountain and Crater Flat. 


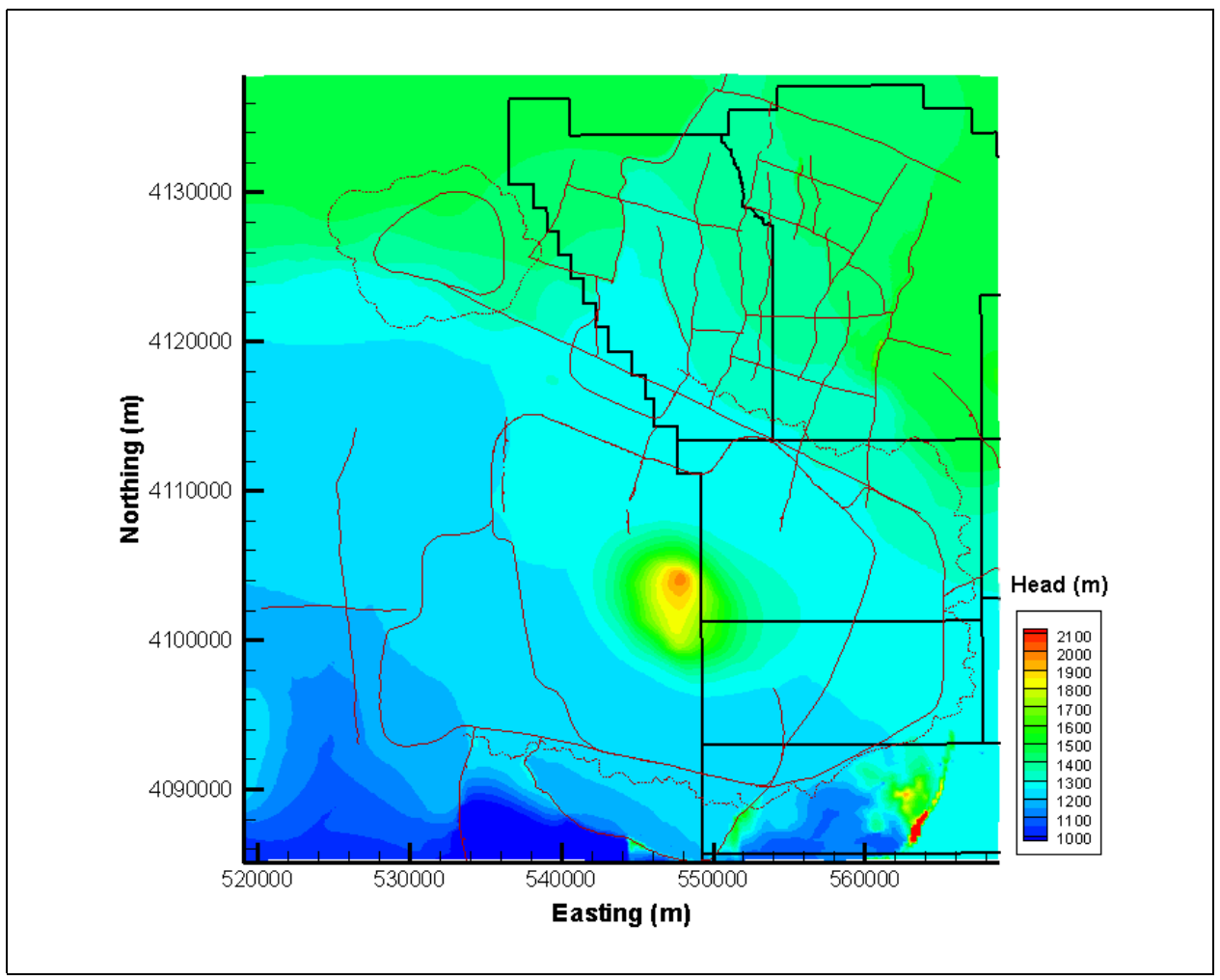

Figure 5-25

Simulated Water Table for BN-MME-SDA

Particle tracking from each of the NTS calibration wells was run until all particles discharged from the model or ceased to move (Figure 5-26). Because the flow field is steady state, porosity does not change the trajectories, and an arbitrary value of effective porosity can be used. In southern Area 20, where the influence of the Purse Fault on the calibration was pronounced, flow is west-southwest but quickly changes at the end of the Purse Fault to southeasterly and then hugs the western flank of Timber Mountain to the southwest because of the influence of the simulated recharge mound under Timber Mountain. Note that some of the wells shown do not have tracks leaving them; this is because the motion of the particle was so minor that it does not show a legible trace. This occurred at PM-2 and UE-20p in northern Area 20. The particle release points in PM-2 are nearly $1 \mathrm{~km}$ bmsl. The flow velocities are apparently simulated as being very low in this area of the model. There is only minor flow from Area 18, southern Area 19, and the Rainier Mesa area south down Fortymile Canyon. Particles that go to the west of Timber Mountain are all in the TMCM, and then move into the FCA in the lower part of Oasis Valley. Flow paths rise in elevation as flow converges into Oasis Valley. Moreover, they also rise near Bare Mountain due to the complex arrangement of rocks caused by the Bare Mountain Fault and the UCCU. 


\subsubsection{All HSU Depth Decay and Anisotropy (ADA)}

In the UGTA regional model (DOE/NV, 1997), depth decay and horizontal-to-vertical anisotropy were assigned to every HSU. Parameterization of the base HFM described in this section was designed to examine whether this approach would result in a reasonable calibration. Corrective action unit model calibration began with parameters developed from the regional model analysis performed to evaluate CAU-model boundary flows as presented in the Pahute Mesa hydrologic data document (SNJV, 2004a).

Figures 5-27 through 5-30 show the observed (or otherwise estimated) and unweighted simulated values for the calibration wells, springs, Oasis Valley discharge, and boundary flows, respectively. On Figures 5-27 and 5-28, the line of perfect agreement is shown, and ideally the data would plot exactly onto this line. However, in practice there is always some model misfit. The scatter around the line of perfect agreement is generally random in Figure 5-27, until an observed head of 1,450 $\mathrm{m}$ is exceeded. At the very highest-observed observation well water levels, the model has a tendency towards undersimulation. However, the highest water level (and the largest error) shown is associated with the ER-19-1 shallow completion, which may be perched (Fenelon, 2000). The remaining errors above $1,450 \mathrm{~m}$ are all in far eastern Area 19, where data became very sparse and uncertainty increases. Figure 5-31 shows a histogram of weighted observation well errors. There is a strong central tendency, with a few undersimulated wells (positive values) with errors greater than 20 (WW-8 and ER-EC-7). The behavior of this parameterization with respect to WW-8 is investigated further in Section 6.2. 
Table 5-13

Calibration Summary Statistics for BN-MME-ADA

\begin{tabular}{||l|c|c|c|c|c||}
\hline $\begin{array}{c}\text { Calibration } \\
\text { Data }\end{array}$ & $\begin{array}{c}\text { Number of } \\
\text { Data }\end{array}$ & $\begin{array}{c}\text { Mean } \\
\text { Weighted } \\
\text { Error }\end{array}$ & $\begin{array}{c}\text { Maximum } \\
\text { Weighted } \\
\text { Residual }\end{array}$ & $\begin{array}{c}\text { Minimum } \\
\text { Weighted } \\
\text { Residual }\end{array}$ & $\begin{array}{c}\text { Error Standard } \\
\text { Deviation }\end{array}$ \\
\hline \hline Well Head & 152 & 1.5 & $\begin{array}{c}48 \\
(\text { WW-8) }\end{array}$ & $\begin{array}{c}-25 \\
(\mathrm{U}-20 \mathrm{~g})\end{array}$ & 8.5 \\
\hline Spring Head & 28 & 2.9 & $\begin{array}{c}19 \\
(\text { Torrance } \\
\text { Spring) }\end{array}$ & $\begin{array}{c}-7.9 \\
(\text { Spring id 180) }\end{array}$ & 6.9 \\
\hline $\begin{array}{l}\text { Oasis Valley } \\
\text { Discharge }\end{array}$ & 7 & -5.9 & $\begin{array}{c}37 \\
(\text { Zone 3) }\end{array}$ & $\begin{array}{c}-47 \\
(\text { Zone 1) }\end{array}$ & 30 \\
\hline Boundary Flow & 4 & -8.9 & $\begin{array}{c}25 \\
\text { (West) }\end{array}$ & $\begin{array}{c}-33 \\
(\text { South })\end{array}$ & 23 \\
\hline
\end{tabular}

aPositive sign is undersimulation of target data, negative is oversimulation.

Table 5-14

Contribution to Model Goodness of Fit by Data Type for BN-MME-ADA

\begin{tabular}{|l|c|c|}
\hline \multicolumn{1}{|c|}{ Data Type } & Value (-) & \% of total \\
\hline \hline Well Head & 11,060 & 52 \\
\hline Spring Head & 1,331 & 6 \\
\hline Oasis Valley Discharge & 6,638 & 31 \\
\hline Boundary Flow & 2,263 & 11 \\
\hline Total & 21,292 & 100 \\
\hline
\end{tabular}

Flow paths were qualitatively assessed during calibration by inspecting the simulated water table configuration and tracking particles forward from NTS calibration well locations. Figures 5-33 and 5-34 show the simulated water table and travel paths for this model case. The water table shows higher heads on the eastern edge at a northing of about 4,120,000 $\mathrm{m}$, which is coincident with Gold Meadows stock and the western edge of Rainier Mesa. In the western part of Area 20, the influence of the Purse Fault is evident by nearly $100 \mathrm{~m}$ offset in water levels across it, with more subdued effects also present at West Boxcar Fault. Water flows from Areas 19 and 20 towards the southwest and Oasis Valley. Ubiquitous discharge in Oasis Valley, including flow from Sarcobatus Flat to the 


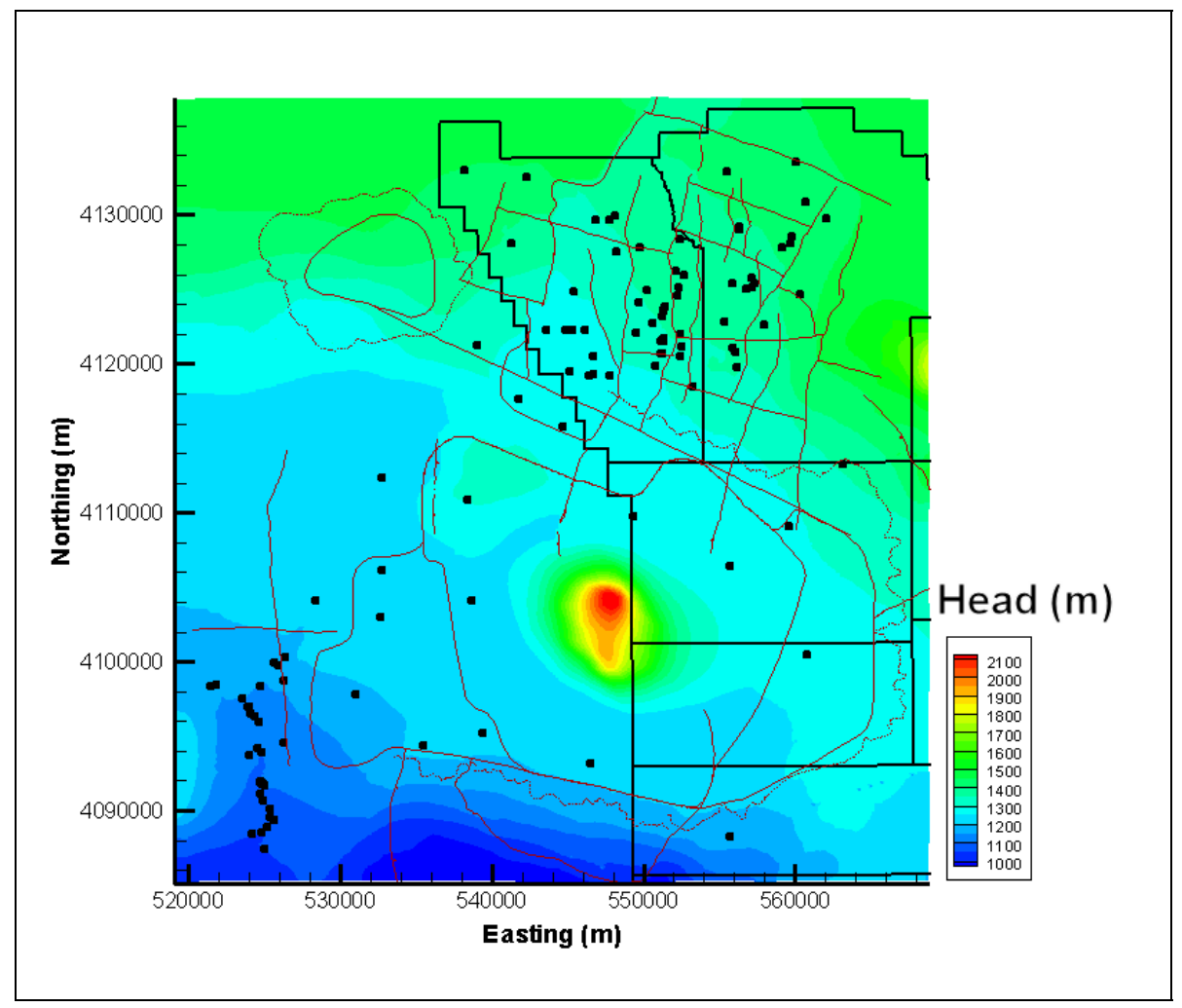

Figure 5-33

Simulated Water Table for BN-MME-ADA

west is also evident. The particle trajectories along the western side of Timber Mountain are influenced by either the contact between the TMCM and TMA, or the fault that defines the contact, and lie mainly within the TMCM.

Particle tracking shows the same generally noted flow paths as SNJV (2004a) with flow noticeably skirting the Purse Fault on the west from flow originating in northwestern Area 20. Like the selected HSU depth decay and anisotropy case, the flow paths become very complicated where the Purse Fault has been assumed to end near the Moat Fault. This case also shows flow along the western flank of Timber Mountain down into Oasis Valley and out to the south. Unlike the selected HSU depth-decay and anisotropy case, particles move from northwestern Area 20 down the western side of Purse Fault. Thus, this parameterization of the base HFM simulates a higher velocity in this area than the selected HSU depth-decay and anisotropy case. This model also has poorer agreement on the edge flows in the direction of oversimulation; thus, it is possible that in order to improve the agreement with the edge flows that permeability must decrease, and the effects are seen in the change in flow velocity in northern Area 20. 
The total estimated Oasis Valley discharge is $227 \mathrm{~kg} / \mathrm{s}$. The simulated discharge, shown in Figure $5-37$, is $192 \mathrm{~kg} / \mathrm{s}$. The total error is nearly within one standard deviation $(30 \mathrm{~kg} / \mathrm{s})$ as reported by Laczniak et al. (2001). As with the other flow models, with the exception of Zone 4 (Figure 4-17), the model trends the same as the data with some scatter, showing that the general representation of Oasis Valley is correct. The northernmost zone is in nearly perfect agreement with the data. The boundary flows (Figure 5-38), estimated from regional model analysis, all trend the correct way (e.g., have the proper sign), with the largest relative misfit on the eastern and western edges.

The quantitative measures of the model calibration are given by summary statistics shown in Table 5-17. Note that the ME for the well heads is better than some of the previous models for the base HFM, but that the standard deviation is nearly 50 percent larger than for depth decay and anisotropy applied to all HSUs case in Section 5.6.3. The low ME is a reflection of the even scatter of larger residuals towards both under and overprediction seen earlier in the weighted residual histogram. The total model goodness-of-fit statistic is 31,869 , which is nearly double that of the selected depth-decay and anisotropy case in Section 5.6.2 and 150 percent of the all depth-decay and anisotropy case in Section 5.6.3. Table 5-18 shows the contribution of each data type to the total model goodness of fit.

Table 5-17

Calibration Summary Statistics for SCCC-MME-SDA

\begin{tabular}{||c|c|c|c|c|c||}
\hline $\begin{array}{c}\text { Calibration } \\
\text { Data }\end{array}$ & $\begin{array}{c}\text { Number of } \\
\text { Data }\end{array}$ & $\begin{array}{c}\text { Mean } \\
\text { Weighted } \\
\text { Error }^{2}\end{array}$ & $\begin{array}{c}\text { Maximum } \\
\text { Weighted } \\
\text { Residual }\end{array}$ & $\begin{array}{c}\text { Minimum } \\
\text { Weighted } \\
\text { Residual }\end{array}$ & $\begin{array}{c}\text { Error } \\
\text { Standard } \\
\text { Deviation }\end{array}$ \\
\hline \hline Well Head & 152 & 0.34 & $\begin{array}{c}43 \\
\text { (WW-8) }\end{array}$ & $\begin{array}{c}-39 \\
\text { (U-20c) }\end{array}$ & 11 \\
\hline Spring Head & 28 & 2.5 & $\begin{array}{c}19 \\
\text { (Torrance } \\
\text { Spring) }\end{array}$ & $\begin{array}{c}-43 \\
\text { (Spring id 163) }\end{array}$ & 11 \\
\hline $\begin{array}{c}\text { Oasis Valley } \\
\text { Discharge }\end{array}$ & 7 & 9.9 & $\begin{array}{c}45 \\
\text { (Zone 5) }\end{array}$ & $\begin{array}{c}-23 \\
\text { (Zone 4) }\end{array}$ & 25 \\
\hline Boundary Flow & 4 & -16 & $\begin{array}{c}20 \\
\text { (West) }\end{array}$ & (North) & 30 \\
\hline
\end{tabular}

aPositive is undersimulation of target data, negative is oversimulation. 
Table 5-18

Contribution to Model Goodness of Fit by Data Type for SCCC-MME-SDA

\begin{tabular}{|c|c|c|}
\hline Data Type & Value (-) & \% of Total \\
\hline \hline Well Head & 19,998 & 63 \\
\hline Spring Head & 3,538 & 11 \\
\hline Oasis Valley Discharge & 4,681 & 15 \\
\hline Boundary Flow & 3,632 & 11 \\
\hline Total & 31,849 & 100 \\
\hline
\end{tabular}

Flow paths were qualitatively assessed during calibration by inspecting the simulated water table configuration and tracking particles forward from calibration well locations. Figures 5-41 and 5-42 show the simulated water table and travel paths, respectively, for this model case. As shown on these figures, water flows from Areas 19 and 20 towards the southwest and Oasis Valley as suggested by observed regional groundwater potentials and geochemical analysis. The effects of the West Boxcar Fault can be seen clearly. Observed heads at PM-3 are more than $100 \mathrm{~m}$ higher than those in southern Area 20, and it is the relatively shallow and disconnected Purse Fault in this alternative that allows groundwater from PM-3 and the eastern side of Black Mountain to spill into Area 20. This causes misfit at both PM-3 and the wells throughout southern Area 20. A slight mound is simulated under Timber Mountain. Discharge in Oasis Valley, including flow from Sarcobatus Flat to the west, is also evident. Unlike the other HFMs discussed in this section, the SCCC has more particle tracks going down Fortymile Canyon. The flow paths in southern Area 20 are nearly due south, in contrast to the base HFM models and the observed water-table surface. While the goodness of fit and qualitative assessment of the residuals suggest that this HFM does not perform as well as the base HFM, the broad characteristics of the flow system are still correct. This may be at least a partial consequence of specifying head around the edges of the CAU model.

The properties used to parameterize this model are shown in Tables 5-19 and 5-20 for HSU and faults, respectively. 


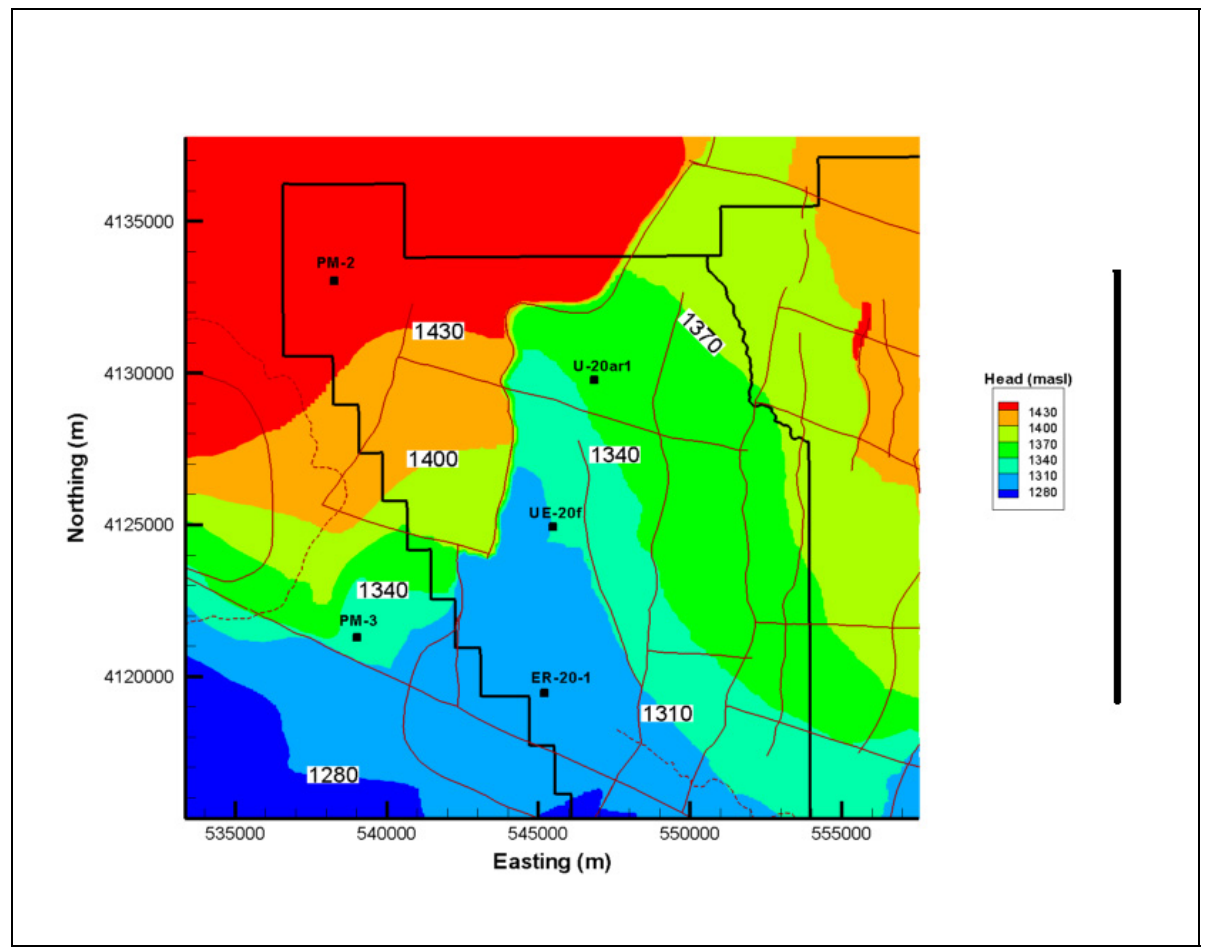

Figure 5-44

Simulated Heads Near the Purse Fault for BN-MME-SDA

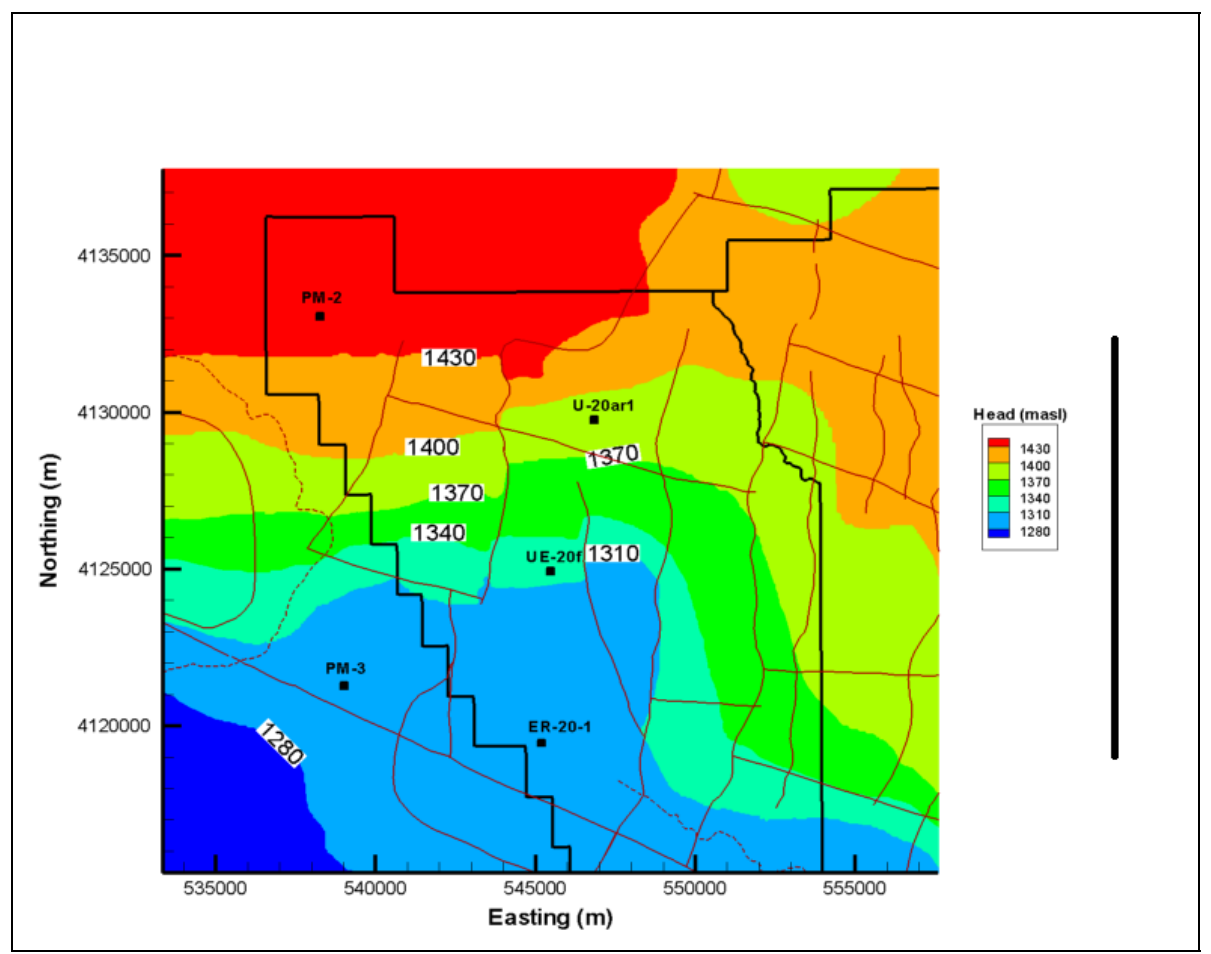

Figure 5-45

Simulated Heads Near the Purse Fault for SCCC-MME-SDA 

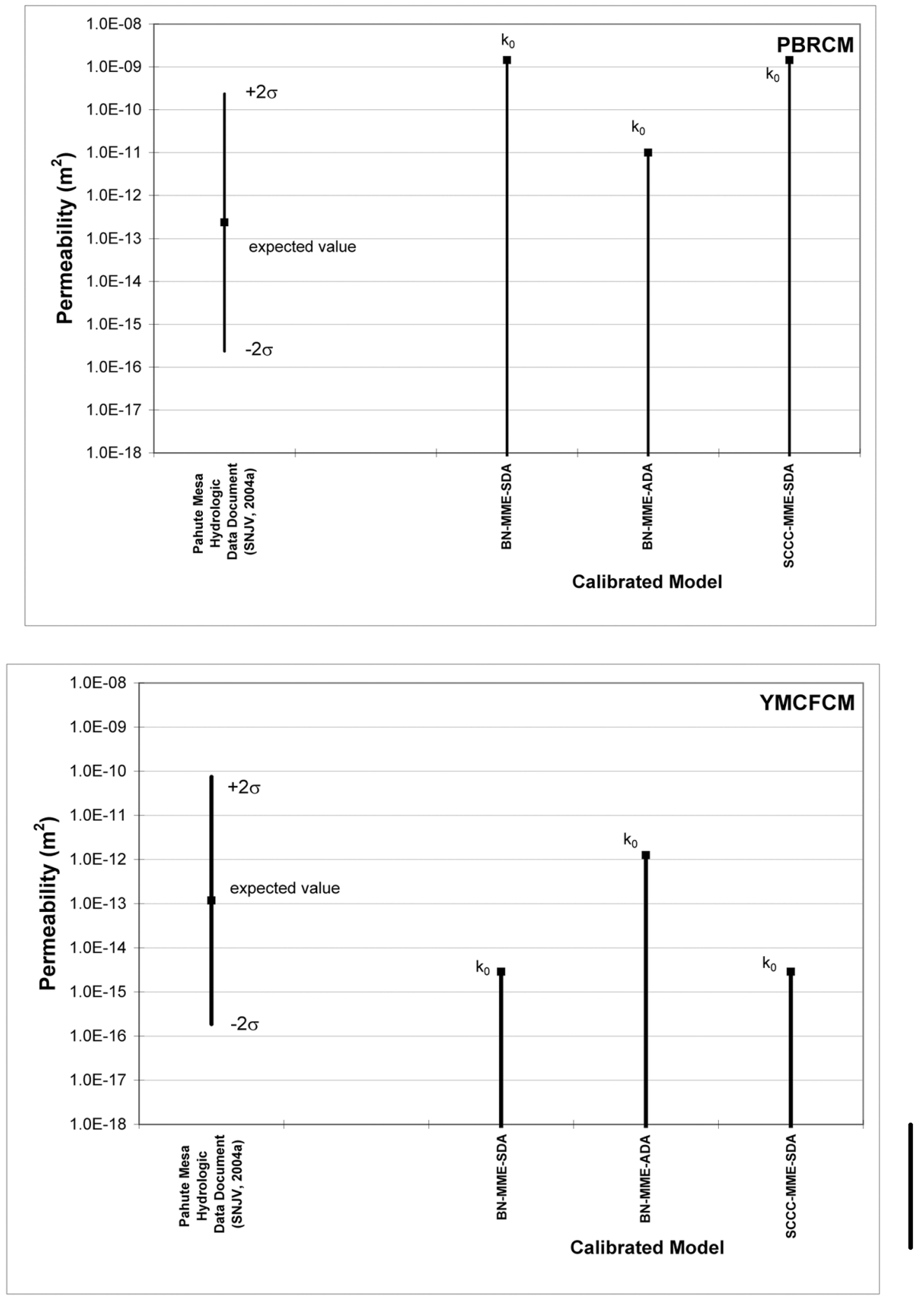

Figure 5-54

Comparison of Model and Estimated Permeabilities for PBRCM and YMCFCM 
resulted in approximately 200 parameters that were varied. Generating results for this perturbation analysis required approximately 1,400 simulations.

Plots of mean difference in heads, difference in the objective function and its constituents, and difference in boundary fluxes were generated for each of the approximately 200 parameters in the base HFM - all HSU depth-decay and anisotropy model perturbation analysis. The file names of these plots are listed in Appendix D and are available on the enclosed CD. Figures 6-19 through 6-24 describe selected sensitivity relationships.

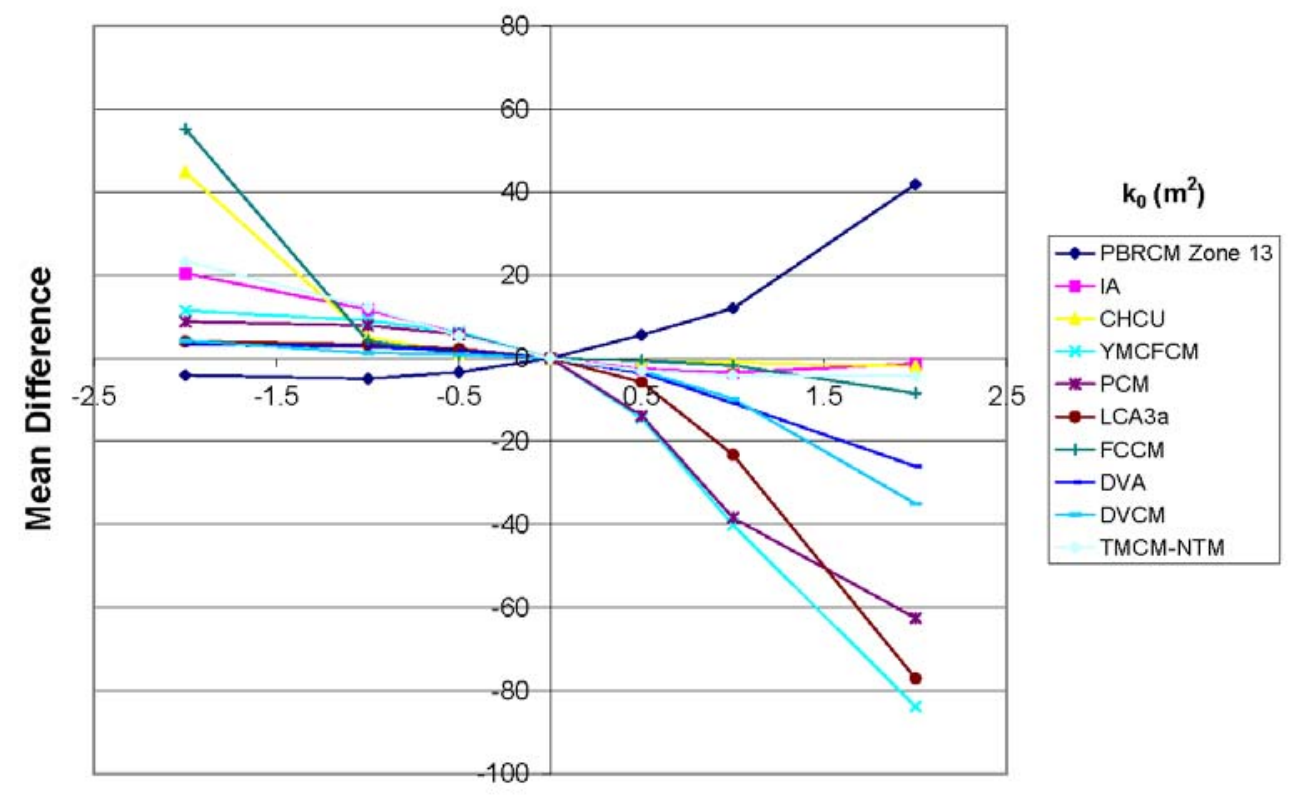

Base Value +l-Standard Deviation

Figure 6-19

Mean Head Difference for BN-MME-ADA

Figures 6-19 through 6-21 depict select perturbation plots for the mean difference in heads at target locations. Figures 6-19 and 6-20 show that the $\mathrm{k}_{0}$ and depth-decay parameters exhibit a nonlinear sensitivity relationship. It is also interesting that increases in the permeability for some HSUs results in higher heads while the opposite is true for other HSUs. Figure 6-19 indicates that the reference permeability of YMCFCM, LCA3a, and PCM have the greatest effect on simulated heads, although the DVCM, DVA, and PBRCM under Pahute Mesa also have noticeable influence. The YMCFCM and PCM are likely sensitive because (as discussed in the previous section) they lie along the southern edge of the model and can control both flow and head in the model. The PBRCM under 
The most sensitive parameters with respect to the objective function are different than for the selected HSU depth-decay and anisotropy parameterization approach. Notably, the IA $\mathrm{k}_{0}$ has some control on mean heads. Some parameters are sensitive in both this parameterization approach and in the BN-MME-SDA case (see Section 6.2.2.1), including the PCM, YMCFCM, and DVCM. The PCM and YMCFCM have depth decay in the all HSU and selected HSU decay cases, but DVCM does not, and yet it is still sensitive. On the other hand, the LCCU1 permeability was very sensitive without depth decay, but much less so with depth decay (this is explored further in Section 6.2.4.2).

\subsubsection{SCCC HFM - Selected Depth-Decay and Anisotropy (SCCC-MME-SDA) Model Parameter Perturbation Analysis}

For the SCCC HFM - selected depth-decay and anisotropy model (SCCC-MME-SDA), 45 permeability (including $\mathrm{k}_{0}$ ) parameters, 10 vertical anisotropy parameters, 15 depth-decay parameters, and 29 fault permeability multiplier parameters were varied. In addition, vertical anisotropy was varied as a single grouped parameter and depth decay was varied as two groups one for the carbonates and one for the volcanics as well as by HSU. This resulted in approximately 100 parameters that were varied. To generate results for each perturbation case required approximately 600 model runs.

Plots of mean difference in heads, difference in the objective function and its constituents, and difference in boundary fluxes were generated for each of the approximately 100 parameters in the SCCC-MME-SDA model perturbation analysis. The file names of these plots are listed in Appendix D and are available on the enclosed CD. Figures 6-25 through 6-28 describe selected sensitivity relationships.

Figures 6-25 through 6-28 show selected perturbation plots for the mean difference in heads at target locations. These figures indicate that the permeability, $\mathrm{k}_{0}$, depth decay, and fault permeability multiplier parameters generally exhibit the same type of sensitivity relationships as observed in the base HFM where an increase in a parameter value is accompanied by a consistent trend of either an increase or decrease in the simulated head. In particular, $\mathrm{PCM} \mathrm{k}_{0}$ and DVCM permeability have the same one-sided behavior for all three models analyzed, where average head drops with increasing value; PCM much less so for this HFM. This is reasonable because outside the Silent Canyon Caldera all the HFMs are the same. The PBRCM $\mathrm{k}_{0}$ also affects heads in the same one-sided fashion in all three models with head rising at higher values. The CHCU permeability, which in the SCCC 
Table 6-14

Calibration Summary Statistics for BN-MME-SDA Reduced LCCU1 Permeability Alternative

\begin{tabular}{||c|c|c|c|c|c|}
\hline $\begin{array}{c}\text { Calibration } \\
\text { Data }\end{array}$ & $\begin{array}{c}\text { Number of } \\
\text { Data }\end{array}$ & $\begin{array}{c}\text { Mean } \\
\text { Weighted } \\
\text { Errora }\end{array}$ & $\begin{array}{c}\text { Maximum } \\
\text { Weighted } \\
\text { Residual }\end{array}$ & $\begin{array}{c}\text { Minimum } \\
\text { Weighted } \\
\text { Residual }\end{array}$ & $\begin{array}{c}\text { Error } \\
\text { Standard } \\
\text { Deviation }\end{array}$ \\
\hline \hline Well Head & 152 & -0.056 & 21 (WW-8) & -24 (U-19ad) & 7.3 \\
\hline Spring Head & 28 & 2.6 & $\begin{array}{c}19 \text { (Torrance } \\
\text { Spring) }\end{array}$ & $\begin{array}{c}-6.3(\text { Spring id } \\
159)\end{array}$ & 6.8 \\
\hline $\begin{array}{c}\text { Oasis Valley } \\
\text { Discharge }\end{array}$ & 7 & 3.4 & 41 (Zone 3) & -29 (Zone 4) & 23 \\
\hline Boundary Flow & 4 & -13 & 26 (West) & -47 (North) & 29 \\
\hline
\end{tabular}

aPositive sign is undersimulation of target data, negative is oversimulation.

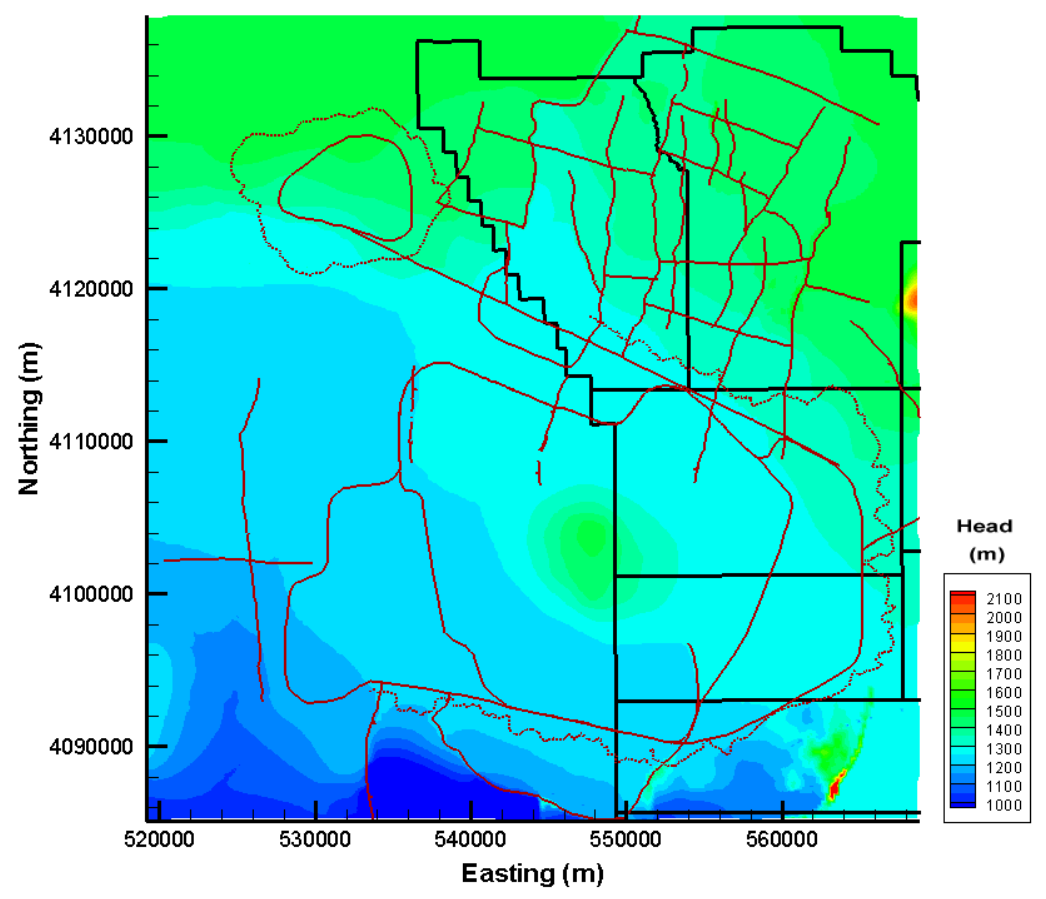

Figure 6-73

Simulated Water Table for BN-MME-SDA Reduced LCCU1 Permeability Alternative 


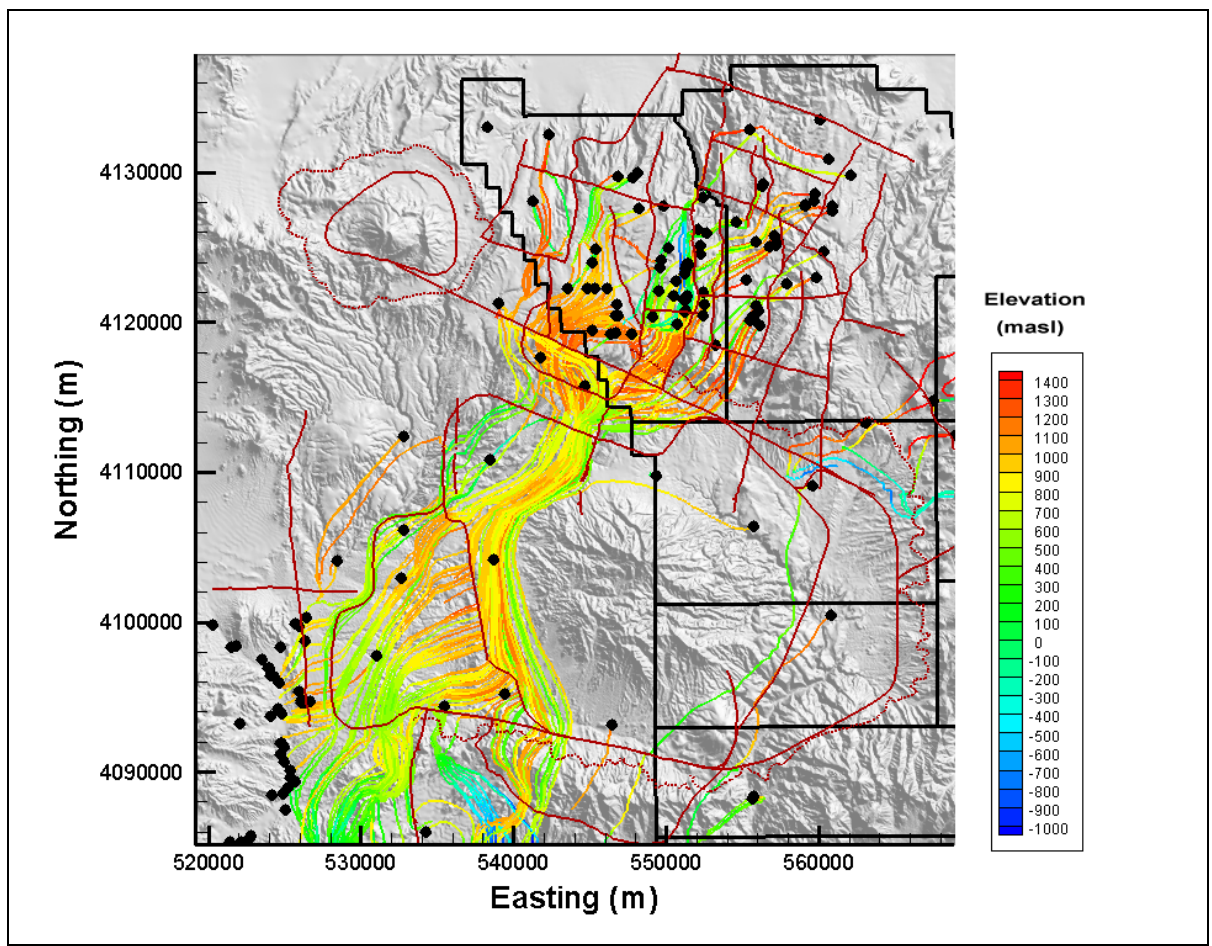

Figure 6-74

Particle Tracks for BN-MME-SDA

Reduced LCCU1 Permeability Alternative

\subsubsection{Chimney Permeability Enhancement}

Pawloski et al. (2001) used chimney permeability values that were at least 70 times higher than the native rock to simulate groundwater flow near CHESHIRE. The chimneys were incorporated in the CAU flow model mesh where the tests were below the water table, and their effect on the flow model was investigated by applying a permeability multiplier of 70 for the chimney nodes. Table 6-15 summarizes the calibration statistics. The objective function changed slightly to 16,609 from 16,651 in the base HFM. Figure 6-75 shows the simulated flow paths, which are very similar to the base HFM - selected HSU depth-decay and anisotropy results. It is concluded that there is very little flow model sensitivity to chimney permeability alteration.

Conceptually this is correct, because the overall scale of alteration is relatively small and any observation well close enough to a test to detect the chimney permeability alteration would be so affected by the test that it would be difficult to use in the calibration. 
Table 6-15

Calibration Summary Statistics for Chimney Permeability Enhancement

\begin{tabular}{||c|c|c|c|c|c||}
\hline $\begin{array}{c}\text { Calibration } \\
\text { Data }\end{array}$ & $\begin{array}{c}\text { Number of } \\
\text { Data }\end{array}$ & $\begin{array}{c}\text { Mean } \\
\text { Weighted } \\
\text { Error }^{\mathrm{a}}\end{array}$ & $\begin{array}{c}\text { Maximum } \\
\text { Weighted } \\
\text { Residual }\end{array}$ & $\begin{array}{c}\text { Minimum } \\
\text { Weighted } \\
\text { Residual }\end{array}$ & $\begin{array}{c}\text { Error } \\
\text { Standard } \\
\text { Deviation }\end{array}$ \\
\hline \hline Well Head & 152 & -0.4 & 19 (ER-OV-06a) & $\begin{array}{c}-27 \text { (UE-20n \#1 } \\
1,005.84 \mathrm{~m})\end{array}$ & 7.5 \\
\hline Spring Head & 28 & 2.8 & $\begin{array}{c}19 \text { (Torrance } \\
\text { Spring) }\end{array}$ & $\begin{array}{c}-5.5(\text { Ute } \\
\text { Springs Culvert) }\end{array}$ & 6.7 \\
\hline $\begin{array}{c}\text { Oasis Valley } \\
\text { Discharge }\end{array}$ & 7 & 4.9 & 41 (Zone 3) & -26 (Zone 4) & 24 \\
\hline Boundary Flow & 4 & -14 & 26 (West) & -36 (South) & 27 \\
\hline
\end{tabular}

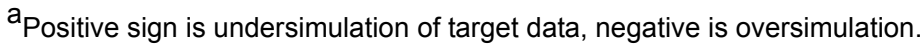

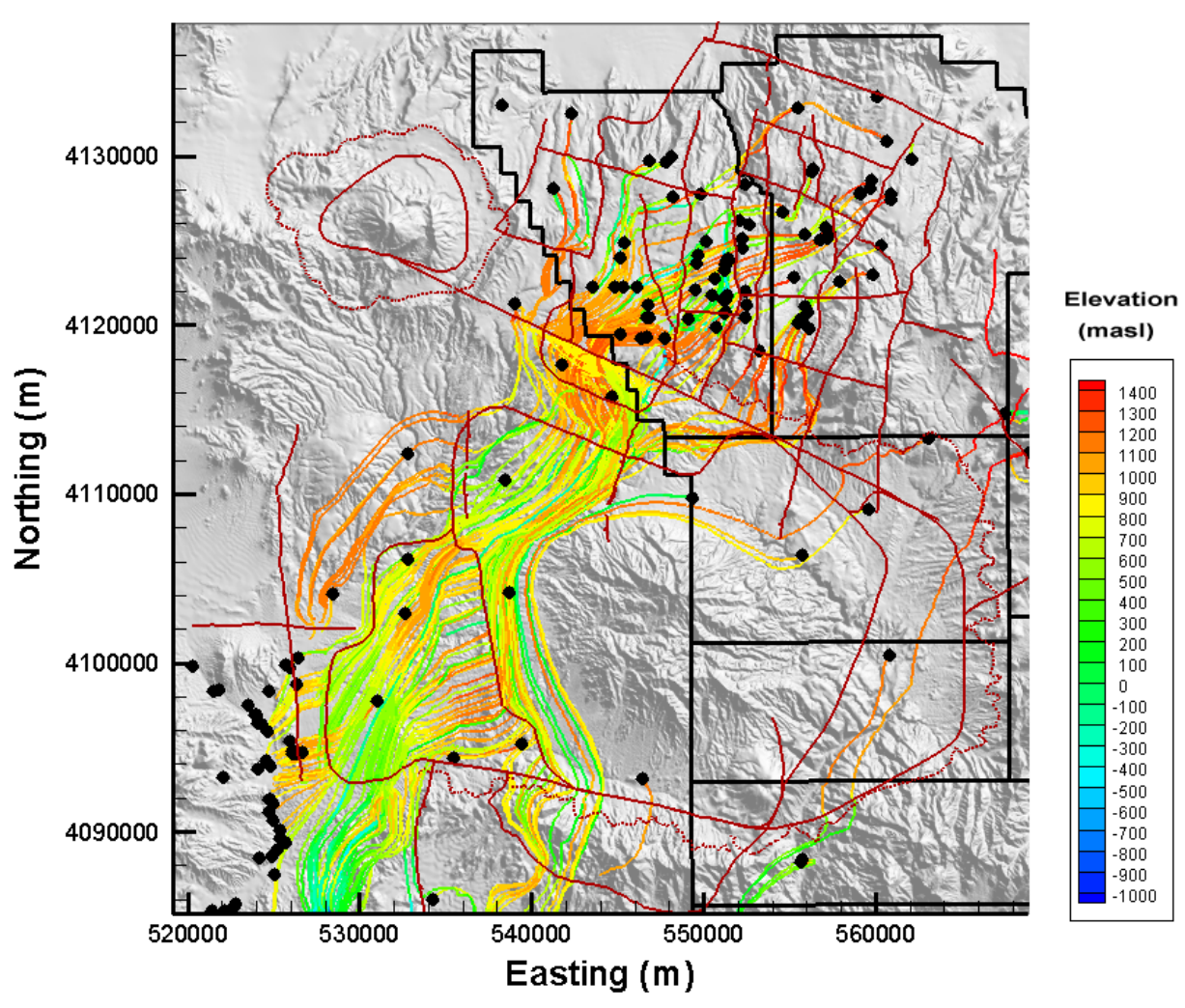

Figure 6-75

Particle Tracks for Chimney Permeability Enhancement 


\subsubsection{Fortymile Canyon Alternative}

This variation was designed to test the model sensitivity to flow down Fortymile Canyon. The TMCM Northern Timber Mountain eastern subdivision, Timber Mountain Dome, and Ammonia Tanks eastern subdivision permeabilities were all raised an order of magnitude to try to direct more flow down Fortymile Canyon. The LCCU1 permeability was dropped an order of magnitude to remove its influence and test the ability of recharge in the canyon to support the flow field. This analysis was done only on the base HFM selected HSU depth-decay and anisotropy parameterization, with the USGSD recharge model (which generally tends to give the best calibration results).

Calibration summary statistics are shown in Table 6-16, with simulated Oasis Valley (179 simulated versus $227 \mathrm{~kg} / \mathrm{s}$ observed) discharge is noticeably lower as the mean observation well error with respect to Table 5-9 in Section 5.6.2. The simulated Oasis Valley discharge is about two standard deviations (about $30 \mathrm{~kg} / \mathrm{s}$ ) away from the estimated value; thus, this model has a lower plausibility than others that agree better with Oasis Valley discharge data. WW-8 is the well with the highest undersimulation in this case, which is consistent with the effects of dropping the LCCU1 permeability. The objective simulation for these results is 19,588 , which is slightly worse than the value of 16,651 shown in Section 5.6.2, but still better than the SCCC-MME-SDA and BN-MME-ADA cases.

Table 6-16

Calibration Summary Statistics for BN-MME-SDA Fortymile Canyon Alternative

\begin{tabular}{|c|c|c|c|c|c|}
\hline $\begin{array}{c}\text { Calibration } \\
\text { Data }\end{array}$ & $\begin{array}{c}\text { Number of } \\
\text { Data }\end{array}$ & $\begin{array}{c}\text { Mean } \\
\text { Weighted } \\
\text { Errora }\end{array}$ & $\begin{array}{c}\text { Maximum } \\
\text { Weighted } \\
\text { Residual }\end{array}$ & $\begin{array}{c}\text { Minimum } \\
\text { Weighted } \\
\text { Residual }\end{array}$ & $\begin{array}{c}\text { Error } \\
\text { Standard } \\
\text { Deviation }\end{array}$ \\
\hline \hline Well Head & 152 & 1.3 & 52 (WW-8) & -23 (U-19ad) & 8.7 \\
\hline Spring Head & 28 & 3.1 & $\begin{array}{c}19 \text { (Torrance } \\
\text { Spring) }\end{array}$ & $\begin{array}{c}-5.3 \text { (Spring id } \\
159)\end{array}$ & 6.8 \\
\hline $\begin{array}{c}\text { Oasis Valley } \\
\text { Discharge }\end{array}$ & 7 & 14 & 47 (Zone 2) & -11 (Zone 3) & 26 \\
\hline Boundary Flow & 4 & 2.8 & 30 (East) & -32 (North) & 24 \\
\hline
\end{tabular}

aPositive sign is undersimulation of target data, negative is oversimulation. 
Table 6-17

Calibration Summary Statistics for LCCU1-MME-SDA with Selected HSU Horizontal Anisotropy of 5:1

\begin{tabular}{|c|c|c|c|c|c|}
\hline $\begin{array}{c}\text { Calibration } \\
\text { Data }\end{array}$ & $\begin{array}{c}\text { Number of } \\
\text { Data }\end{array}$ & $\begin{array}{c}\text { Mean } \\
\text { Weighted } \\
\text { Errora }\end{array}$ & $\begin{array}{l}\text { Maximum } \\
\text { Weighted } \\
\text { Residual }\end{array}$ & $\begin{array}{l}\text { Minimum } \\
\text { Weighted } \\
\text { Residual }\end{array}$ & $\begin{array}{c}\text { Error } \\
\text { Standard } \\
\text { Deviation }\end{array}$ \\
\hline Well Head & 152 & -0.74 & $\begin{array}{c}20 \\
(\text { ER-OV-06a) }\end{array}$ & $\begin{array}{c}-21 \\
(U E-20 n \text { \#1 } \\
1,005.84 \mathrm{~m})\end{array}$ & 7.4 \\
\hline Spring Head & 28 & 5.2 & $\begin{array}{c}19 \\
\text { (Torrance } \\
\text { Spring) }\end{array}$ & $\begin{array}{c}-6.5 \\
\text { (Spring id 159) }\end{array}$ & 8.5 \\
\hline $\begin{array}{l}\text { Oasis Valley } \\
\text { Discharge }\end{array}$ & 7 & -5.0 & $\begin{array}{c}62 \\
\text { (Zone 5) }\end{array}$ & $\begin{array}{c}-104 \\
\text { (Zone 4) }\end{array}$ & 51 \\
\hline Boundary Flow & 4 & -9.1 & $\begin{array}{c}38 \\
\text { (West) }\end{array}$ & $\begin{array}{c}-33 \\
\text { (South) }\end{array}$ & 29 \\
\hline
\end{tabular}

apositive sign is undersimulation of target data, negative is oversimulation.

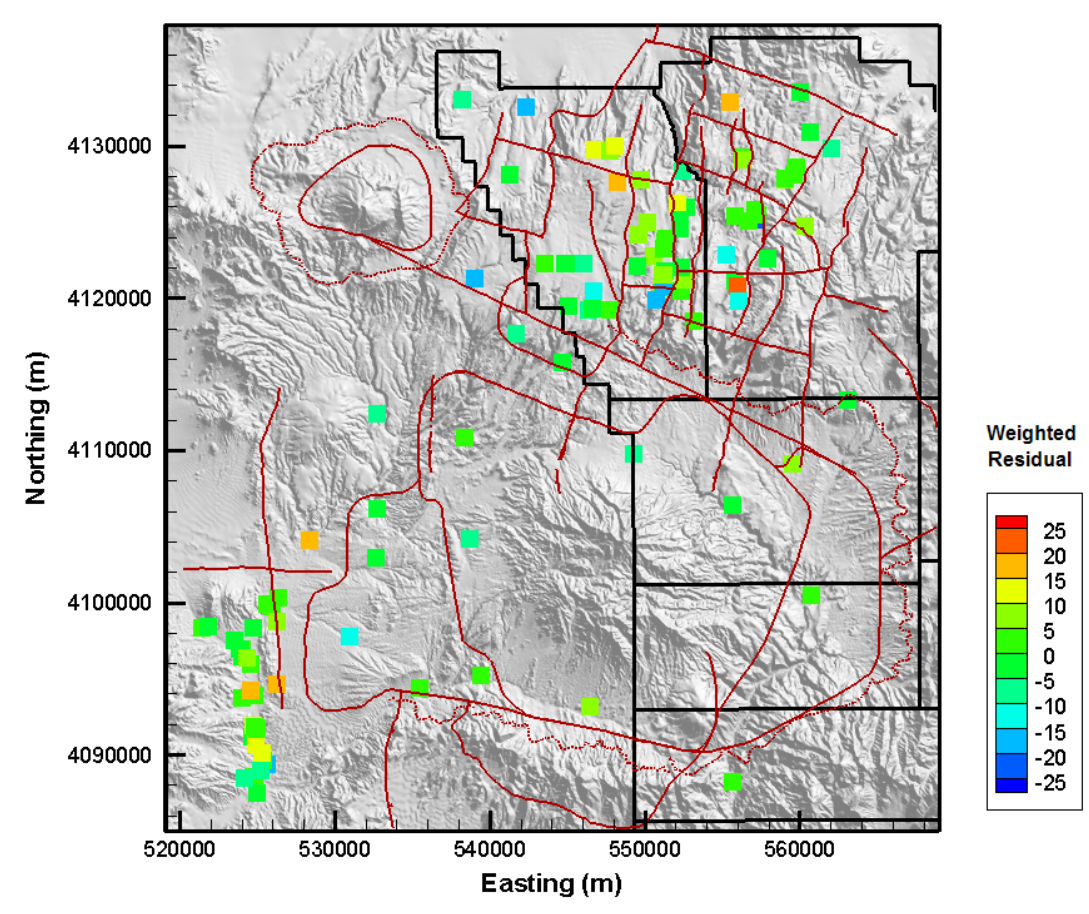

Figure 6-82

Post Plot of Weighted Well and Spring Head Residuals for BN-MME-SDA Reduced LCCU1 Permeability Alternative with 5:1 North-South Anisotropy 
Table 6-18

Calibration Summary Statistics for Timber Mountain Dome Sensitivity

\begin{tabular}{|c|c|c|c|c|c|}
\hline $\begin{array}{l}\text { Calibration } \\
\text { Data }\end{array}$ & $\begin{array}{c}\text { Number } \\
\text { of Data }\end{array}$ & $\begin{array}{c}\text { Mean } \\
\text { Weighted } \\
\text { Error }^{\mathrm{a}}\end{array}$ & $\begin{array}{c}\text { Maximum } \\
\text { Weighted Residual }\end{array}$ & $\begin{array}{l}\text { Minimum } \\
\text { Weighted } \\
\text { Residual }\end{array}$ & $\begin{array}{c}\text { Error } \\
\text { Standard } \\
\text { Deviation }\end{array}$ \\
\hline Well Head & 152 & $\begin{array}{l}0.44^{b} \\
1.4^{c} \\
0.12^{d}\end{array}$ & $\begin{array}{l}23(\mathrm{WW}-8) \\
27 \text { (WW-8) } \\
41(\mathrm{WW}-8)\end{array}$ & $\begin{array}{c}-23 \text { (U-19ad) } \\
-21 \text { (U-19ad) } \\
-24(\text { UE-20n \#1 } \\
1,005.84 \mathrm{~m})\end{array}$ & $\begin{array}{l}7.3 \\
7.8 \\
8.8\end{array}$ \\
\hline Spring Head & 28 & $\begin{array}{l}2.6 \\
2.5 \\
2.7\end{array}$ & $\begin{array}{l}19 \text { (Torrance Spring) } \\
19 \text { (Torrance Spring) } \\
19 \text { (Torrance Spring) }\end{array}$ & $\begin{array}{l}-6.4 \text { (Spring id 159) } \\
-6.3 \text { (Spring id 159) } \\
-5.5 \text { (Spring id 159) }\end{array}$ & $\begin{array}{l}6.8 \\
6.9 \\
6.8\end{array}$ \\
\hline $\begin{array}{l}\text { Oasis Valley } \\
\text { Discharge }\end{array}$ & 7 & $\begin{array}{l}2.8 \\
1.1 \\
-2.9\end{array}$ & $\begin{array}{l}1 \text { (Zone 3) } \\
40 \text { (Zone 3) } \\
33 \text { (Zone 3) }\end{array}$ & $\begin{array}{l}-30 \text { (Zone 4) } \\
-33 \text { (Zone 4) } \\
-53 \text { (Zone 4) }\end{array}$ & $\begin{array}{l}23 \\
24 \\
29\end{array}$ \\
\hline Boundary Flow & 4 & $\begin{array}{l}-12.7 \\
-11.9 \\
-10.3\end{array}$ & $\begin{array}{l}26 \text { (West) } \\
26 \text { (West) } \\
26 \text { (West) }\end{array}$ & $\begin{array}{l}-47 \text { (North) } \\
-45 \text { (North) } \\
-57 \text { (North) }\end{array}$ & $\begin{array}{l}29 \\
29 \\
35\end{array}$ \\
\hline
\end{tabular}

apositive sign is undersimulation of target data, negative is oversimulation.

bMaterial 74 Timber Mountain Dome x 10

'Material 74 Timber Mountain Dome x 100

dHomogenous TMCM

Figure 6-90 shows the posted weighted residuals. The most notable change is the increasing underprediction in the area of WW- 8 as the Timber Mountain Dome reference permeability increases, and in the homogenous case. Forming the mound under Timber Mountain clearly has an effect in this area, although less so elsewhere. Figure 6-91 shows the simulated water table, and Figure 6-92 shows the simulated flow paths. As the Timber Mountain Dome reference permeability increases, decreasing the simulated mound, the potentiometric surface grows flatter (as it conceptually should). The flow paths become more diffuse through the Timber Mountain area as the mound diminishes and no longer focuses flow on its northwest and northeast shoulders. 
Addendum to GFM CAUs 101 and 102

Final Document Date: June 2006

Revision: 0

Section 6.3.1, Page 6-119

Addendum Date: May 2007

The remainder of this section describes the calibration of the five major alternate models (those for which EV models were constructed) to the MME recharge and boundary flow targets. The selected HSU depth-decay and anisotropy approach described in Section 5.6.2 was used in parameterizing the models beginning with the calibrated parameters as shown in Section 5.6.2. Calibration was stopped when the objective function was less than the worst calibrated model described in Section 5.0, a value of about 30,000. It is computationally infeasible to investigate these alternatives with the other parameterization approaches discussed in Section 5.6.

\subsubsection{Thirsty Canyon Lineament Alternative (TCL-MME-SDA)}

The Thirsty Canyon Lineament is a geophysically inferred structure. Because of its northwest trend, presence in Oasis Valley, and short distance from western Area 20 if this feature is caused by faulting it could be an enhanced flow path, although it may also be a barrier. This alternative places more permeable fractured rocks in the area. See Section 6.4 in BN (2002) for more information.

Plots of observed versus simulated values for the calibration wells, springs, Oasis Valley discharge, and boundary flows are shown in Figures 6-94 through 6-97. The scatter around the line of perfect agreement is generally random in Figure 6-94, until an observed head of 1,450 $\mathrm{m}$ is exceeded. At the very highest observed observation well heads, the model has a tendency toward undersimulation. The remaining errors above 1,450 $\mathrm{m}$ are all in far eastern Area 19, where data become very sparse and uncertainty increases. Figure 6-98 shows a histogram of weighted observation well residuals. The bulk of the weighted errors are less than 10 . The errors are very symmetrically distributed around zero. The total errors above +10 and below -10 appear to be about the same.

The Oasis Valley discharge and boundary flow components provide the water-balance constraint on the model. The total estimated Oasis Valley discharge in the CAU model domain; the simulated discharge, shown in Figure 6-96, is $209 \mathrm{~kg} / \mathrm{s}$. The total error is within one standard deviation $(30 \mathrm{~kg} / \mathrm{s})$ as reported by Laczniak et al. (2001). The model trends the same as the data with some scatter, showing that the general representation of the area is correct. The boundary flows, estimated from regional model analysis, all trend the correct way (e.g., have the proper sign), with the largest relative misfit on the western edge. 


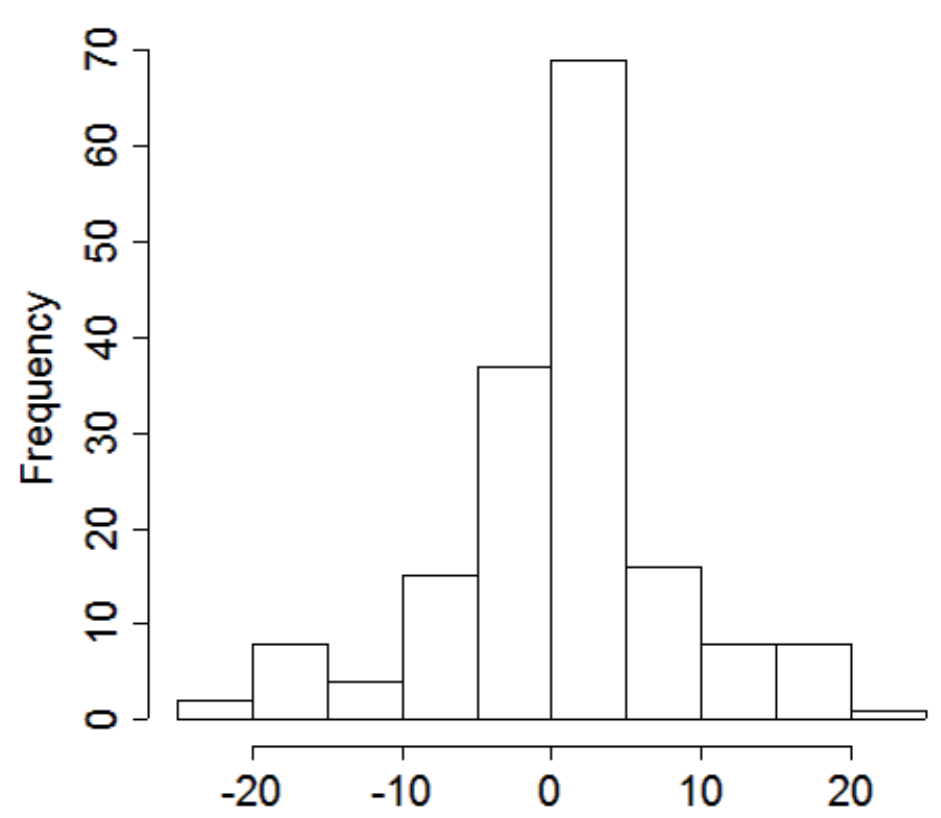

Figure 6-98

Histogram of Weighted Head Residuals for TCL-MME-SDA

The weighted head and spring errors are shown on Figure 6-99, color coded by value and sign. The driest, or undersimulated, well was U-19x. The single wettest well was UE-20n \#1. In general, the errors are randomly distributed, although there is a slight dry bias in northern Area 20 at Easting and Northing of about 547,500 and 4,130,000 m, which includes Wells U-20i, UE-20e \#1, U-20e, and U-20ar \#1.

The quantitative measures of the model calibration are given by summary statistics shown in Table 6-21. These statistics alone are not used to judge model calibration; they are used to highlight errors in conjunction with the graphical approaches described previously. The mean error in well head is nearly zero (recall the symmetric residual histogram), a slight dry bias in the spring heads, with a slight overprediction bias for the flows. The total model objective function was 16,564; only 87 different than the base HFM $(16,651)$. Table 6-22 shows the contribution of each data type to the total model goodness of fit.

Figure 6-100 shows the simulated water table for this model case. In the western part of Area 20, the influence of the Purse Fault is evident by the large offset in heads across it, with more subdued effects 


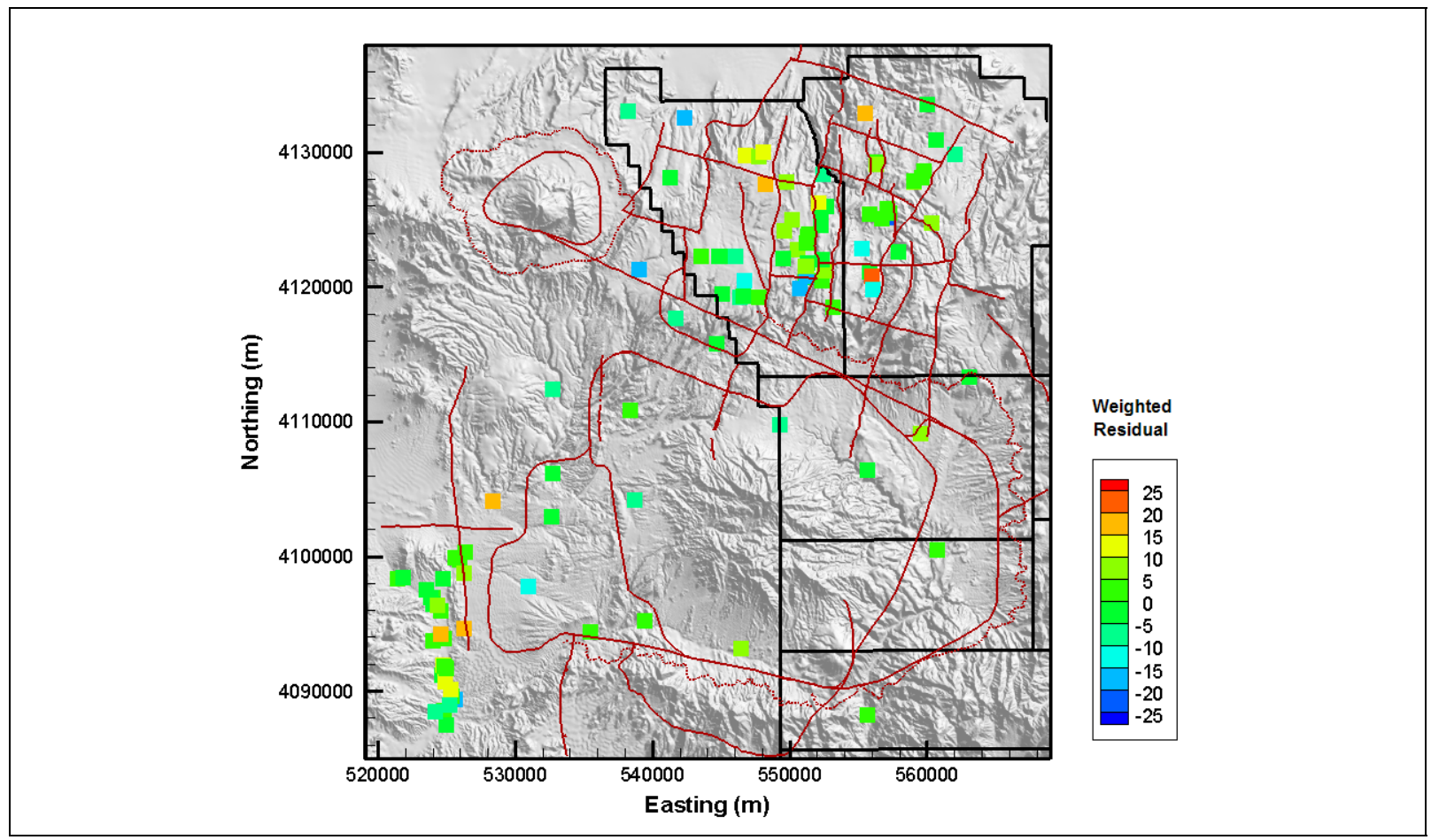

Figure 6-99

Post Plot of Weighted Well and Spring Head Residuals for TCL-MME-SDA

Table 6-21

Calibration Summary Statistics for TCL-MME-SDA

\begin{tabular}{|c|c|c|c|c|c|}
\hline $\begin{array}{c}\text { Calibration } \\
\text { Data }\end{array}$ & $\begin{array}{c}\text { Number of } \\
\text { Data }\end{array}$ & $\begin{array}{c}\text { Mean } \\
\text { Weighted } \\
\text { Error }^{\mathrm{a}}\end{array}$ & $\begin{array}{c}\text { Maximum } \\
\text { Weighted } \\
\text { Residual }\end{array}$ & $\begin{array}{c}\text { Minimum } \\
\text { Weighted } \\
\text { Residual }\end{array}$ & $\begin{array}{c}\text { Error } \\
\text { Standard } \\
\text { Deviation }\end{array}$ \\
\hline \hline Well Head & 152 & -0.09 & $22(\mathrm{U}-19 \mathrm{x})$ & -24 (UE-20n \#1) & 7.4 \\
\hline Spring Head & 28 & 2.7 & $\begin{array}{c}19 \text { (Torrance } \\
\text { Spring) }\end{array}$ & $\begin{array}{c}-5.5 \text { (Spring id } \\
159)\end{array}$ & 6.8 \\
\hline $\begin{array}{c}\text { Oasis Valley } \\
\text { Discharge }\end{array}$ & 7 & 4.8 & 39 (Zone 3) & -29 (Zone 4) & 24 \\
\hline Boundary Flow & 4 & -14 & 26 (West) & -35 (South) & 27 \\
\hline
\end{tabular}

aPositive sign is undersimulation of target data, negative is oversimulation.

also present at West Boxcar Fault. Water flows from Areas 19 and 20 toward the southwest and Oasis Valley. Particle tracking (Figure 6-101) from each of the NTS wells shows the same generally noted flow paths as shown in Appendix A of the Pahute Mesa hydrologic data document (SNJV, 2004a). 
accounted for by LCA. This alternative distributes the BA, TCA, TSA, and CFCM further south so that they pinch out or truncate against the older, presumably less permeable units that form the bench, disrupting flow paths from Pahute Mesa. See Section 6.3 in BN (2002) for more information.

Plots of observed versus simulated values for the calibration wells, springs, Oasis Valley discharge, and boundary flows are shown in Figures 6-102 through 6-105. The scatter around the line of perfect agreement is generally random in Figure 6-102, until an observed head of 1,450 m is exceeded. At the very highest observed observation well heads, the model has a tendency toward undersimulation. On Figure 6-103, the line of perfect agreement is shown, and ideally the data would plot exactly onto this line. However, in general, the model has a tendency to under simulate spring head. The plot is not significantly different than those shown in Section 5.6.2. Figure 6-105 presents a plot of observed versus simulated values for boundary flows.

Figure 6-106 shows a histogram of weighted observation well residuals. The bulk of the weighted errors are less than \pm 10 . The errors are not symmetrically distributed around zero, with larger oversimulated (negative sign) wells. The total errors above +10 and below -10 appear to be about the same.

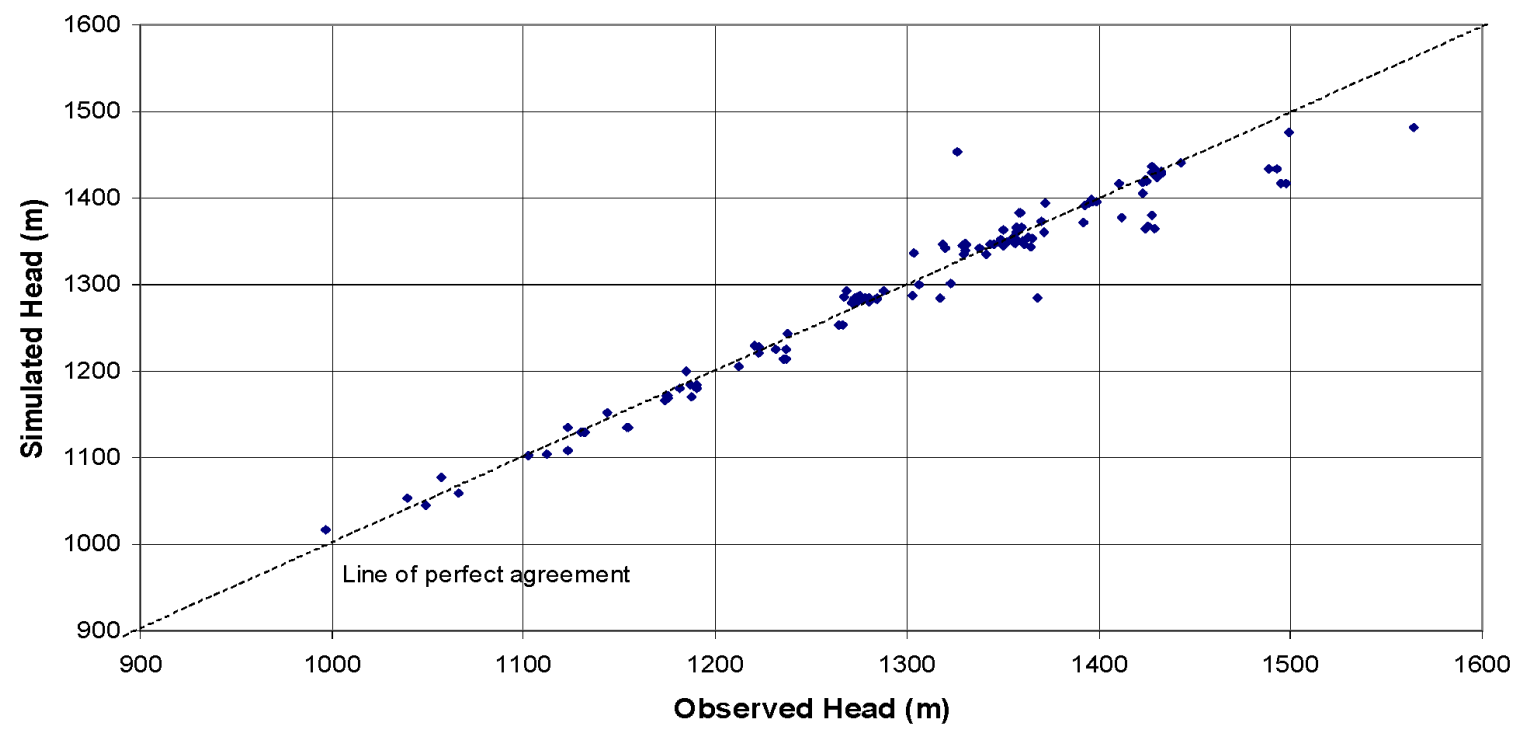


The Oasis Valley discharge and boundary flow components provide the water-balance constraint on the model. The total estimated Oasis Valley discharge in the CAU model domain is $227 \mathrm{~kg} / \mathrm{s}$; the simulated discharge, shown in Figure 6-104, is $183 \mathrm{~kg} / \mathrm{s}$. This is about a 1.5 standard deviation less than the estimated value, which makes this model less good than most others in this regard. The model trends the same as the data with some scatter, showing that the general representation of Oasis Valley is correct. The boundary flows, estimated from regional model analysis, all trend the correct way (e.g., have the proper sign), with the largest relative misfit on the western edge.

The weighted head and spring errors are shown on Figure 6-107, color coded by value and sign. The driest, or undersimulated, well was U-20m. The most overpredicted head was at Well UE-20n \#1. In general, the errors are randomly distributed, although there is a slight dry bias in northern Area 20 at Easting and Northing of about 547,500 and 4,130,000 m, which includes Wells U-20i, UE-20e \#1, U-20e, and U-20ar \#1.

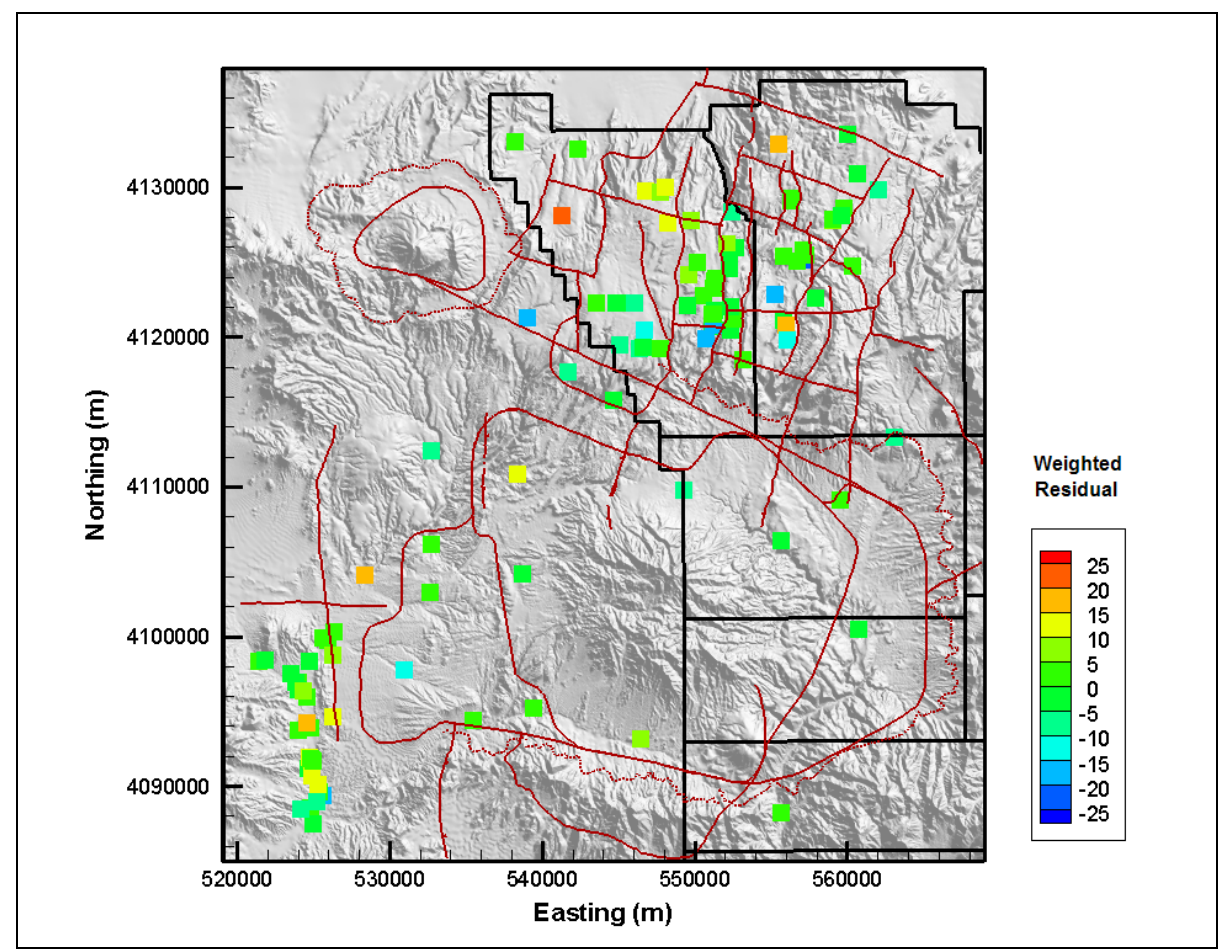

Figure 6-107

Post Plot of Weighted Well and Spring Head Residuals for RIDGE-MME-SDA

The quantitative measures of the model calibration are given by summary statistics shown in Table 6-24. There is a slight oversimulation bias for well heads. There is a slight dry bias in the 
spring heads, with a slight overprediction bias for the flows. The total model objective function was 18,459, which is slightly worse than the best base HFM calibration (BN-MME-SDA). Table 6-25 shows the contribution of each data type to the total model goodness of fit.

Table 6-24

Calibration Summary Statistics for RIDGE-MME-SDA

\begin{tabular}{|c|c|c|c|c|c|}
\hline $\begin{array}{c}\text { Calibration } \\
\text { Data }\end{array}$ & $\begin{array}{c}\text { Number of } \\
\text { Data }\end{array}$ & $\begin{array}{c}\text { Mean Weighted } \\
\text { Errora }\end{array}$ & $\begin{array}{c}\text { Maximum } \\
\text { Weighted } \\
\text { Residual }\end{array}$ & $\begin{array}{c}\text { Minimum } \\
\text { Weighted } \\
\text { Residual }\end{array}$ & $\begin{array}{c}\text { Error } \\
\text { Standard } \\
\text { Deviation }\end{array}$ \\
\hline \hline Well Head & 152 & -0.07 & $23($ U-20m) & -27 (UE-20n \#1) & 7.8 \\
\hline Spring Head & 28 & 2.8 & $\begin{array}{c}19 \text { (Torrance } \\
\text { Spring) }\end{array}$ & $\begin{array}{c}-5.4 \text { (Spring id } \\
159)\end{array}$ & 6.8 \\
\hline $\begin{array}{c}\text { Oasis Valley } \\
\text { Discharge }\end{array}$ & 7 & 12 & 53 (Zone 3) & -13 (Zone 4) & 26 \\
\hline Boundary Flow & 4 & -17 & 20 (West) & -35 (East) & 28 \\
\hline
\end{tabular}

aPositive sign is undersimulation of target data, negative is oversimulation.

Table 6-25

Contribution to Model Goodness of Fit by Data Type for RIDGE-MME-SDA

\begin{tabular}{|c|c|c|}
\hline Data Type & Value (-) & Percent of Total \\
\hline \hline Well Head & 9,351 & 51 \\
\hline Spring Head & 1,289 & 25 \\
\hline Oasis Valley Discharge & 4,665 & 17 \\
\hline Boundary Flow & 3,154 & 100 \\
\hline Total & 18,459 & 7 \\
\hline
\end{tabular}

Figure 6-108 shows the simulated water table for this model case. In the western part of Area 20, the influence of the Purse Fault is evident by the large offset in heads across it, with more subdued effects also present at West Boxcar Fault. Particle tracking (Figure 6-109) from each of the NTS wells shows the same generally noted flow paths as shown by in Appendix A of the Pahute Mesa hydrologic data document (SNJV, 2004a). Relative to the base HFM calibration shown in Section 5.6.2, the particle tracks exit Area 20 further west and with a more even distribution. This is the effect of the truncation of BA, TCA, TSA, and CFCM against older, lower permeable units as described by BN (2002).

The parameters from BN-MME-SDA were mapped onto this HFM, and the calibration shown was obtained with no additional effort. Thus, the effects of this HFM on flow model metrics is modest. 
The nodes that were changed from the base HFM for selected HSUs are summarized in Table 6-26. A total of 89,346 nodes were changed for RIDGE. The count is the largest of all the alternatives because this case makes changes in southern Pahute Mesa where the node spacing is relatively fine. The major change is from BA to FCCU; from high to low permeability. The TCA and TSA also change as described by BN (2002) and seen in Table 6-26 to less permeable HSUs. The properties used to parameterize this model are summarized in Section 6.3.6.

Table 6-26

Selected Node Changes for RIDGE HFM Alternative

\begin{tabular}{|c|c|c|}
\hline Base HSU & Alternative HSU & Node Count \\
\hline \hline BA & FCCU & 14,609 \\
\hline CHCU & CFCU & 10,329 \\
\hline UPCU & CHCU & 4,701 \\
\hline TCA & CHCU & 4,568 \\
\hline TSA & CFCU & 2,865 \\
\hline
\end{tabular}

\subsubsection{Raised Pre-Tertiary Surface Alternative (PZUP-MME-SDA)}

The determination of depth to Paleozoic basement assumed a density/depth relation for gravity inversion. Two such distributions have been described for Pahute Mesa, which cause up to a 2-km variation in the position of the Paleozoic basement. This alternative raised the basement as much as possible and still remains in agreement with the hard data. The consequences were thought to be facilitation of groundwater flow around the eastern side of Timber Mountain. See Section 6.5 in BN (2002) for more information.

Plots of observed versus simulated values for the calibration wells, springs, Oasis Valley discharge, and boundary flows are shown in Figures 6-110 through 6-113. The scatter around the line of perfect agreement is generally random in Figure 6-110, until an observed head of 1,450 m is exceeded. At the very highest observed observation well heads, the model has a tendency toward undersimulation. On Figure 6-111, the line of perfect agreement is shown, and ideally the data would plot exactly onto this line. However, in general, the model has a tendency to under simulate spring head. The plot is not significantly different than those shown in Section 5.6.2. Figure 6-113 presents a plot of observed versus simulated values for boundary flows. Figure 6-114 shows a histogram of weighted observation well residuals. The bulk of the weighted errors 


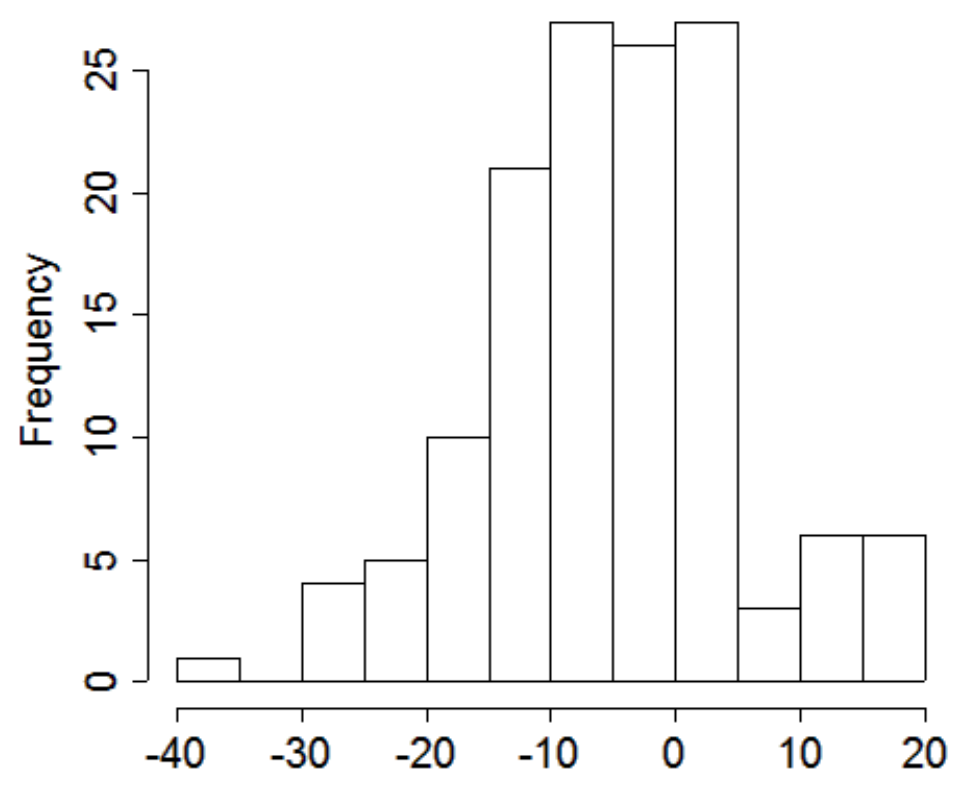

Figure 6-114 Histogram of Weighted Head Residuals for PZUP-MME-SDA

are less than \pm 10 . The errors are not symmetrically distributed around zero, with a larger proportion of oversimulated (negative sign) wells.

The total estimated Oasis Valley discharge in the CAU model domain is $227 \mathrm{~kg} / \mathrm{s}$; the simulated discharge, shown in Figure 6-112, is $209 \mathrm{~kg} / \mathrm{s}$. The total error is within one standard deviation (30 kg/s) as reported by Laczniak et al. (2001). The model trends the same as the data with some scatter, showing that the general representation of the area is correct. The boundary flows, estimated from regional model analysis, all trend the correct way (e.g., have the proper sign), with the largest relative misfit on the western edge.

The weighted head and spring errors are shown on Figure 6-115, color coded by value and sign. There is a clear tendency to oversimulate heads, although this result is not associated with commensurate oversimulation of Oasis Valley discharge. The driest, or undersimulated, well was ER-OV-03a. The single wettest well was UE-20n \#1. 


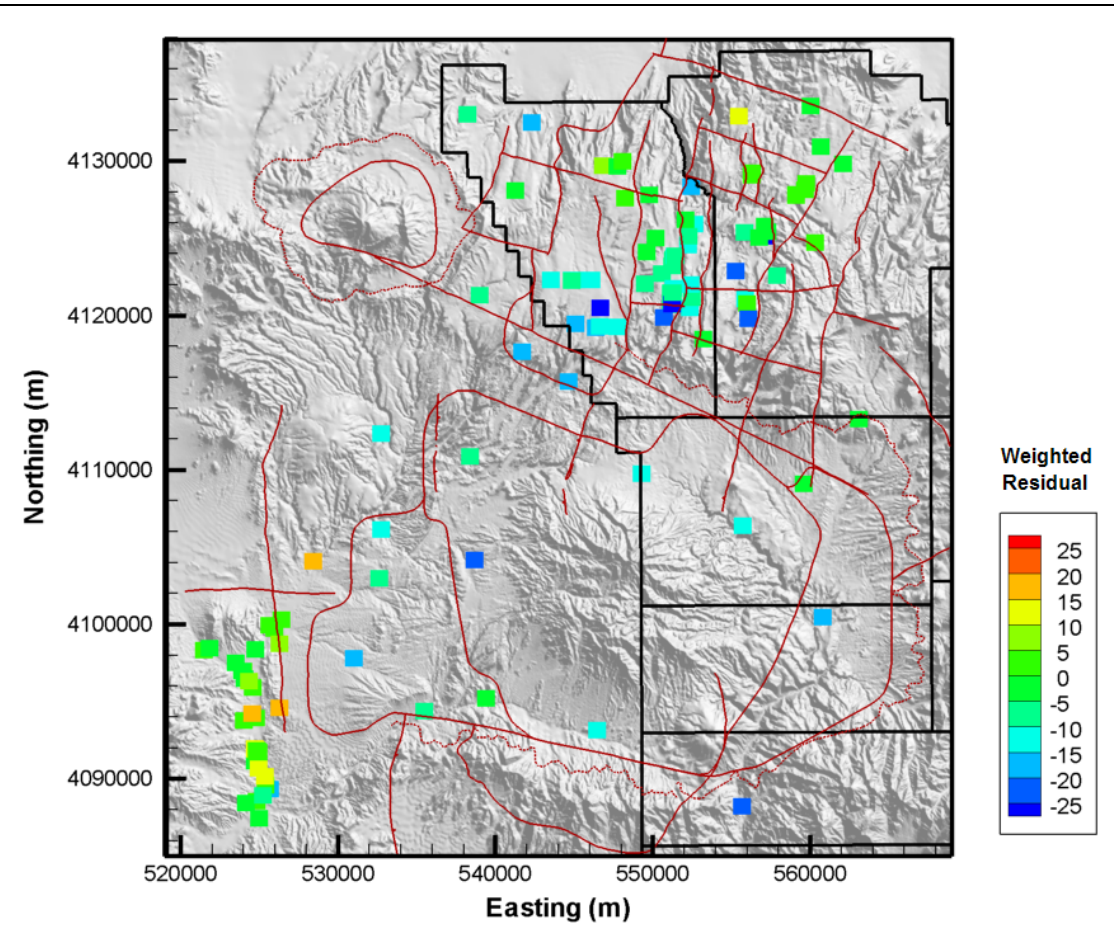

Figure 6-115

Post Plot of Weighted Well and Spring Head Residuals for PZUP-MME-SDA

The quantitative measures of the model calibration are given by summary statistics shown in Table 6-27. There is a slight dry bias in the spring heads, with a slight overprediction bias for the flows. The total model objective function was 22,513 . Table 6-28 shows the contribution of each data type to the total model goodness of fit.

Figure 6-116 shows the simulated water table for this model case. In the western part of Area 20, the influence of the Purse Fault is evident by the large offset in heads across it, with more subdued effects also present at West Boxcar Fault. Water flows from Areas 19 and 20 toward the southwest and Oasis Valley. Particle tracking (Figure 6-117) from each of the NTS wells shows the same generally noted flow paths as shown in Appendix A of the Pahute Mesa hydrologic data document (SNJV, 2004a).

The initial results from this HFM were greatly different and required substantial effort to recalibrate. The number of changed nodes and associated HSUs for the four largest categories in this alternative are shown in Table 6-29. Notice that the changes are from higher permeability units to lower permeability units found at greater depth in the base HFM. Thus, the changes for this alternative are consistent with the intent of BN (2002) to raise the pre-Tertiary/Paleozoic contact and accentuate the 
Table 6-27

Calibration Summary Statistics for PZUP-MME-SDA

\begin{tabular}{||c|c|c|c|c|c|}
\hline $\begin{array}{c}\text { Calibration } \\
\text { Data }\end{array}$ & $\begin{array}{c}\text { Number of } \\
\text { Data }\end{array}$ & $\begin{array}{c}\text { Mean Weighted } \\
\text { Error }^{\mathrm{a}}\end{array}$ & $\begin{array}{c}\text { Maximum } \\
\text { Weighted } \\
\text { Residual }\end{array}$ & $\begin{array}{c}\text { Minimum } \\
\text { Weighted } \\
\text { Residual }\end{array}$ & $\begin{array}{c}\text { Error } \\
\text { Standard } \\
\text { Deviation }\end{array}$ \\
\hline \hline Well Head & 152 & 5.1 & $18(\mathrm{U}-19 \mathrm{x})$ & $\begin{array}{c}-39 \text { (ER-OV- } \\
\text { 03b) }\end{array}$ & 10 \\
\hline $\begin{array}{c}\text { Spring Head } \\
\text { Oasis Valley } \\
\text { Discharge }\end{array}$ & 28 & 2.6 & $\begin{array}{c}19 \text { (Torrance } \\
\text { Spring) }\end{array}$ & $\begin{array}{c}-8.7 \text { (Spring id } \\
180)\end{array}$ & 6.9 \\
\hline Boundary Flow & 7 & -6.5 & 35 (Zone 3) & -64 (Zone 4) & 34 \\
\hline
\end{tabular}

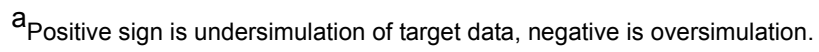

Table 6-28

Contribution to Model Goodness of Fit by Data Type for PZUP-MME-SDA

\begin{tabular}{|c|c|c|}
\hline Data Type & Value (-) & Percent of Total \\
\hline \hline Well Head & 16,416 & 61 \\
\hline Spring Head & 1,337 & 5 \\
\hline Oasis Valley Discharge & 7,865 & 5 \\
\hline Boundary Flow & 1,500 & 100 \\
\hline Total & 27,118 & 29 \\
\hline
\end{tabular}

shallow flow system. The total number of changed nodes is 55,554 . The properties used to parameterize this model are summarized in Section 6.3.6. 
Table 6-29

Selected Node Changes for PZUP HFM Alternative

\begin{tabular}{|c|c|c|}
\hline Base HSU & Alternative HSU & Node Count \\
\hline \hline TMCM & ATICU & 10,637 \\
\hline PBRCM & LCA & 9,576 \\
\hline TMCM & RMICU & 5,388 \\
\hline PBRCM & LCCU1 & 5,188 \\
\hline
\end{tabular}

\subsubsection{Deeply Rooted Belted Thrust Fault Alternative (DRT-MME-SDA)}

The Belted Range Fault is the principal pre-Tertiary structure in the model region and controls the distribution of pre-Tertiary rocks. The fault is poorly constrained over the model area, and an alternative was developed in which the fault extends deeper, resulting a thick sheet of LCCU over most of the model area. The anticipated consequence was the focusing of the flow system higher in the model from the reduction in the amount of permeable rocks, thus increasing flow velocity. See Section 6.7 in BN (2002) for more information.

Plots of observed versus simulated values for the calibration wells, springs, Oasis Valley discharge, and boundary flows are shown in Figures 6-118 through 6-121. The scatter around the line of perfect agreement is generally random in Figure 6-118, until an observed head of 1,450 m is exceeded. At the very highest observed observation well heads, the model has a tendency toward undersimulation. Moreover, on Figure 6-119, the line of perfect agreement is shown, and ideally the data would plot exactly onto this line. However, in general, the model has a tendency to under simulate spring head. The plot is not significantly different than those shown in Section 5.6.2. Figure 6-121 presents a plot of observed versus simulated values for boundary flows. The agreement in Figure 6-121 between the regional and CAU models is generally good and, in general, the simulated boundary flows from the regional and CAU models are comparable. Figure 6-122 shows a histogram of weighted observation well residuals. The bulk of the weighted errors are less than \pm 10 . The errors are not symmetrically distributed around zero, with a large proportion oversimulated (negative sign) wells and a single large (almost equal to 60) underprediction.

The total estimated Oasis Valley discharge in the CAU model domain is $227 \mathrm{~kg} / \mathrm{s}$; the simulated discharge, shown in Figure 6-120, is $214 \mathrm{~kg} / \mathrm{s}$. The total error is within one standard deviation $(30 \mathrm{~kg} / \mathrm{s})$ as reported by Laczniak et al. (2001). The model trends the same as the data with some 


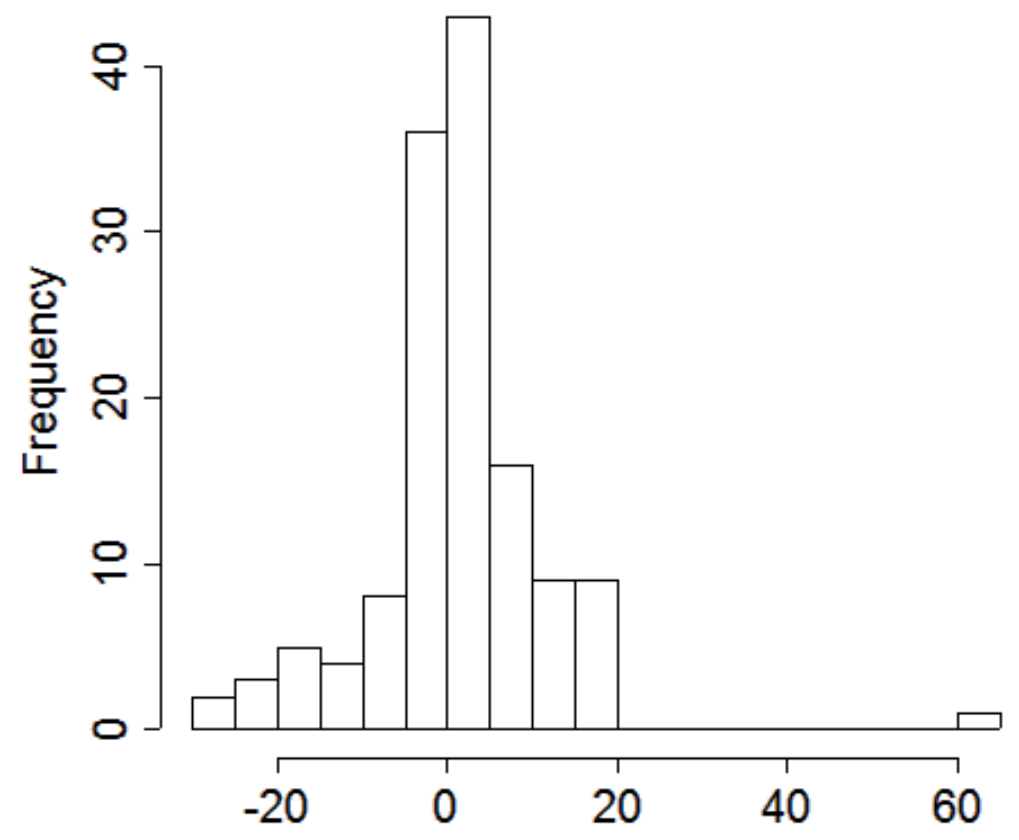

Figure 6-122

Histogram of Weighted Head Residuals for DRT-MME-SDA

scatter, showing that the general representation of the area is correct. The boundary flows, estimated from regional model analysis, all trend the correct way (e.g., have the proper sign), with the largest relative misfit on the eastern edge.

The weighted head and spring errors are shown on Figure 6-123, color coded by value and sign. The driest, or undersimulated, well was WW-8. The single wettest well was UE-20p. In general, the errors are randomly distributed, although there is a slight dry bias near WW-8 in the east-central model area, and an oversimulation bias in the north-central area (e.g., PM-2 and PM-3).

The quantitative measures of the model calibration are given by summary statistics shown in Table 6-30. The total model objective function was 26,240. Table 6-31 shows the contribution of each data type to the total model goodness of fit. Relative to other models in this section, the overall errors are clearly larger, but no worse than the SCCC HFM discussed in Section 5.7. While the model agreement with wells and boundary flow is clearly worse than the base HFM, the Oasis Valley discharge is only slightly affected. This may be because the deep-rooted thrust does not affect the units that control the flow of water into Oasis Valley. 


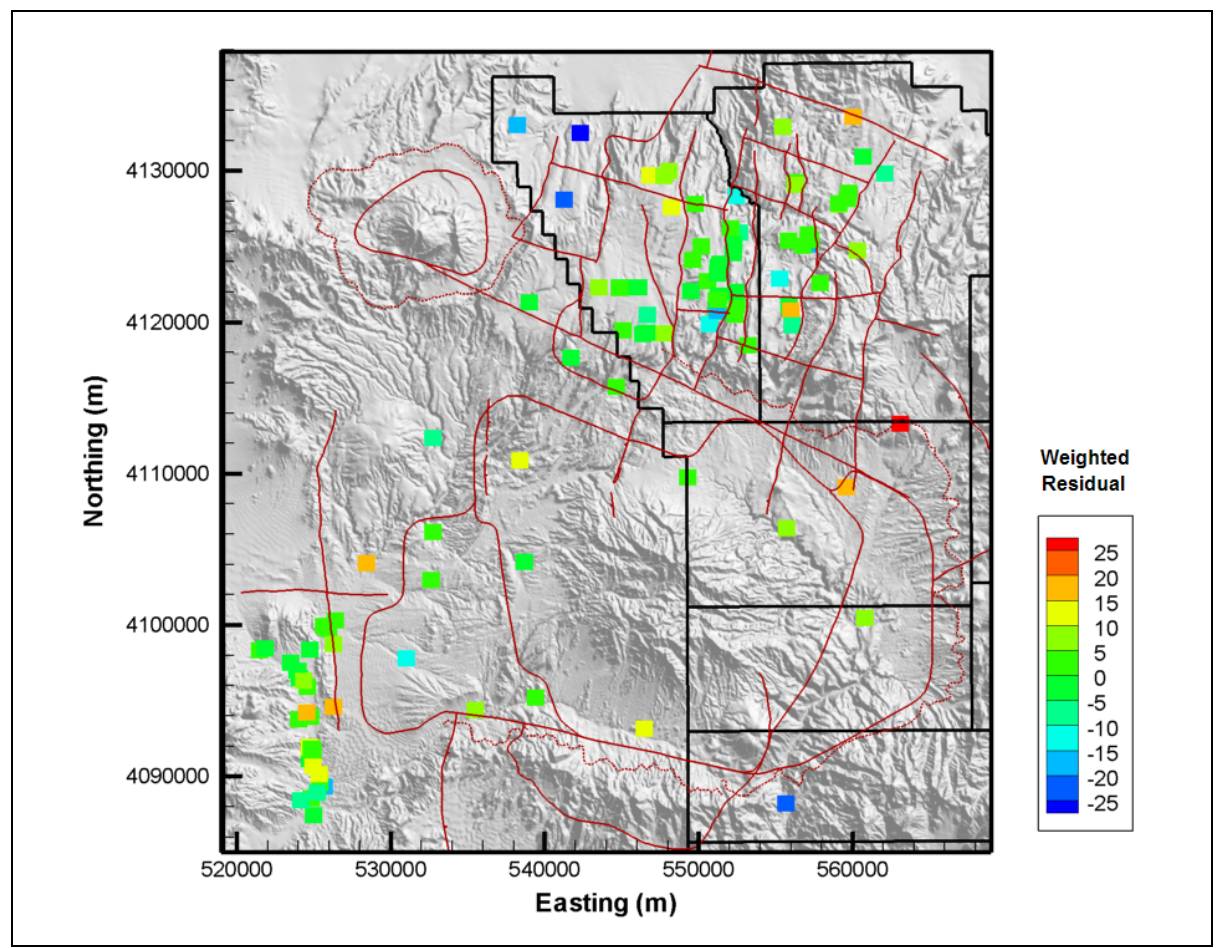

Figure 6-123

Post Plot of Weighted Well and Spring Head Residuals for DRT-MME-SDA

Table 6-30

Calibration Summary Statistics for DRT-MME-SDA

\begin{tabular}{||c|c|c|c|c|c|}
\hline $\begin{array}{c}\text { Calibration } \\
\text { Data }\end{array}$ & $\begin{array}{c}\text { Number of } \\
\text { Data }\end{array}$ & $\begin{array}{c}\text { Mean } \\
\text { Weighted } \\
\text { Error }^{2}\end{array}$ & $\begin{array}{c}\text { Maximum } \\
\text { Weighted } \\
\text { Residual }\end{array}$ & $\begin{array}{c}\text { Minimum } \\
\text { Weighted } \\
\text { Residual }\end{array}$ & $\begin{array}{c}\text { Error } \\
\text { Standard } \\
\text { Deviation }\end{array}$ \\
\hline \hline Well Head & 152 & 0.27 & 61 (WW-8) & -27 (UE-20p) & 9.6 \\
\hline Spring Head & 28 & 2.9 & $\begin{array}{c}19 \text { (Torrance } \\
\text { Spring) }\end{array}$ & $\begin{array}{c}-5.5 \text { (Spring id } \\
159)\end{array}$ & 6.8 \\
\hline $\begin{array}{c}\text { Oasis Valley } \\
\text { Discharge }\end{array}$ & 7 & 3.5 & 37 (Zone 3) & -27 (Zone 4) & 23 \\
\hline Boundary Flow & 4 & -13 & 24 (West) & -78 (North) & 42 \\
\hline
\end{tabular}

${ }^{\text {ap }}$ ositive sign is undersimulation of target data, negative is oversimulation.

Figure 6-124 shows the simulated water table for this model case. In the western part of Area 20, the influence of the Purse Fault is evident by the large offset in heads across it, with more subdued effects also present at West Boxcar Fault. Particle tracking (Figure 6-125) from each of the NTS wells shows the same generally noted flow paths as shown in Appendix A of the Pahute Mesa hydrologic data document (SNJV, 2004a). 


\subsubsection{Contiguous Imbricate Thrust Sheet Alternative (SEPZ-MME-SDA)}

In the eastern part of the model, an imbricate thrust fault is modeled that places LCA over UCCU. This relation is based on TW-1 and exposures east of the model area. A small surface exposure of the LCA occurs in this area that is thought to represent a small erosional remnant. This alternative explores the possibility that this feature is not a local remnant, but a continuous sheet. The expected consequence was to facilitate flow on the eastern side of Timber Mountain. See Section 6.6 in BN (2002) for more information.

Plots of observed versus simulated values for the calibration wells, springs, Oasis Valley discharge, and boundary flows are shown in Figures 6-126 through 6-129. The scatter around the line of perfect agreement is generally random in Figure 6-126, until an observed head of 1,450 m is exceeded. At the very highest observed observation well heads, the model has a tendency toward undersimulation. On Figure 6-127, the line of perfect agreement is shown, and ideally the data would plot exactly onto this line. However, in general, the model has a tendency to under simulate spring head. The plot is not significantly different than those shown in Section 5.6.2. Figure 6-129 presents a plot of observed versus simulated values for boundary flows. The agreement in Figure 6-129 between the regional and CAU models is generally good and, in general, the simulated boundary flows from the regional and CAU models are comparable. Figure 6-130 shows a histogram of weighted observation well residuals. The bulk of the weighted errors are less than \pm 10 . The errors are not symmetrically distributed around zero, with a large proportion of oversimulated (negative sign) wells.

The Oasis Valley discharge and boundary flow components provide the water-balance constraint on the model. The total estimated Oasis Valley discharge in the CAU model domain is $227 \mathrm{~kg} / \mathrm{s}$; the simulated discharge, shown in Figure $6-128$, is $210 \mathrm{~kg} / \mathrm{s}$. The total error is within one standard deviation $(30 \mathrm{~kg} / \mathrm{s})$ as reported by Laczniak et al. (2001). The model trends the same as the data with some scatter, showing that the general representation of the area is correct. The boundary flows, estimated from regional model analysis, all trend the correct way (e.g., have the proper sign), with the largest relative misfit on the western edge.

The weighted head and spring errors are shown on Figure 6-131, color coded by value and sign. The two driest, or undersimulated, wells were ER-OV-06a and ER-OV-01. The single wettest well was U-19ad in northern Area 19. In general, the errors are randomly distributed, although there is a slight 
dry bias in northern Area 20 at Easting and Northing of about 547,500 and 4,130,000 m, which includes Wells U-20i, UE-20e\#1, U-20e, and U-20ar \#1.

The quantitative measures of the model calibration are given by summary statistics shown in Table 6-33. These statistics are very similar to those shown in Section 5.6.2 for BN-MME-SDA. There is a slight dry bias in the spring heads, with a slight overprediction bias for the flows. The total model objective function was 16,159; slightly better than the best HFM calibration described in Section 5.6.2. Table 6-34 shows the contribution of each data type to the total model goodness of fit.

Table 6-33

Calibration Summary Statistics for SEPZ-MME-SDA

\begin{tabular}{|c|c|c|c|c|c|}
\hline $\begin{array}{c}\text { Calibration } \\
\text { Data }\end{array}$ & $\begin{array}{c}\text { Number of } \\
\text { Data }\end{array}$ & $\begin{array}{c}\text { Mean Weighted } \\
\text { Error }\end{array}$ & $\begin{array}{c}\text { Maximum } \\
\text { Weighted } \\
\text { Residual }\end{array}$ & $\begin{array}{c}\text { Minimum } \\
\text { Weighted } \\
\text { Residual }\end{array}$ & $\begin{array}{c}\text { Error } \\
\text { Standard } \\
\text { Deviation }\end{array}$ \\
\hline \hline Well Head & 152 & -0.46 & $20(\mathrm{U}-19 \mathrm{x})$ & -27 (UE-20n \#1) & 7.2 \\
\hline Spring Head & 28 & 2.8 & 19 (Torrance) & $\begin{array}{c}-5.5 \text { (Spring id } \\
159)\end{array}$ & 6.8 \\
\hline $\begin{array}{c}\text { Oasis Valley } \\
\text { Discharge }\end{array}$ & 7 & 4.6 & 41 (Zone 3) & -26 (Zone 4) & 24 \\
\hline Boundary Flow & 4 & -13 & 26 (West) & -36 (South) & 27 \\
\hline
\end{tabular}

aPositive sign is undersimulation of target data, negative is oversimulation.

Table 6-34

Contribution to Model Goodness of Fit by Data Type for SEPZ-MME-SDA

\begin{tabular}{|c|c|c|}
\hline Data Type & Value (-) & Percent of Total \\
\hline \hline Well Head & 7,979 & 49 \\
\hline Spring Head & 1,284 & 24 \\
\hline Oasis Valley Discharge & 3,898 & 19 \\
\hline Boundary Flow & 2,999 & 100 \\
\hline Total & 16,160 & \\
\hline
\end{tabular}

Figure 6-132 shows the simulated water table for this model case. In the western part of Area 20, the influence of the Purse Fault is still evident by the large offset in heads across it, with more subdued effects also present at West Boxcar Fault. Particle tracking (Figure 6-133) from each of the NTS wells shows the same generally noted flow paths as shown in Appendix A of the Pahute Mesa hydrologic data document (SNJV, 2004a). 
The alternative HFM required no additional effort to recalibrate, and appears to have little impact on flow model metrics. A summary of the major node HSU changes is shown in Table 6-35. The total node change count was 8,425. The changes are consistent with increasing the continuity of the LCA in the southeast corner of the domain as described by BN (2002). The properties used to parameterize this model are summarized in Section 6.3.6.

Table 6-35

Selected Node Changes for SEPZ HFM Alternative

\begin{tabular}{|c|c|c|}
\hline Base HSU & Alternative HSU & Node Count \\
\hline \hline UCCU & LCA3a & 6,148 \\
\hline LCA & UCCU & 2,277 \\
\hline
\end{tabular}




\subsubsection{HFM Uncertainty Analysis Summary}

The calibrated HSU parameters for all five alternative HFMs and the calibrated HSU parameters for the base HFM (BN-MME-SDA) considered in this section are shown in Table 6-36. In the case of TCL, RIDGE, and SEPZ alternatives, they are nearly identical to those used for the selected HSU depth-decay and anisotropy model (see Section 5.6.2) because the effects of the HSU changes required minimal parameter adjustment. However, DRT and PZUP caused dramatic changes in model output and required substantial effort to calibrate. A summary of flow model results for HFM uncertainty is presented in Table 6-37.

The estimates of HSU permeability used to guide the calibration were developed from the interpretation of hydraulic tests. As a qualitative model check, permeability from the model nodes associated with each test was extracted and arithmetically averaged in the case of a test zone with more than one associated node. These are shown in Figures 5-51 and 5-52 with the estimated values. Also shown is the mean permeability estimated for the test HSU as given by SNJV (2004a). Wells ER-EC-1, ER-EC-4, UE-19e, UE-19h, UE-20f, and UE-20h had noisy test data, and the estimated permeability should be considered to have larger uncertainty. The model calibrated permeabilities at the two observation wells from the BULLION FGE (ER-20-6 \#1 and ER-20-6 \#2) are about an order of magnitude and a half lower than the test values and lower than the value estimated $\left(1.13 \times 10^{-13} \mathrm{~m}^{2}\right)$ from model calibration by Wolfsberg et al. (2002) for the CHZCM, although within the range of uncertainty (at $2 \sigma$ ) estimated from the mean and standard deviation published by SNJV (2004a) between about $7 \times 10^{-12}$ to $7 \times 10^{-14} \mathrm{~m}^{2}$. The permeability calibrated at UE- $19 \mathrm{~h}$ has the largest scatter among the HFMs, but the test value is fairly uncertain. There is some observed scatter that appears to be related to HFM. For instance, at ER-EC-7 the SCCC HFM has a permeability an order of magnitude and a half less than the base HFMs, which themselves are half an order of magnitude less than the estimated test value, but in good agreement with the estimated mean value. Similar results are also seen at Wells ER-EC-1 and ER-EC-6, and at ER 18-2 the SCCC HFM is actually quite a bit lower than the other data. However, no general conclusions can be drawn from the permeability comparison about the goodness of the HFMs because at Wells ER-EC-8, ER-EC-4, UE-19c, and UE-19gS the selected depth-decay and SCCC cases compare better to each other than the all depth-decay case (two different HFMs that were parameterized the same way).

All the alternative HFMs described here were parameterized with the selected HSU depth-decay and anisotropy approach (applied to the same HSUs as well) described in Section 5.6.2. They also were 


\subsubsection{Base Geologic Model Water-Balance Uncertainty Analysis}

The base HFM with the selected HSU depth decay and anisotropy (BN-SDA) parameterization as described in Section 5.6.2 was used as the basis for analyzing water-balance uncertainty. Four combinations of recharge model and boundary flows are considered as follows:

1. DRIA recharge and boundary flow

2. DRIAE recharge and boundary flow

3. USGSD recharge and USGSND boundary flow (boundary flows with the USGSD recharge model were not calculated from the UGTA regional model)

4. USGSND recharge and USGSND boundary flow

In addition, the LCCU1 variation described in Section 6.2.4.2 is also investigated.

\subsubsection{DRI Recharge Model}

The base HFM - selected HSU depth-decay and anisotropy was calibrated with the DRIA and DRIAE recharge and boundary flows. Tables 6-38 and 6-39 summarize the calibration statistics for DRIAE and DRIA, respectively. The objective function is nearly the same, 21,407 versus 20,716. The results shown in Tables 6-38 and 6-39 are very similar, and only the DRIA recharge model will be carried for further analyses because it tends to spread recharge around the domain to a greater extent and the elevation screen only affects lower elevations.

Table 6-38

Calibration Summary Statistics for BN-DRIAE-SDA

\begin{tabular}{||c|c|c|c|c|c||}
\hline $\begin{array}{c}\text { Calibration } \\
\text { Data }\end{array}$ & $\begin{array}{c}\text { Number of } \\
\text { Data }\end{array}$ & $\begin{array}{c}\text { Mean Weighted } \\
\text { Error }^{\mathrm{a}}\end{array}$ & $\begin{array}{c}\text { Maximum } \\
\text { Weighted } \\
\text { Residual }\end{array}$ & $\begin{array}{c}\text { Minimum } \\
\text { Weighted } \\
\text { Residual }\end{array}$ & $\begin{array}{c}\text { Error } \\
\text { Standard } \\
\text { Deviation }\end{array}$ \\
\hline \hline Well Head & 152 & -1.8 & 20 (ER-OV-03a) & $\begin{array}{c}-32(\text { UE-20n \#1 } \\
1,005.84 \mathrm{~m})\end{array}$ & 8.1 \\
\hline Spring Head & 28 & 3.1 & $\begin{array}{c}19 \text { (Torrance } \\
\text { Spring) }\end{array}$ & $\begin{array}{c}-5.4(\text { Spring id } \\
159)\end{array}$ & 6.9 \\
\hline $\begin{array}{c}\text { Oasis Valley } \\
\text { Discharge }\end{array}$ & 7 & 2.0 & 41 (Zone 3) & -18 (Zone 4) & 21 \\
\hline Boundary Flow & 4 & -24 & 23 (West) & -60 (North) & 42 \\
\hline
\end{tabular}

apositive sign is undersimulation of target data, negative is oversimulation. 
Table 6-39

Calibration Summary Statistics for BN-DRIA-SDA

\begin{tabular}{||c|c|c|c|c|c||}
\hline $\begin{array}{c}\text { Calibration } \\
\text { Data }\end{array}$ & $\begin{array}{c}\text { Number of } \\
\text { Data }\end{array}$ & $\begin{array}{c}\text { Mean } \\
\text { Weighted } \\
\text { Error }^{\mathrm{a}}\end{array}$ & $\begin{array}{c}\text { Maximum } \\
\text { Weighted } \\
\text { Residual }\end{array}$ & $\begin{array}{c}\text { Minimum } \\
\text { Weighted } \\
\text { Residual }\end{array}$ & $\begin{array}{c}\text { Error } \\
\text { Standard } \\
\text { Deviation }\end{array}$ \\
\hline \hline Well Head & 152 & -1.5 & 20 (ER-OV-03a) & $\begin{array}{c}-31 \text { (UE-20n \#1 } \\
1,005.84 \mathrm{~m})\end{array}$ & 7.9 \\
\hline Spring Head & 28 & 3.1 & $\begin{array}{c}19 \text { (Torrance } \\
\text { Spring) }\end{array}$ & $\begin{array}{c}-5.3 \text { (Ute } \\
\text { Springs Culvert) }\end{array}$ & 6.9 \\
\hline $\begin{array}{c}\text { Oasis Valley } \\
\text { Discharge }\end{array}$ & 7 & 3.1 & 42 (Zone 3) & -18 (Zone 4) & 21 \\
\hline Boundary Flow & 4 & -23 & 23 (West) & -58 (North) & 41 \\
\hline
\end{tabular}

aPositive sign is undersimulation of target data, negative is oversimulation.

Figure 6-135 shows the posted weighted residuals; there is a perceptible bias to oversimulate heads that is also suggested by the mean error. Simulated Oasis Valley discharge is $219 \mathrm{~kg} / \mathrm{s}$ (versus an estimated discharge of $227 \mathrm{~kg} / \mathrm{s}$ ). Figure 6-136 shows the simulated water table, and Figure 6-137 shows the simulated flow paths from NTS wells. The water table and flow paths have the same general character seen in all the simulations, but there is an intensified flow path out to the south at Easting of about 540,000 m. The DVCM, PCM, BRA, and YMCFCM permeabilities (including $\mathrm{k}_{0}$ ) all increased between a quarter and half an order of magnitude over the values used to calibrate the MME recharge in order to bleed off the additional recharge (nearly double that of the MME) imposed by the DRIA recharge model. This increase in permeability causes the increased flow across the southern boundary through the PCM and YMCFCM that is seen in the simulated flow paths.

The reduced LCCU1 permeability alternative variation of the model (Section 6.2.4.2) was also investigated with the DRIA recharge map. Table 6-40 shows the summary calibration statistics; the objective function is 27,712 .

Figure 6-138 shows the posted weighted residuals; the error appears random with a slight oversimulation bias. Simulated Oasis Valley discharge is 216 versus $227 \mathrm{~kg} / \mathrm{s}$ estimated. Figure 6-139 shows the simulated water table, and Figure 6-140 shows the simulated flow paths from NTS wells. 


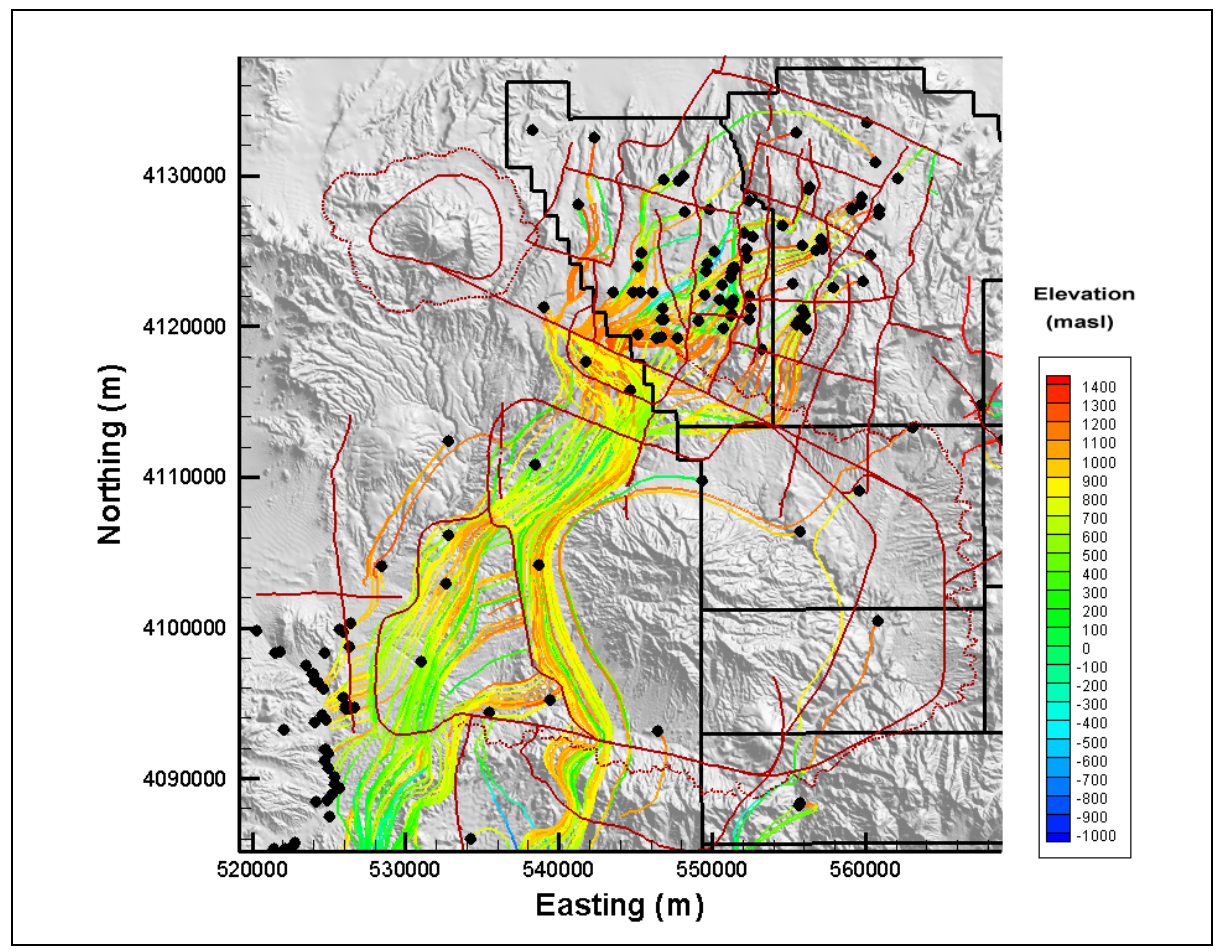

Figure 6-137

Particle Tracks for BN-DRIA-SDA

Table 6-40

Calibration Summary Statistics for BN-DRIA-SDA Reduced LCCU1 Permeability Alternative

\begin{tabular}{|c|c|c|c|c|c|}
\hline $\begin{array}{c}\text { Calibration } \\
\text { Data }\end{array}$ & $\begin{array}{c}\text { Number of } \\
\text { Data }\end{array}$ & $\begin{array}{c}\text { Mean } \\
\text { Weighted } \\
\text { Error }^{\mathrm{a}}\end{array}$ & $\begin{array}{l}\text { Maximum } \\
\text { Weighted } \\
\text { Residual }\end{array}$ & $\begin{array}{l}\text { Minimum } \\
\text { Weighted } \\
\text { Residual }\end{array}$ & $\begin{array}{c}\text { Error } \\
\text { Standard } \\
\text { Deviation }\end{array}$ \\
\hline Well Head & 152 & 1.4 & 76 (WW-8) & $\begin{array}{c}-24 \text { (UE-20n \#1 } \\
\text { 1,005.84 m) }\end{array}$ & 9.6 \\
\hline Spring Head & 28 & 3.1 & $\begin{array}{c}19 \text { (Torrance } \\
\text { Spring) }\end{array}$ & $\begin{array}{c}-6.0 \text { (Spring id } \\
159)\end{array}$ & 6.9 \\
\hline $\begin{array}{l}\text { Oasis Valley } \\
\text { Discharge }\end{array}$ & 7 & 2.9 & 41 (Zone 3) & -19 (Zone 4) & 20 \\
\hline Boundary Flow & 4 & -23 & 22 (East) & -70 (South) & 49 \\
\hline
\end{tabular}

apositive sign is undersimulation of target data, negative is oversimulation. 


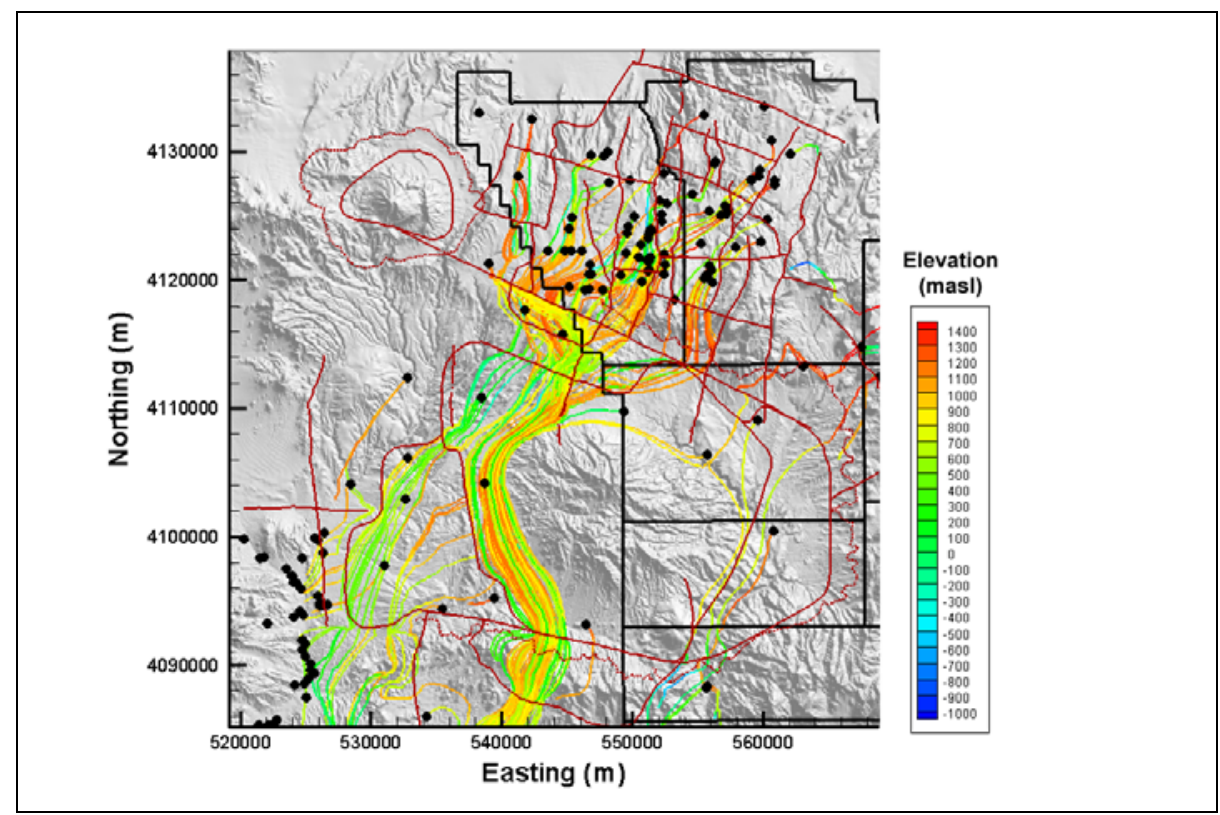

Figure 6-140

\section{Particle Tracks for BN-DRIA-SDA Reduced LCCU1 Permeability Alternative}

The clear change between the base calibrated HFM and lower reduced LCCU1 permeability alternative for both the MME and DRI recharge models is the poor matching of WW-8. It does seem not conceptually reasonable that the LCCU1 should support the hydraulic head in this area via its connection to the higher boundary heads, but again, there is no information as to the properties of the LCCU1.

\subsubsection{USGS Recharge Model}

The summary calibration statistics for the base HFM with the USGSND and USGSD recharge models are shown in Tables 6-41 and 6-42. The objective functions are 11,615 and 14,054, respectively. The USGSND model has the lowest recharge volume of all the alternatives and the best objective function. In general, the USGS recharge models calibrate far better than the MME and DRI recharge models. This is because the lower recharge results in fewer local changes in head from recharge accretion. The USGSND recharge model calibrates better than the USGSD model for similar reasons. However, conceptually it does not seem reasonable to neglect the basic watershed processes of runoff and run-on in estimating recharge; thus, the USGSND recharge model is not considered further. Furthermore, goodness of calibration is not the sole metric on which models should be judged. 
Table 6-41

Calibration Summary Statistics for BN-USGSND-SDA

\begin{tabular}{|c|c|c|c|c|c|}
\hline $\begin{array}{c}\text { Calibration } \\
\text { Data }\end{array}$ & $\begin{array}{c}\text { Number of } \\
\text { Data }\end{array}$ & $\begin{array}{c}\text { Mean } \\
\text { Weighted } \\
\text { Error }^{\mathrm{a}}\end{array}$ & $\begin{array}{l}\text { Maximum } \\
\text { Weighted } \\
\text { Residual }\end{array}$ & $\begin{array}{l}\text { Minimum } \\
\text { Weighted } \\
\text { Residual }\end{array}$ & $\begin{array}{c}\text { Error } \\
\text { Standard } \\
\text { Deviation }\end{array}$ \\
\hline Well Head & 152 & 0.42 & 19 (ER-OV-03a) & $\begin{array}{c}-24 \text { (UE-20n \#1 } \\
1,005.84 \mathrm{~m})\end{array}$ & 6.2 \\
\hline Spring Head & 28 & 2.8 & $\begin{array}{c}19 \text { (Torrance } \\
\text { Spring) }\end{array}$ & $\begin{array}{c}-5.3 \text { (Ute } \\
\text { Springs Culvert) }\end{array}$ & 6.7 \\
\hline $\begin{array}{l}\text { Oasis Valley } \\
\text { Discharge }\end{array}$ & 7 & 7.9 & 43 (Zone 3) & -19 (Zone 4) & 23 \\
\hline Boundary Flow & 4 & 5.2 & 26 (West) & -5.8 (South) & 14 \\
\hline
\end{tabular}

apositive sign is undersimulation of target data, negative is oversimulation.

Table 6-42

Calibration Summary Statistics for BN-USGSD-SDA

\begin{tabular}{|c|c|c|c|c|c||}
\hline $\begin{array}{c}\text { Calibration } \\
\text { Data }\end{array}$ & $\begin{array}{c}\text { Number of } \\
\text { Data }\end{array}$ & $\begin{array}{c}\text { Mean } \\
\text { Weighted } \\
\text { Error }\end{array}$ & $\begin{array}{c}\text { Maximum } \\
\text { Weighted } \\
\text { Residual }\end{array}$ & $\begin{array}{c}\text { Minimum } \\
\text { Weighted } \\
\text { Residual }\end{array}$ & $\begin{array}{c}\text { Error } \\
\text { Standard } \\
\text { Deviation }\end{array}$ \\
\hline \hline Well Head & 152 & -1.9 & 18 (ER-OV-03a) & $\begin{array}{c}-30 \text { (UE-20n \#1 } \\
1,005.84 \mathrm{~m})\end{array}$ & 7.0 \\
\hline Spring Head & 28 & 2.7 & $\begin{array}{c}19 \text { (Torrance } \\
\text { Spring) }\end{array}$ & $\begin{array}{c}-5.3 \text { (Ute } \\
\text { Springs Culvert) }\end{array}$ & 6.8 \\
\hline $\begin{array}{c}\text { Oasis Valley } \\
\text { Discharge }\end{array}$ & 7 & 3.2 & 42 (Zone 3) & -23 (Zone 1) & 25 \\
\hline Boundary Flow & 4 & -1.7 & 26 (West) & -14 (East) & 16 \\
\hline
\end{tabular}

aPositive sign is undersimulation of target data, negative is oversimulation.

Post plots of weighted well and spring head residuals are shown in Figures 6-141 and 6-142 for the USGSND and USGSD recharge models, respectively. The USGSND results show a more uniform degree of error, but there is a slight bias in central Area 20 to undersimulated heads. In contrast, the USGSD recharge model shows a systematic, but small, bias to oversimulated heads. The difference is entirely caused by differences in the recharge maps because the same set of hydraulic parameters was used for both cases. Figures 6-143 and 6-144 show the simulated water tables, which are very similar and show the broad features of the flow system correctly. Simulated Oasis Valley discharge is 199 and $215 \mathrm{~kg} / \mathrm{s}$ for the USGSND and USGSD recharge models, respectively. 
Table 6-43

Calibration Summary Statistics for BN-USGSD-SDA Reduced LCCU1 Permeability Alternative

\begin{tabular}{|c|c|c|c|c|c|}
\hline $\begin{array}{c}\text { Calibration } \\
\text { Data }\end{array}$ & $\begin{array}{c}\text { Number of } \\
\text { Data }\end{array}$ & $\begin{array}{c}\text { Mean Weighted } \\
\text { Error }^{2}\end{array}$ & $\begin{array}{c}\text { Maximum } \\
\text { Weighted } \\
\text { Residual }\end{array}$ & $\begin{array}{c}\text { Minimum } \\
\text { Weighted } \\
\text { Residual }\end{array}$ & $\begin{array}{c}\text { Error } \\
\text { Standard } \\
\text { Deviation }\end{array}$ \\
\hline \hline Well Head & 152 & 0.33 & $\begin{array}{c}18 \\
\text { (ER-OV-06a) }\end{array}$ & $\begin{array}{c}-24 \\
(\text { UE-20n \#1 } \\
1,005.84 \mathrm{~m})\end{array}$ & 6.0 \\
\hline Spring Head & 28 & 2.7 & $\begin{array}{c}19 \\
\text { (Torrance } \\
\text { Spring })\end{array}$ & $\begin{array}{c}-7.2 \\
(\text { Spring id 159) }\end{array}$ & 6.9 \\
\hline $\begin{array}{c}\text { Oasis Valley } \\
\text { Discharge }\end{array}$ & 7 & 5.3 & $\begin{array}{c}45 \\
(\text { Zone 3) }\end{array}$ & $\begin{array}{c}-18 \\
(\text { Zone 4) }\end{array}$ & 21 \\
\hline Boundary Flow & 4 & 5.1 & $\begin{array}{c}21 \\
\text { (West })\end{array}$ & $\begin{array}{c}-4.4 \\
(\text { North })\end{array}$ & 11 \\
\hline
\end{tabular}

aPositive sign is undersimulation of target data, negative is oversimulation.

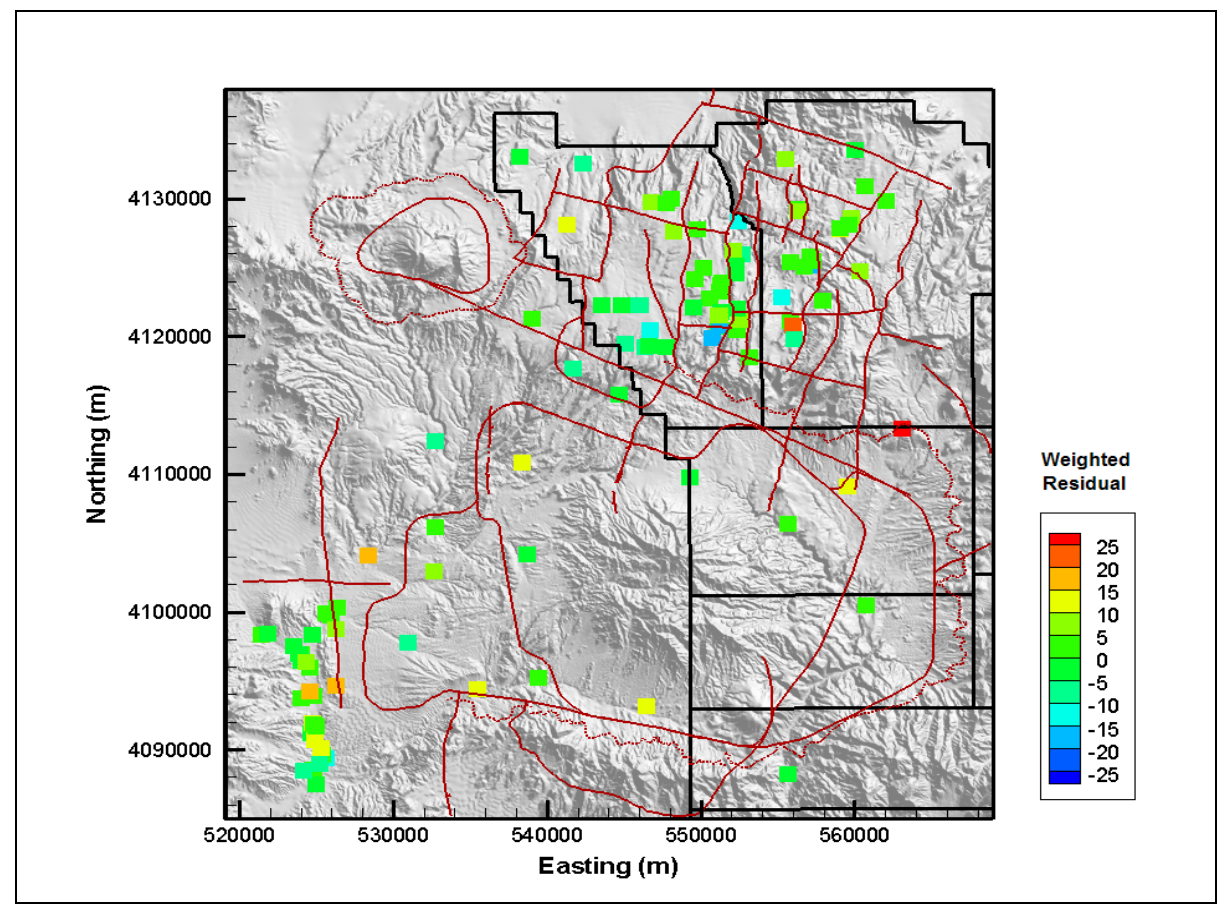

Figure 6-147

Post Plot of Weighted Well and Spring Head Residuals for BN-USGSD-SDA Reduced LCCU1 Permeability Alternative 


\subsubsection{SCCC Geologic Model Water-Balance Uncertainty Analysis}

The SCCC HFM as described in Section 5.7 was used as the basis for analyzing water-balance uncertainty. Based on the results of Section 6.4.3, only two combinations of recharge model and boundary flows are considered as follows:

1. DRIA recharge and boundary flow

2. USGSD recharge and USGSND boundary flow

\subsubsection{DRI Recharge Model}

Calibration summary statistics for the SCCC HFM with the DRIA recharge model (SCCC-DRIA) are shown in Table 6-44. In spite of the high recharge associated with this map, the simulated observation well data are biased slightly low. The error standard deviations are slightly higher than those for the MME recharge calibration shown in Section 5.6. The model objective function is 31,086 versus 31,800 for calibration with the MME recharge model.

Table 6-44

Calibration Summary Statistics for SCCC-DRIA-SDA

\begin{tabular}{|c|c|c|c|c|c|}
\hline $\begin{array}{c}\text { Calibration } \\
\text { Data }\end{array}$ & $\begin{array}{c}\text { Number of } \\
\text { Data }\end{array}$ & $\begin{array}{c}\text { Mean Weighted } \\
\text { Error }^{a}\end{array}$ & $\begin{array}{l}\text { Maximum } \\
\text { Weighted } \\
\text { Residual }\end{array}$ & $\begin{array}{l}\text { Minimum } \\
\text { Weighted } \\
\text { Residual }\end{array}$ & $\begin{array}{c}\text { Error } \\
\text { Standard } \\
\text { Deviation }\end{array}$ \\
\hline Well Head & 152 & 2.2 & $\begin{array}{c}33 \\
\text { (PM-3 Piezometer } \\
2 \text { ) }\end{array}$ & $\begin{array}{c}-30 \\
(U-20 c)\end{array}$ & 11 \\
\hline Spring Head & 28 & 2.5 & $\begin{array}{c}19 \\
\text { (Torrance Spring) }\end{array}$ & $\begin{array}{c}-45 \\
\text { (Spring id 163) }\end{array}$ & 11 \\
\hline $\begin{array}{l}\text { Oasis Valley } \\
\text { Discharge }\end{array}$ & 7 & 9.0 & $\begin{array}{c}42 \\
\text { (Zone 5) }\end{array}$ & $\begin{array}{c}-28 \\
\text { (Zone 4) }\end{array}$ & 26 \\
\hline Boundary Flow & 4 & -27 & $\begin{array}{c}-38 \\
\text { (North) }\end{array}$ & $\begin{array}{c}-64 \\
\text { (West) }\end{array}$ & 35 \\
\hline
\end{tabular}

aPositive sign is undersimulation of target data, negative is oversimulation. 
Figure 6-150 shows the posted weighted residuals; there is a strong underprediction in the eastcentral part of the model including Wells WW-8, ER-30-1, UE-18t, and ER-18-2 that is also suggested by the mean error. Wells WW-8 and PM-3 were undersimulated in the MME calibration as well, and this error is thus a consequence of the HFM, not the recharge model. Simulated Oasis Valley discharge is $195 \mathrm{~kg} / \mathrm{s}$. Figure 6-151 shows the simulated water table, and Figure 6-152 shows the simulated flow paths from NTS wells. The water table and flow paths have the same general character seen in all the simulations, but there is a large number of paths simulated as flowing around the eastern side of Timber Mountain. In the MME calibration, flow paths exit southern Area 20 on a nearly due south trajectory and then turn west around Timber Mountain. Slight shifts in head gradient were induced in the recalibration to the DRIA recharge model that caused a large amount of flow paths to go down Fortymile Canyon instead of into Oasis Valley. The parameter that changed the most was the permeability of the Calico Hills unit (recall that five HSUs from the base HFM were lumped into one Calico Hills HSU in the SCCC HFM), which increased nearly an order of magnitude. The PCM $\mathrm{k}_{0}$ also increased by about half an order of magnitude. Sensitivity analysis showed that the PCM affected heads in the domain by controlling flow out to the south. The PCM increased permeability in this high recharge case is interpreted as being necessary in order to reduce heads elevated by the additional recharge in the DRIA recharge model. The TCVA and DVCM permeabilities also increased slightly. The increase in the DVCM permeability compensates for more flow apparently going down Fortymile Canyon by allowing more inflow from the west to maintain Oasis Valley discharge. This interpretation is supported by the result that the oversimulation of ET discharge Zone 4 is larger in this case than most others, and that Zone 5 in the southern part of Oasis Valley (which does not appear in any other model variation as a large error) has too low a discharge. This combination of HFM and recharge model does not appear to be reasonable. 


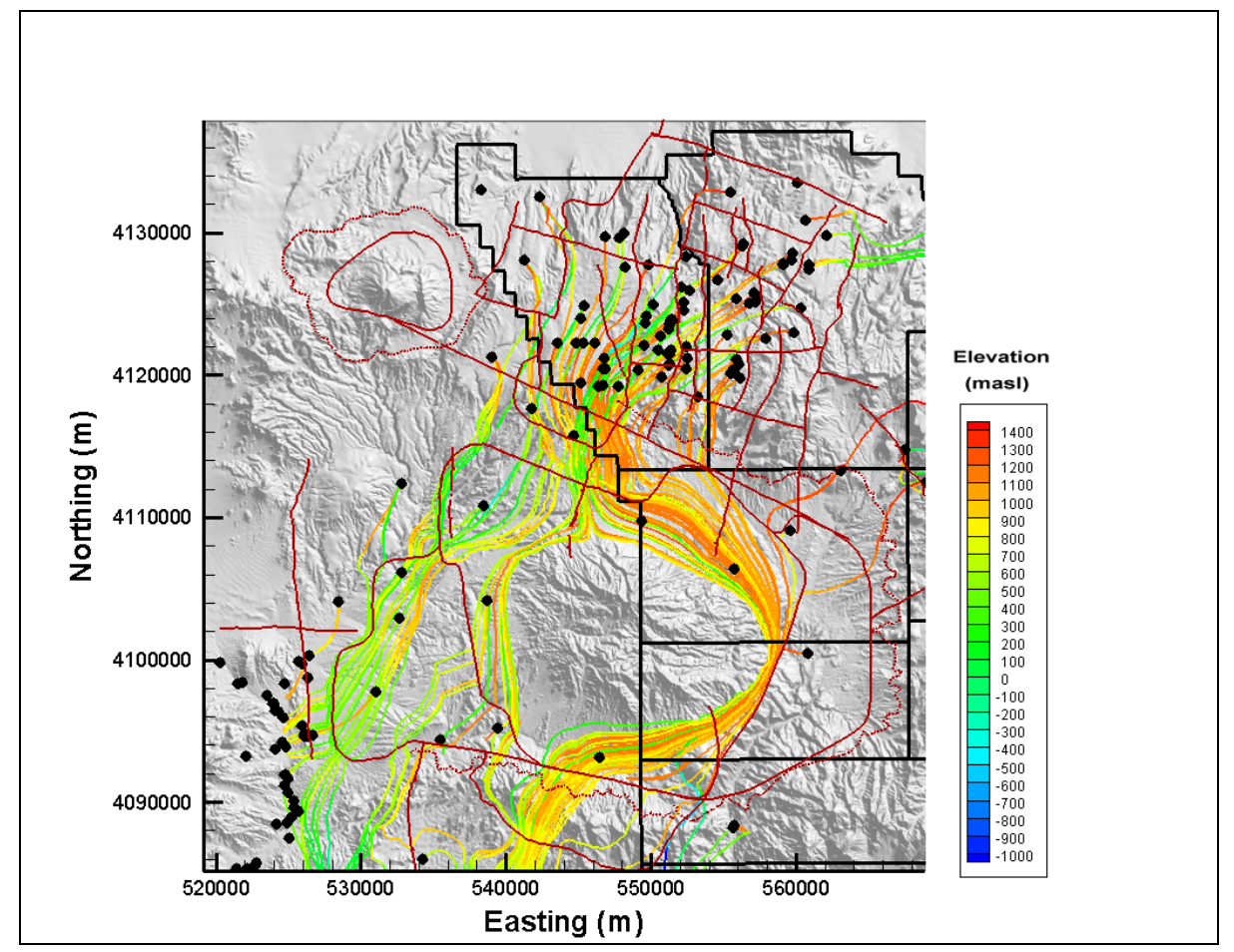

Figure 6-152

Particle Tracks for SCCC-DRIA-SDA

\subsubsection{USGS Recharge Model}

The calibration summary statistics for the SCCC HFM with the USGSD recharge model are shown in Table 6-45. The model objective function is 32,254 versus 31,800 for calibration with the MME recharge model.

Figure 6-153 shows the posted weighted residuals; there is a strong underprediction including WW-8 and PM-3 (which were also undersimulated in the MME calibration shown in Section 5.7). There is a bias to undersimulation in east-central Area 19. Simulated Oasis Valley discharge is $220 \mathrm{~kg} / \mathrm{s}$.

Figure 6-154 shows the simulated water table, and Figure 6-155 shows the simulated flow paths from NTS wells. The water table and flow paths have the same general character seen in all the simulations, but there are more simulated flow paths around the eastern side of Timber Mountain, down Fortymile Canyon, and back around the southern part of Timber Mountain than with the MME recharge. The flow paths for the USGS recharge model are more like the DRIA recharge flow paths than the MME, which is surprising given that these two recharge models are at the opposite end of the spectrum of values. The parameters that changed the most in calibrating the SCCC HFM with the 
Table 6-45

Calibration Summary Statistics for SCCC-USGSD-SDA

\begin{tabular}{|c|c|c|c|c|c|}
\hline $\begin{array}{c}\text { Calibration } \\
\text { Data }\end{array}$ & $\begin{array}{c}\text { Number of } \\
\text { Data }\end{array}$ & $\begin{array}{c}\text { Mean } \\
\text { Weighted } \\
\text { Error }^{a}\end{array}$ & $\begin{array}{l}\text { Maximum } \\
\text { Weighted } \\
\text { Residual }\end{array}$ & $\begin{array}{l}\text { Minimum } \\
\text { Weighted } \\
\text { Residual }\end{array}$ & $\begin{array}{c}\text { Error } \\
\text { Standard } \\
\text { Deviation }\end{array}$ \\
\hline Well Head & 152 & -0.20 & $\begin{array}{c}31 \\
(U-19 x)\end{array}$ & $\begin{array}{c}-44 \\
(U-20 c)\end{array}$ & 12 \\
\hline Spring Head & 28 & 2.7 & $\begin{array}{c}19 \\
\text { (Torrance } \\
\text { Spring) }\end{array}$ & $\begin{array}{c}-44 \\
\text { (Spring id 163) }\end{array}$ & 11 \\
\hline $\begin{array}{l}\text { Oasis Valley } \\
\text { Discharge }\end{array}$ & 7 & 1.9 & $\begin{array}{c}34 \\
\text { (Zone 3) }\end{array}$ & $\begin{array}{c}-34 \\
\text { (Zone 4) }\end{array}$ & 23 \\
\hline Boundary Flow & 4 & 16 & $\begin{array}{l}37 \\
\text { (East) }\end{array}$ & $\begin{array}{c}-14 \\
\text { (North) }\end{array}$ & 25 \\
\hline
\end{tabular}

aPositive sign is undersimulation of target data, negative is oversimulation

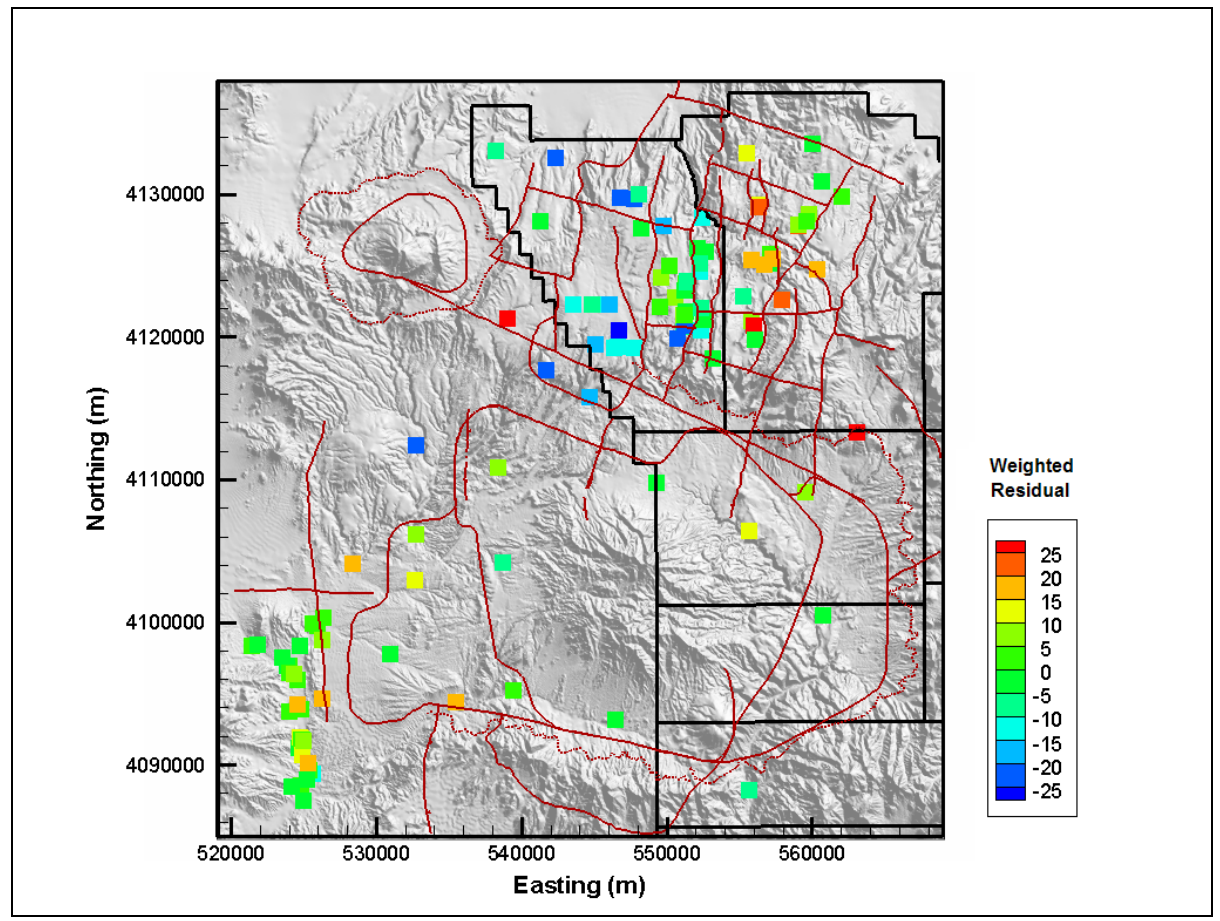

Figure 6-153

Post Plot of Weighted Well and Spring Head Residuals for SCCC-USGSD-SDA

USGSD recharge map include the permeability of the PBRCM, FCCM, DVCM, Calico Hills, LCA3, and PCM. The PBRCM permeability increased by an order of magnitude, with lesser increases in the PCM and DVCM, and LCA3. Physically, this is interpreted as being necessary to allow more flow in 
on the north and east model edges (through PBRCM and LCA3) and support the heads, and to allow more inflow from the west to maintain flow in Oasis Valley (through DVCM), and to balance out the increased flow and heads in the northern domain (through PCM). Because of the decreased recharge the FCCM permeability, which rings Timber Mountain, had to decrease to hold heads up, as did the Calico Hills permeability.

\subsubsection{Summary of Water-Balance Uncertainty Analysis}

Recalibrating the base and SCCC HFMs to a suite of recharge models and boundary flows addresses the water-balance component of flow model uncertainty. A total of eight combinations of recharge model, boundary flow, and HFM were considered (Table 6-46). Alternative recharge models included the two variations of the USGS distributed parameter model and two variations of the DRI chloride mass-balance model. In addition, a sub-variation of the base HFM with reduced LCCU1 permeability alternative was also considered. The boundary flows developed from the UGTA regional model (DOE/NV, 1997) analysis for the corresponding recharge models were used in conjunction with each respective recharge model. For example, the DRIA recharge model was used along with the UGTA regional model boundary flows resulting from the DRIA recharge model. In general, reducing recharge via the USGS recharge model had the effect of dropping permeability, with the converse resulting from the DRI recharge model. This is expected behavior in a steady-state model. Some of the downward changes, notably the IA for the USGS recharge model cases, are to the lower limit of estimated parameter uncertainty. No such issue was noted on the estimated upper end of parameter uncertainty with the DRI recharge model.

In general, all the combinations of HFM, recharge models, and boundary flows could be as well calibrated as with the MME recharge and boundary flow. This recalibration, however, can result in a few marginal parameter values as noted for the IA. The poorest-performing HFM considered under all recharge models was the SCCC alternative, as was also noted in Section 5.8. The lack of deep faults, particularly along the Purse Fault, limits the degree of freedom necessary to give a reasonable calibration. The SCCC HFM also showed the greatest sensitivity of simulated flow paths to recharge model, with significantly more flow paths down Fortymile Canyon for the DRIA and the USGSD recharges than for the MME recharge, or any other HFM and recharge combination. The combination of HFM and water-balance uncertainty is further addressed in Section 6.5. 
Table 6-46

Summary of Flow Model Results for Water-Balance Uncertainty

\begin{tabular}{|c|c|l|l||}
\hline HFM & $\begin{array}{c}\text { Water-Balance } \\
\text { Condition }\end{array}$ & \multicolumn{1}{|c|}{ Calibration Issues } & \multicolumn{1}{c|}{$\begin{array}{c}\text { Qualitative Flow Path } \\
\text { Assessment }\end{array}$} \\
\hline \hline BN & DRIA & Slight oversimulation bias in Area 19 & $\begin{array}{l}\text { Fewer particles go west into northern } \\
\text { Oasis Valley }\end{array}$ \\
\hline BN & DRIAE & Slight oversimulation bias in Area 19 & $\begin{array}{l}\text { Fewer particles go west into northern } \\
\text { Oasis Valley }\end{array}$ \\
\hline BN & USGSD & $\begin{array}{l}\text { Third-best calibration } \\
\text { Slight oversimulation bias }\end{array}$ & $\begin{array}{l}\text { Particles go deeper along northeastern } \\
\text { Timber Mountain, but stay shallower } \\
\text { after crossing Moat Fault than in base }\end{array}$ \\
\hline $\begin{array}{c}\text { BN Reduced } \\
\text { Alternative }\end{array}$ & USGSND & Second-best calibration & $\begin{array}{l}\text { Particles go deeper along northeastern } \\
\text { Timber Mountain, but stay shallower } \\
\text { after crossing Moat Fault than in base }\end{array}$ \\
\hline $\begin{array}{c}\text { BN Reduced } \\
\text { LCCU1 Permeability } \\
\text { Alternative }\end{array}$ & USGSD & Best calibration & $\begin{array}{l}\text { Particle tracks concentrated on } \\
\text { western flank of Timber Mountain, } \\
\text { fewer go to Oasis Valley than in base }\end{array}$ \\
\hline SCCC & DRIA & Little change from MME & Very similar to base \\
\hline SCCC & USGSD & Little change from SCCC with MME & $\begin{array}{l}\text { Particle tracks mainly go down } \\
\text { Fortymile Canyon }\end{array}$ \\
\hline Fortymile Canyon
\end{tabular}

The particle paths, with the notable exception of the SCCC HFM, tend to behave similarly across all recharge alternatives, suggesting that HFM uncertainty plays a greater role than recharge uncertainty.

\subsection{Combining HFM and Water-Balance Uncertainty}

The Pahute Mesa CAIP (DOE/NV, 1999) requires that HFM and boundary condition uncertainty be considered in the flow model analysis. This section presents the approach used to address the joint effects of HFM and water-balance uncertainty and the results of the analysis.

Table 6-1 in Section 6.1.2 shows the matrix of HFM, recharge, and boundary flow uncertainties. Section 6.3 addresses HFM uncertainty by evaluating five alternative HFMs (in addition to base and SCCC) with the MME recharge model and associated boundary flows, and Section 6.4 addresses water-balance uncertainty by evaluating the USGSD, USGSND, DRIA, and DRIAE recharge models with the base and SCCC HFMs. The final assessment is the conjunction of HFM and water-balance uncertainty. 
The first component of this assessment is the selection of alternative HFMs for evaluation. The SCCC HFM, the major alternative, has already been considered in Section 6.4, and its calibration is discussed in Section 5.7. The five alternative HFMs derived from the base HFM that were considered in Section 6.3 are also candidates for this evaluation. Of the five alternative HFMs considered in Section 6.3 two are distinctly different: the PZUP and DRT alternatives. Other, subtler differences were noticed between the remaining alternatives, but PZUP and DRT had pronounced differences. Therefore, the PZUP and DRT HFMs are chosen for additional water-balance uncertainty analysis.

The water-balance uncertainty was bounded by considering the DRIA and USGSD recharge models and associated UGTA regional boundary flows. The DRIAE and USGSND were assessed in Section 6.4, and it was decided that DRIA and USGSD have physical characteristics that make them desirable and that these two recharge alternates are sufficient to bound uncertainty. The areal distribution and mass flows associated with these recharge models is shown in Section 4.3.1.

The PZUP and DRT HFMs were calibrated with the MME recharge model in Section 6.3. The DRIA and USGSD recharge models were applied and the models recalibrated; the results are described in the following sections.

\subsubsection{Raised Pre-Tertiary Surface (PZUP) HFM}

The PZUP HFM with the selected HSU depth-decay and anisotropy (PZUP-MME-SDA) parameterization as described in Section 5.6.2 was used as the basis for analyzing the joint effects of HFM and water-balance uncertainty. Based on the results of Section 6.4.3, only two combinations of recharge model and boundary flows are considered as follows:

1. DRIA recharge and boundary flow

2. USGSD recharge and USGSND boundary flow

\subsubsection{DRIA Recharge Model}

Table 6-47 summarizes the calibration statistics. It is interesting to note that the mean head error is slightly positive, but with this high recharge model and potentially reduced transmissivity, the opposite result would be expected. The scatter of error as shown by the high error standard deviation in fitting the boundary flows is the worst of all models considered; MME recharge with this HFM 
Table 6-47

Calibration Summary Statistics for PZUP-DRIA-SDA

\begin{tabular}{||c|c|c|c|c|c||}
\hline $\begin{array}{c}\text { Calibration } \\
\text { Data }\end{array}$ & $\begin{array}{c}\text { Number of } \\
\text { Data }\end{array}$ & $\begin{array}{c}\text { Mean Weighted } \\
\text { Error }^{\mathrm{a}}\end{array}$ & $\begin{array}{c}\text { Maximum } \\
\text { Weighted } \\
\text { Residual }\end{array}$ & $\begin{array}{c}\text { Minimum } \\
\text { Weighted } \\
\text { Residual }\end{array}$ & $\begin{array}{c}\text { Error } \\
\text { Standard } \\
\text { Deviation }\end{array}$ \\
\hline \hline Well Head & 152 & 0.45 & $\begin{array}{c}31 \text { (USW UZ- } \\
\text { N91) }\end{array}$ & $\begin{array}{c}-25(\text { UE-20n \#1 } \\
1,005.84 \mathrm{~m})\end{array}$ & 7.4 \\
\hline Spring Head & 28 & 2.8 & $\begin{array}{c}19 \text { (Torrance } \\
\text { Spring) }\end{array}$ & $\begin{array}{c}-5.3(\text { Spring id } \\
159)\end{array}$ & 6.7 \\
\hline $\begin{array}{c}\text { Oasis Valley } \\
\text { Discharge }\end{array}$ & 7 & -17 & 27 (Zone 3) & -47 (Zone 1) & 30 \\
\hline Boundary Flow & 4 & -34 & 59 (West) & -93 (East) & 67 \\
\hline
\end{tabular}

aPositive sign is undersimulation of target data, negative is oversimulation.

also had some of the larger boundary flow errors. The increased volume of mainly lower permeability rocks limits the ability of this model to move water across the boundaries. The objective function is 33,713 . Relative to the calibration with MME recharge this calibration is worse, but not greatly so.

Figure 6-156 shows the posted weighted residuals; there is a slight bias to undersimulate heads that is also suggested by the mean error. The visual impression of the residuals shows more scatter to high and low values than most other results. Simulated Oasis Valley discharge is $286 \mathrm{~kg} / \mathrm{s}$ (versus $227 \mathrm{~kg} / \mathrm{s}$ estimated), one of the highest simulated Oasis Valley discharges of all models. This is nearly two standard deviations above the estimated value (e.g., the upper 95 percent confidence limit on Oasis Valley discharge). This is interpreted as arising from the larger accretion of recharge that must move through shallower high-permeability HSUs, which can still satisfy Oasis Valley discharge while the boundary flows are otherwise more poorly matched than in other cases. Figure 6-157 shows the simulated water table, and Figure 6-158 shows the simulated flow paths. The water table and flow paths have the same general character seen in all the simulations. The mound under Black Mountain is from the substitution of TCVA with low permeability BMICU. The DVCM, BRA, LCA Zone 1, CHZCM, and YMCFCM permeabilities (including $\mathrm{k}_{0}$ ) all increased between a quarter and an order of magnitude over the values used to calibrate the MME recharge in order to bleed off the additional recharge (nearly double that of the MME) imposed by the DRIA recharge model. 


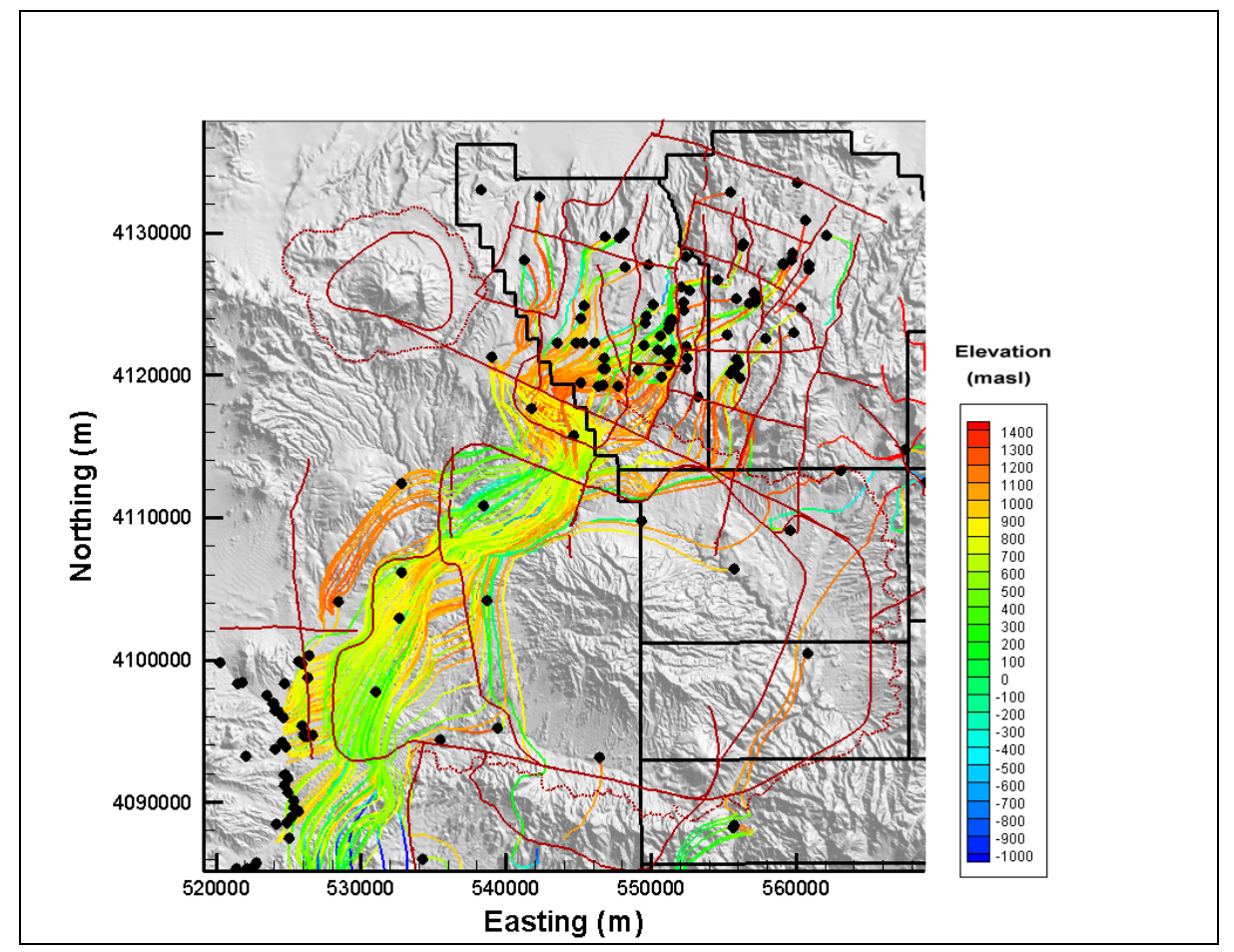

Figure 6-158

Particle Tracks for PZUP-DRIA-SDA

\subsubsection{USGSD Recharge Model}

The summary calibration statistics for the PZUP HFM and USGSD recharge model and USGSND boundary flows are shown in Table 6-48. There is a definite bias to undersimulate observation well heads. The objective function is 29,666, slightly worse than the calibration with the MME recharge model, but marginally better than the DRIA calibration.

Post plots of weighted well and spring head residuals are shown in Figure 6-159 for the USGSD recharge model. There is definite bias to undersimulate heads by 20 to $25 \mathrm{~m}$ in central Pahute Mesa that is also seen in the mean error. However, the boundary flows are matched well with an error standard deviation less than with both the MME and DRIA recharge models, although some of this effect may be artificial because the boundary flows for this recharge model are the lowest in magnitude. Figure 6-160 shows the simulated water table, which appears to show the broad features of the flow system correctly. Simulated Oasis Valley discharge is $208 \mathrm{~kg} / \mathrm{s}$. Thus, the controlling factor for Pahute Mesa head is not entirely the same as that which controls Oasis Valley discharge (which was noted in the sensitivity analysis as well). Figure 6-161 show the simulated flow paths, 
Table 6-48

Calibration Summary Statistics for PZUP-USGSD-SDA

\begin{tabular}{||c|c|c|c|c|c||}
\hline $\begin{array}{c}\text { Calibration } \\
\text { Data }\end{array}$ & $\begin{array}{c}\text { Number of } \\
\text { Data }\end{array}$ & $\begin{array}{c}\text { Mean Weighted } \\
\text { Error }^{\mathrm{a}}\end{array}$ & $\begin{array}{c}\text { Maximum } \\
\text { Weighted } \\
\text { Residual }\end{array}$ & $\begin{array}{c}\text { Minimum } \\
\text { Weighted } \\
\text { Residual }\end{array}$ & $\begin{array}{c}\text { Error } \\
\text { Standard } \\
\text { Deviation }\end{array}$ \\
\hline \hline Well Head & 152 & 5.8 & $42(\mathrm{U}-19 \mathrm{x})$ & $\begin{array}{c}-17 \\
\text { (ER-OV-04a) }\end{array}$ & 13 \\
\hline Spring Head & 28 & 3.0 & $\begin{array}{c}19 \text { (Torrance } \\
\text { Spring) }\end{array}$ & $\begin{array}{c}-5.3 \text { (Ute } \\
\text { Springs Culvert) }\end{array}$ & 6.7 \\
\hline $\begin{array}{c}\text { Oasis Valley } \\
\text { Discharge }\end{array}$ & 7 & 5.3 & 37 (Zone 3) & -26 (Zone 4) & 23 \\
\hline Boundary Flow & 4 & 6.0 & 15 (West) & -5.9 (East) & 9.9 \\
\hline
\end{tabular}

apositive sign is undersimulation of target data, negative is oversimulation.

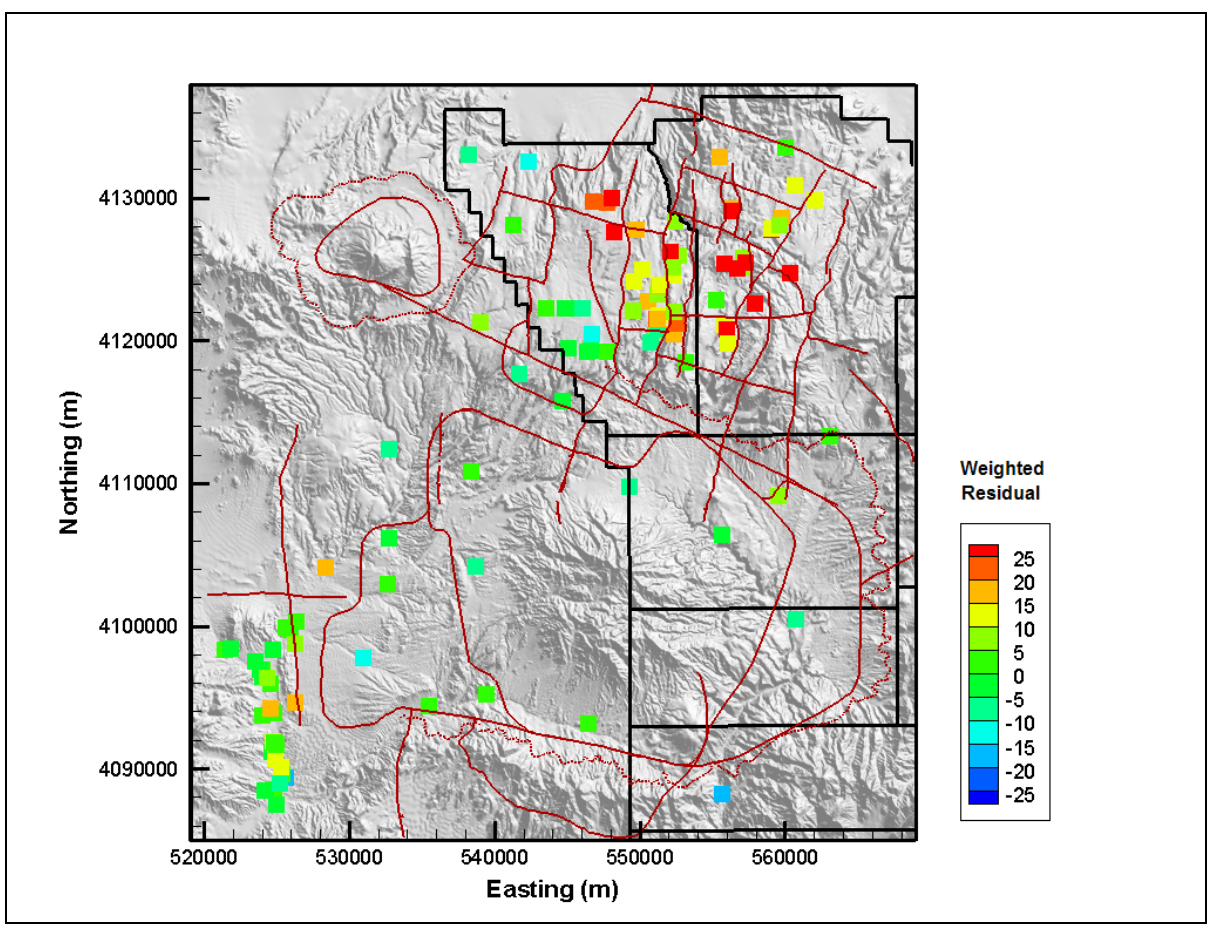

Figure 6-159

Post Plot of Weighted Well and Spring Head Residuals for PZUP-USGSD-SDA

which, in spite of the bias in head, show flow paths that appear quite reasonable. Hence, the overall direction of the hydraulic gradient is still reasonable in this case. 
The HSU permeabilities that changed the most between the MME and USGS recharge models are the LCA3, PCM, TMA, and the various TMCM HSUs, all of which had modest decreases (a quarter an order of magnitude or less). Thus, the effect of dropping the recharge rate was to require permeability to decrease in order to enhance the effect of the lower recharge in maintaining head.

\subsubsection{Deeply Rooted Belted Thrust Fault (DRT) HFM}

The DRT HFM as described in Section 2.0 and Section 6.3 was also used for analyzing joint HFM and water-balance uncertainty. Based on the results of Section 6.4.3, only two combinations of recharge model and boundary flows are considered as follows:

1. DRIA recharge and boundary flow

2. USGSD recharge and USGSND boundary flow

\subsubsection{DRIA Recharge Model}

Calibration summary statistics for the DRT HFM with the DRIA recharge model are shown in Table 6-49. The error standard deviations are noticeably higher than those for the MME recharge calibration shown in Section 6.3. The scatter on boundary flows is comparable to the PZUP HFM and DRIA combination; this is because the LCCU1 is propagated extensively throughout the model and its low permeability makes it difficult to move water in and out of the model (similarly to the PZUP HFM). The model objective function is 37,630 versus 26,240 for calibration with the MME recharge model.

Figure 6-162 shows the posted weighted residuals; there is a strong underprediction at WW-8, although UE-18t and ER-18-2, which are often undersimulated when WW-8 is undersimulated, are reasonably matched. This is because of the higher recharge that applies more water locally that can correct bias. Simulated Oasis Valley discharge is $236 \mathrm{~kg} / \mathrm{s}$, one of the larger values from the suite of models tested, although not as large as the PZUP HFM and DRIA recharge. Figure 6-163 shows the simulated water table, and Figure 6-164 shows the simulated flow paths from NTS wells. The water table and flow paths have the same general character seen in all the simulations, but there is shift in flow paths such that many exit along the southern boundary at about 540,000 m Easting. This result is also noted in Section 6.3; thus, it is concluded that the shift in flow paths is due to the HFM and not the recharge model. 
Table 6-49

Calibration Summary Statistics for DRT-DRIA-SDA

\begin{tabular}{||c|c|c|c|c|c||}
\hline $\begin{array}{c}\text { Calibration } \\
\text { Data }\end{array}$ & $\begin{array}{c}\text { Number of } \\
\text { Data }\end{array}$ & $\begin{array}{c}\text { Mean Weighted } \\
\text { Error }^{\mathrm{a}}\end{array}$ & $\begin{array}{c}\text { Maximum } \\
\text { Weighted } \\
\text { Residual }\end{array}$ & $\begin{array}{c}\text { Minimum } \\
\text { Weighted } \\
\text { Residual }\end{array}$ & $\begin{array}{c}\text { Error } \\
\text { Standard } \\
\text { Deviation }\end{array}$ \\
\hline \hline Well Head & 152 & -0.88 & 69 (WW-8) & -35 (U-19ad) & 10 \\
\hline Spring Head & 28 & 2.6 & $\begin{array}{c}19 \text { (Torrance } \\
\text { Spring) }\end{array}$ & $\begin{array}{c}-6.0 \text { (Spring id } \\
159)\end{array}$ & 6.9 \\
\hline $\begin{array}{c}\text { Oasis Valley } \\
\text { Discharge }\end{array}$ & 7 & -2.8 & 45 (Zone 5) & -44 (Zone 4) & 30 \\
\hline Boundary Flow & 4 & -40 & 6.6 (West) & -85 (South) & 58 \\
\hline
\end{tabular}

aPositive sign is undersimulation of target data, negative is oversimulation.

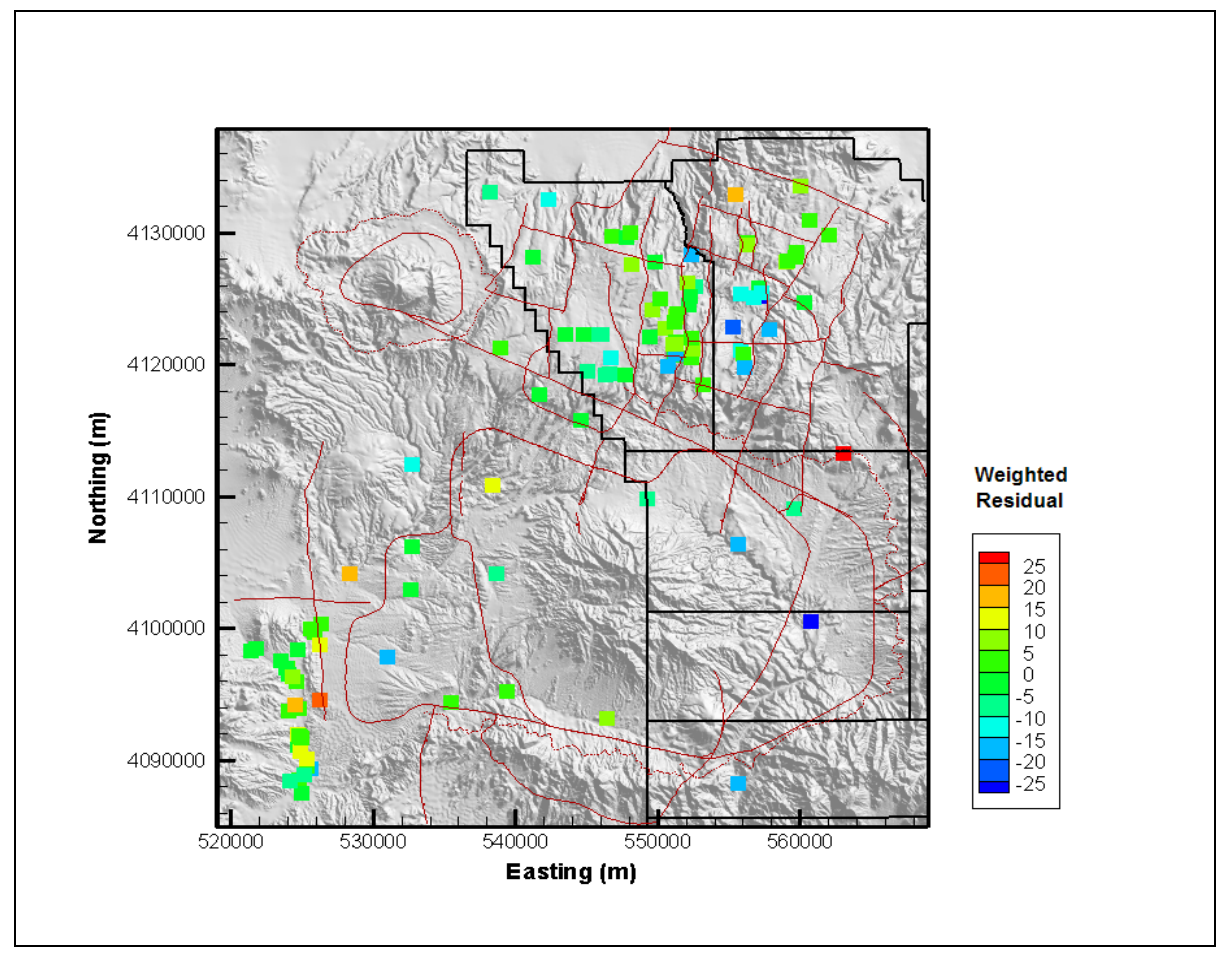

Figure 6-162

\section{Post Plot of Weighted Well and Spring Head Residuals for DRT-DRIA-SDA}

The HSU permeabilities that changed the most in calibrating the DRT HFM between the MME and DRIA recharge models include those of the CHZCM (an increase of just over an order of magnitude), DVCM (a slight decrease), LCA3 (an order of magnitude increase), CFCM (order of magnitude increase), PCM (slight increase), PBRCM Zone 84 (this zone controls flow from the north into Oasis 
Valley, about half an order of magnitude decrease). The interpretation of these changes is that the CHZCM and CFCM increased in permeability in order to move water out of Areas 19 and 20. Sensitivity analysis showed that PCM has a strong effect on average head in the domain, and its increased permeability is interpreted to be necessary to bleed off head by moving more water out of the system. The PBRCM Zone 84 and DVCM became tighter to limit flow to Oasis Valley from the north and west boundaries, respectively, because so much more is available from recharge accretion.

\subsubsection{USGSD Recharge Model}

The calibration summary statistics for the DRT HFM with the USGSD recharge model are shown in Table 6-50. The model objective function is 19,043 versus 26,240 for calibration with the MME recharge model. The calibration of this HFM and recharge model is much better than with the DRIA recharge model.

Table 6-50

Calibration Summary Statistics for DRT-USGSD-SDA

\begin{tabular}{||c|c|c|c|c|c|}
\hline $\begin{array}{c}\text { Calibration } \\
\text { Data }\end{array}$ & $\begin{array}{c}\text { Number of } \\
\text { Data }\end{array}$ & $\begin{array}{c}\text { Mean } \\
\text { Weighted } \\
\text { Errora }\end{array}$ & $\begin{array}{c}\text { Maximum } \\
\text { Weighted } \\
\text { Residual }\end{array}$ & $\begin{array}{c}\text { Minimum } \\
\text { Weighted } \\
\text { Residual }\end{array}$ & $\begin{array}{c}\text { Error } \\
\text { Standard } \\
\text { Deviation }\end{array}$ \\
\hline \hline Well Head & 152 & 1.3 & 37 (WW-8) & $\begin{array}{c}-32 \text { (USW UZ- } \\
\text { N91) }\end{array}$ & 9.0 \\
\hline Spring Head & 28 & 2.6 & $\begin{array}{c}19 \text { (Torrance } \\
\text { Spring) }\end{array}$ & $\begin{array}{c}-6.3 \text { (Spring id } \\
159)\end{array}$ & 6.8 \\
\hline $\begin{array}{c}\text { Oasis Valley } \\
\text { Discharge }\end{array}$ & 7 & 6.8 & 39 (Zone 3) & -21 (Zone 4) & 22 \\
\hline Boundary Flow & 4 & -3.9 & 20 (West) & -33 (North) & 23 \\
\hline
\end{tabular}

aPositive sign is undersimulation of target data, negative is oversimulation.

Figure 6-165 shows the posted weighted residuals; there is a strong underprediction including wells WW-8, UE-18t, and ER-18-2. There appears to be a modest bias to undersimulate heads in north-central Area 20, in central Area 19, and in the east-central area near the head of Fortymile Canyon. Simulated Oasis Valley discharge is $203 \mathrm{~kg} / \mathrm{s}$. Figure 6-166 shows the simulated water table, and Figure 6-167 shows the simulated flow paths from NTS wells. Flow paths are more concentrated with this recharge model than with the DRIA, and flow paths are also shallower than with the DRIA recharge model. This is interpreted as a consequence of the reduced permeabilities 


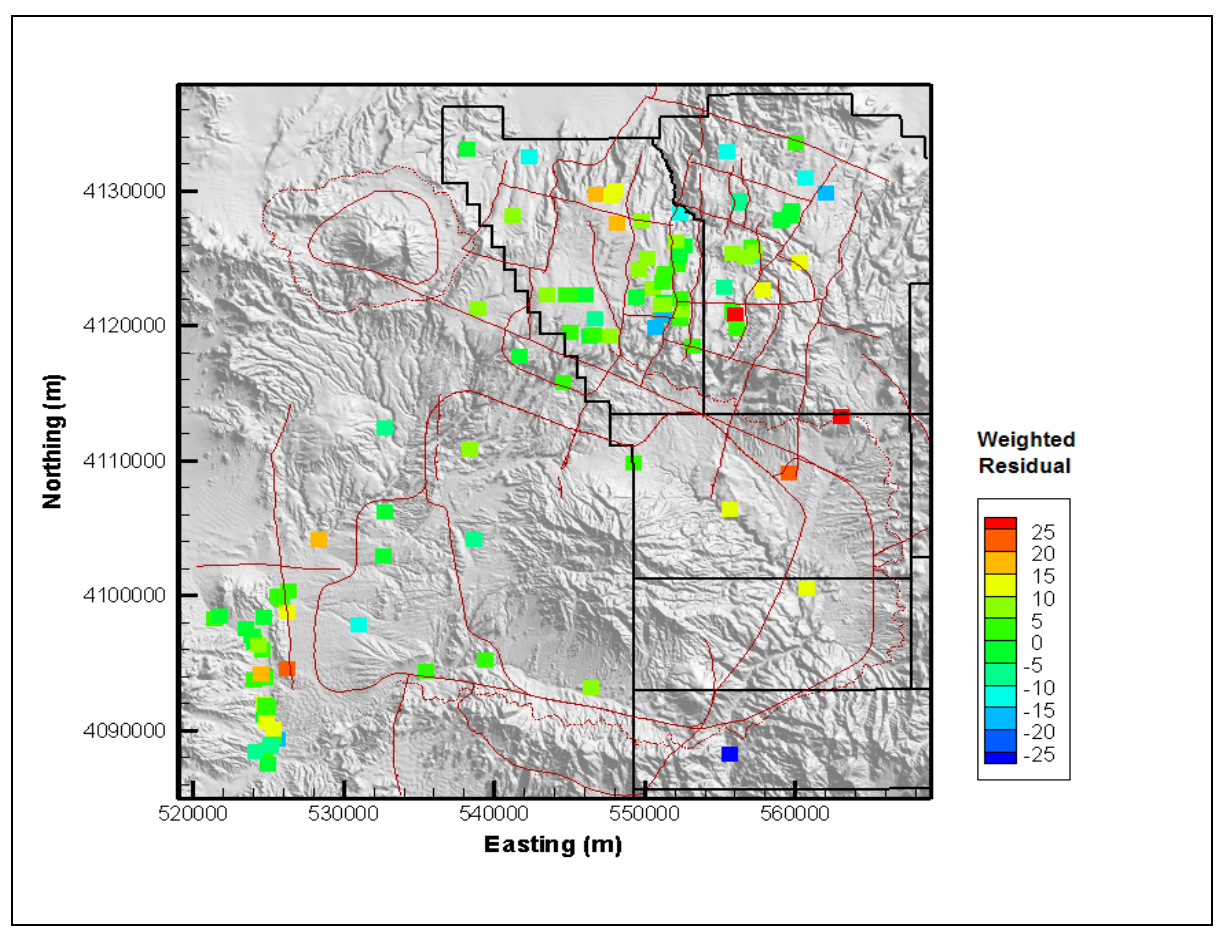

Figure 6-165

\section{Post Plot of Weighted Well and Spring Head Residuals for DRT-USGSD-SDA}

required to hold up model heads. The flow paths also show (like DRT-DRIA) a strong component of flow exiting the model at about Easting 540,000 m. In conclusion this is a function of HFM, not the recharge model.

The HSU permeabilities that changed between the DRIA and MME recharge models are the CFCU (two order of magnitude reduction), CFCM (one order of magnitude reduction), BRA (half an order of magnitude reduction), and CHZCM (one-quarter order of magnitude reduction). All these reductions are compensation for the reduced recharge in the USGSD model versus the MME model. 
Table 7-2

Fractions of Groundwater from Various Upgradient Wells Present in Groundwater at Well UE-18r

\begin{tabular}{|c|c|c|}
\hline Mixing Component & Minimum Fraction & Maximum Fraction \\
\hline \hline ER-18-2 & 0.087 & 0.122 \\
\hline ER-EC-7 & 0.000 & 0.000 \\
\hline WW-8 & 0.000 & 0.000 \\
\hline Test Well \#1 & 0.000 & 0.000 \\
\hline UE-19h & 0.370 & 0.429 \\
\hline UE-19c WW & 0.484 & 0.543 \\
\hline
\end{tabular}

Table 12 from Kwicklis et al. (2005). Note: Groundwater from ER-EC-7 was used to represent recharge from infiltration at Timber Mountain. See Kwicklis et al. (2005) for discussion of uncertainty tolerances and rock water reactions for the calculations represented in this specific table.

In some of the model simulations, highly localized, large flows across the eastern boundary at Gold Meadows near the water table are clearly due to the high fixed boundary heads at Gold Meadows coupled with relatively large calibrated LCCU1 permeabilities (see Sections 6.2 and 6.2.4.4). With a high boundary head and a high-permeability conduit, it is not surprising that significant simulated flow enters the model domain at this location. These flows do not adversely affect the head and flux calibrations, but they do result in unsupportable geochemical sources at UE-18r. Thus, this analysis serves to identify and quantify this error, as discussed in Section 7-5.

\subsubsection{BN-MME-SDA Reduced LCCU1 Permeability Alternative}

In the first alternative model, the LCCU1 permeability was fixed at about one order of magnitude lower than in the base case before recalibration of other HSU permeabilities, resulting in substantially less flow across the eastern boundary at Gold Meadows. For comparison, Figure 7-11 shows the reverse-particle-tracking simulation and the zone comparison to the geochemistry mixing targets for the BN-MME-SDA with reduced LCCU1 permeability alternative (described in Section 6.2.4.4). In this model, the reverse particles from UE-18r leave the system within the model domain in areas of high recharge in Area 19. Approximately 60 percent of the water at UE-18r originates within the northeast quadrant of the flow model domain in this simulation, but to the southeast of Wells UE-19h and UE-19c WW. In the absence of groundwater chemistry data in the area where the simulated recharge occurs (southeastern Area 19), it is assumed that the groundwater chemical composition is 
Table 7-13

Comparison of Alternative Models at ER-OV-01

\begin{tabular}{|c|c|c|c|c|}
\hline HFM & $\begin{array}{l}\text { Water-Balance } \\
\text { Condition }\end{array}$ & $\begin{array}{l}\text { Underpredicts } \\
\text { North-Central } \\
\text { and/or } \\
\text { Northeast } \\
\text { Source }\end{array}$ & $\begin{array}{l}\text { Overpredicts } \\
\text { the Northwest } \\
\text { Source }\end{array}$ & $\begin{array}{c}\text { Overpredicts } \\
\text { Local } \\
\text { Recharge }\end{array}$ \\
\hline \multirow{3}{*}{$\begin{array}{l}\text { BN-SDA reduced LCCU1 } \\
\text { permeability alternative }\end{array}$} & MME & $x$ & & $x$ \\
\hline & USGSD & $x$ & $x$ & $x$ \\
\hline & DRIA & $x$ & $x$ & $x$ \\
\hline \multirow{3}{*}{ BN-SDA } & MME & $x$ & & $x$ \\
\hline & USGSD & $x$ & $x$ & $x$ \\
\hline & DRIA & $x$ & $x$ & $x$ \\
\hline BN-ADA & MME & $x$ & & $x$ \\
\hline \multirow{3}{*}{ SCCC-SDA } & MME & $x$ & & $x$ \\
\hline & USGSD & $x$ & $x$ & \\
\hline & DRIA & $x$ & $x$ & \\
\hline PZUP & MME & $x$ & & $x$ \\
\hline DRT & MME & $x$ & & $x$ \\
\hline RIDGE & MME & & & $x$ \\
\hline $\mathrm{TCL}$ & MME & $x$ & & $x$ \\
\hline SEPZ & MME & $x$ & & $x$ \\
\hline \multirow{2}{*}{ PZUP } & USGSD & & $\mathrm{x}$ & $x$ \\
\hline & DRIA & & & \\
\hline \multirow{2}{*}{ DRT } & USGSD & $x$ & $x$ & $x$ \\
\hline & DRIA & $x$ & $x$ & $x$ \\
\hline
\end{tabular}

Note: Uppercase Xs indicate the issue is worse than lowercase $\mathrm{x}$ symbols. 


\subsubsection{ER-OV-05}

\subsubsection{Alternative Water-Balance Conditions, BN HFM}

As with the BN-MME-SDA reduced LCCU1 permeability alternative, the simulated mixing at ER-OV-05 for the USGSD and DRIA water-balance conditions match the targets well with a simple flow path from the northwest to the target well (Figures 7-61 and 7-62). It is interesting to note the effects of the different recharge maps, as represented by the locations and densities of reverse particles leaving the two different models. Not surprisingly, the BN-MME-SDA (high LCCU1 permeability) with both USGSD and DRIA water-balance conditions and the BN-MMEADA model estimate the northwest source well (Figures 7-63 and 7-64).

\subsubsection{SCCC Alternative HFM}

Due to the boundary conditions and lack of HFM complexity on the west side of the model, flow is predominantly north to south. Thus, the SCCC alternative HFM model results with MME water-balance conditions are not significantly different from the BN HFM models (Figure 7-65). The only notable aspect of the alternative water-balance model calibrations with the SCCC HFM (Figure 7-66) is that when DRIA is used, a significant component of the mixing source is from local recharge. However, considering data control in this portion of the domain and the arbitrary boundaries for the different zones leads one to simply note that the recharge source for water at ER-OV-05 in this model is somewhat further south than in most other models.

\subsubsection{PZUP, DRT, RIDGE, TCL, and SEPZ Alternative HFMs}

As with all ER-OV-05a cases described thus far, there are no substantial differences between the alternative HFM and MME water-balance scenarios (Figures 7-67 through 7-69). When considering the alternative water-balance conditions for PZUP and DRT (Figures 7-70 and 7-71), the only notable features is that the location of some of the local recharge for the DRIA models is further south than the other water-balance condition models.

\subsubsection{Summary: ER-OV-05}

All of the models considered for ER-OV-05a produce reasonable results. There are no discriminating features in the geochemistry target matching that were identified for this well. 


\subsection{THERMAL SENSITIVITY AND VERIFICATION}

\subsection{Introduction}

The flow model calibration described in earlier sections utilizes a thermal field based upon calibration of the heat flux at the base of the model domain (Appendix C). In calibrating the heat fluxes with a conduction-only model to minimize residuals between observed and simulated temperatures in boreholes, certain anomalies were identified indicating convective flow. These anomalies indicate that cooler water from near the water table is likely flowing vertically downward, resulting in borehole temperatures cooler than would be explained with the pure convection model. Therefore, Section 8.2 investigates whether such downward flow is captured with the calibrated flow model, thus providing qualitative confirmation. Section 8.3 investigates the sensitivity (qualitatively again) of the variable heat-flux-based temperatures as compared to much simpler linear temperature profiles in the flow model.

\subsection{Flow Model Verification to Vertical Flow Indicated by Temperature Analysis}

The role and potential value of thermal data analysis for constraining groundwater flow models is presented in Appendix C. One of the primary results of that analysis is the identification of specific locations where pure vertical conduction of heat does not adequately explain thermal anomalies observed in borehole temperature profiles. The process of identifying such locations involved calibrating heat-conduction-only models to the thermal data in the Pahute Mesa CAU model domain (described in Appendix C). Then, following calibration, temperature datasets that still are not matched well and that show a systematic variance from the conduction-only simulations are examined with respect to other datasets and potential vertical groundwater (and hence heat) convection. Four locations within the CAU flow model domain where downward vertical flow would explain convective cooling are discussed in detail in Appendix C. They are summarized here, and the flow model is evaluated for consistency with respect to the hypothesized downward flow through the use of reverse-particle-tracking simulations. Only the BN-MME-SDA reduced LCCU1 permeability 
Addendum to GFM CAUs 101 and 102

Final Document Date: June 2006

Revision: 0

Section 8.2.1, Page 8-2

Addendum Date: May 2007

alternative is evaluated here, but the results are qualitatively representative for any of the calibrated flow models.

\subsubsection{Southwestern Silent Canyon Caldera}

In the southwestern part of the SCCC, it is likely that the deep heat flux is actually higher than the heat flux of 73 milliwatts per square meter $\left(\mathrm{mW} / \mathrm{m}^{2}\right)$ estimated for the caldera complex as a whole with the variable heat-flux model described in Appendix C, and that cool groundwater from the shallow saturated zone flows downward through the upper units. These interpretations are supported by a detailed examination of temperature residuals from this area. The heat-conduction model with a uniform heat flux of $85 \mathrm{~mW} / \mathrm{m}^{2}$ provides a good match to the measured temperatures at borehole ER-EC-6, but underestimates the deepest measurement in the region - the temperature of 121 degrees Celsius $\left({ }^{\circ} \mathrm{C}\right)$ measured at a $12,270 \mathrm{ft}$ depth in borehole UE-20f. Conversely, simulated temperatures in nearby boreholes U-20c, U-20d, and ER-20-5 \#3 in the southwest part of the caldera complex are warmer than the measured temperatures for deep heat fluxes of either 85 or $73 \mathrm{~mW} / \mathrm{m}^{2}$. A heat flux of $85 \mathrm{~mW} / \mathrm{m}^{2}$ would improve the match between simulated and measured temperatures at boreholes UE-20f, ER-EC-6, and ER-EC-1, where measured temperatures are underestimated by the model with a deep heat flux of $73 \mathrm{~mW} / \mathrm{m}^{2}$ for the SCCC. However, the use of a higher heat flux in the heat-conduction model would increase the mismatch between simulated and measured temperatures at boreholes U20c, ER-20-5 \#3, and U-20d, which the model indicates are already too warm for a heat flux of $73 \mathrm{~mW} / \mathrm{m}^{2}$.

To offset the temperature increases that would result from higher deep heat fluxes, a mechanism to cool the subsurface temperatures in the southwestern part of the SCCC is required. The downward hydraulic gradient, dipping beds, and discontinuous HSUs across faults in the upper part of southwest Area 20 (Wolfsberg et al., 2002; BN, 2002, cross-sections J-J' and C-C') indicate that hydrogeologic conditions are favorable for cool groundwater near the water table to flow downward along the dipping beds or faults to deeper aquifers such as the IA, thereby reducing temperatures and heat fluxes below the wells in this region.

To test this hypothesis, a reverse streamline particle-tracking simulation (SPTR Module in FEHM simulation) was conducted for calibrated flow model BN-MME-SDA reduced LCCU1 permeability alternative with 1,000 particles originating in the IA, below ER-20-5 \#3 (which terminates in the 
Addendum to GFM CAUs 101 and 102

Final Document Date: June 2006

Revision: 0

Section 8.2.2, Page 8-3

Addendum Date: May 2007

CHZCM). Figure 8-1 shows the particle paths moving upgradient and to higher elevations from their origin. This simulation confirms that cool shallow water from central and northern Areas 20 and 19 can flow vertically to deeper units. In this case, the primary elevation drop occurs at the West Greeley Fault, the Boxcar Fault, and within the block between the two faults. The movement of cool shallow water to depths below wells such as ER-20-5 \#3 would result in the observed cooler temperatures, which lead to lower-than-expected estimations of deep thermal flux in conduction-only models.

\subsubsection{Northeastern Silent Canyon Caldera}

In the northeastern part of the SCCC, the simulated temperatures are higher than the measured temperatures at borehole U-19e for the calibrated variable heat-flux conduction model. Although the temperature data at borehole U-19e are reasonably well matched with a uniform heat flux of $45 \mathrm{~mW} / \mathrm{m}^{2}$, temperatures at borehole U19-i, located about $5 \mathrm{~km} \mathrm{(3} \mathrm{mi)} \mathrm{to} \mathrm{the} \mathrm{south}$ of borehole U-19e, are underestimated using this low heat flux, and better matched with a heat flux of $85 \mathrm{~mW} / \mathrm{m}^{2}$ (consistent with what is reasonable for other parts of the Silent Canyon Caldera). A hydrologic explanation is that downward groundwater movement through the Halfbeak Fault or Split Ridge Fault and along the down-dipping Belted Range Aquifer (BRA) (see BN, 2002, cross-section C-C') significantly cools the rocks and reduces heat flux near borehole U-19e.

To test this hypothesis, a reverse-particle-tracking simulation was conducted for calibrated flow model BN-MME-SDA reduced LCCU1 permeability alternative with 1,000 particles originating in the BRA below ER-19e. Figure 8-2 shows the reverse-particle paths moving upgradient to the Split Ridge Fault, which defines the Silent Canyon Caldera Margin, and then vertically upward to the water table. This simulation confirms that cool shallow water from the northeast can flow vertically to deeper HSUs along the Silent Canyon Caldera margin. In this case, the primary elevation drop occurs at the Split Ridge Fault, with additional elevation drop along dip with the BRA. The elevation drop of cool shallow water to depth below Well U-19e would result in the observed cooler temperatures, which lead to lower-than-expected estimations of deep thermal flux in conduction-only models at this well. 


\subsubsection{Eastern Timber Mountain Caldera}

Borehole UE-18r was characterized by Gillespie (2003) as having dominantly conductive heat flow (about $25 \mathrm{~mW} / \mathrm{m}^{2}$ ) and reliable temperature measurements above the bottom of the borehole casing at a depth of $496.5 \mathrm{~m}$ (elevation 1,192 m). Unfortunately, simulated temperatures at these elevations are dominated by the upper boundary conditions and are insensitive to the assumed thermal conductivity estimates and lower boundary conditions. Hence, it was necessary to use a deep temperature measurement from below the borehole casing as a calibration target in the inverse models. The simulated temperatures are significantly warmer than this deep measurement from borehole UE-18r for all lower boundary conditions considered in this report. The consistent overestimation of the measured temperature indicates that downward groundwater flow may have cooled the rocks near the bottom of the temperature profile. Borehole UE-18r penetrates a fault breccia at depth, which suggests that groundwater flow along the fault associated with this breccia or a nearby similar fault may have cooled nearby temperatures. This interpretation is also consistent with the relatively low heat flux of $25 \mathrm{~mW} / \mathrm{m}^{2}$ estimated by Gillespie (2003, Table 7) above elevations of 1,192 $\mathrm{m}$ and the much larger heat flux (greater than $75 \mathrm{~mW} / \mathrm{m}^{2}$ ) estimated below the elevation of $443 \mathrm{~m}$. Based on one-dimensional scoping simulations (Appendix C), heat flux is expected to decrease with elevation in areas of downward groundwater flow. However, groundwater carbon-14 measured in the borehole is very low (Chapman et al., 1995), ruling out modern recharge as a likely influence on groundwater temperatures and suggesting that the downward movement of groundwater from laterally upgradient areas is a more likely explanation for the decrease in heat flux with elevation at borehole UE-18r.

Figure 8-3 shows the reverse-particle paths originating in the fault breccia zone of UE-18r for BN-MME-SDA reduced LCCU1 permeability alternative. The paths show a major elevation change along the Timber Mountain Caldera structural margin fault (the fault intersected by UE-18r is not explicitly identified in the CAU flow model). As the reverse particles encounter the fault, they change elevation drastically. Also consistent with the age consideration mentioned above, the reverse particles do not leave the system immediately upon gaining shallow depths. Rather, they move laterally until finally leaving the flow model at higher elevations in Area 19. The combination of the distance between where the recharge occurs and UE-18r coupled with the permeability of the porous media may be sufficient to produce large residence times that would result in low carbon-14 signatures. 


\subsubsection{Extra Caldera Zone Western Timber Mountain Caldera}

Measured temperatures at borehole ER-EC-4 are consistently cooler than the temperatures calculated with the calibrated variable heat-flux model. These temperature differences, along with a decrease in the estimated heat flux from 54 to $28 \mathrm{~mW} / \mathrm{m}^{2}$ through the lower part of the borehole, indicate the presence of downward groundwater movement affecting temperatures below this borehole. One hypothesis that explains the low temperatures and heat flux at borehole ER-EC-4 is that cool shallow groundwater in the northwest flows to depth in this area within the southward dipping LCA (BN, 2002, cross-section G-G'). As groundwater moves southward through this area, the downward flow component induced by the dip of the beds causes the groundwater to become warmer, thereby consuming heat and decreasing the temperature and heat flux in the overlying rocks.

Figure 8-4 shows the complex origins of water in the LCA below ER-EC-4 as mapped with 1,000 reverse tracking particles in model BN-MME-SDA reduced LCCU1 permeability alternative. The primary sources include: (a) a small component from the northeast, (b) inflow within the LCA along the northern boundary, and (c) shallow groundwater between the Black Mountain and Silent Canyon Calderas north of ER-EC-4. The latter source is consistent with the hypothesis that cool, shallow water flows to depth below ER-EC-4, reducing the temperature and giving and apparent lower heat flux for conduction-only models. Likewise, LCA water entering along the northern boundary has a shallower and, thus, cooler source to the north of the model domain.

\subsubsection{Summary}

Four different locations within the CAU model domain were identified as being affected by downward-groundwater flow. Identification was made for thermal profiles in wells that could not be explained with a heat conduction-only model. Following these identifications, reverseparticle-tracking simulations were conducted to investigate whether shallow groundwater sources were feasible at the depths indicated in the heat-conduction study. For two locations within the Silent Canyon Caldera, one within the Timber Mountain Caldera, and one to the west of the Timber Mountain Caldera, these simulations demonstrate that the flow model qualitatively captures the convective components identified, thus supporting the hypothesis that convective cooling explains the apparent low conductive fluxes. 
Addendum to GFM CAUs 101 and 102

Final Document Date: June 2006

Revision: 0

Section 9.0, Page 9-13

Addendum Date: May 2007

models in the two worst clusters are judged to be in direct conflict with the interpreted geochemistry, and are to be eliminated from further consideration in future transport analyses. The remaining cluster of five calibrated models has less severe problems than the worst two clusters, and for some metrics even performs better than the best cluster. These models will be considered in less detail during transport calculations, perhaps in sensitivity analysis.

Thermal analysis was also used as a qualitative test of model consistency. Thermal analysis suggested areas where flow of cooler water downward could explain temperature anomalies. Reverse-particle tracking was conducted at the four locations of cooler thermal anomalies to test whether simulated flow paths were such that cooler water from upgradient could be seen to flow to the well. The BN-MME-SDA reduced LCCU1 permeability model was able to simulate such flow paths.

Bredehoeft (2005) suggests that selecting the proper conceptual model (that is, addressing conceptual model uncertainty) is a major problem in groundwater modeling analysis. He suggests that this can be overcome by collecting as much data as feasible using all applicable methods, and by leaving the conceptual model open to change. Recently, Nishikawa (1997) and Harrar et al. (2003) present analyses where alternative geologic conceptual models are tested in simulating groundwater flow and transport results. Nishikawa (1997) found that some conceptual alternatives better explained reality, while Harrar et al. (2003) found that while all the alternative models could replicate the calibration data, their performance in predicting capture zones and breakthrough were quite different, and inverse modeling coupled with alternative geologic models (such as that described in this report) could be used to assess predictive uncertainty. A total of 26 individual flow model calibrations for the Pahute Mesa CAU, and geochemical verification of most of them, were conducted and are presented in this report. These calibrations reflect a variety of combinations of alternative HFMs, recharge models, and water-balance conditions. Thus, the approach taken for the Pahute Mesa flow model attempts to bound the proper conceptualization of HFM and water balance, and at least addresses the high-level uncertainty associated with the conceptual model.

The Pahute Mesa CAU flow model is calibrated to hydraulic head and estimates of boundary flow and Oasis Valley discharge. This information is utilized to give the direction and velocity of groundwater flow, which will be used to compute contaminant transport in conjunction with the 
Addendum to GFM CAUs 101 and 102

Final Document Date: June 2006

Revision: 0

Section 9.0, Page 9-14

Addendum Date: May 2007

appropriate processes (e.g., advection, dispersion, retardation, and radioactive decay). However, the solute transport process has profoundly different characteristics than groundwater flow alone (Anderson, 1979). Mathematically, the steady-state saturated groundwater flow equations are elliptic, with smoothly varying head, while the solute transport equations range from parabolic (with smoothly varying concentrations) in the case of dispersion-diffusion dominated system to hyperbolic (with sharp concentration fronts) in the case of advection-dominated systems. Consequently, calibration to head and flow does not necessarily inform or constrain solute transport. Thus, there may be additional uncertainty associated with the flow model when it is used to make predictions of radionuclide transport. The effects of concentration data on flow model calibration were examined by Weiss and Smith (1993 and 1997). They examined how head and concentration data interact in model calibration with eigenspace and response surface analysis. They showed that, depending on the flow model structure, concentration data could range from being unbeneficial to very beneficial in supplying additional flow model constraint. Scheibe and Chien (2003) showed that calibration of a flow and transport model with a large number of small-scale measurements of concentration and formation properties does not necessarily yield improved predictions, but that broader scale data do. Thus, simply collecting radionuclide or other concentration data does not guarantee improved transport predictions; the data must be collected with an understanding of how the hydrogeologic system (represented by the model) behaves.

The FFACO (1996) requires that the contaminant transport model predict the contaminant boundary at 1,000 years and "at a 95\% level of confidence." The Pahute Mesa Phase I flow model described in this report provides, through the flow fields derived from alternative HFMs and recharge models, one part of the data required to compute the contaminant boundary. Other components include the simplified source term model, which incorporates uncertainty and variability in the factors that control radionuclide release from an underground nuclear test (SNJV, 2004a), and the transport model with the concomitant parameter uncertainty as described in Shaw (2003). The synthesis of all of this information contributes to the calculation of the final contaminant boundary. 
Civilian Radioactive Waste Management System Management and Operating Contractor. 2000. Integrated Site Model Process Report, TDR-NBS-GS-000002, REV 00, ICN 01. Las Vegas, NV: TRW Environmental Safety Systems, Inc.

Cook, P., and J.K. Bohlke. 2000. "Determining Timescales for Groundwater Flow and Solute Transport.” In Environmental Tracers in Subsurface Hydrology, pp.1-30. Boston, MA: Kluwer.

Cover, T.M., and J.A. Thomas. 1991. Elements of Information Theory. New York, NY: John Wiley \& Sons, Inc.

DOE/NV, see U.S. Department of Energy, Nevada Operations Office.

DOE/ORD, see U.S. Department of Energy, Office of Civilian Radioactive Waste Management, Office of Repository Development.

D’Agnese, F.A., C.C. Faunt, A.K. Turner, and M.C. Hill. 1997. Hydrogeologic Evaluation and Numerical Simulation of the Death Valley Regional Ground-water Flow System, Nevada and California: Water-Resources Investigations Report 96-4300, p. 124. Denver, CO: U.S. Geological Survey.

Dash, Z.V. 2000. Validation Test Report (VTR) for the FEHM Application Version 2.10, Yucca Mountain Project Identification Numbers SAN: LANL-1999-046; STN: 10086-2.10-00. Los Alamos, NM: Los Alamos National Laboratory.

Dash, Z.V. 2001. Validation Test Report (VTR) for the FEHM Application Version 2.12, Yucca Mountain Project Identification Numbers SAN: LANL-2001-133; STN: 10086-2.12-00. Los Alamos, NM: Los Alamos National Laboratory.

Dash, Z.V., B.A. Robinson, and G.A. Zyvoloski. 1997. Software Requirements, Design, and Verification and Validation for the FEHM Application - A Finite-Element Heat- and Mass-Transfer Code, LA-13305-MS. Los Alamos, NM: Los Alamos National Laboratory.

Drellack, S.L., and L.B. Prothro. 1997. Descriptive Narrative for the Hydrogeologic Model of Western and Central Pahute Mesa Corrective Action Units. Las Vegas, NV: Bechtel Nevada.

Duffield, G.M., J.J. Benegar, and D.S. Ward. 1996. MODFLOWT, A Modular Three-Dimensional Groundwater Flow and Transport Model, User's Manual, Version 1.1. Sterling, VA: HSI GeoTrans, Inc.

Dynamic Graphics, Inc. 2002. EarthVision 5.1: Software for 3-D Modeling and Visualization. Alameda, CA.

FFACO, see Federal Facility Agreement and Consent Order. 
Faunt, C.C. 1997. Effect of Faulting on Ground-Water Movement in the Death Valley Region, Nevada and California, Water-Resources Investigations Report 95-4132. Denver, CO: U.S. Geological Survey.

Faunt, C.C., J.B. Blainey, M.C. Hill, F.A. D’Agnese, and G.M. O’Brien 2004. “Transient Numerical Model," Chapter F, pp. 265-352. Death Valley Regional Ground-Water Flow System, Nevada and California--Hydrogeologic Framework and Transient Ground-Water Flow Model, Scientific Investigations Report 2004-5205. As accessed at http:// water.usgs.gov/pub/sir/2004/5205/on 10 May 2005. U.S. Geological Survey.

Federal Facility Agreement and Consent Order. 1996, as amended. Agreed to by the State of Nevada, the U.S. Department of Energy, and the U.S. Department of Defense. Appendix VI, which contains the Underground Test Area strategy, was last amended December 7, 2000, Revision No. 1.

Fenelon, J.M. 2000. Quality Assurance and Analysis of Water Levels in Wells on Pahute Mesa and Vicinity, Nevada Test Site, Nye County, Nevada, Water-Resources Investigations Report 00-4014. Carson City, NV: U.S. Geological Survey.

Ferguson, J.F., A.H. Cogbill, and R.G. Warren. 1994. "A Geophysical- Geological Transect of the Silent Canyon Caldera Complex, Pahute Mesa, Nevada." In Ground Water, v. 99(B3): 4323-4339. Columbus, OH: Groundwater Publishing Co.

Freyberg, D.L. 1988. “An Exercise in Ground-Water Model Calibration and Prediction.” In Ground Water, v. 26(N3): 350-360.

Fridrich, C.J., S.A. Minor, and E.A. Mankinen. 1999a. Geologic Evaluation of the Oasis Valley Basin, Nye County, Nevada. U.S. Geological Survey Open-File Report 99-533-A.

Fridrich, C.J., S.A. Minor, P.L. Ryder, and J.L. Slate. 1999b. Geologic Map of the Oasis Valley Basin and Vicinity Nye County, Nevada. U.S. Geological Survey Open-File Report 99-533$\mathrm{B}$, scale 1:62,500.

GeoTrans, see HSI GeoTrans.

Gable, C., and T. Cherry. 2001. Technical Note on Interpolation of MODFLOW Flux onto a Piecewise Linear Surface. Los Alamos, NM: Los Alamos National Laboratory.

Gelhar, L. 1986. "Stochastic Subsurface Hydrology From Theory to Applications." In Water Resources Research, v. 22(9): 135S-145S. Washington, DC: American Geophysical Union.

Gentleman, R., and R. Ihaka. 2005. An Integrated Suite of Software Facilities for Data Manipulation, Calculation and Graphical Display. Auckland, New Zealand: University of Auckland. 
Appendix D 
D.3.1 

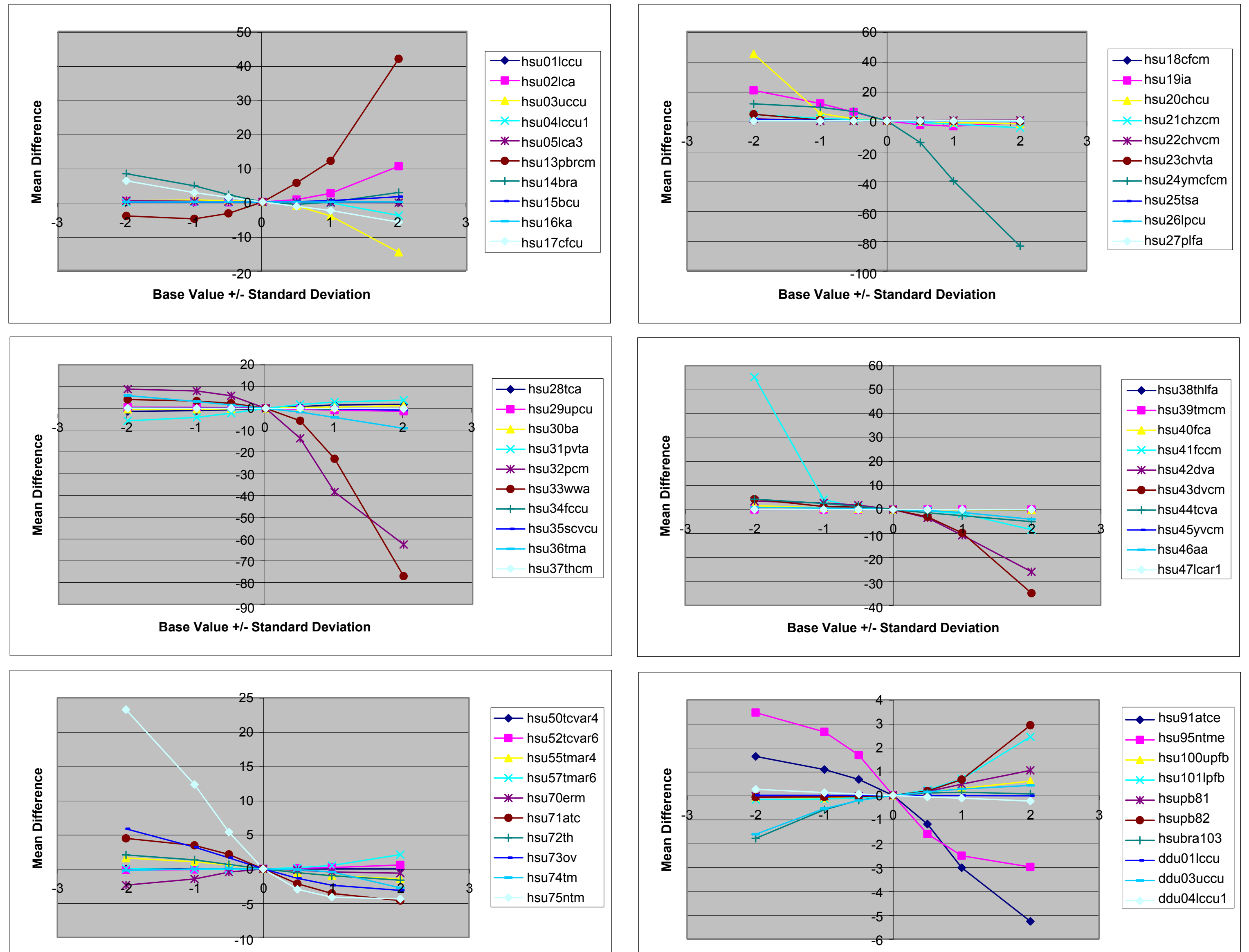

Base Value + - Standard Deviation

Base Value t/. Standard Deviation

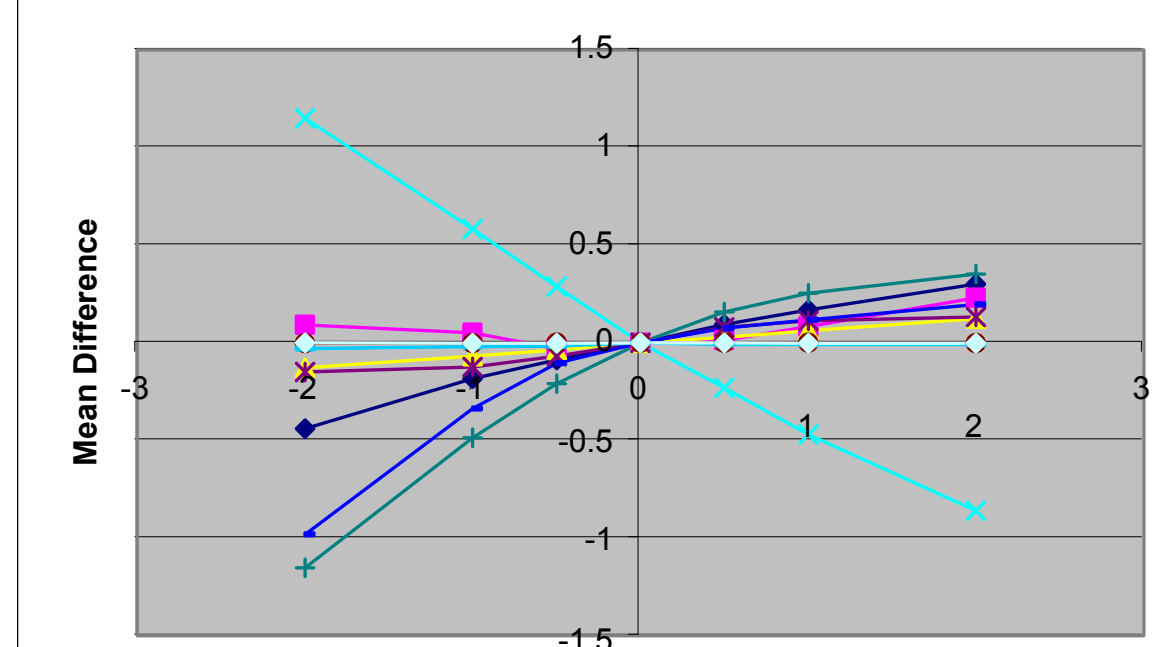

Base Value +l- Standard Deviation

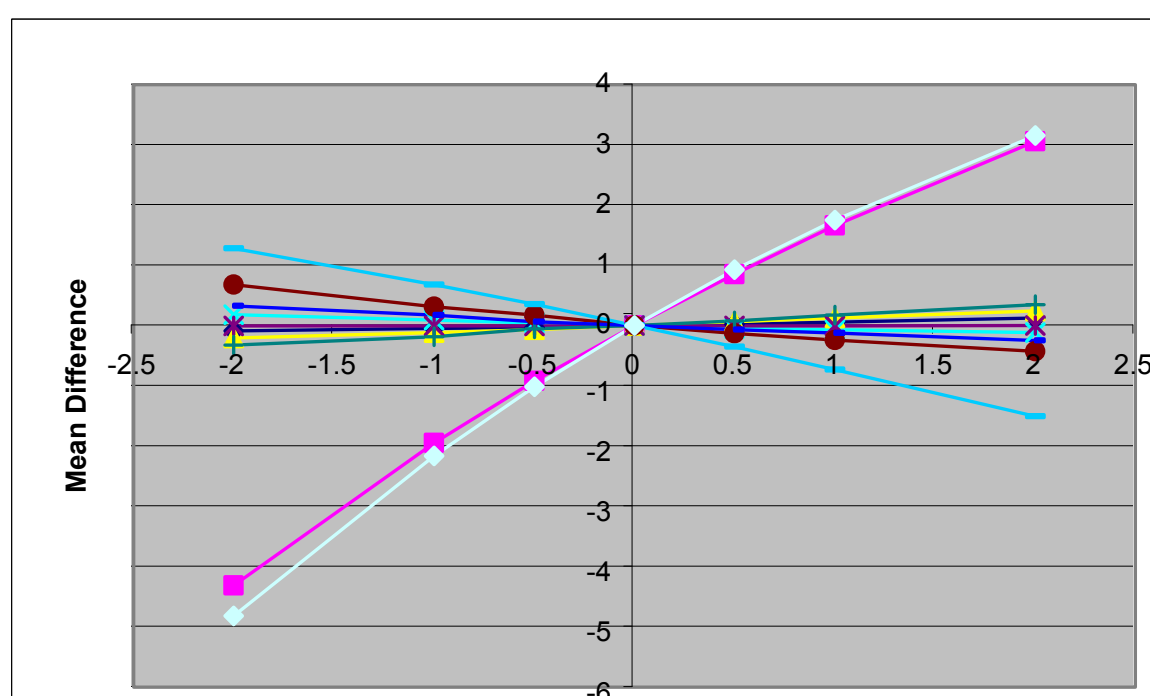

Base Value t+.-Standard Deviation

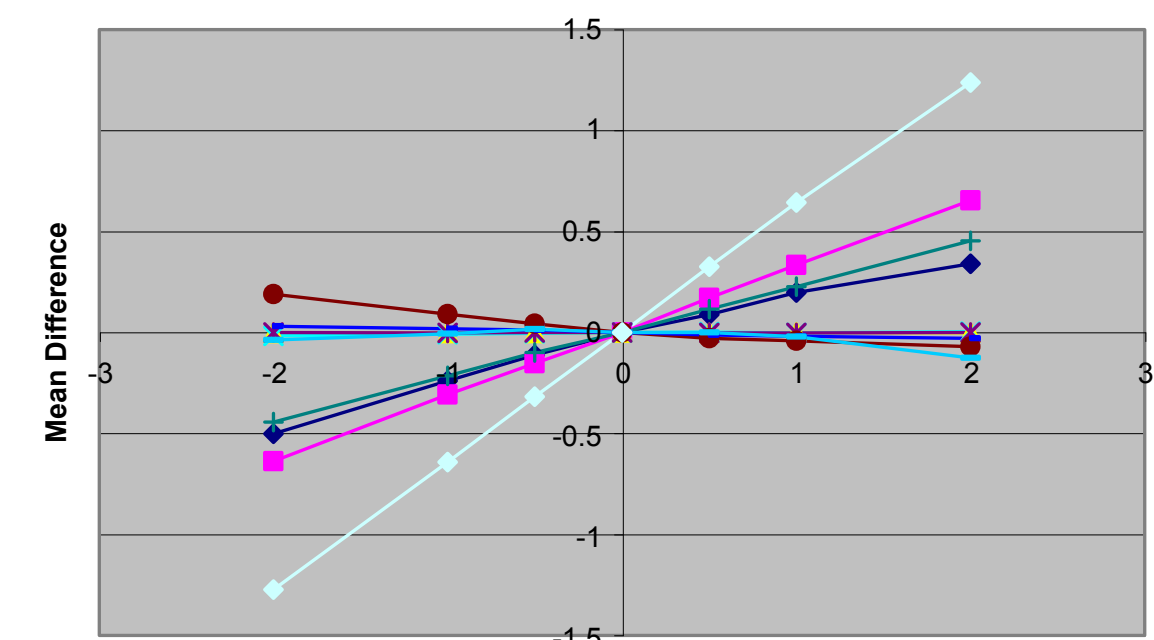

Base Value t+-Standard Deviation

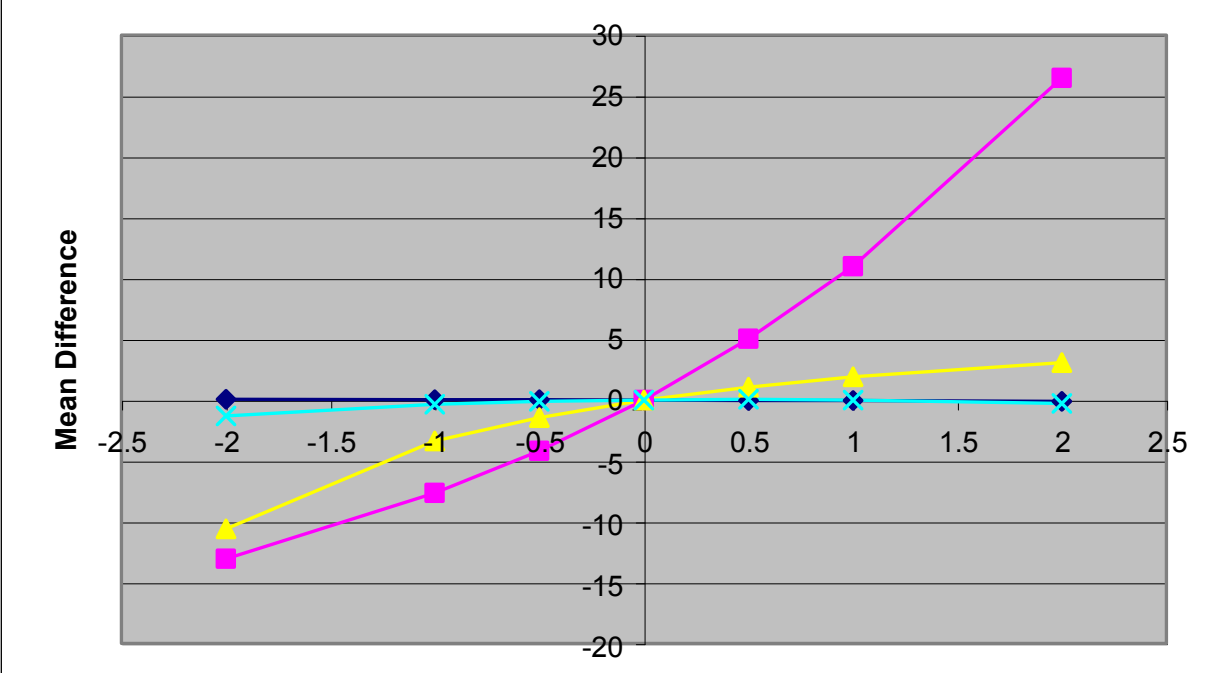

$-20$
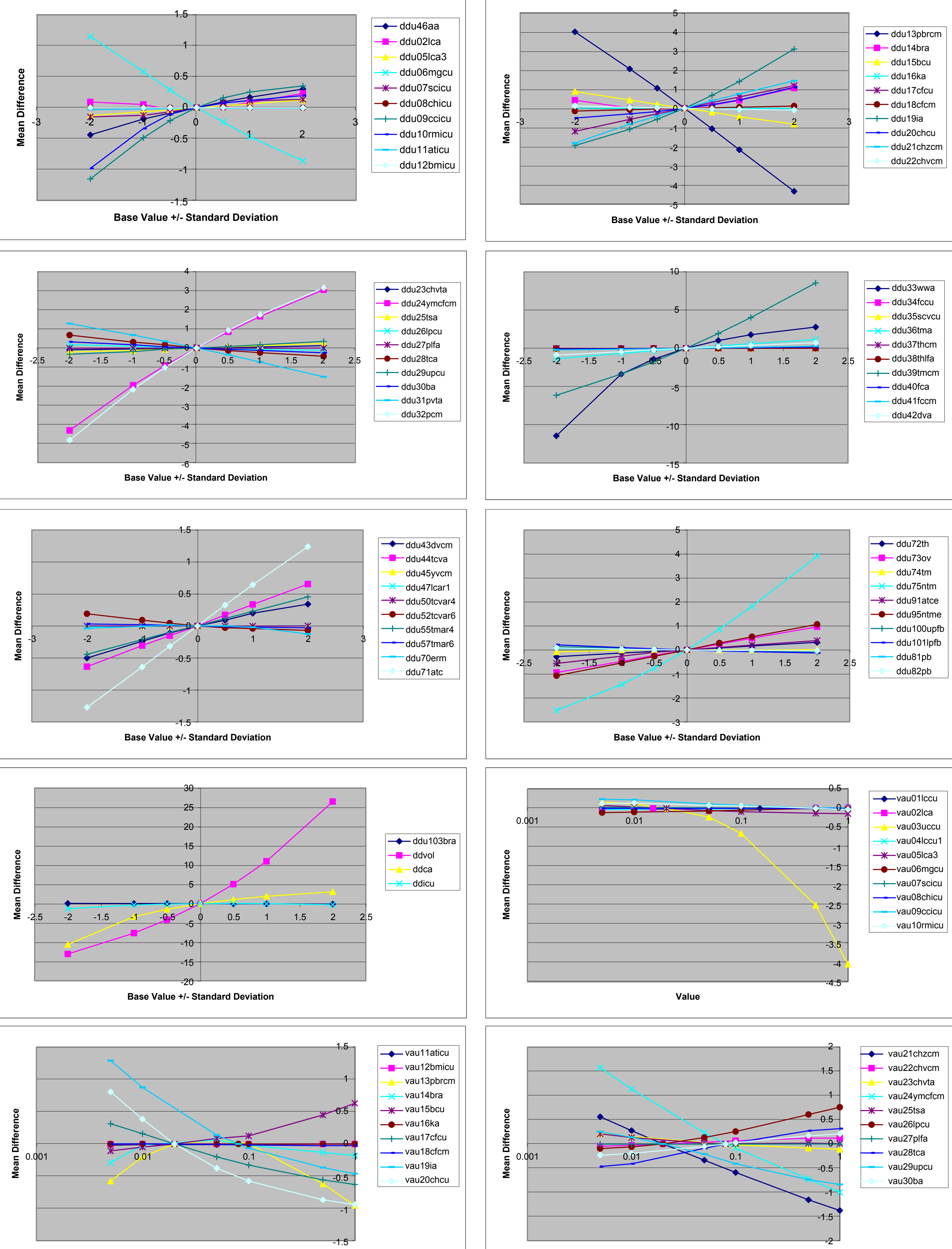

Ese Value + +t. Standard Deviation

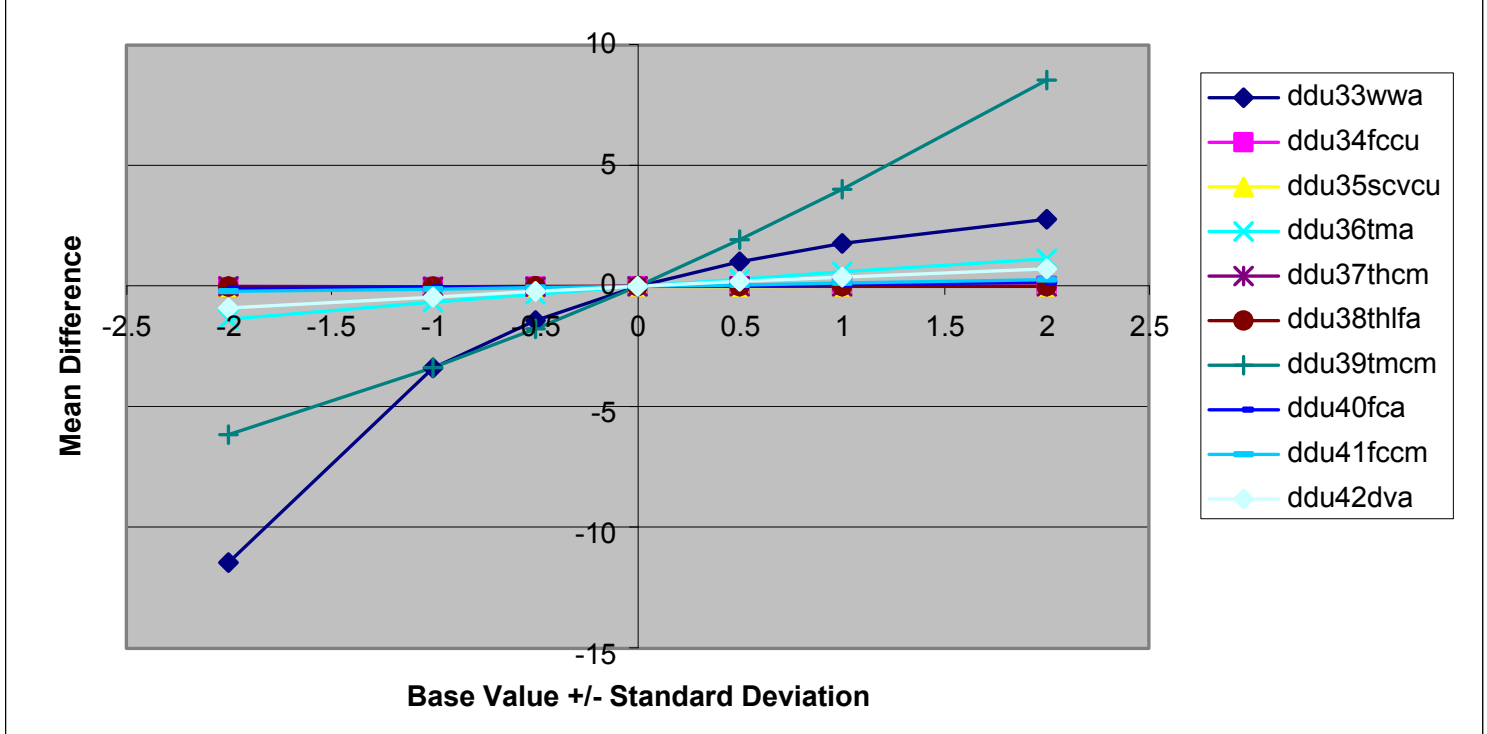

Base Value +1 - Standard Deviation
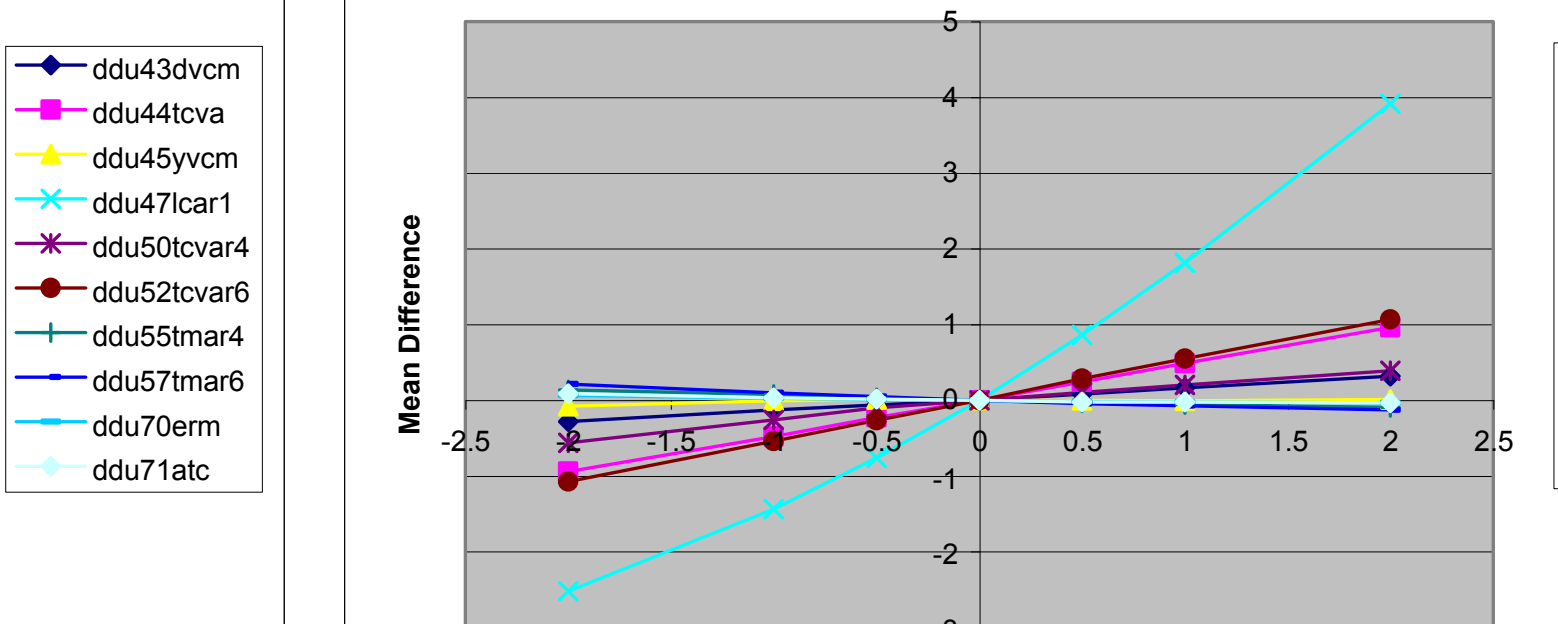

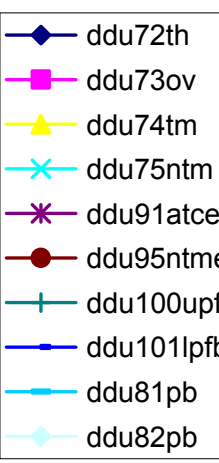

Base Value ++ - Standard Deviation

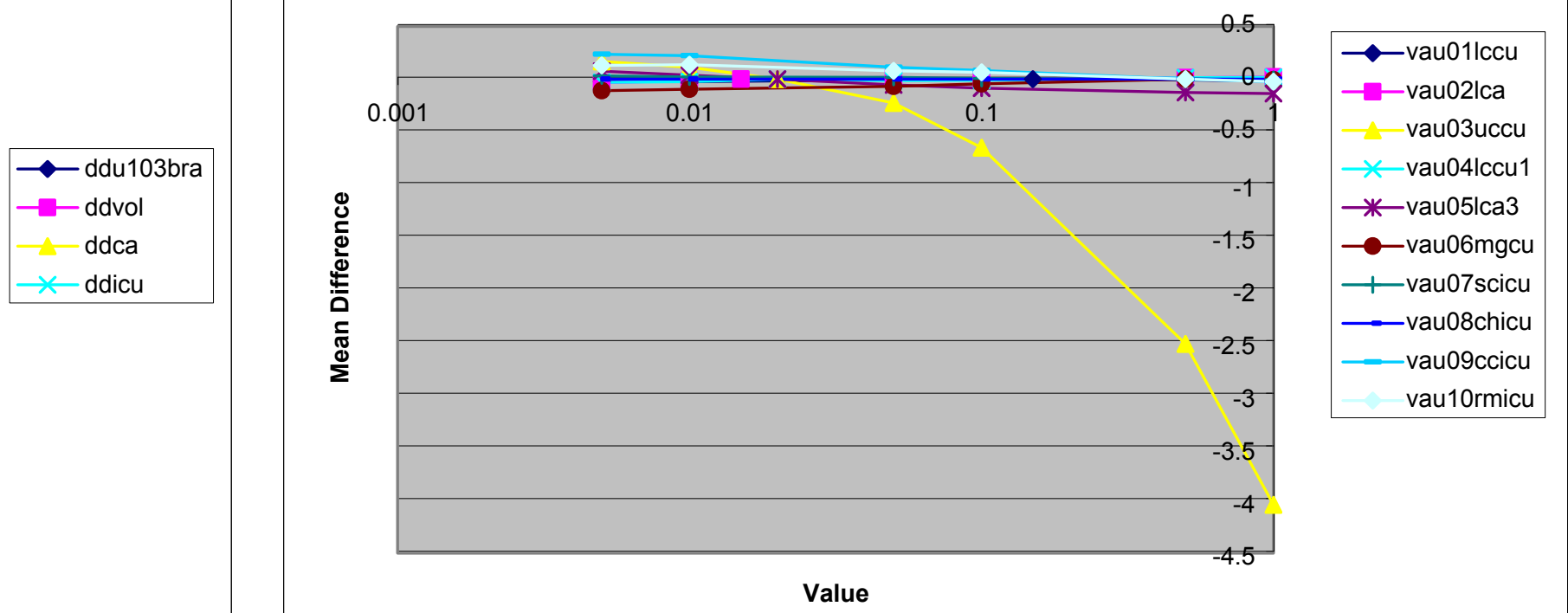

value
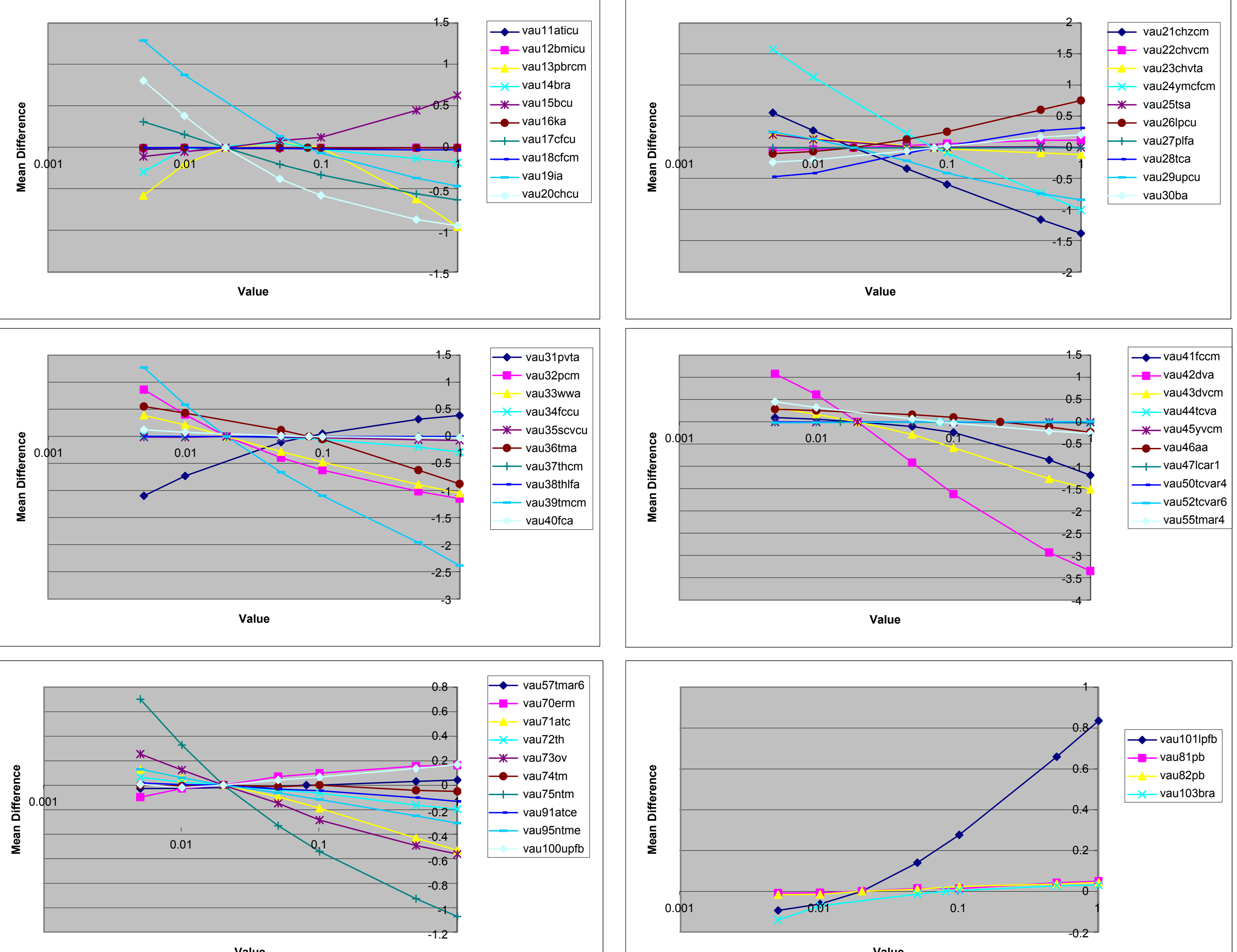


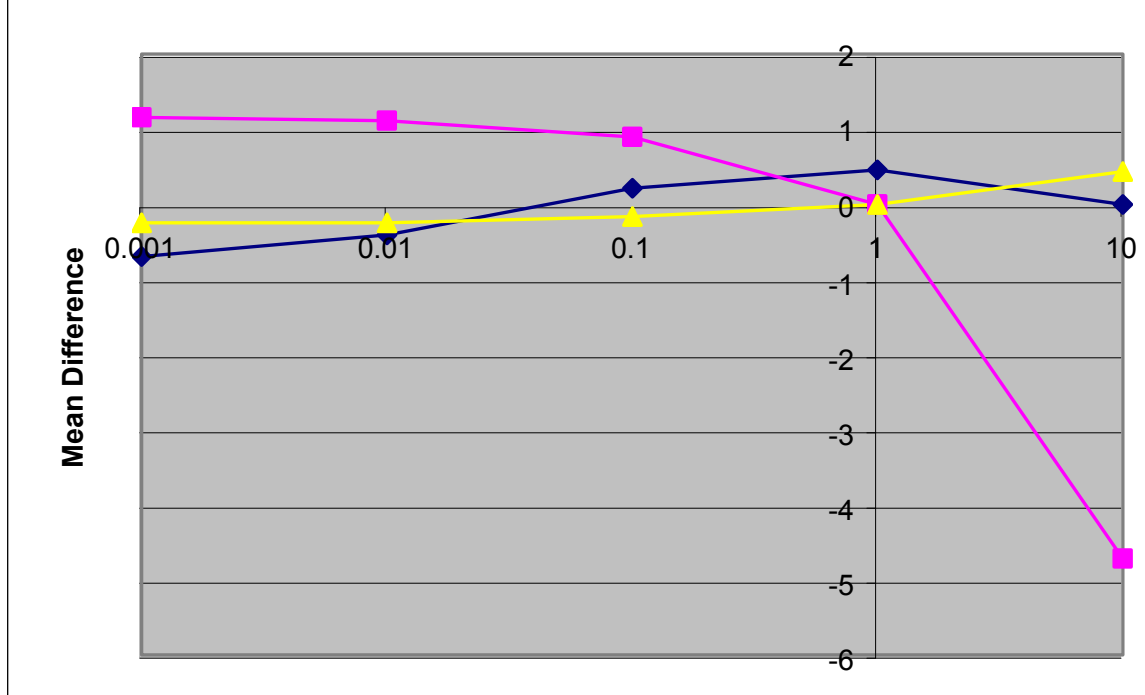

$\longrightarrow$-001_almendro

03_bmcsmwdf

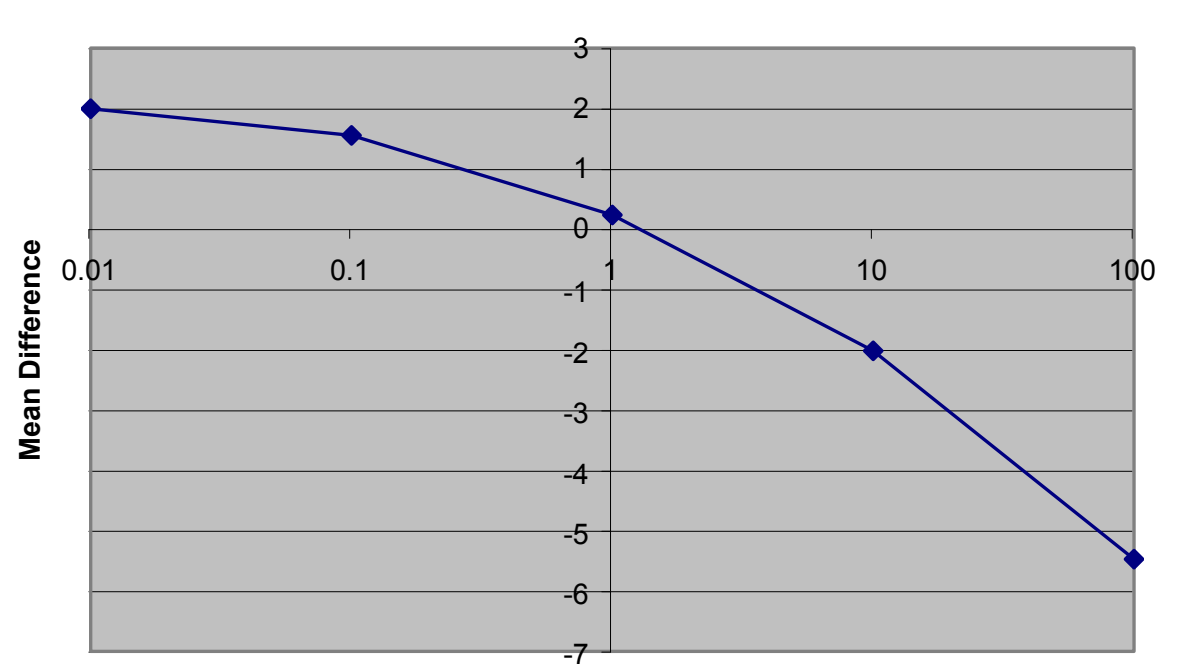

Value
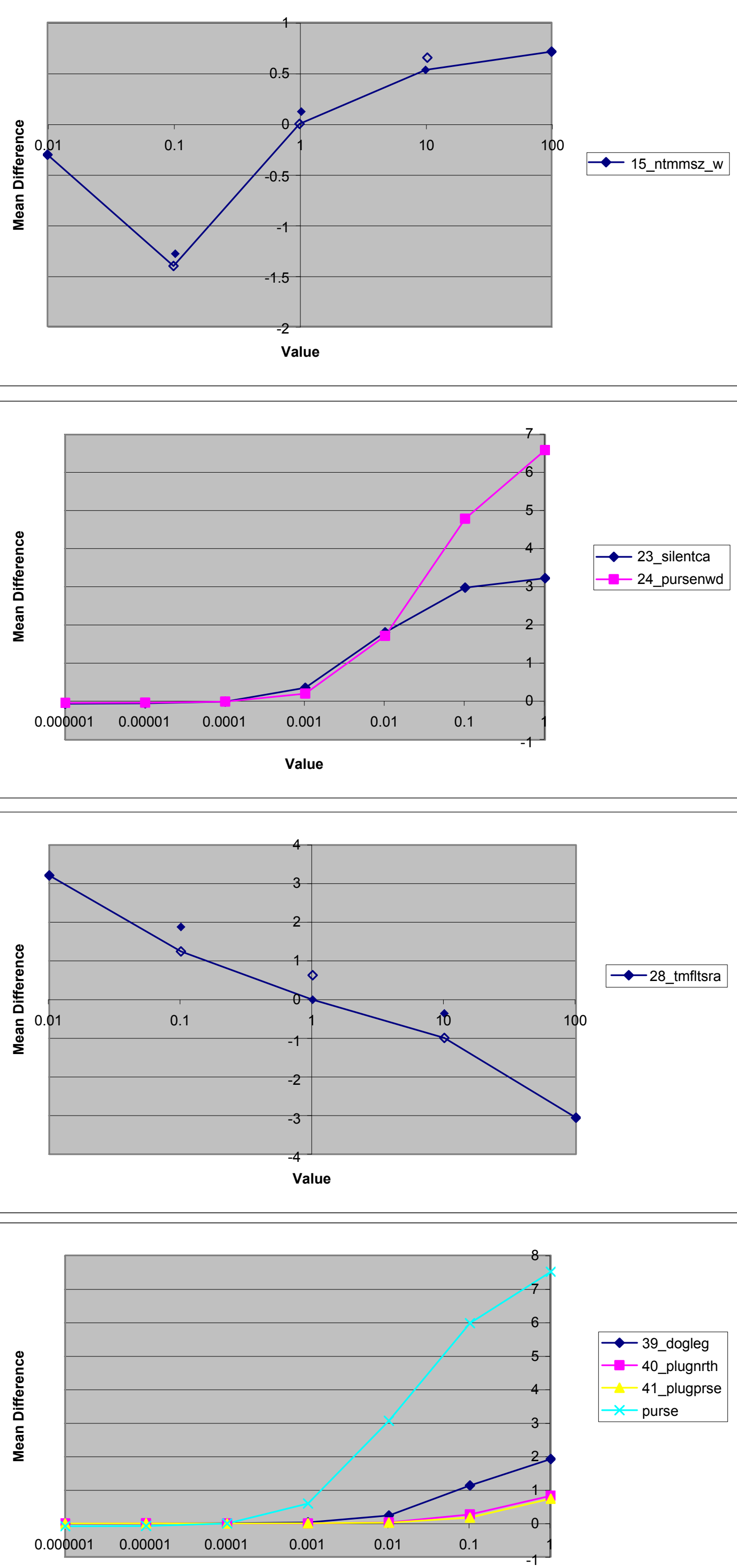

\section{$\multimap-23$ silentca}

-24_pursenwd

- 40 _ plugnrth 41_plugprse

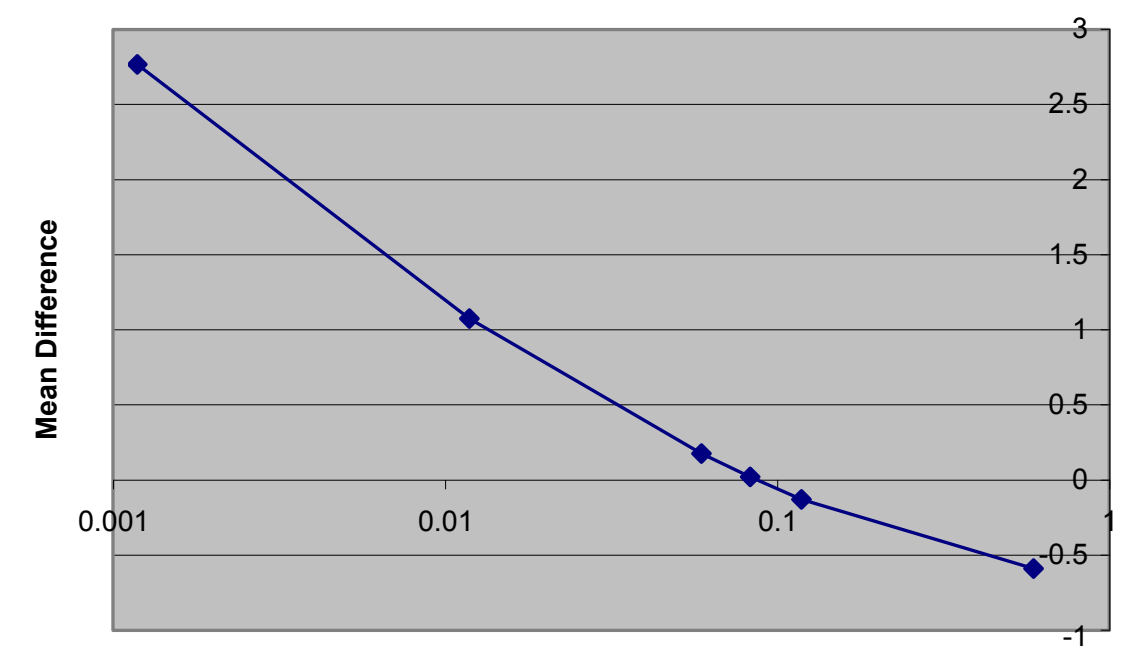

$\multimap-04 \_b o x c a r \_w$

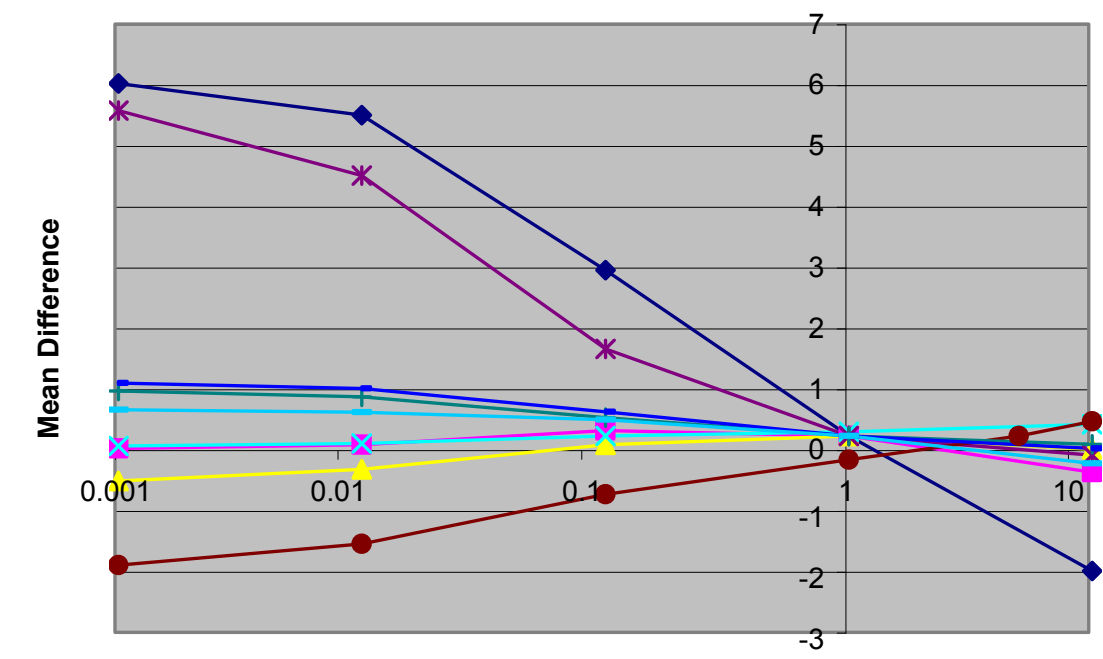

Value

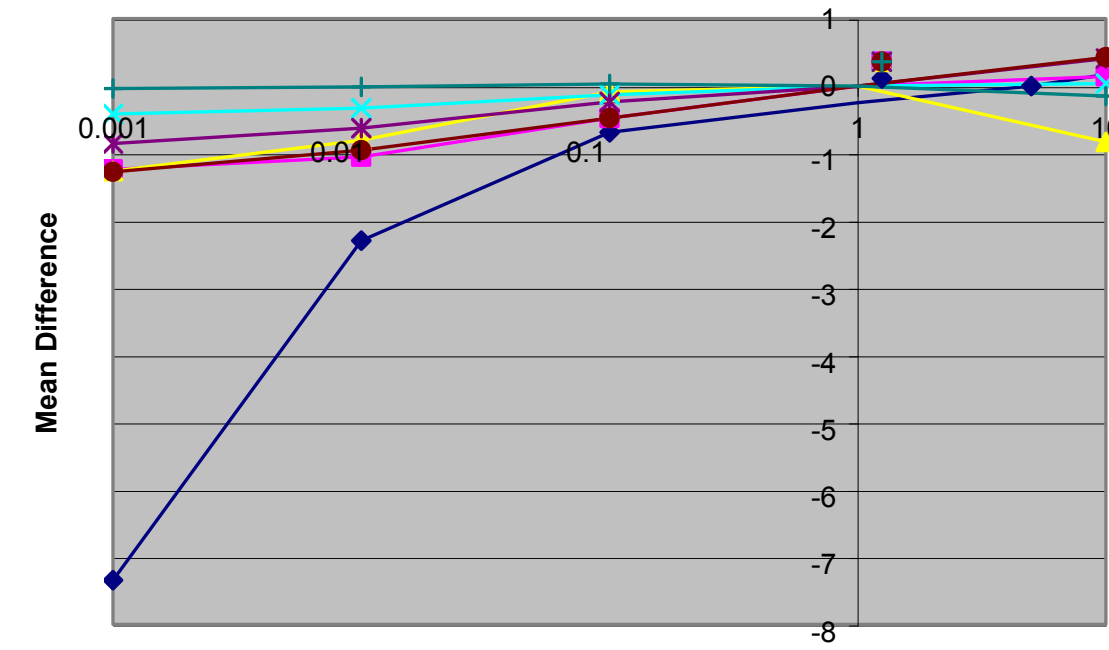

Value

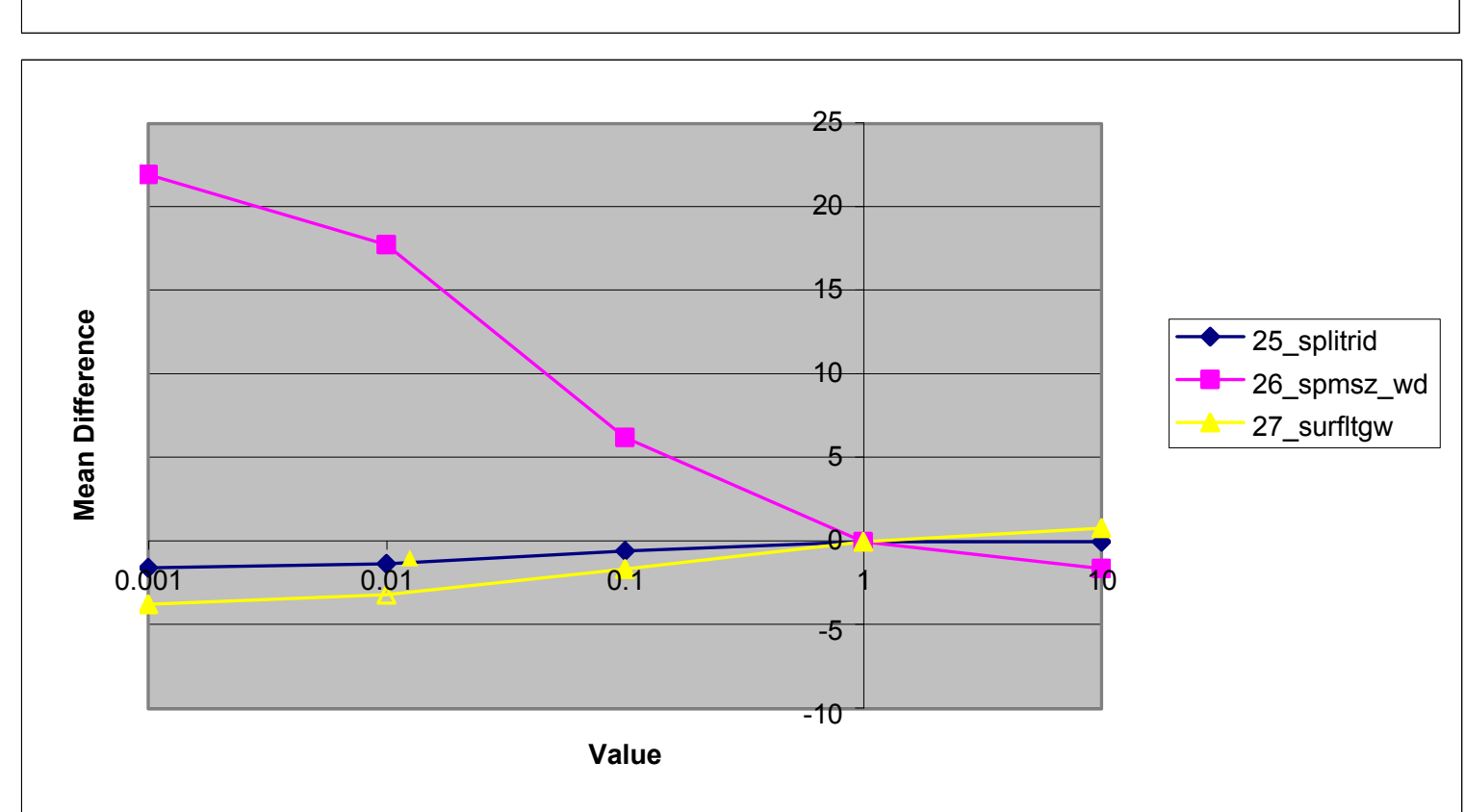

$\longrightarrow$ 25_splitrid

-26_spmsz_wd 27_surfltgw

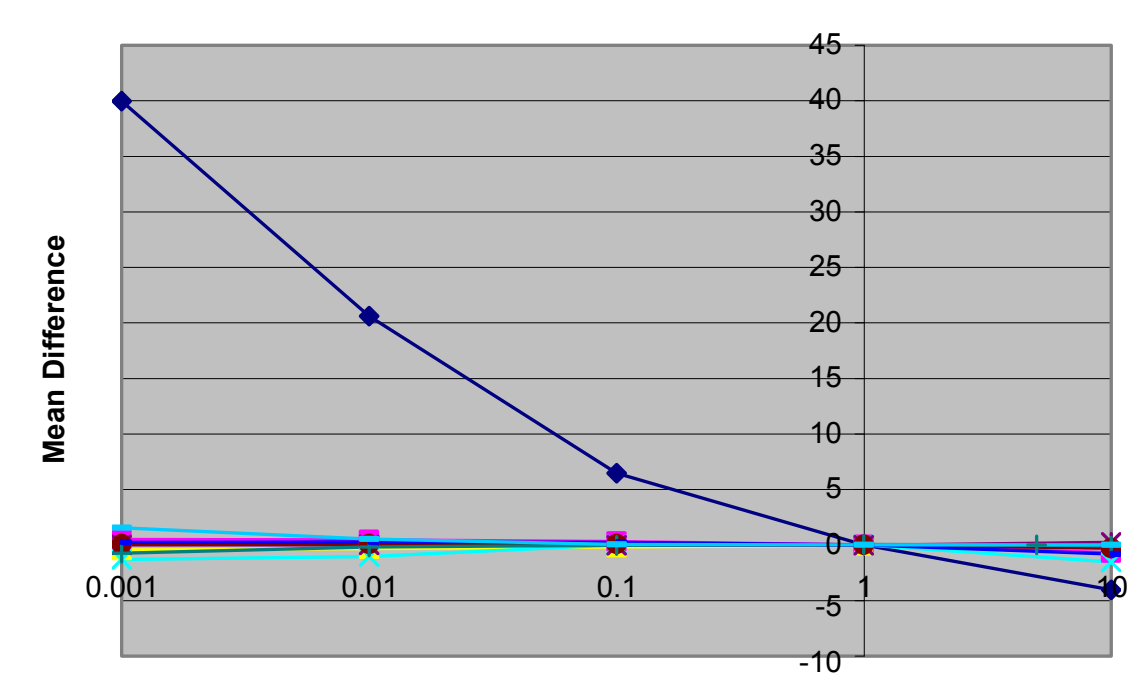

$\longrightarrow$-29_tmfltstm

- 30_tmext2ho

-31_walmendr

$x$ 33_westgree

*-34_westuary

-35 -windywas

+ 36_wscsz_wd

-37_paintbrs

Value

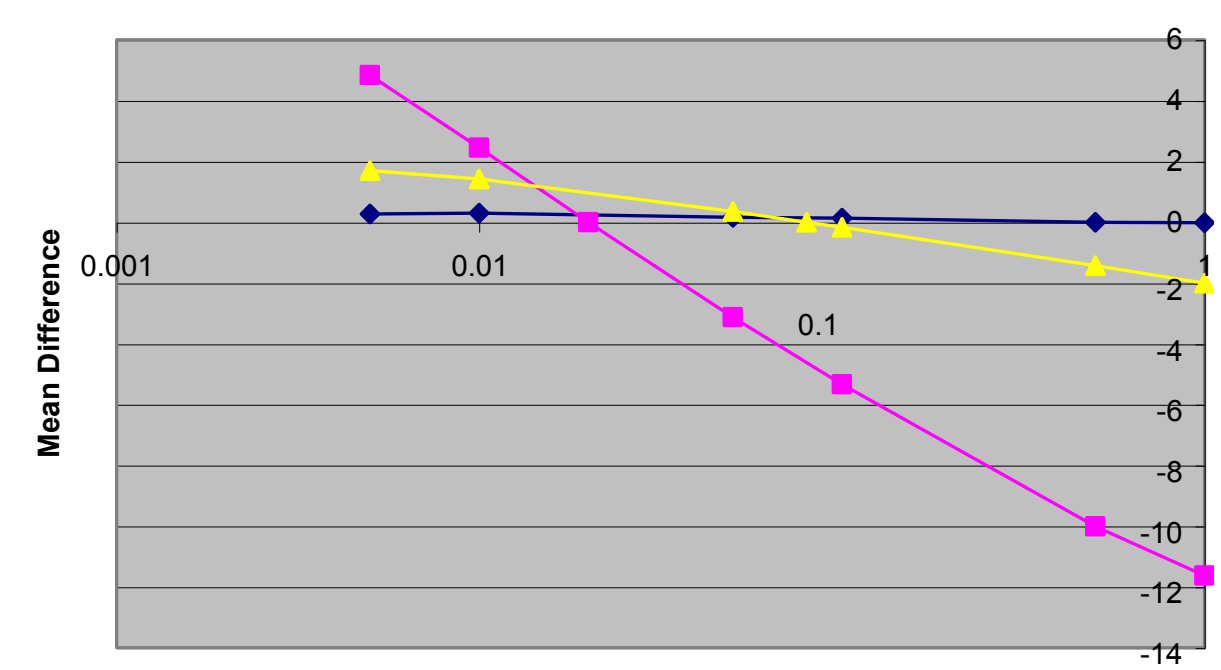

$\rightarrow-$ vaicu 

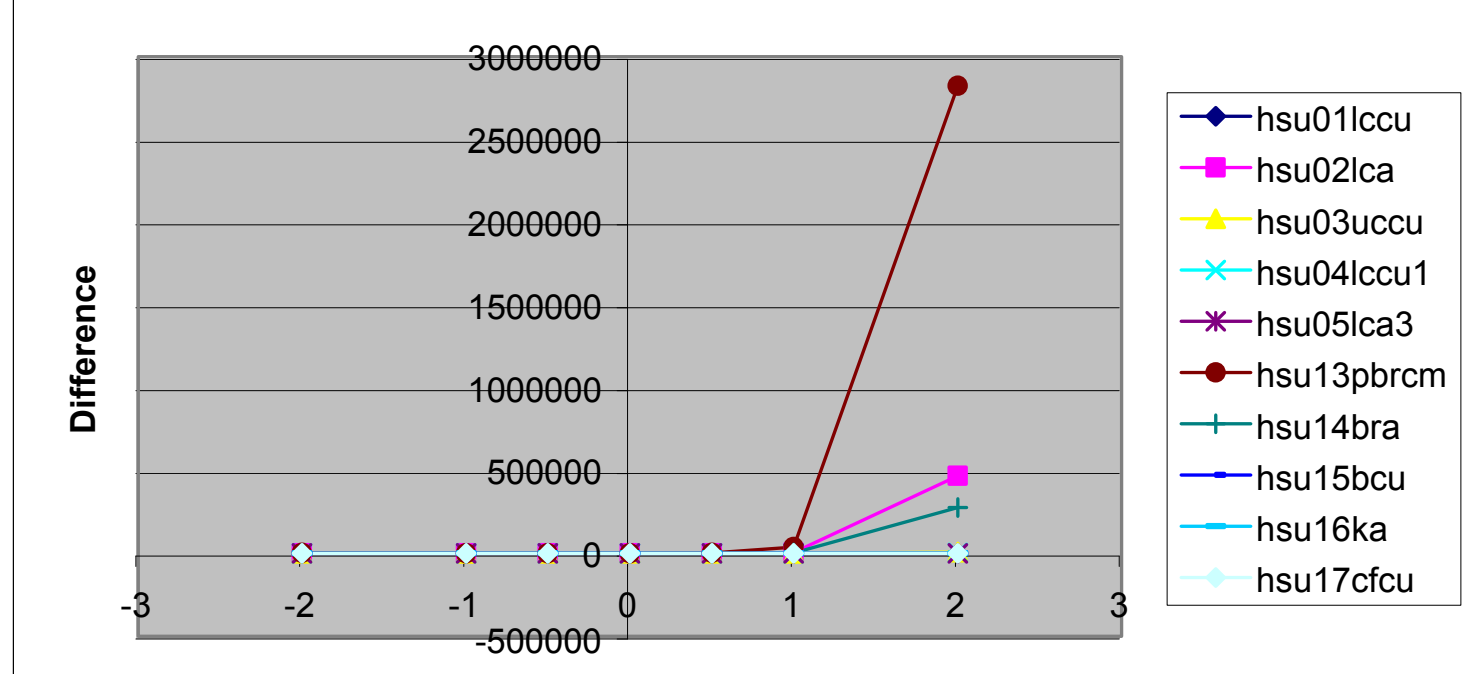

Base Value +/-Standard Deviation

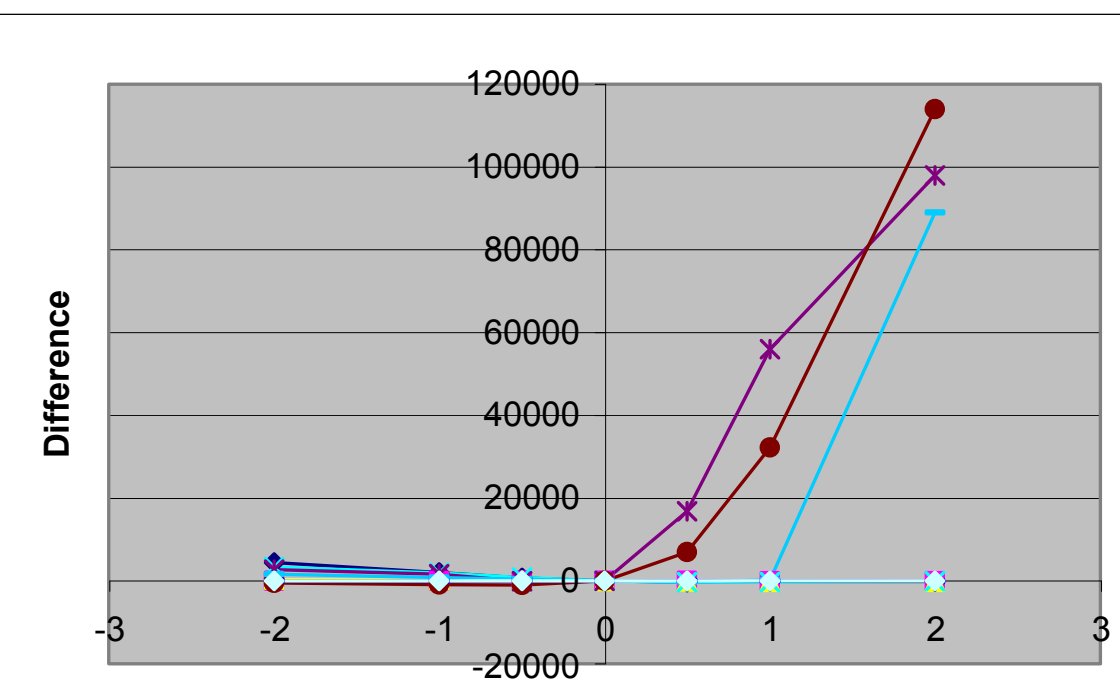

Base Value +/- Standard Deviatio

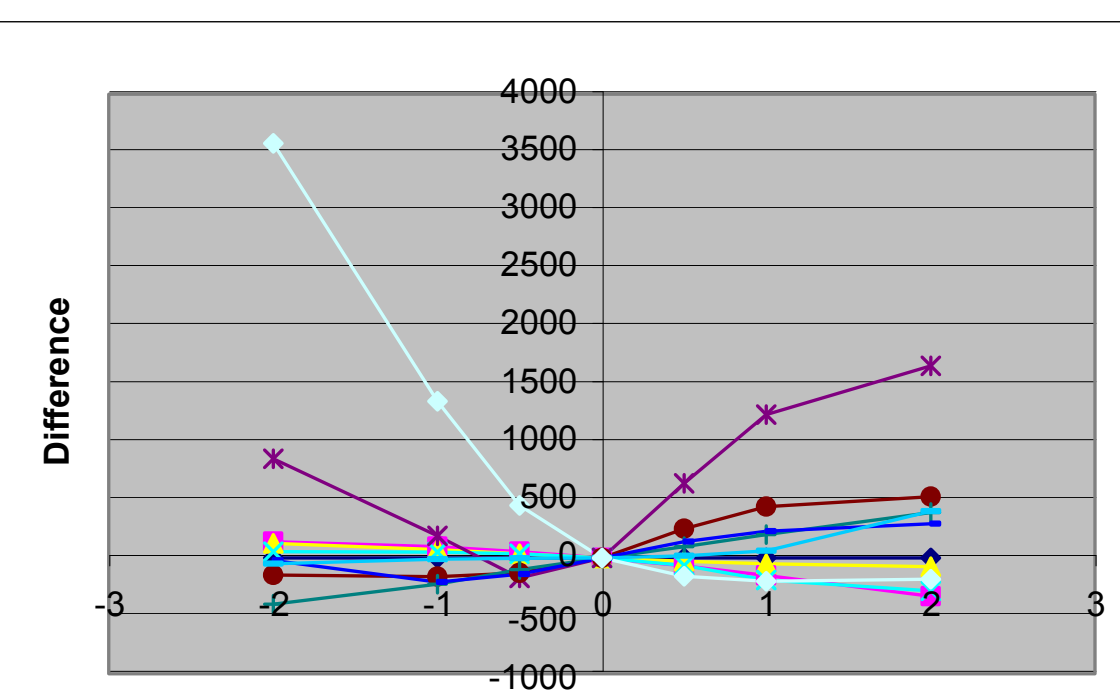

Base Value +/-Standard Deviation
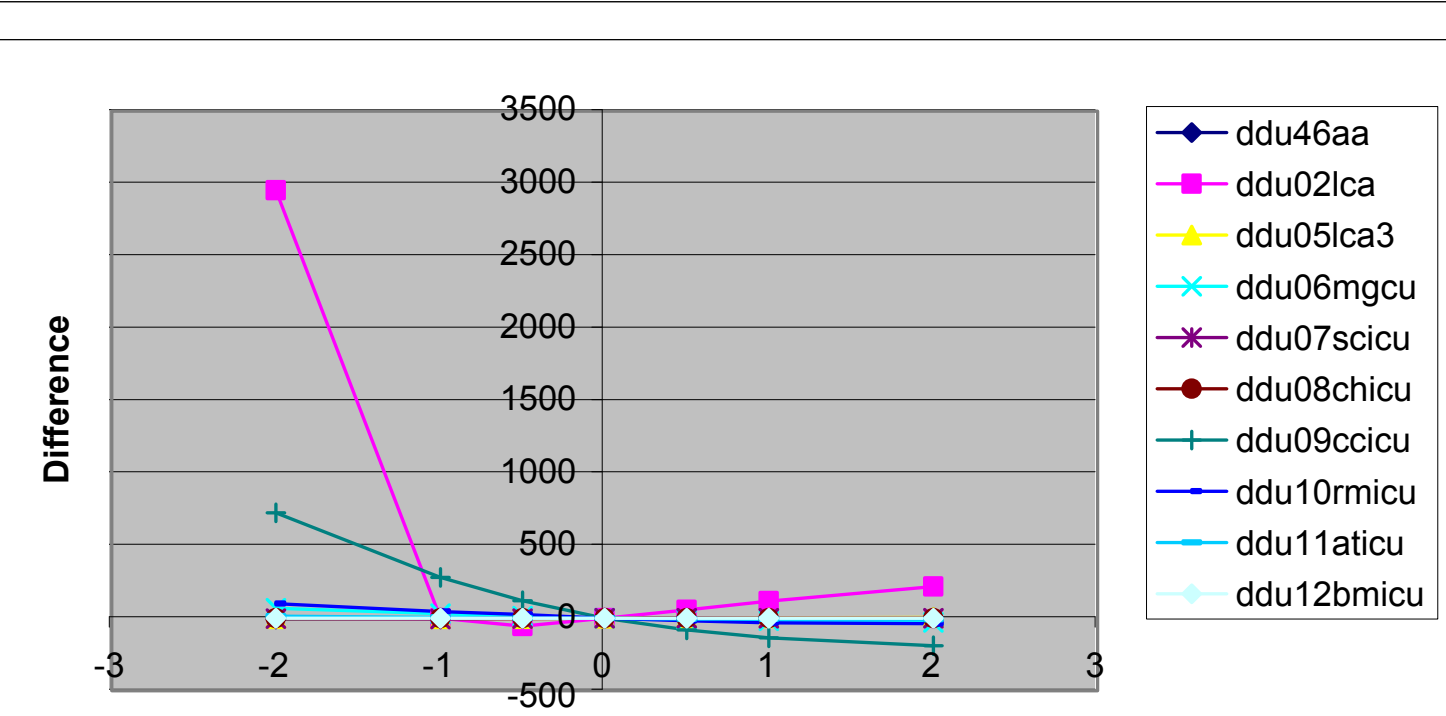

Base Value +/- Standard Deviation

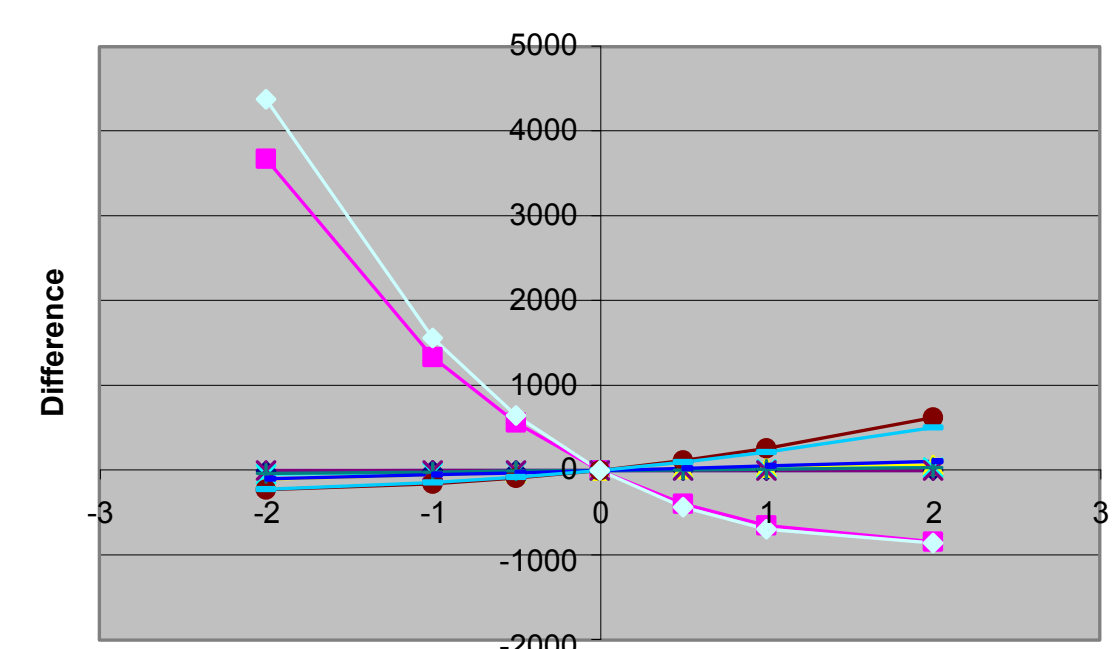

Base Value $+1 /$ - Standard Deviation
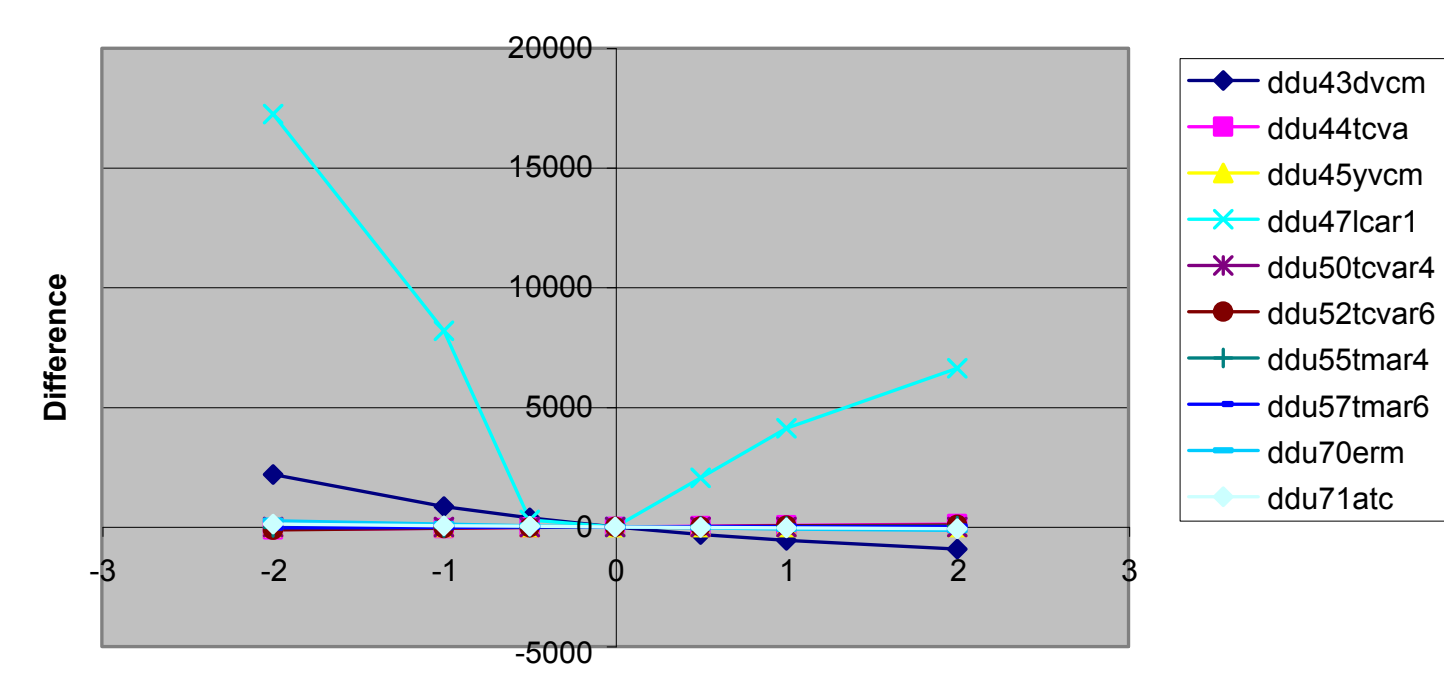

Base Valulue +t/-Standard Deviation
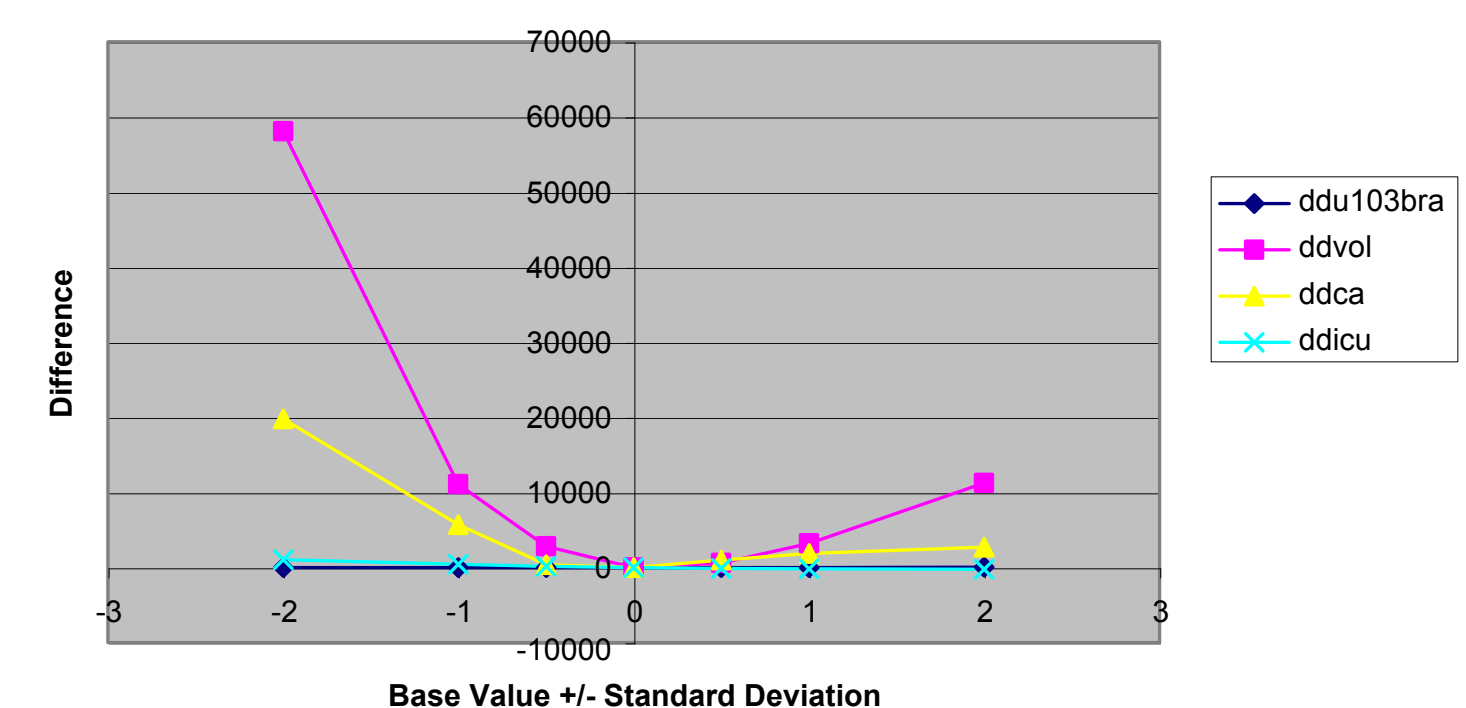

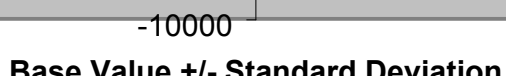
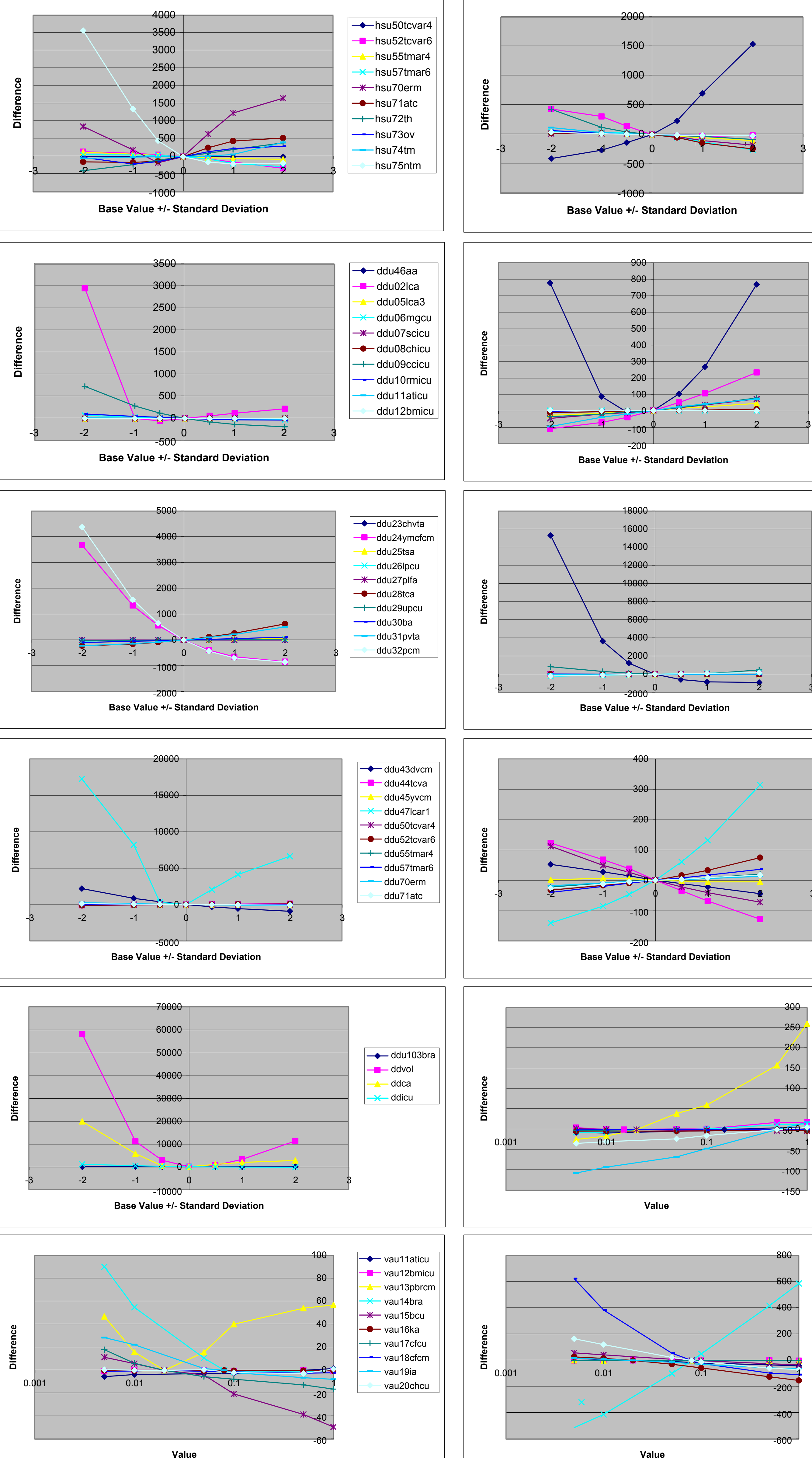

Base Value +/-Standard Deviation
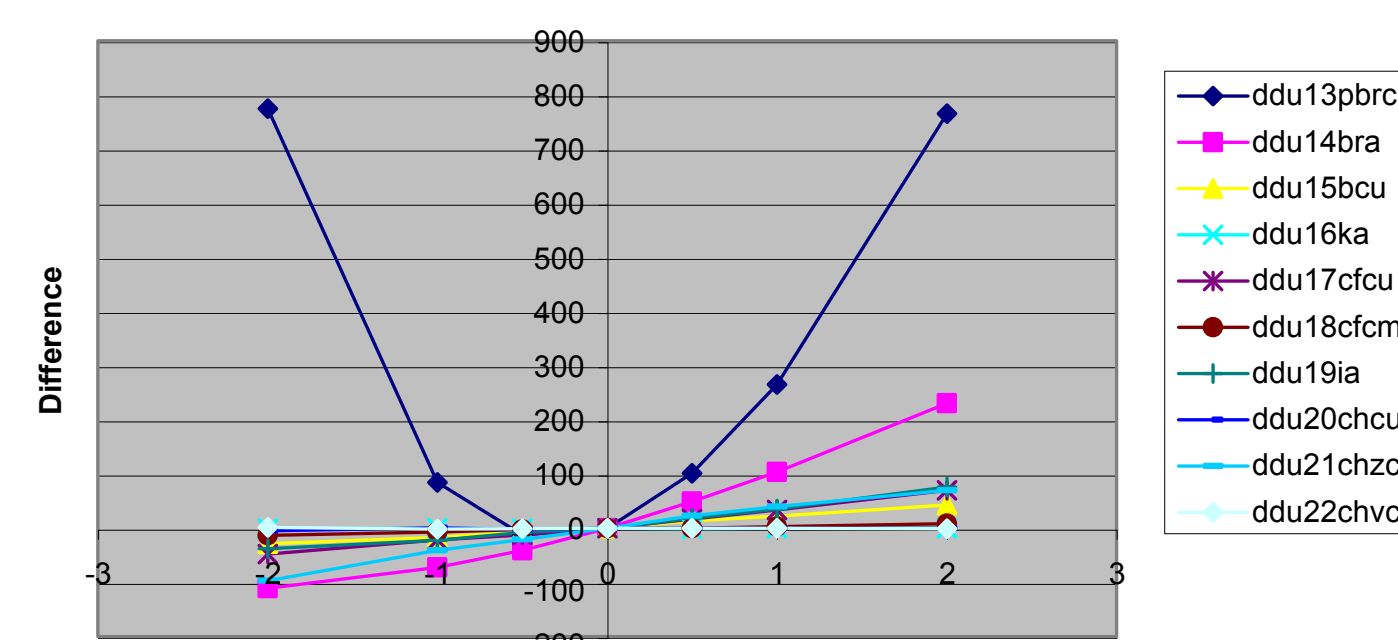

Gase Value +1/. Standard Deviation
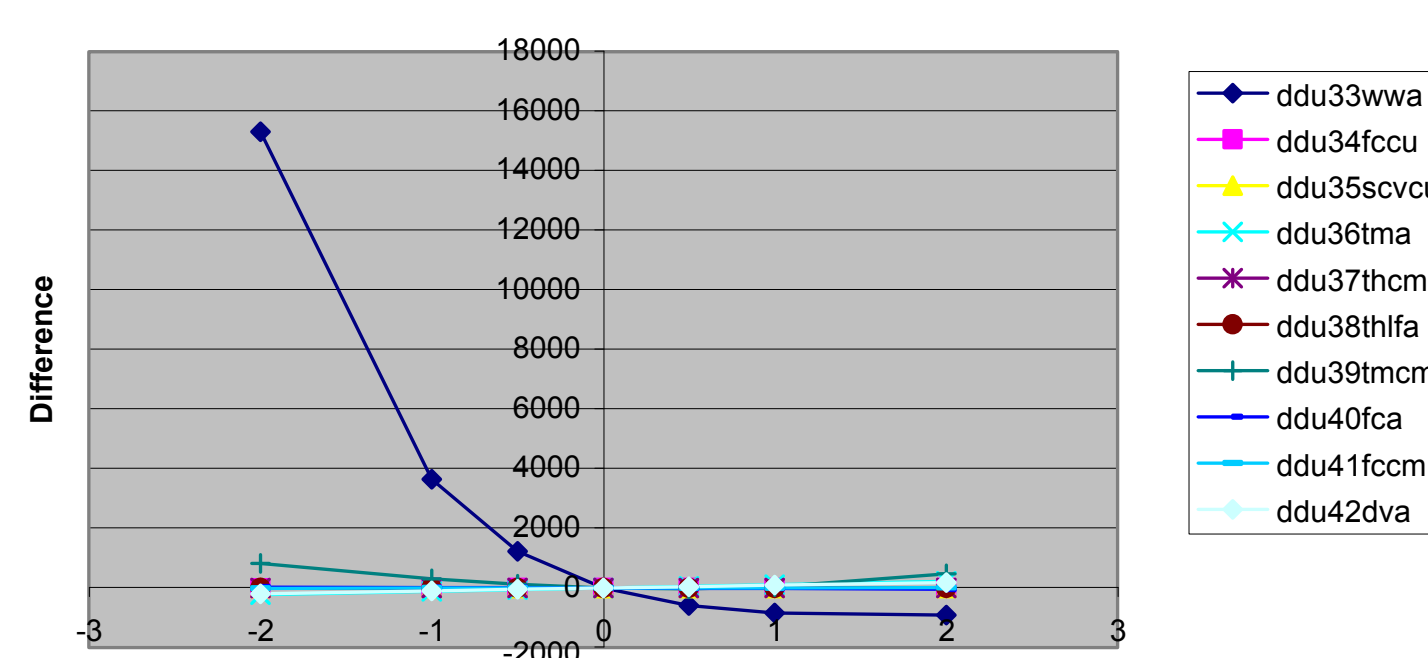

Base Value + +/ Standard Deviation

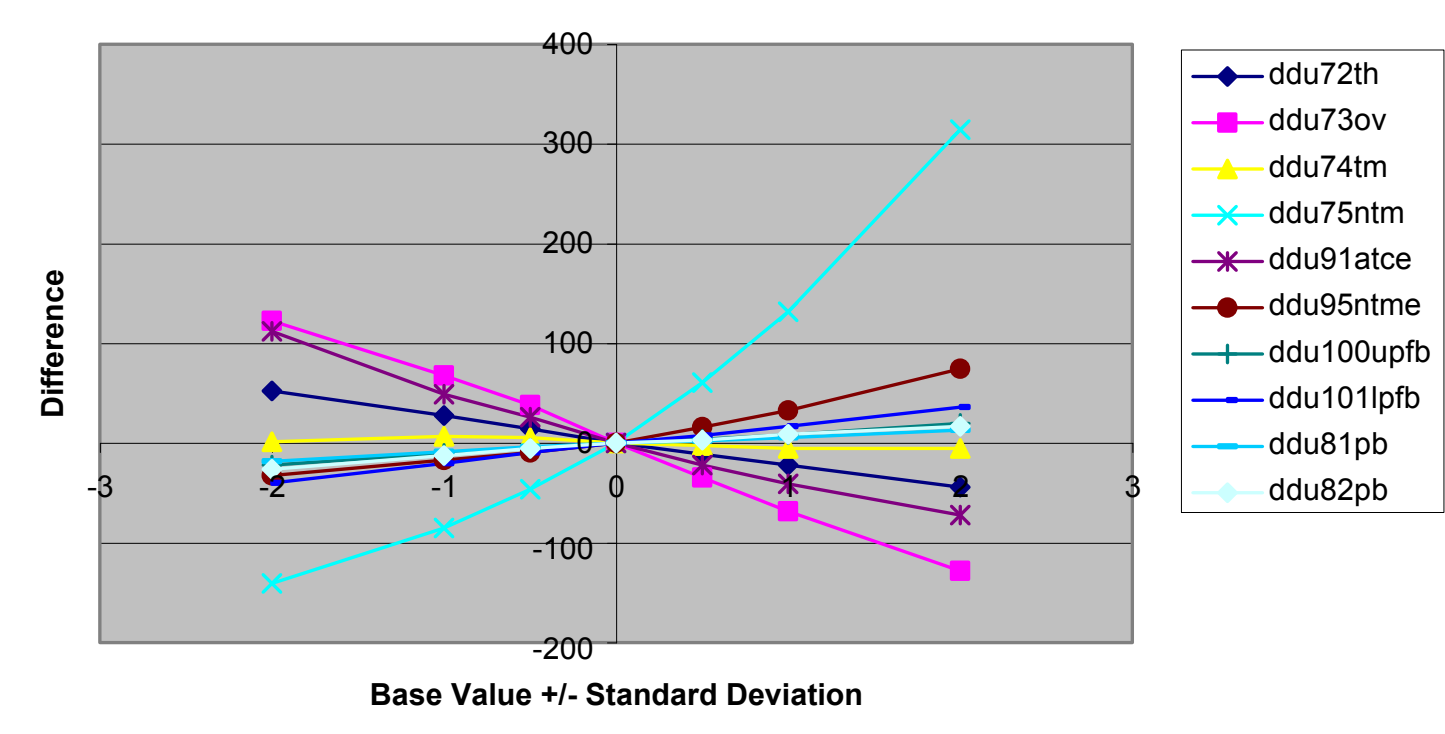

$\stackrel{-200}{-200}$
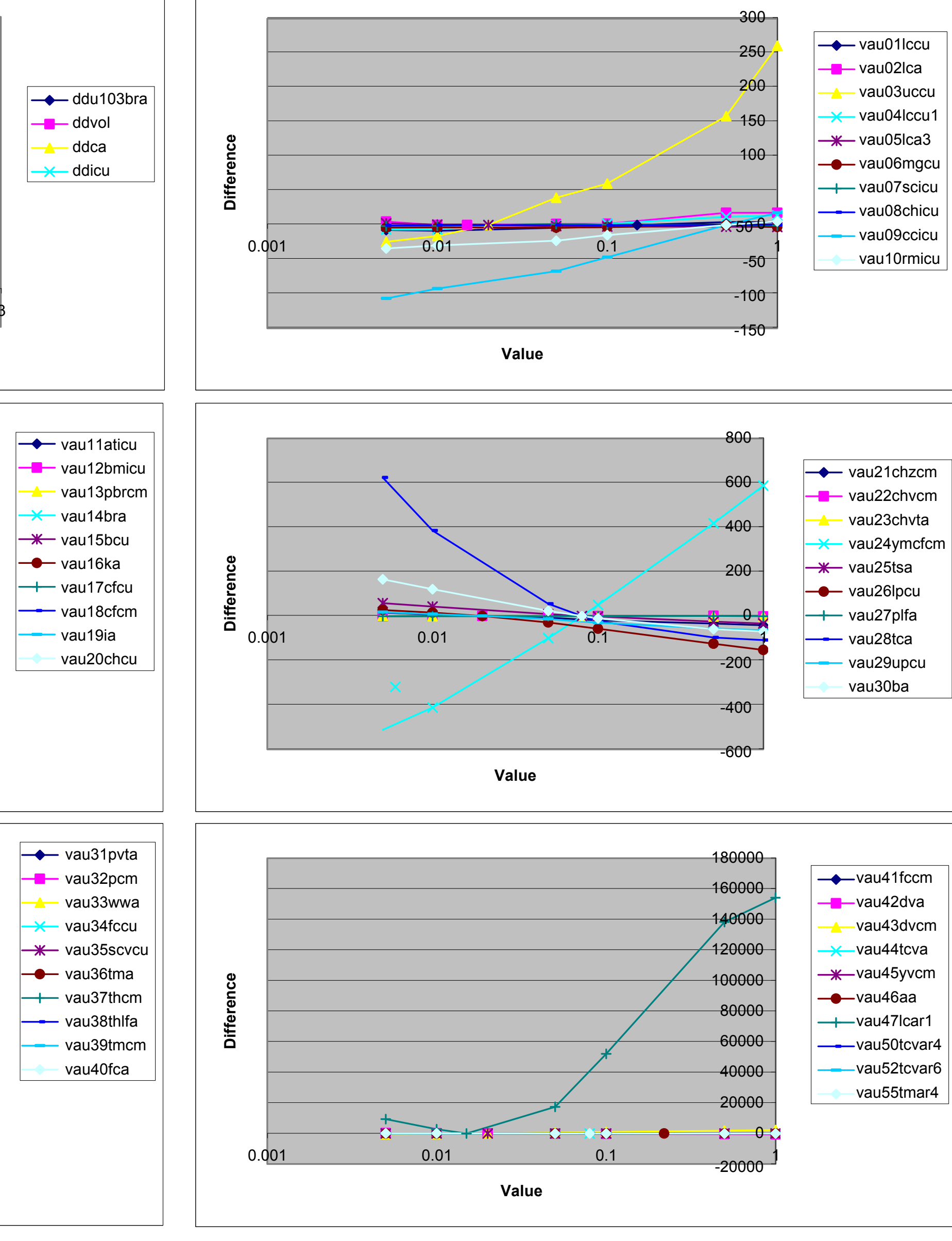

言

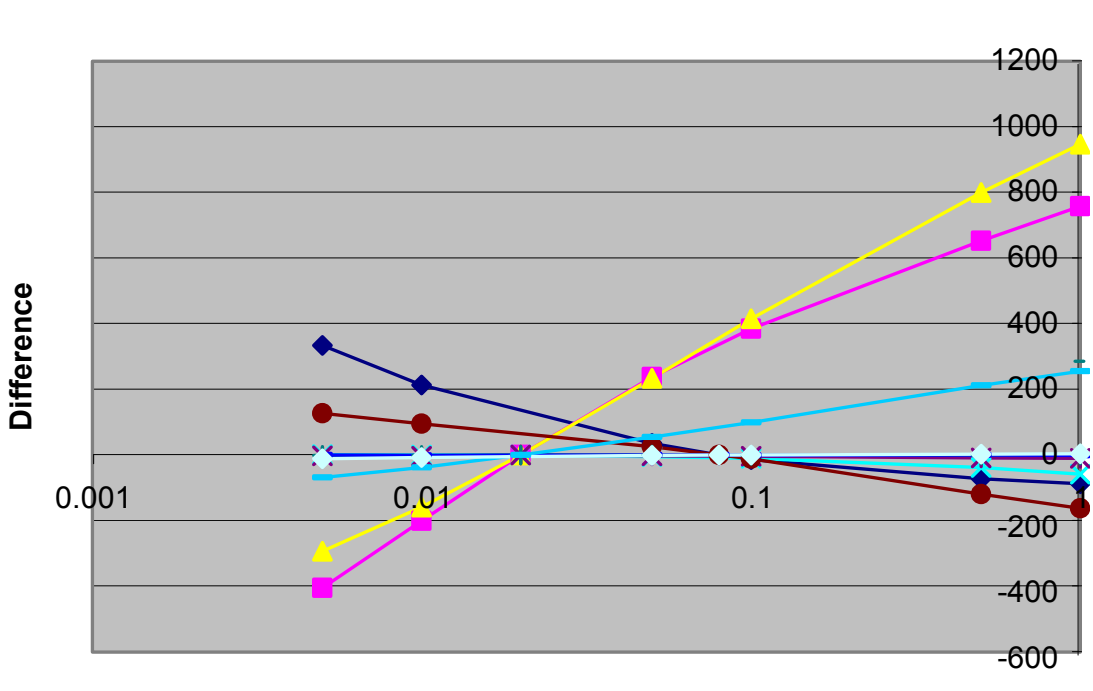
(20)
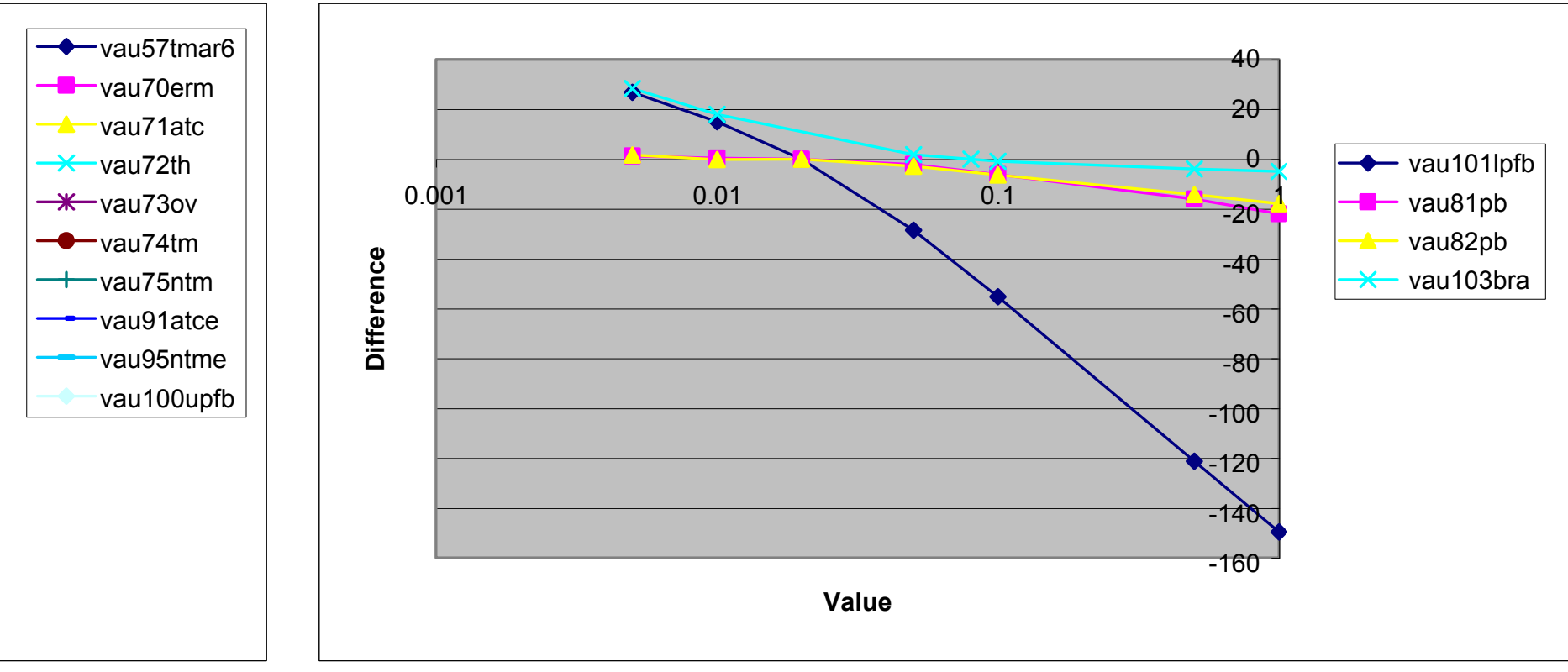

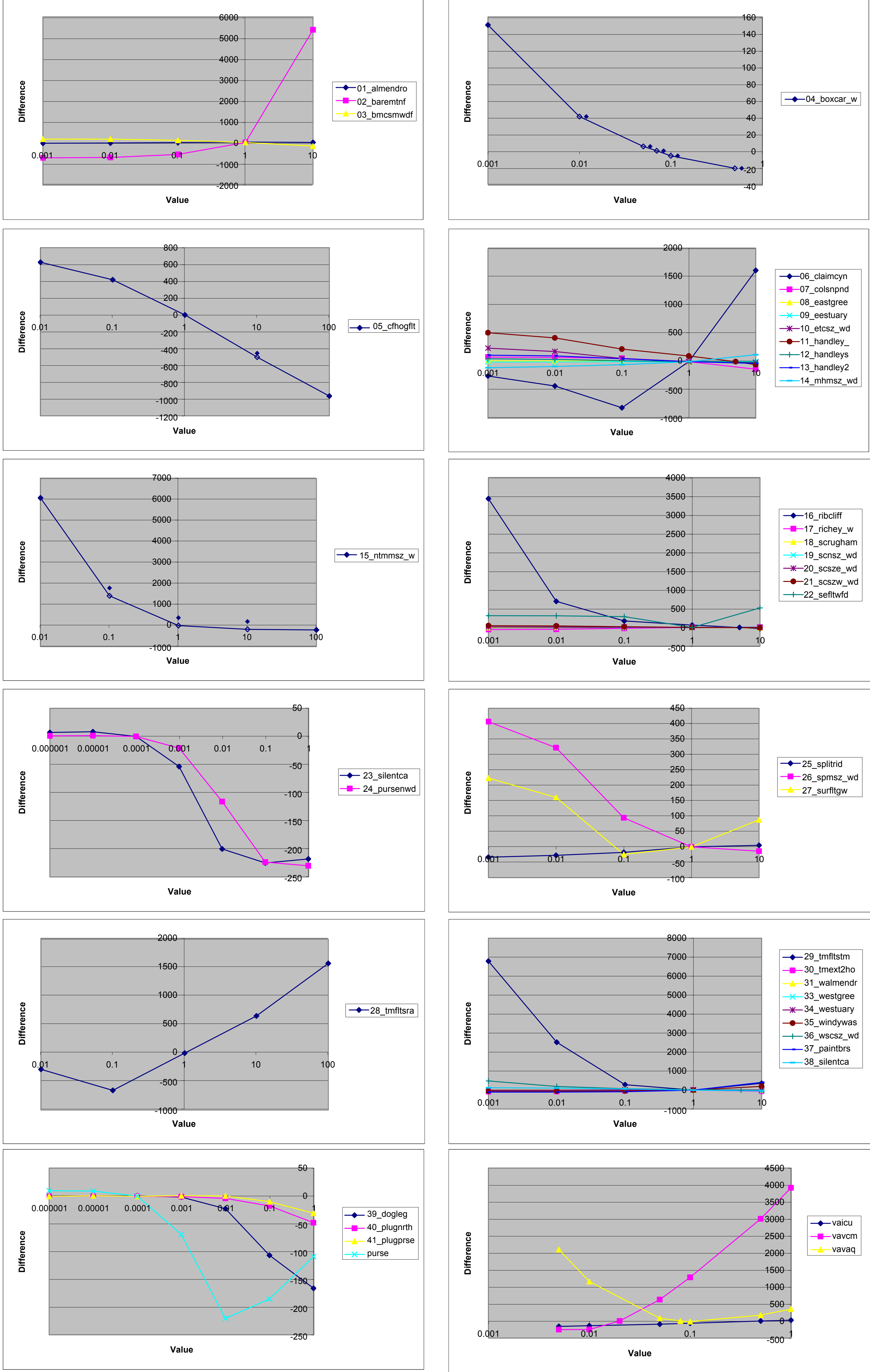

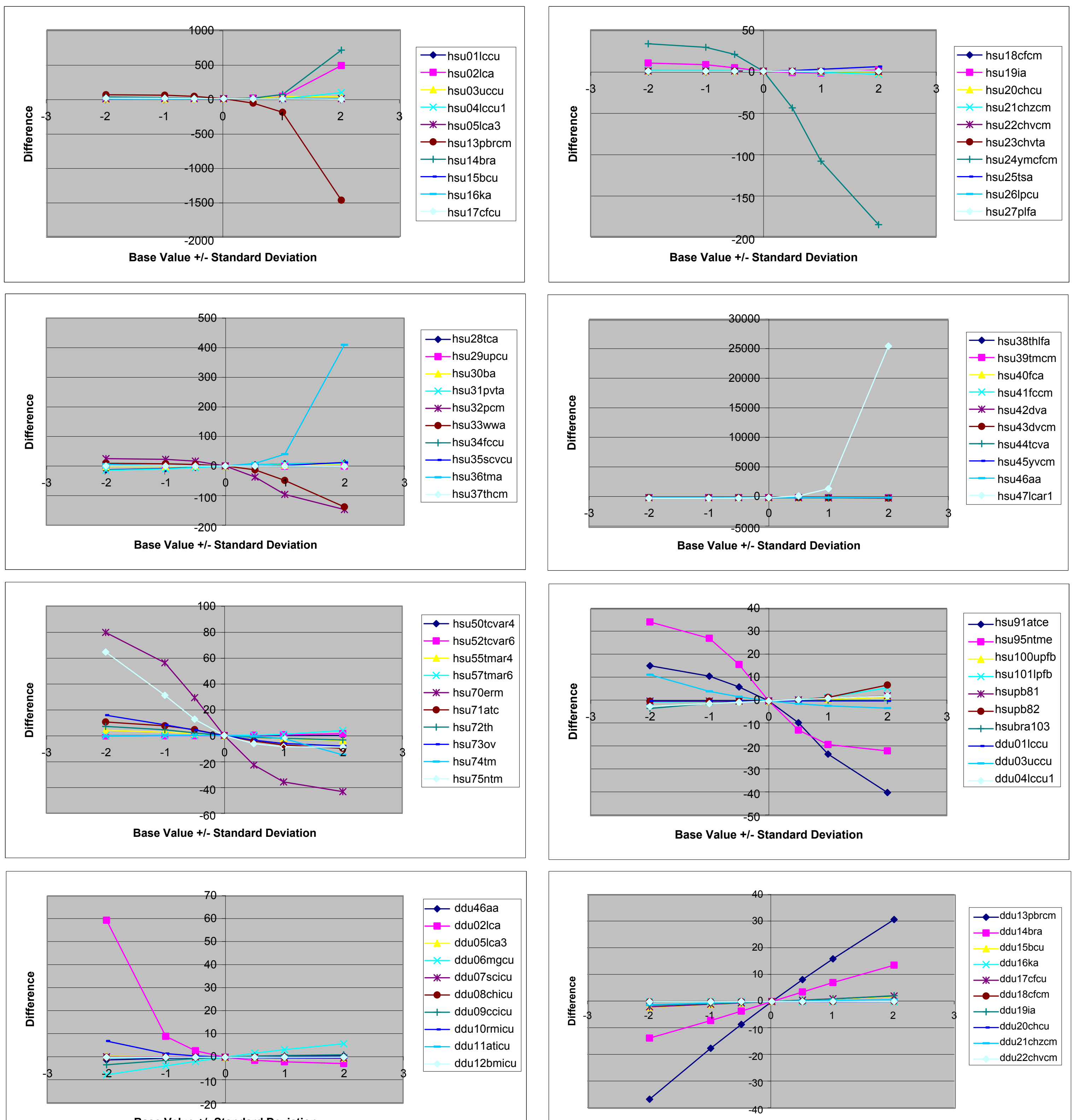

Base Value + -l Standard Deviation
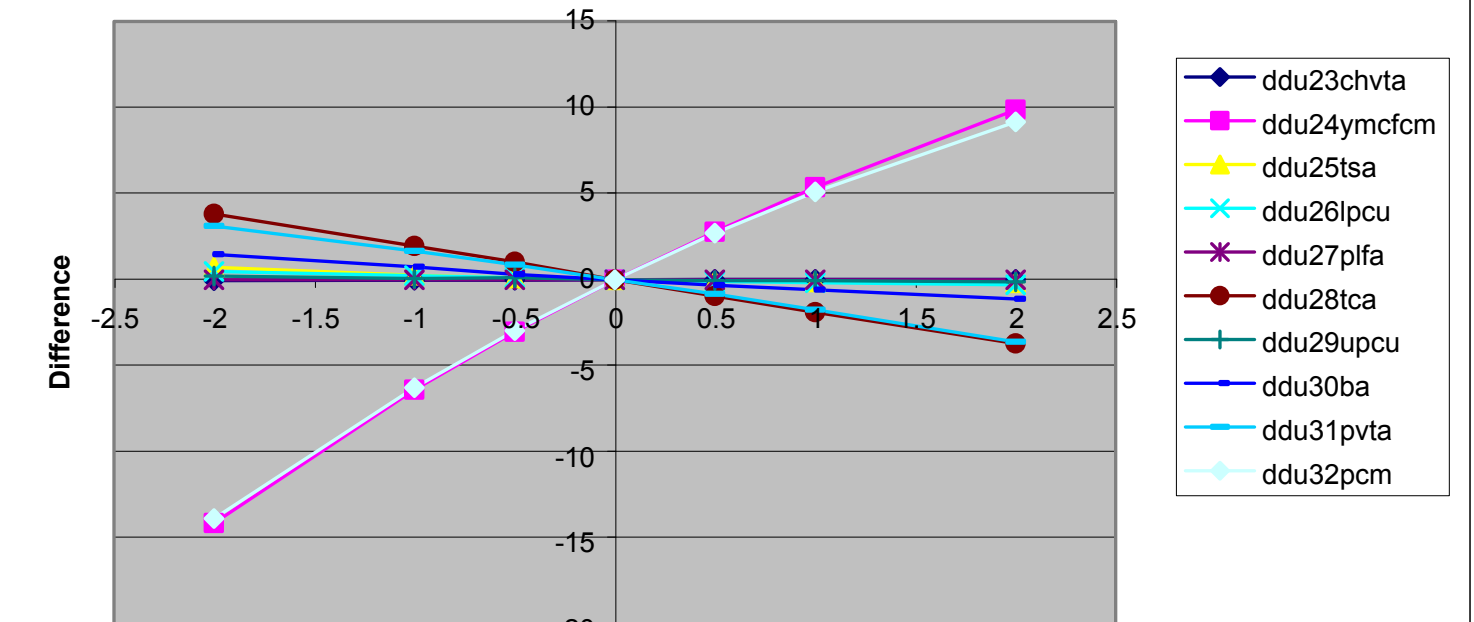

Base Value +1/- Standard Deviation
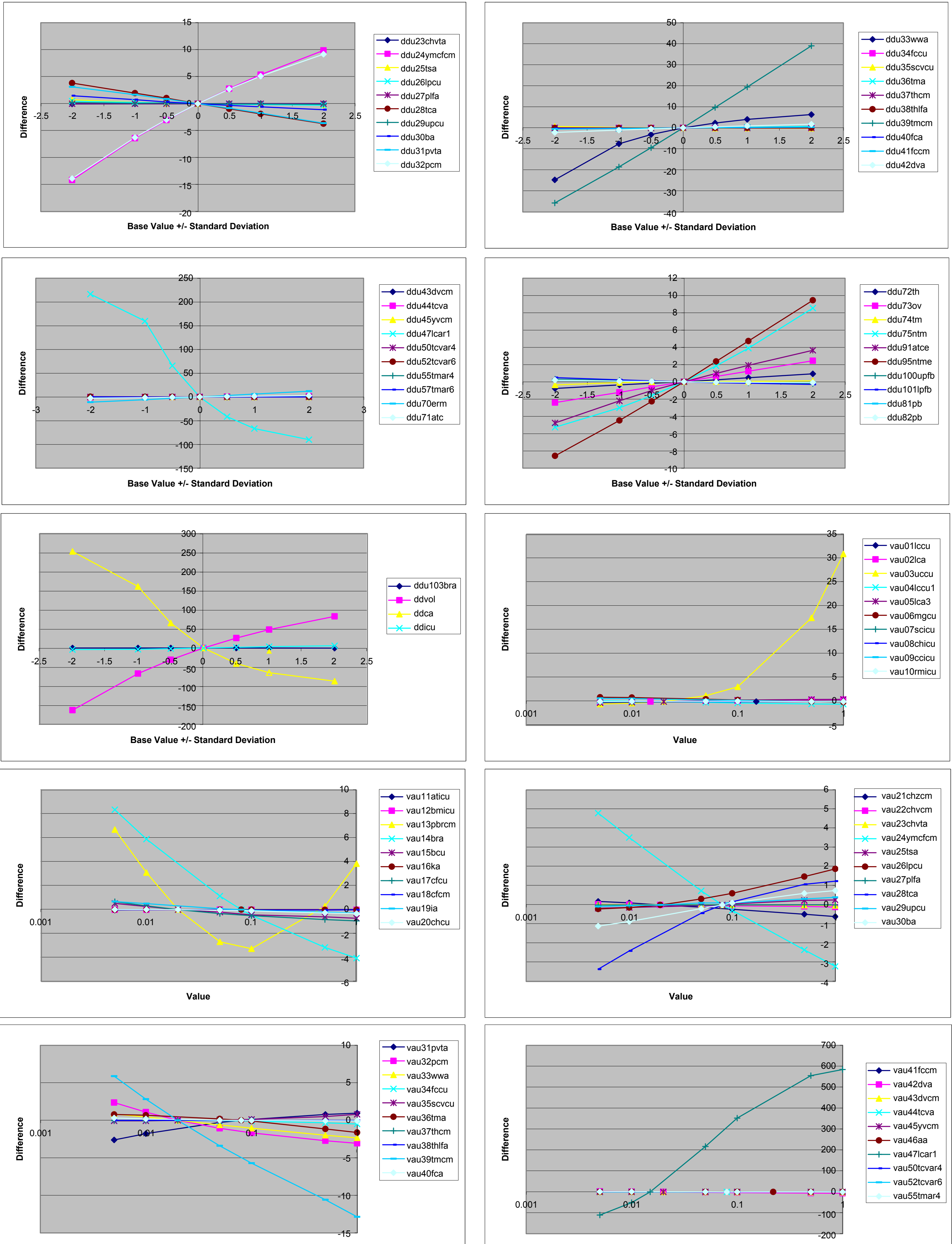

value
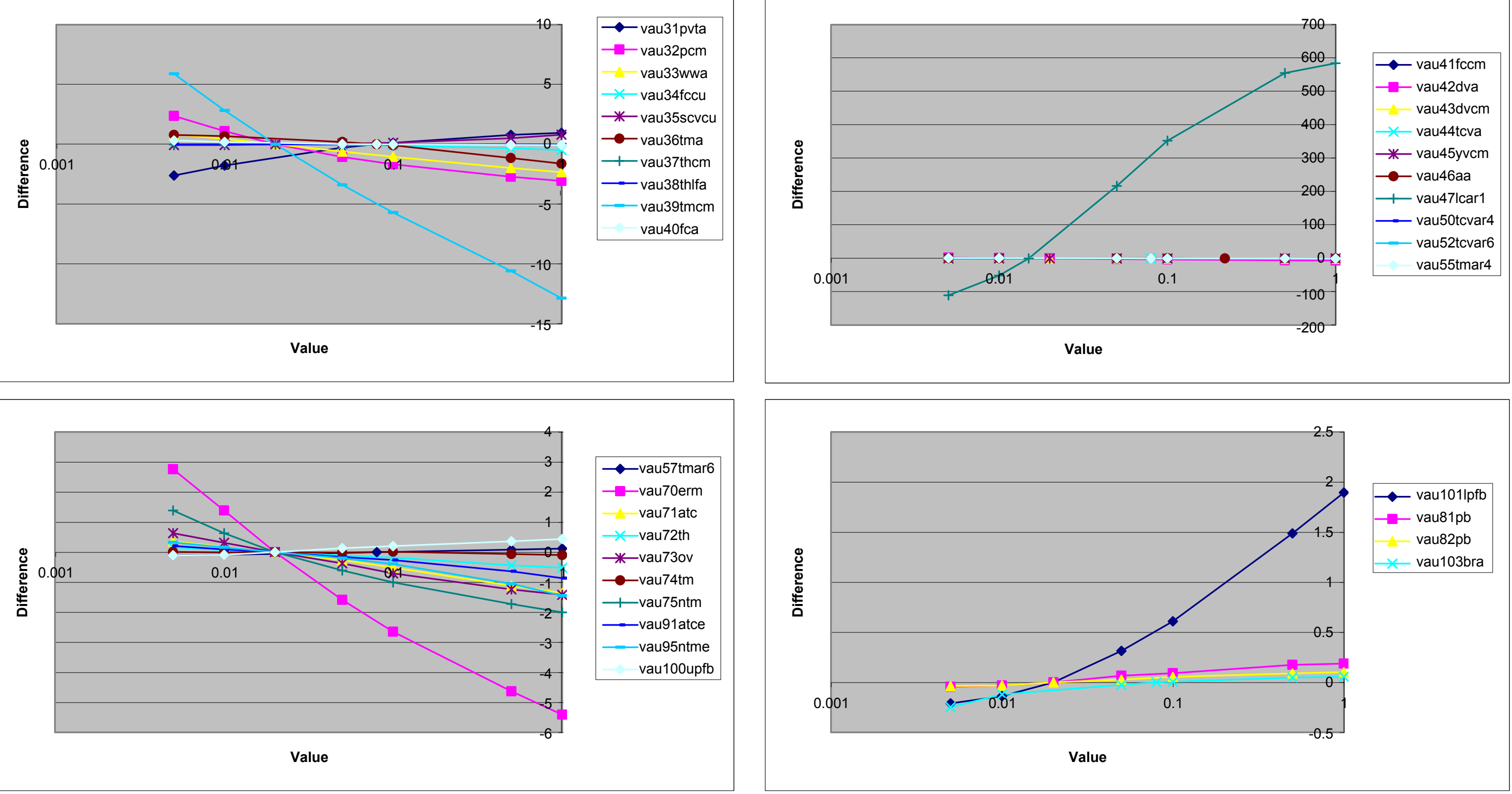

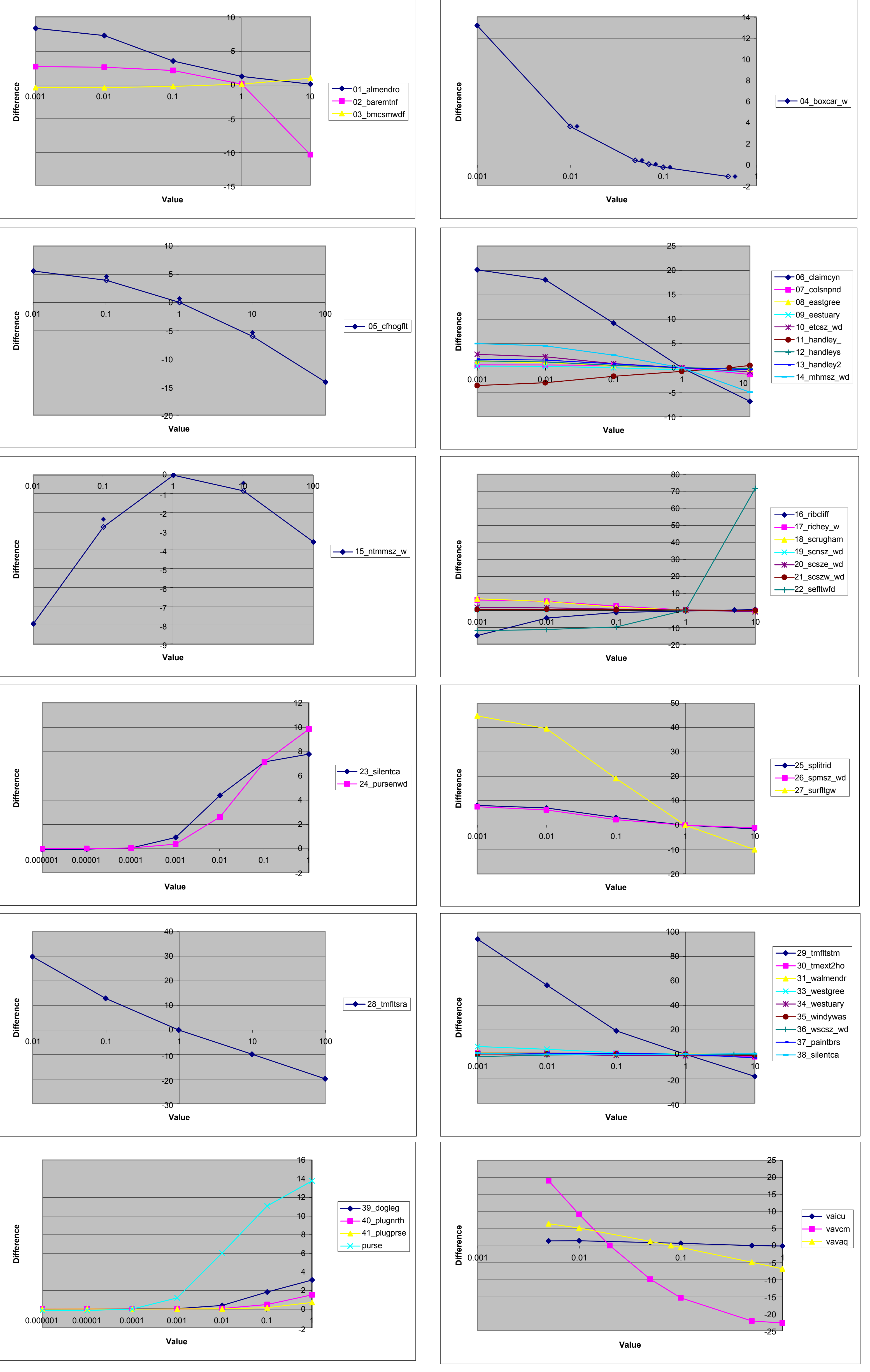

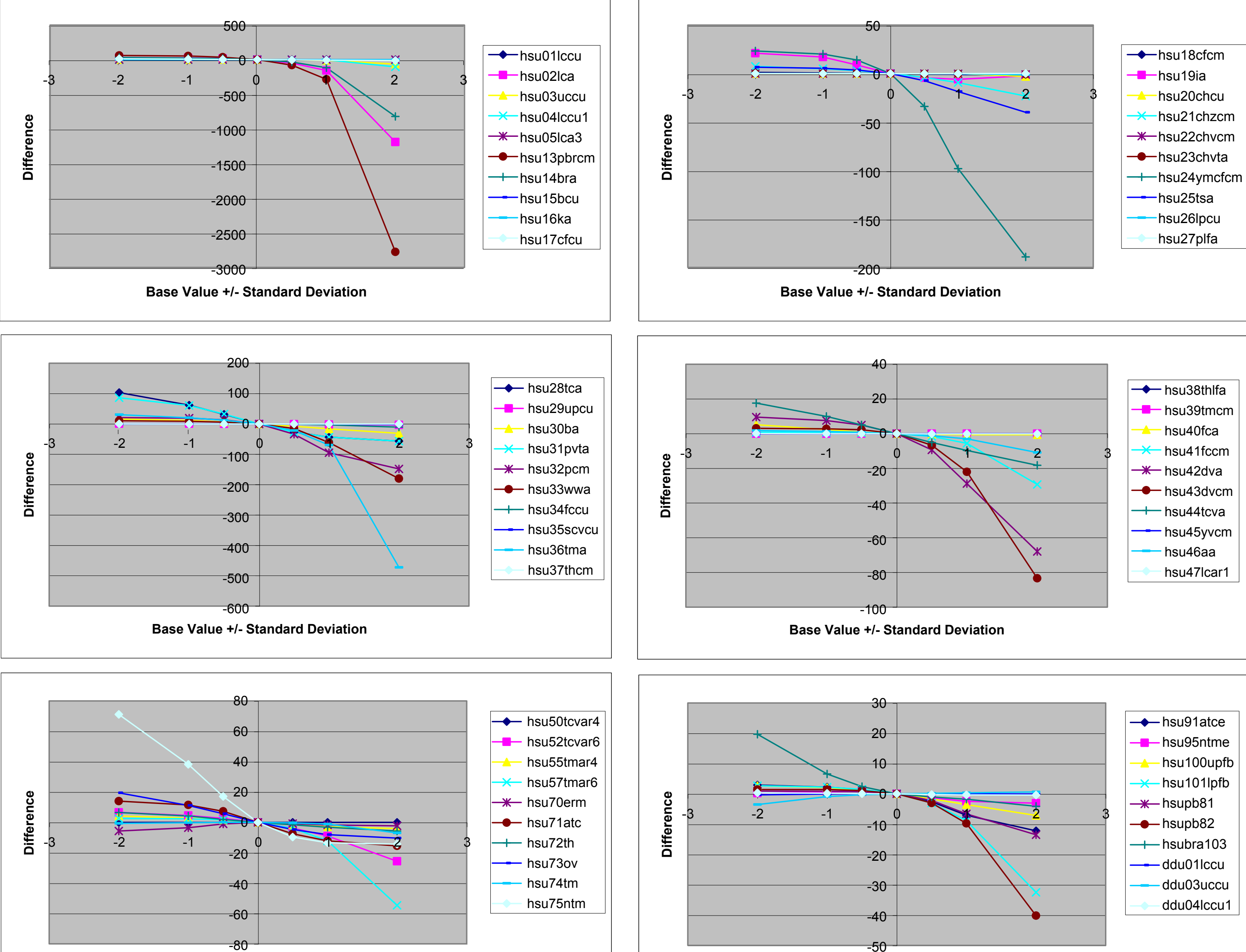

Base Value + / Standard Deviation
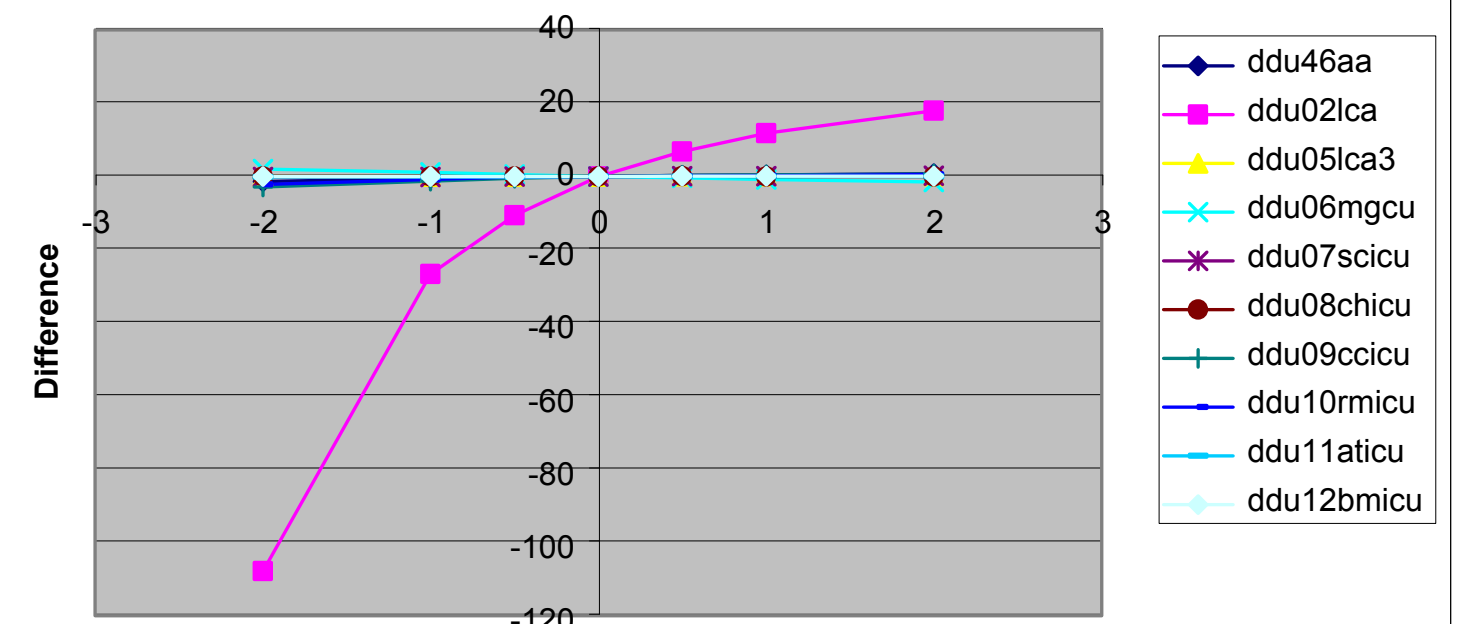

Base Value +// Standard Deviation

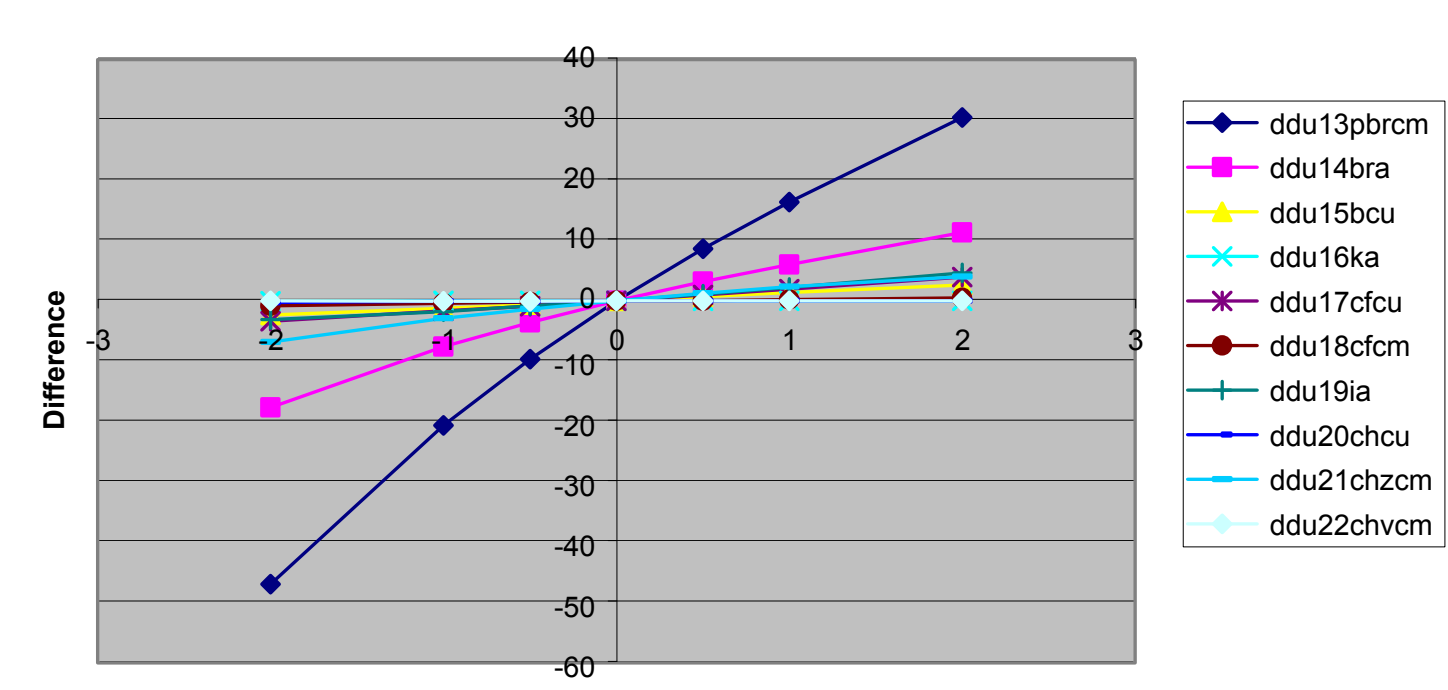

Base Value + - - Standard Deviation
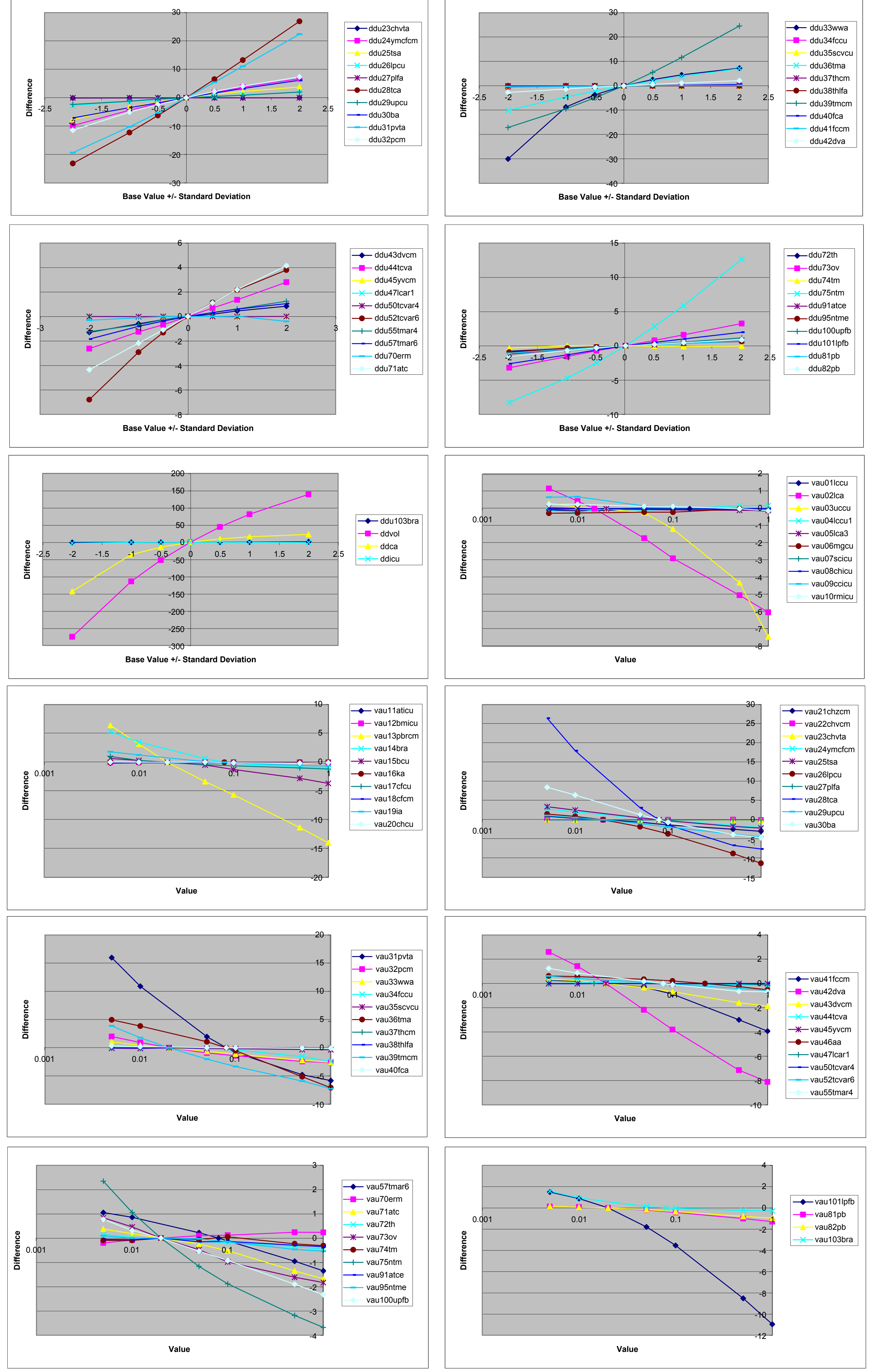


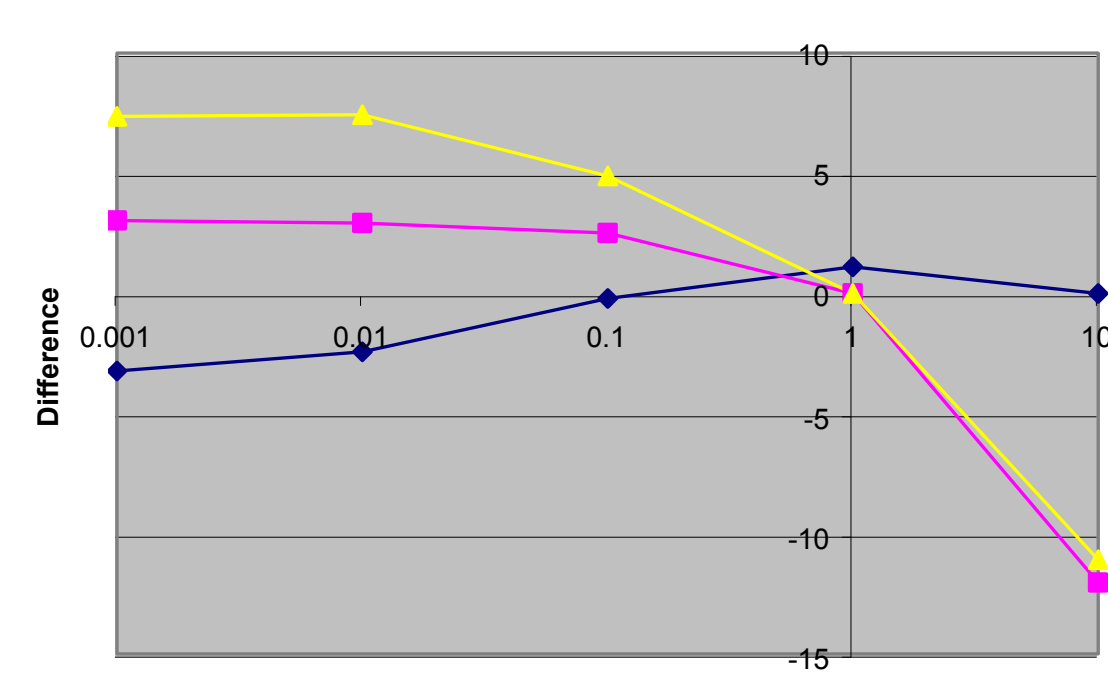

Value

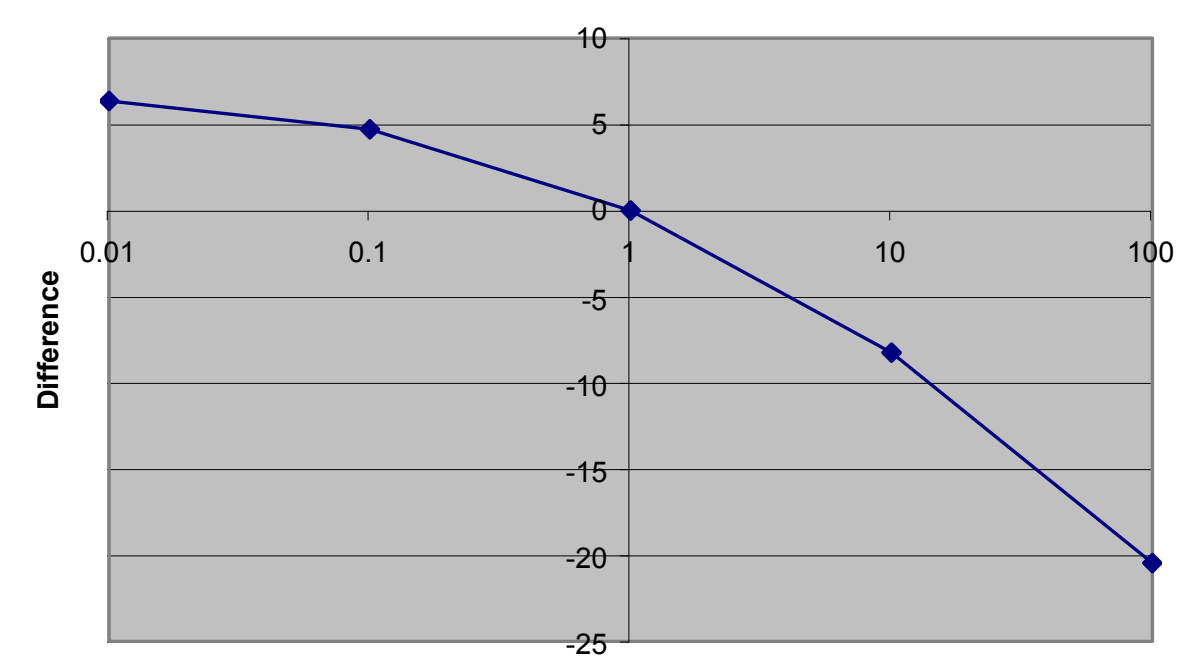

Value

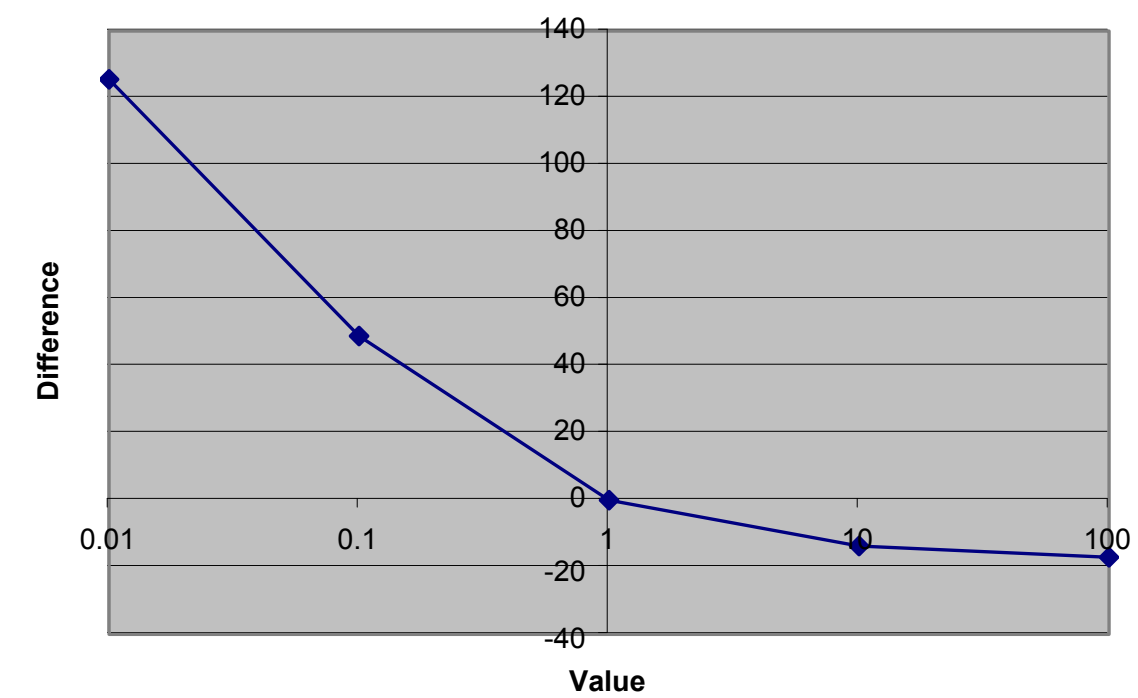

$\rightarrow-15 \_$ntmmsz_w

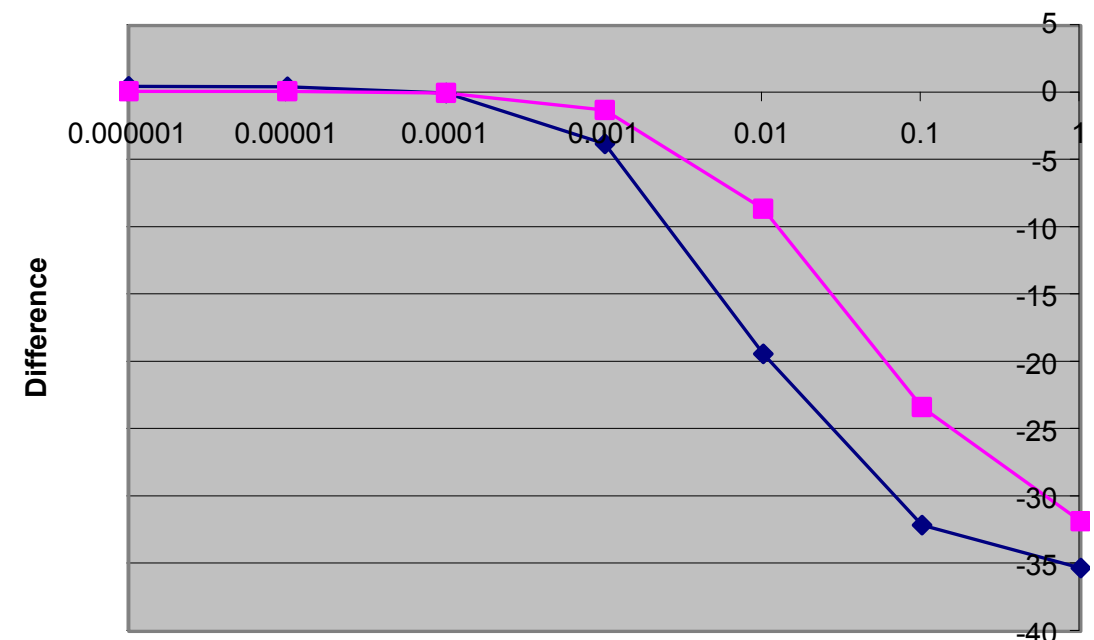

$\multimap-23$ silentca

- 24_pursenwd
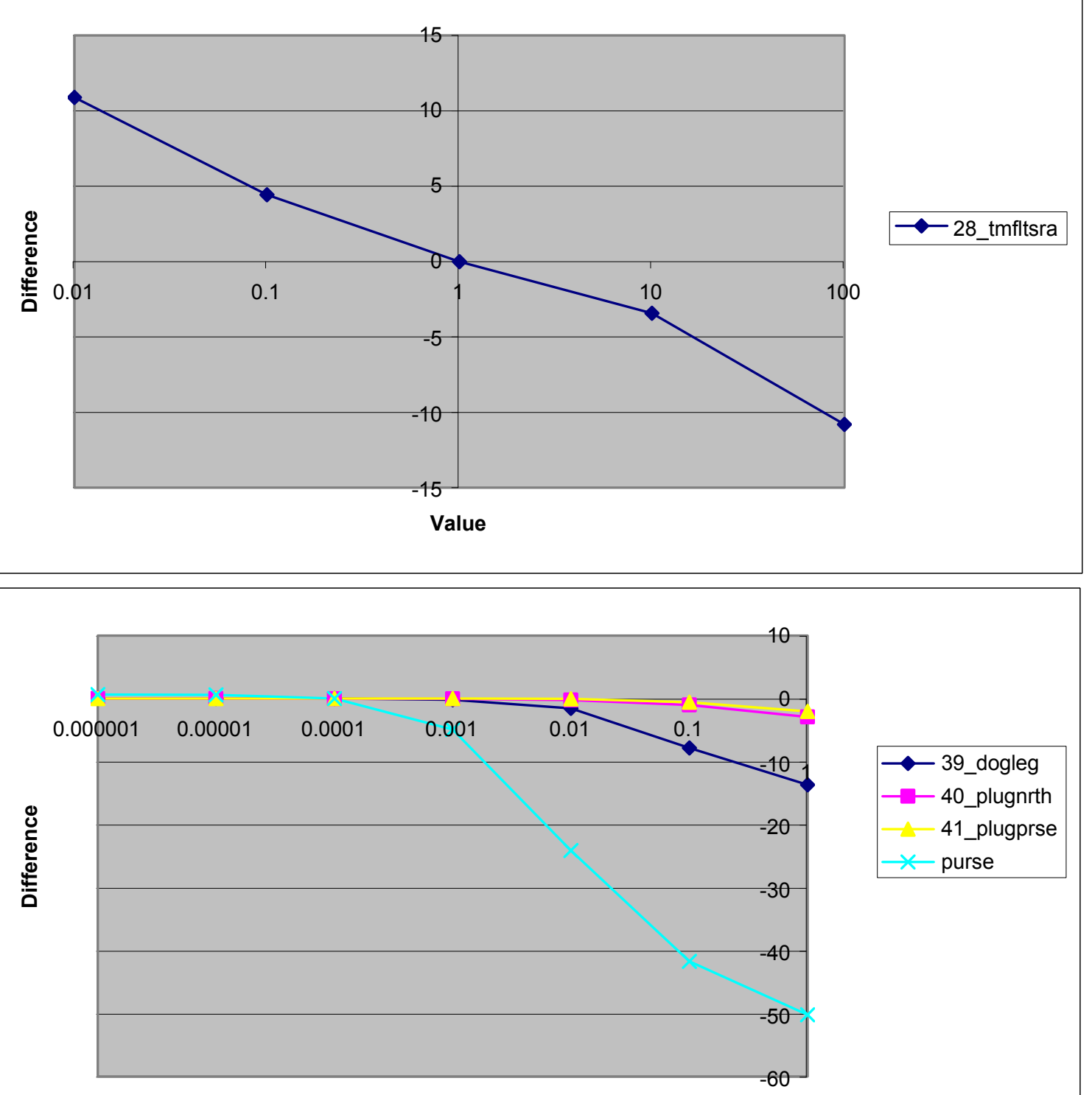

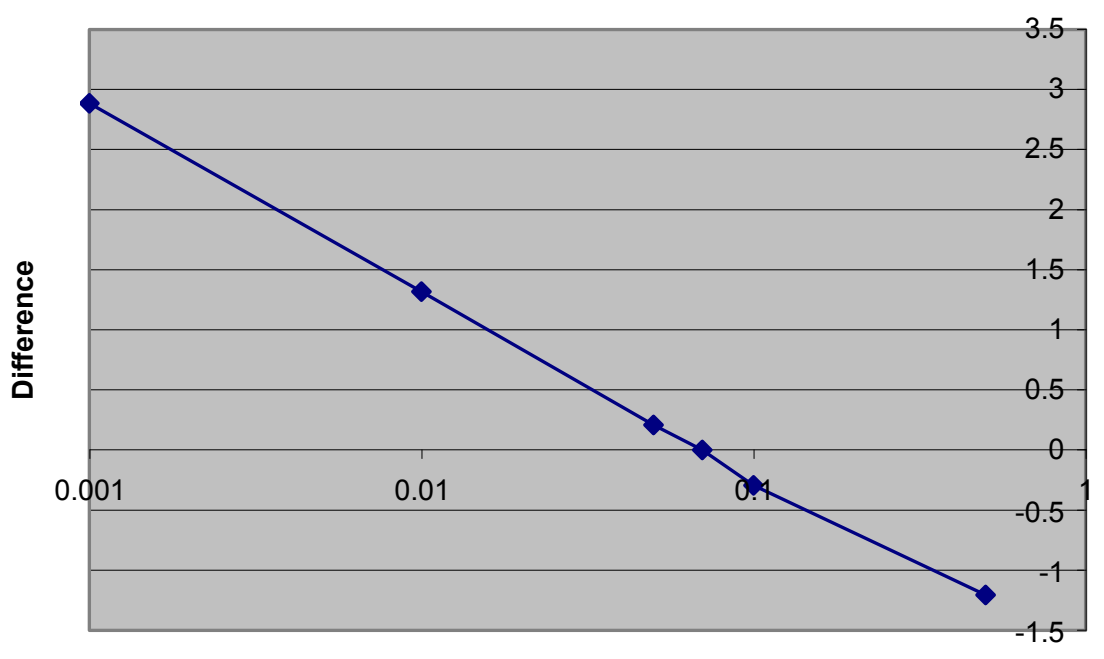

Value

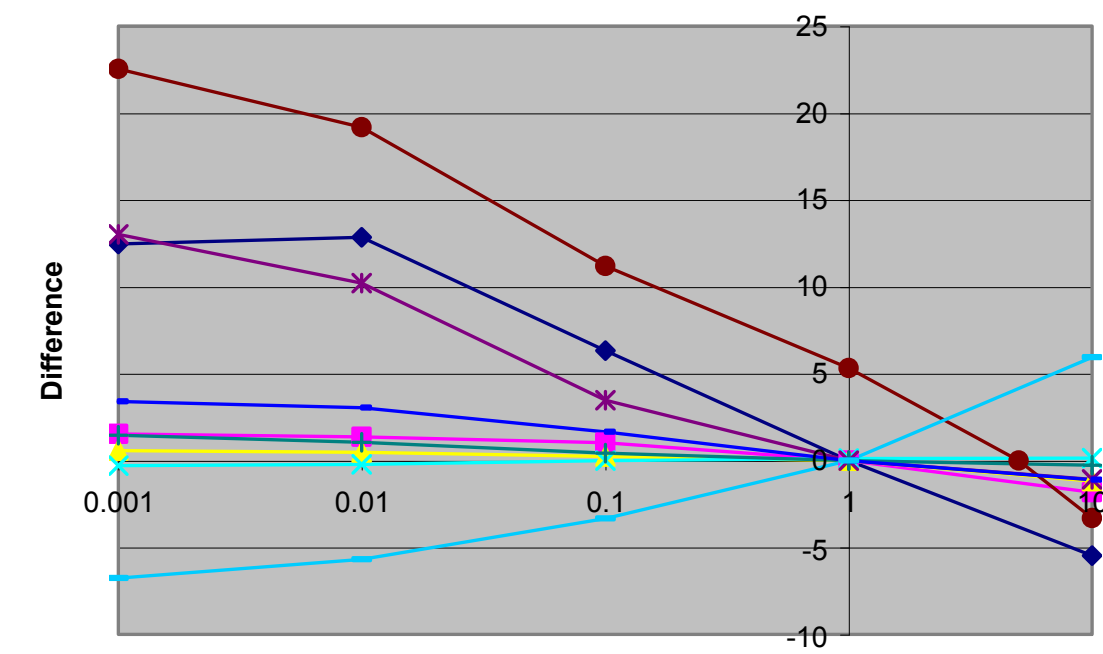

$\longrightarrow 06$ claimcyn

-07 - 0 _olsnpnd
-08 _eastgree

$\times 09$ eestuary

*-10_etcsz_wd

$\rightarrow$ 11_handley_

+12_handleys

-13_handley2

- -14 -mhmsz_wd
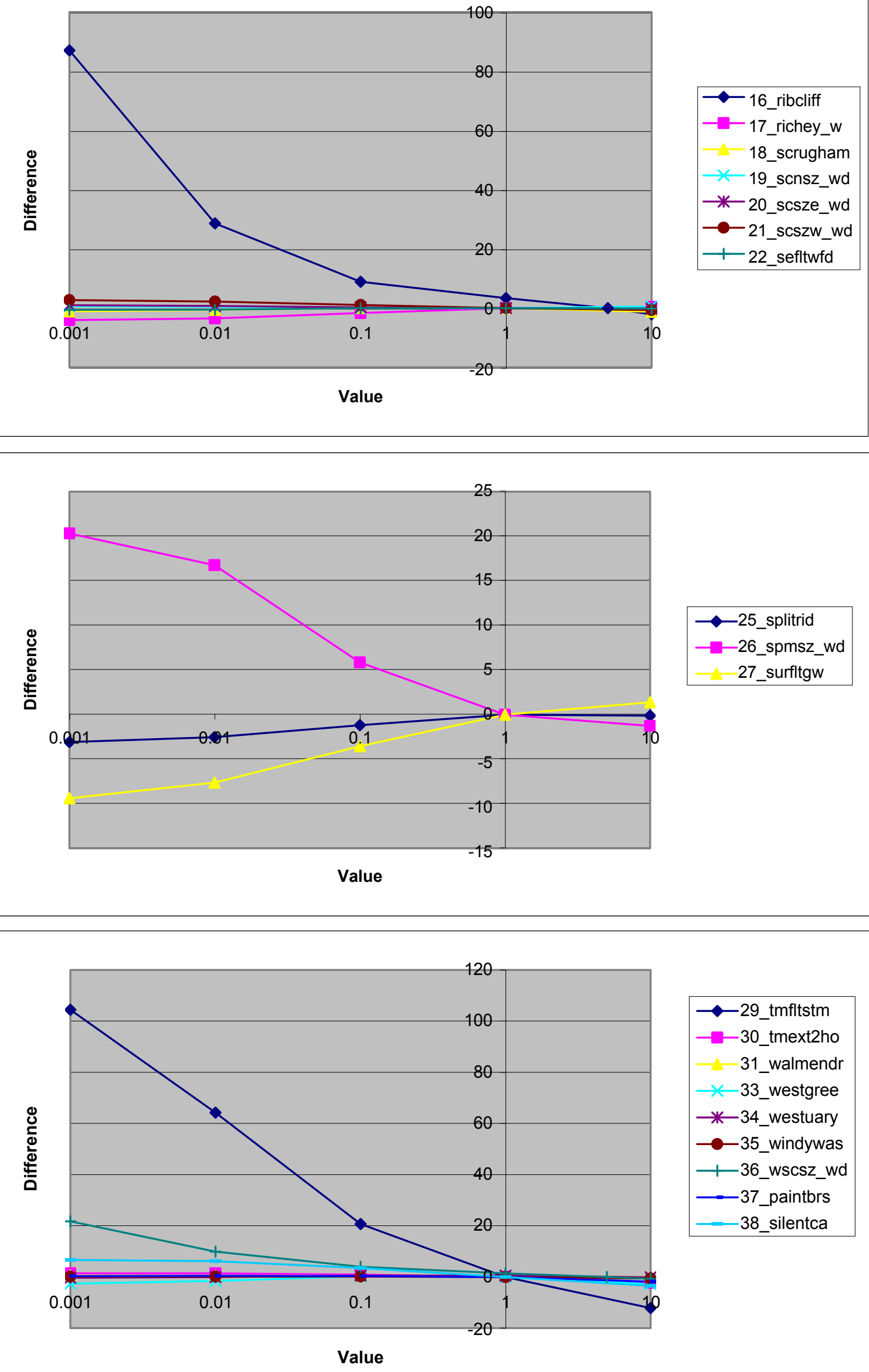

$\longrightarrow$-29_tmfltstm

-30_tmext2ho

31_walmendr

$\times$ 33_westgree

*-34_westuary

$\longrightarrow-35$ _windywas

- 36 _wscsz_wd

-37_paintbrs

- -38 silentca

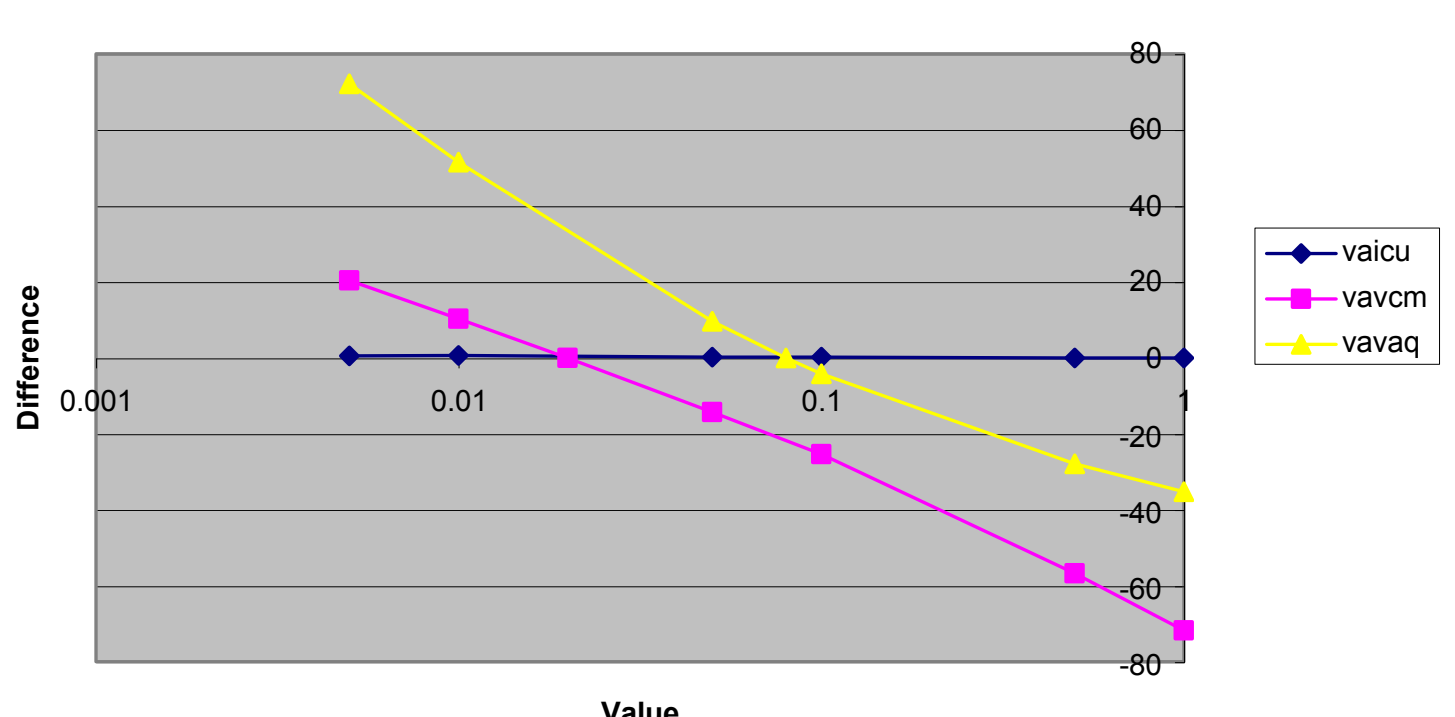




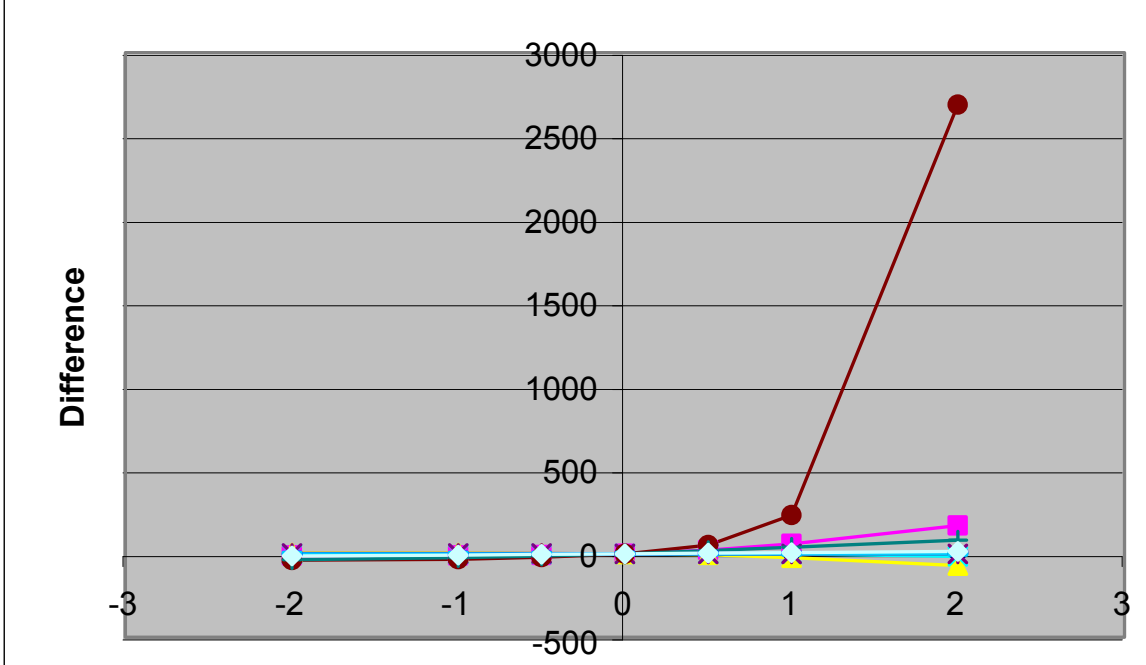

Base Value +/-Standard Deviation

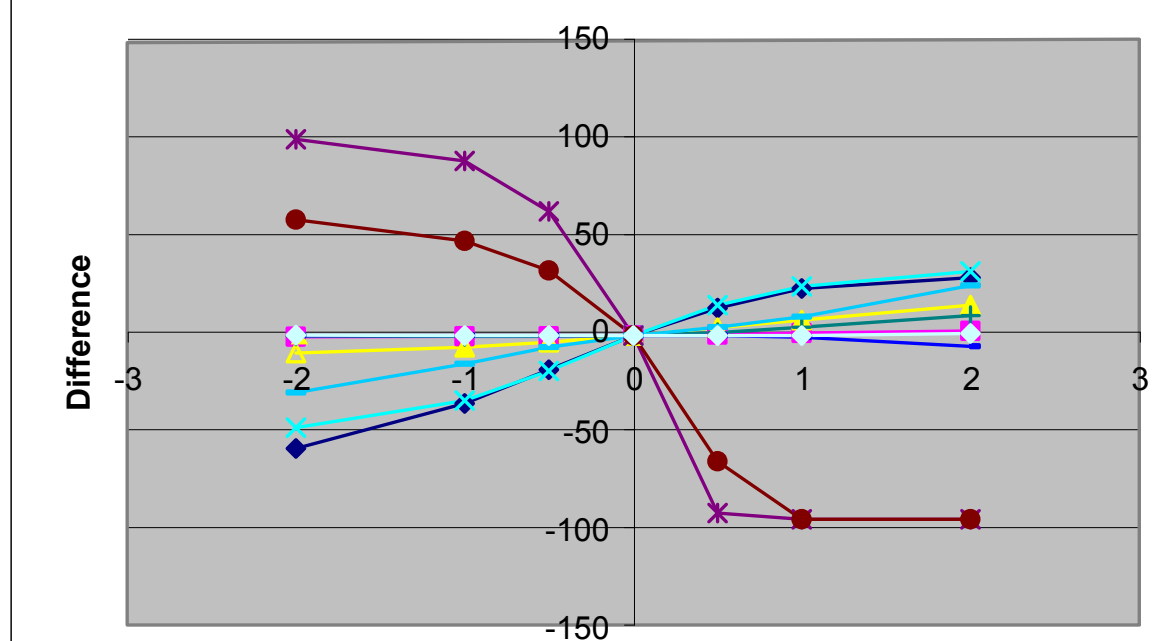

Base Value t/. Standard Deviation

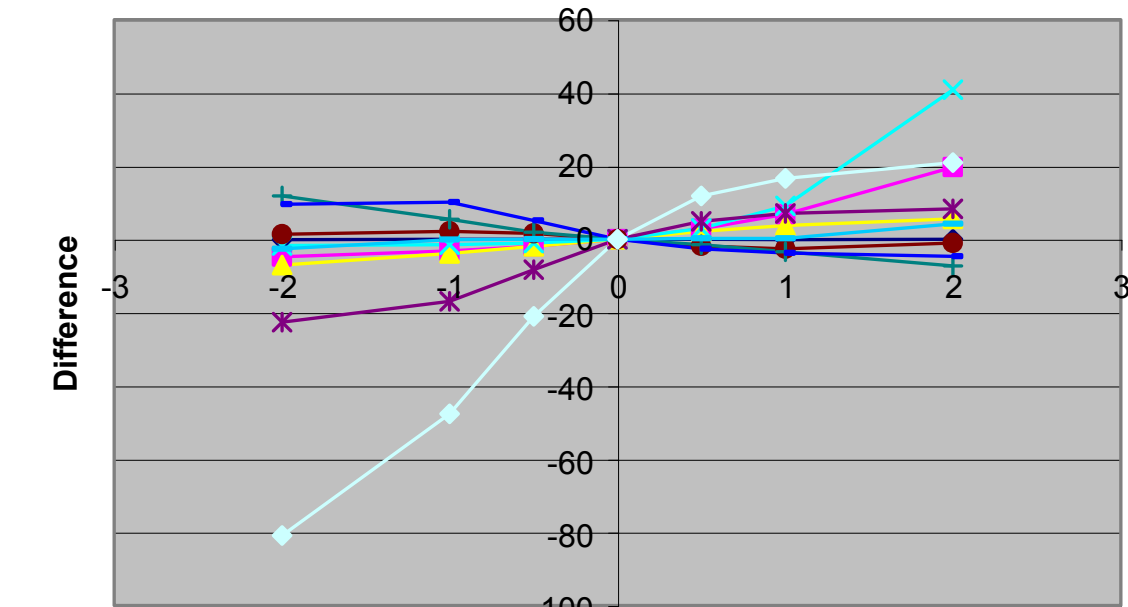

Base Value + - Standard Deviation

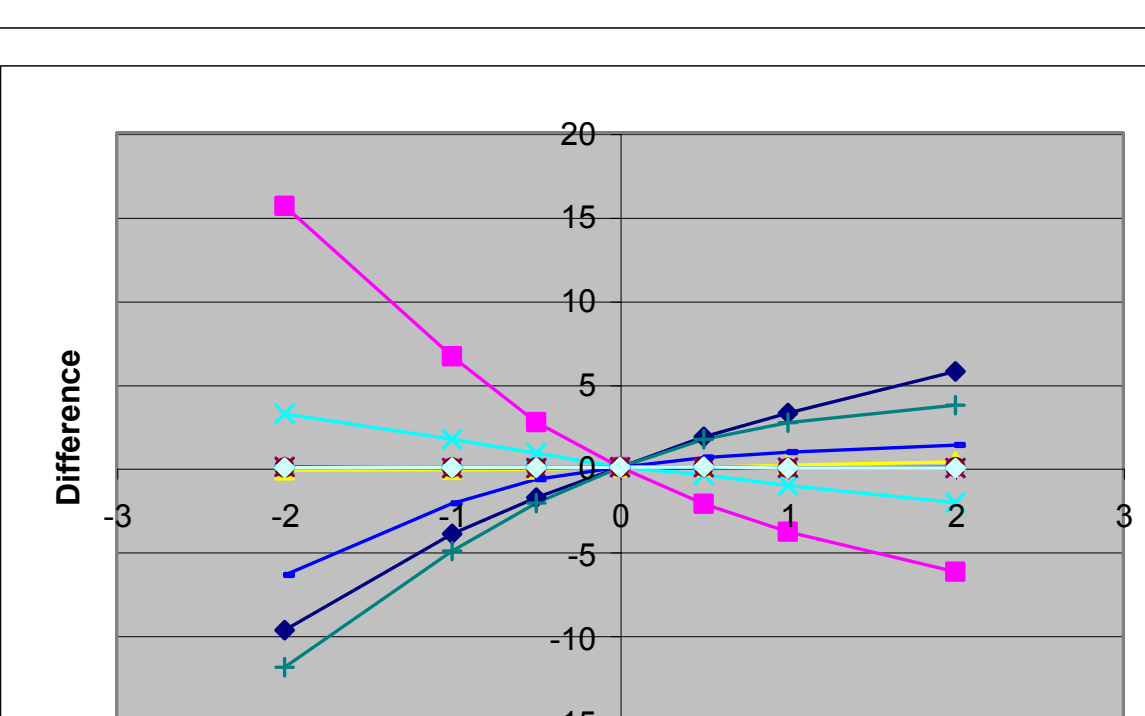

Base Value t// Standard Deviation

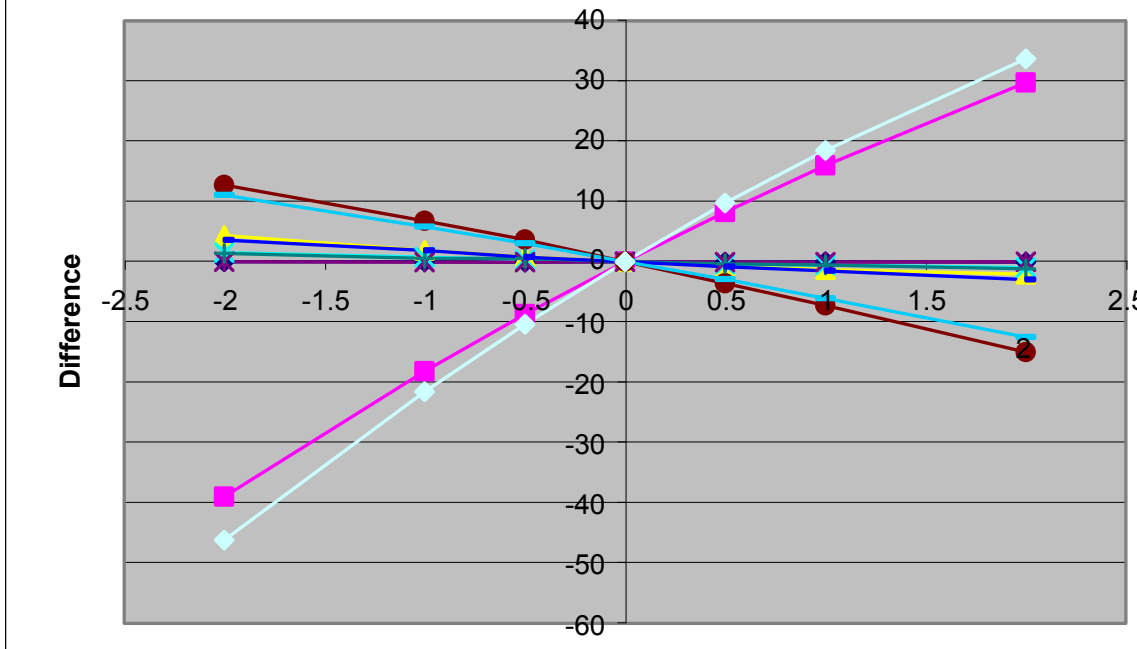

Base Value $+1 /$ - Standard Deviation

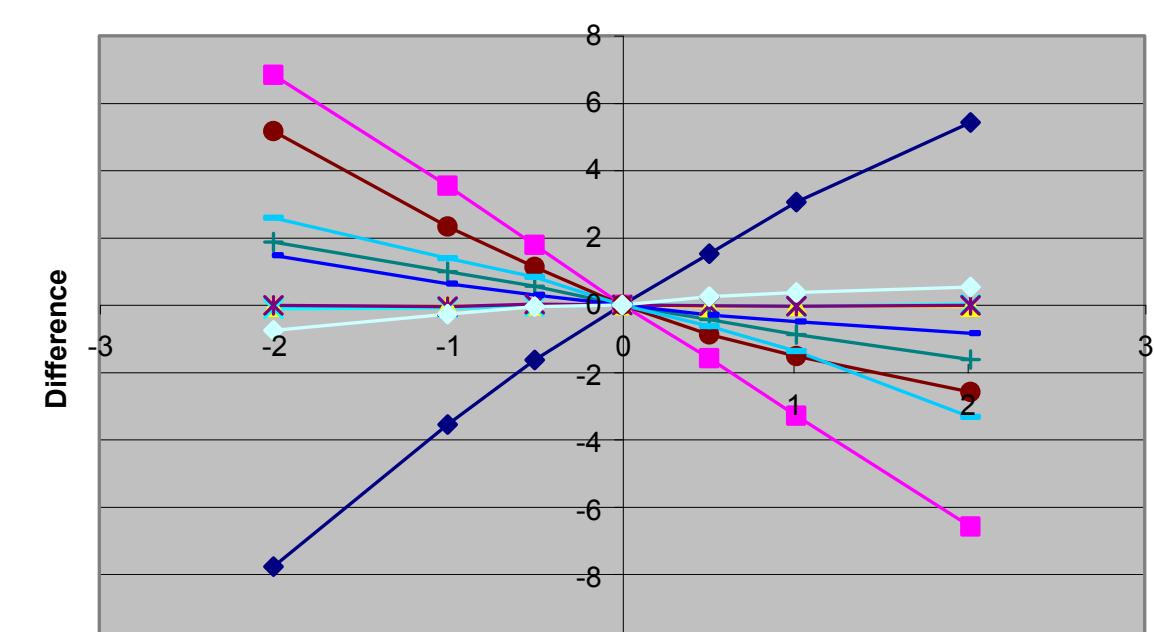

Base Value th- Standard Deviation

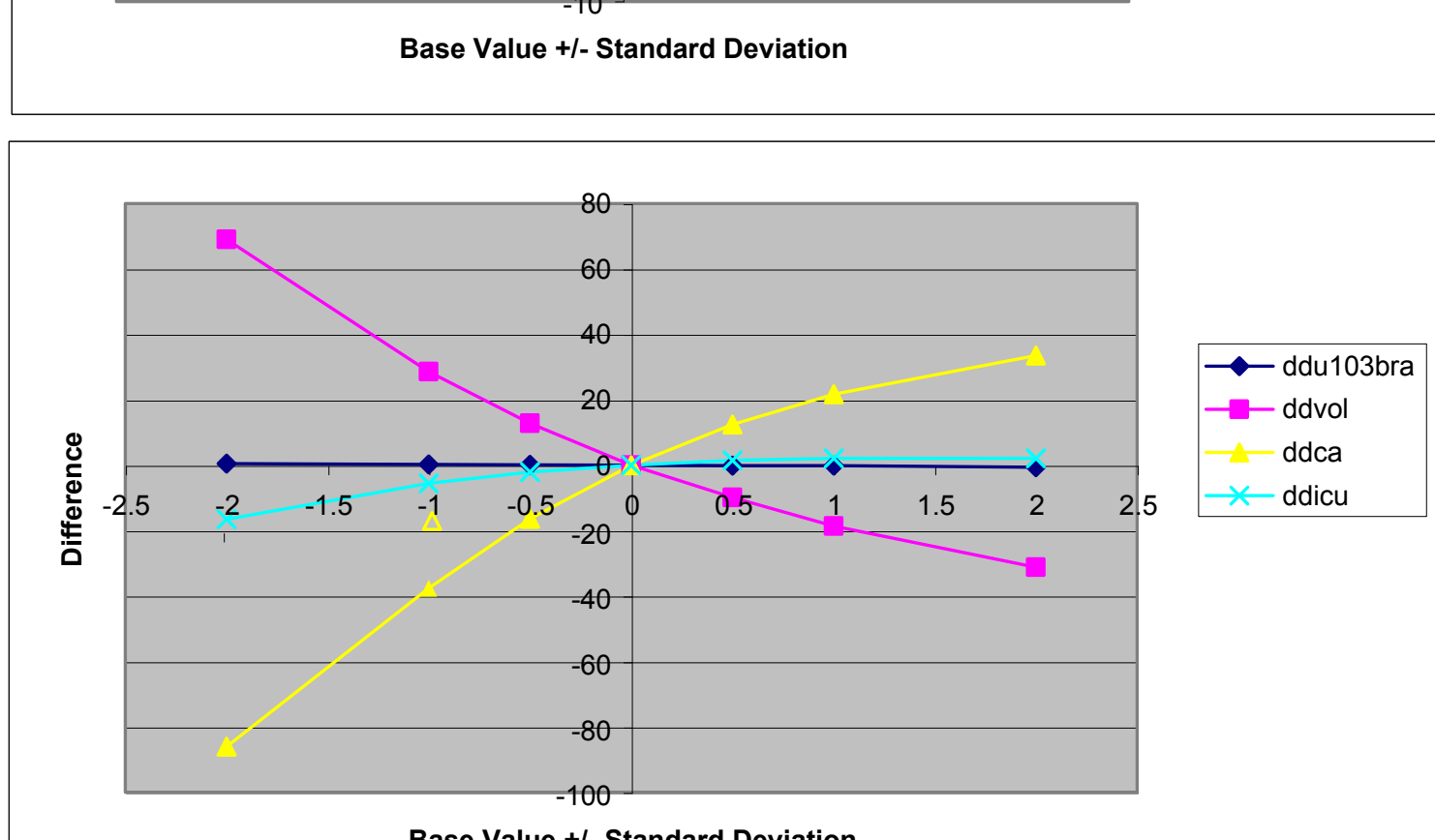

Base Value + +/Standard Deviatio
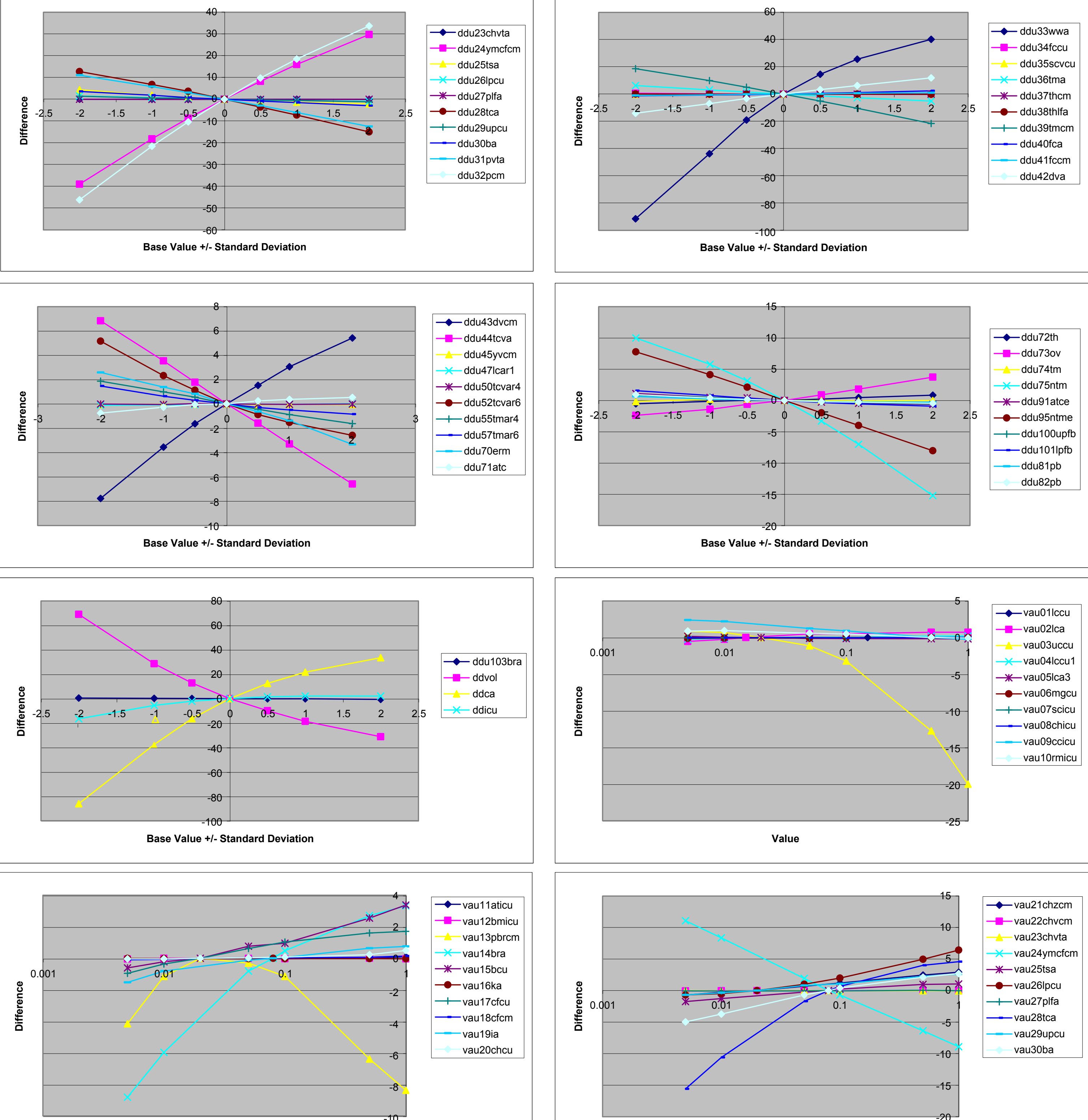

Base value ++ - Standard Deviation

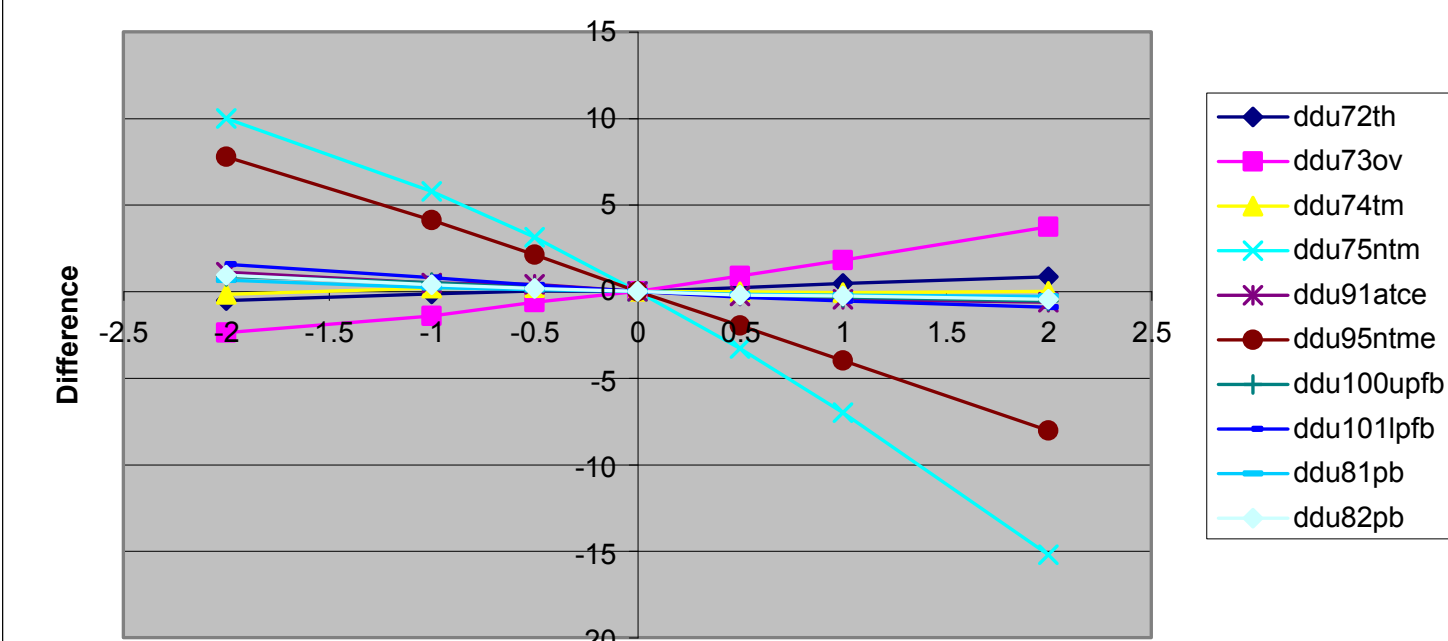

Base Value + + + Standard Deviation
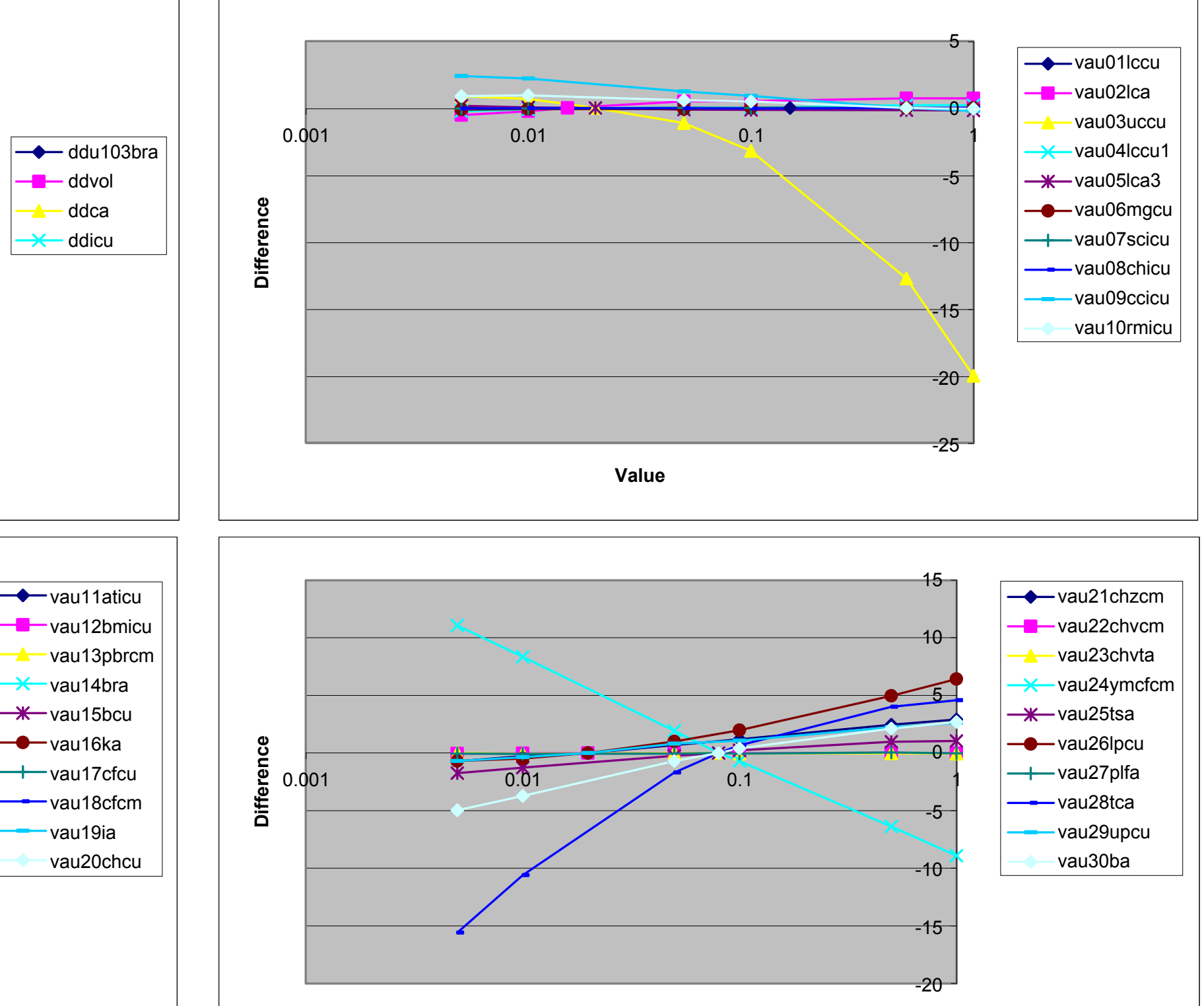

Value
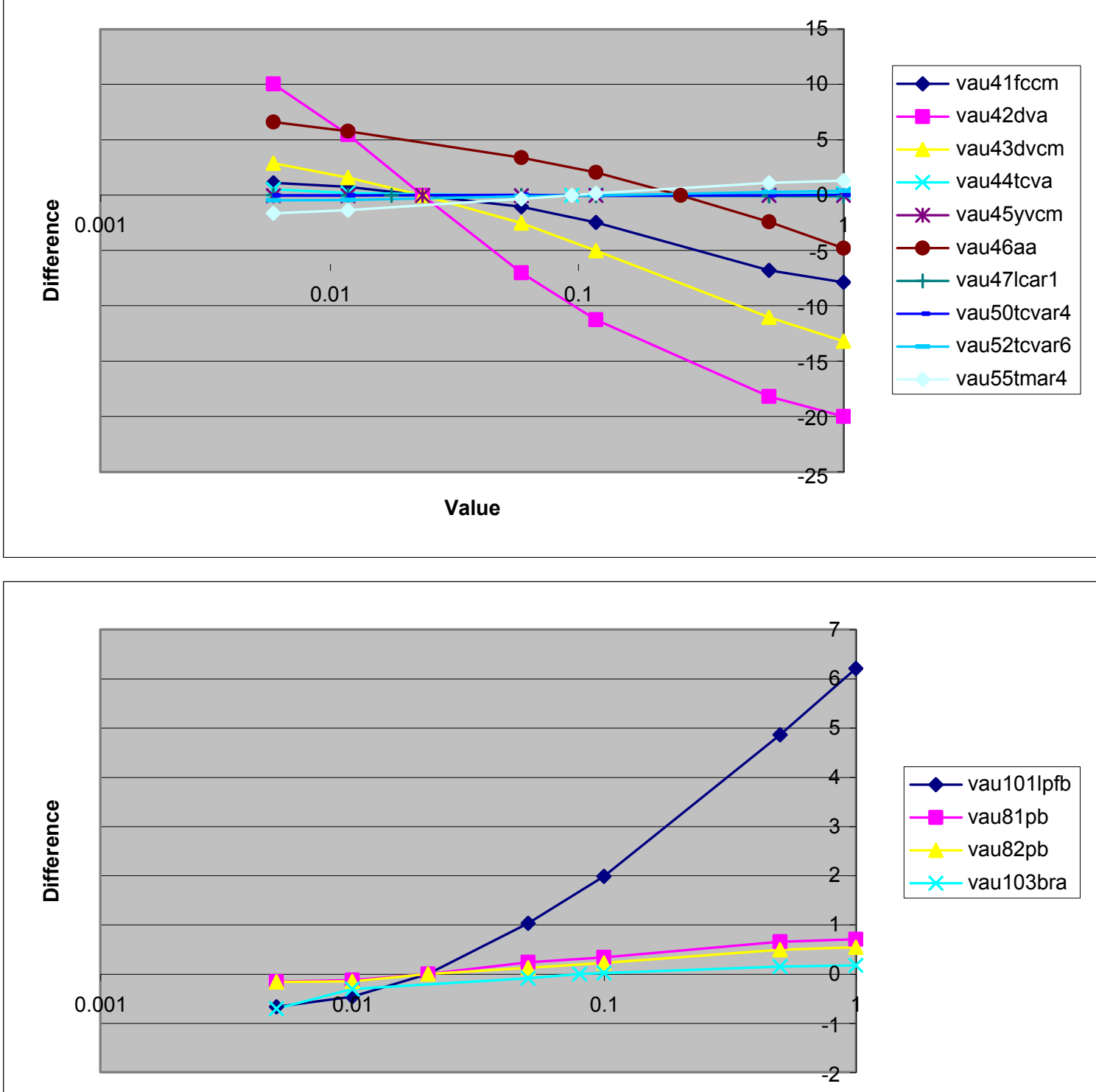

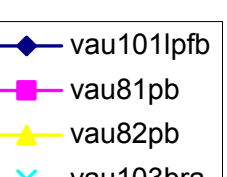




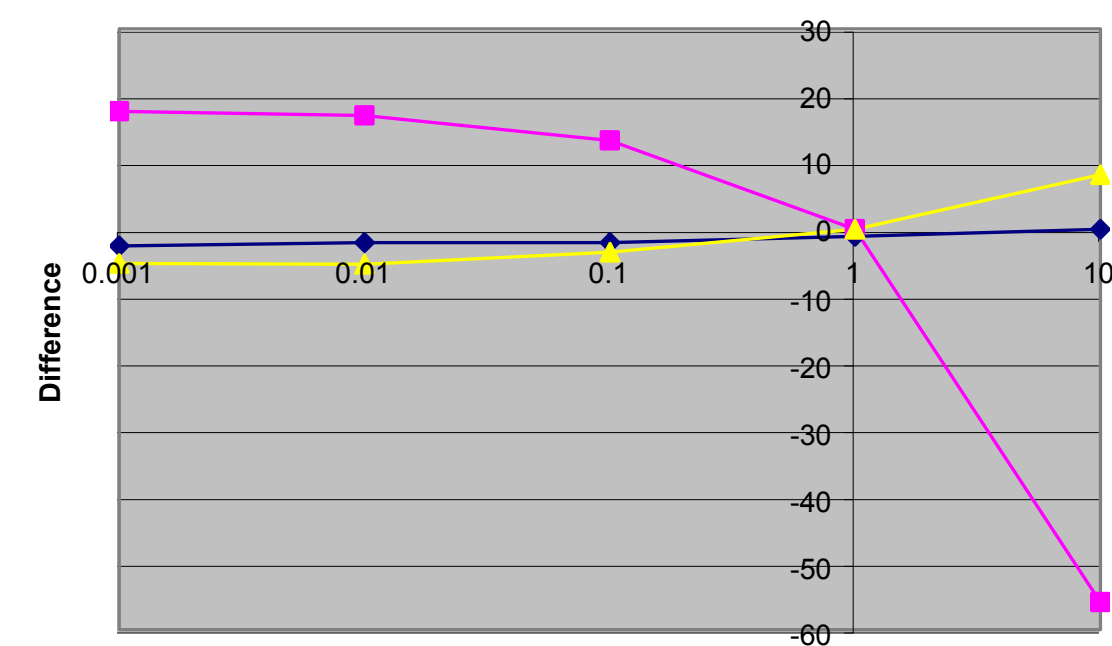

Value
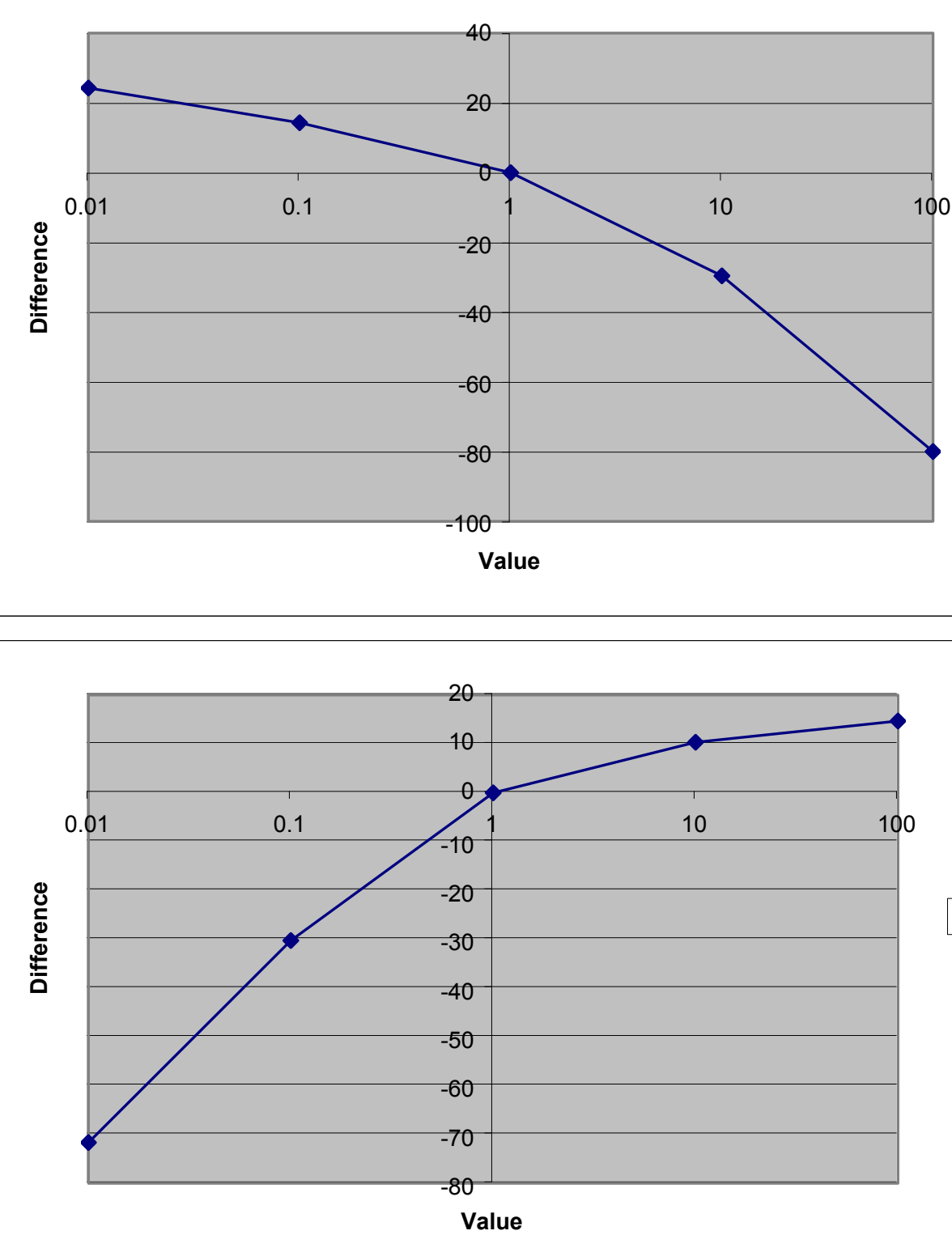

$\bullet \bullet$ 15_ntmmsz_w

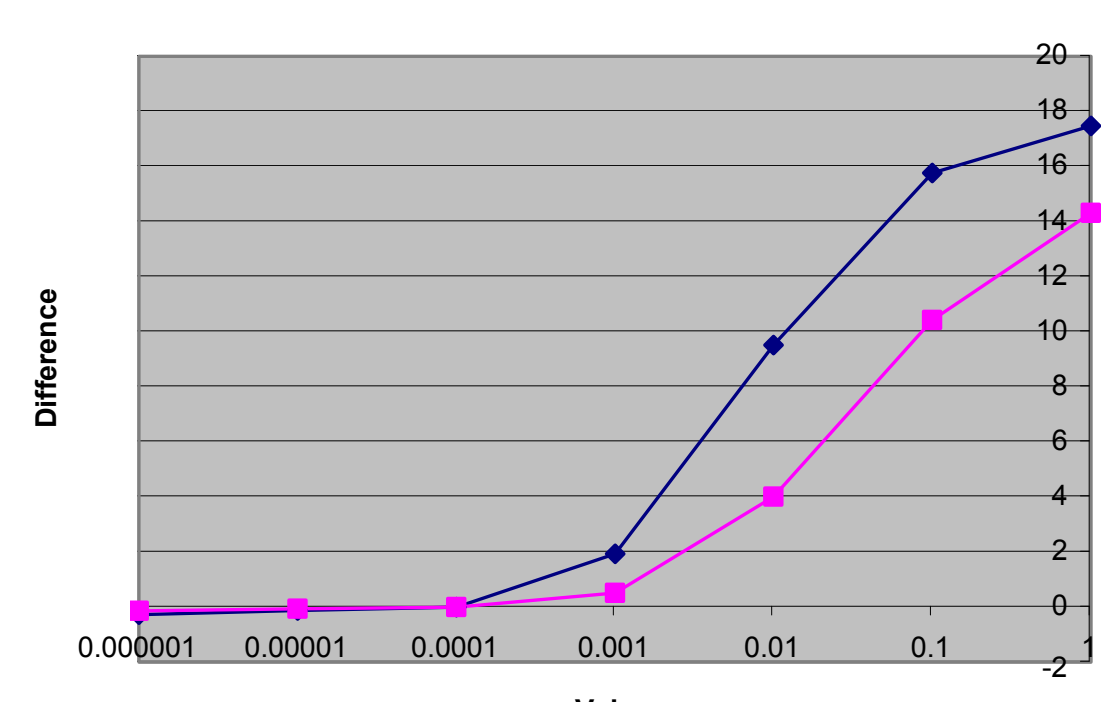

-23 2silentca
-2 -24_pursenwd

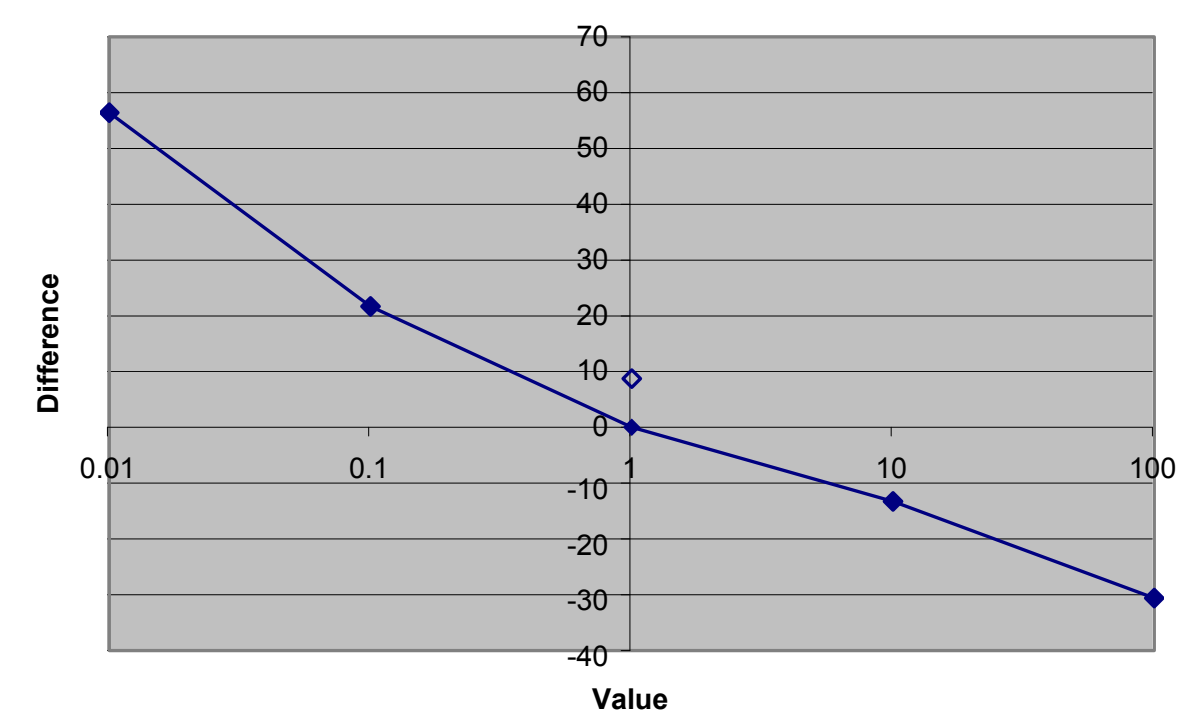

$\multimap-28$ tmfltsra

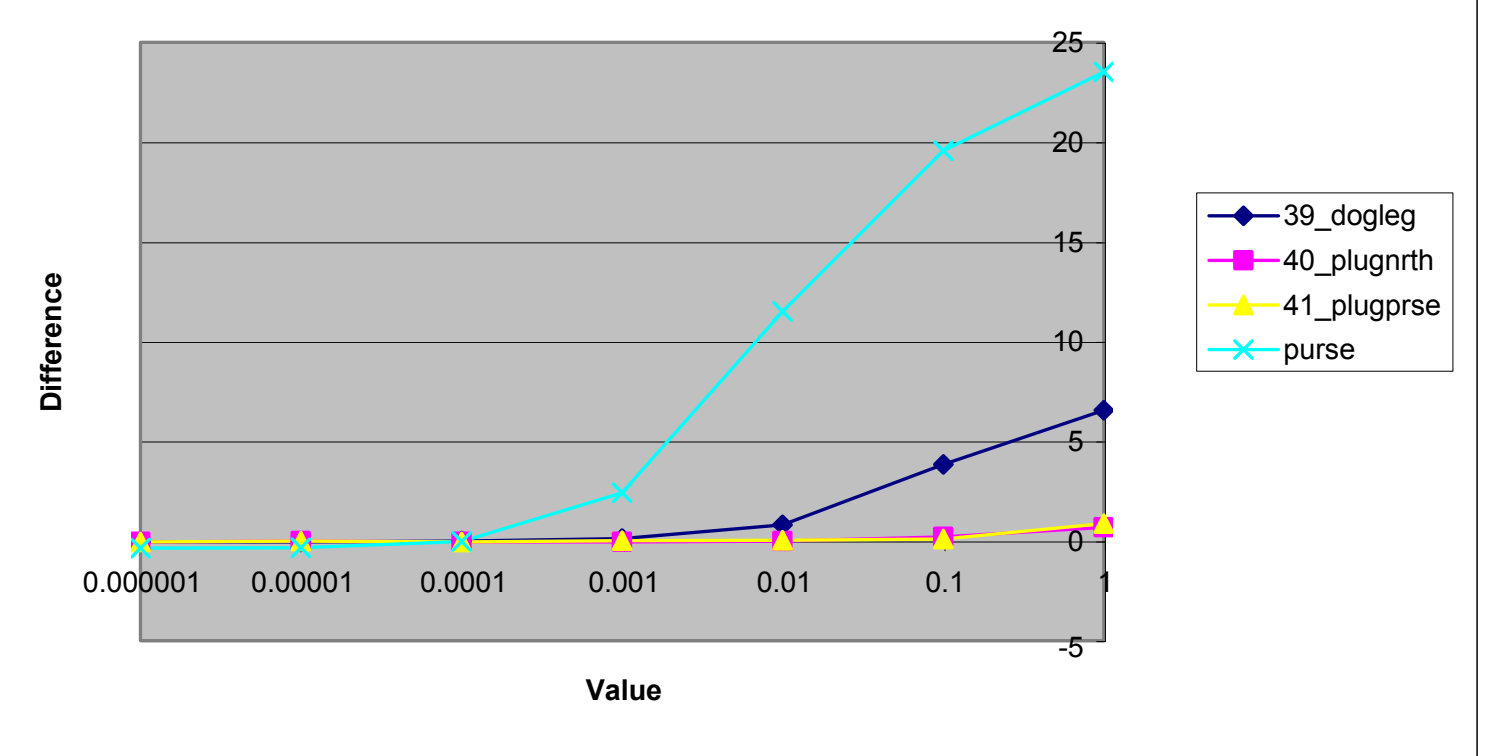

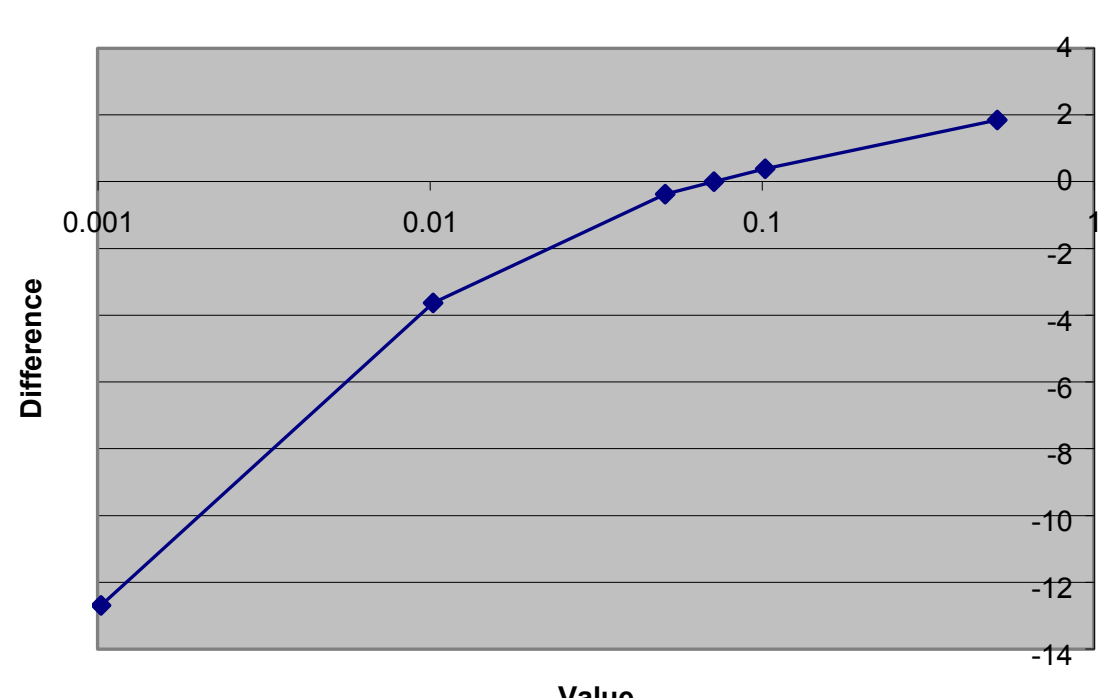

$\longrightarrow \bullet$ 04_boxcar_w

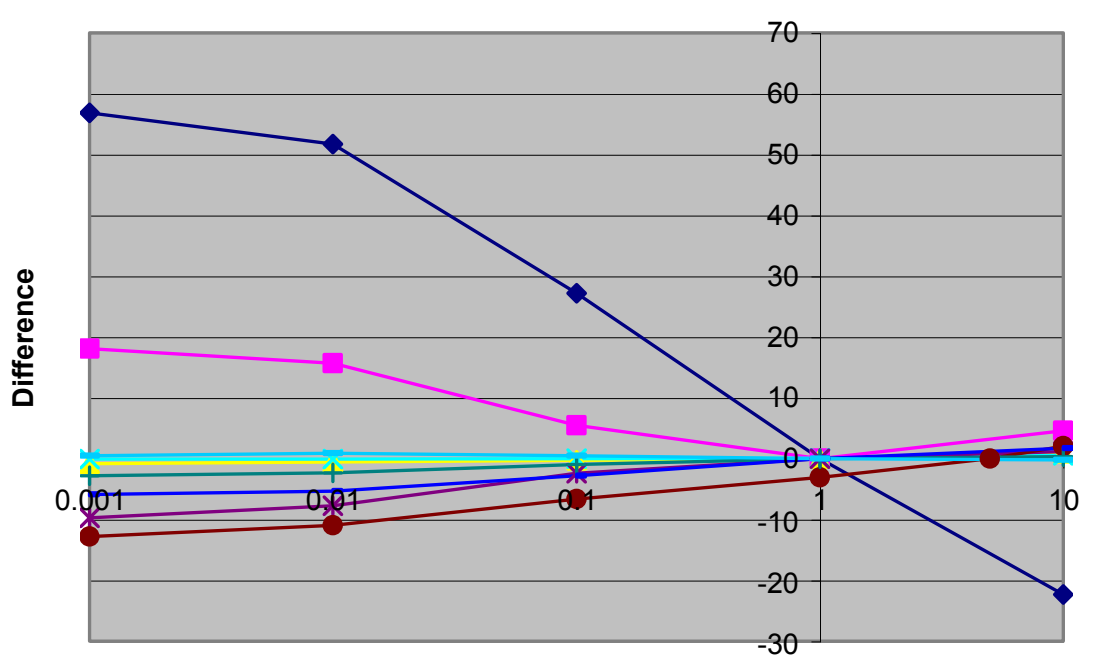

- -06_claimcyn

- 07_colsnpnd

08_eastgree

$\times$ 09_eestuary

*-10_etcsz_wd

-11_handley_

$1-12$ handleys

-13_handley2

- 14 -mhmsz_wd

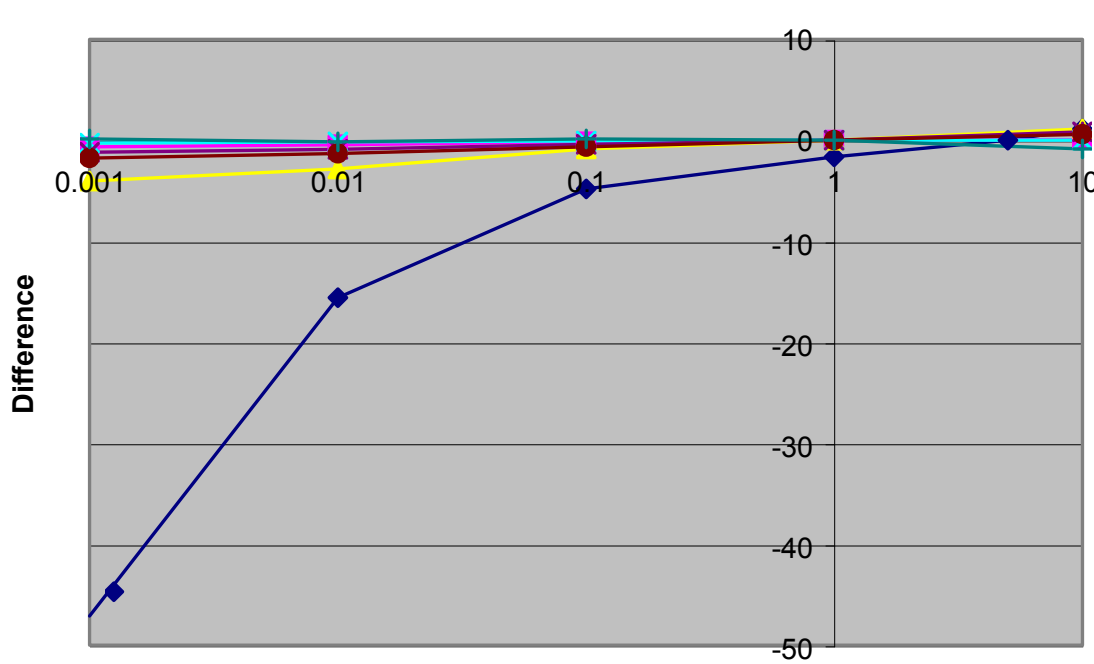

Value

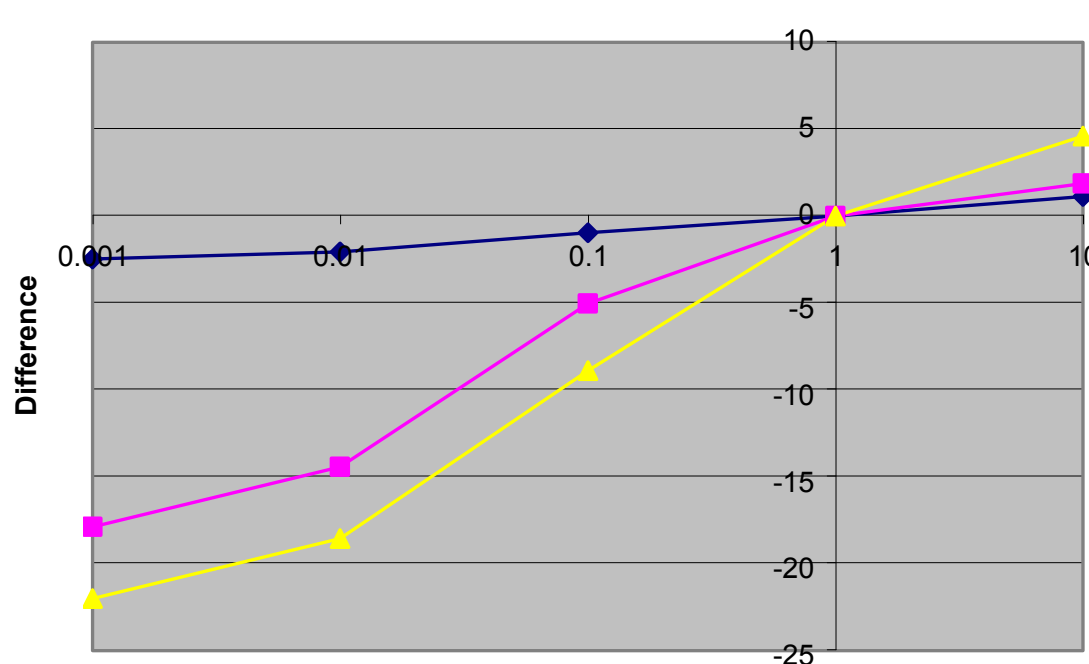

Value

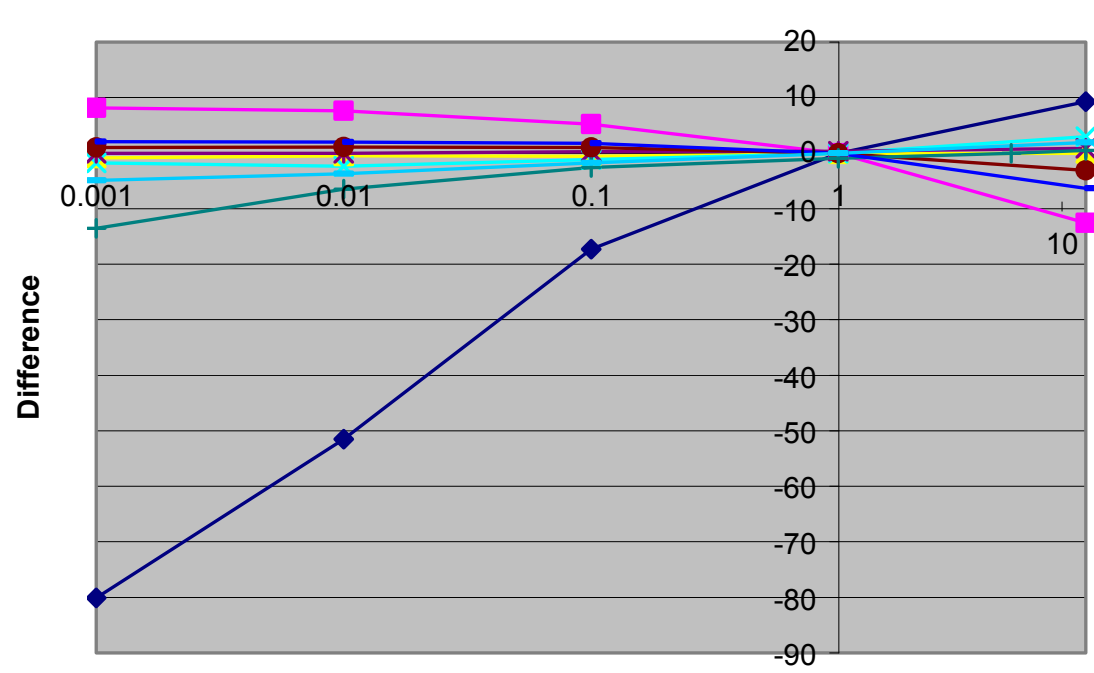

$\longrightarrow-29$ tmfltstm

- 30_tmext2ho 31_walmendr - 33_westgree * 34_westuary - -35 windywas - - 36_wscsz_wd — 37_paintbrs - 38 _silentca

Value

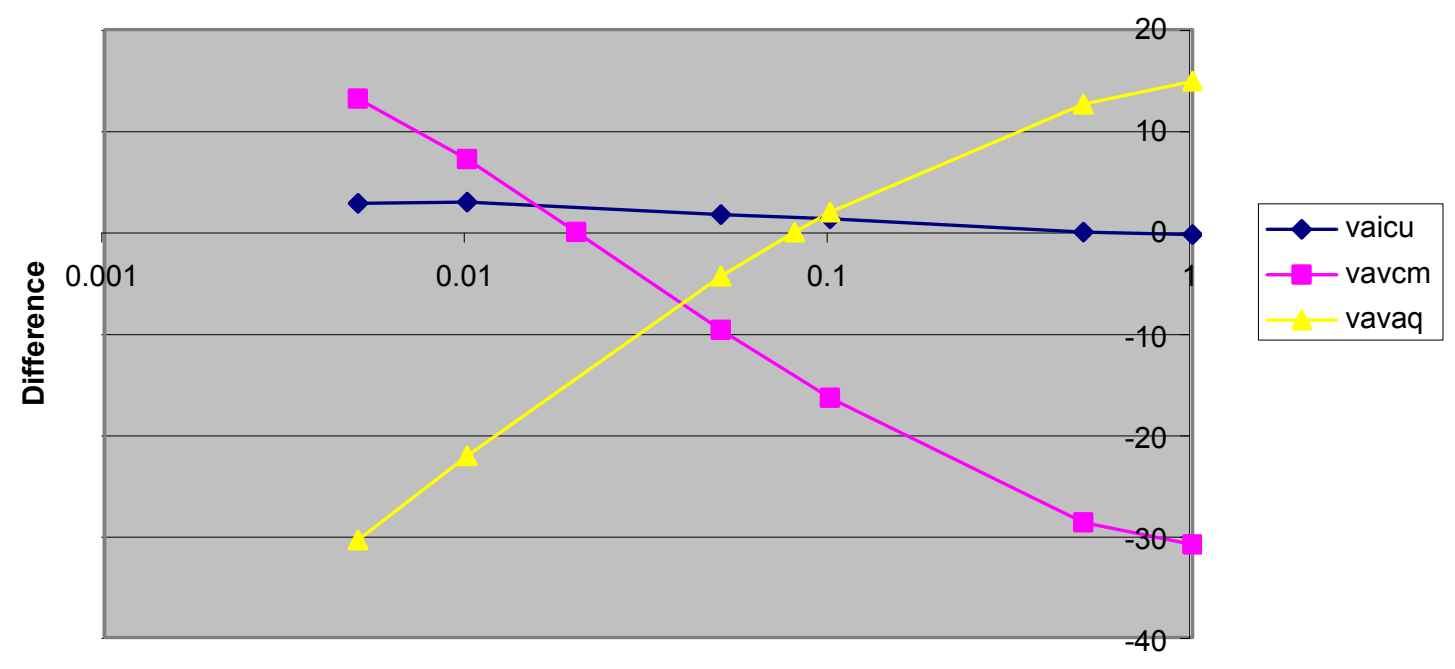



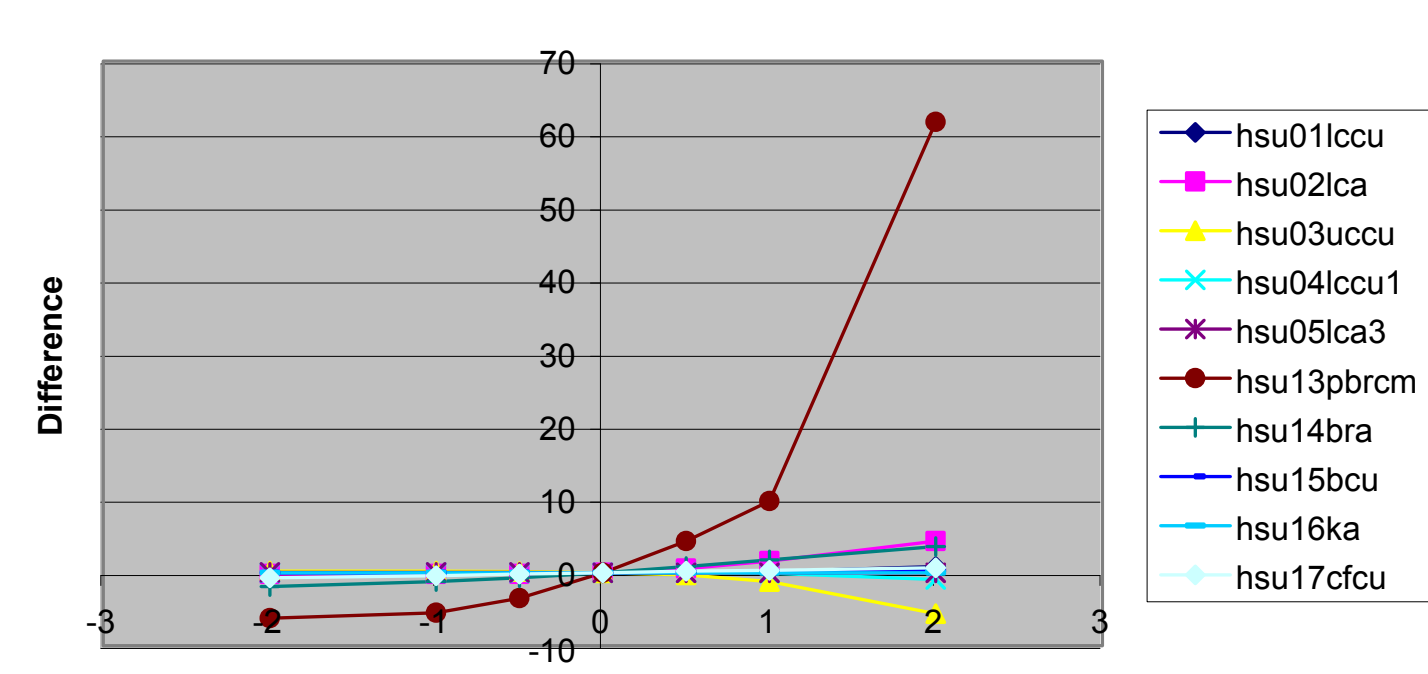

Base Value +// Standard Deviation
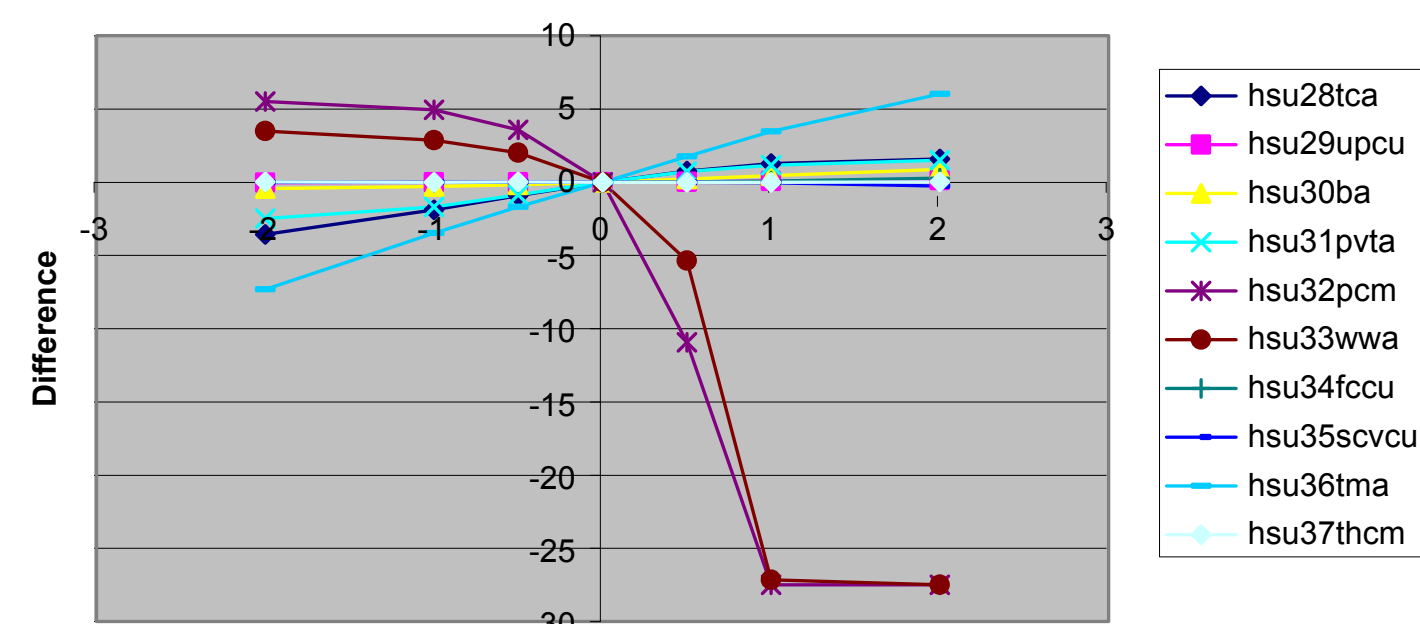

Base Value +/. Standard Deviation
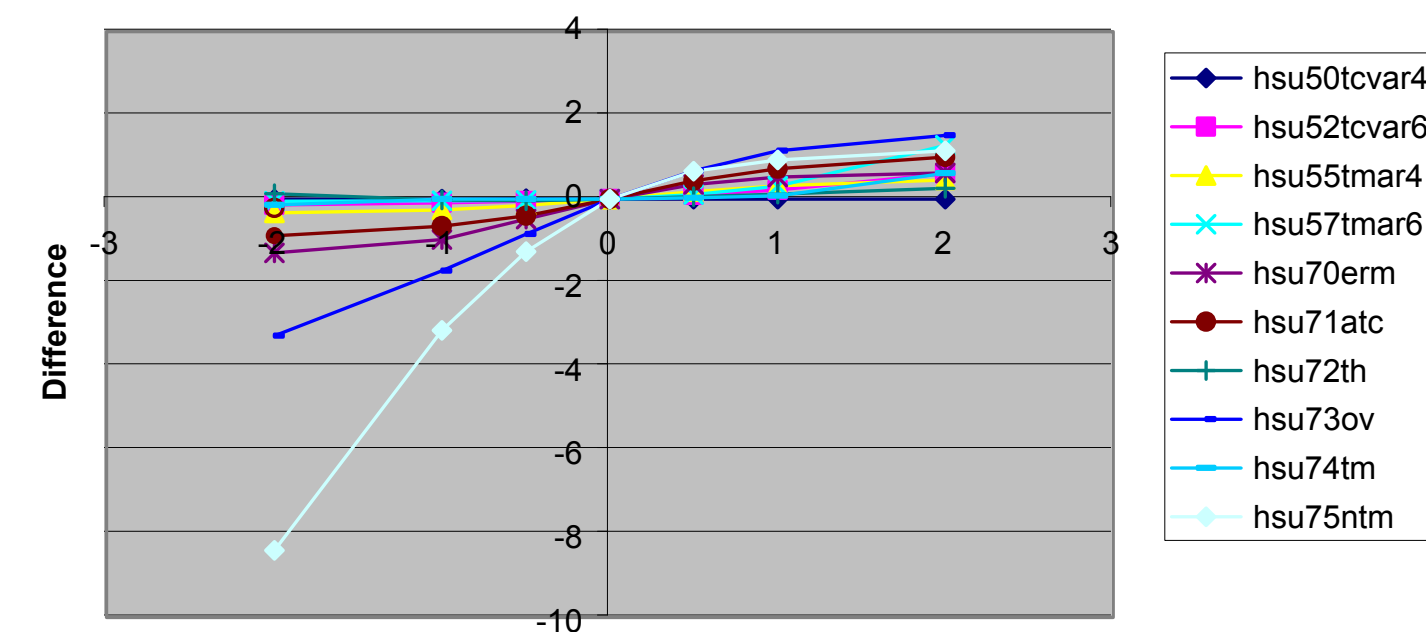

Base Value + // Standard Deviation

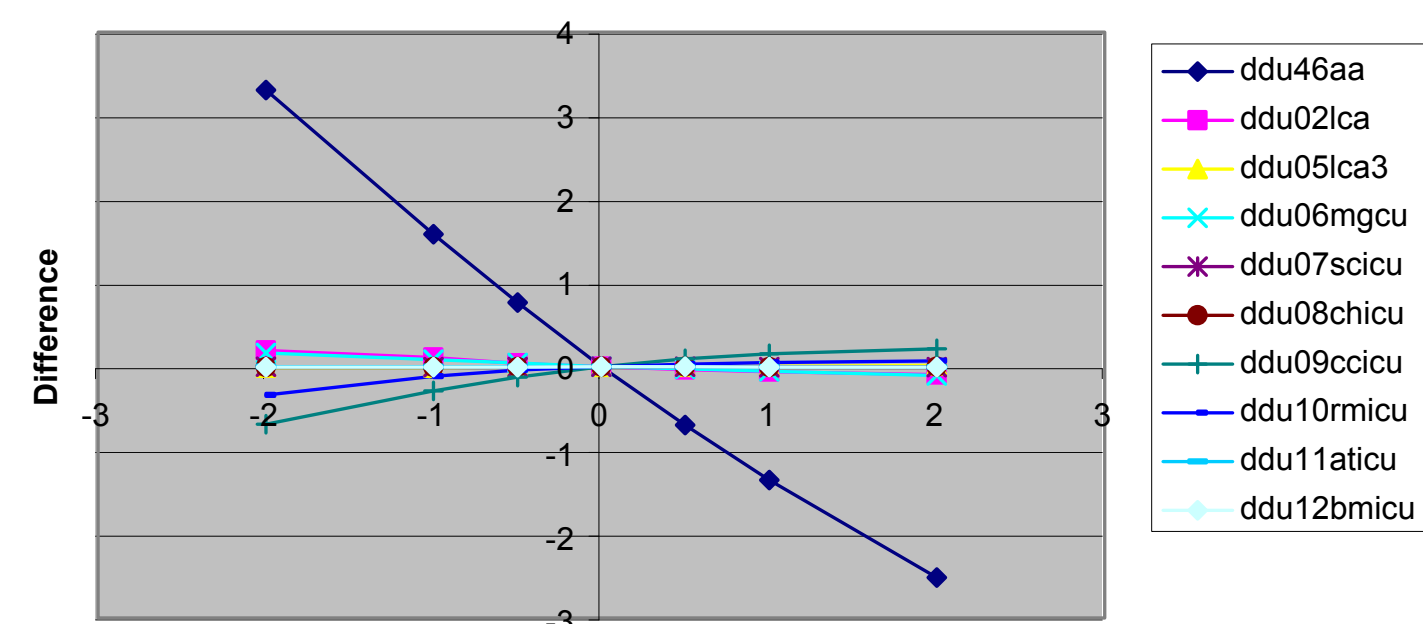

Base Value + //Standard Deviation

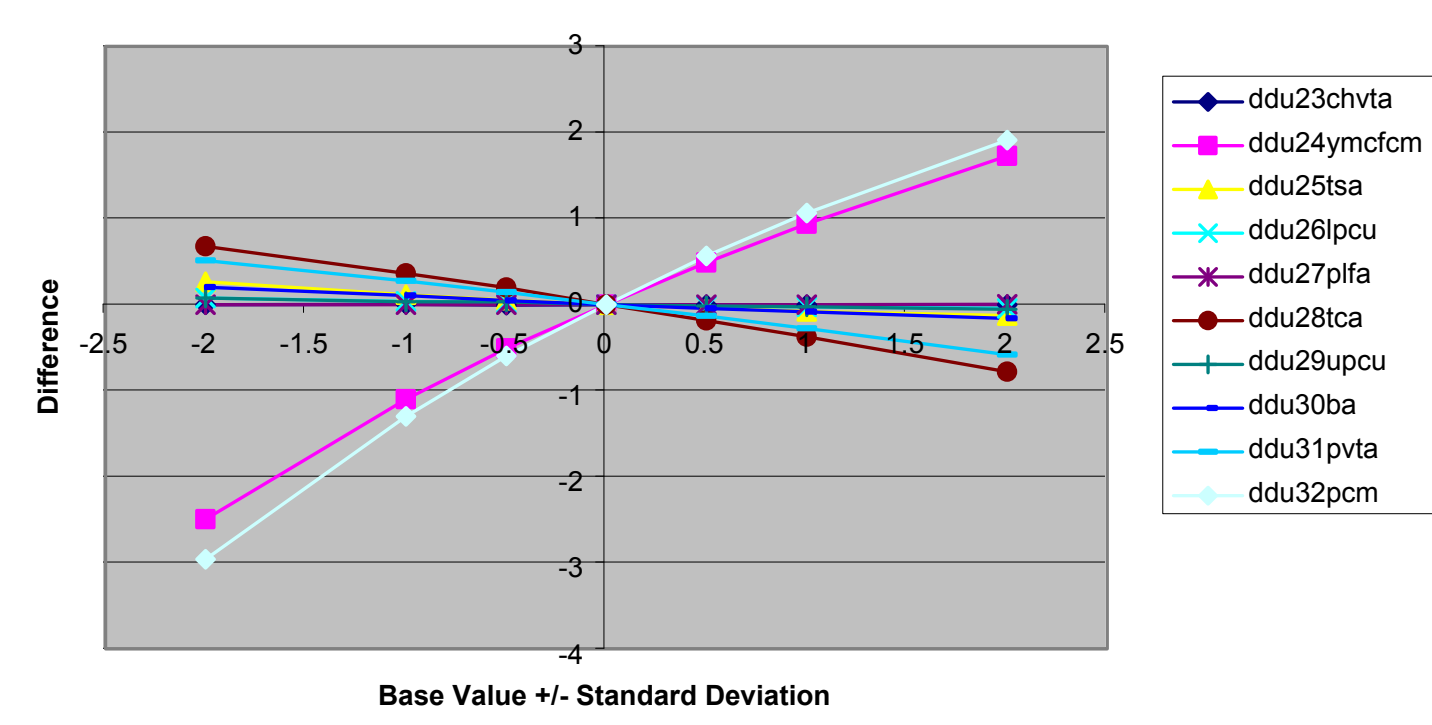

Base value ot/-standard Deviation

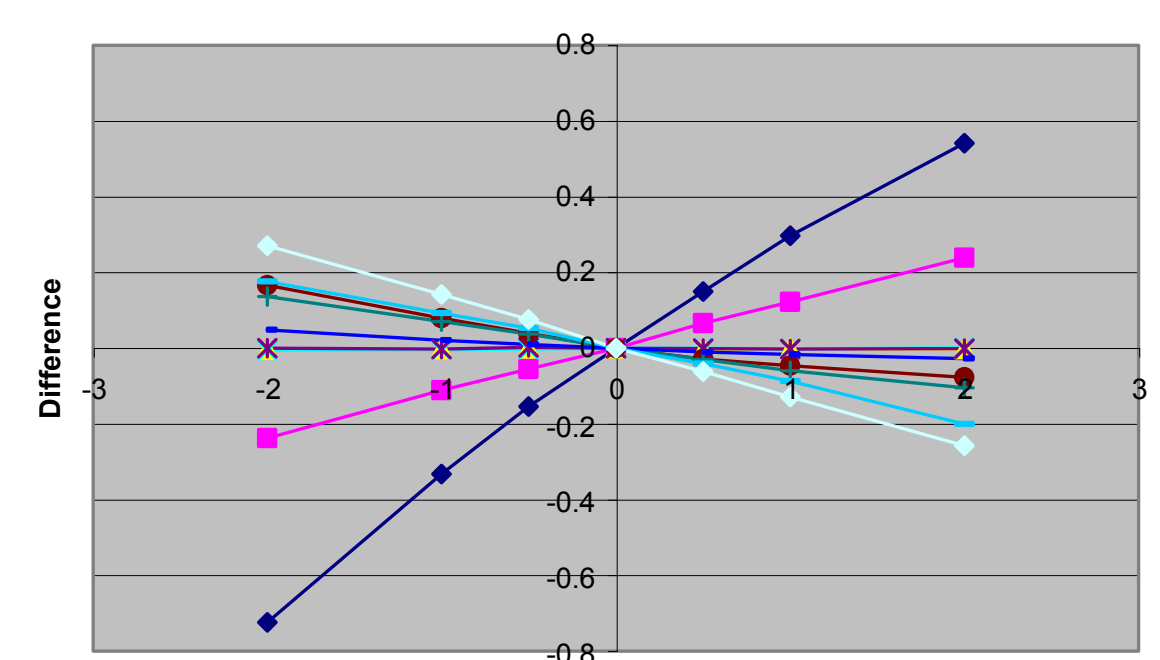

Base Value +t/standard Deviat

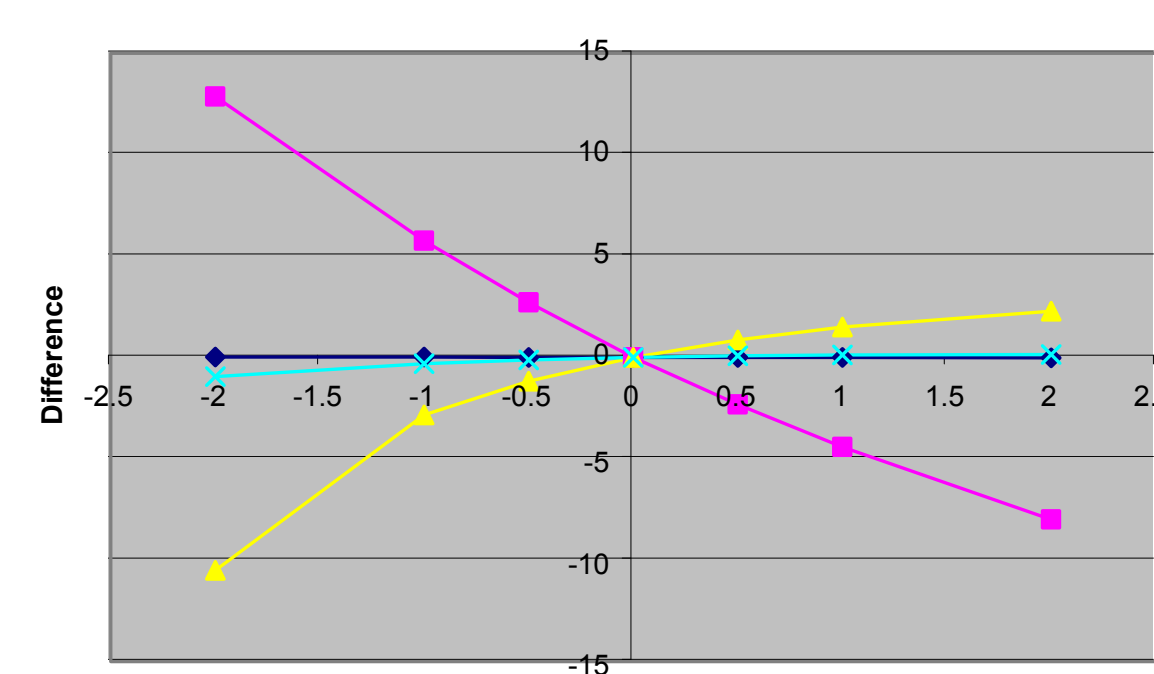

Base Value t/- Standard Deviation
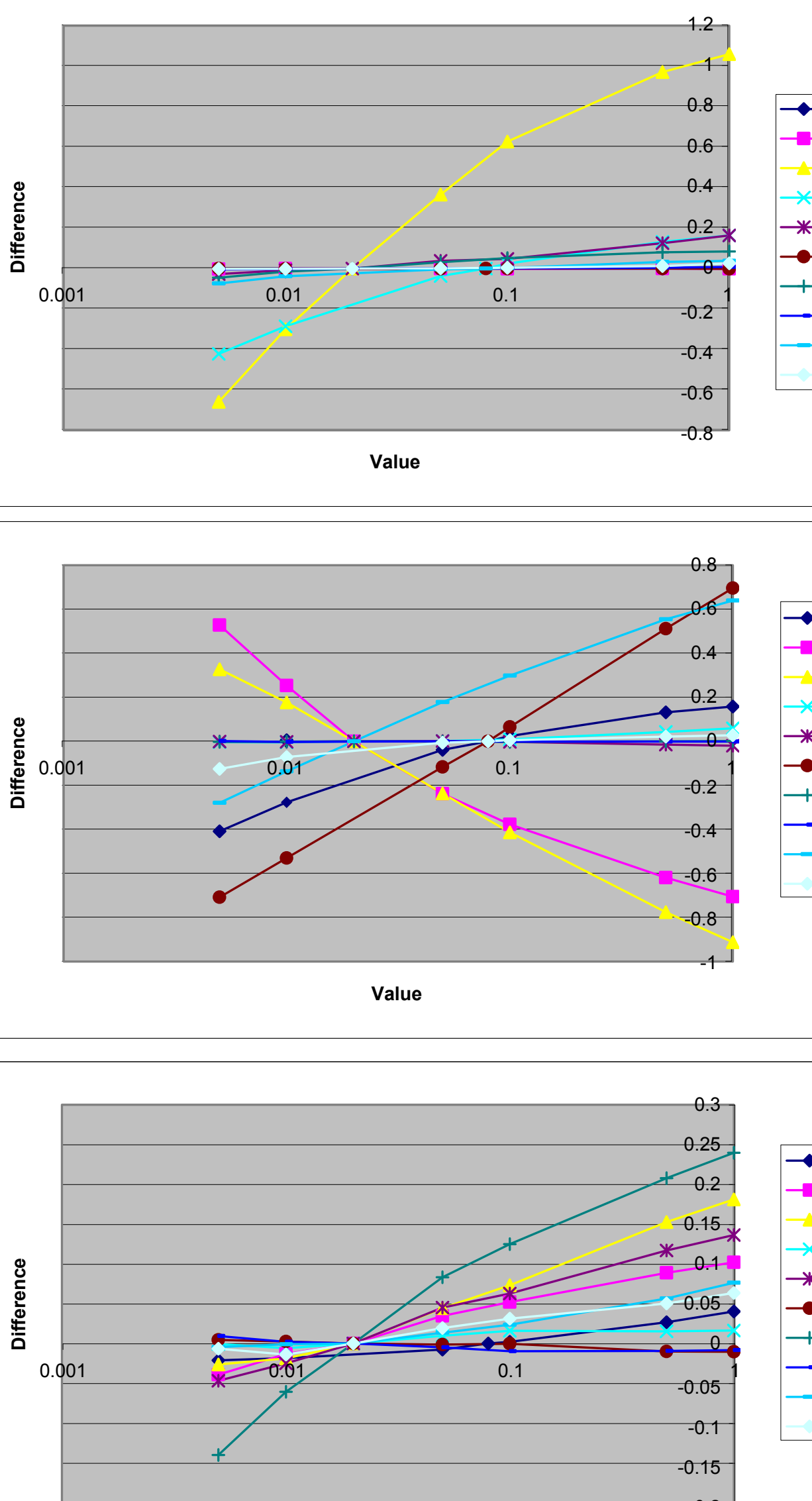

value

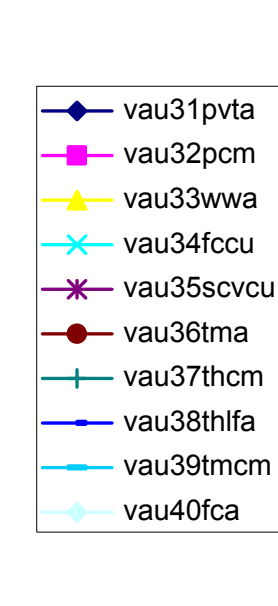

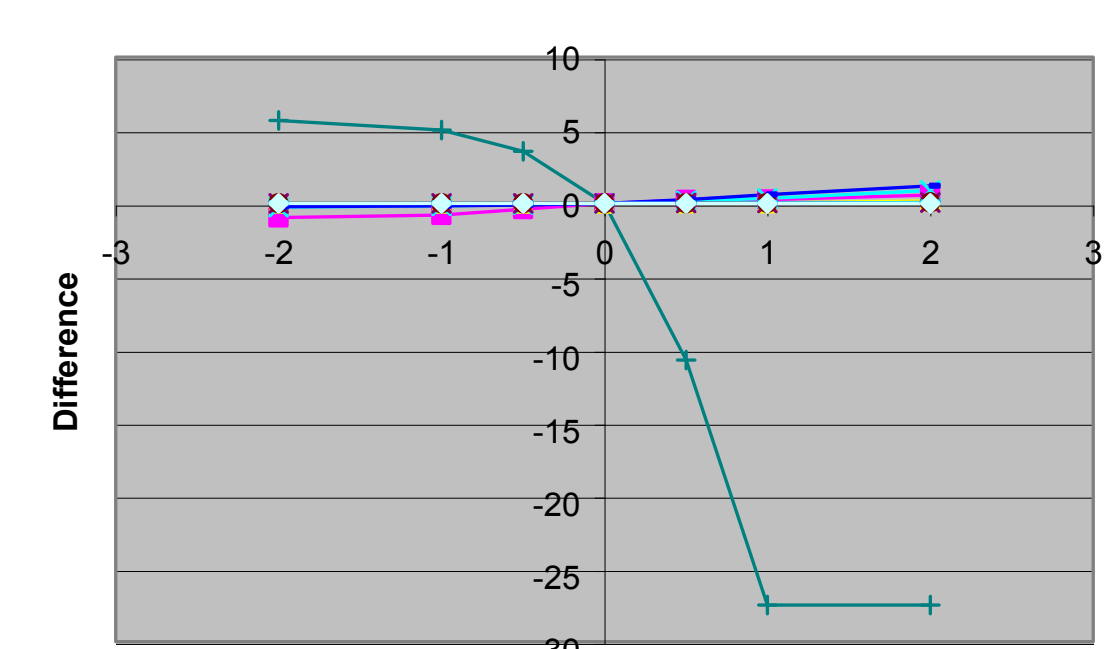

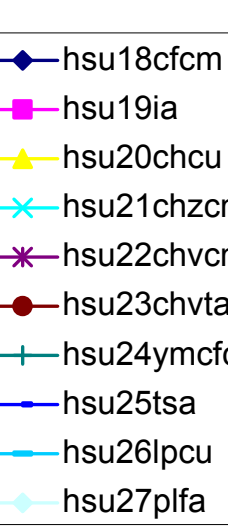

Base Value +/- Standard Deviation

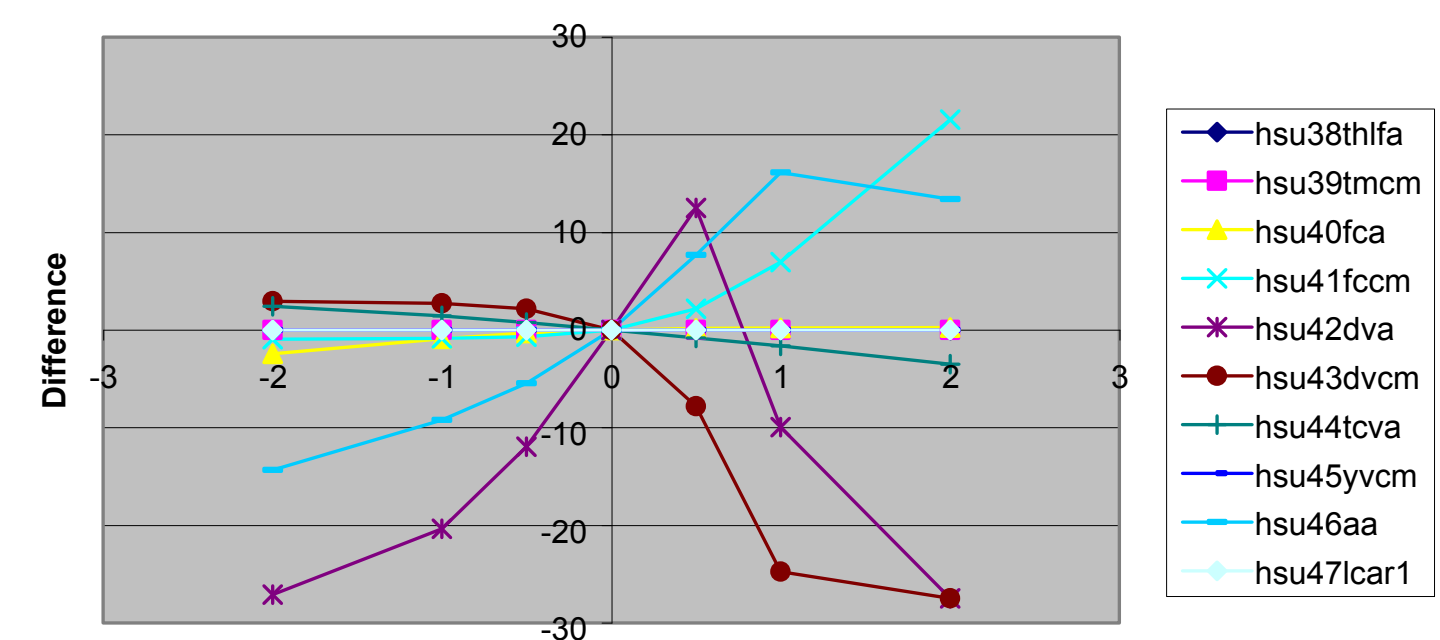

ase Value
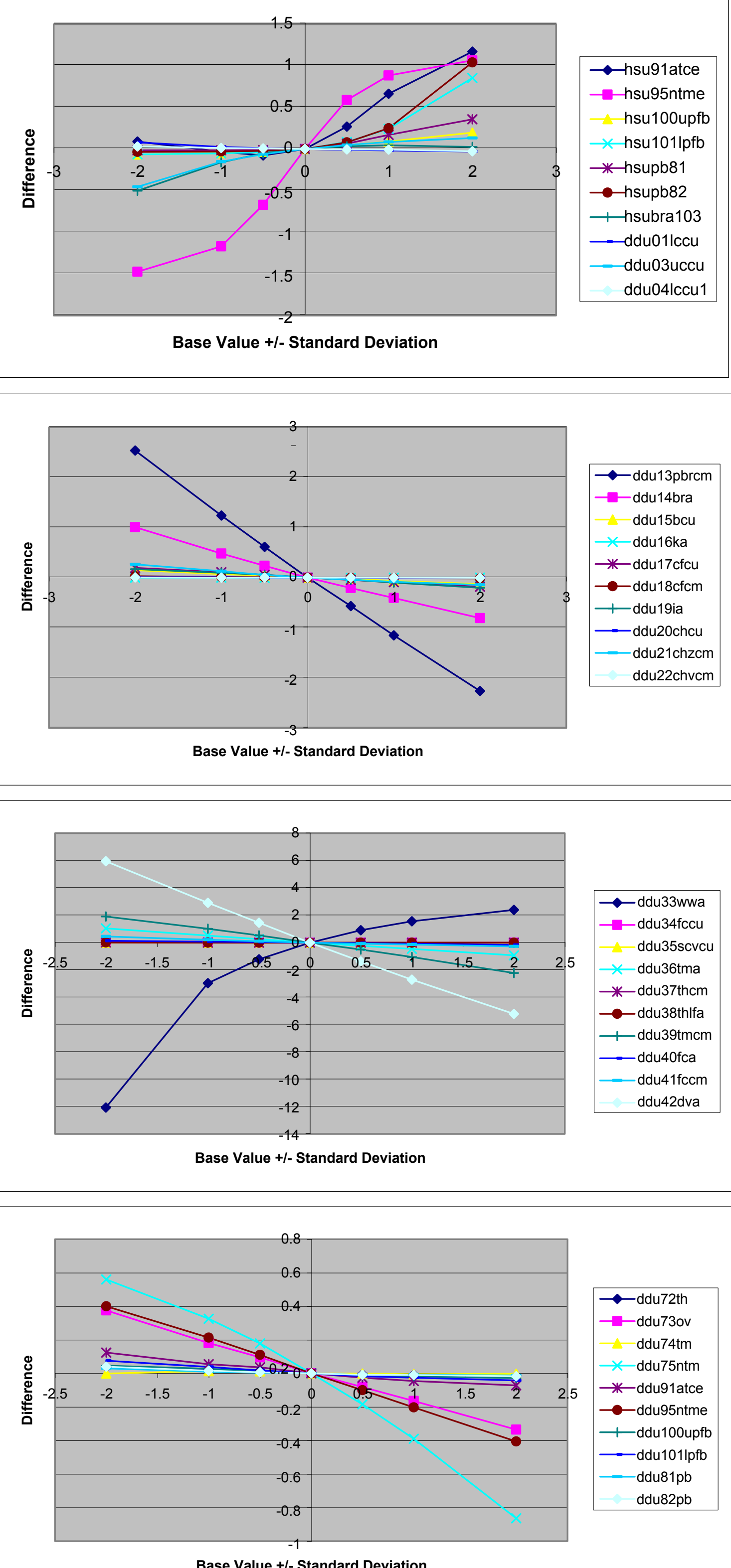

Base Value + +/- Standard Deviation
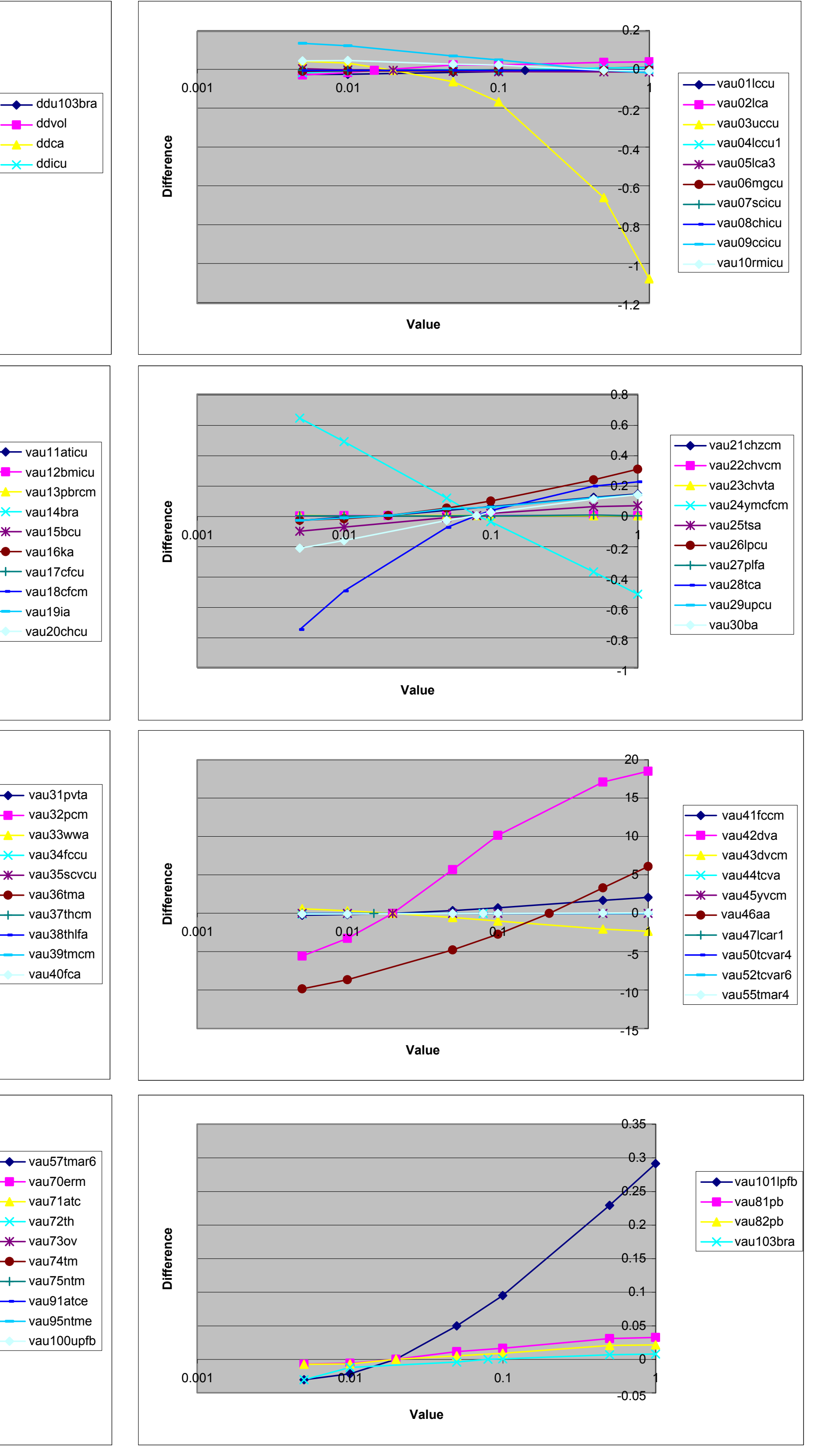


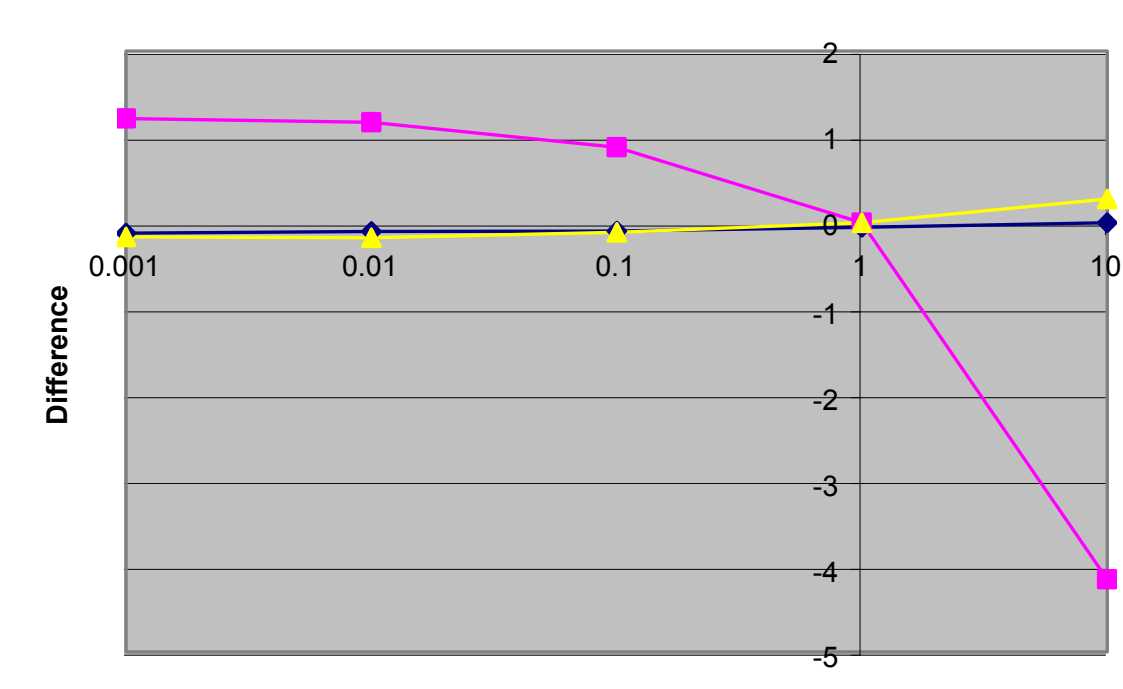

Value
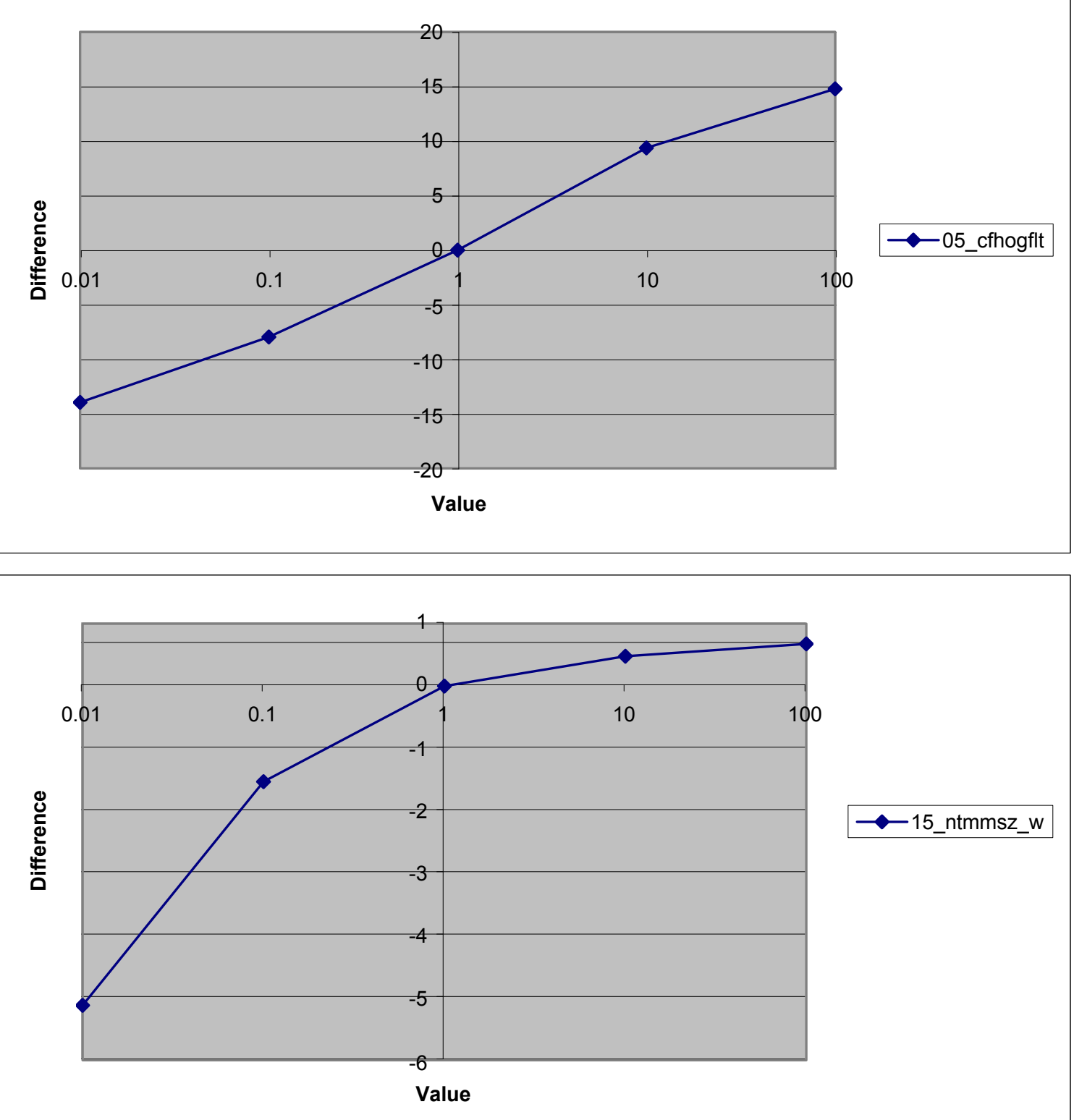

$\rightarrow \bullet$ 15_ntmmsz_w
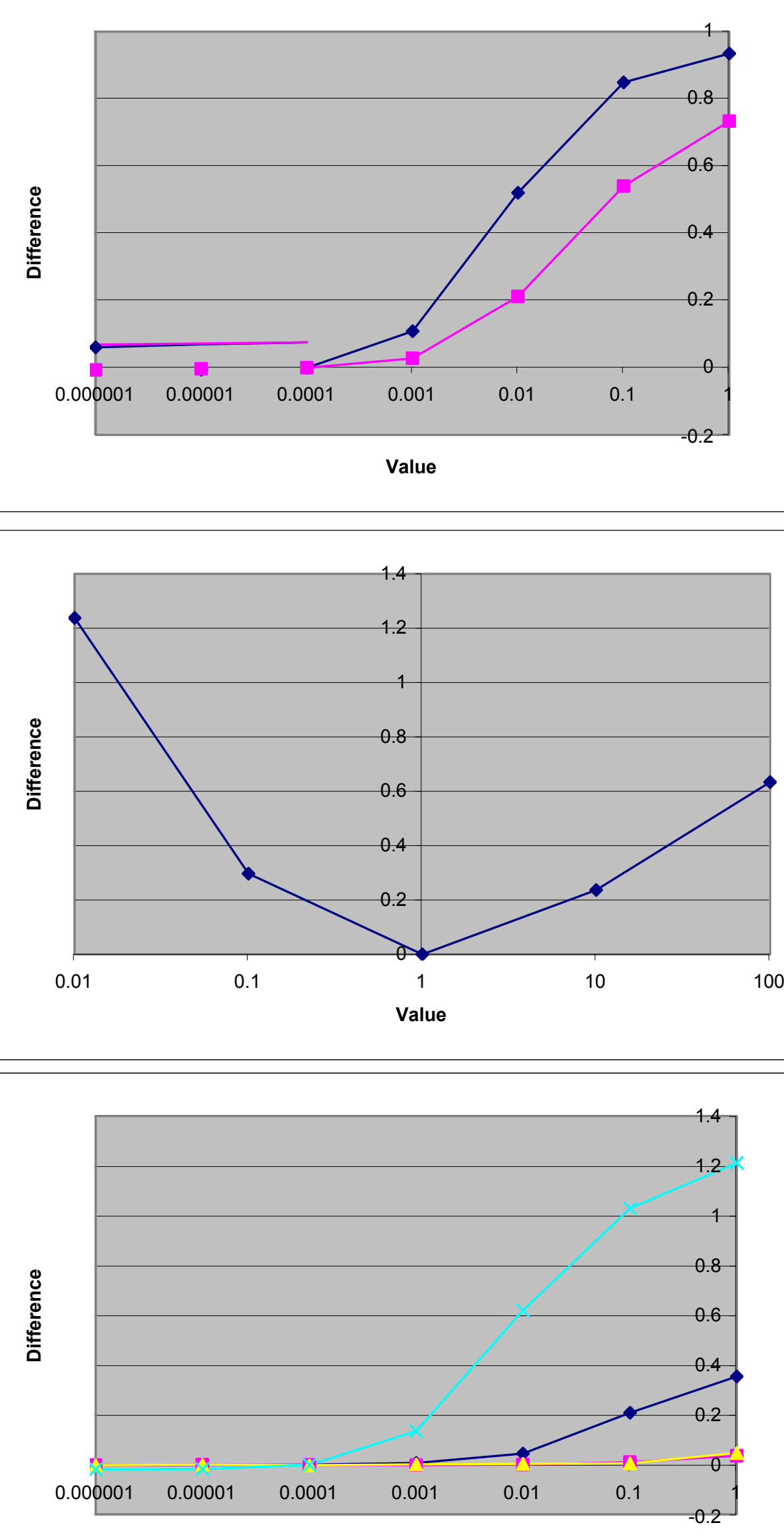

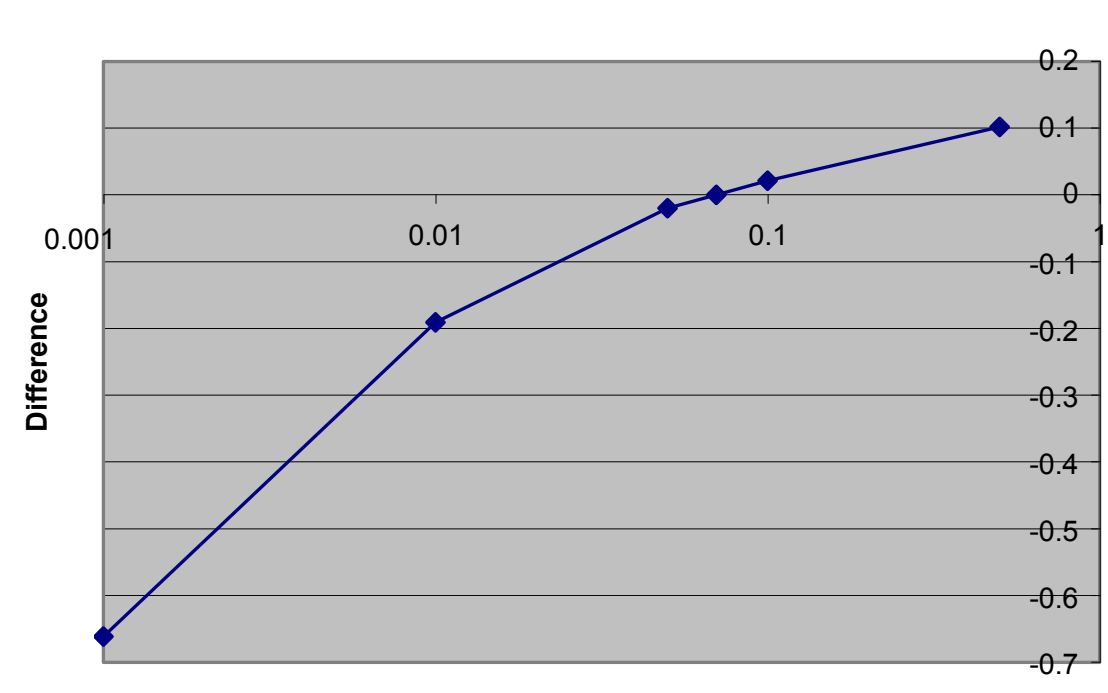

$\rightarrow \bullet-04$ boxcar_w

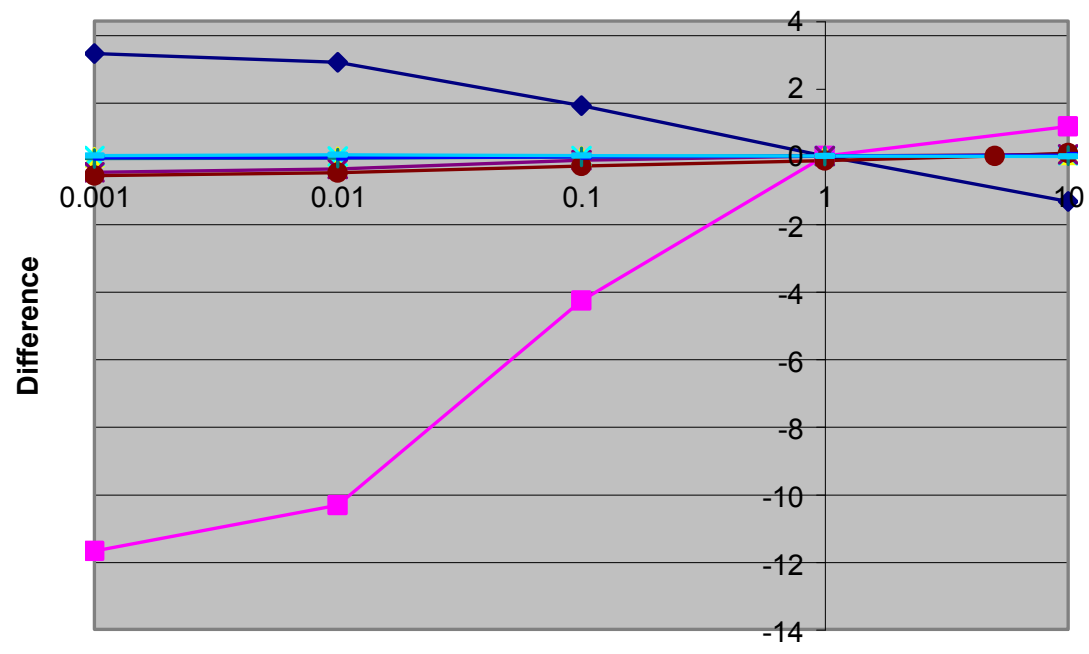

$\longrightarrow \bullet-06$ claimcyn

08_eastgree $\times$ 09_eestuary *-10_etcsz_wd $\longrightarrow$-11_handley_ - 12_handleys -13 handley2 - 14_mhmsz_wd

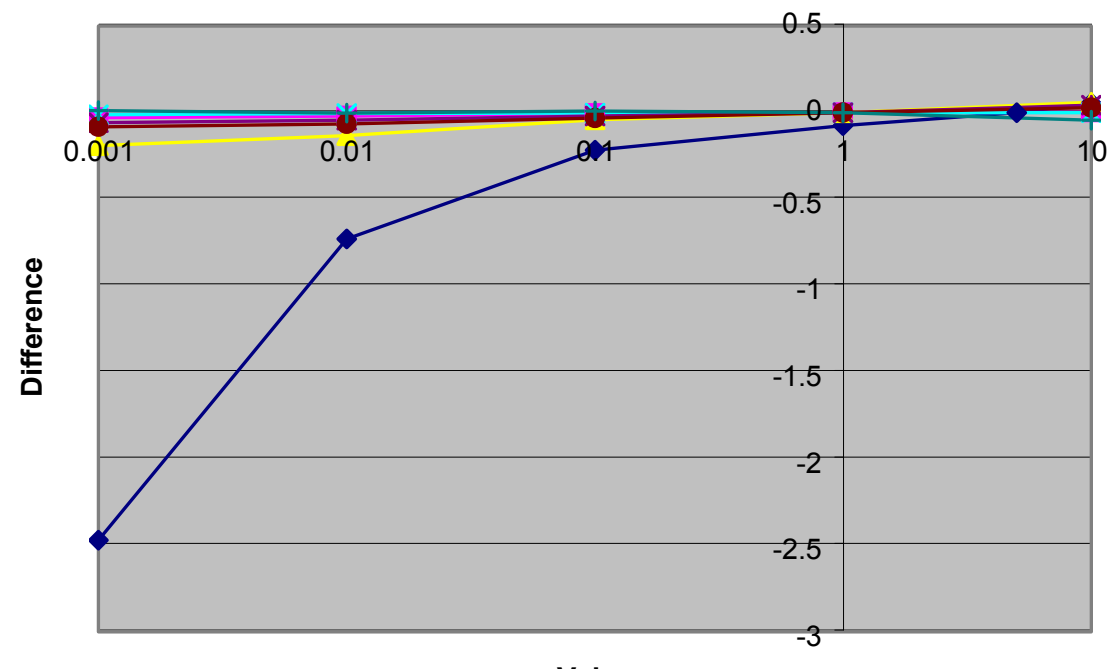

Valu

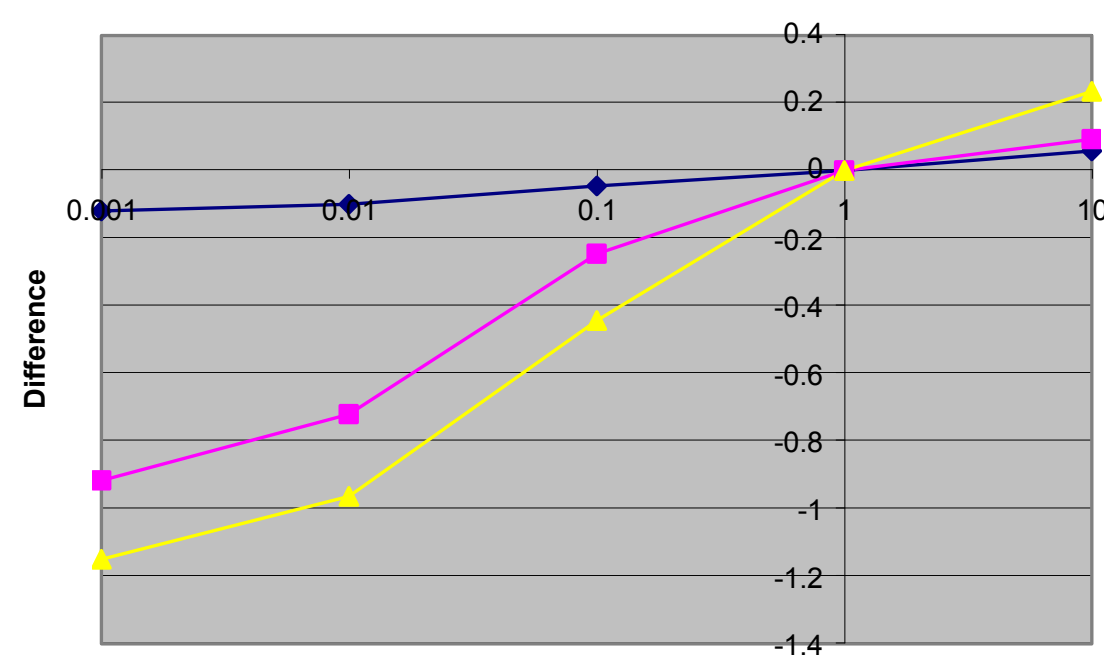

Value

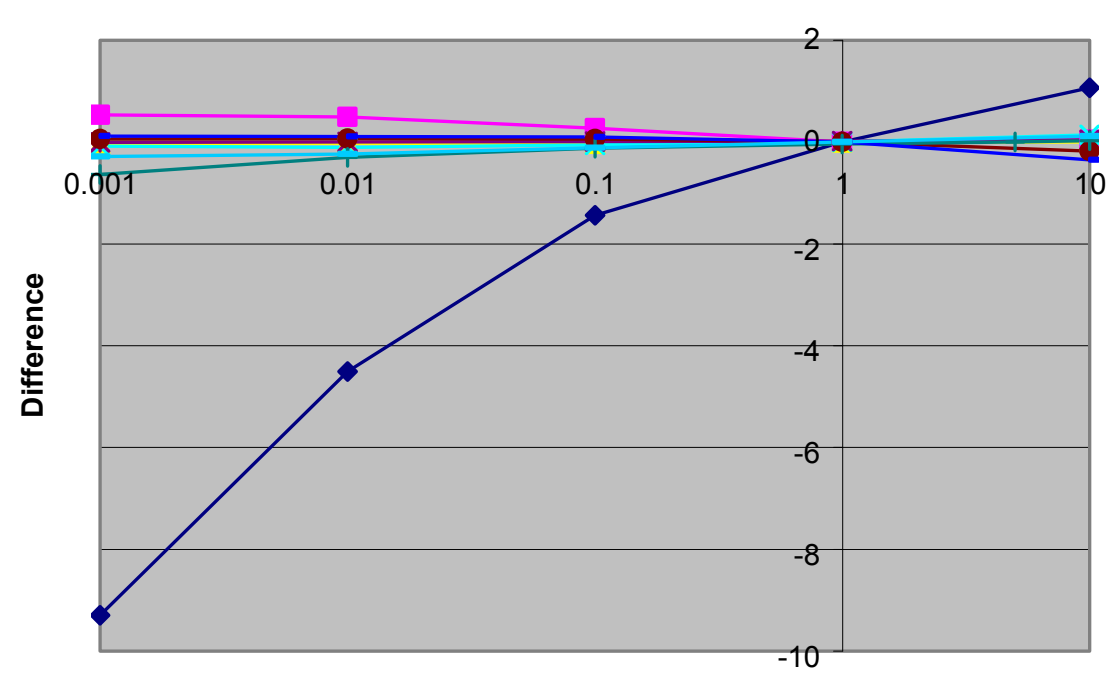

$\multimap-29 \_$tmfltstm - 30_tmext2ho 31_walmendr $x-33$ _westgree * 34_westuary - 35_windywas — - 36_wscsz_wd - 37_paintbrs - 38 - 3ilentca

Value

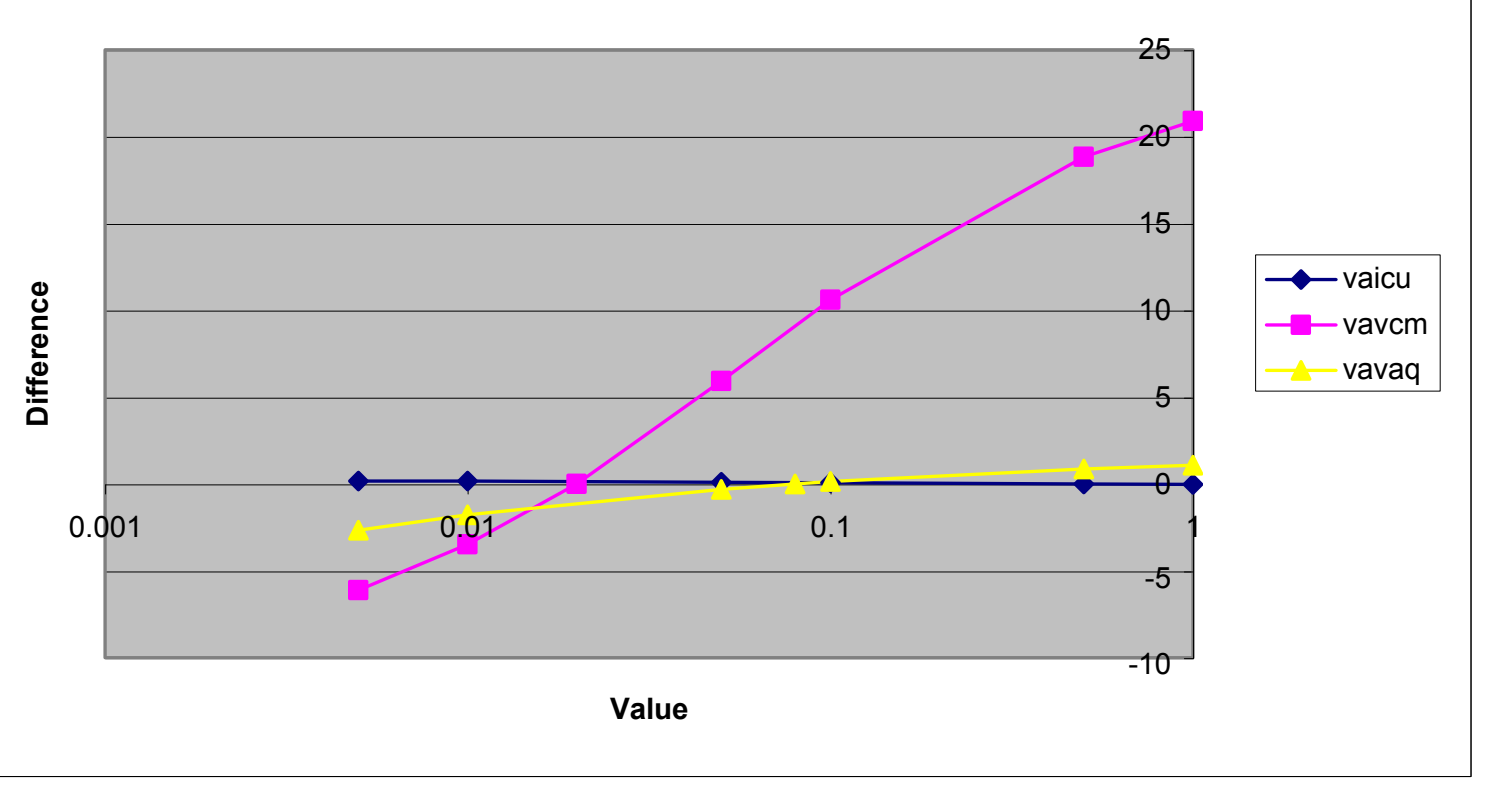



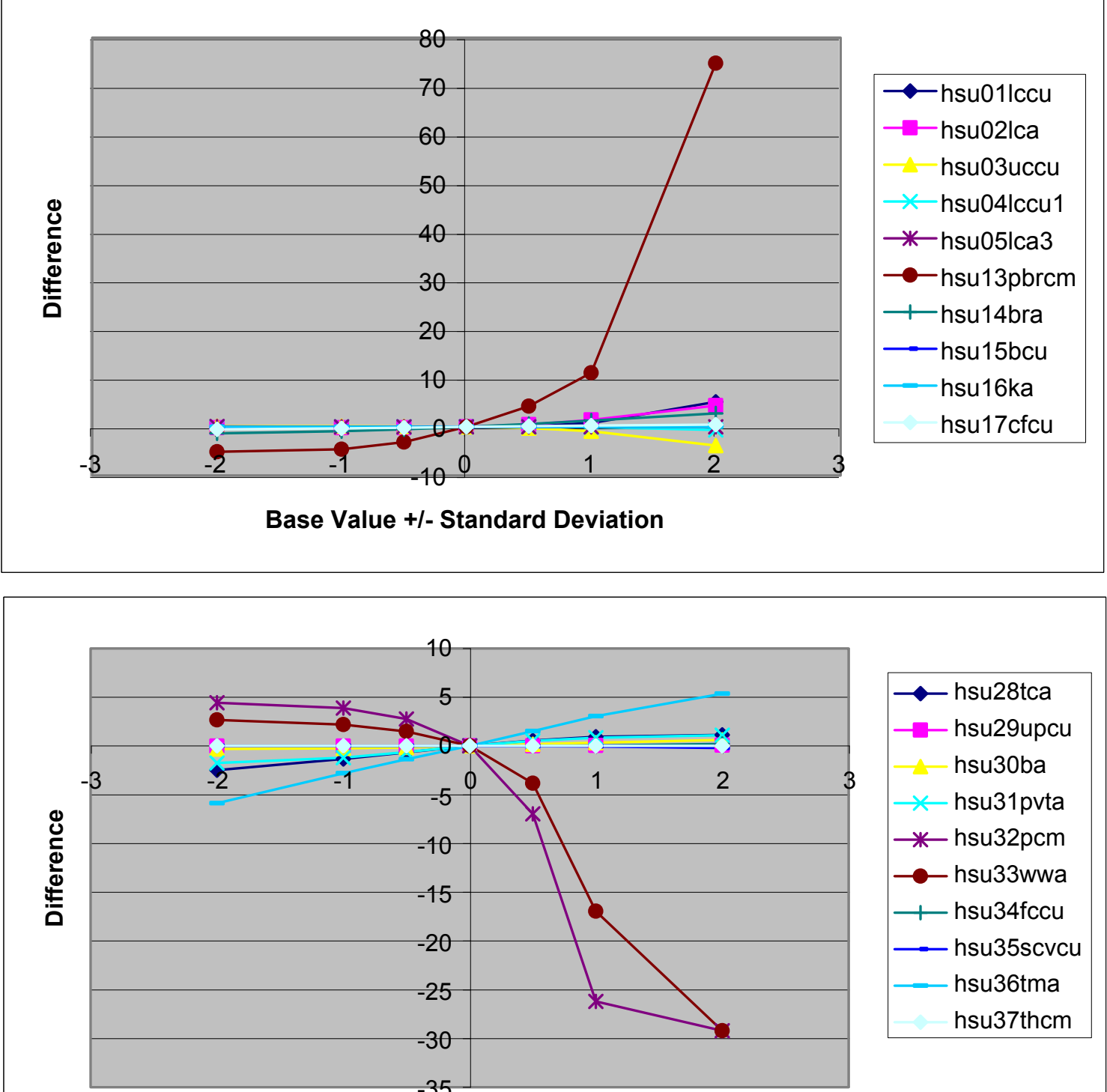

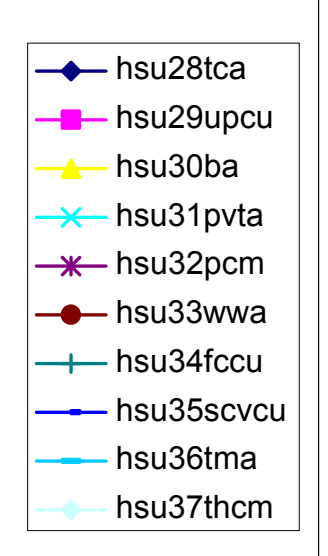
Base Value + +l Standard Deviation
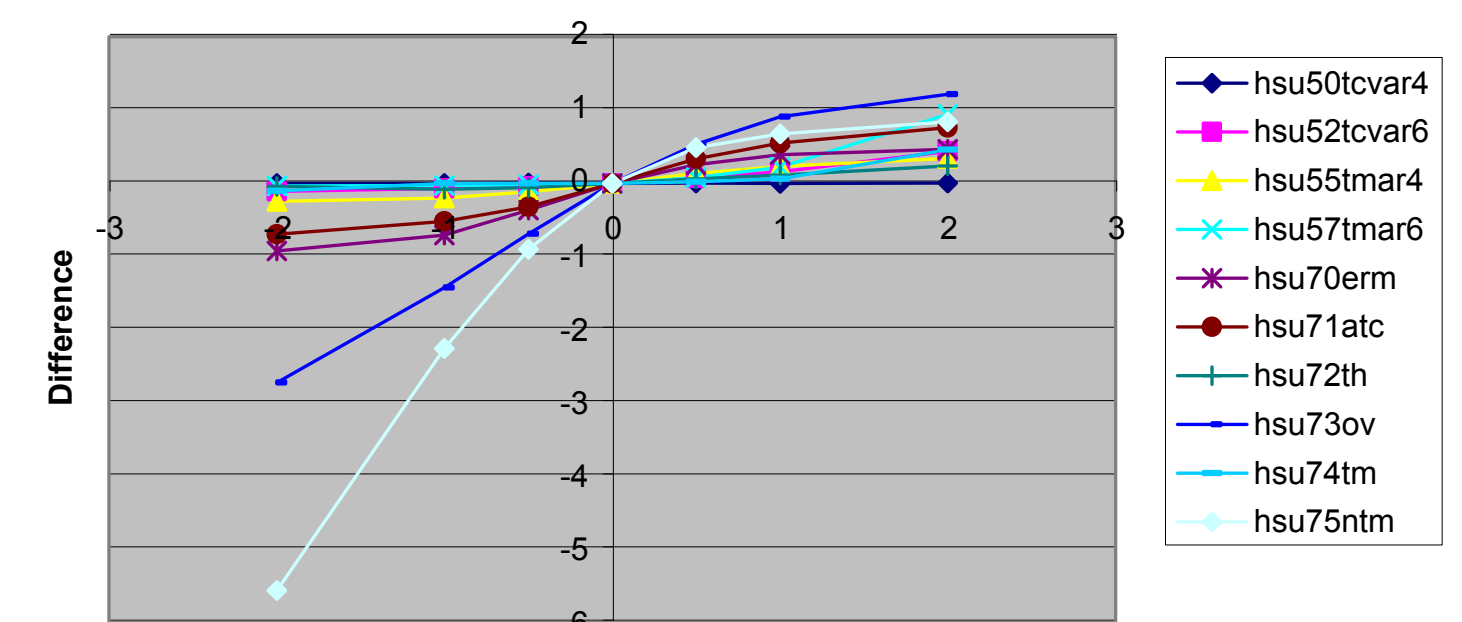

(6)

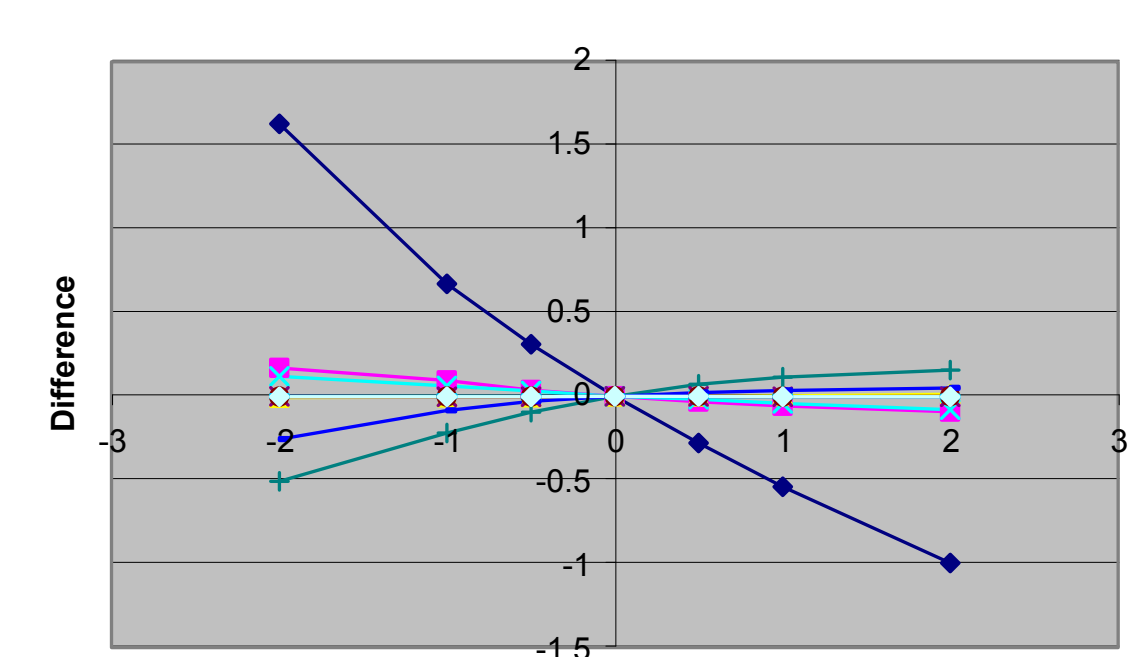

Base Value + +- Standard Deviatio
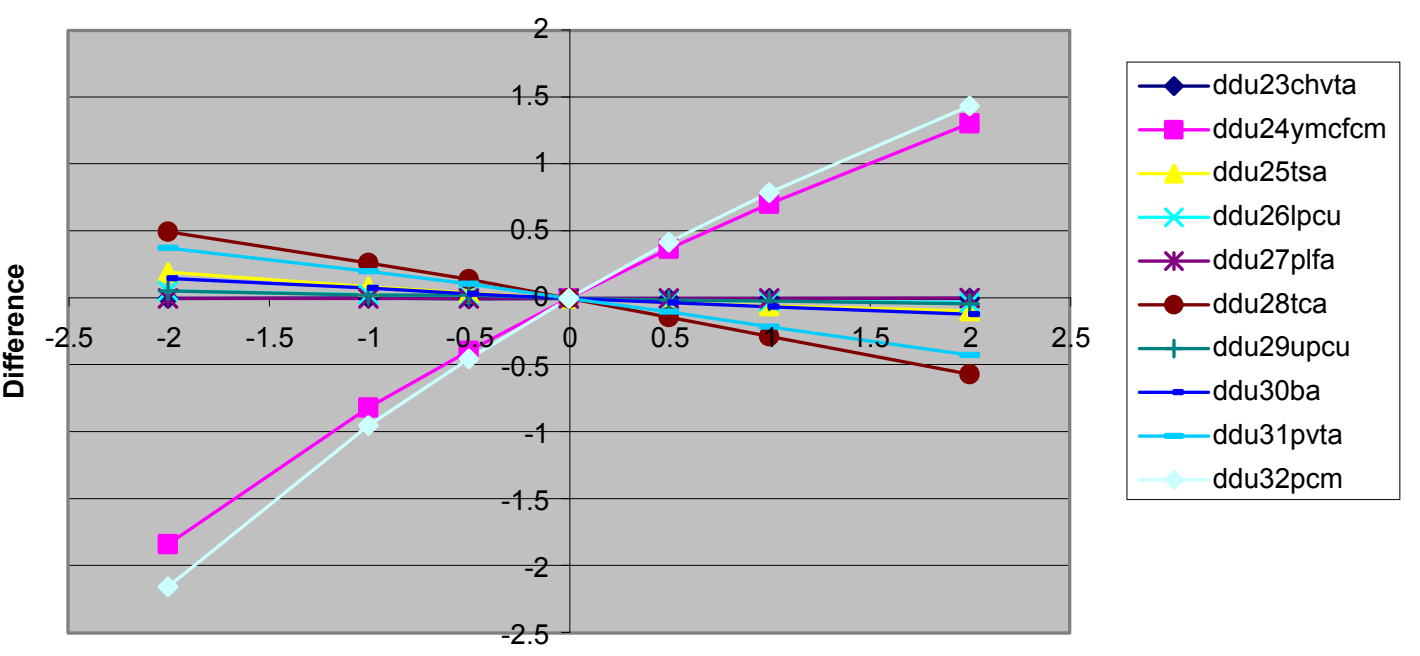

Base Value + - Standard Deviation

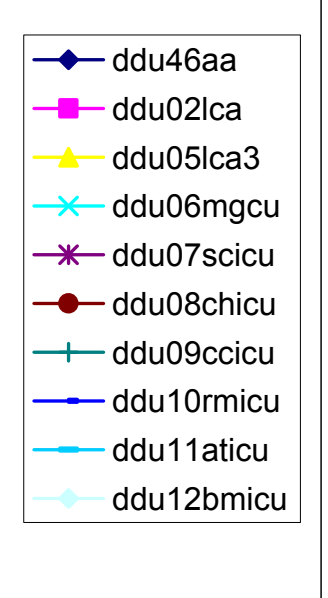

\begin{tabular}{l} 
ddu1 1aticu \\
ddu 2 brmicu \\
\hline
\end{tabular}

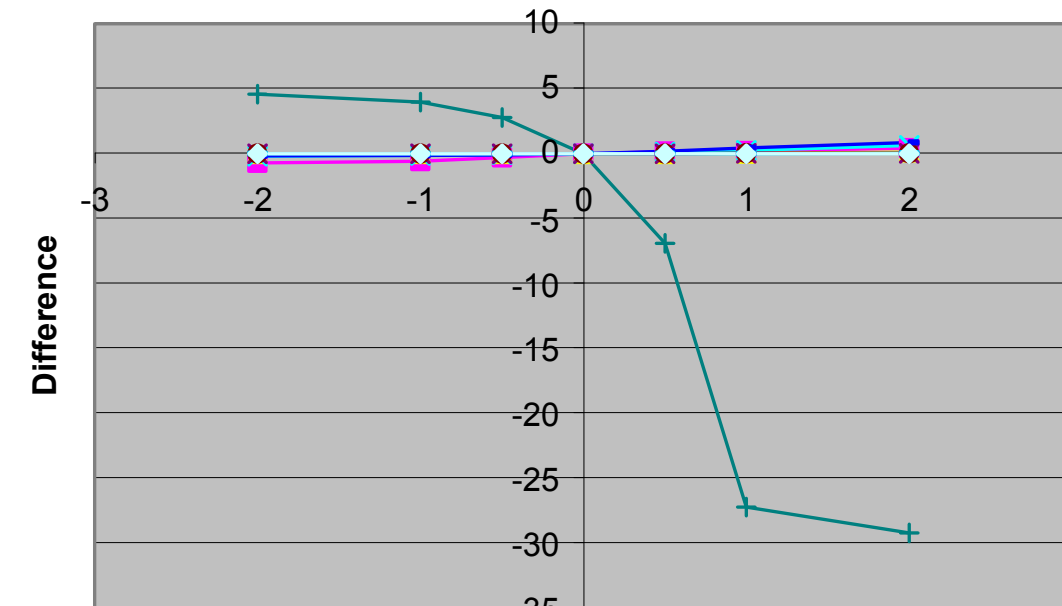

Base Value +l- Standard Deviation
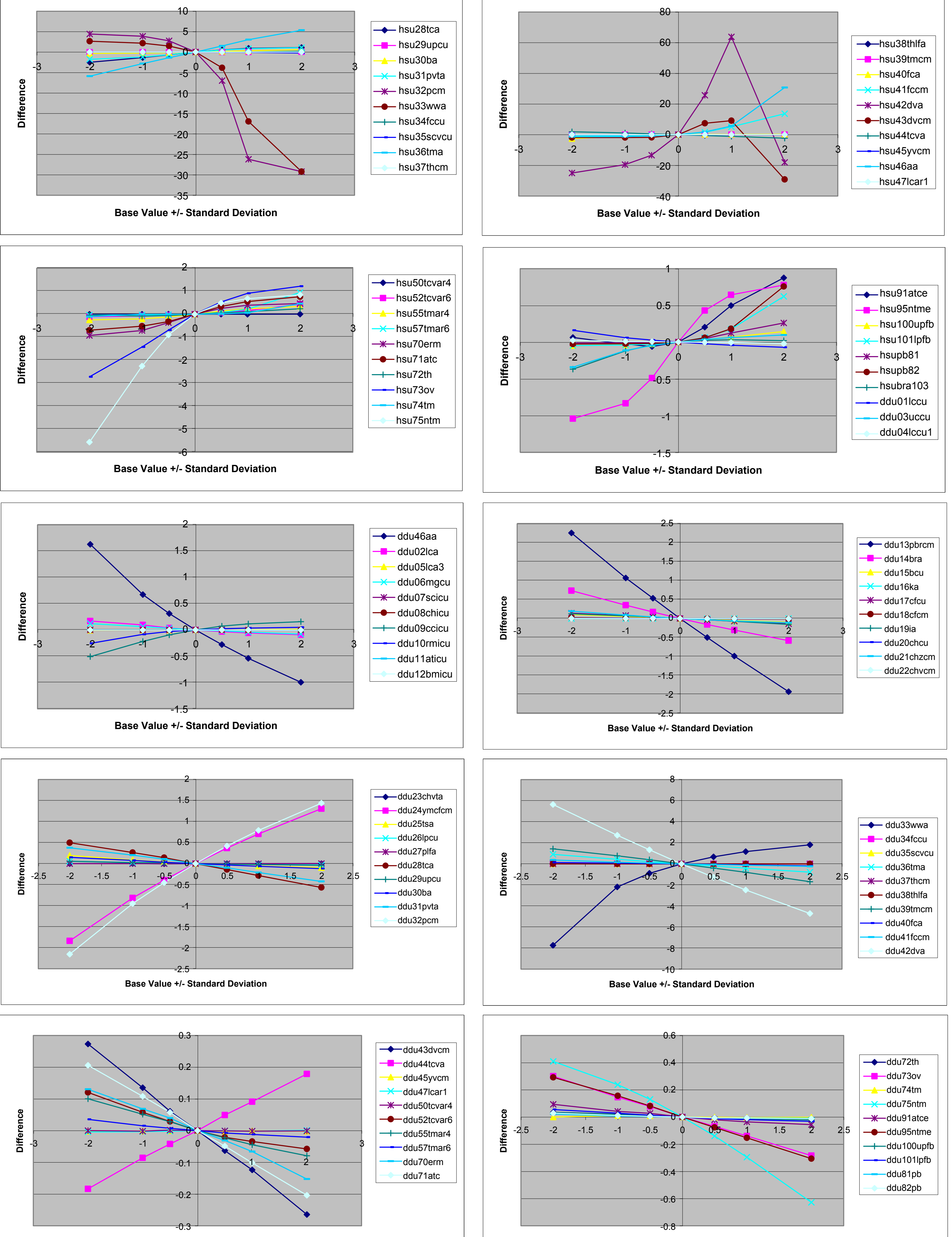

Base Value +t-Standard Deviation
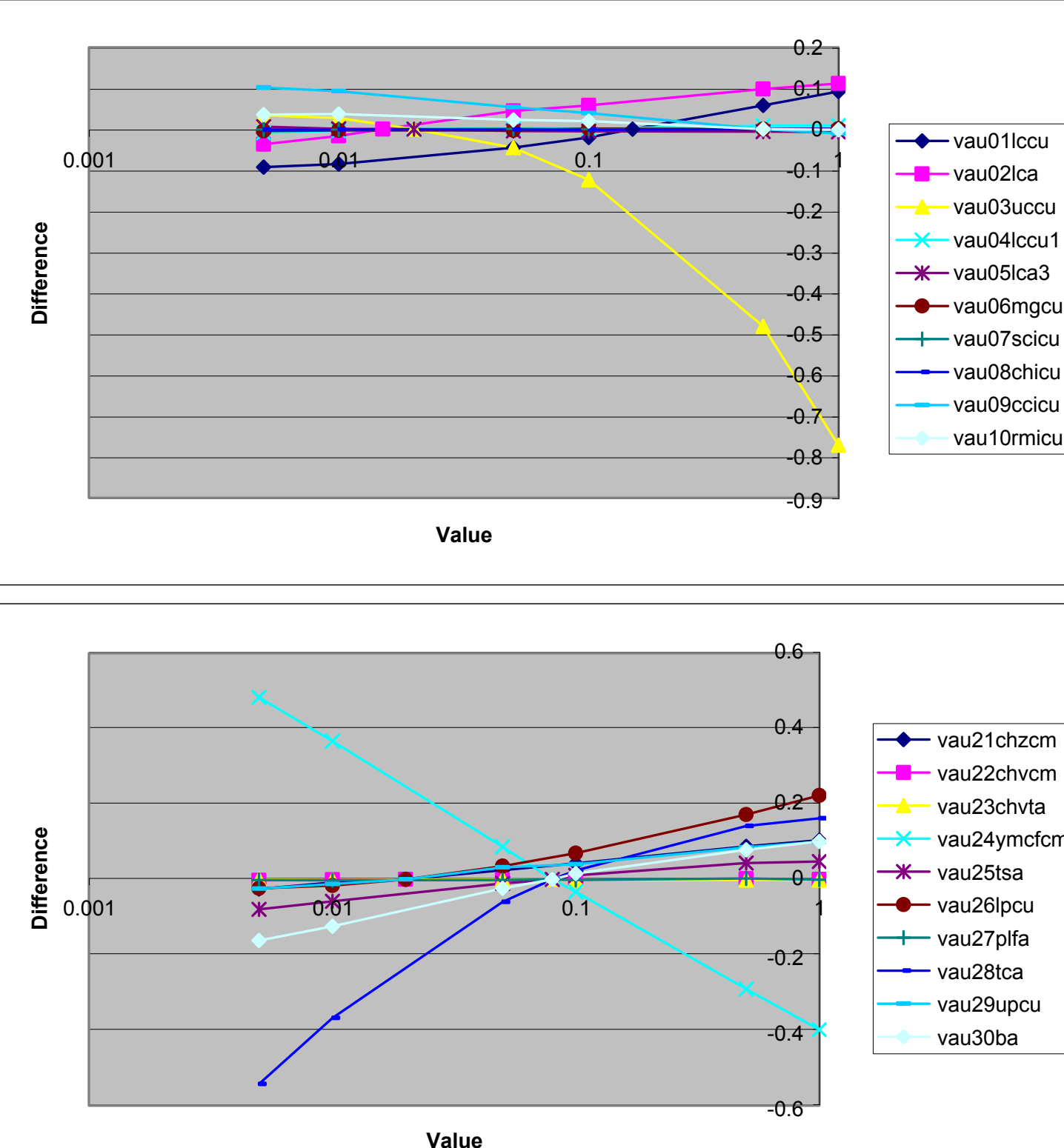

value

value

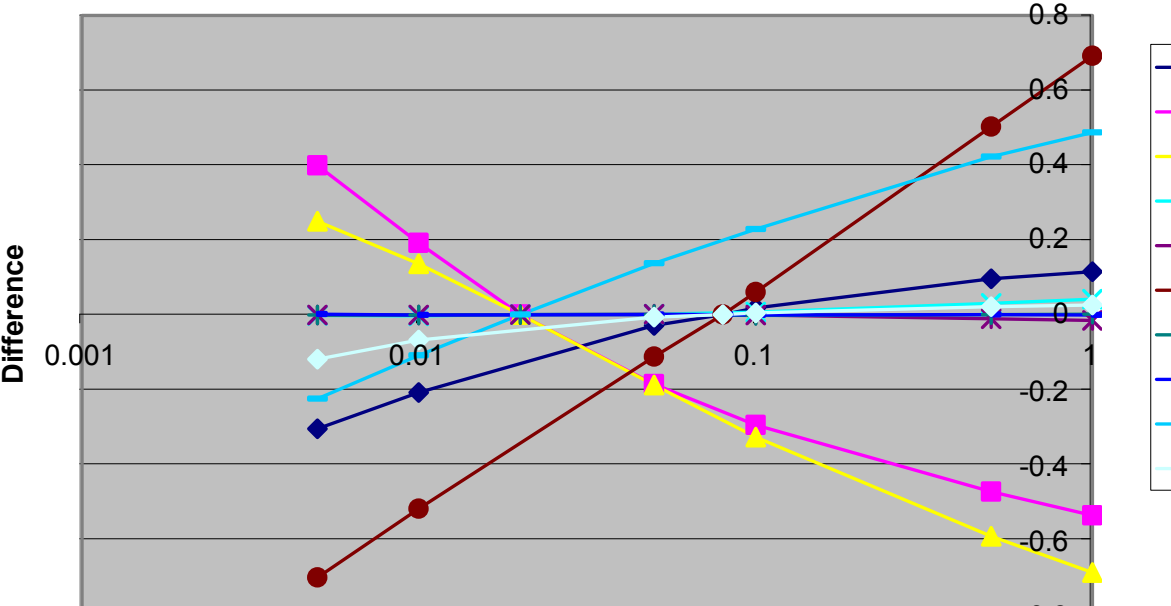

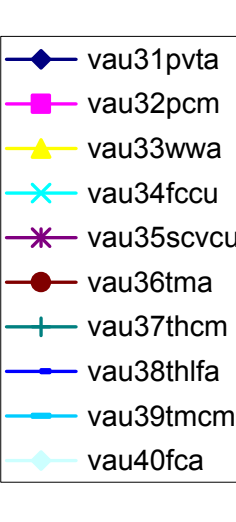

value

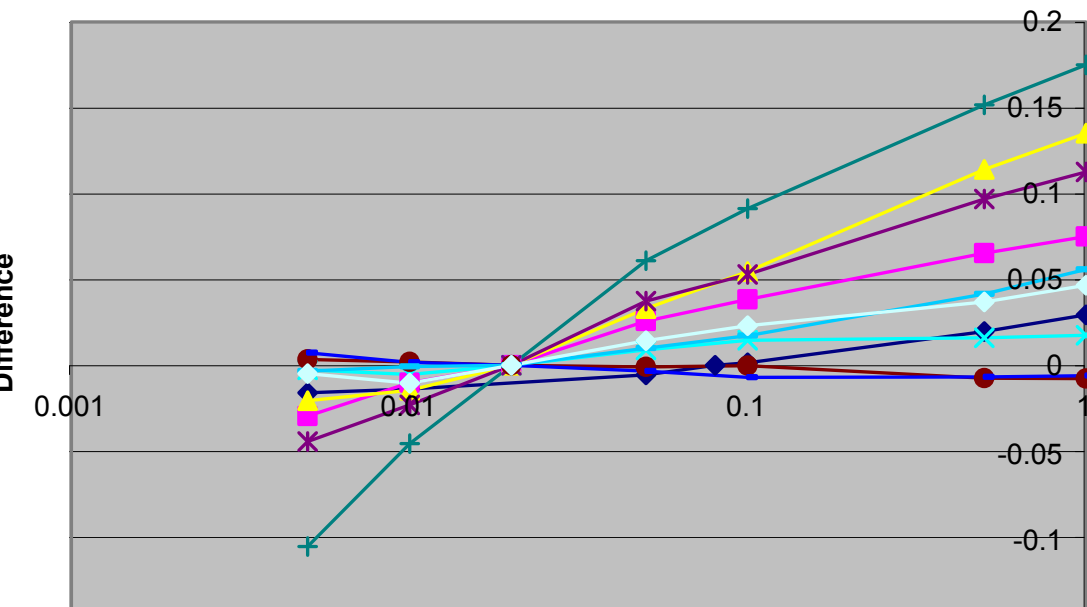

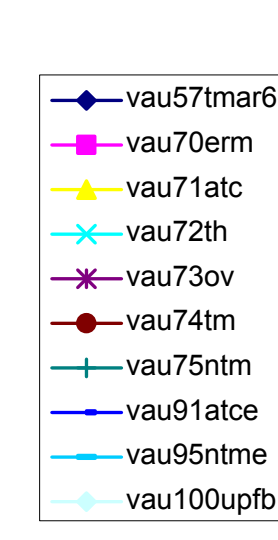
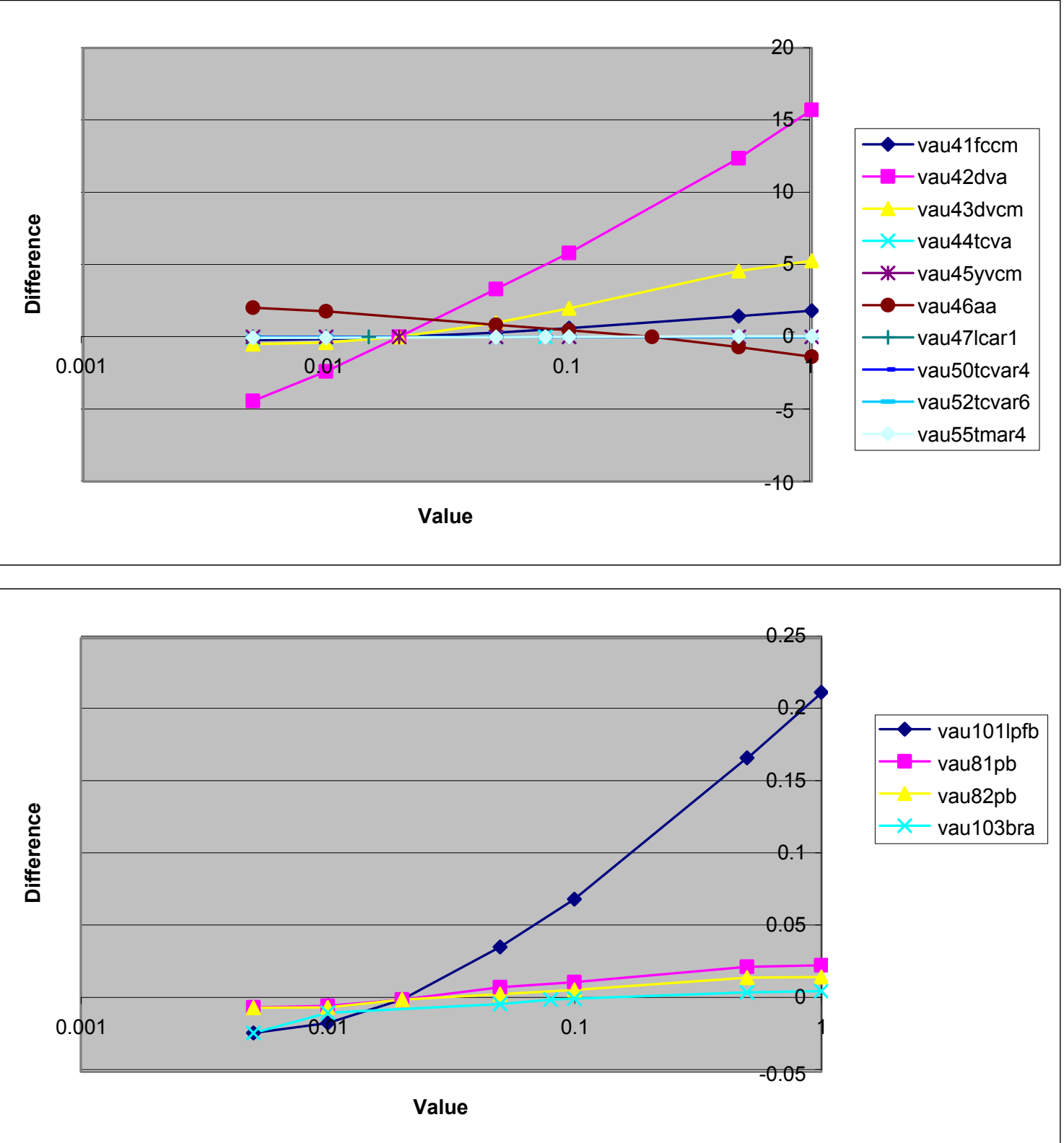


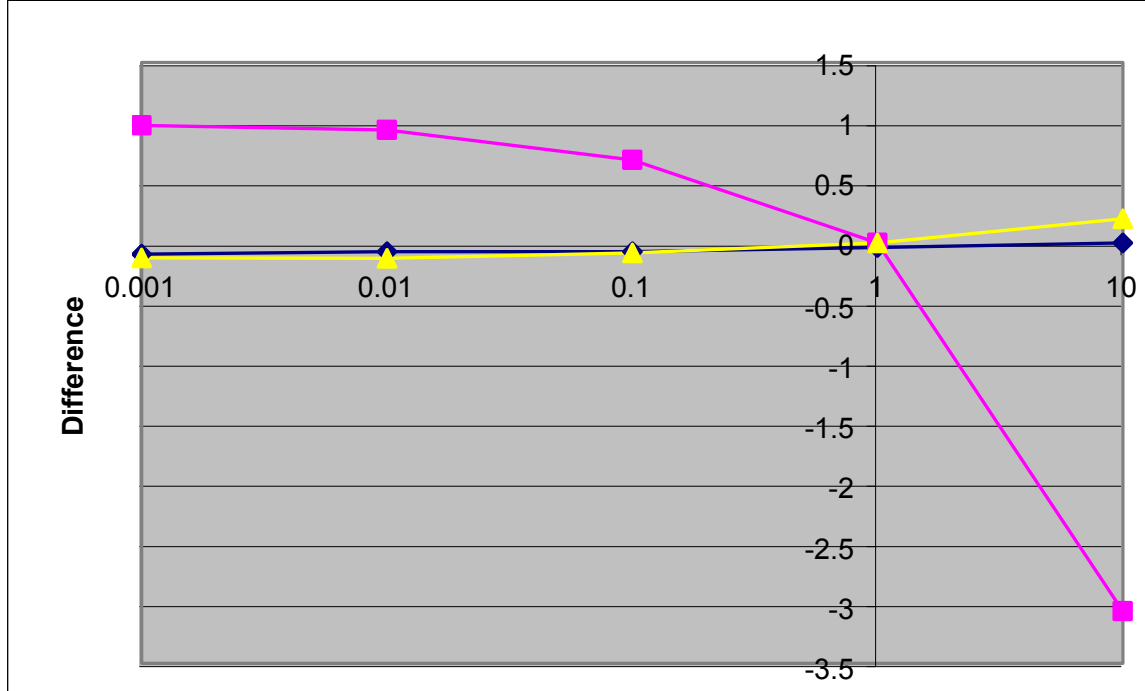

$\rightarrow-01$ almendro

- 02 baremtnf

03_bmcsmwdf

Value
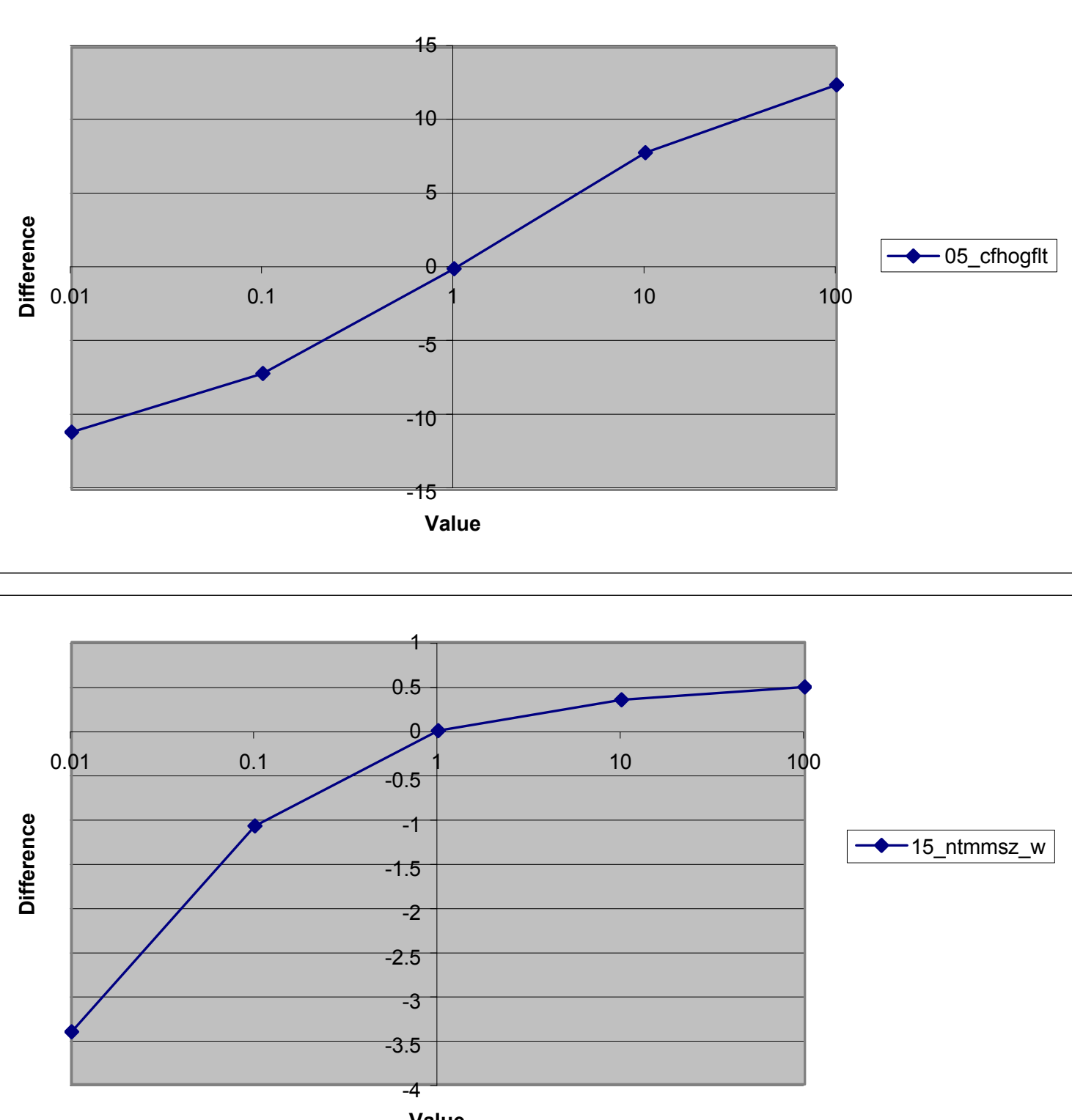

$\rightarrow \bullet$ 15_ntmmsz_w
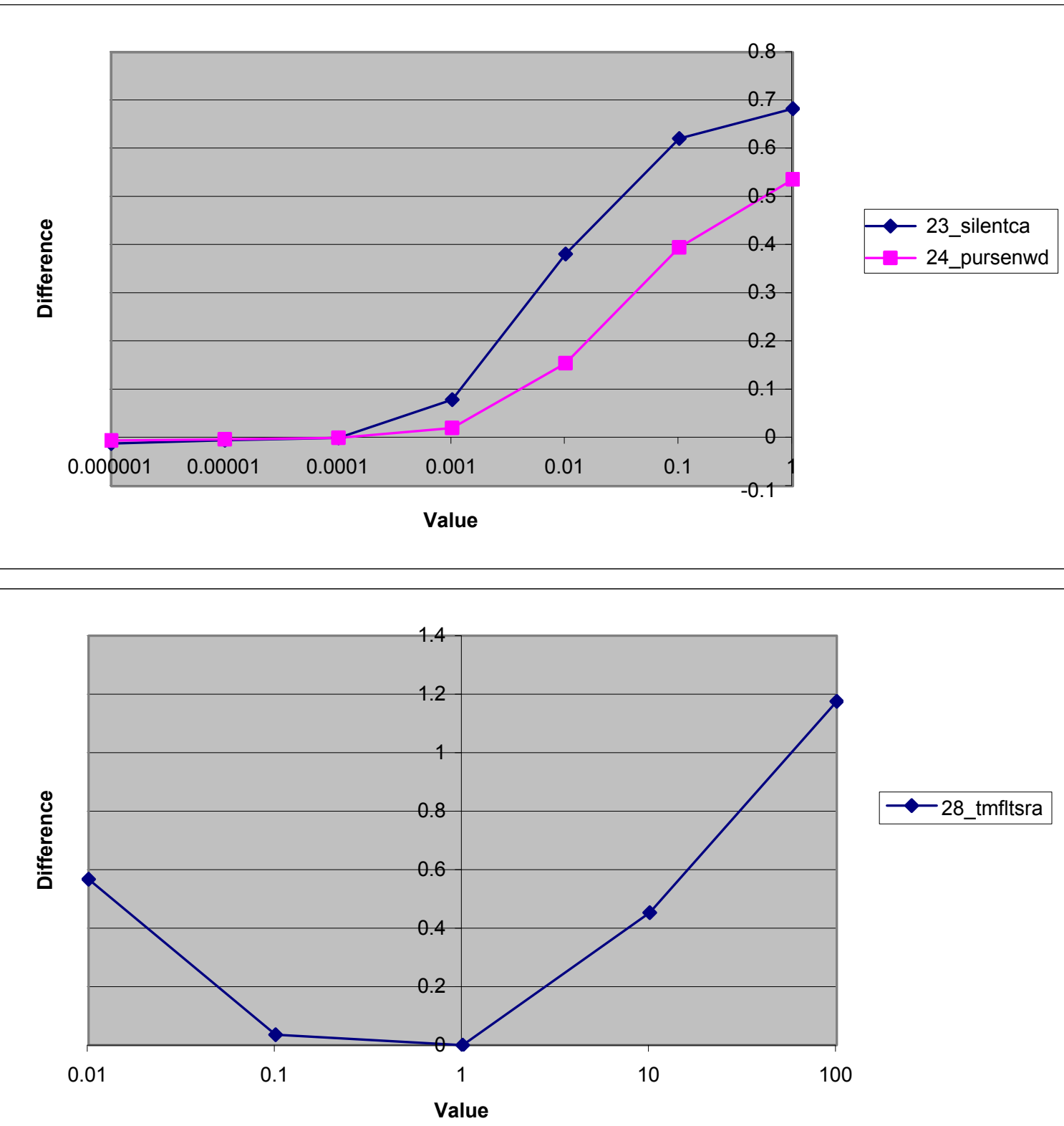

$\longrightarrow \bullet 28$ _tmfltsra

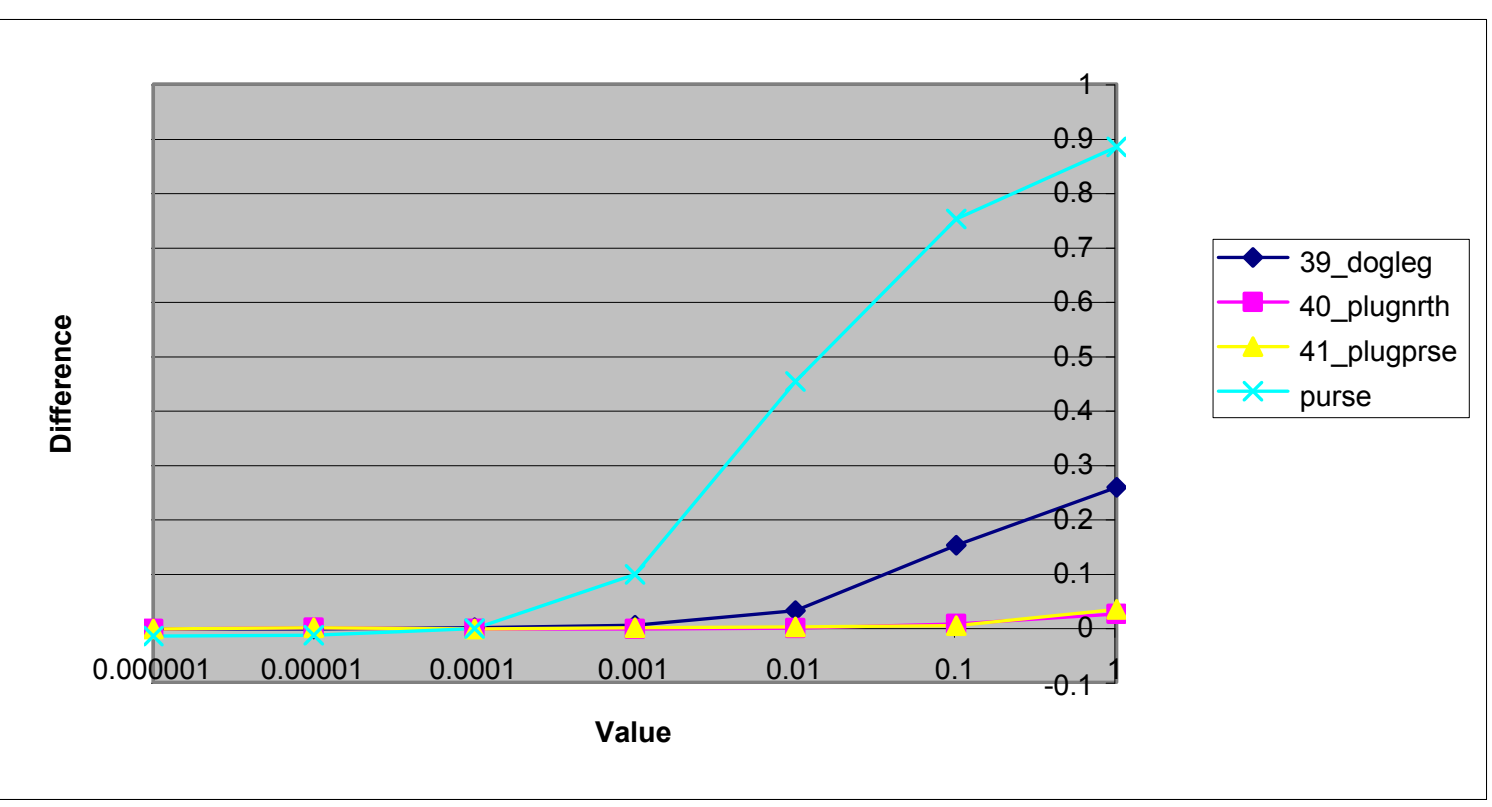

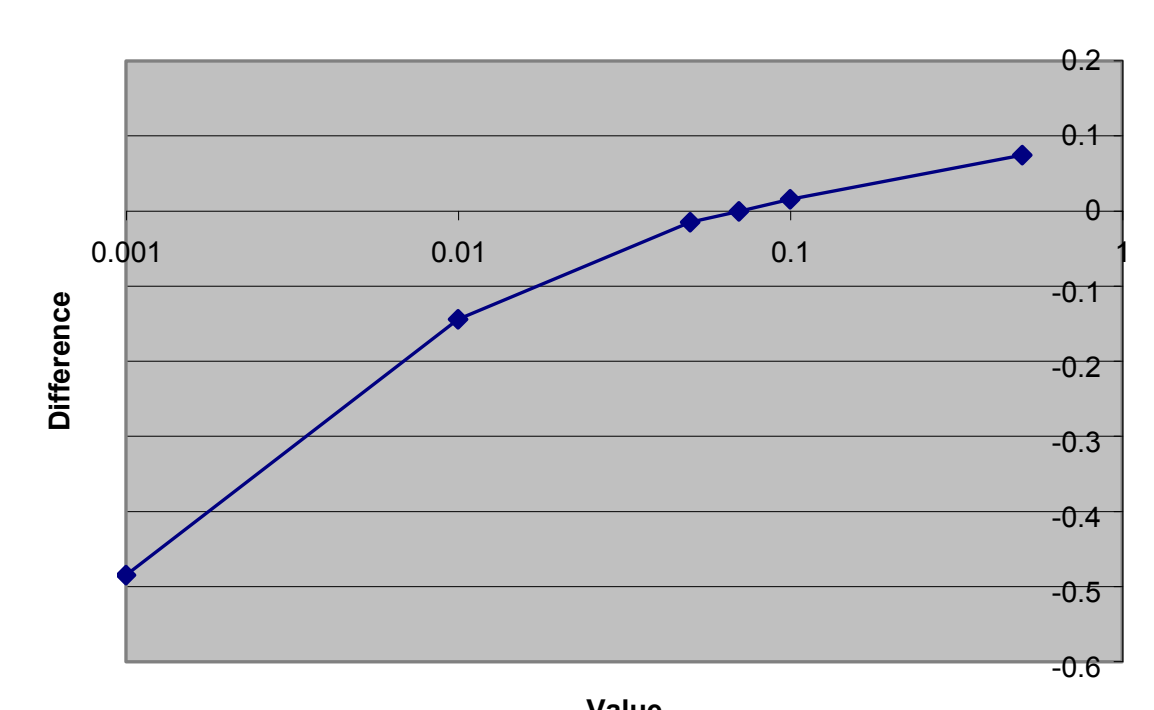

$\multimap \bullet$ 04_boxcar_w

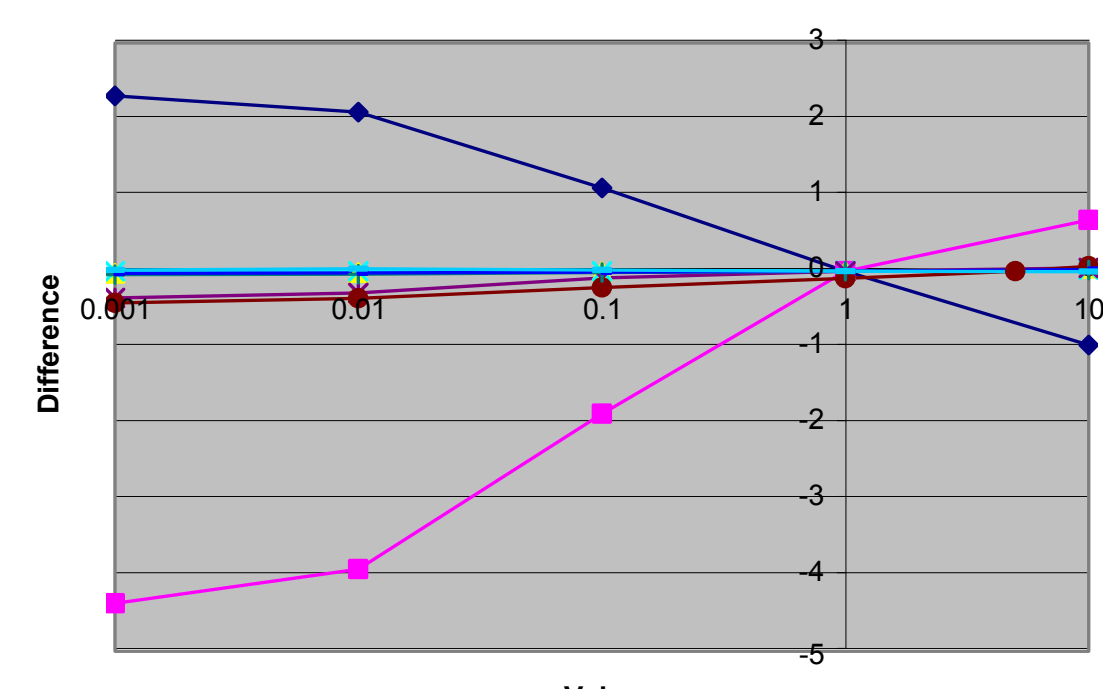

$\multimap-06$ claimcyn

- 07_colsnpnd

08_eastgree

$\times$ 09_eestuary

* 10_etcsz_wd

$\longrightarrow$-11_handley_

1-12_handleys

-13_handley2

Value

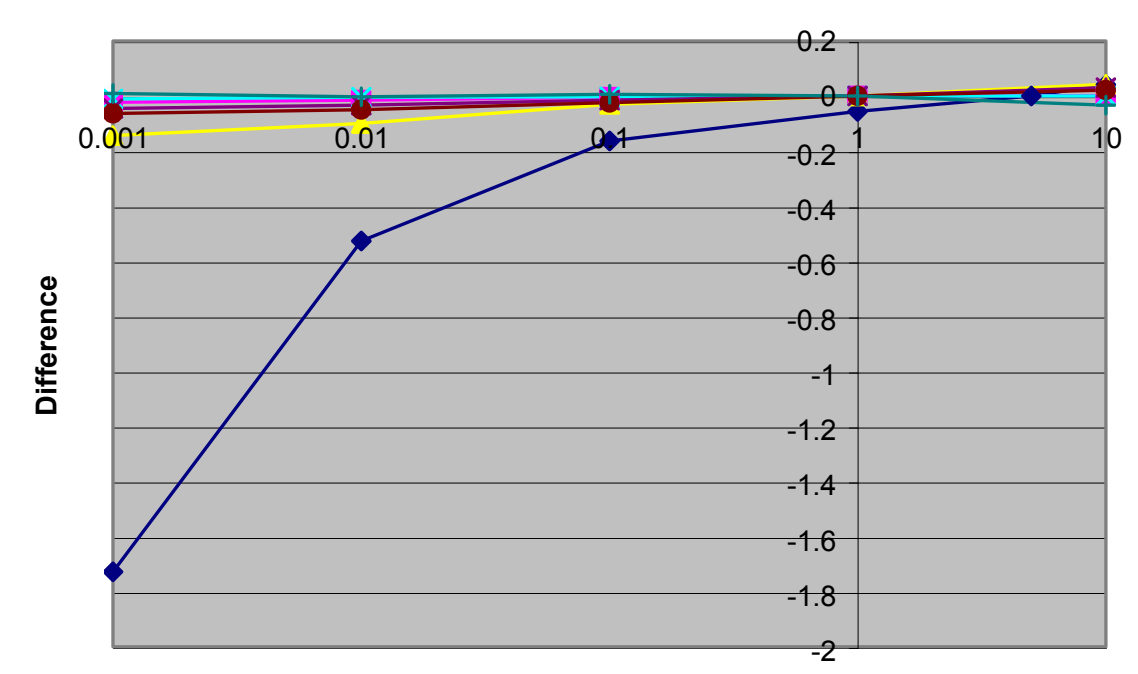

$\multimap$-16 ribcliff

-17_richey_w

18_scrugham

$\times 19$ 19scnsz_wd

*-20_scsze_wd

- -21_scszw_wd

—22_sefltwfd

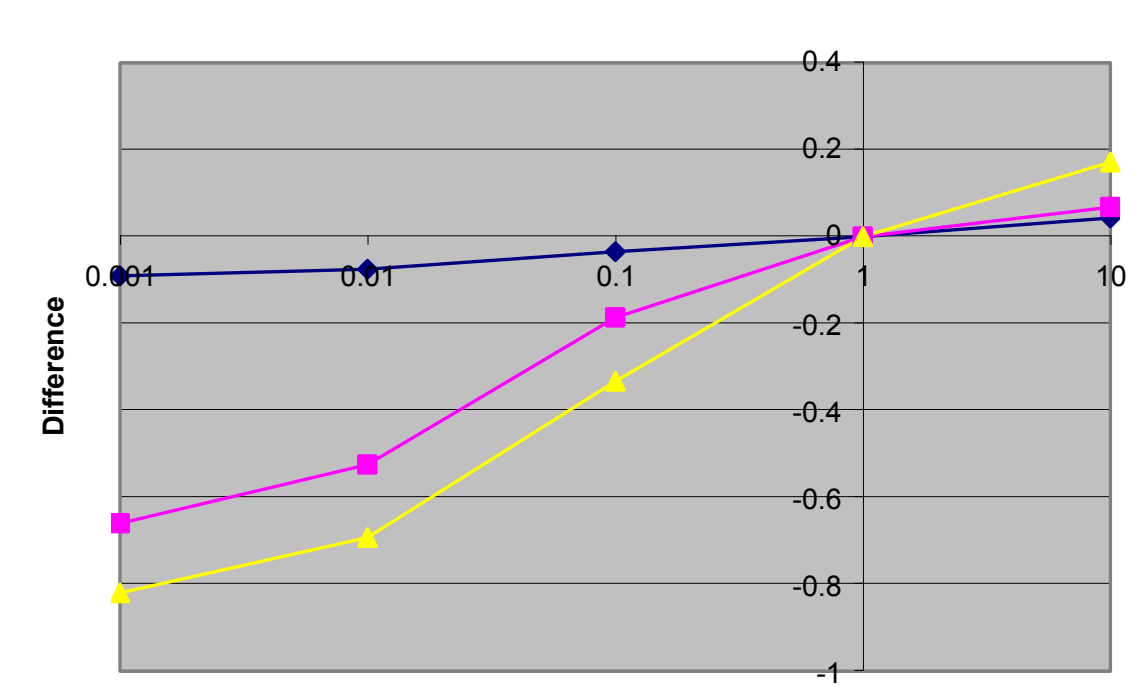

Value
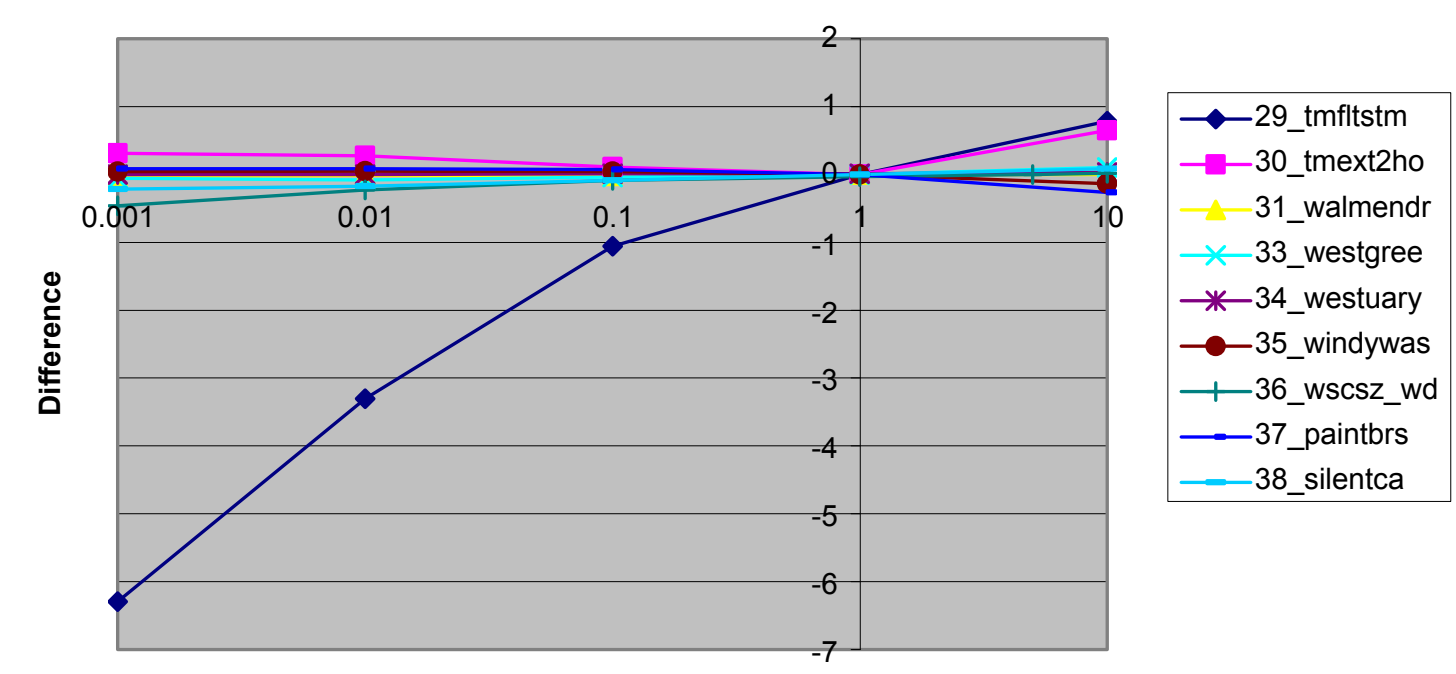

Value

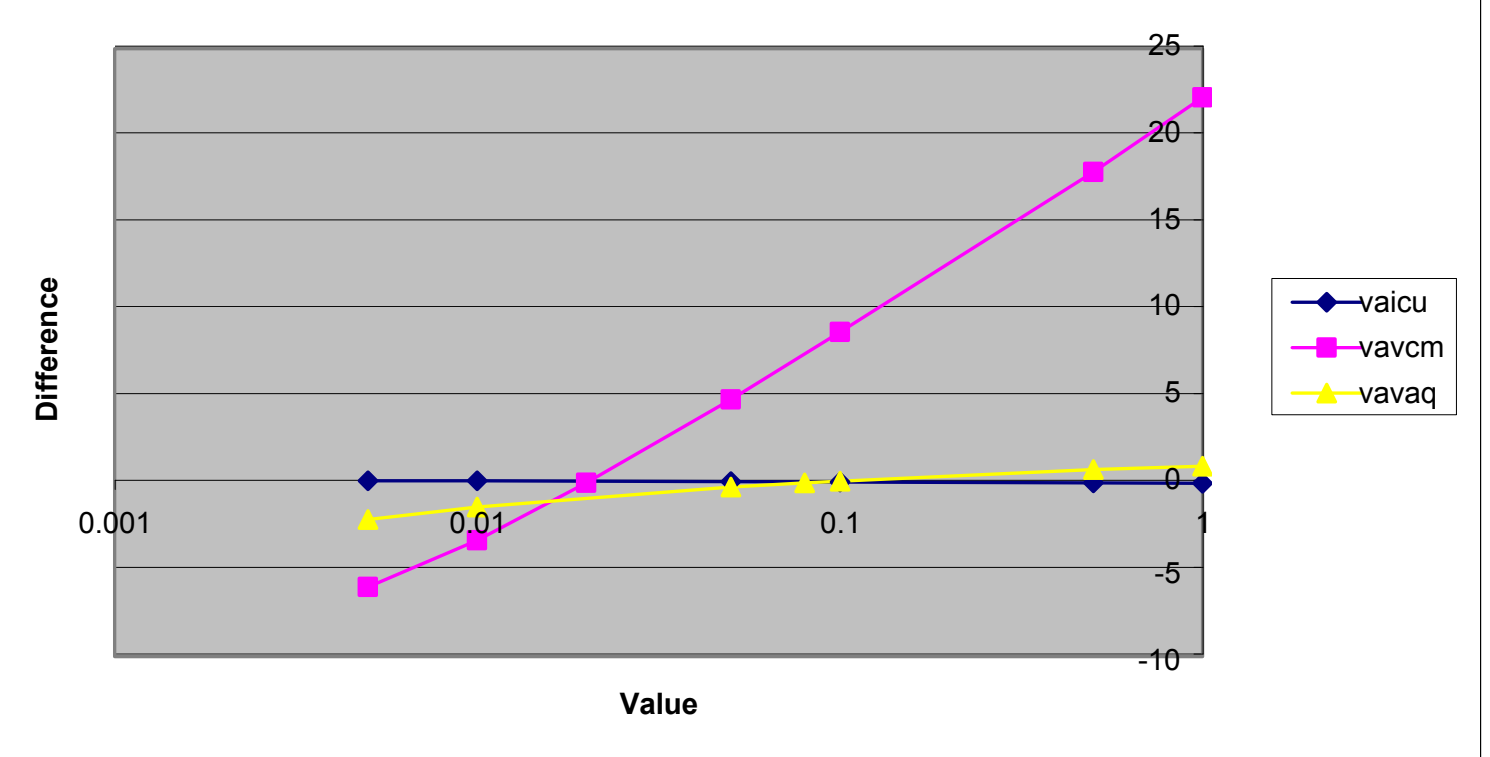




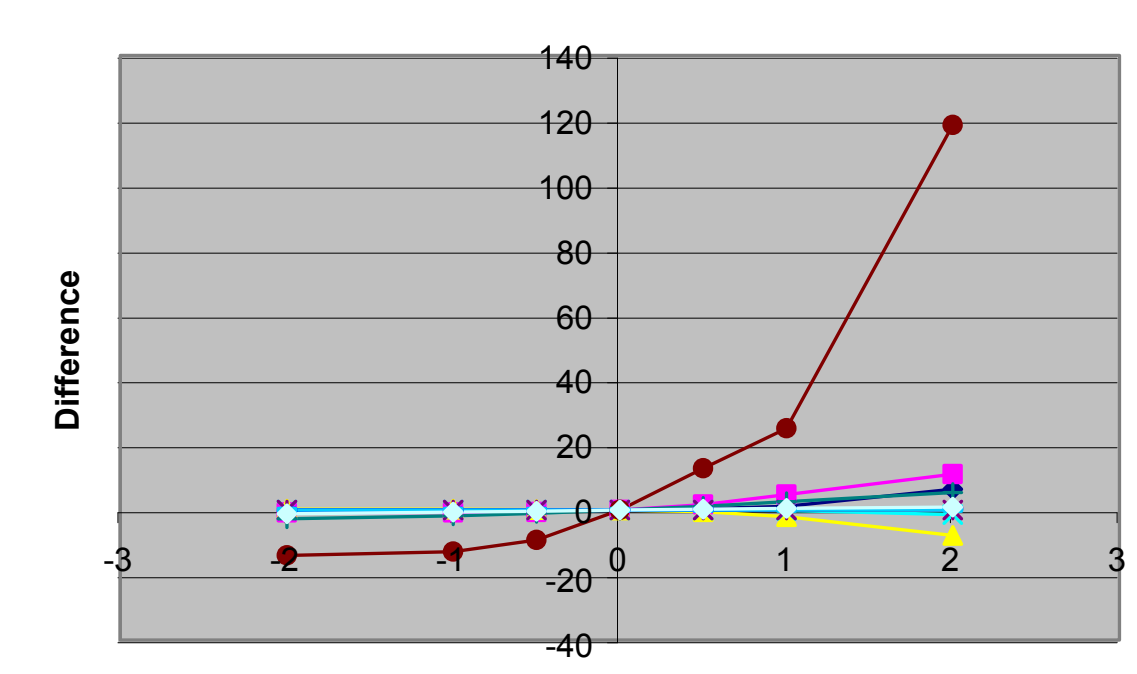

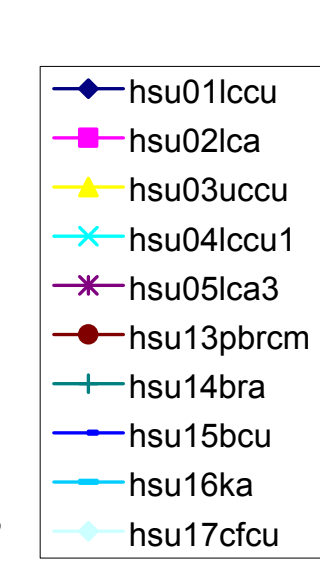

Base Value +1/-Standard Deviation
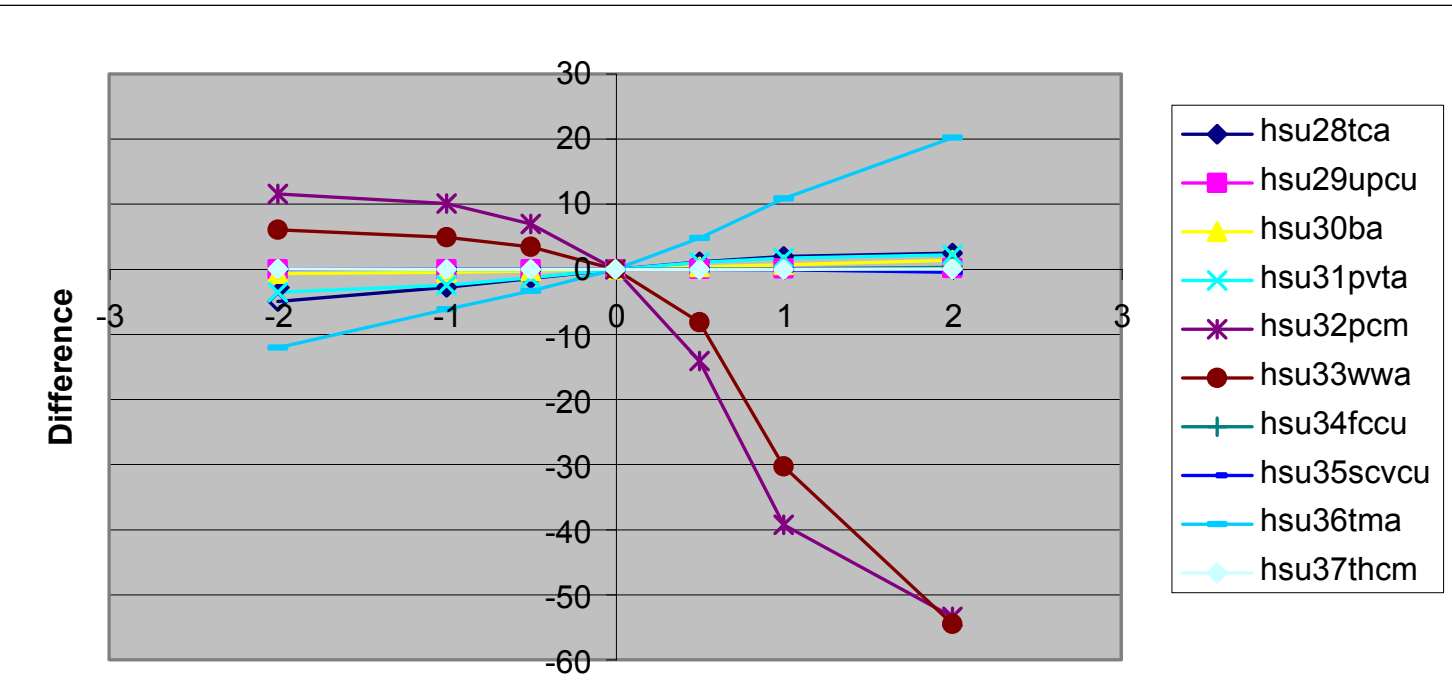

Base Value +1/-Standard Deviation
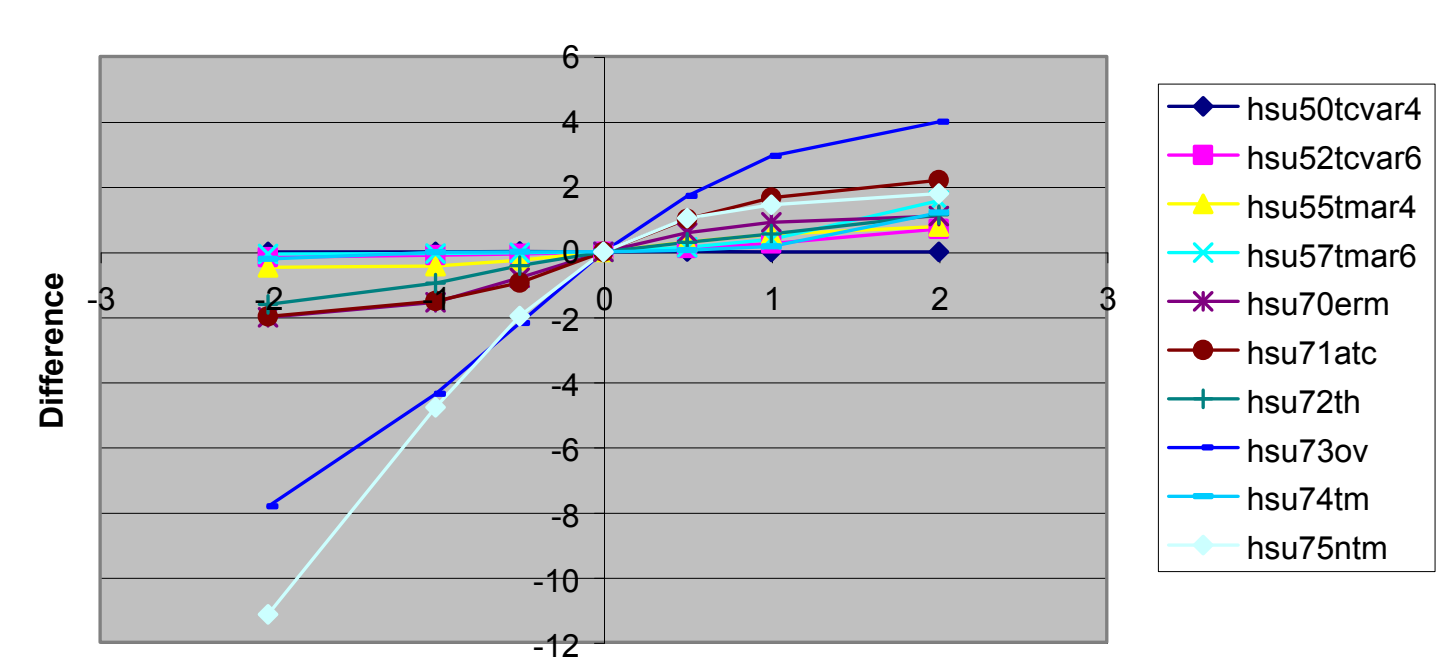

Base Value +/-Standard Deviation
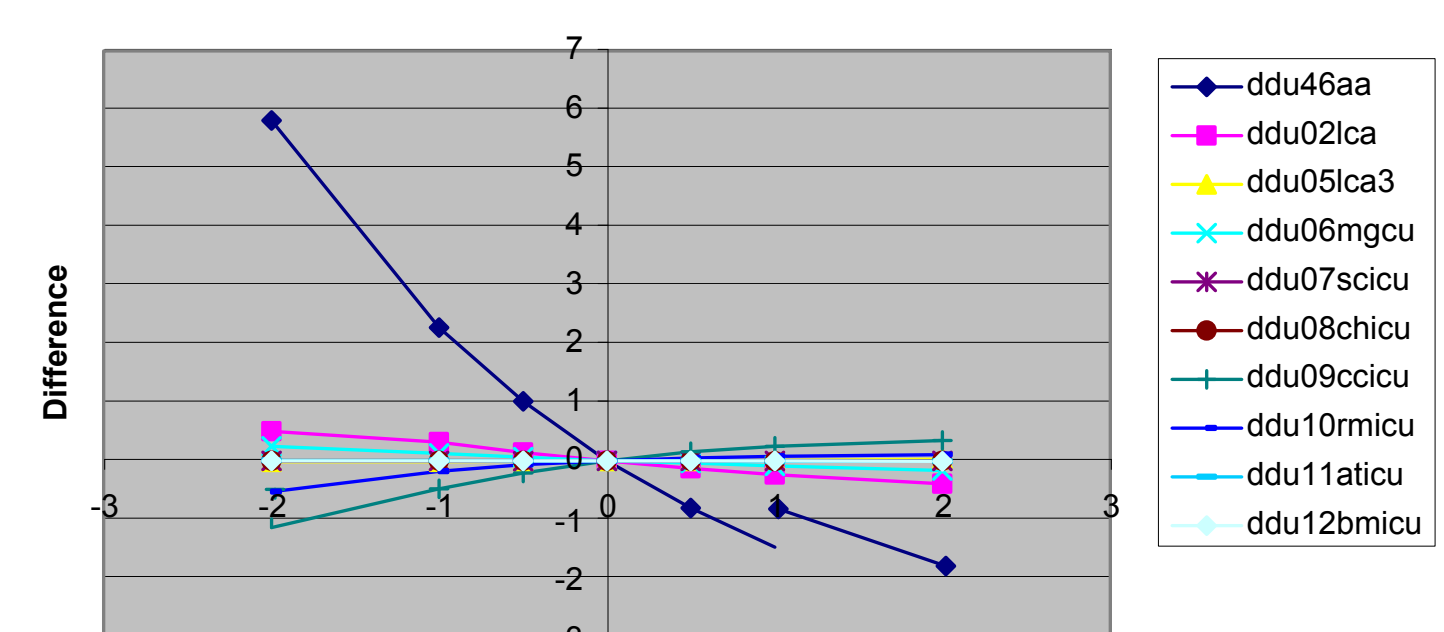

Base Value +//Standard Deviation
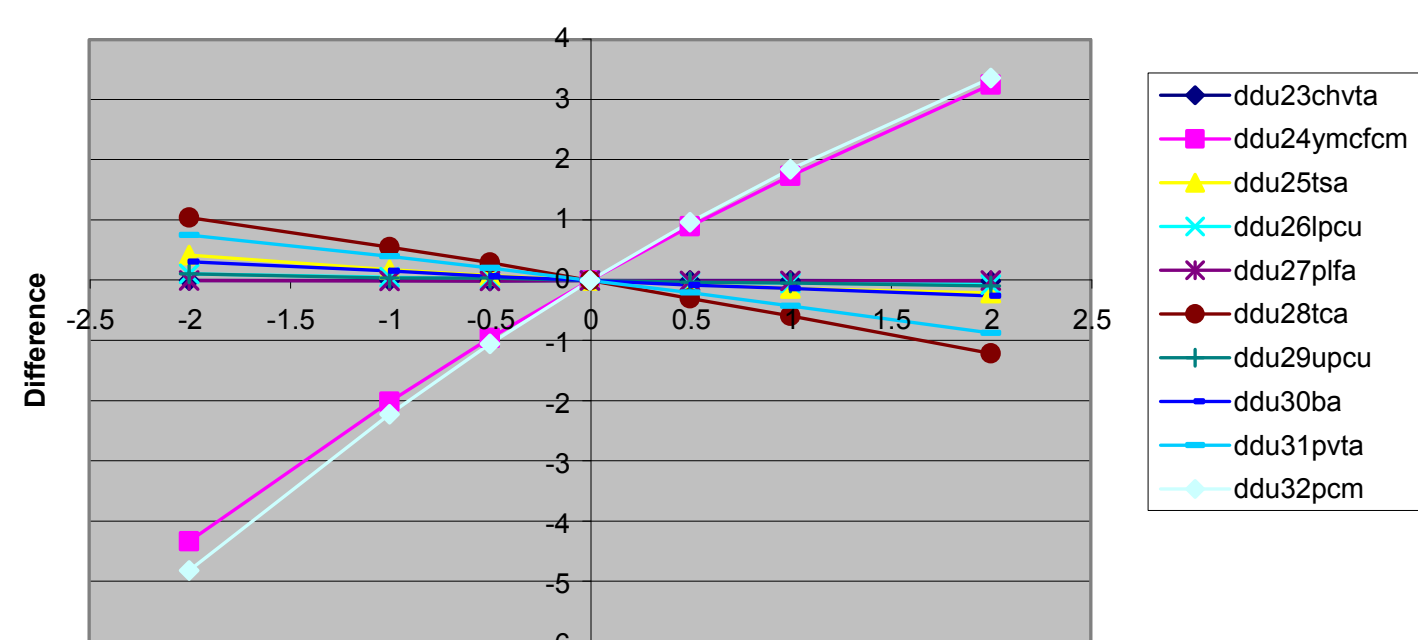

Base Value t/- Standard Deviation
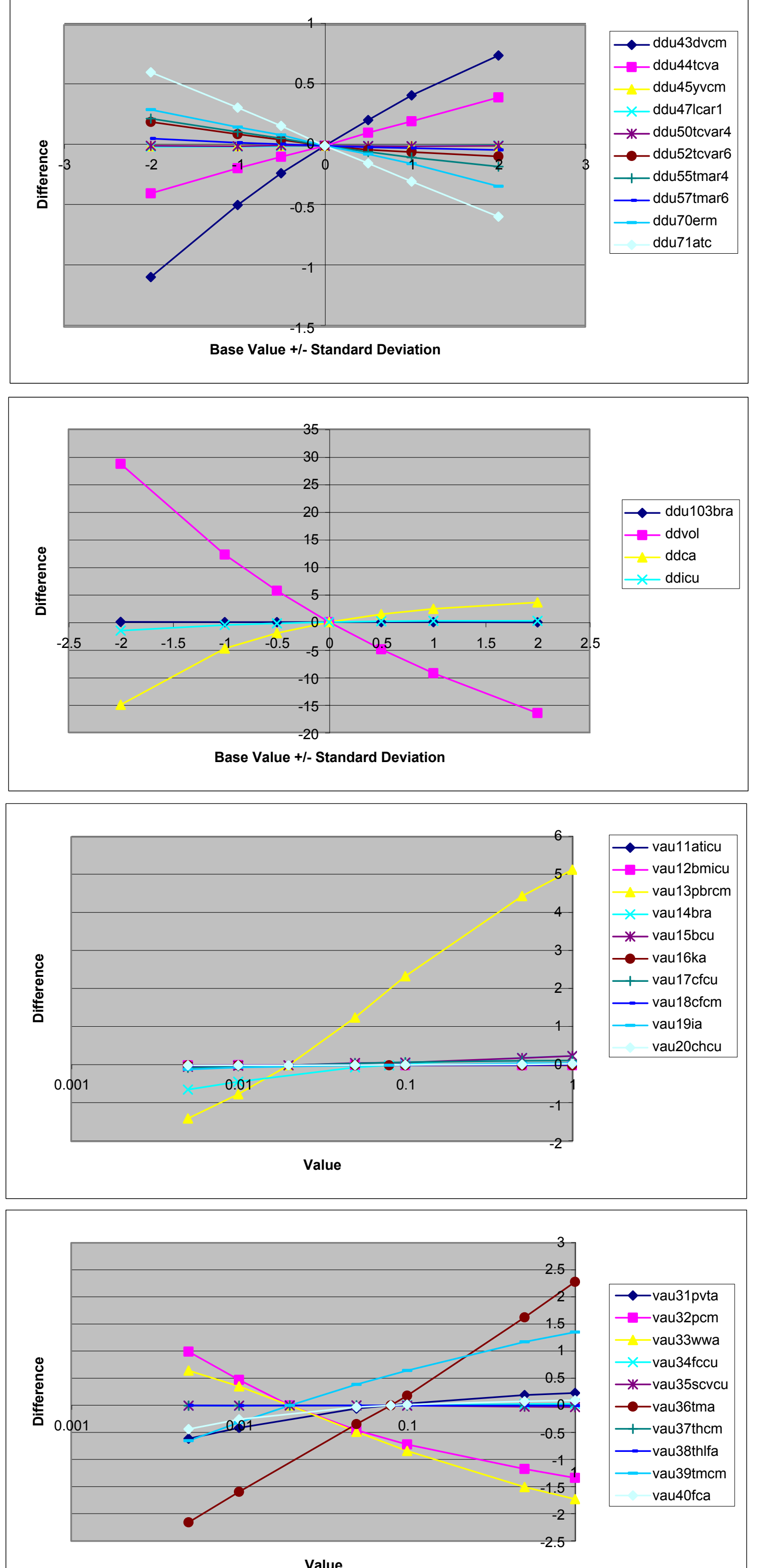

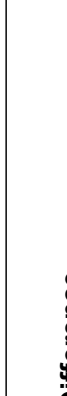

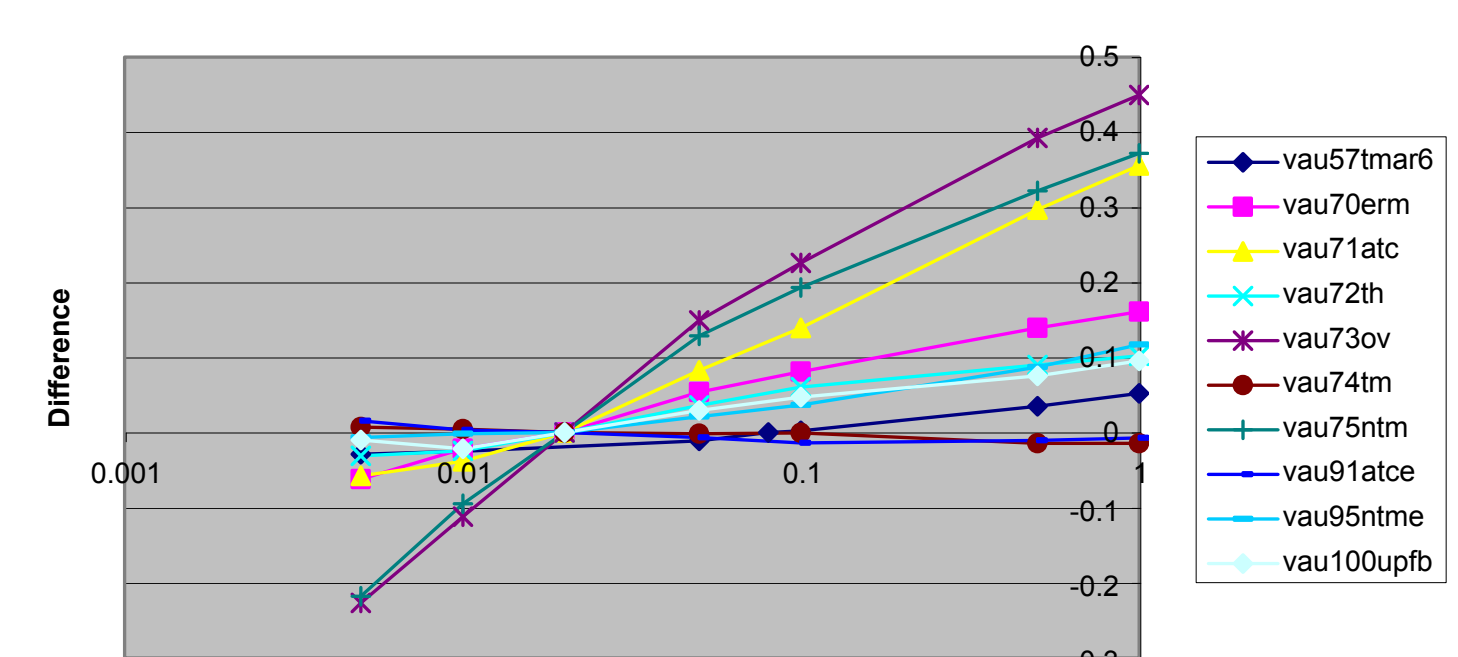

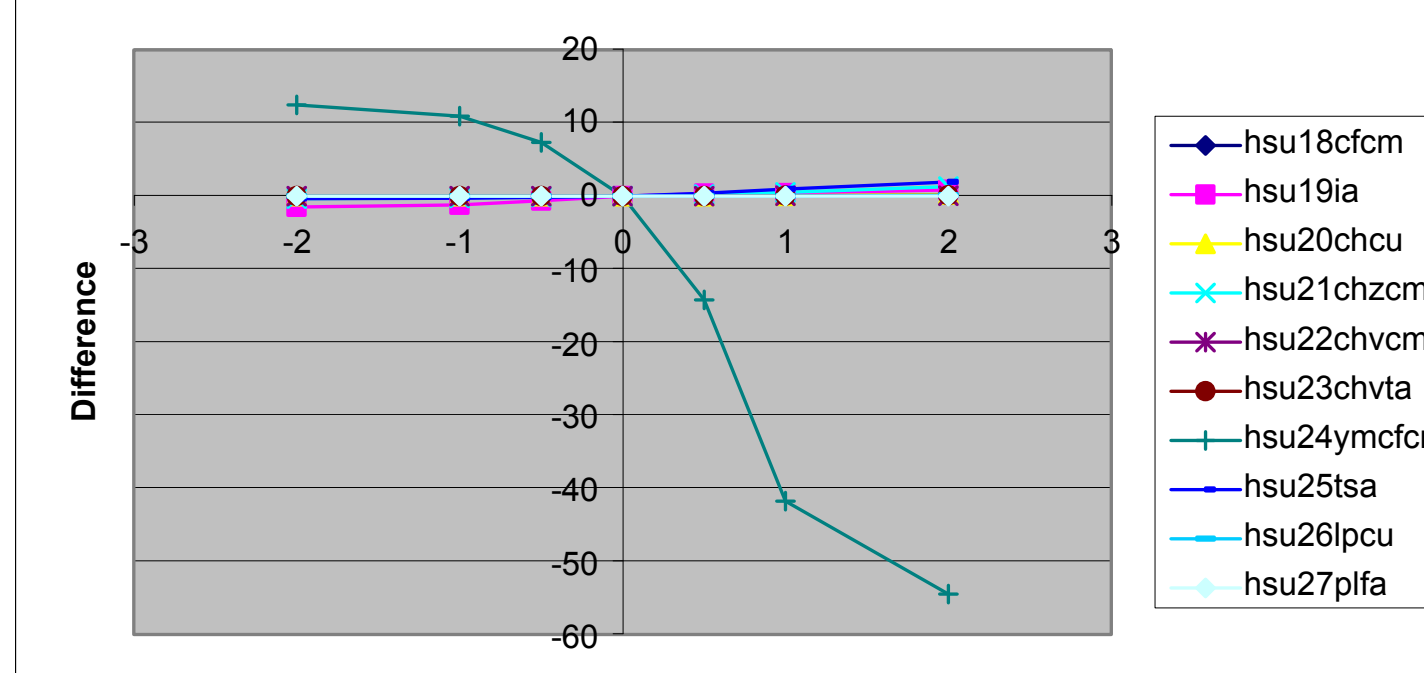

Base Value +1/.Standard Deviation
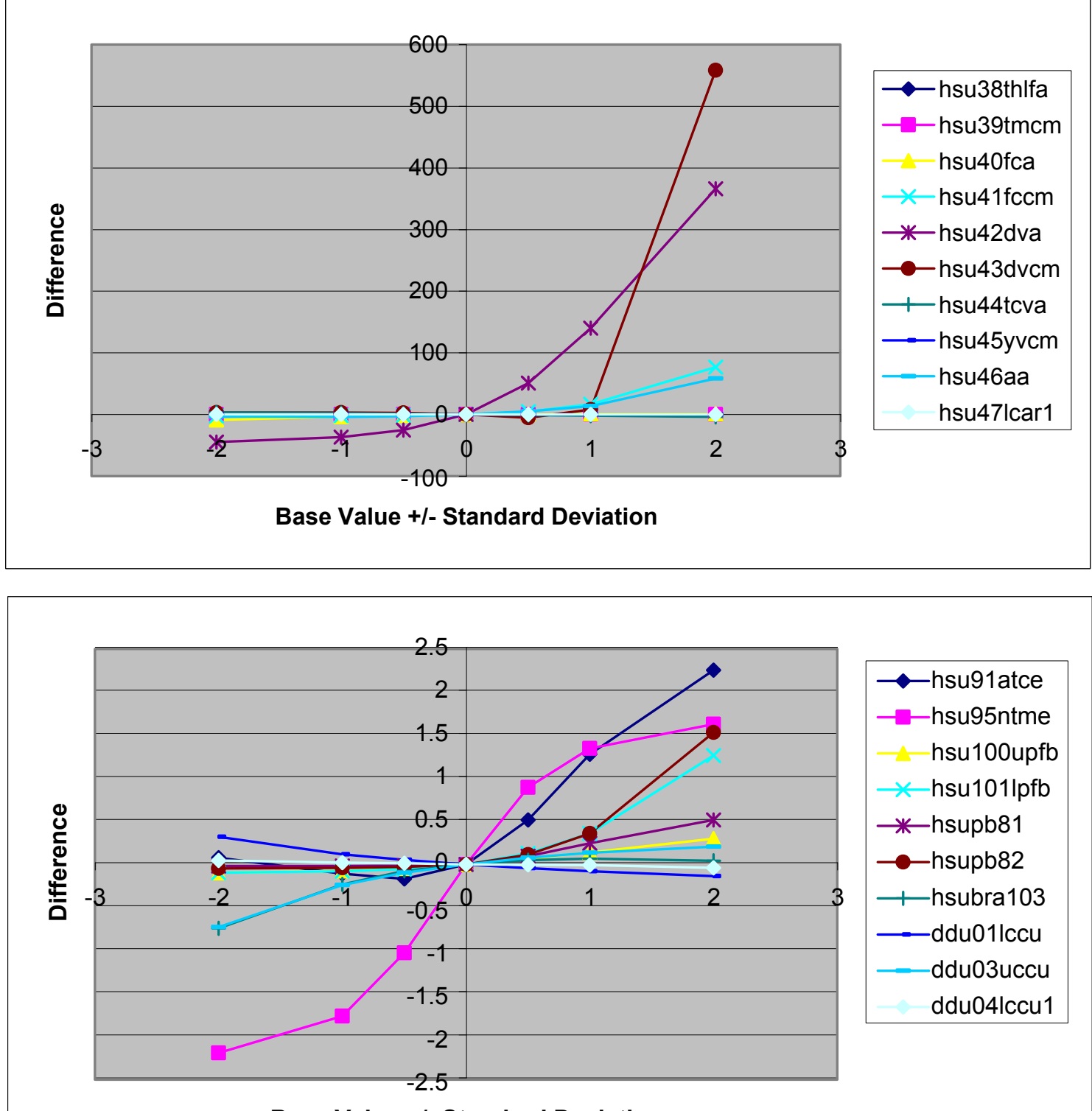

Base Value +1- Standard Deviation

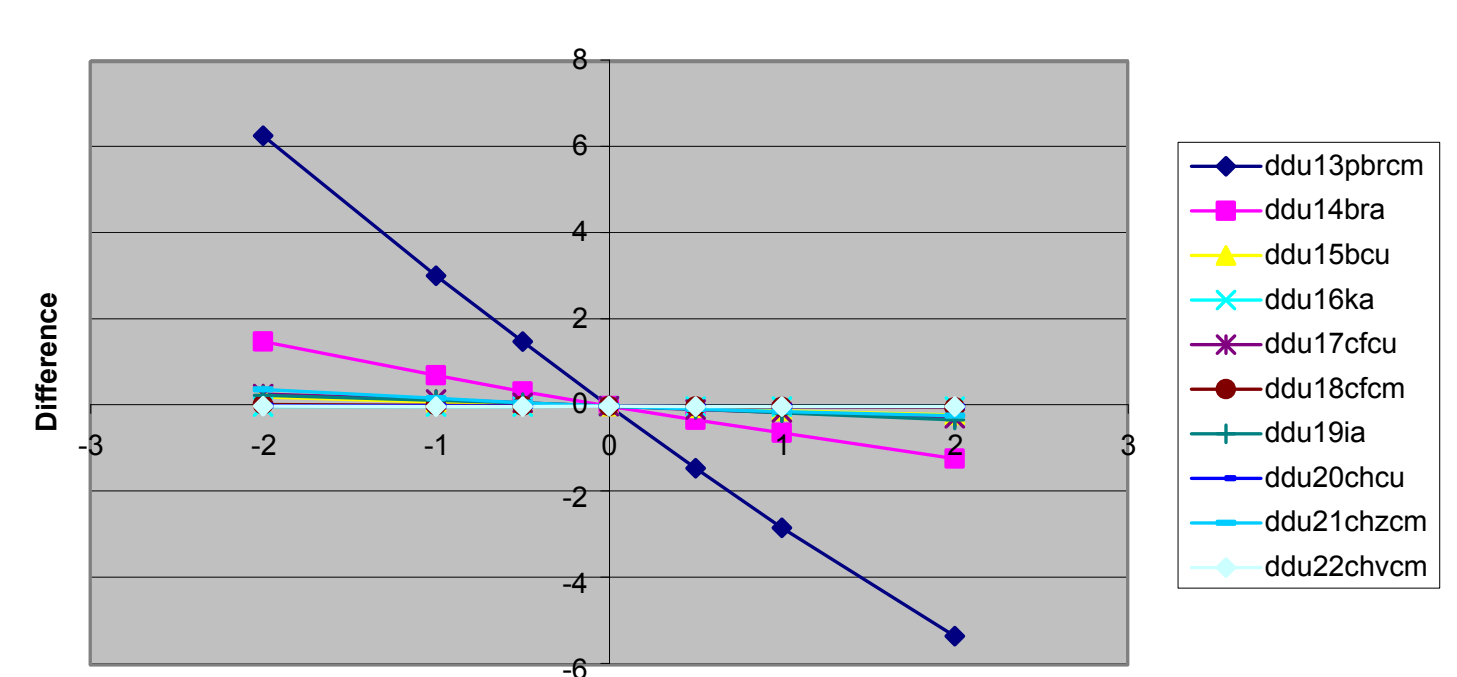

Base Value +t/-Standard Deviation

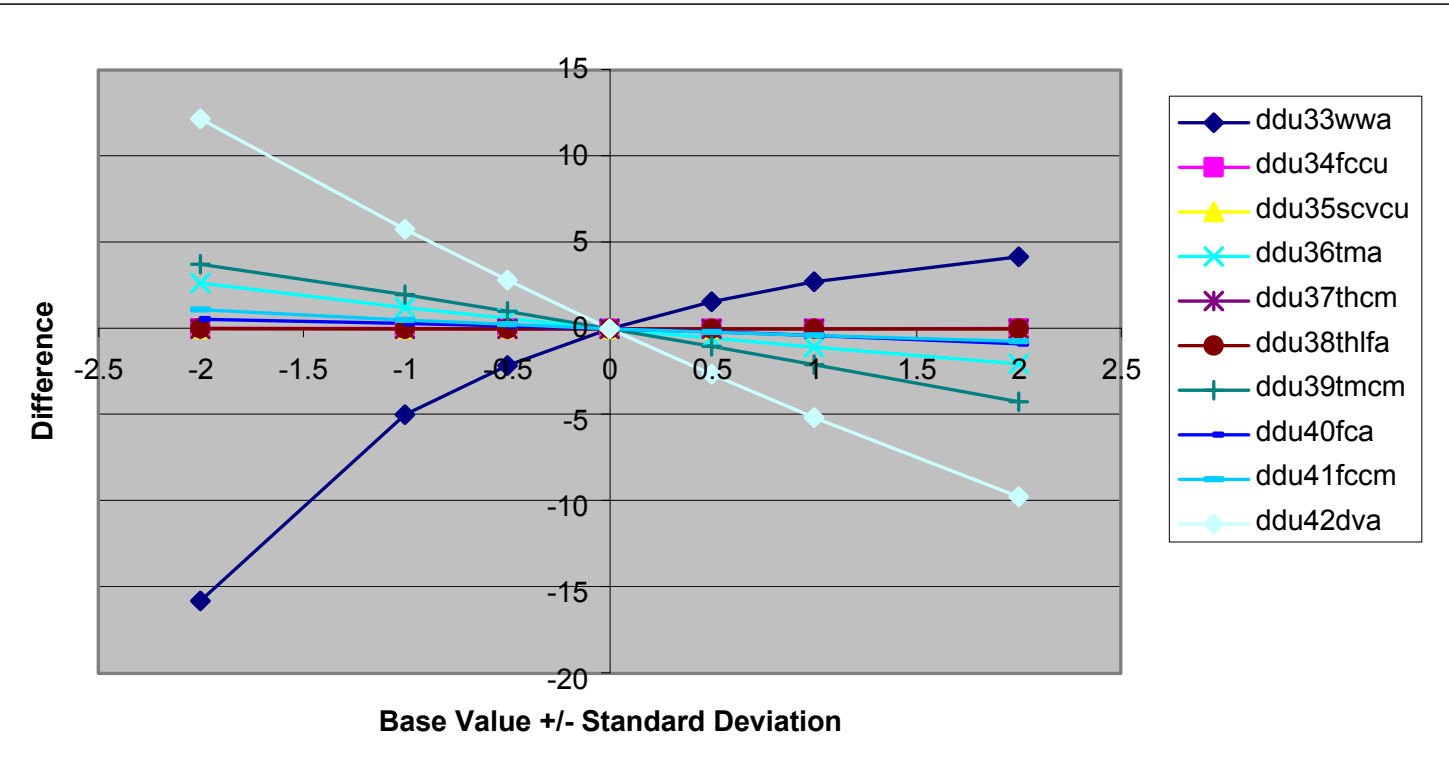

Base Value + - $/$ Standard Deviation
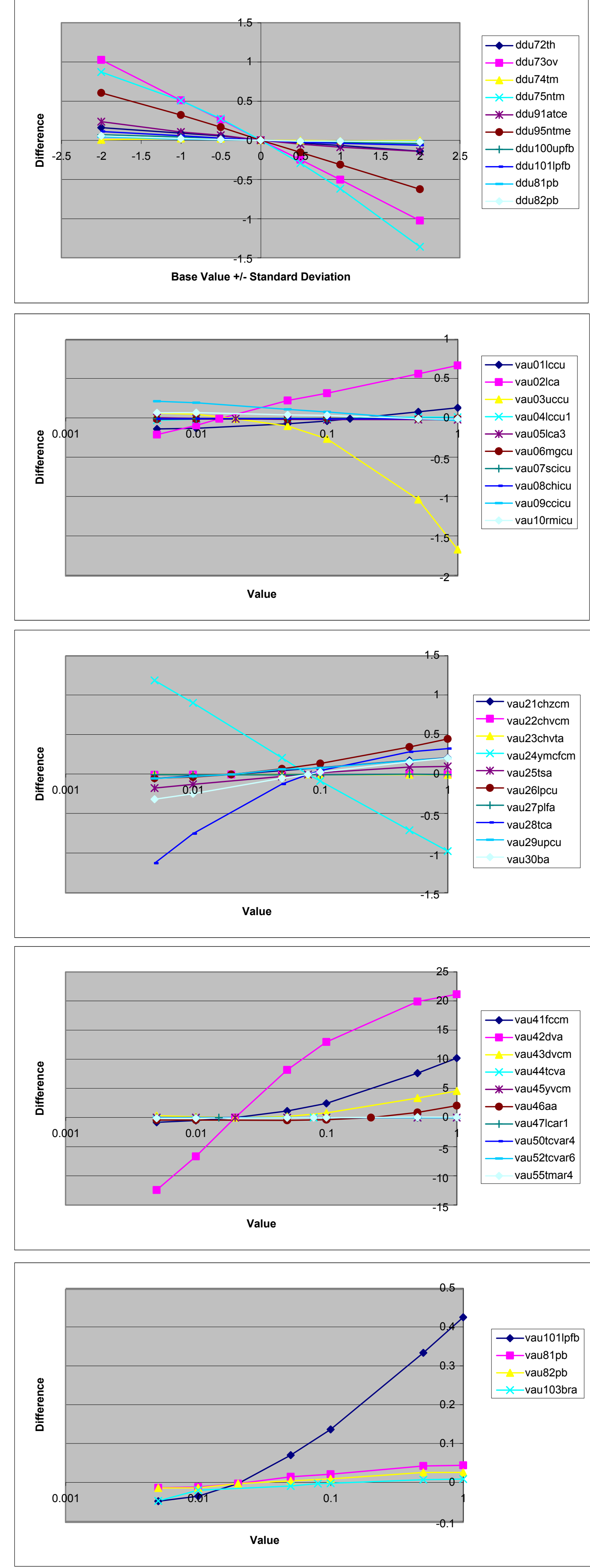


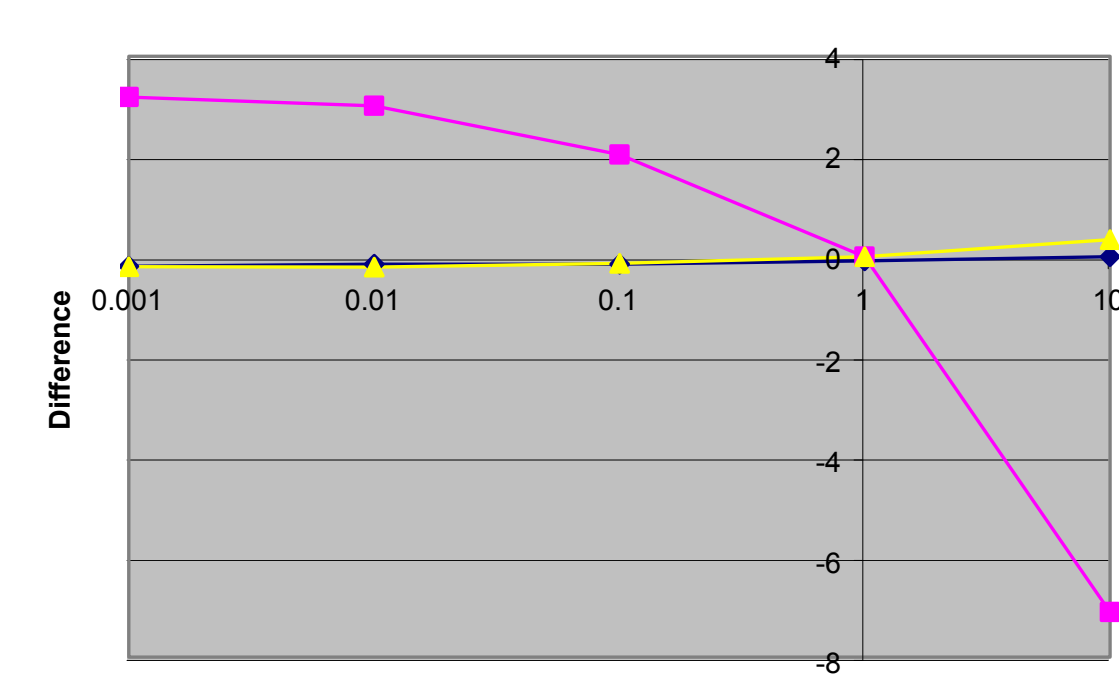

Value

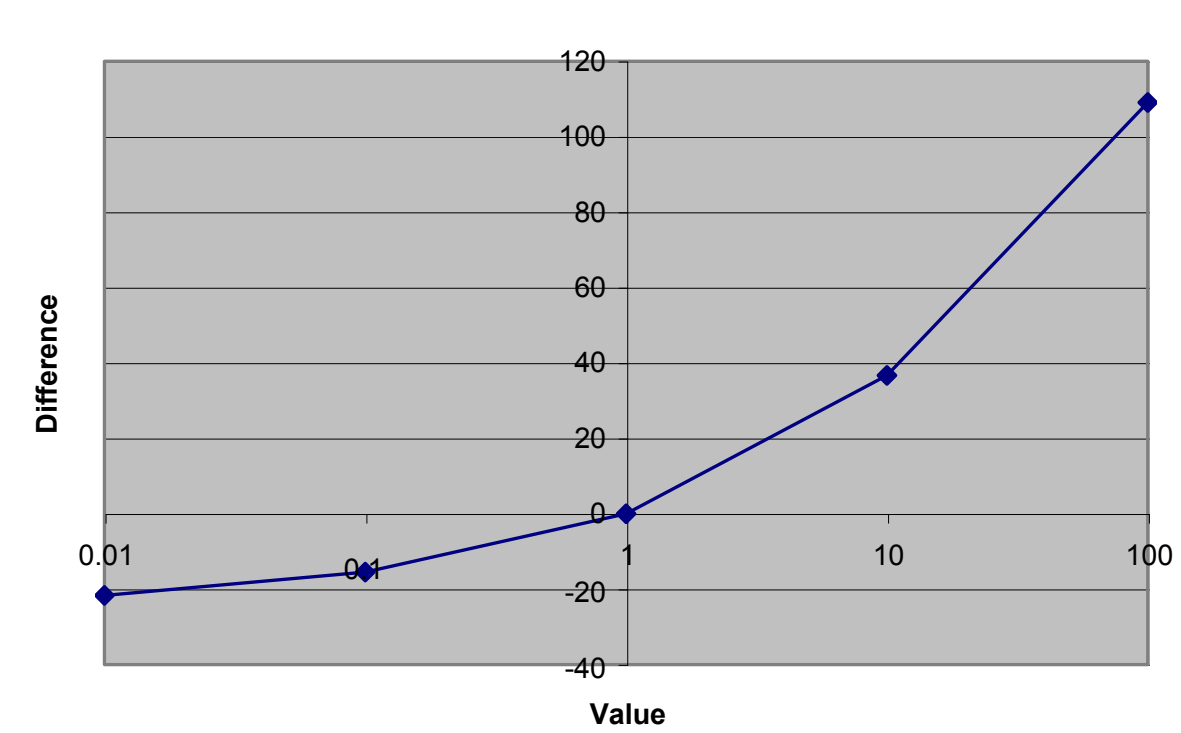

$\rightarrow \bullet 05$ cfhogftt

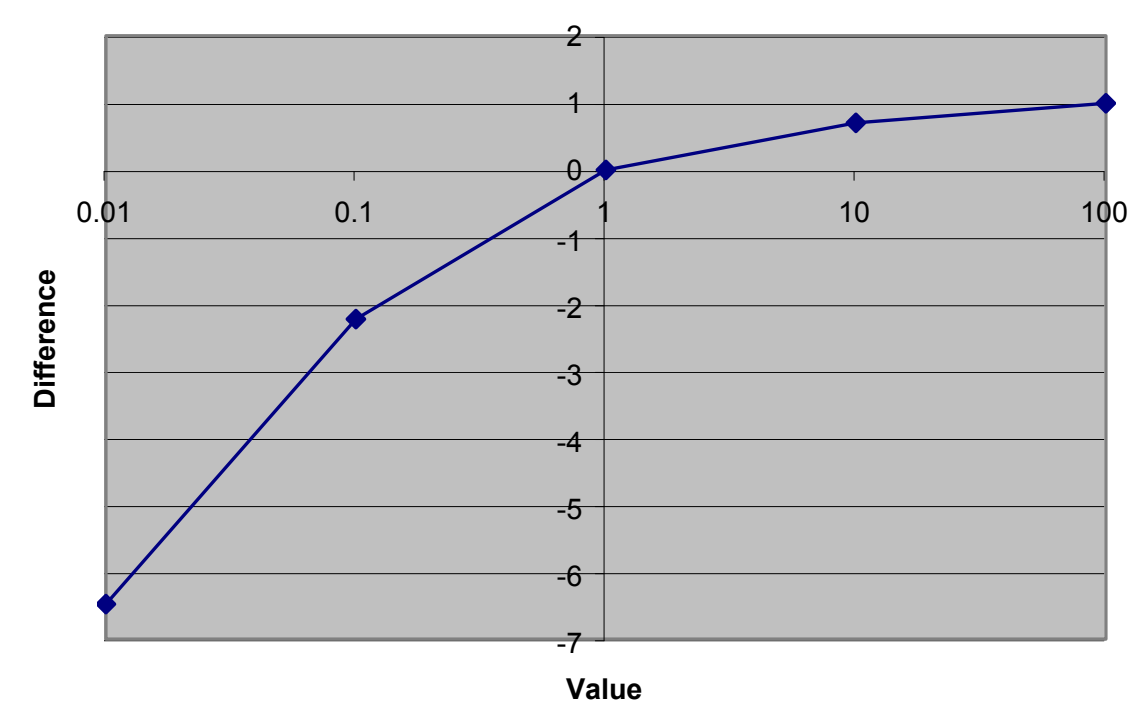

$\rightarrow$-15_ntmmsz_w
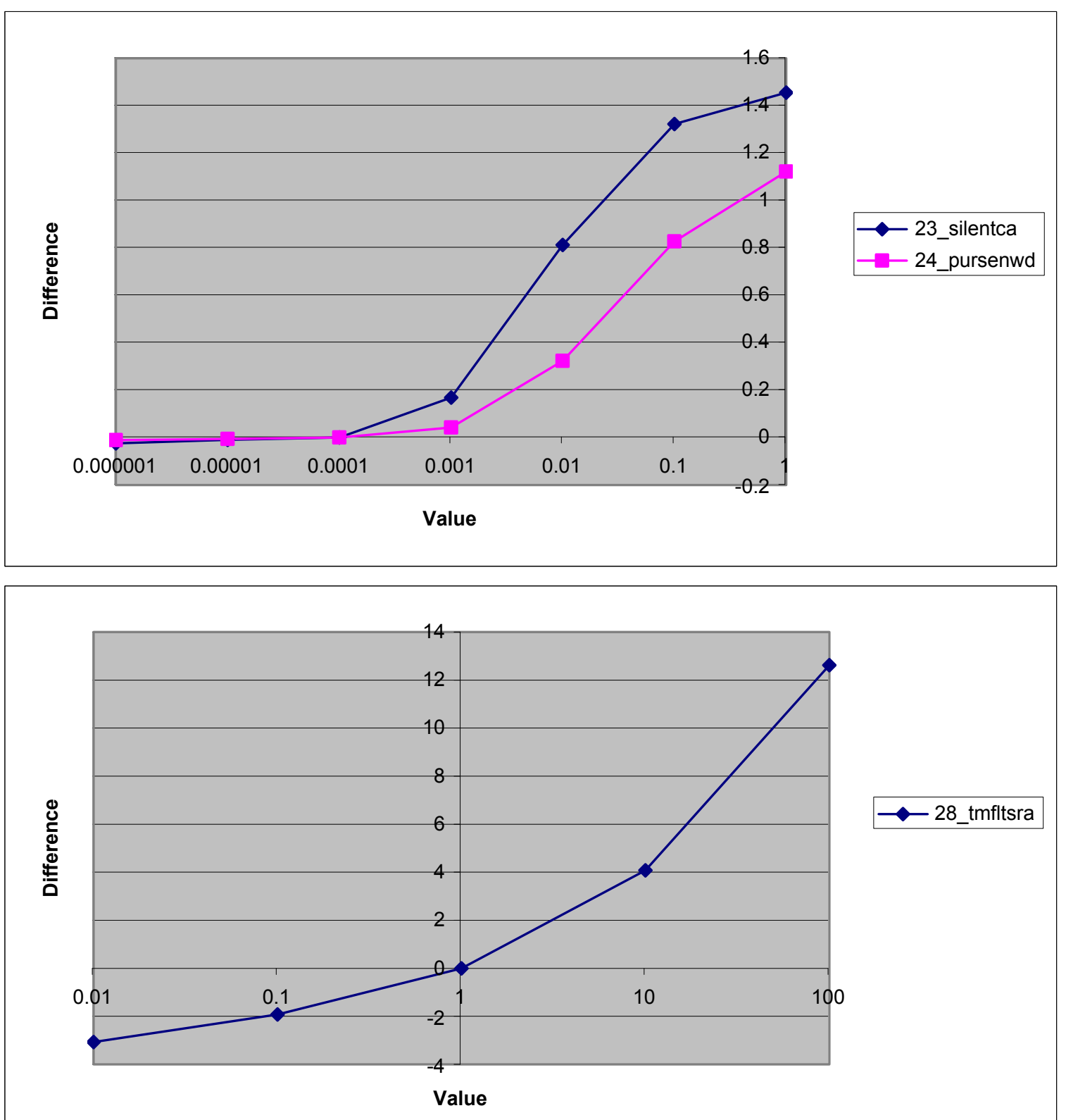

$\bullet \bullet 28$ _tmfltsra

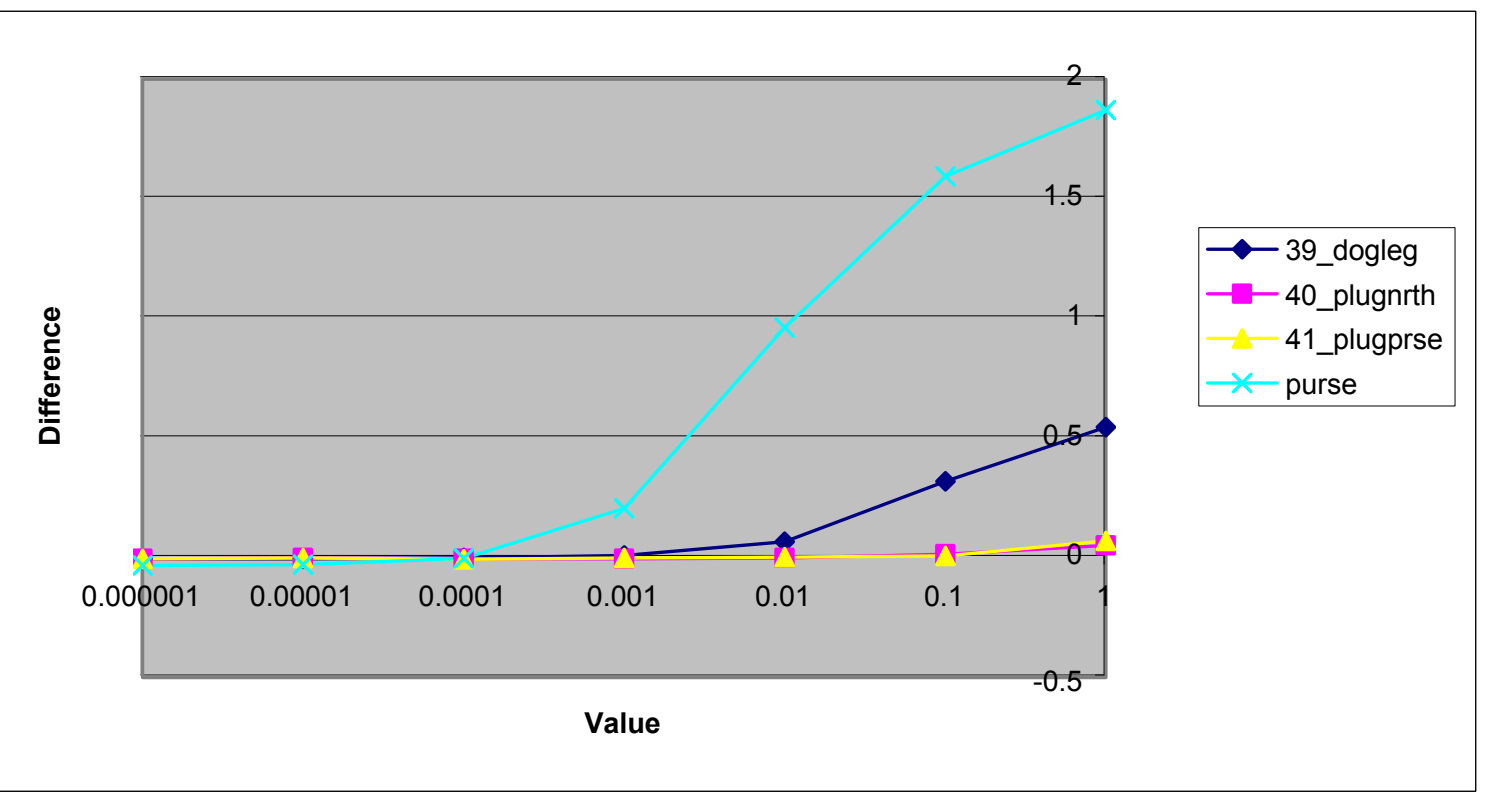

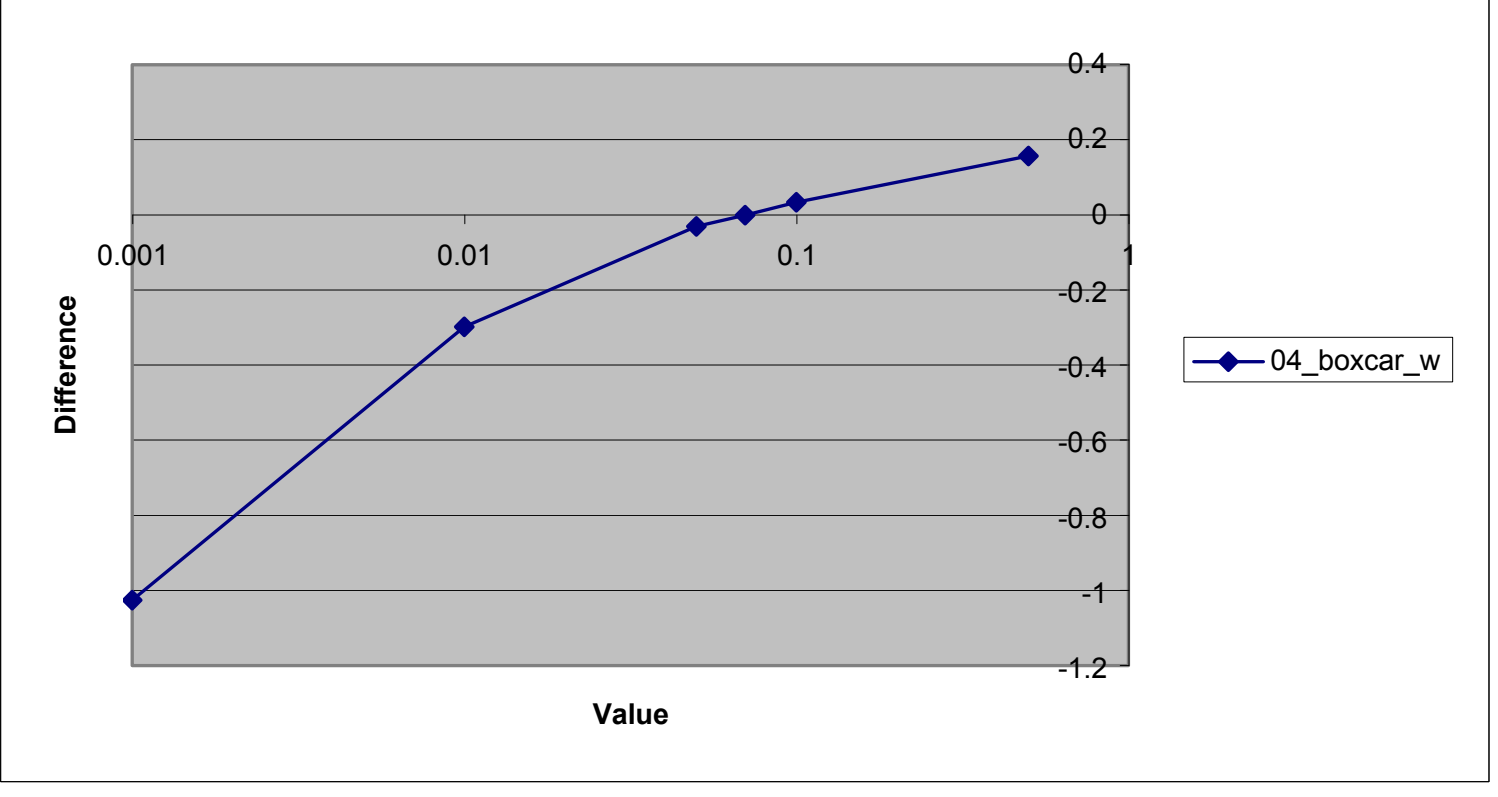
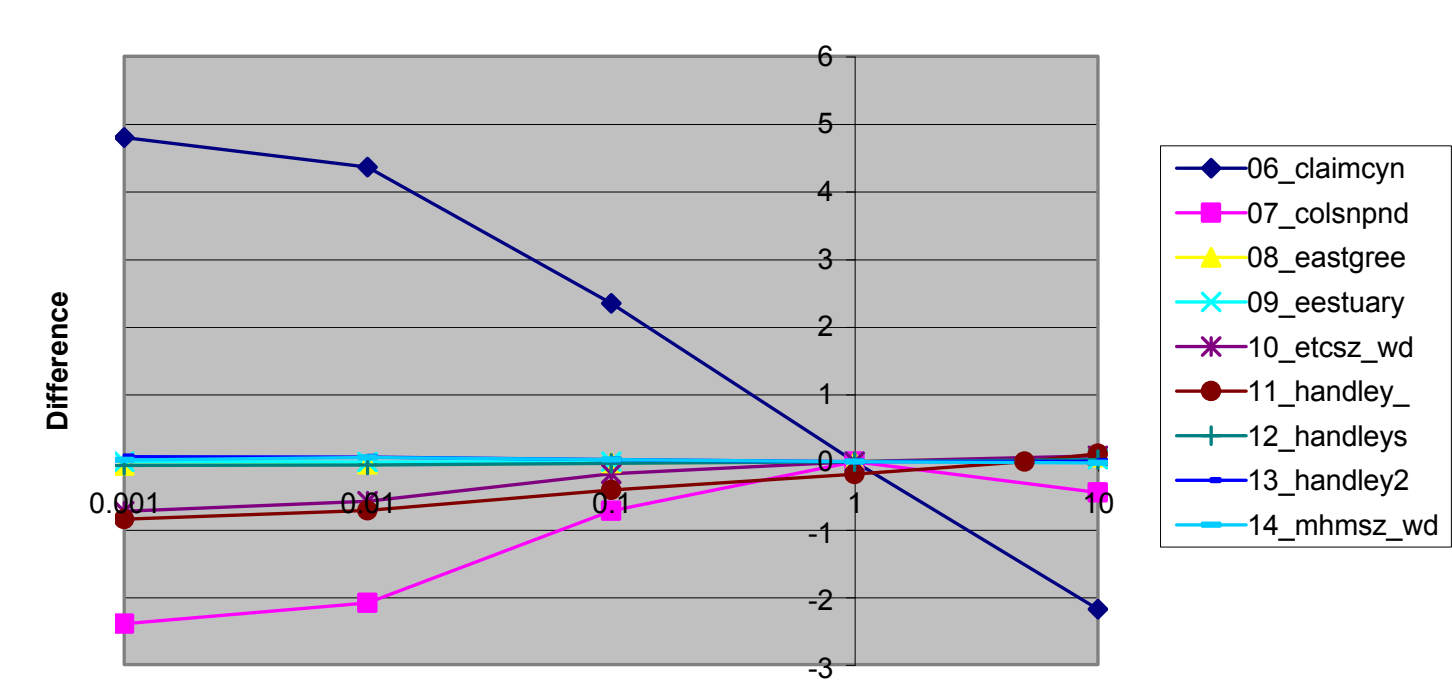

Value

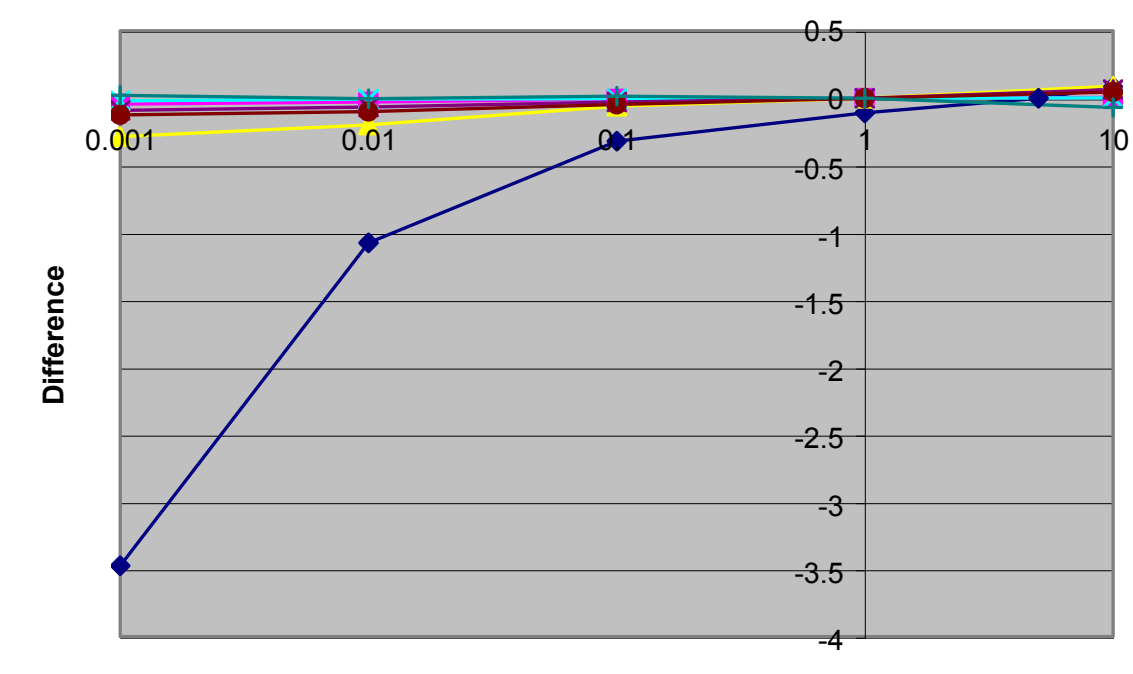

$\multimap-16$ ribcliff

-17_richey_w

18_scrugham

- 19_scnsz_wd

* $-20 \_s c s z e \_w d$
-21 scszw_wd

$-21 \_s c s z w \_w d$
$+-22 \_s e f t$-wfd
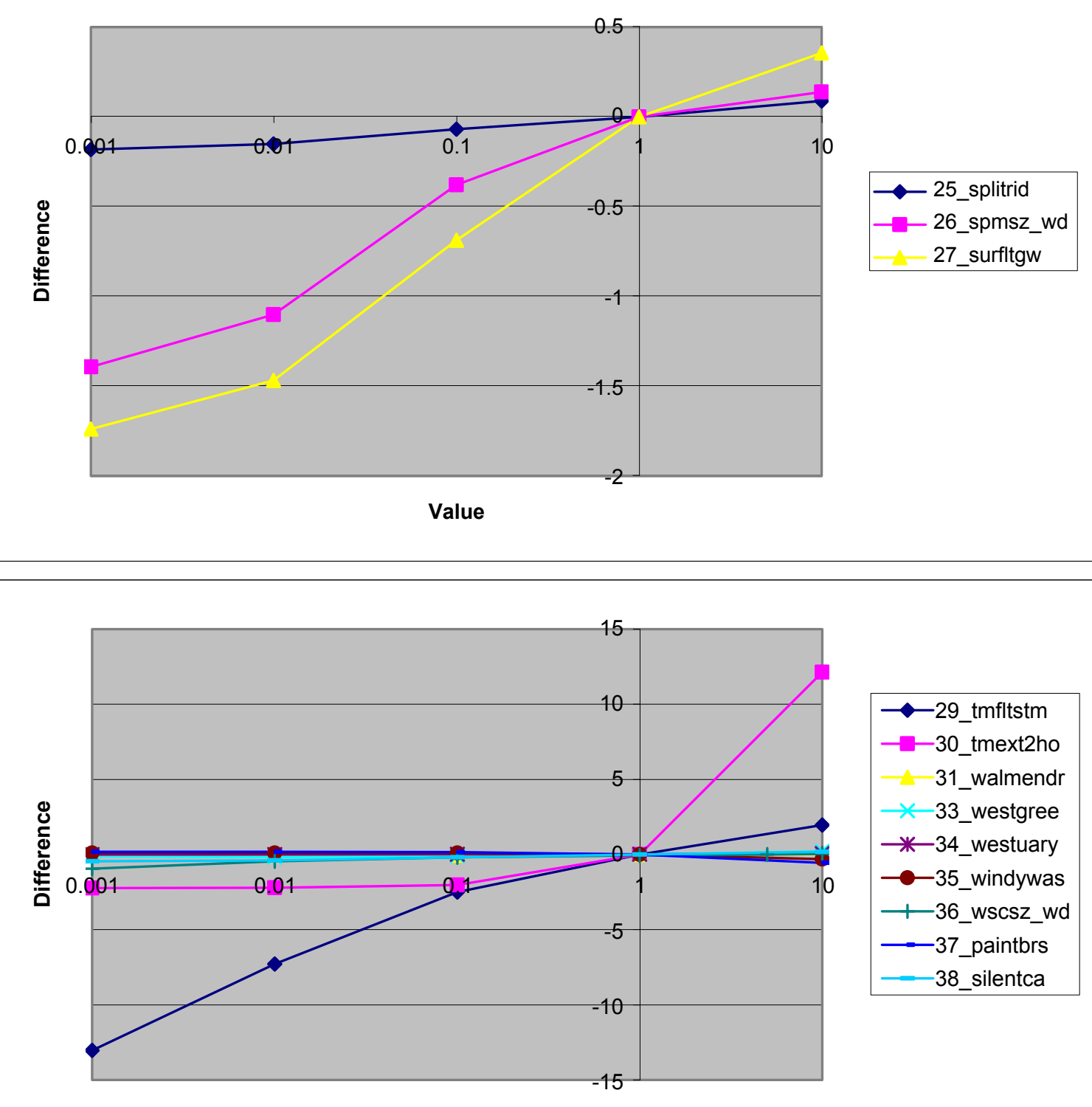

$\longrightarrow-29$ tmfltstm

-30_tmext2ho

31_walmendr

$\times 33$ westgree

*-34_westuary

-35 windywas

+ 36_wscsz_wd

-37_paintbrs

Value

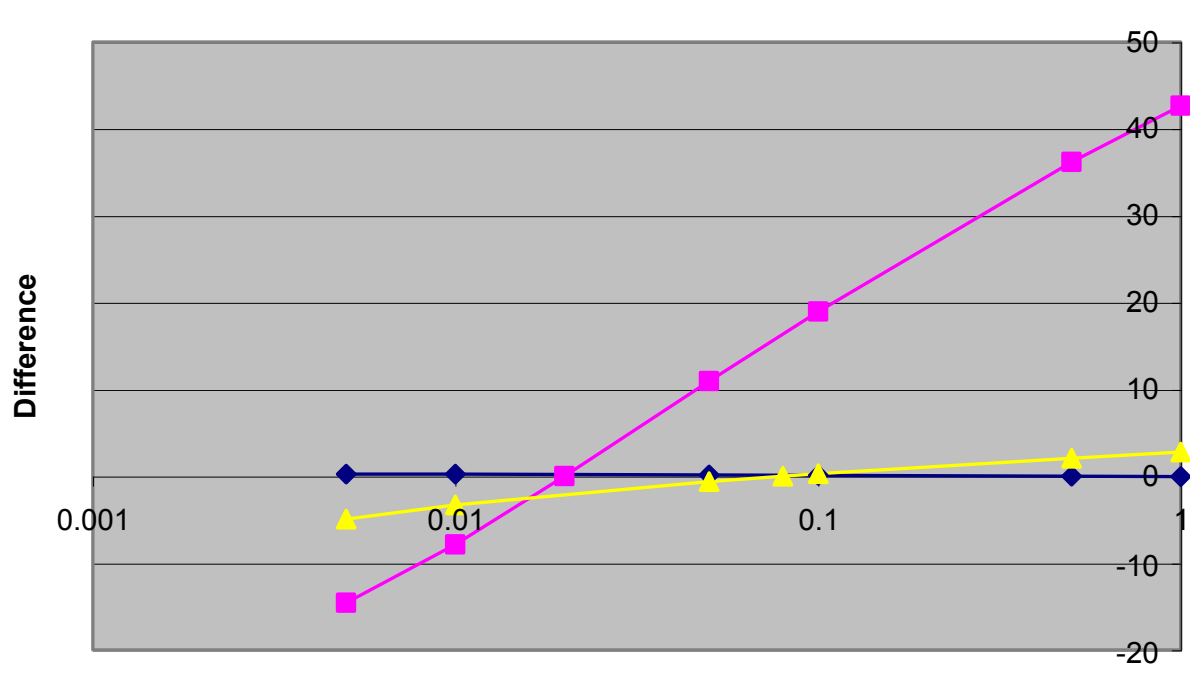

$\longrightarrow$ vaicu

— vavcm

vavaq 

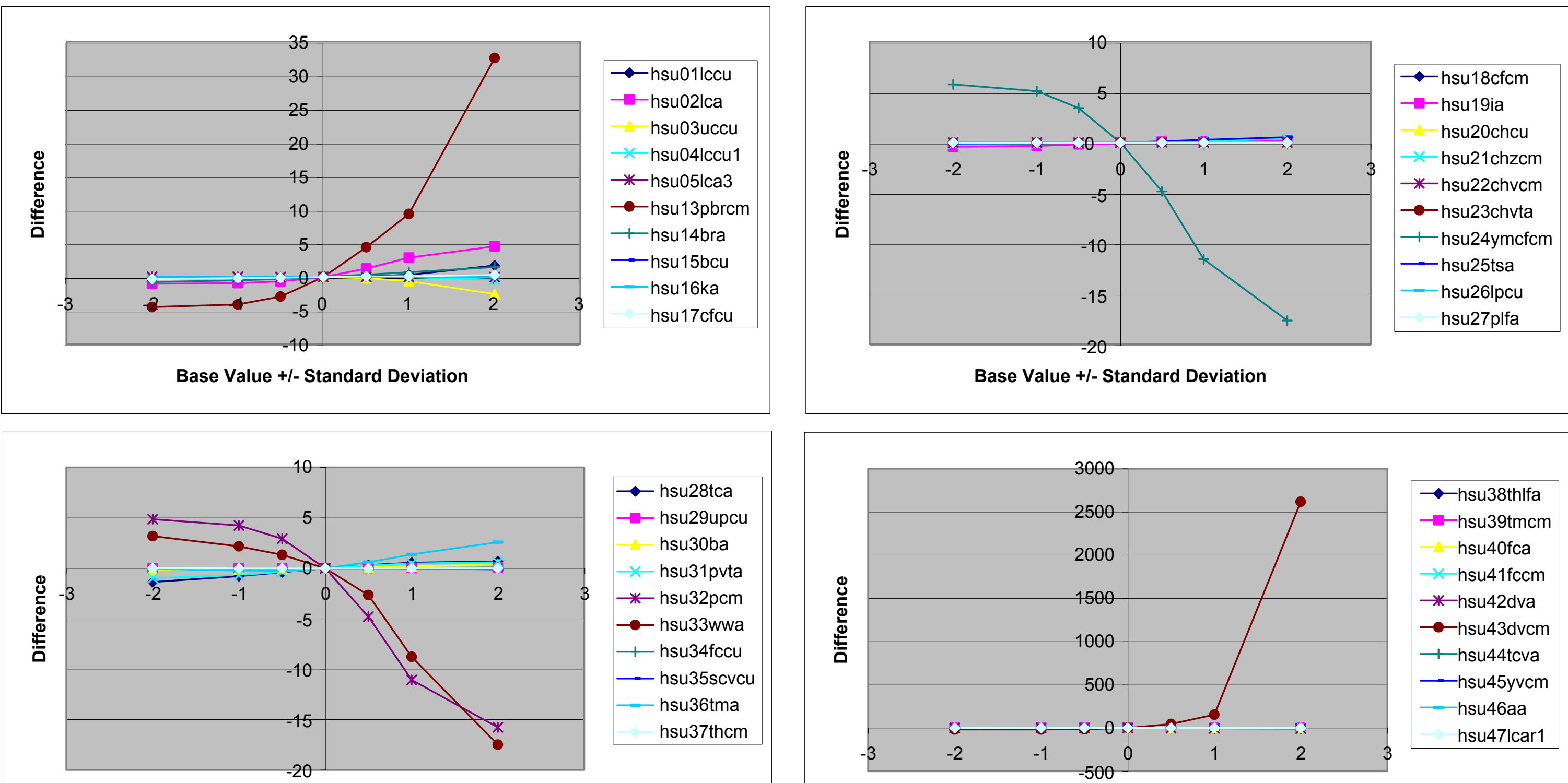

Base Value +/-Standard Deviation

Base Value + + Standard Deviation
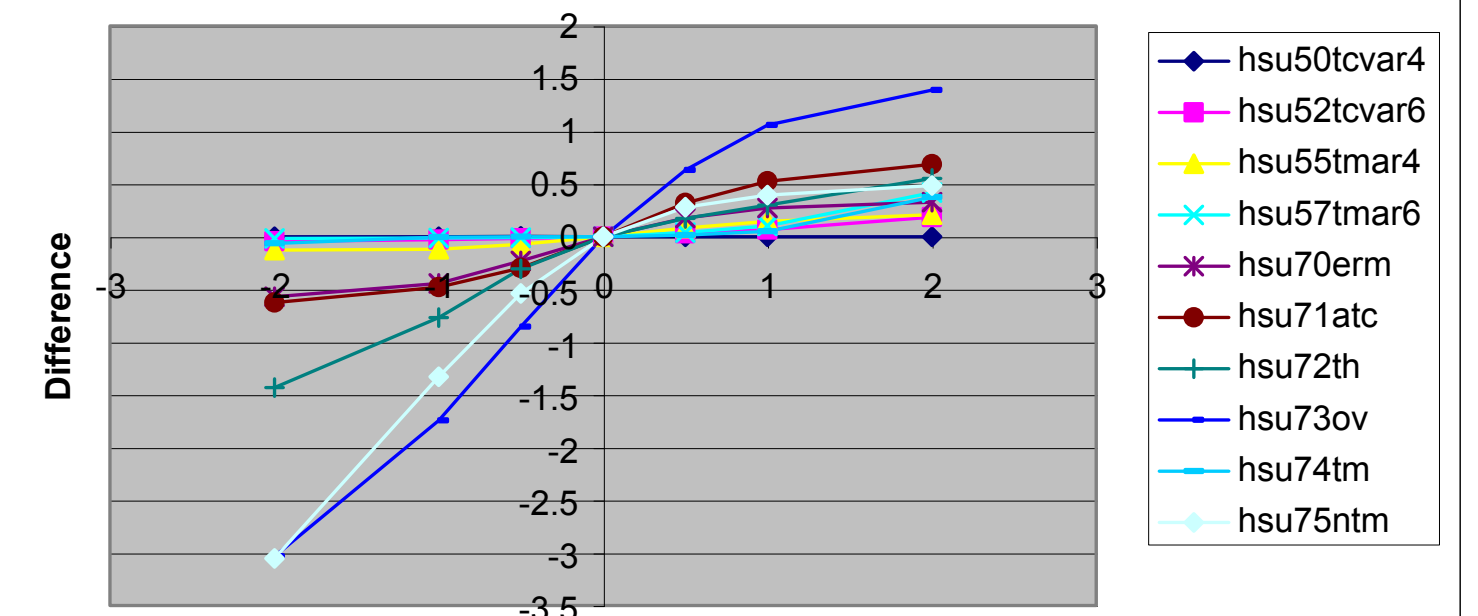

Base Value +/- Standard Deviation
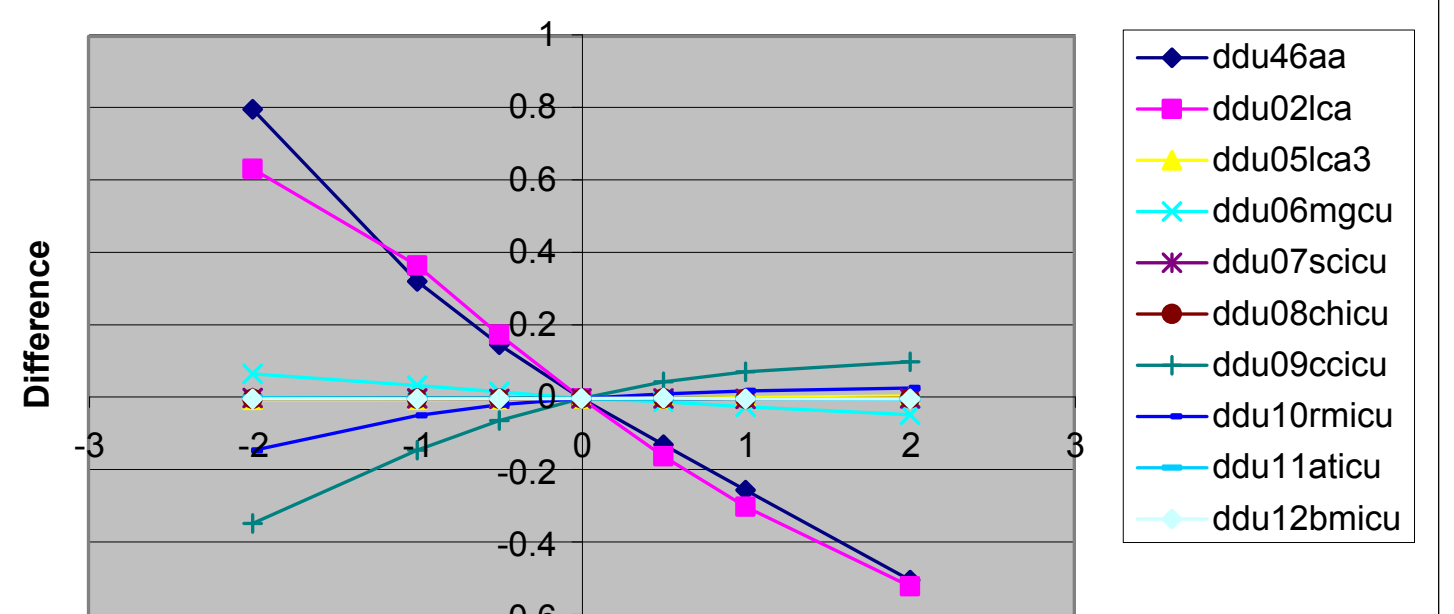

Base Value +/- Standard Deviation
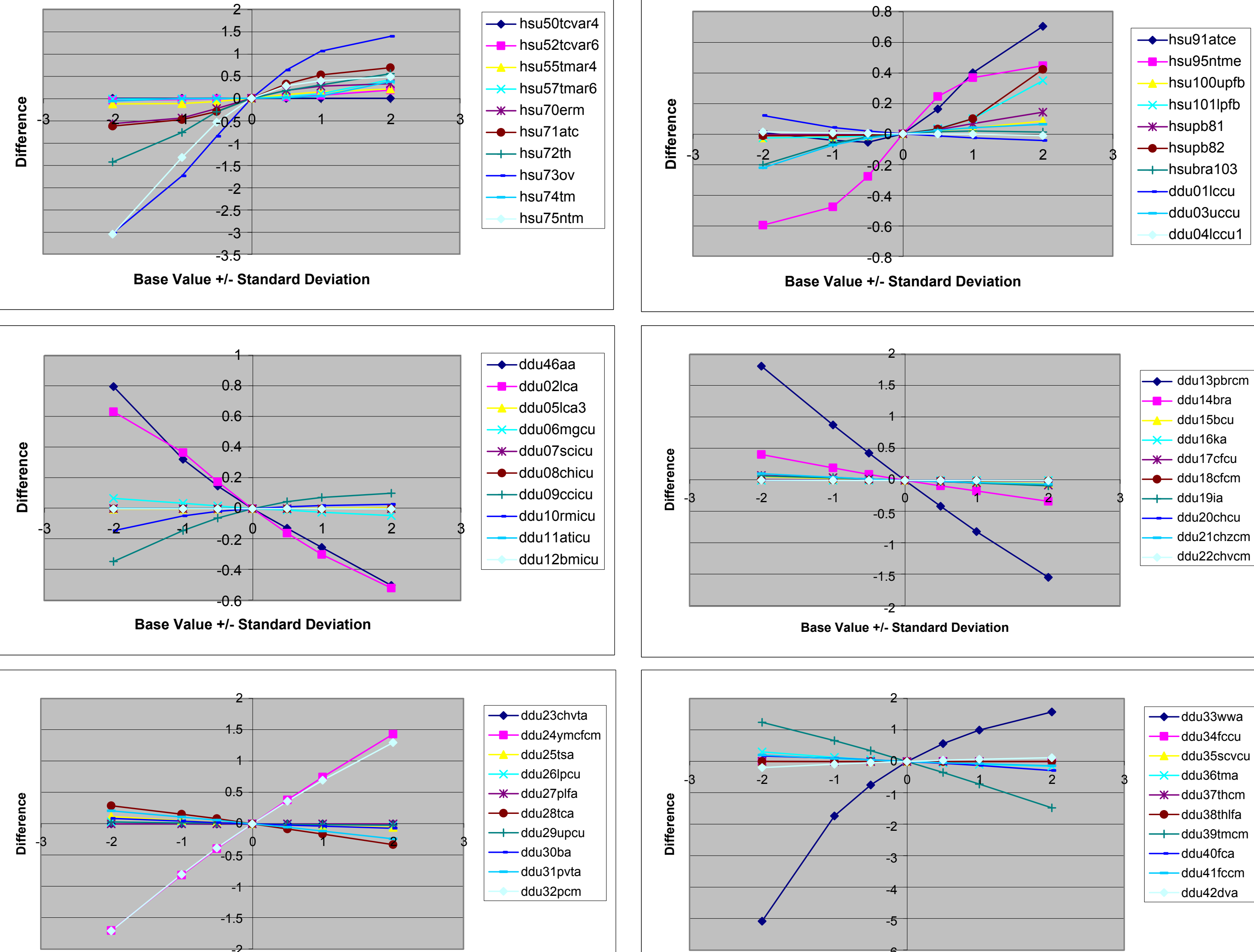

Base Value +/- Standard Deviation

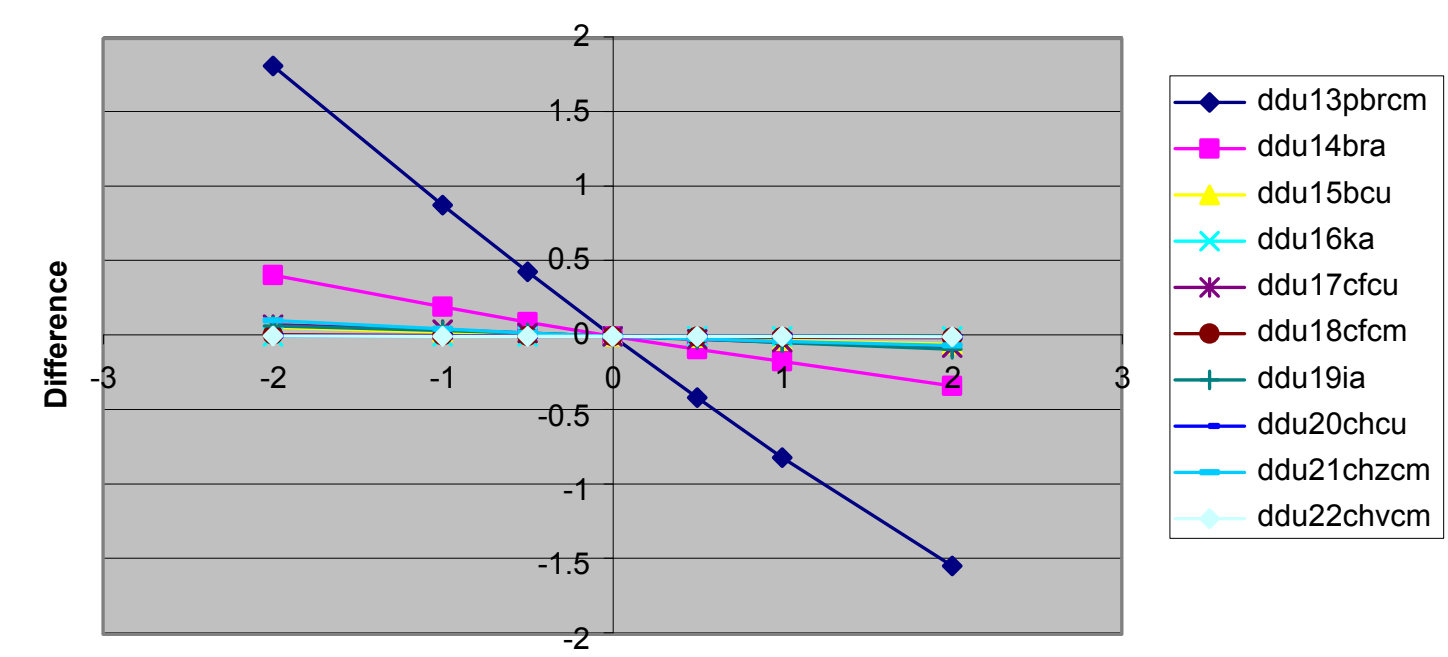

Base Value ++2 - Standard Deviation

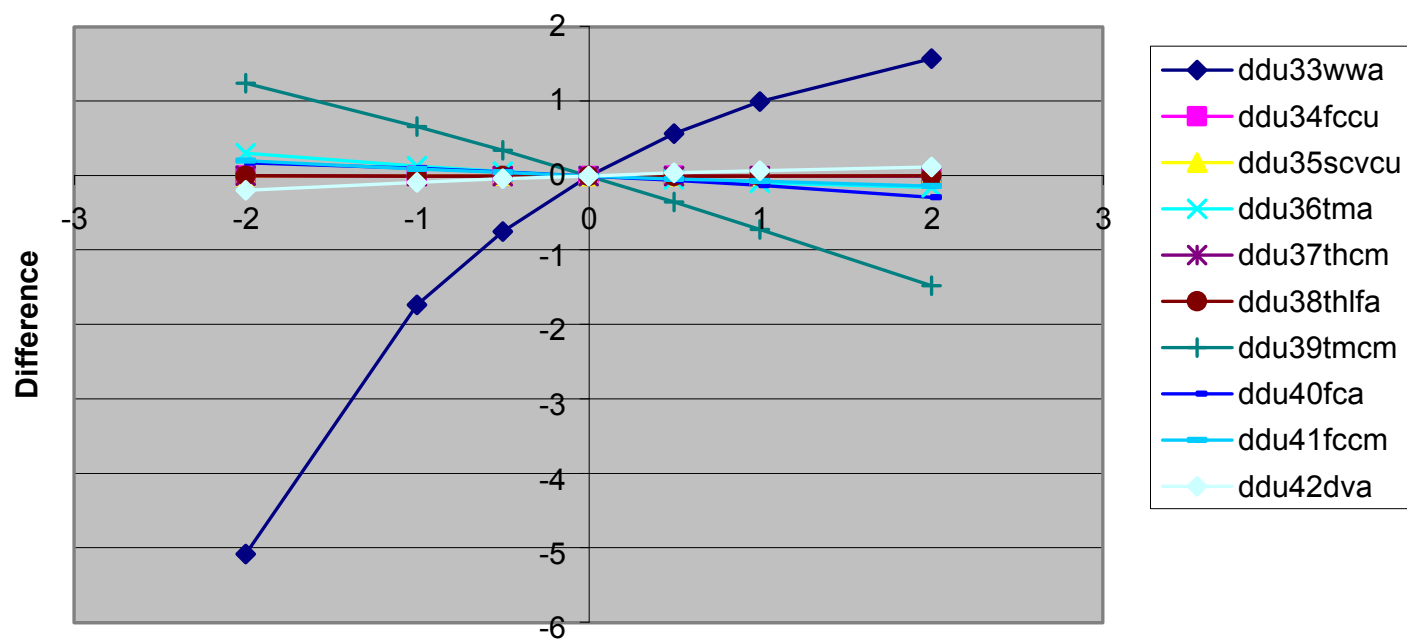

Base Value + +/-Standard Deviation
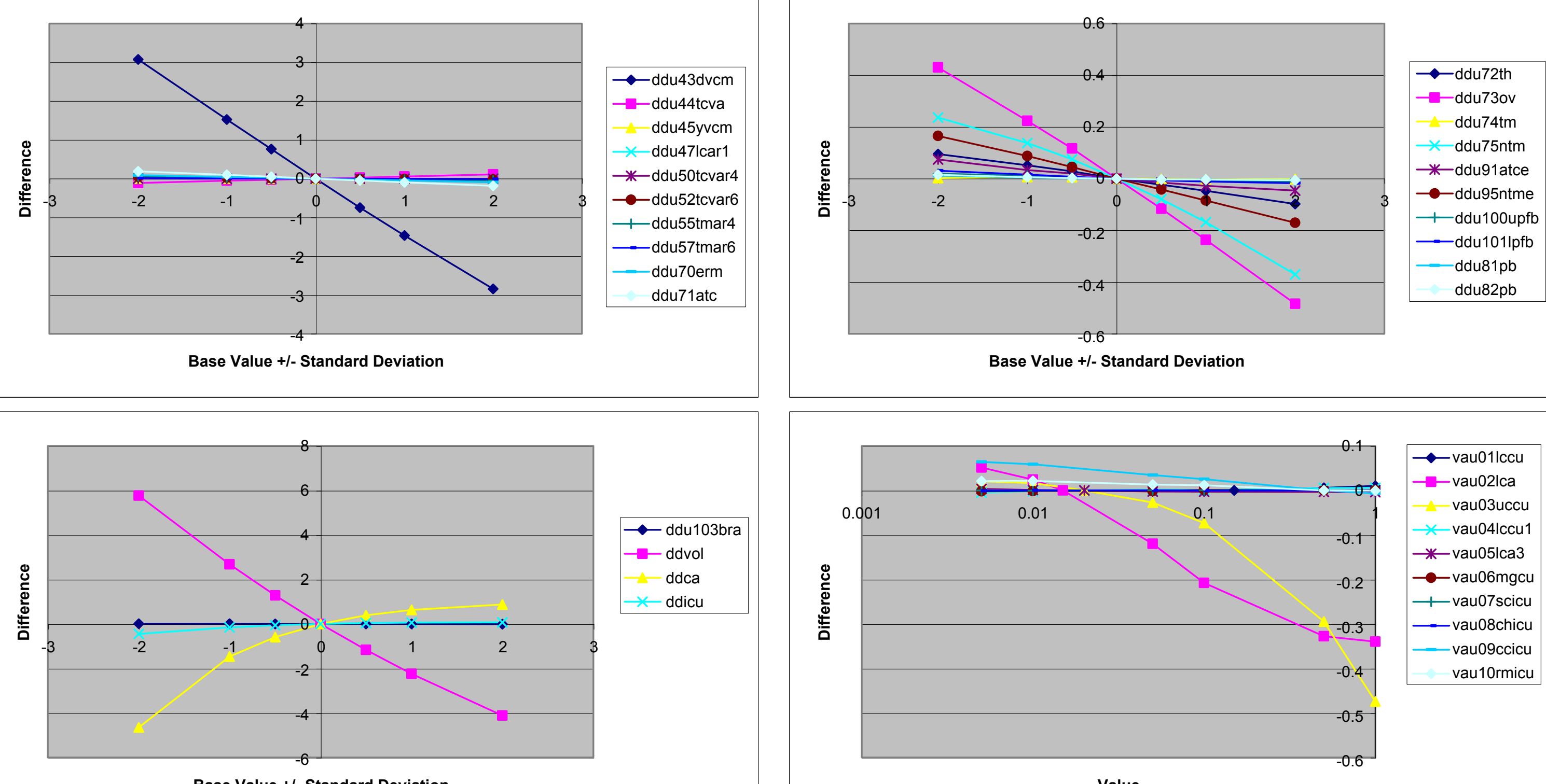

Base Value t/-Standard Deviation
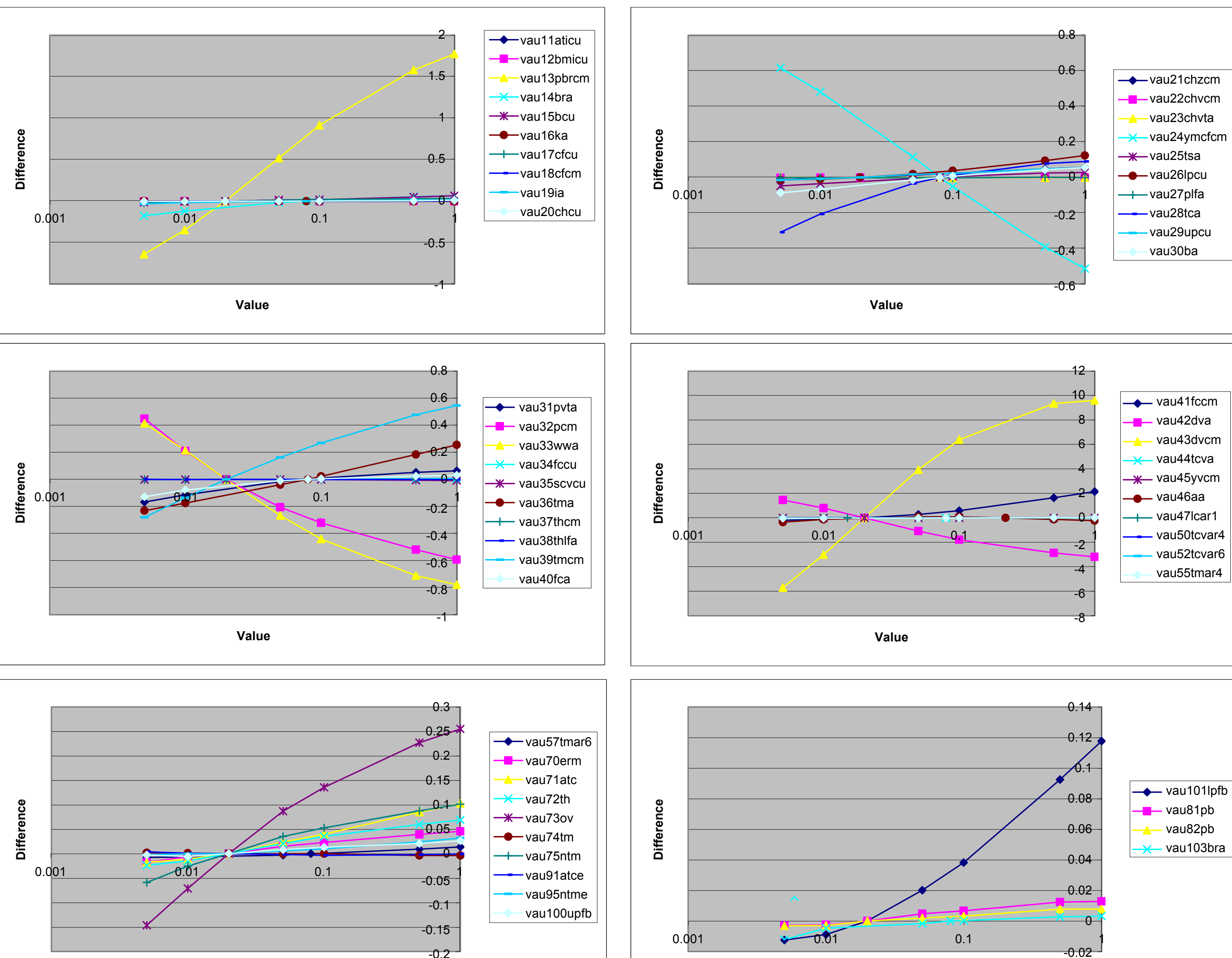

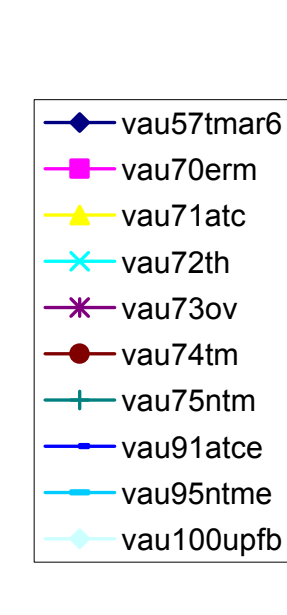

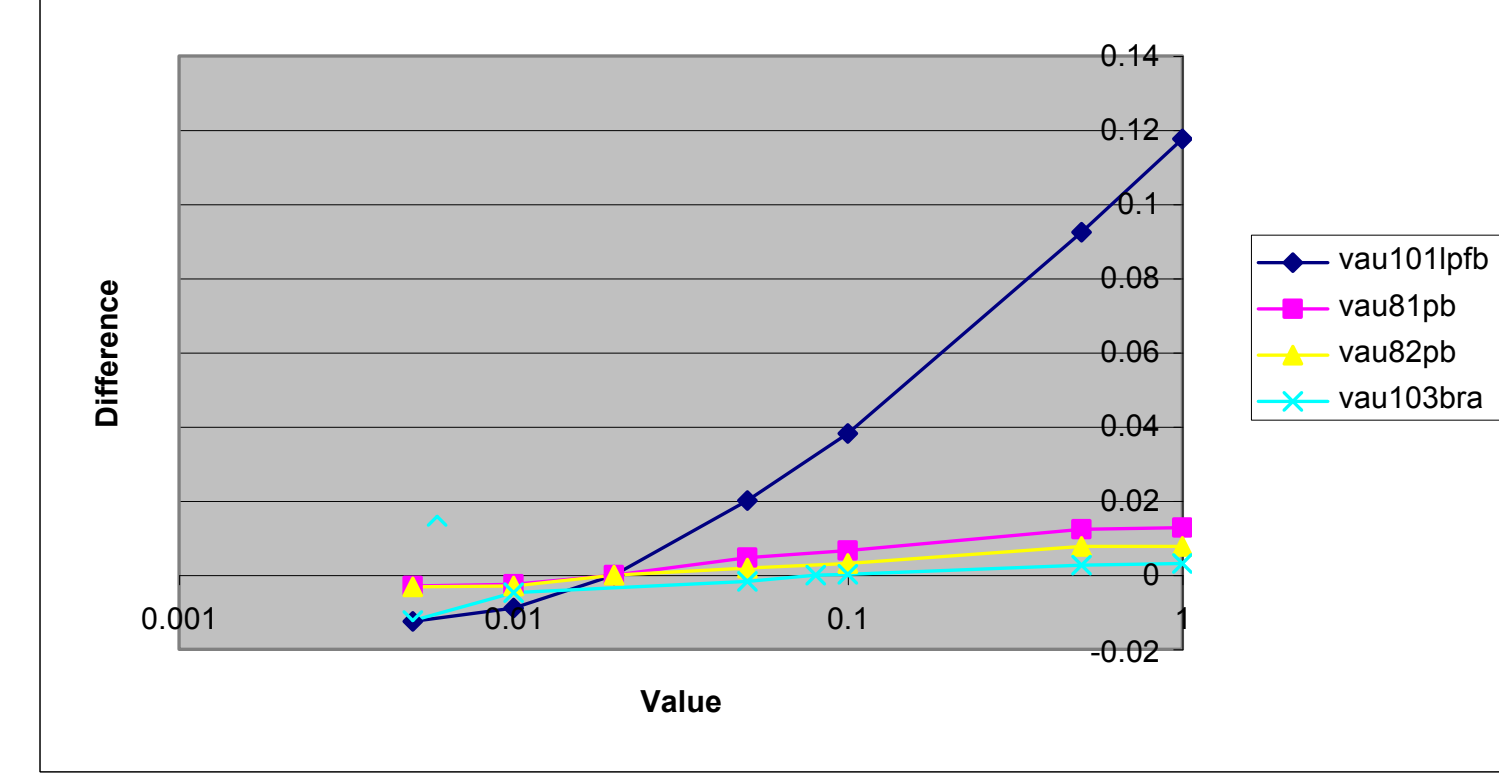




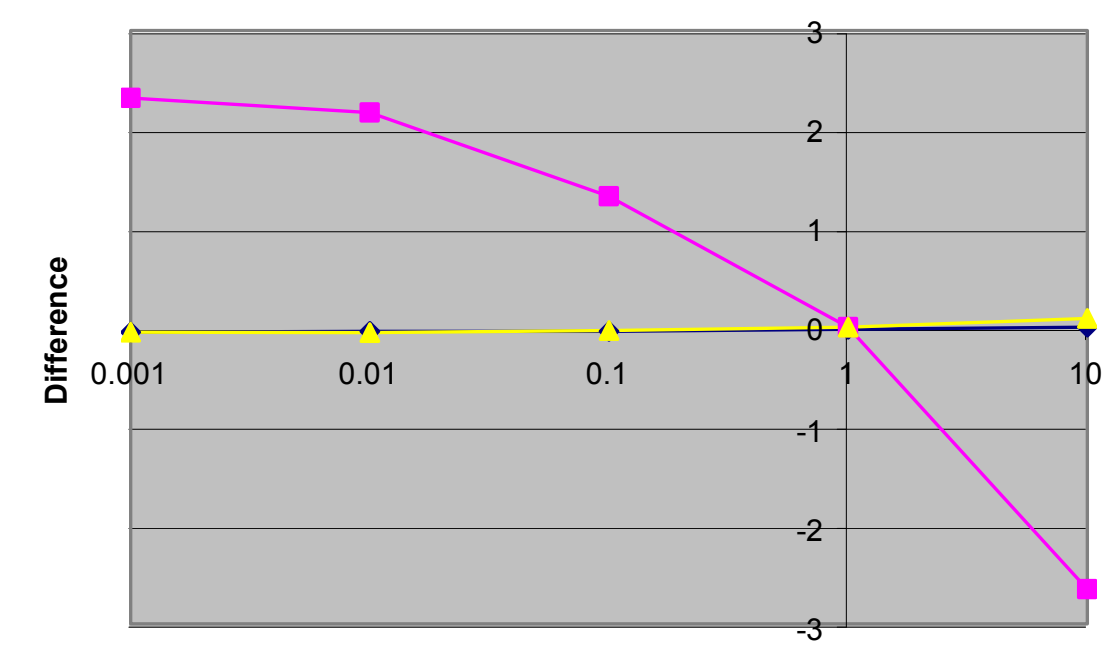

$\longrightarrow 01$ _almendro
$\rightarrow-02$ baremtnf

$03 \_b m c s m w d f$
-

\section{Value}
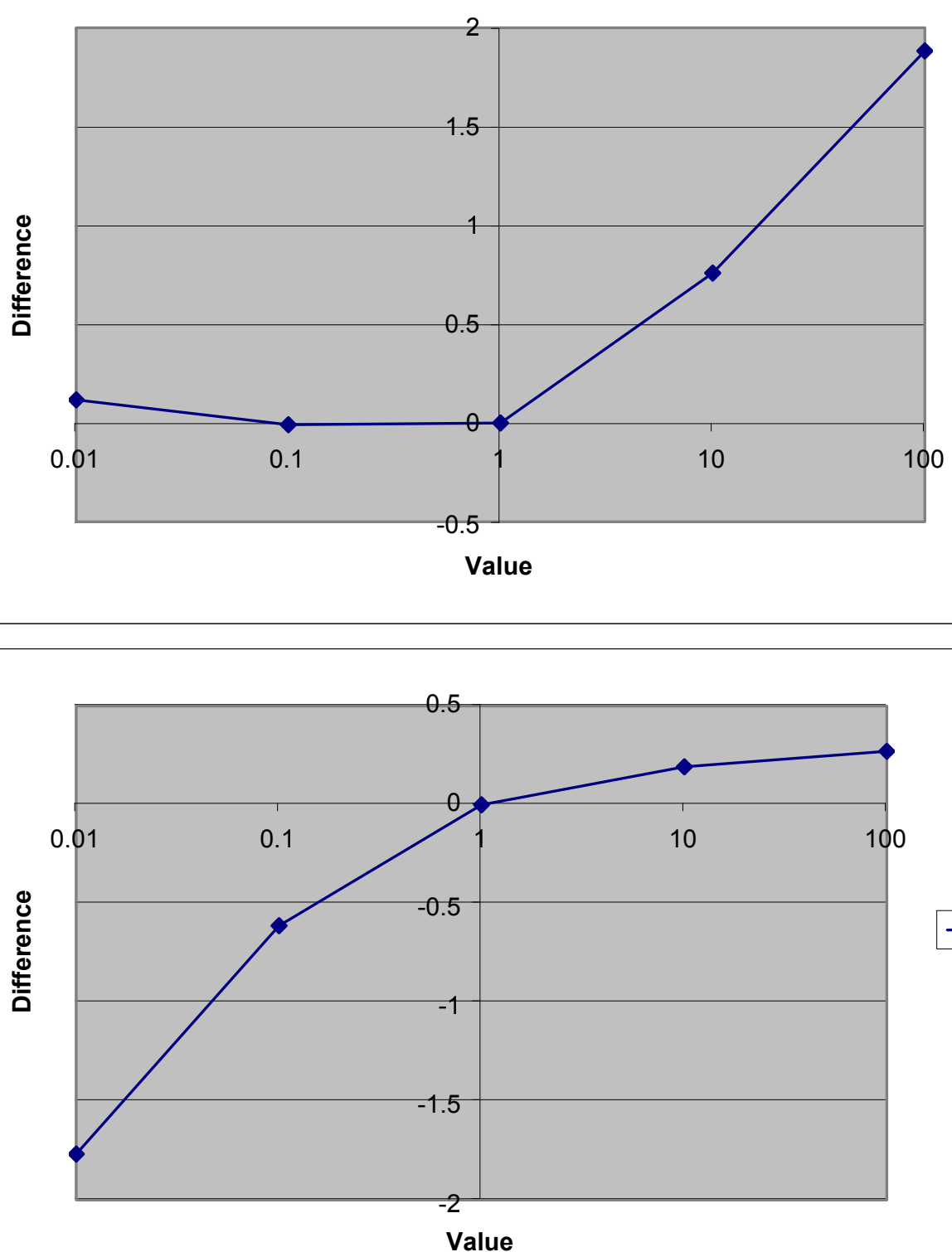

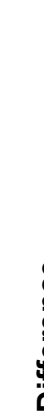

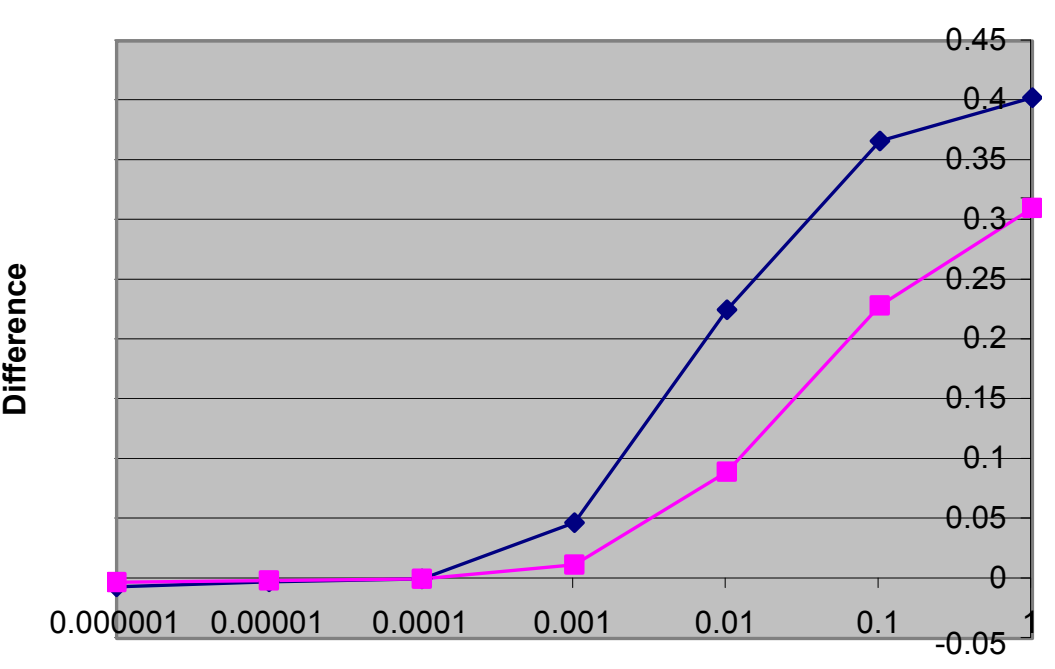

Value

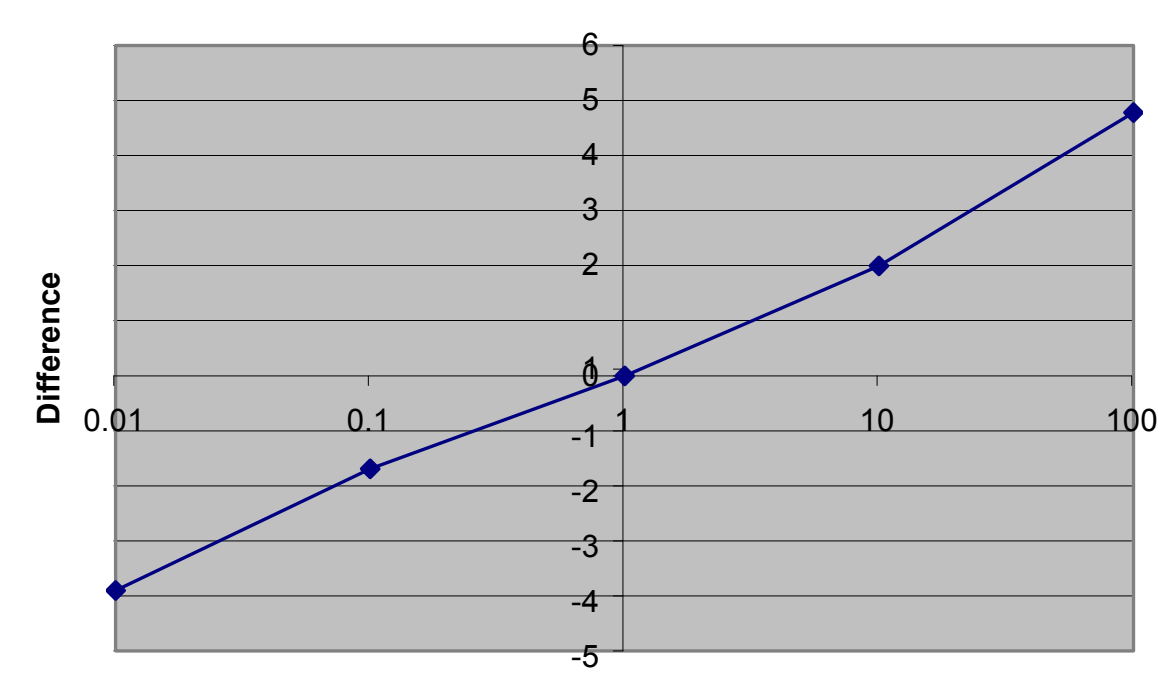

$\bullet \bullet 28$ tmfltsra

$\longrightarrow$-23_silentca
$\rightarrow-24 \_p u r s e n w d$ $\bullet$ - 05_cfhogft

$\bullet-15$ ntmmsz_w

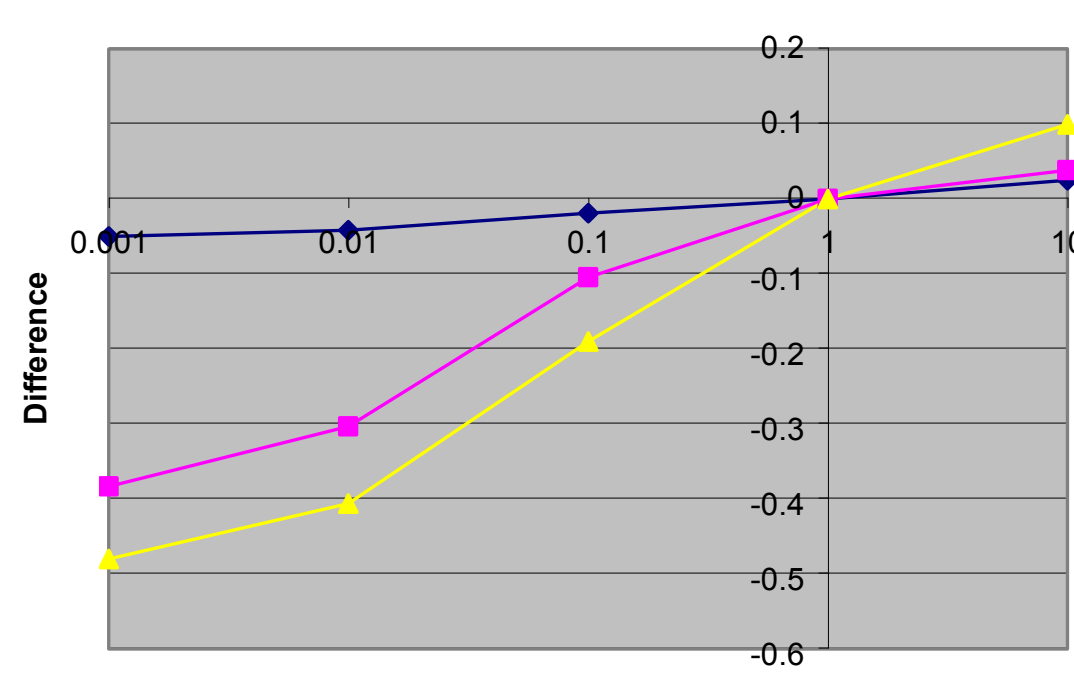

-16_ribcliff

-17_richey_w

-18_scrugham

$\times$ 19_scnsz_wd

*-20_scsze_wd

- -21 scszw_wd

+22_sefttwfd

Value

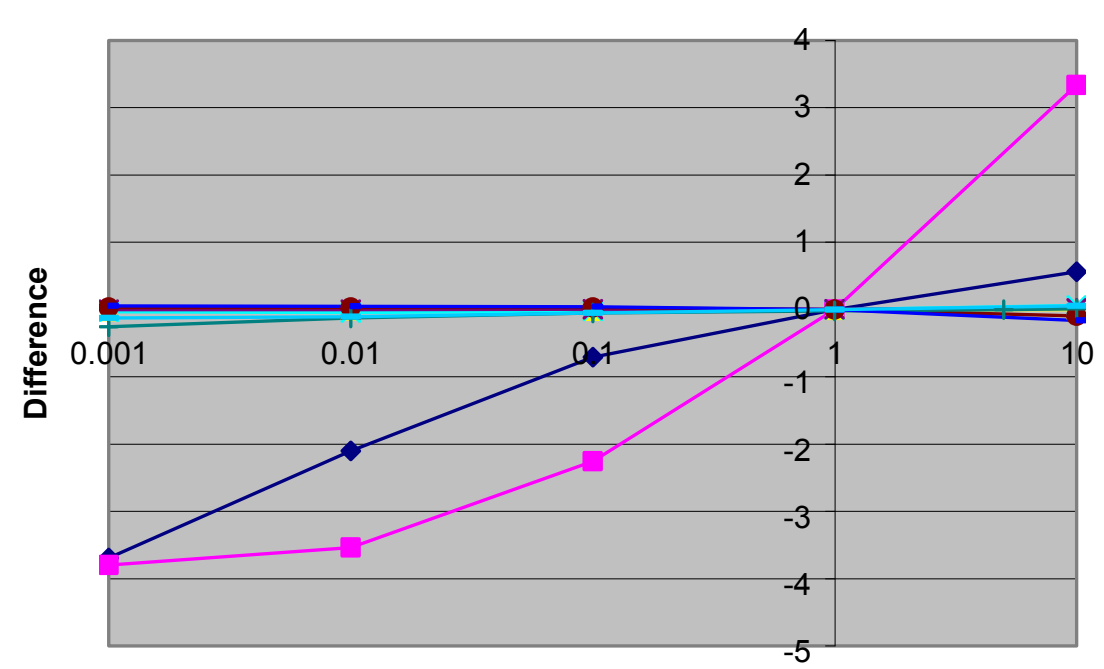

Value $\longrightarrow$ 25_splitrid

-26_spmsz_wd

27_surfltgw

$\longrightarrow-29$ tmfltstm

-30_tmext2ho

31_walmendr

$\times$ 33_westgree

*-34_westuary

- 35 _windywas

— 36_wscsz_wd

-37 paintbrs

- 38 _silentca

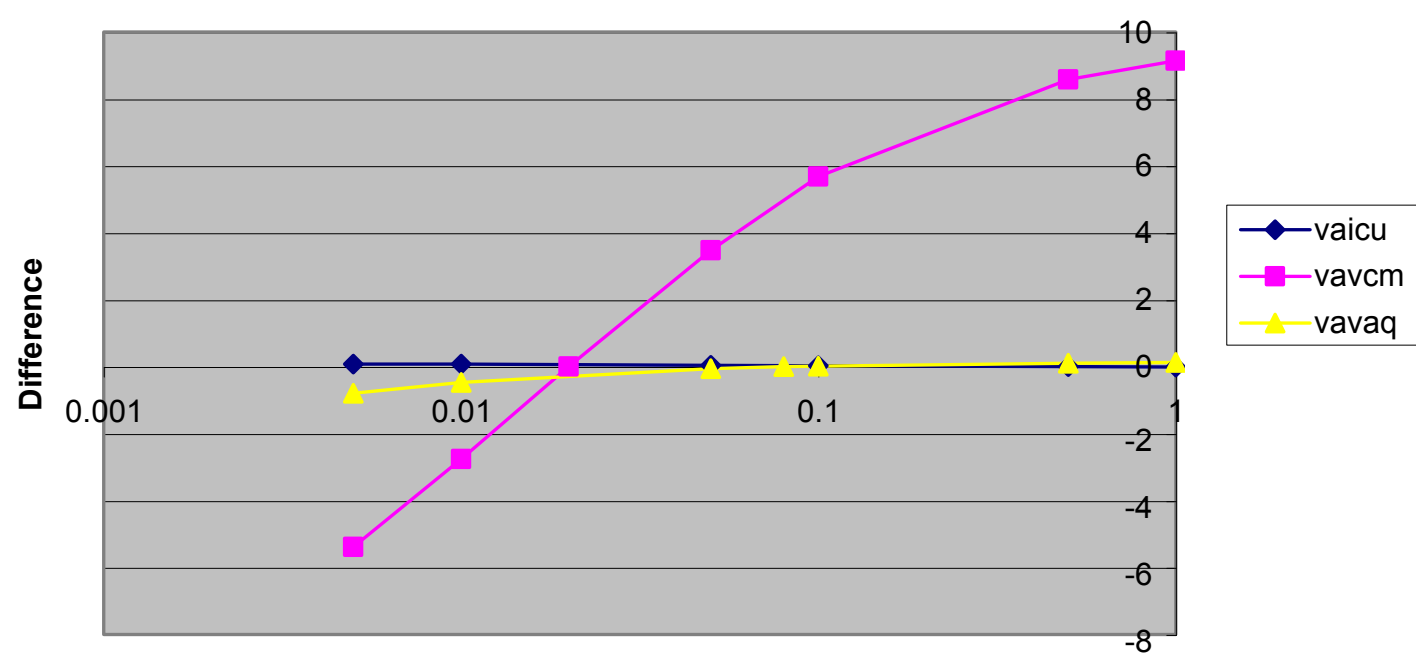

Value

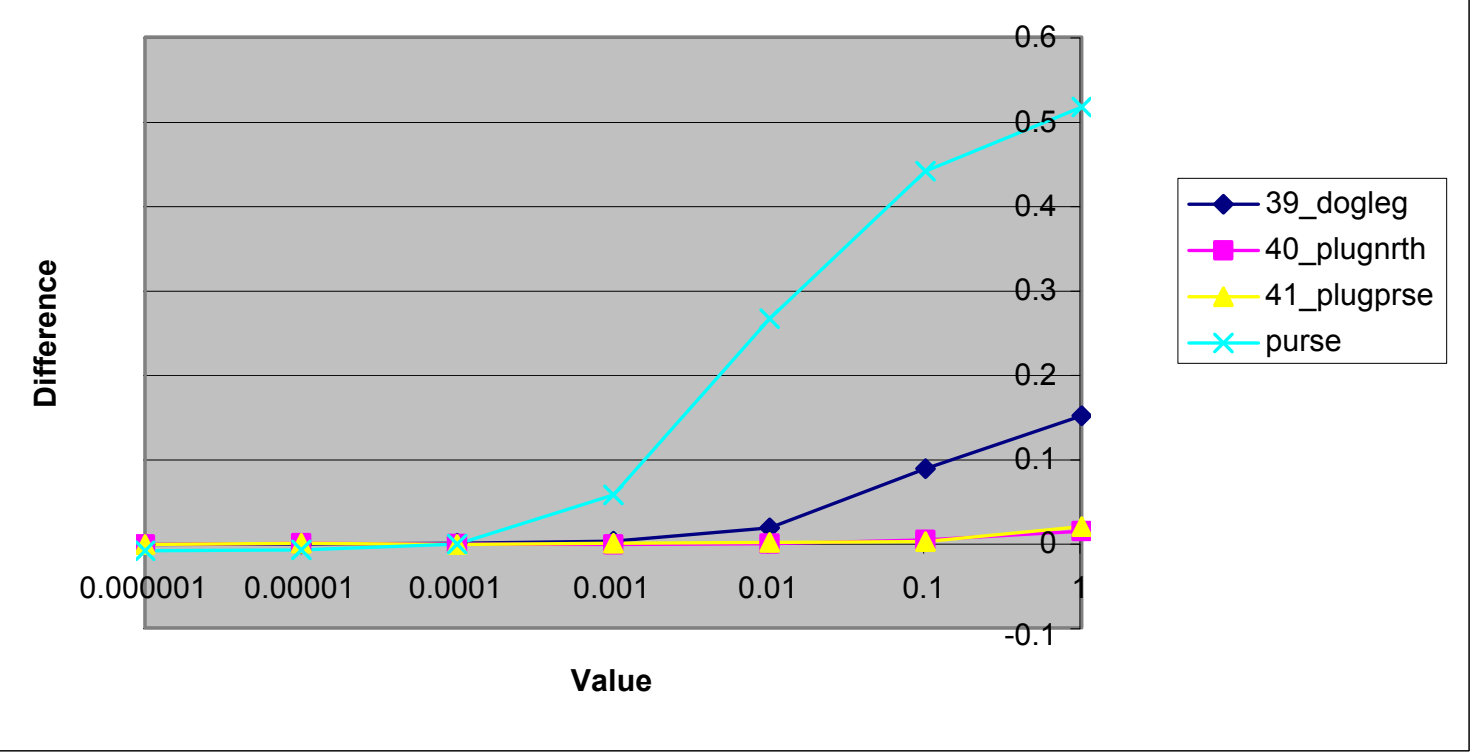



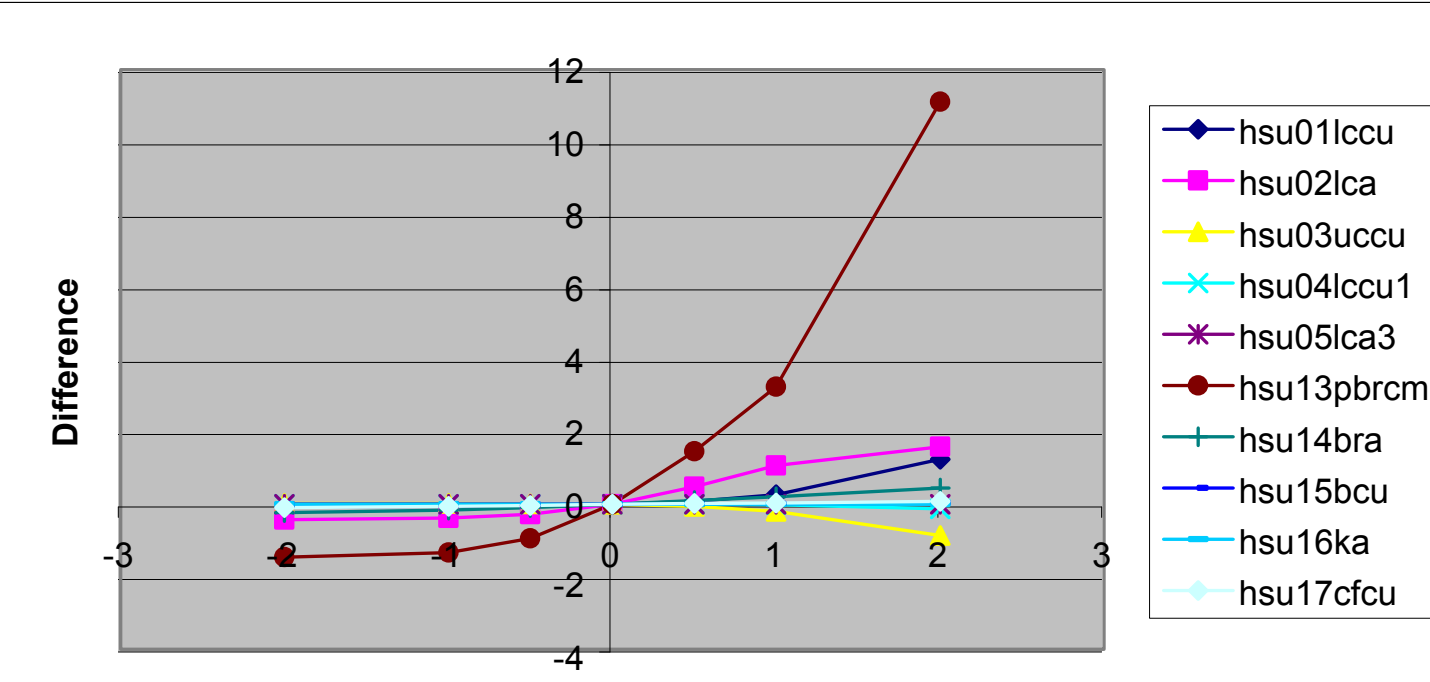

Base Value +/-Standard Deviatio

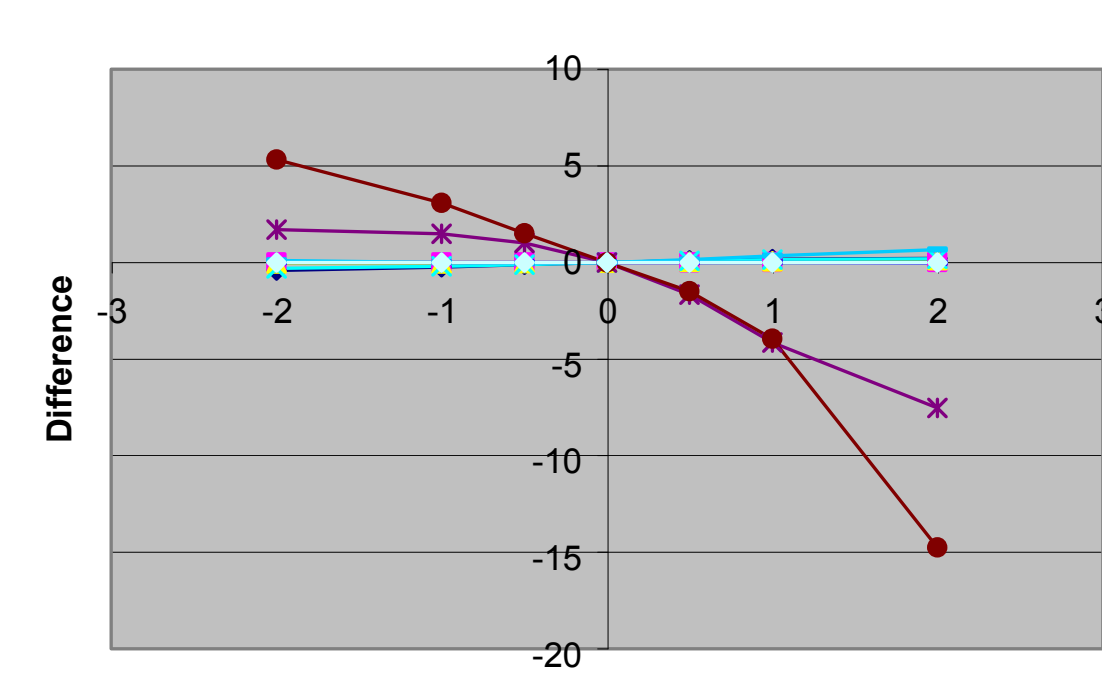

Base Value +1-Standard Deviation

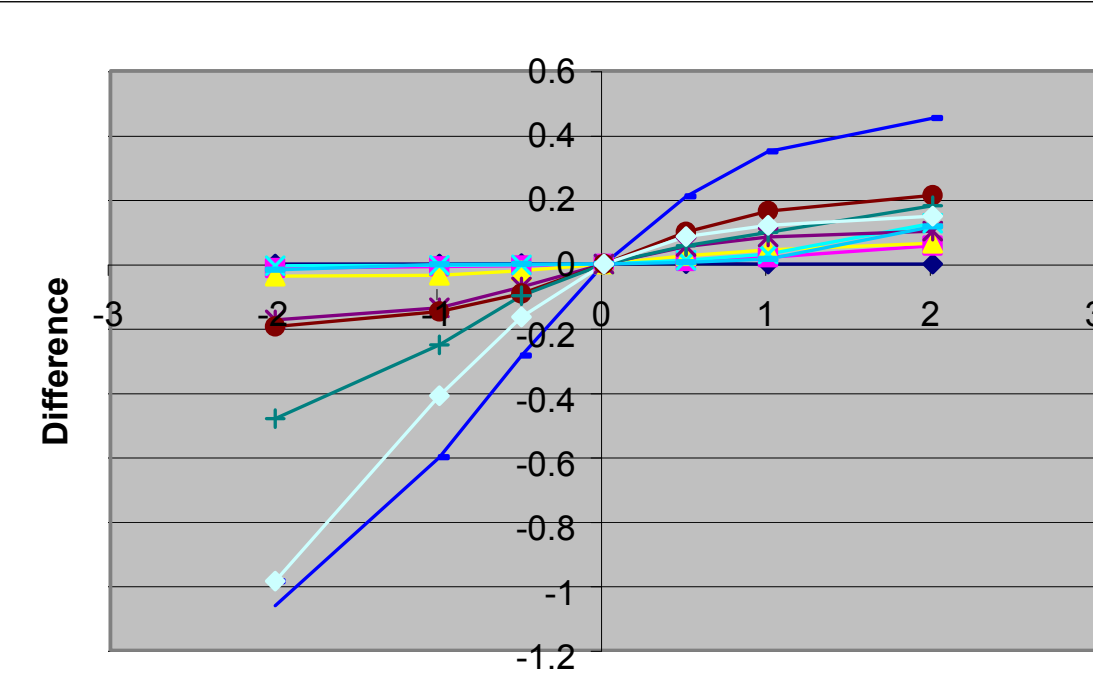

Base Value $+/$-Standard Deviation

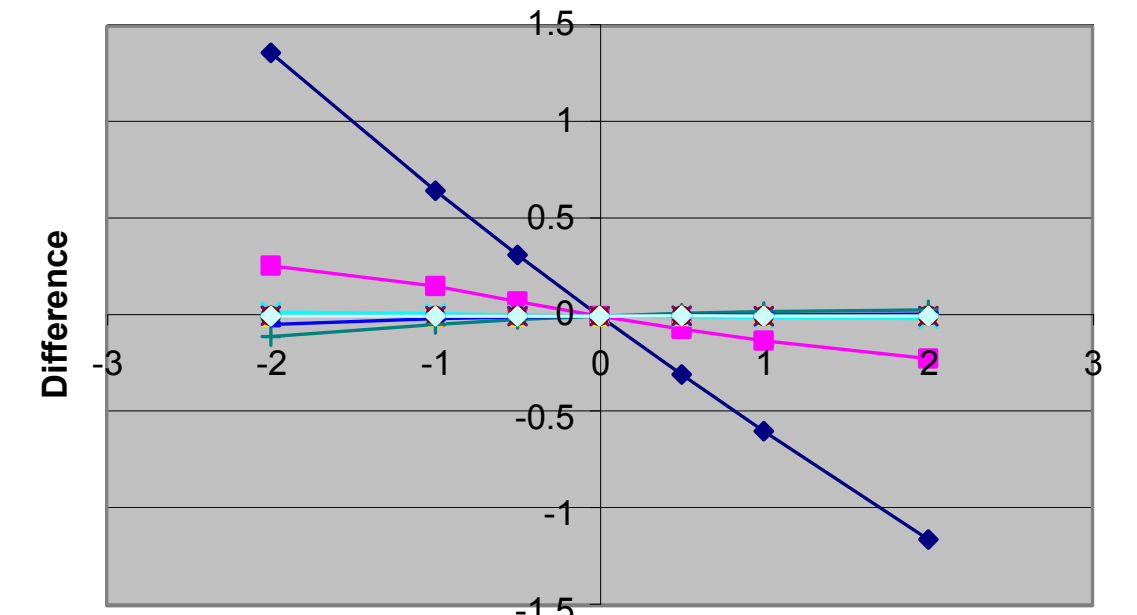

Base Value +1-Standard Deviatio

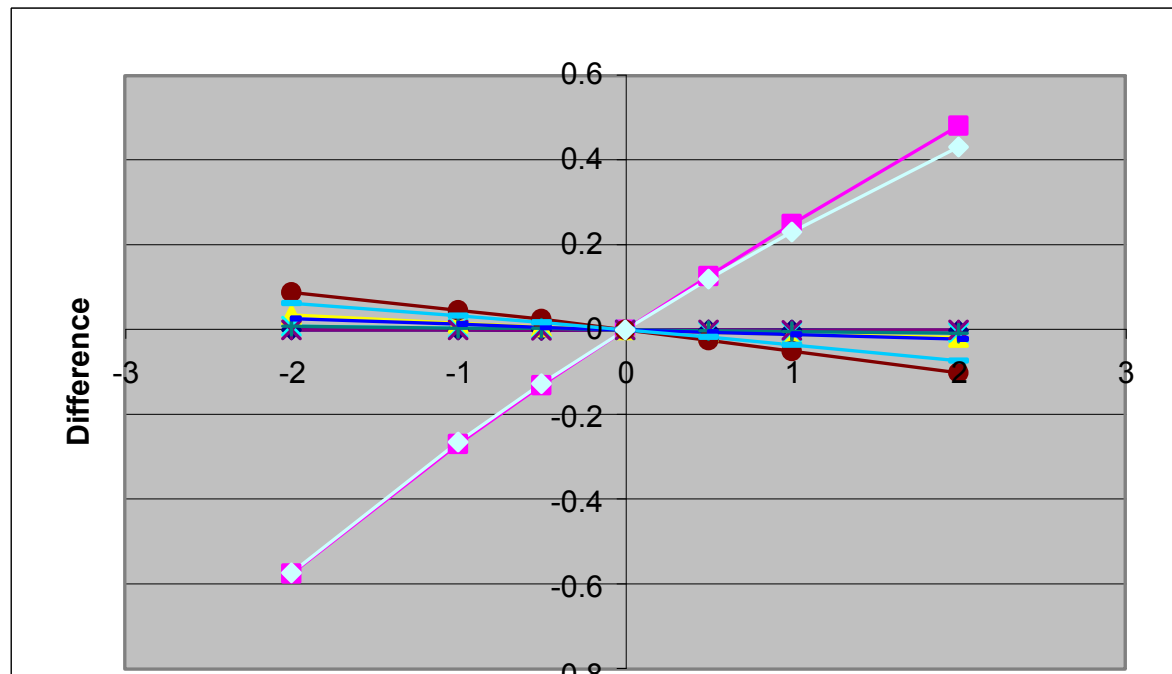

Base value + +. Standard Deviation

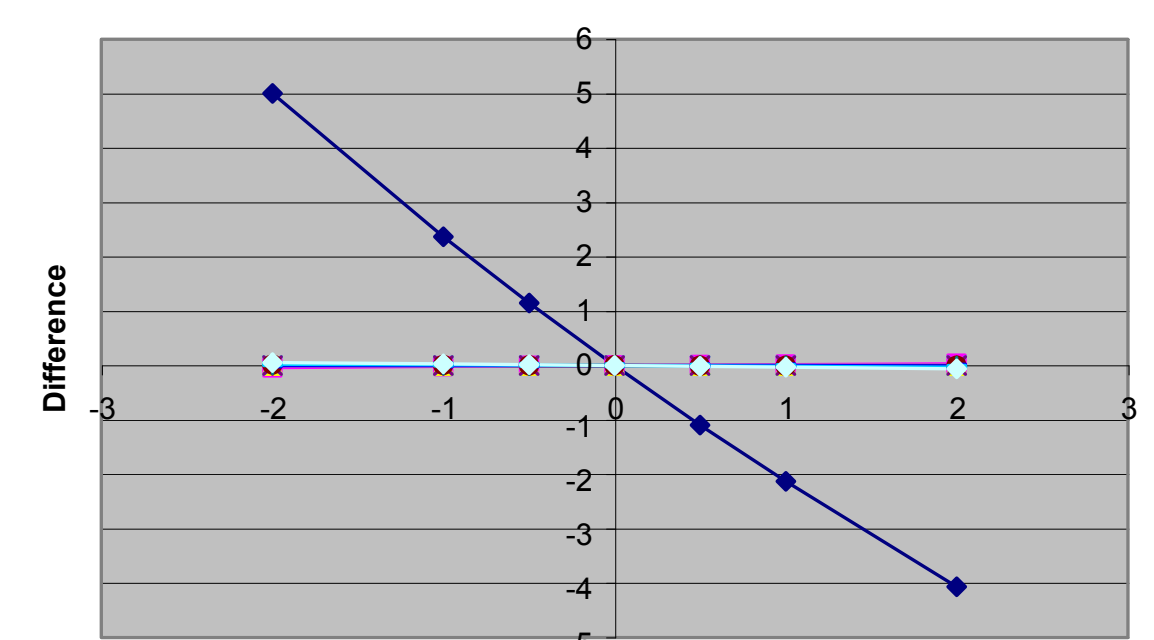

Base Value +5 - Standard Deviation

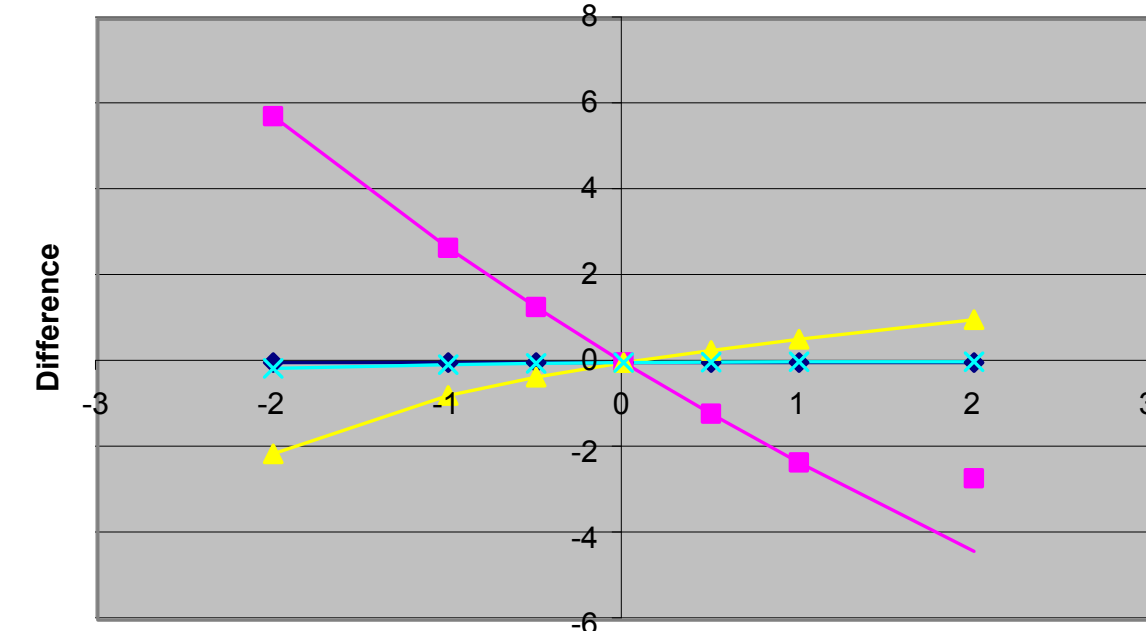

Base value +- -5 Standard Deviation
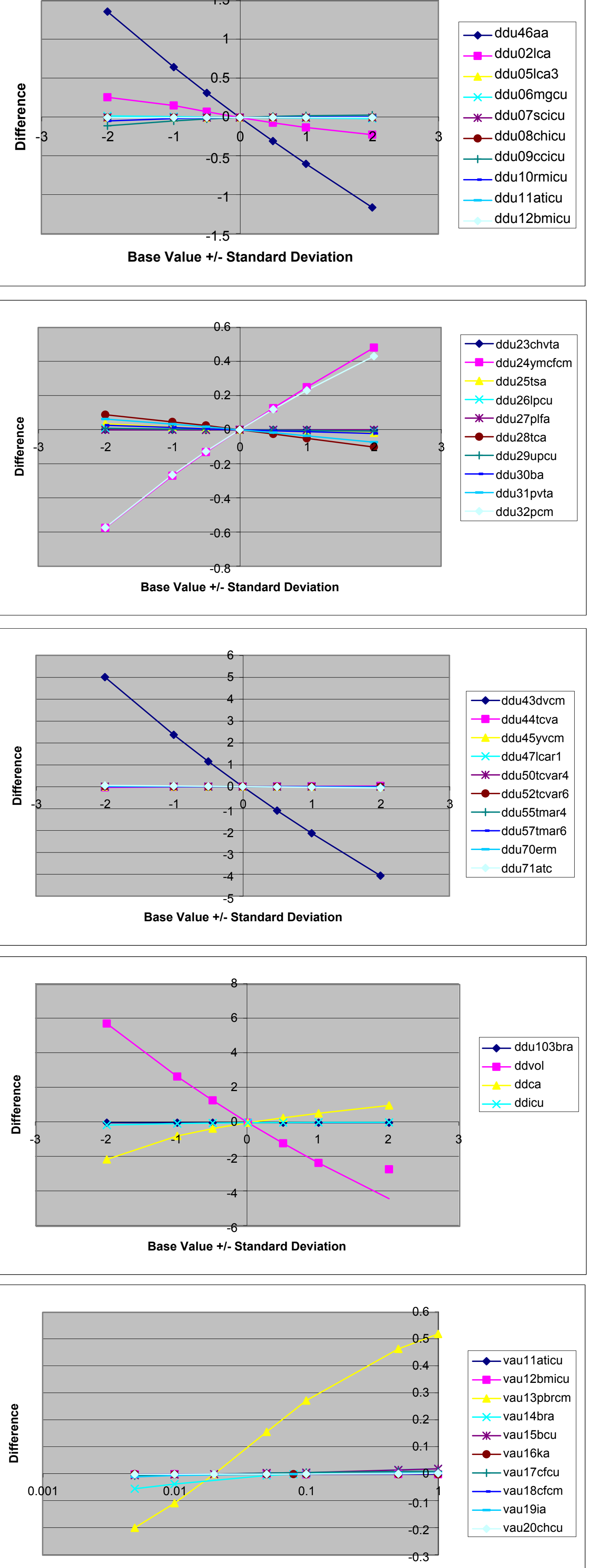

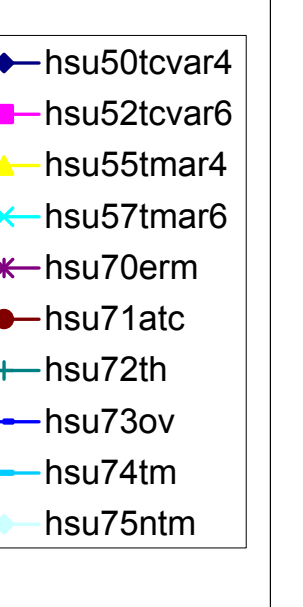
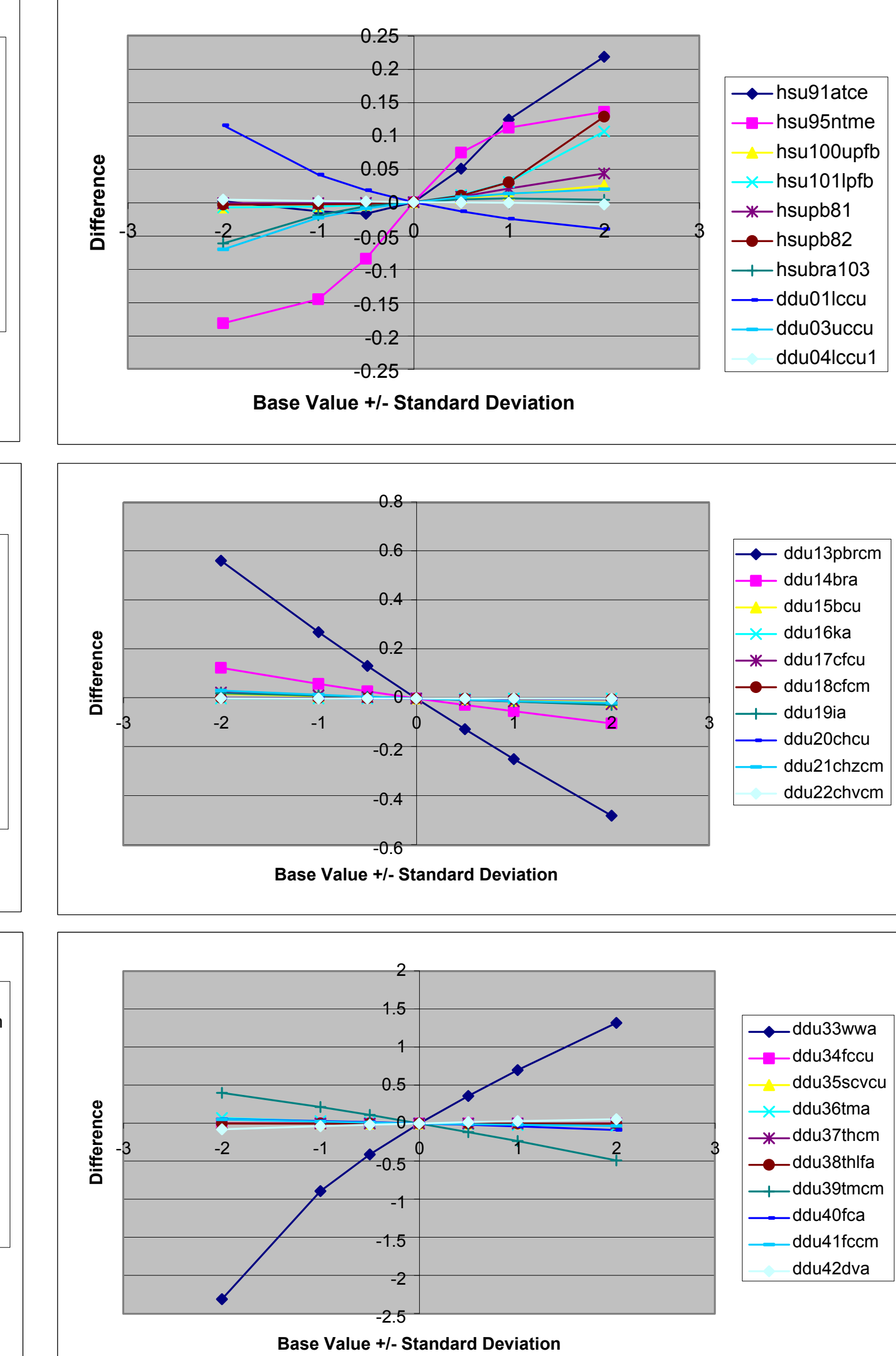

Base Value +t/standard Deviation

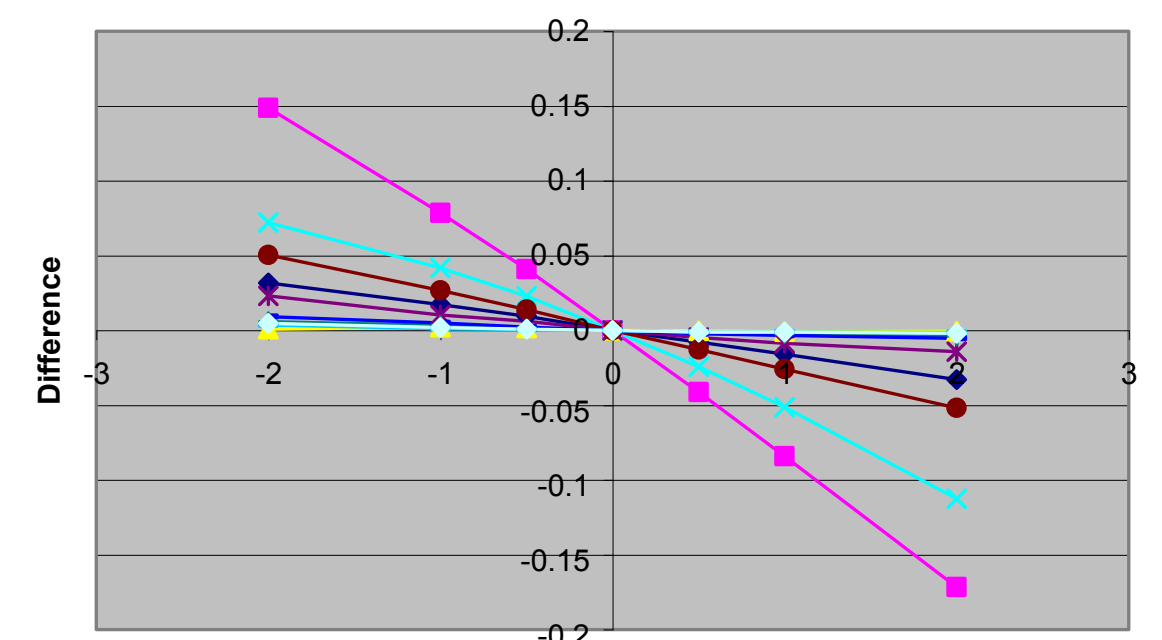

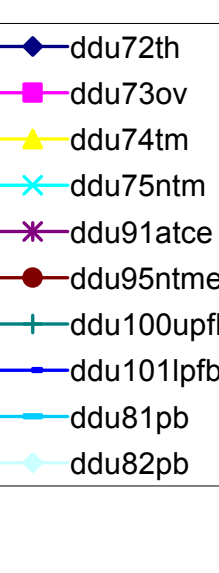

Base Value $+\stackrel{-0.2}{-}$ Standard Deviation
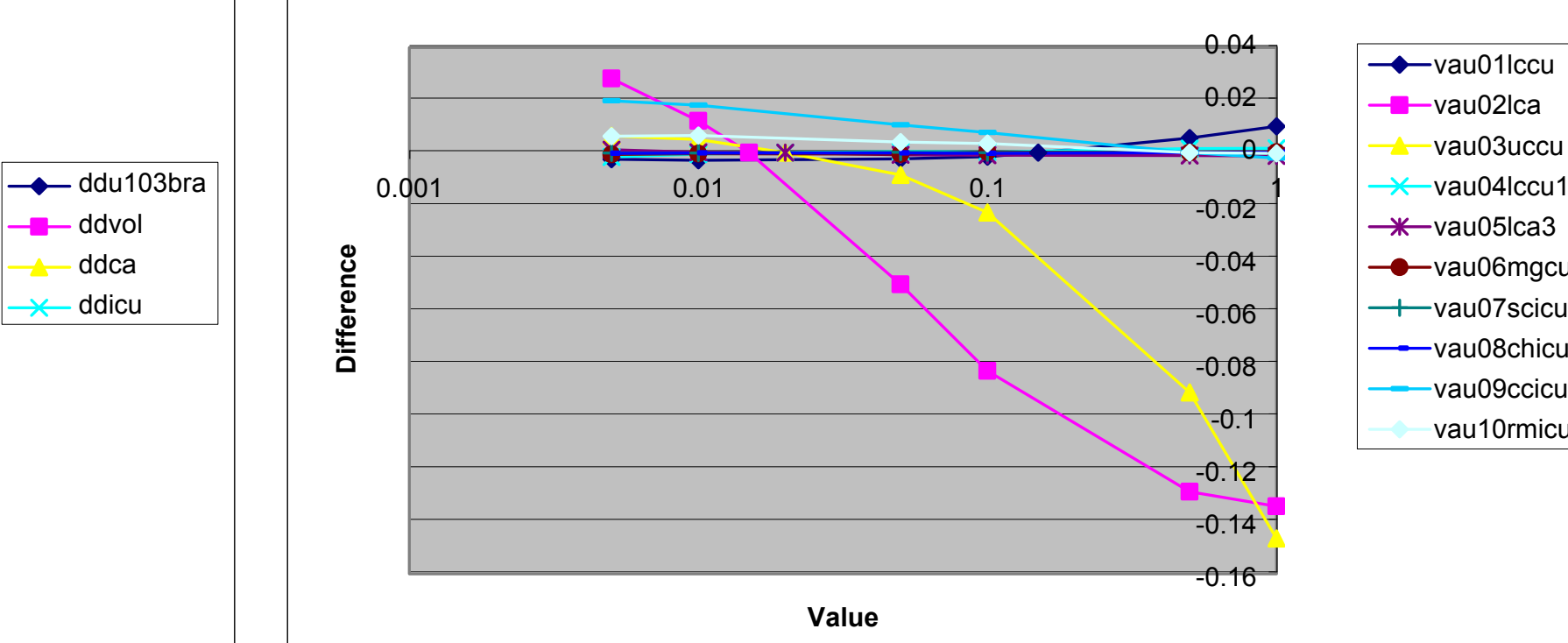

value
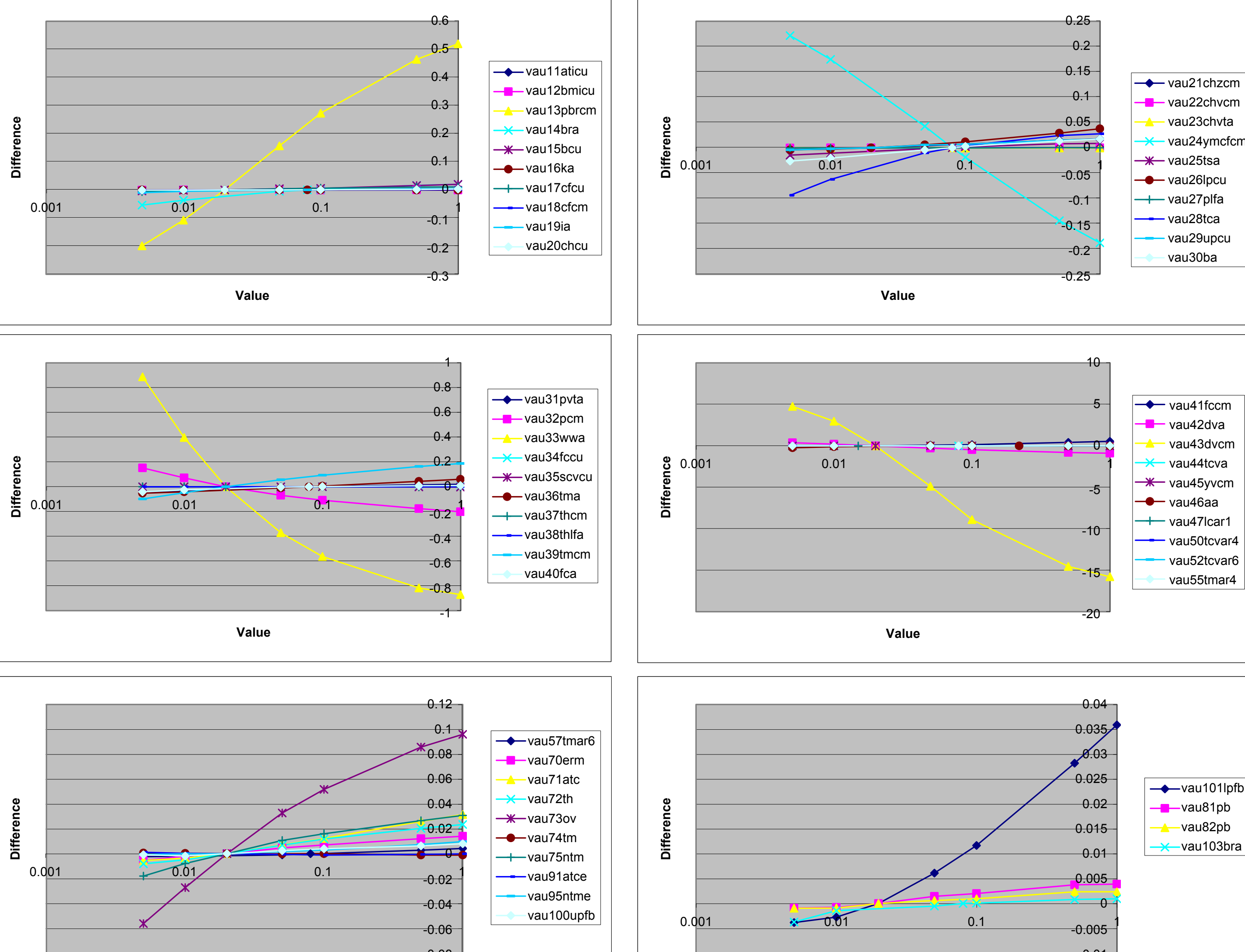

Value

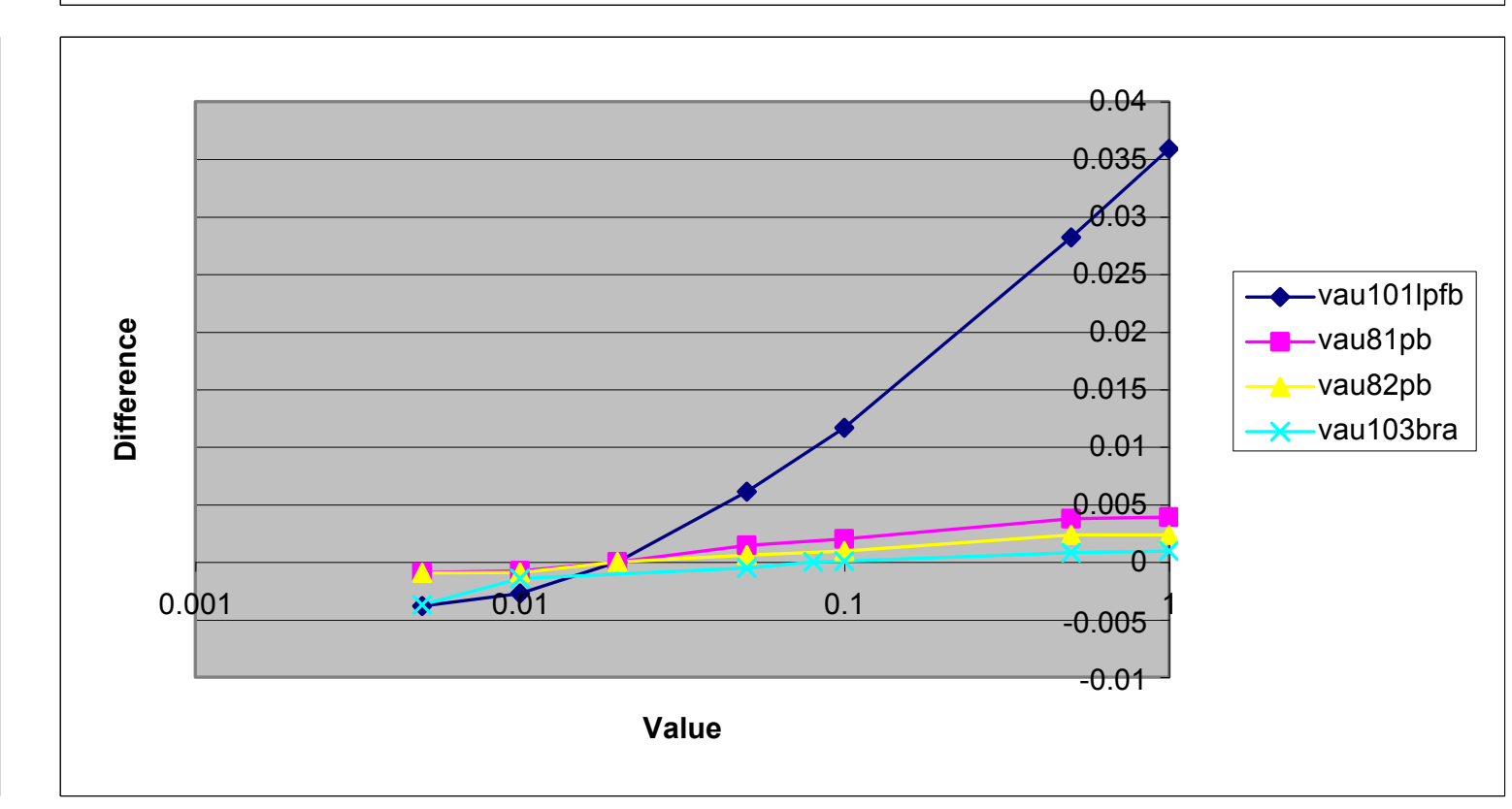




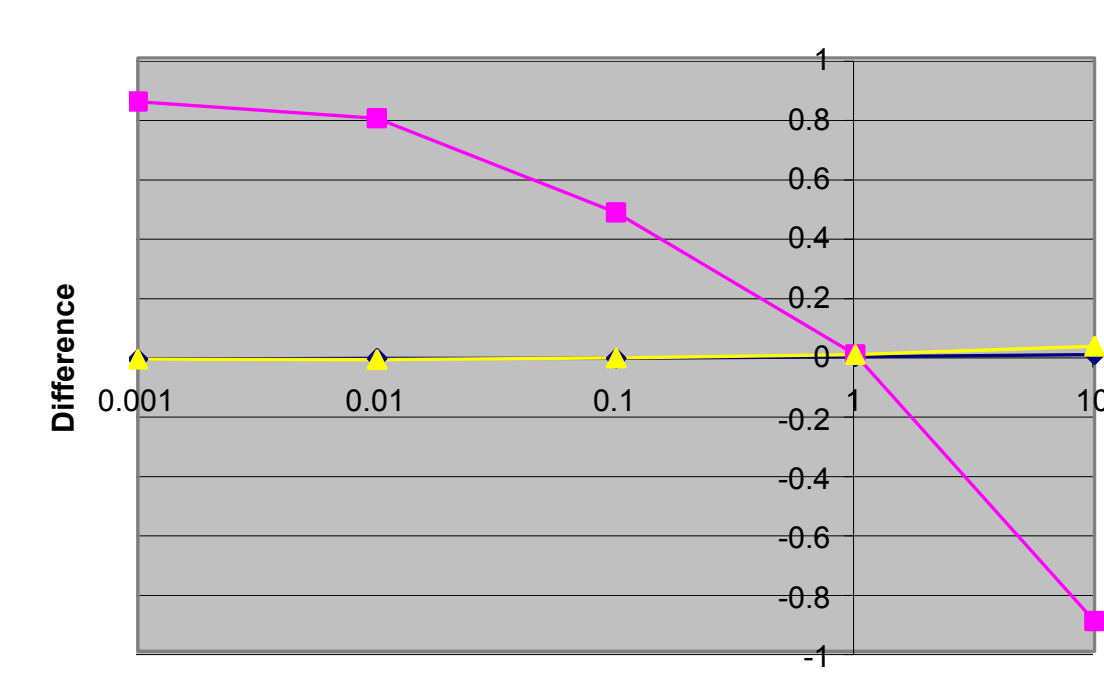

Value
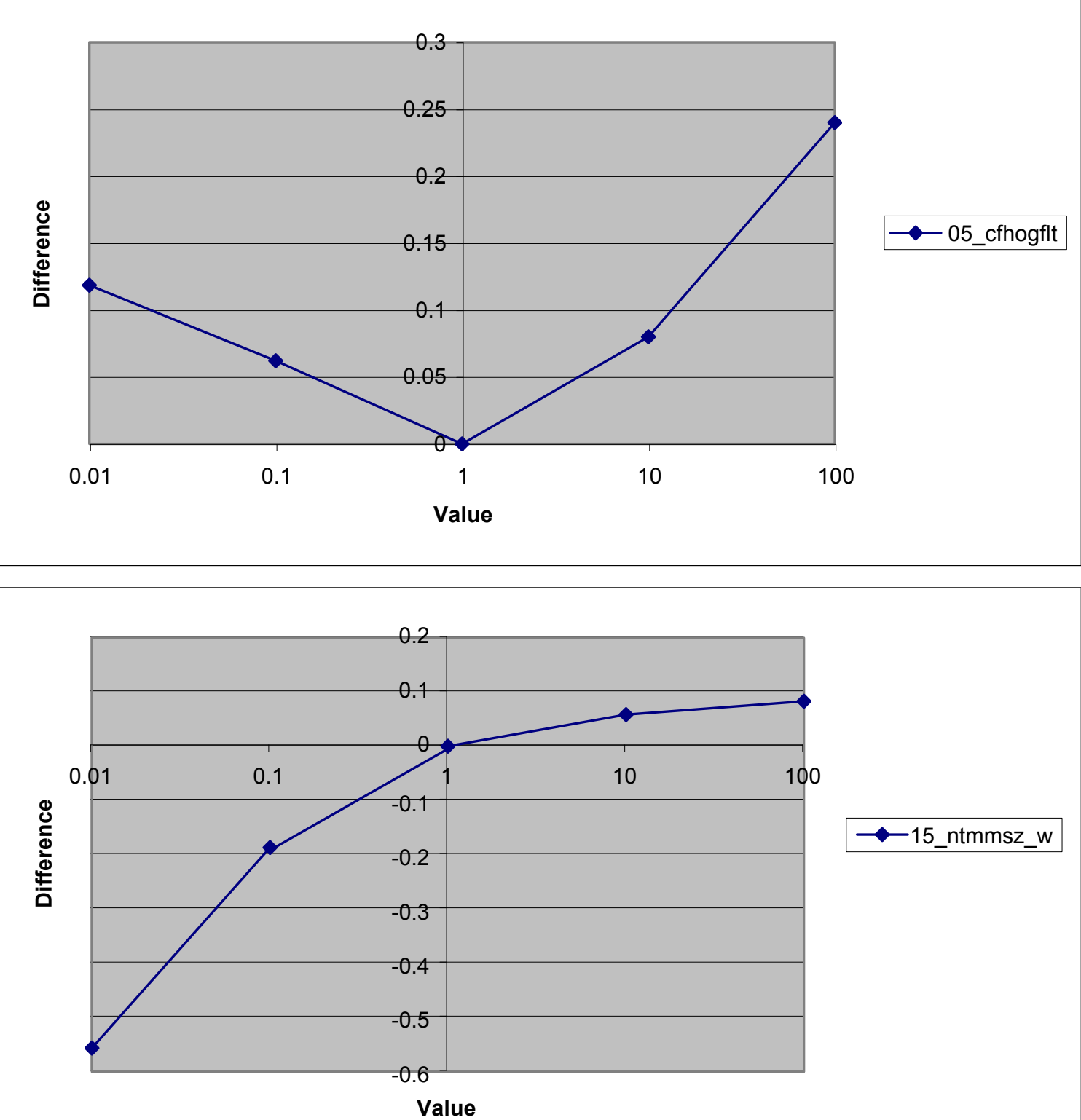

$\multimap$ ๑15_ntmmsz_w
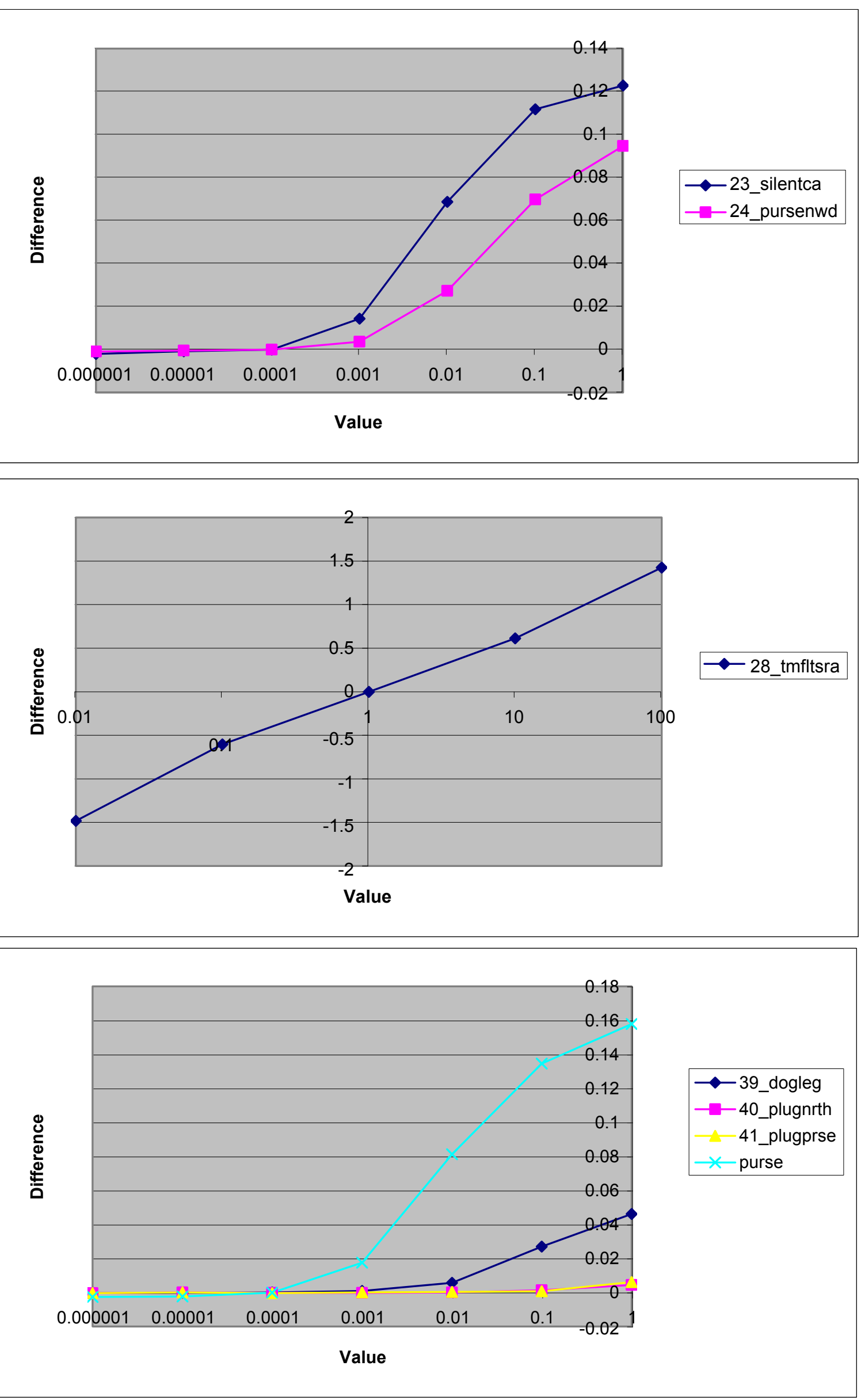

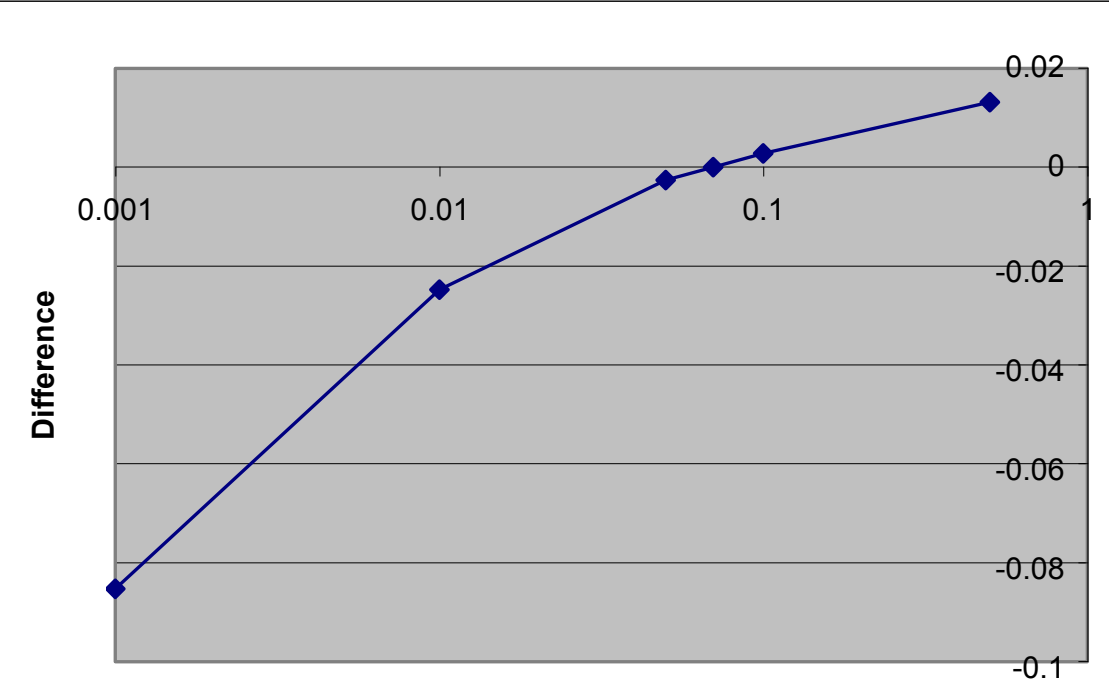

$\bullet \bullet-04 \_b o x c a r \_w$

Value

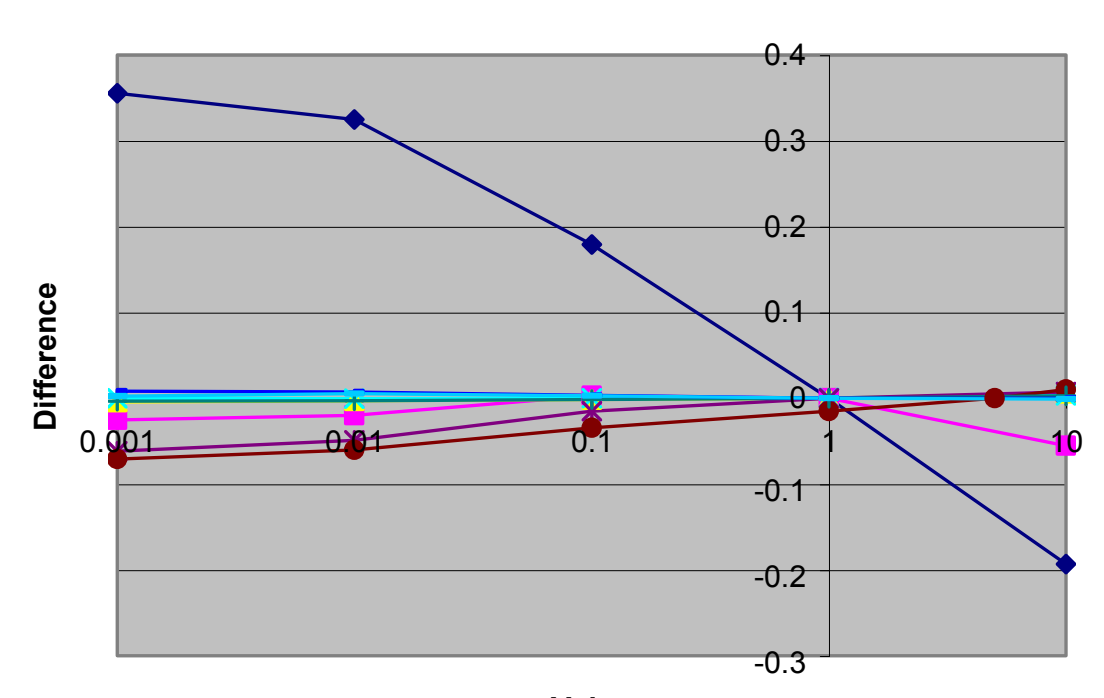

$\rightarrow-06$ claimcyn

-07_colsnpnd

08_eastgree

$\times$ 09_eestuary

*-10_etcsz_wd

-11 handley_

, 12_handleys

-13_handley2

-14_mhmsz_wd

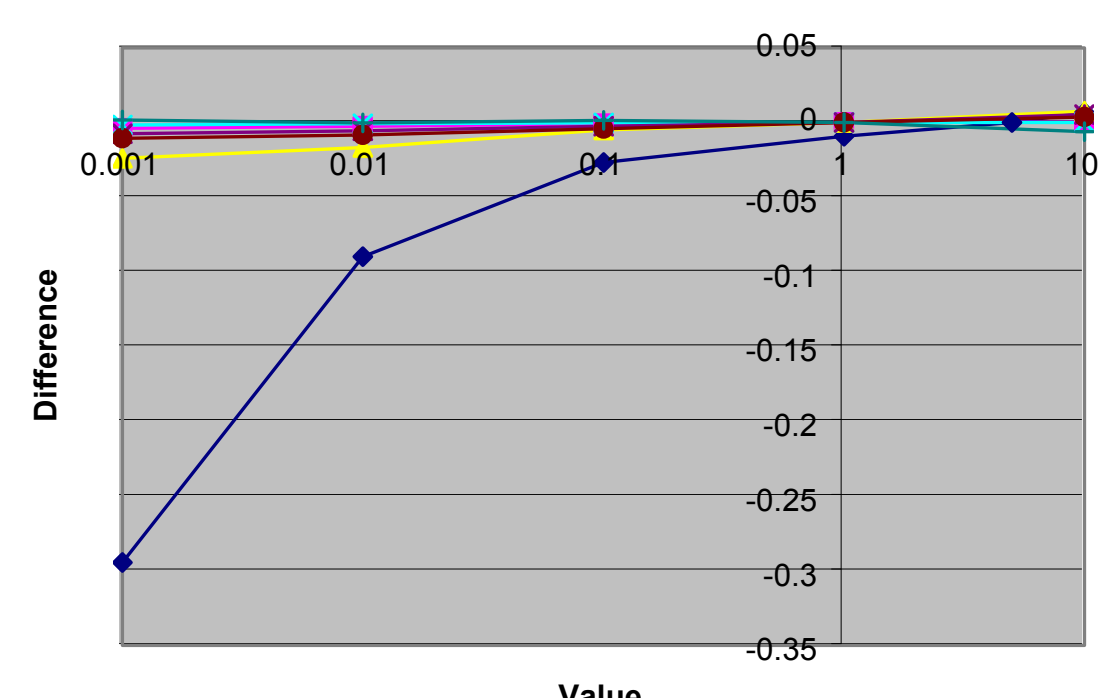

$\longrightarrow$-16_ribcliff

-17_richey_w

18_scrugham

$\times$ 19_scnsz_wd

*-20_scsze_wd

- -21_scszw_wd

+-22_sefltwfd

Value

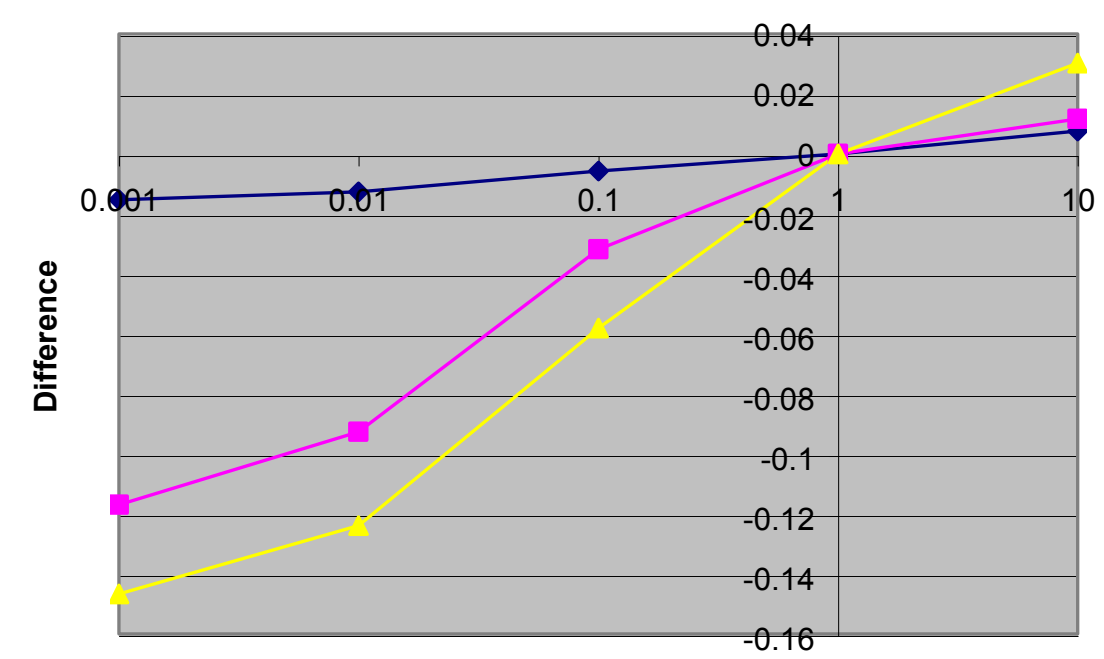

Value

$\multimap-25$ splitrid

- 26 spmsz wd

27_surfltgw

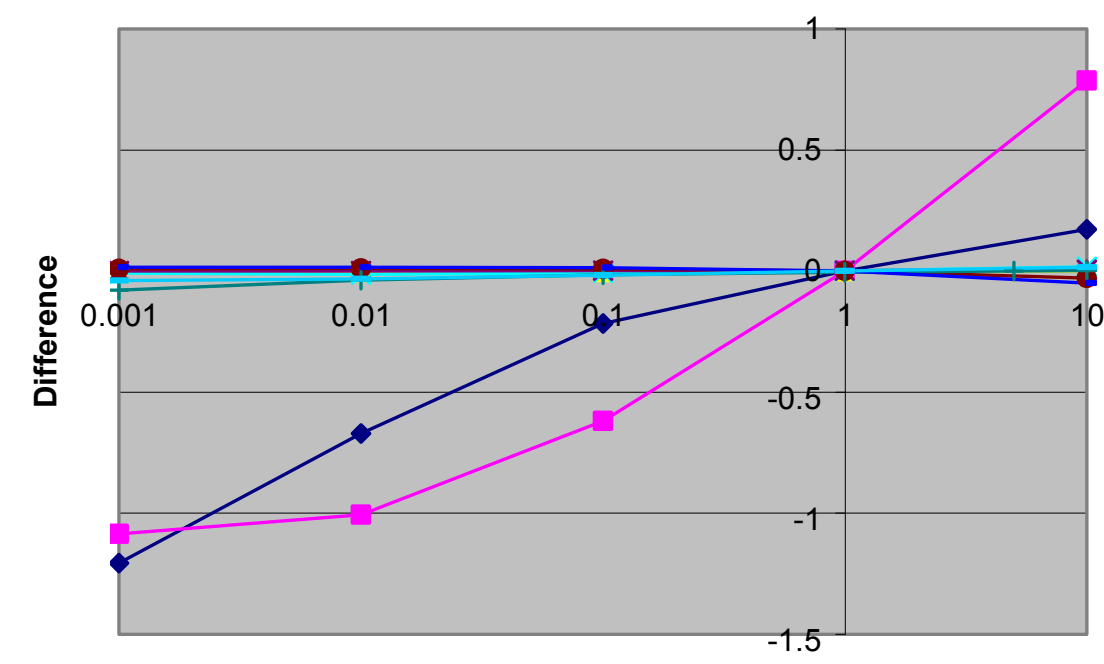

$\rightarrow-29$ tmfltstm

- 30_tmext2ho

31_walmendr

$\star$-33_westgree

* 34_westuary

-35 windywas

— 36_wscsz_wd

- 37_paintbrs

- 38 _silentca

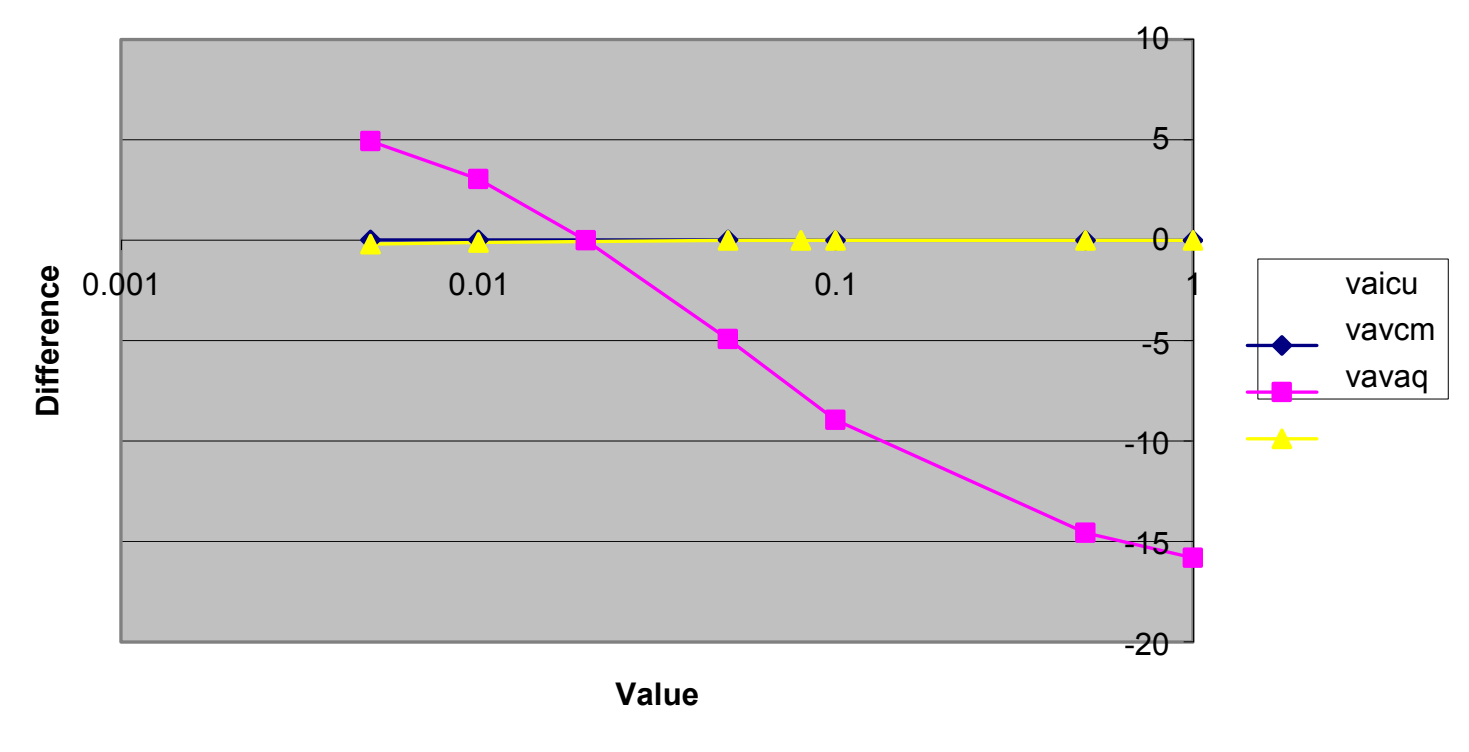




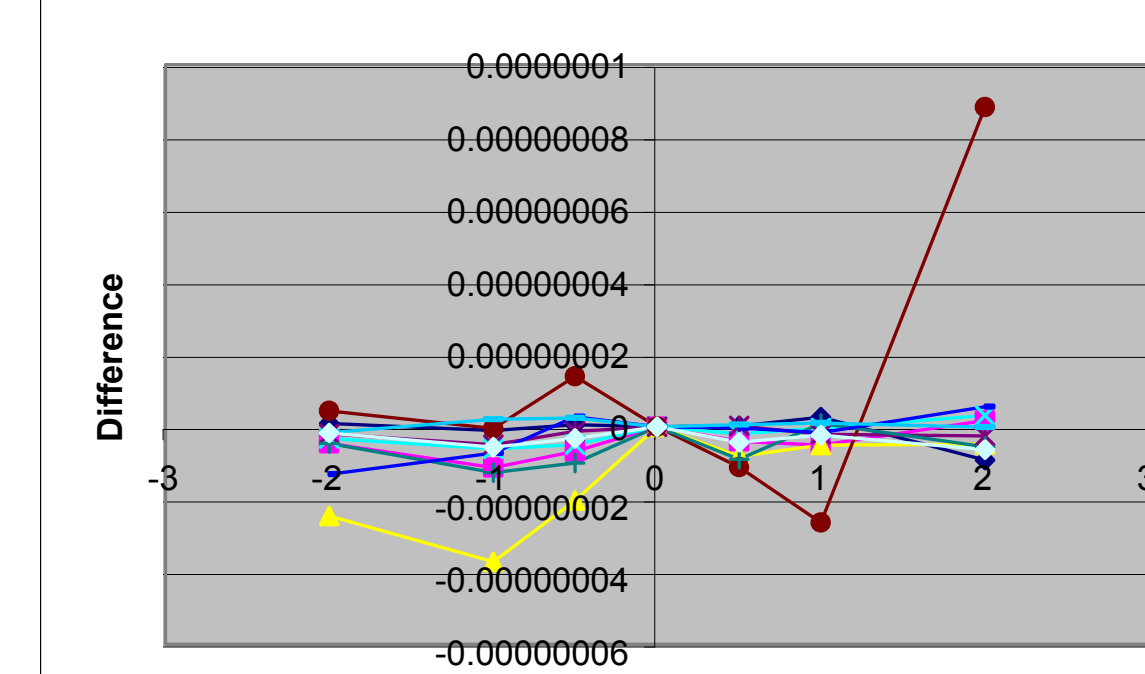

Base Value + +l-Standard Deviation

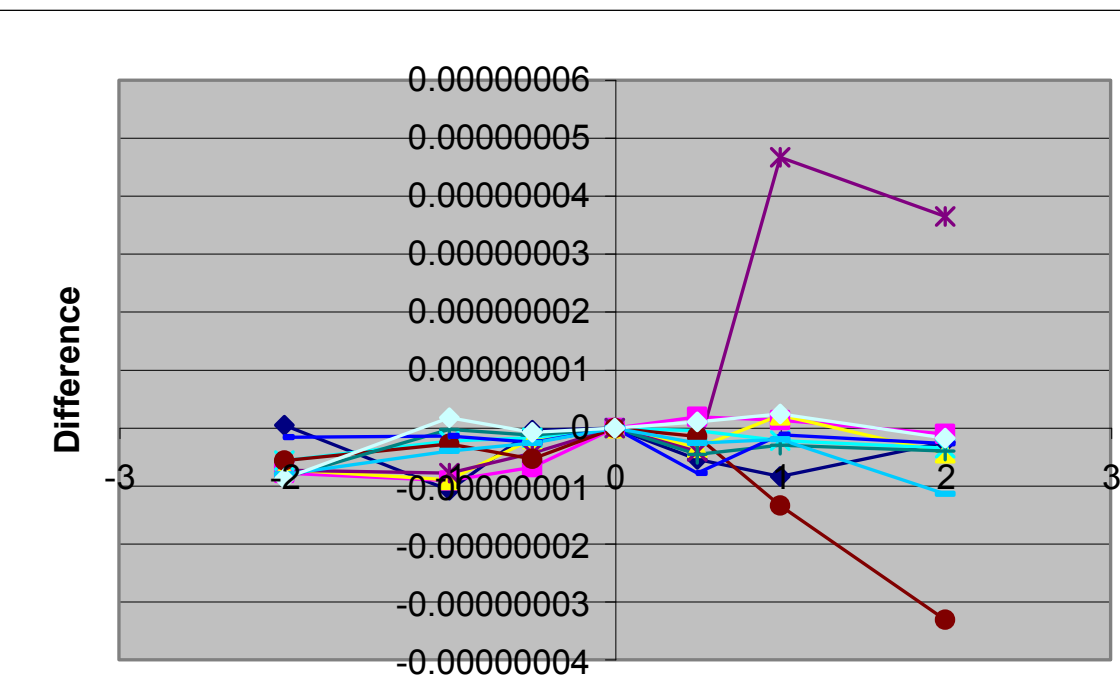

Base Value +/-Standard Deviation

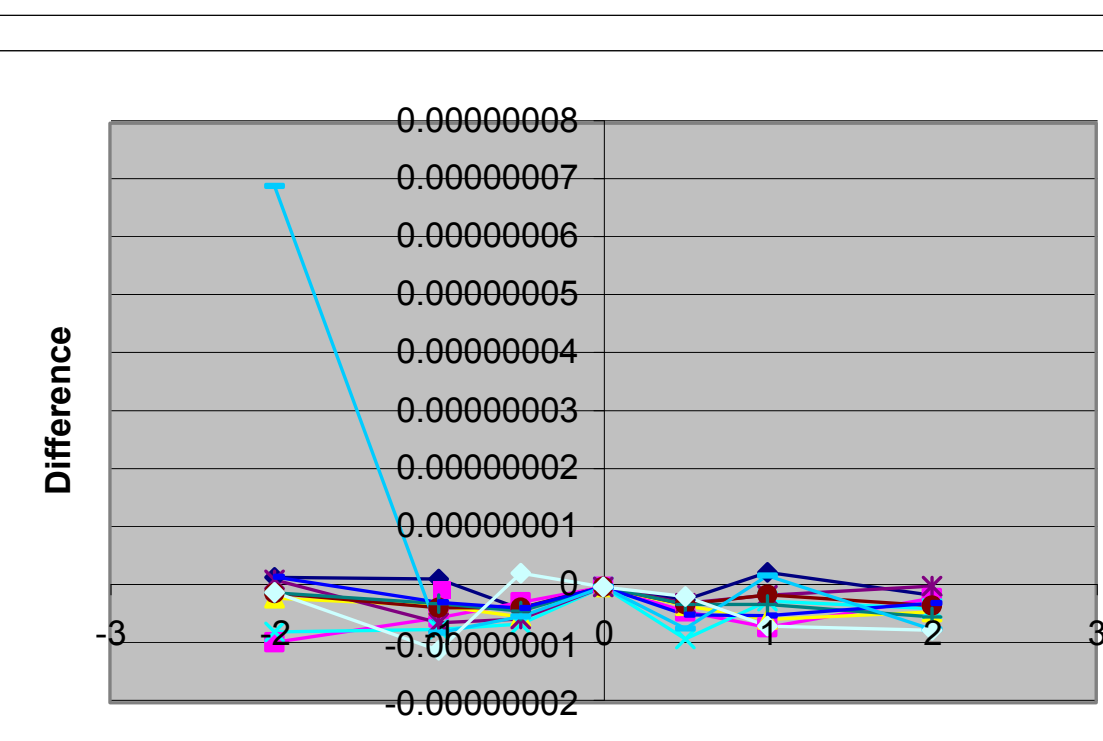

Base Value +/-Standard Deviation

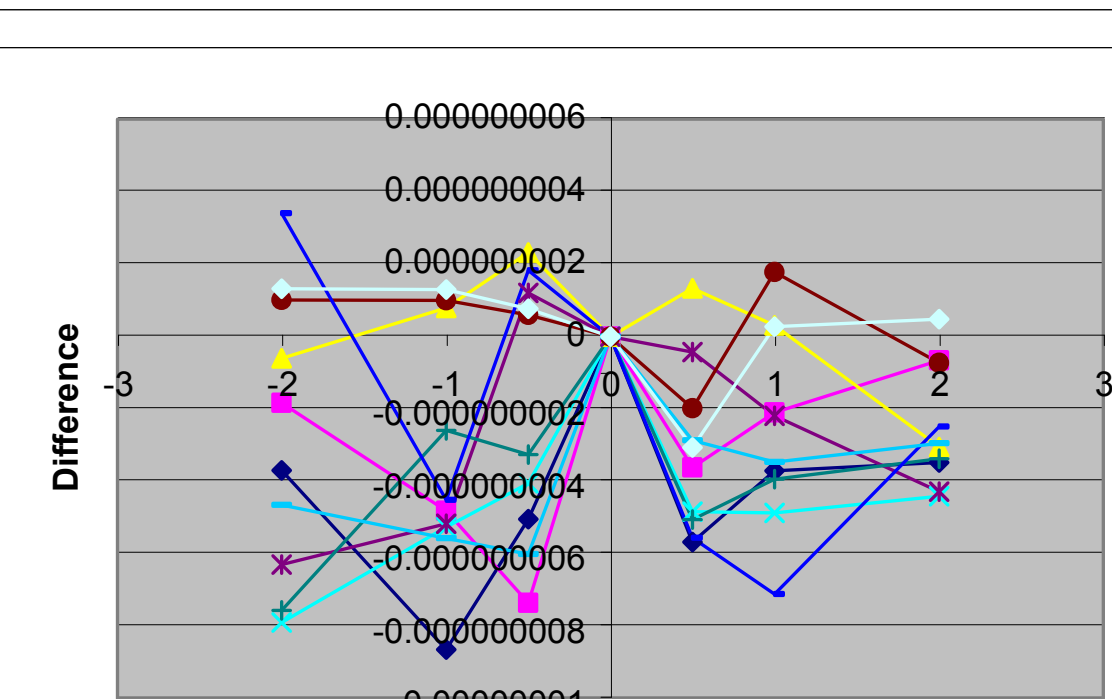

Base Value + + - Standard Deviation

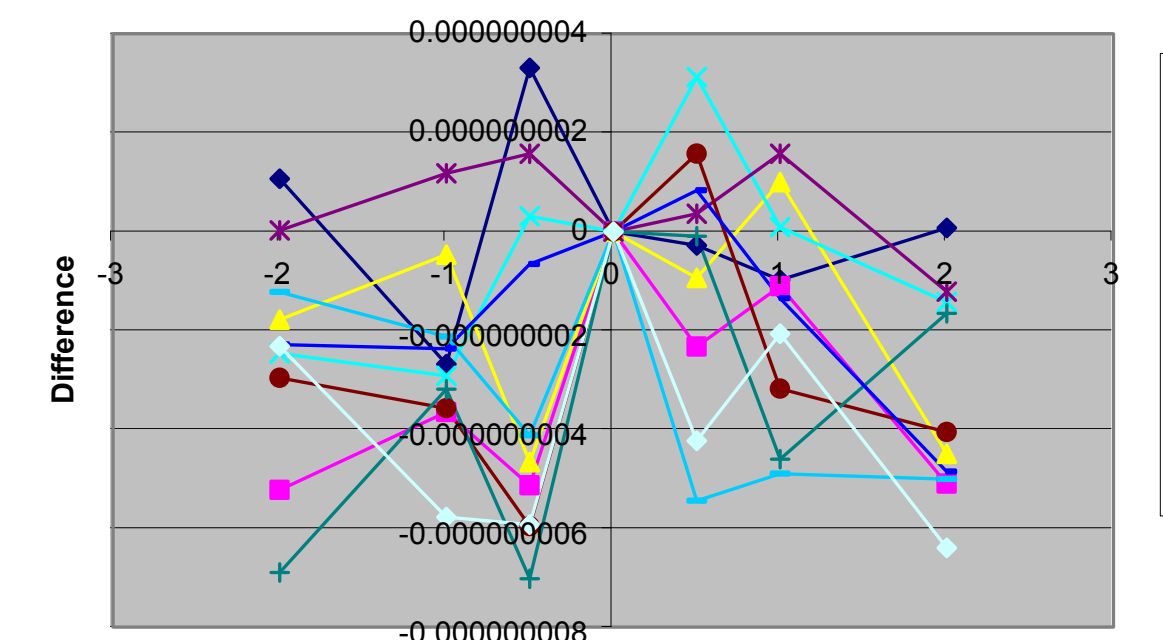

Base value + +l-Standard Deviation
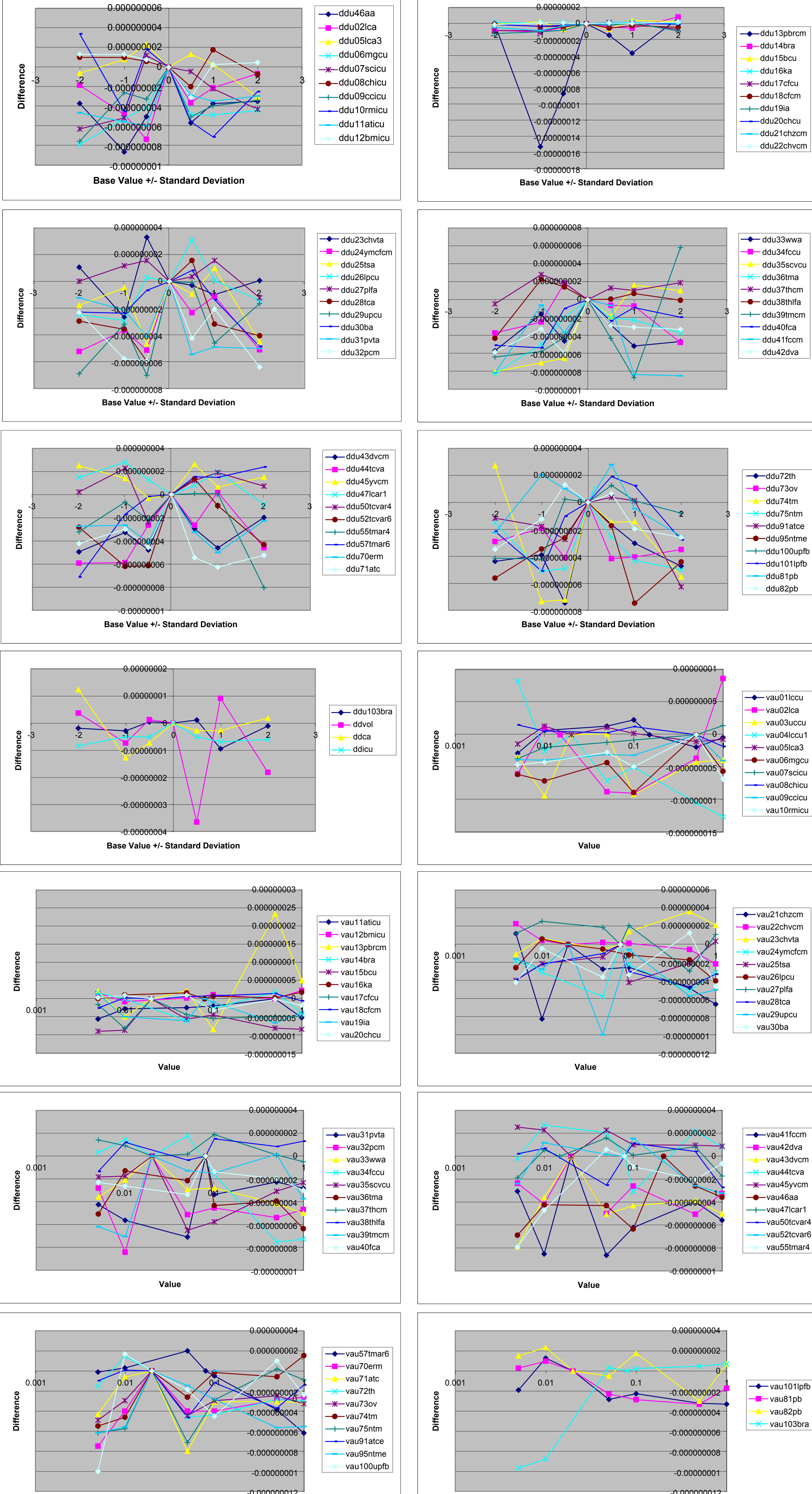

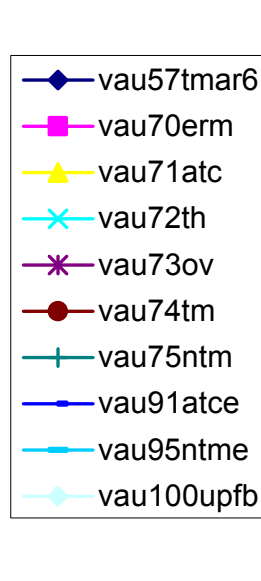
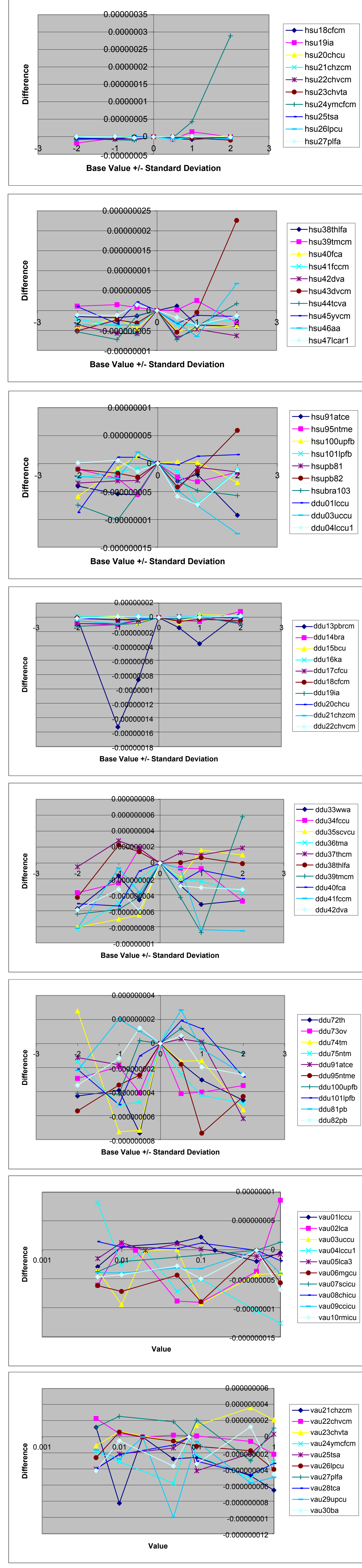

Base Value +/-Standard Deviation
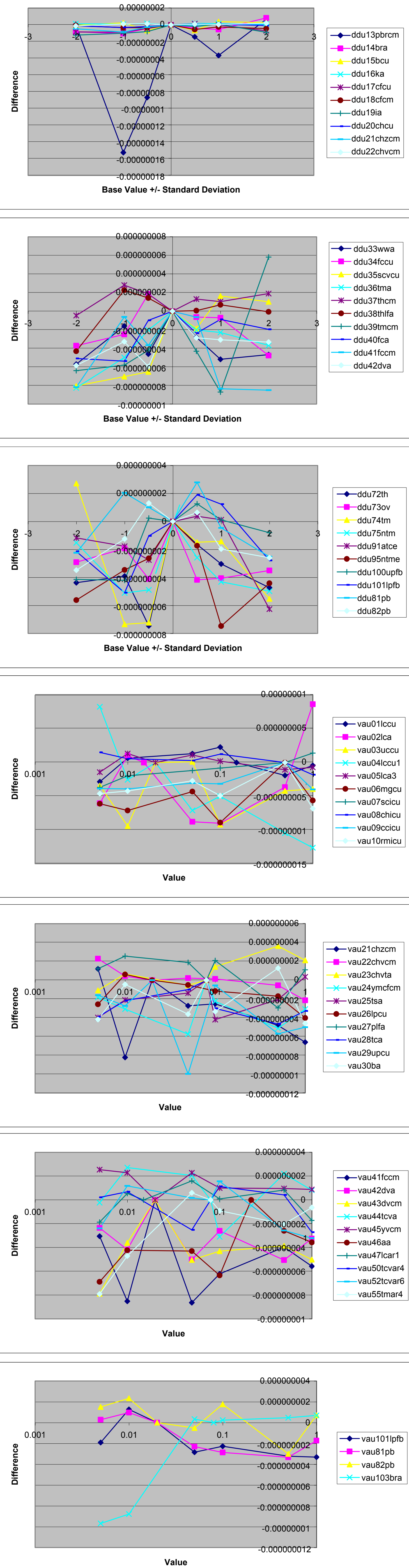


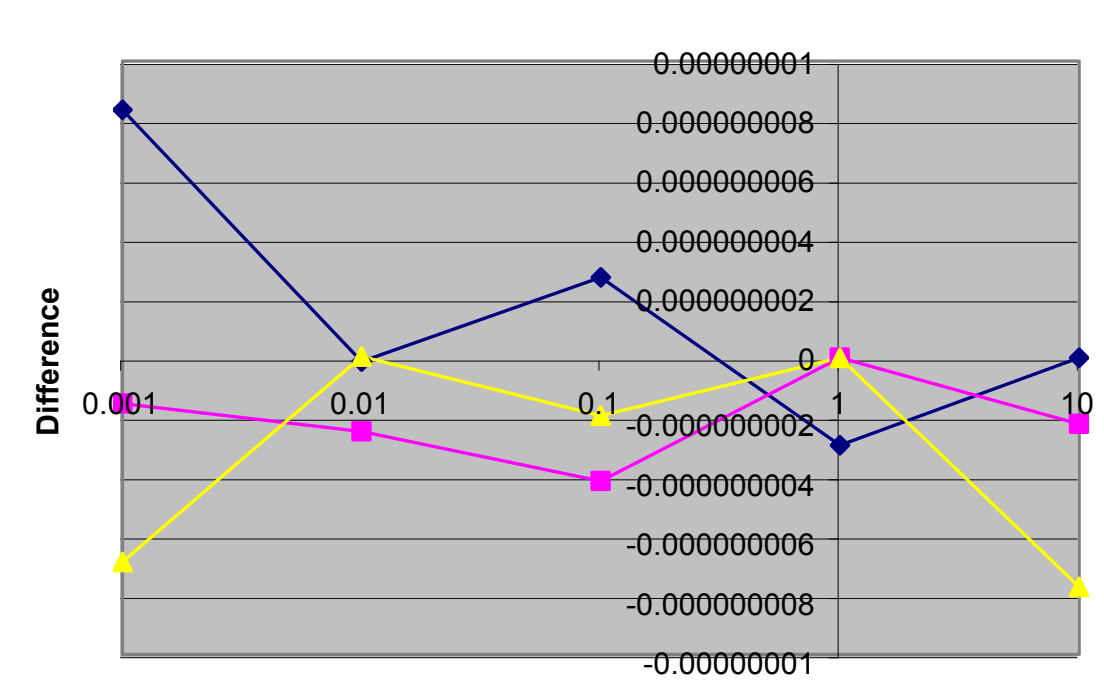

Value

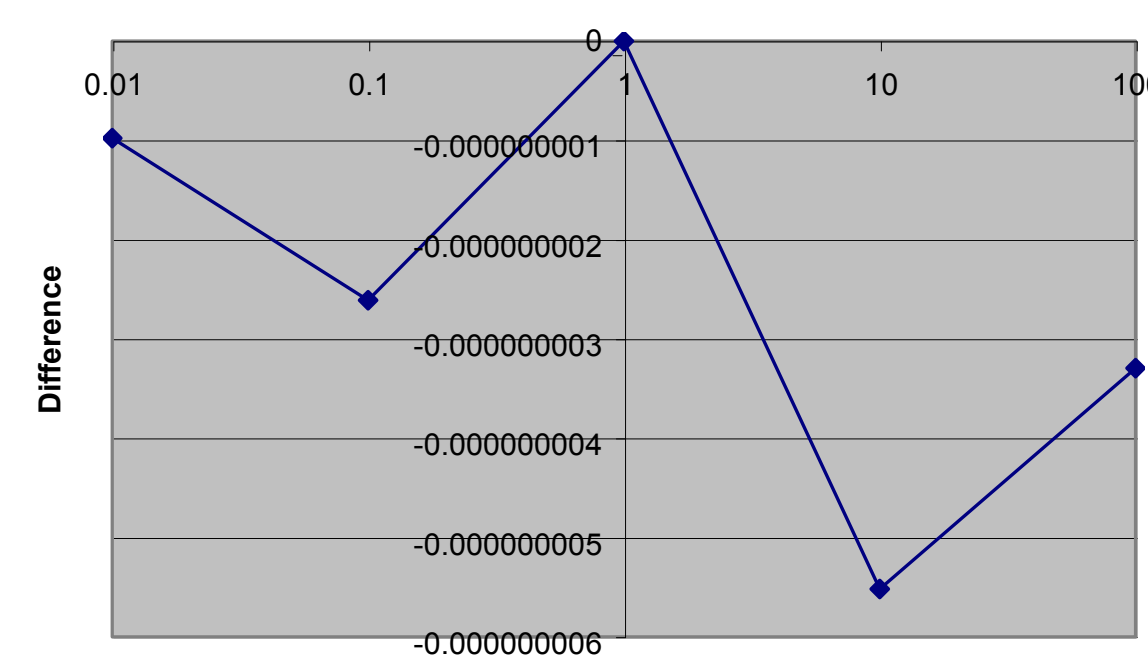

$\rightarrow \bullet 05$ cfhogflt

- 01 almendro

03_bmcsmwdf
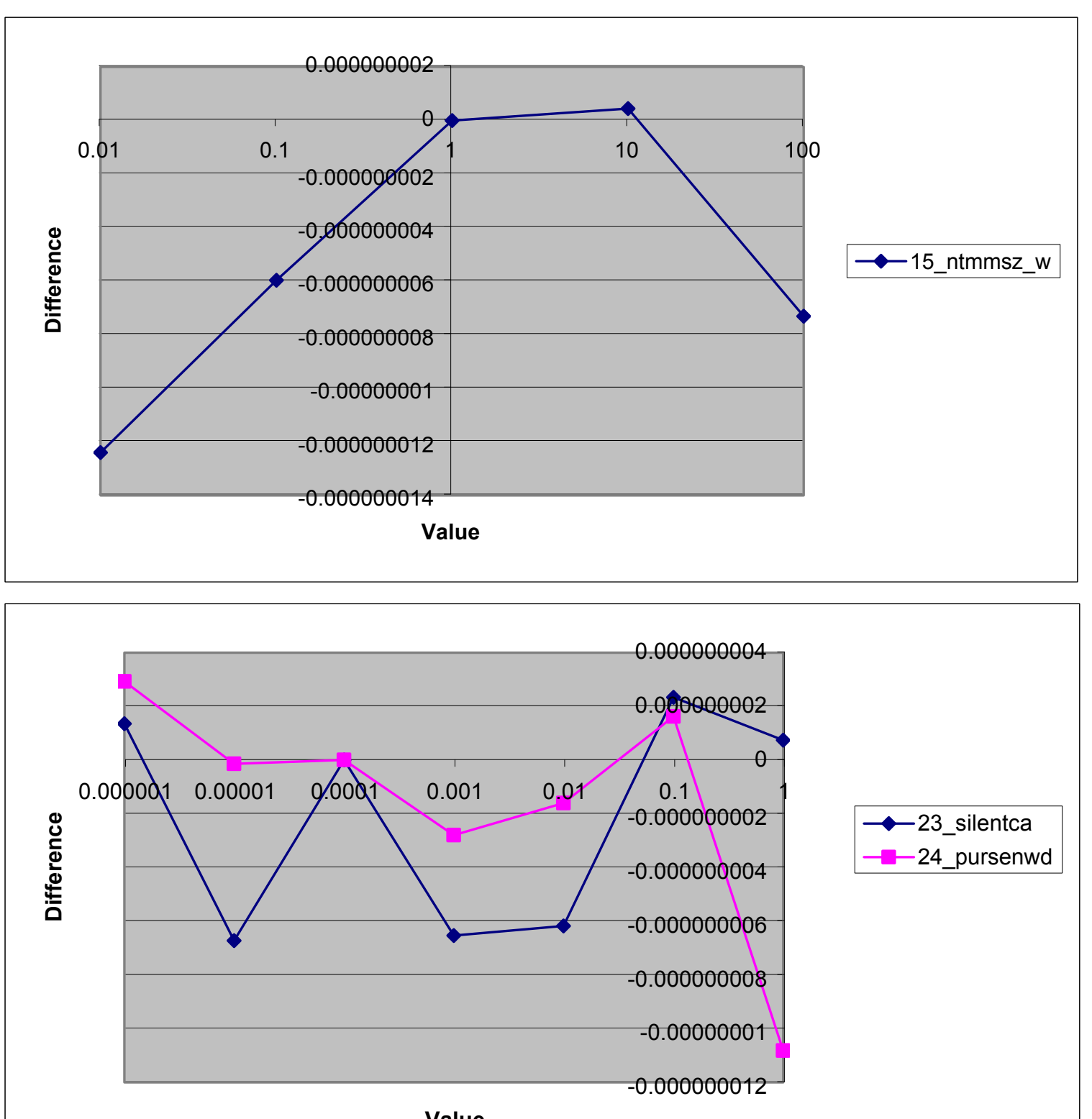

Value

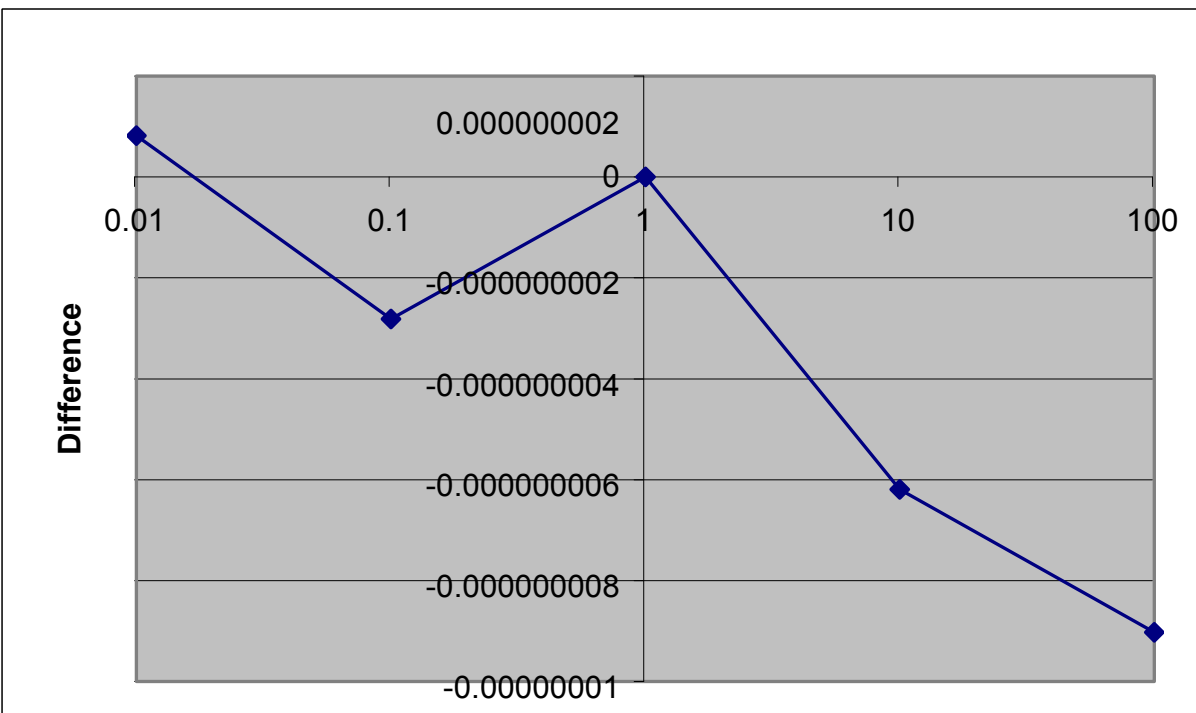

Value

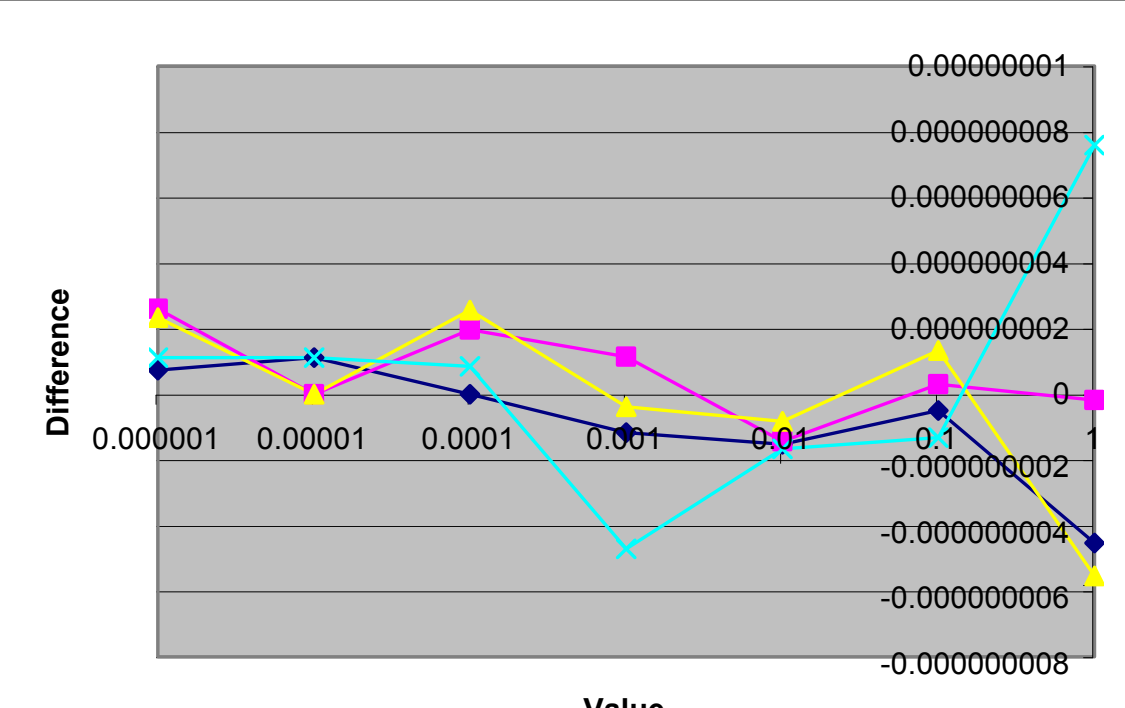

23_silentca -24_pursenwd

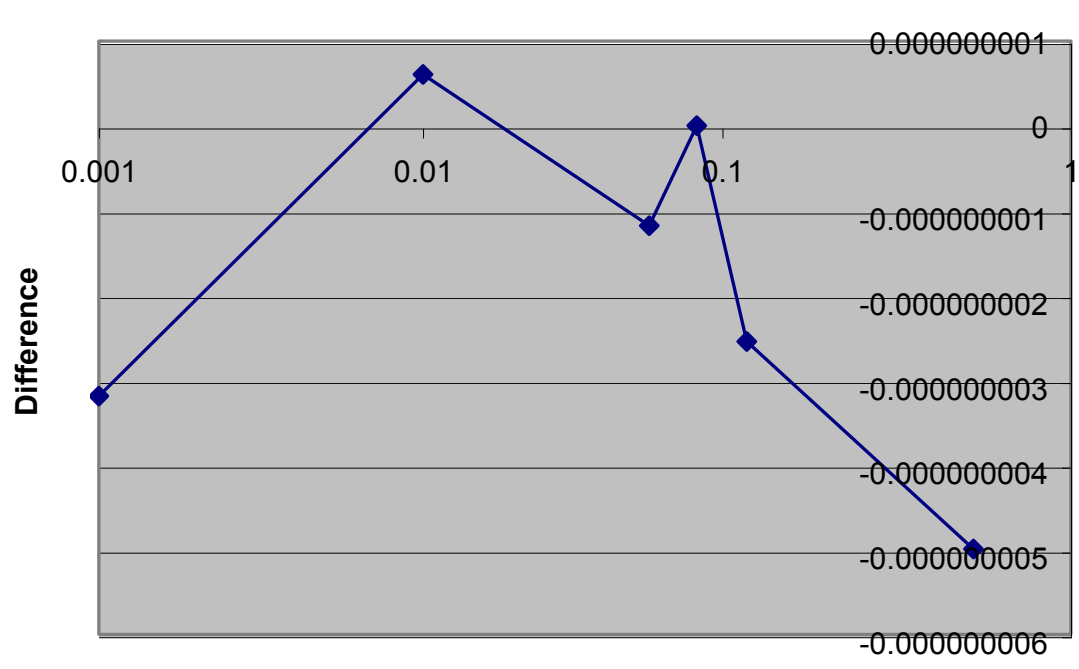

Value
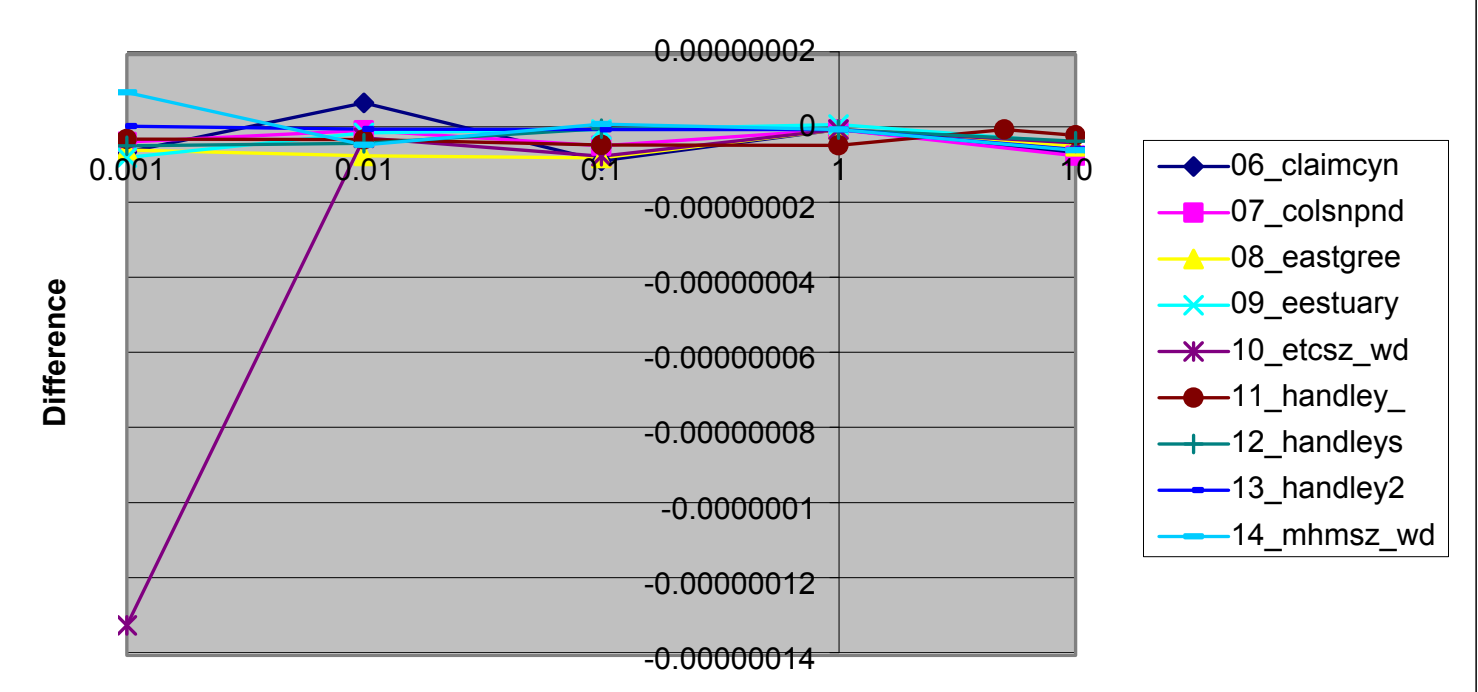

Value
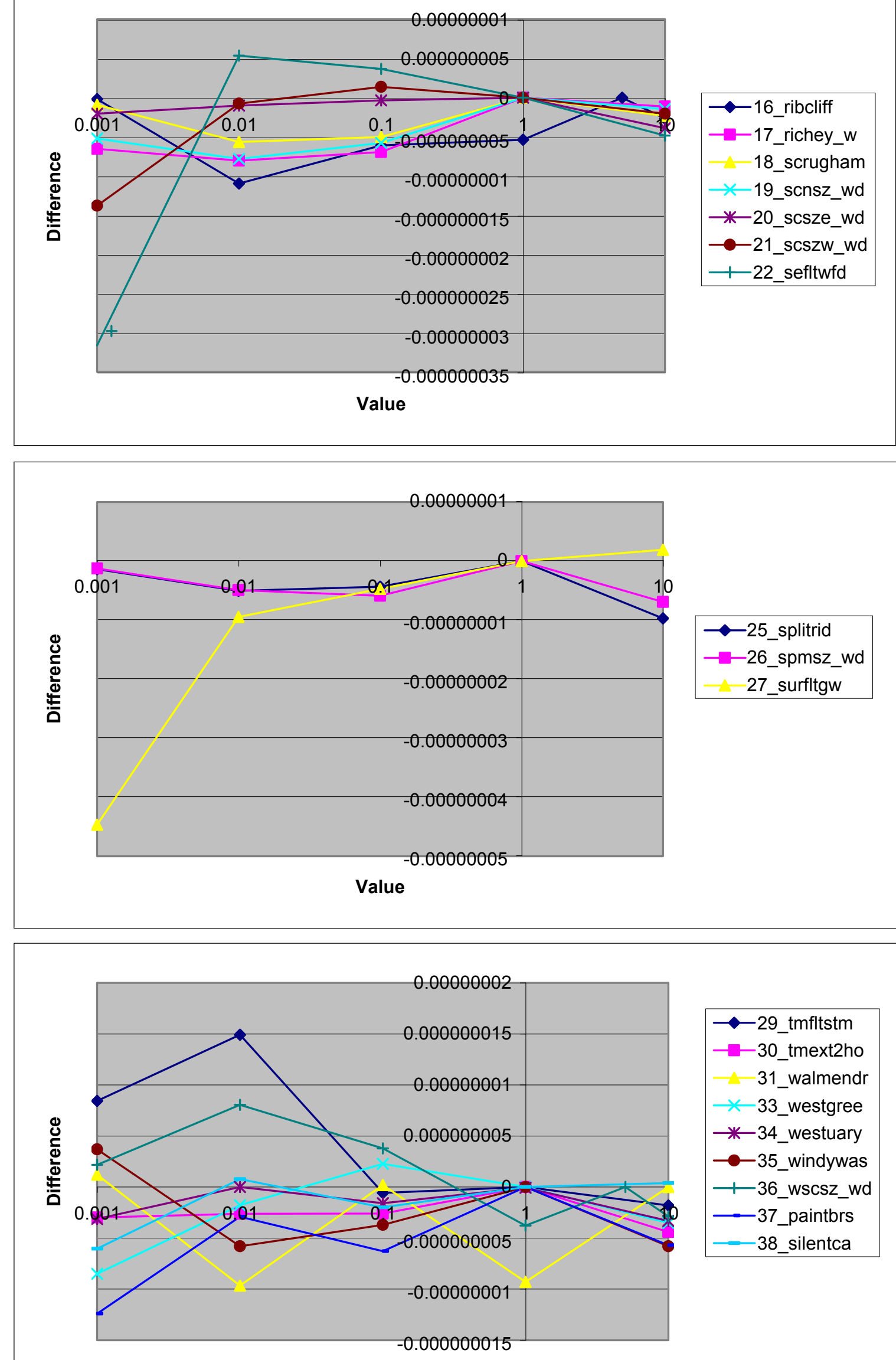

$\longrightarrow-29$ tmfltstm - 30_tmext2ho

-31_walmendr

$x$ 33_westgree

*-34_westuary

- 35 _windywas

+ -36_wscsz_wd

-37_paintbrs

- 38 _silentca

Value

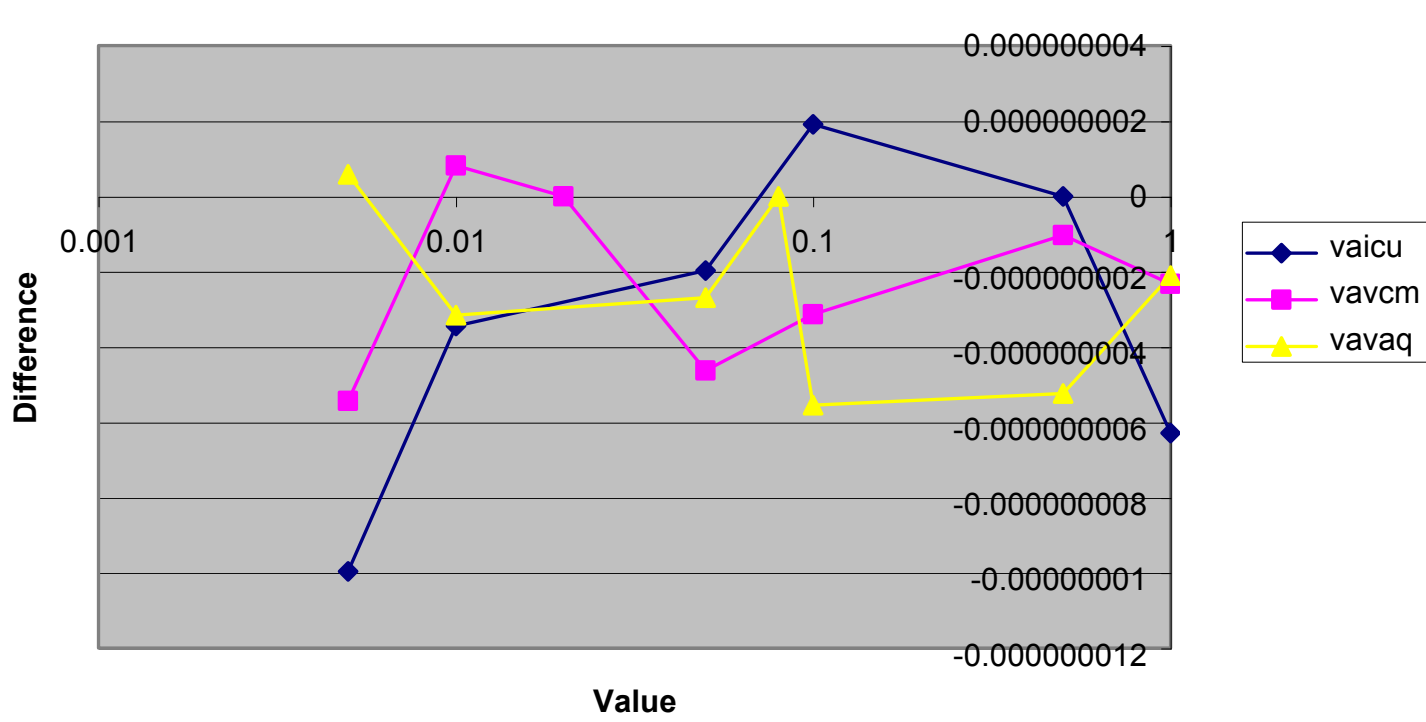




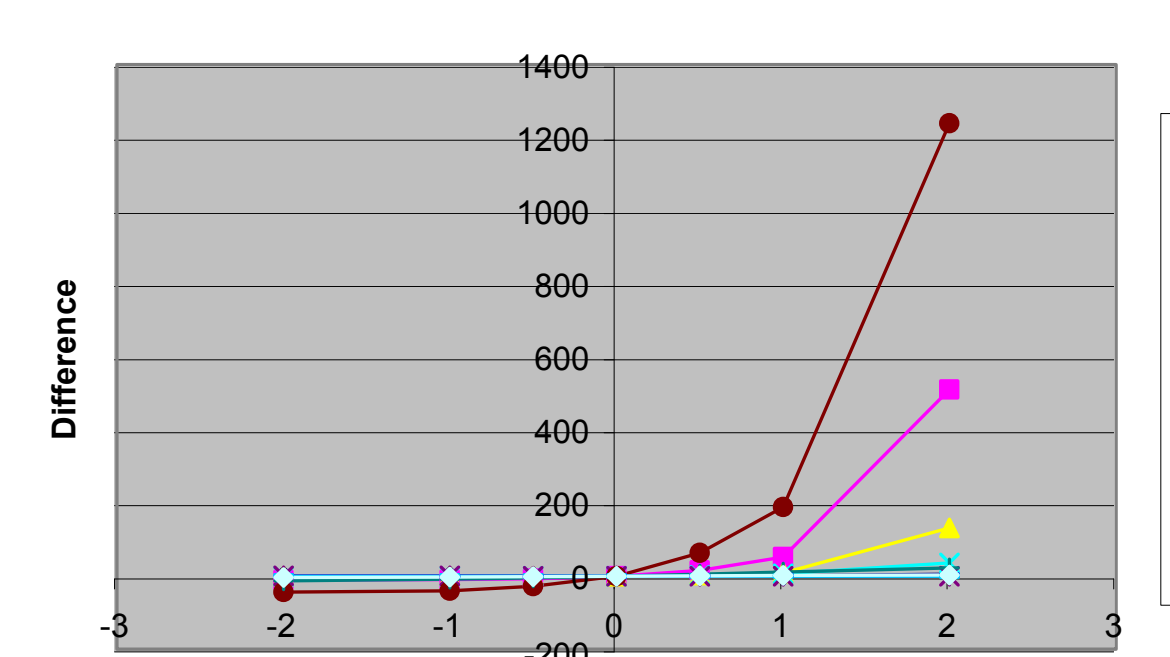

Base Value +/-Standard Deviation

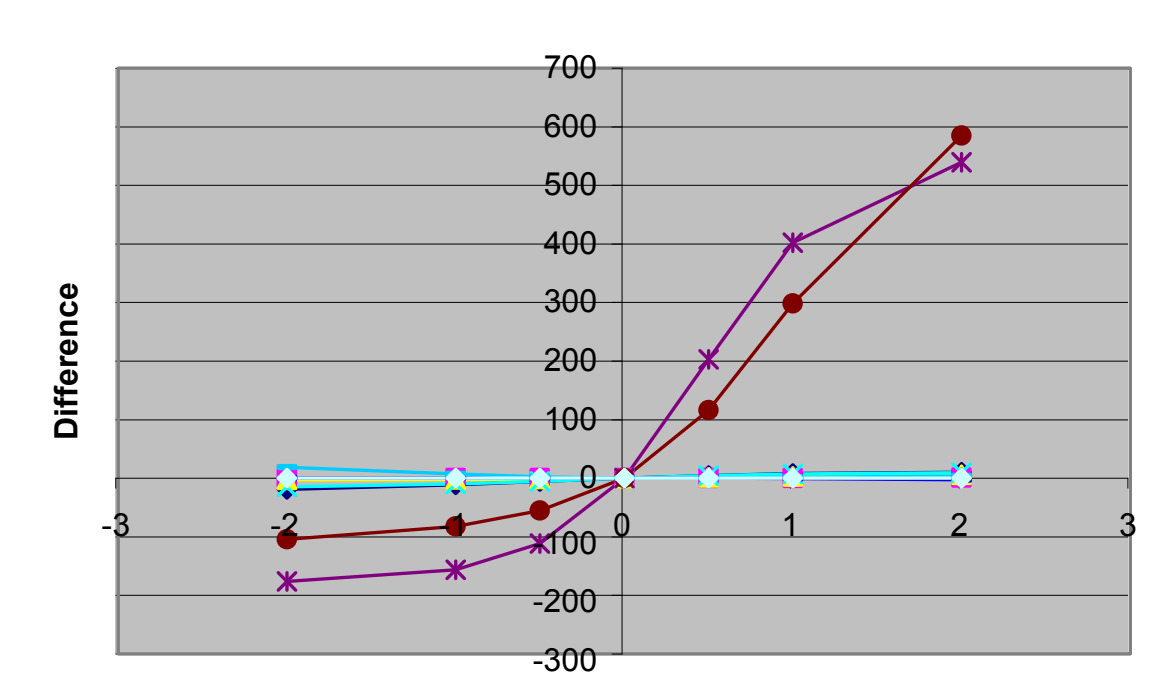

Base Value + + -Standard Deviation

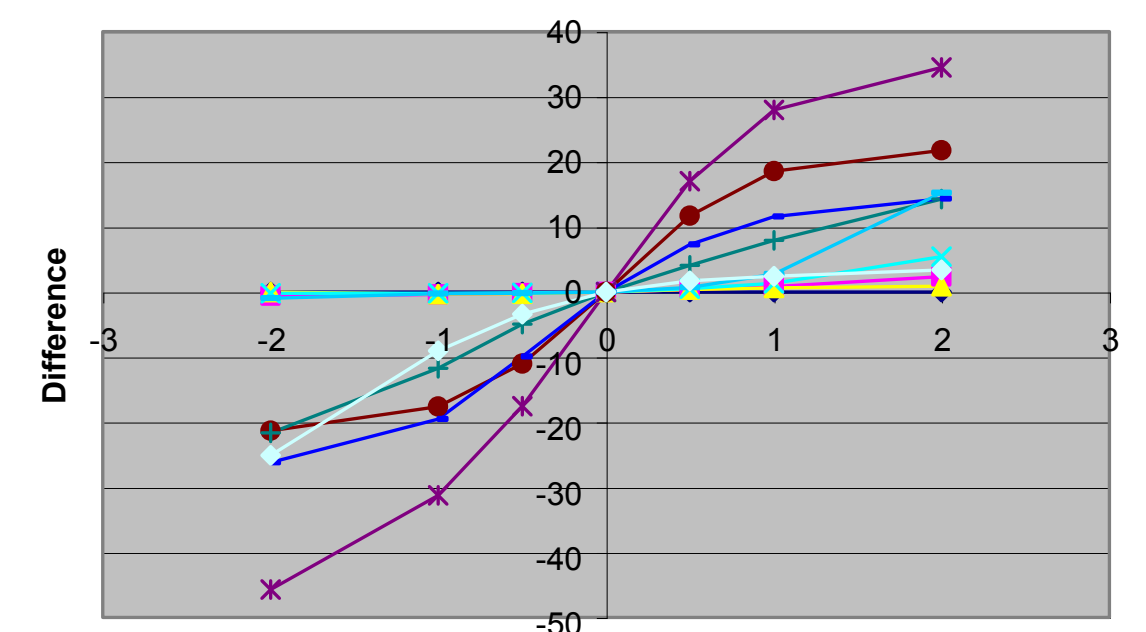

Base Value + - - Standard Deviation

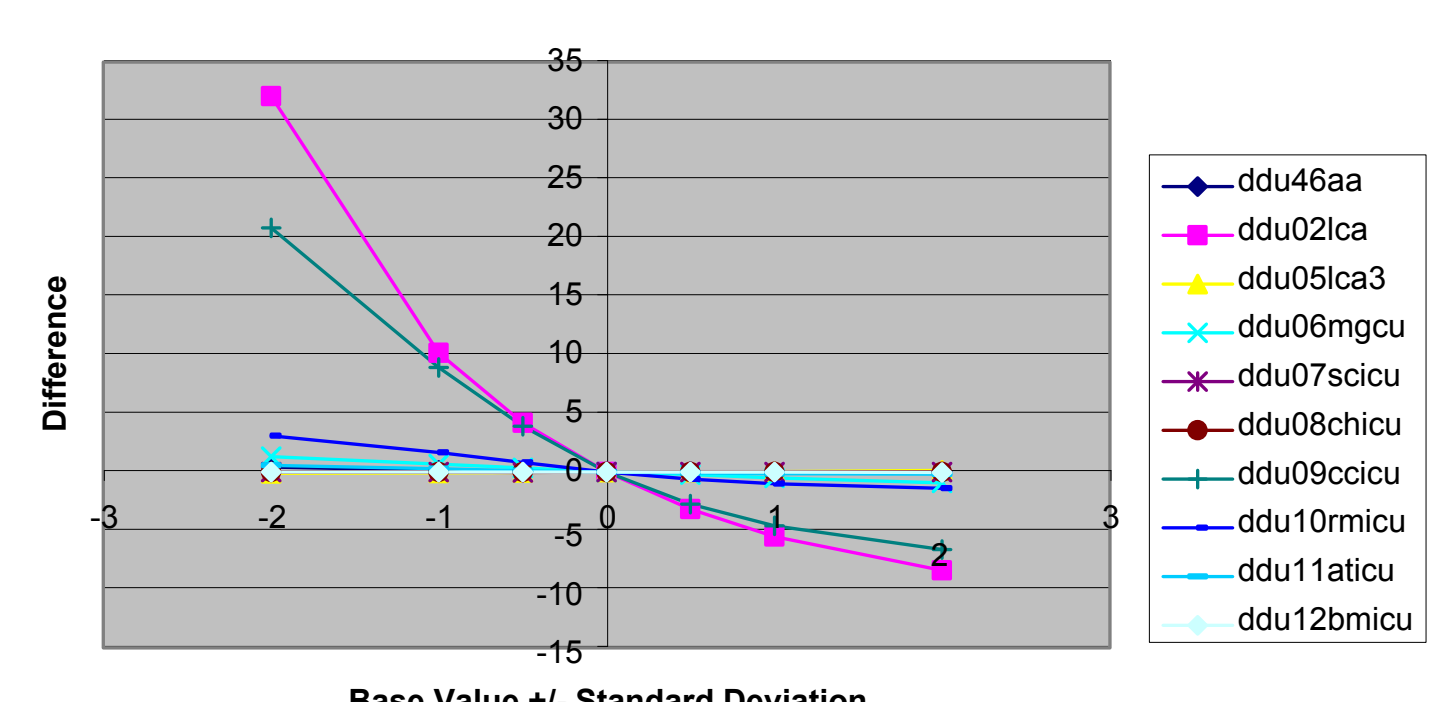
$-15$

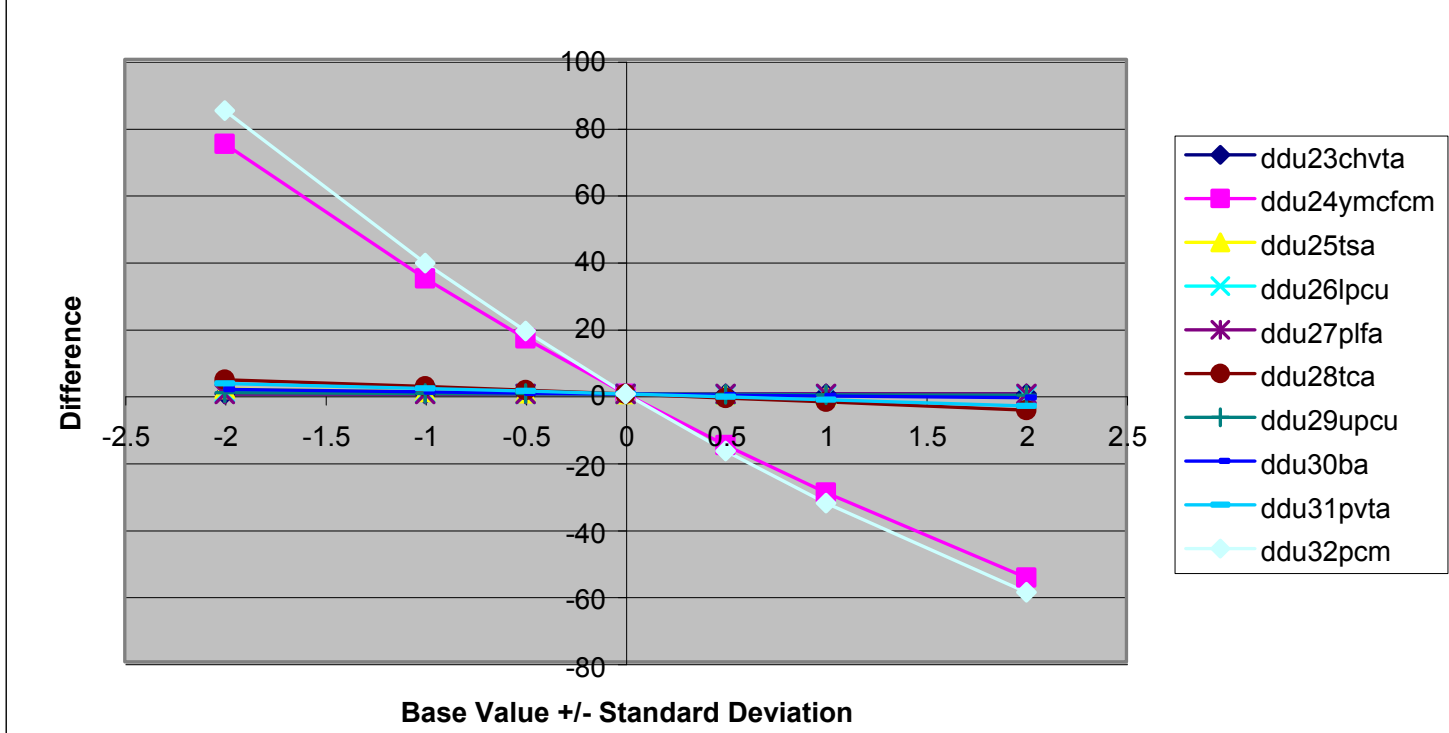

Base Value t/. Standard Deviation

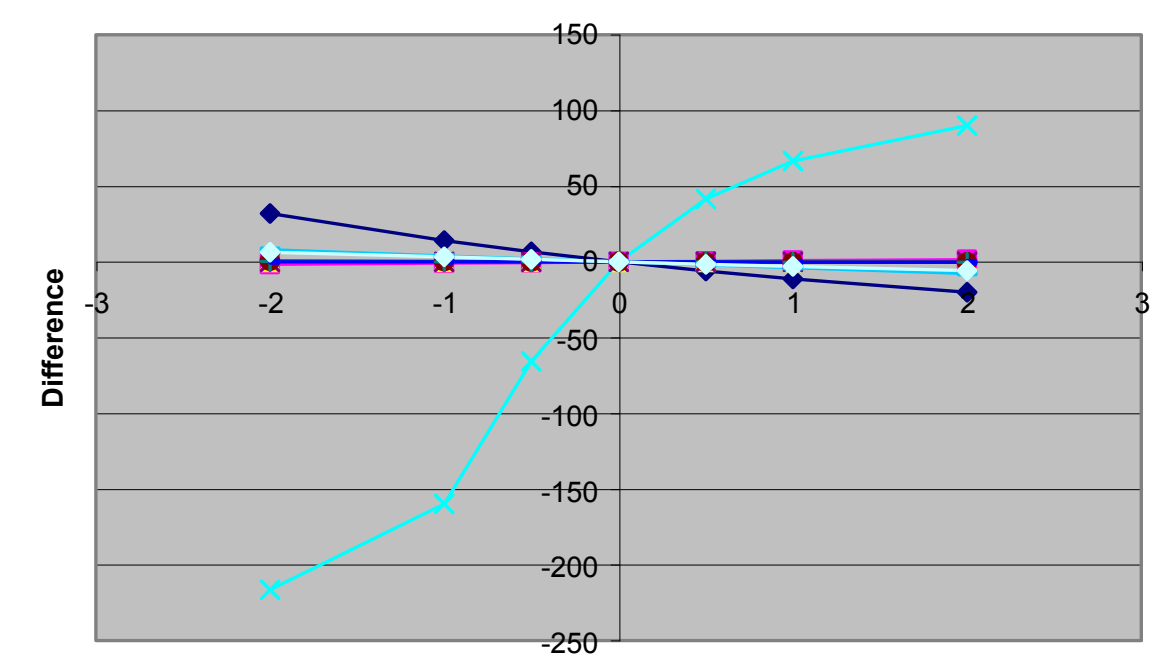

Base Value + +/. Standard Deviatio

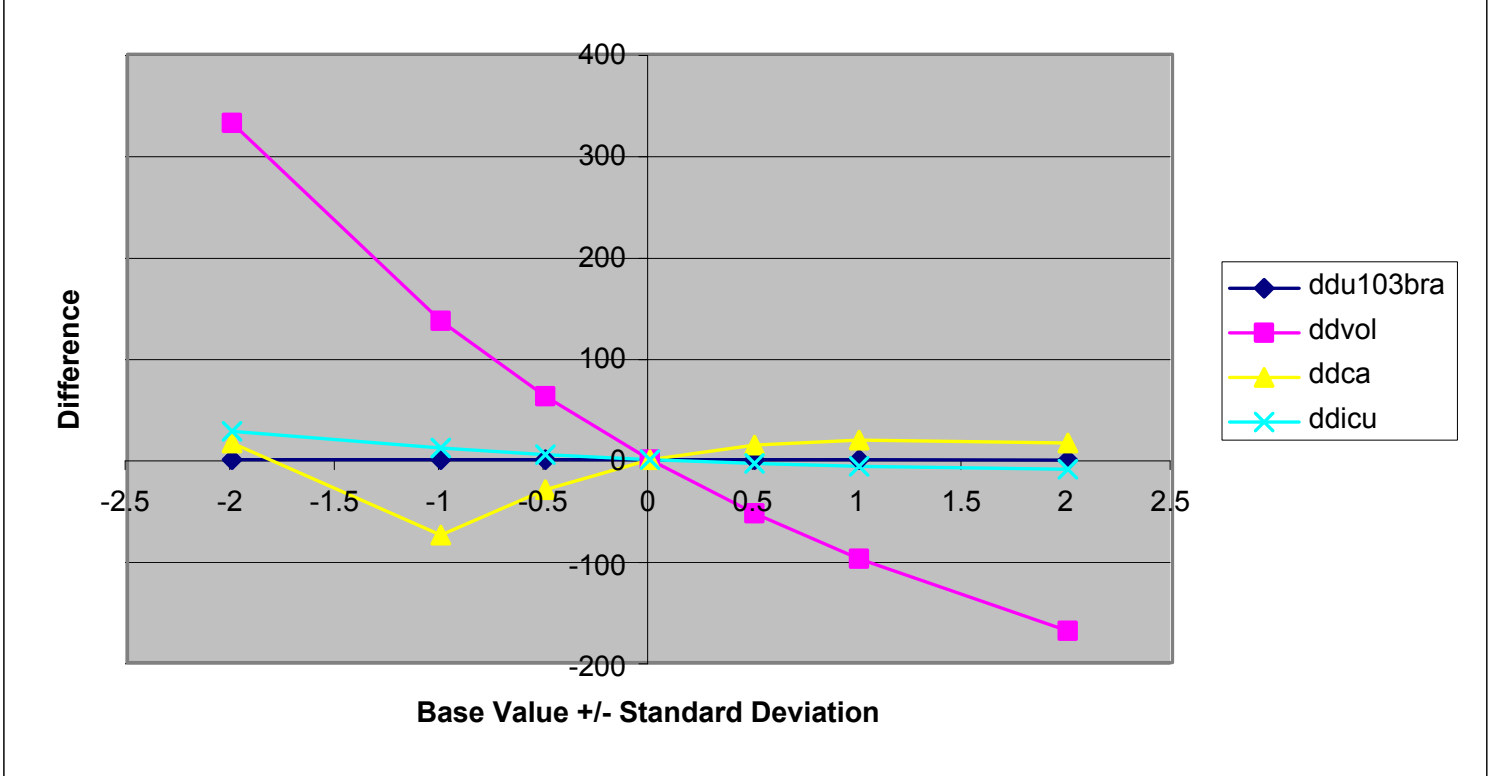

。

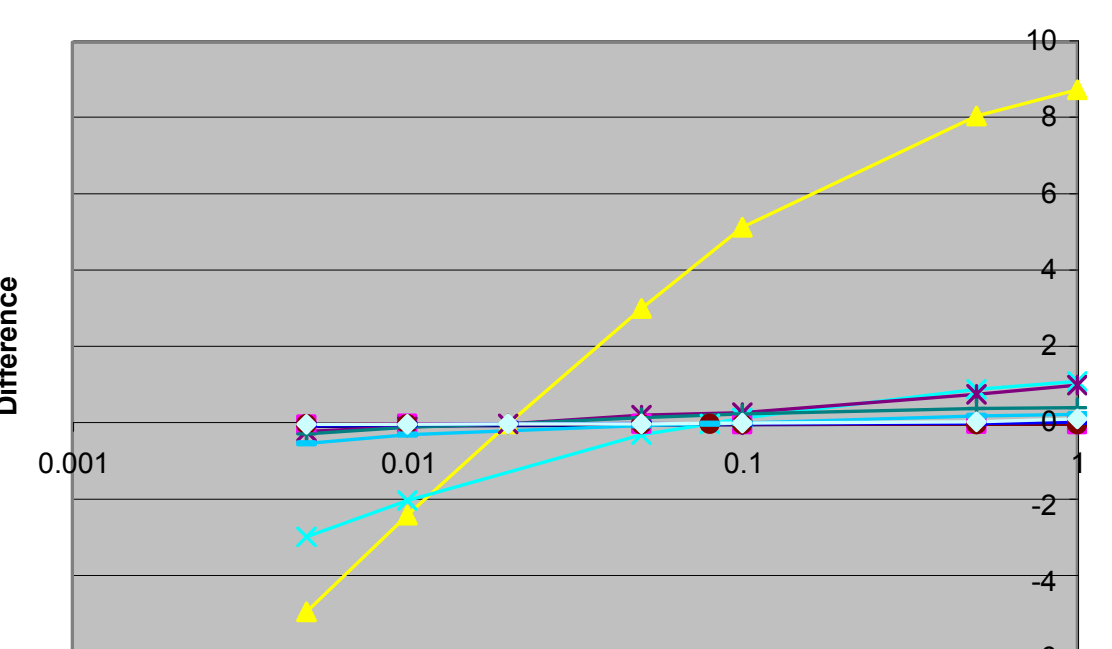

value

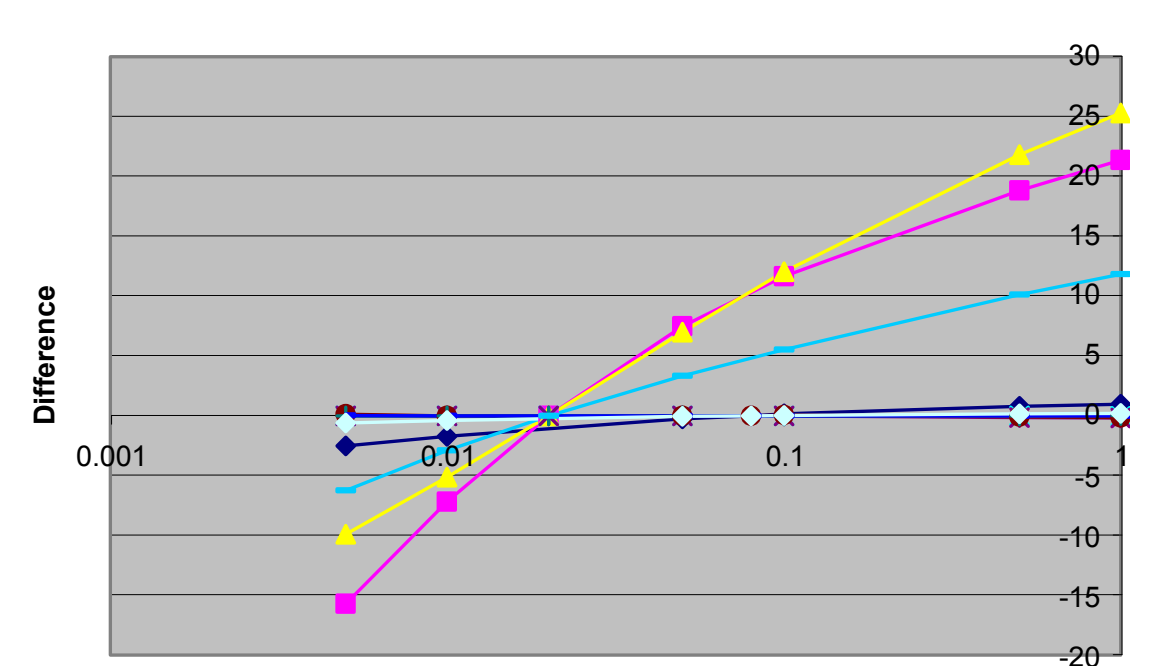

value

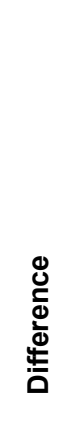

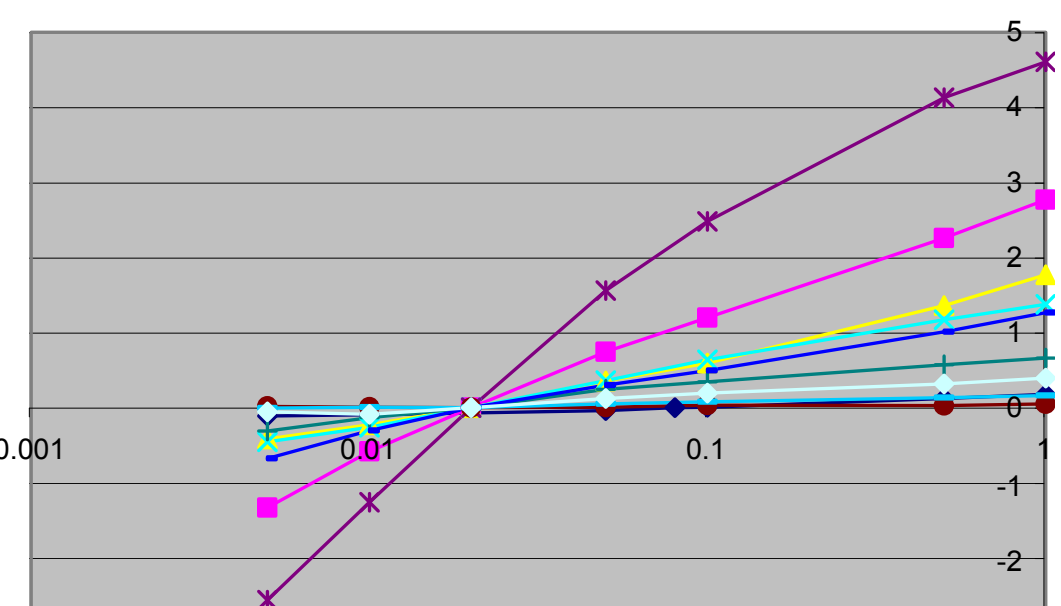

value
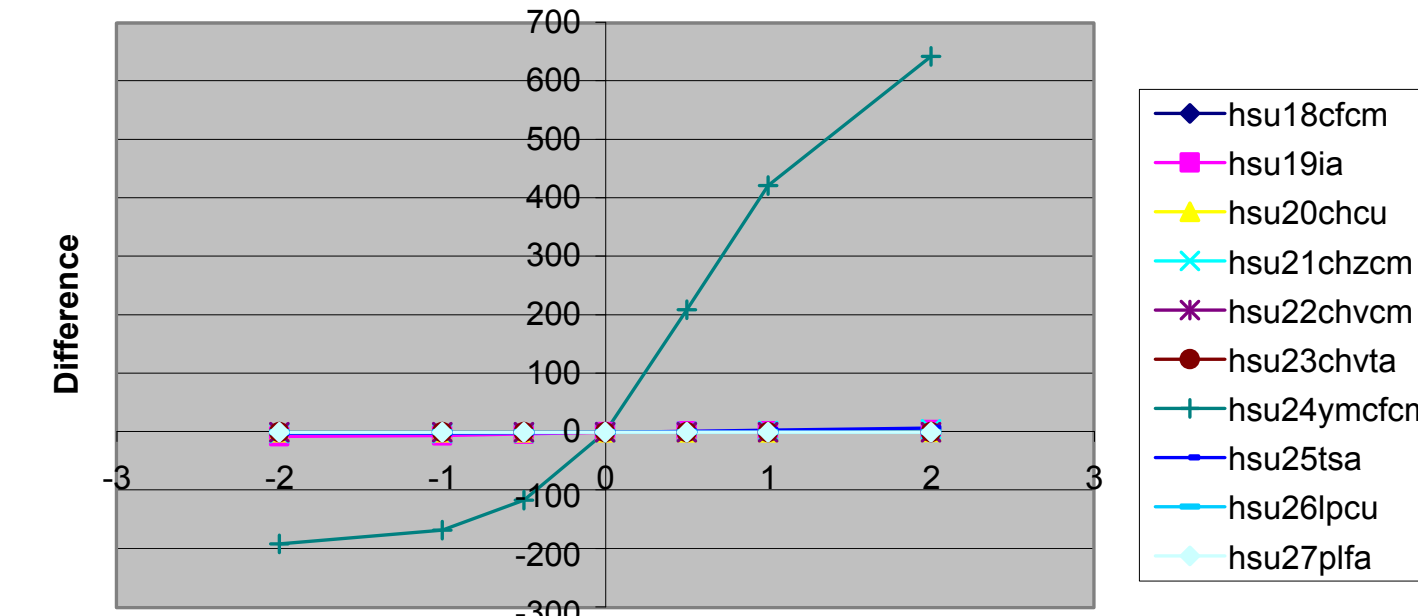

Base Value + +/ Standard Deviation

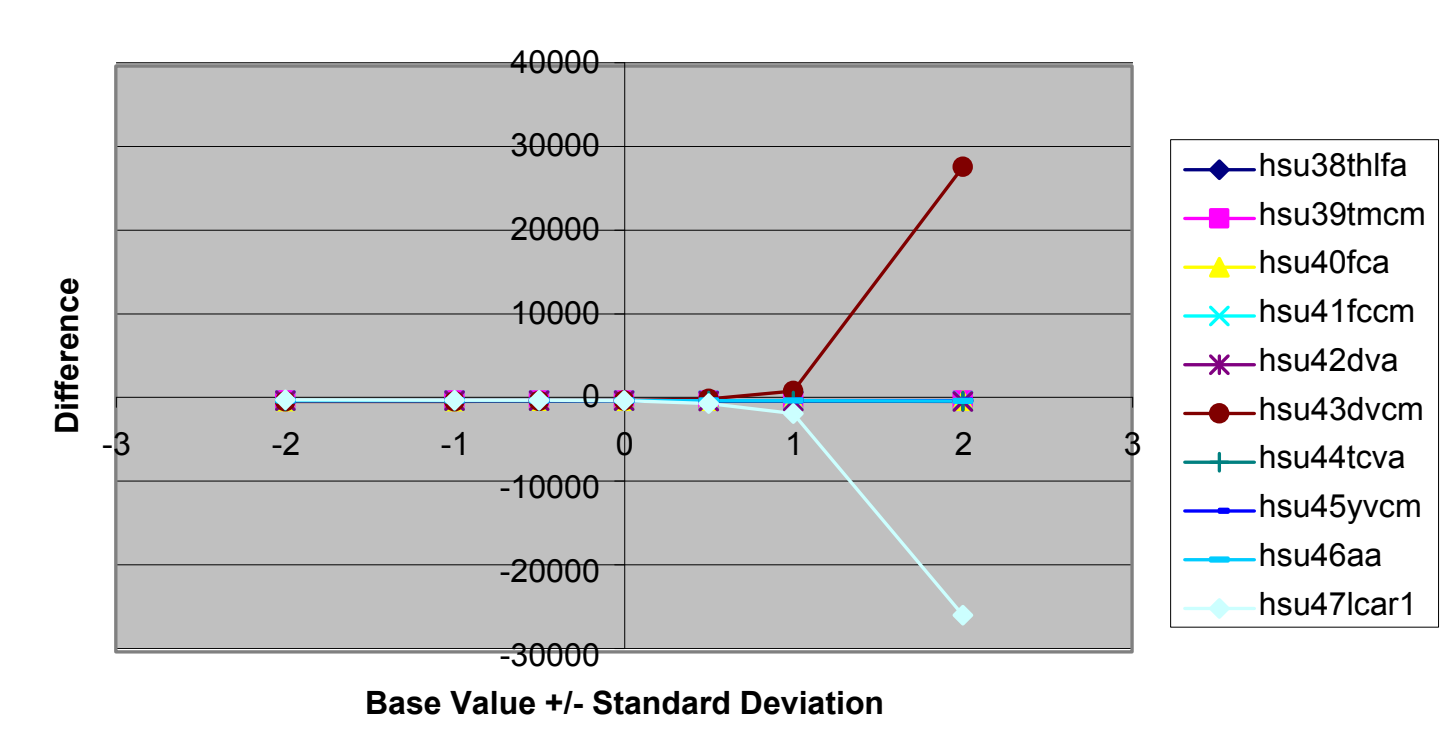

Base Value +t/- Standard Deviation

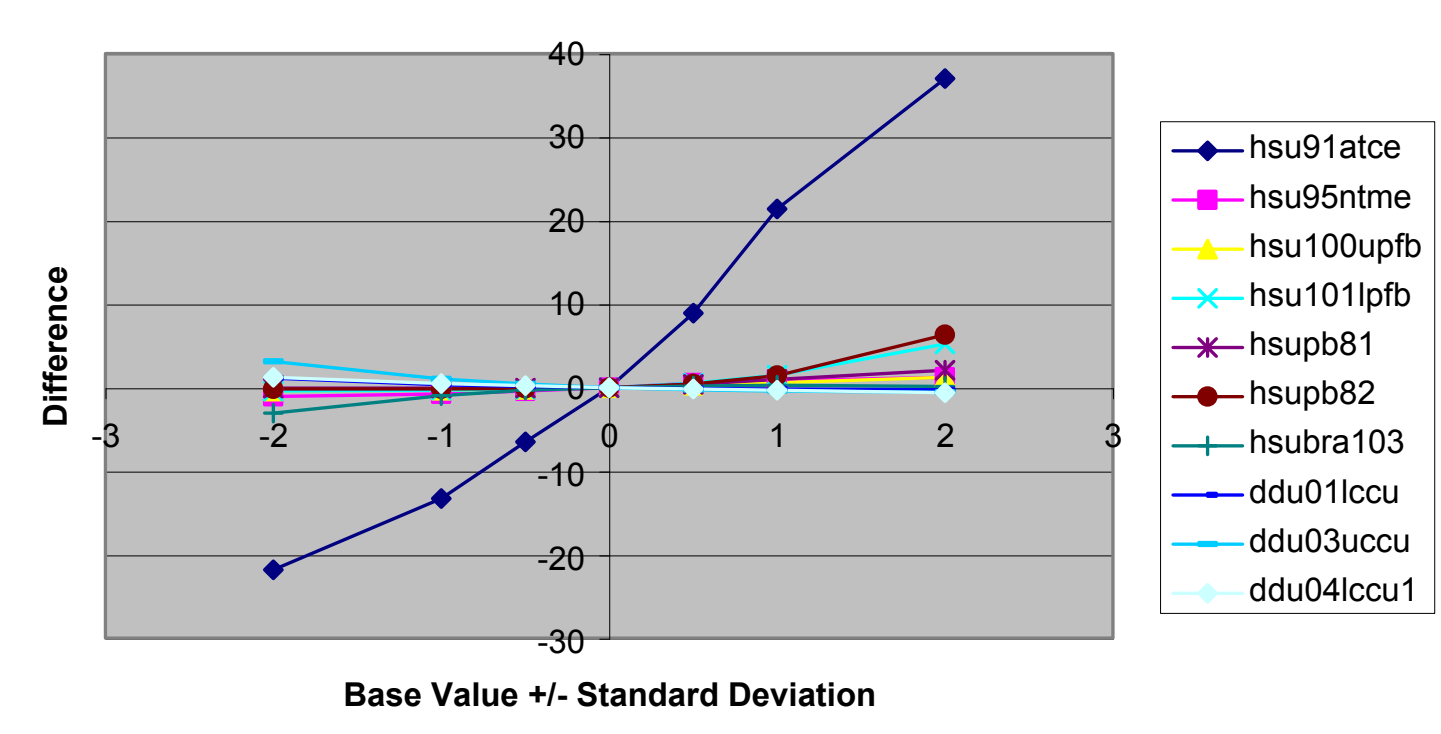

Base Value + +l- Standard Deviation
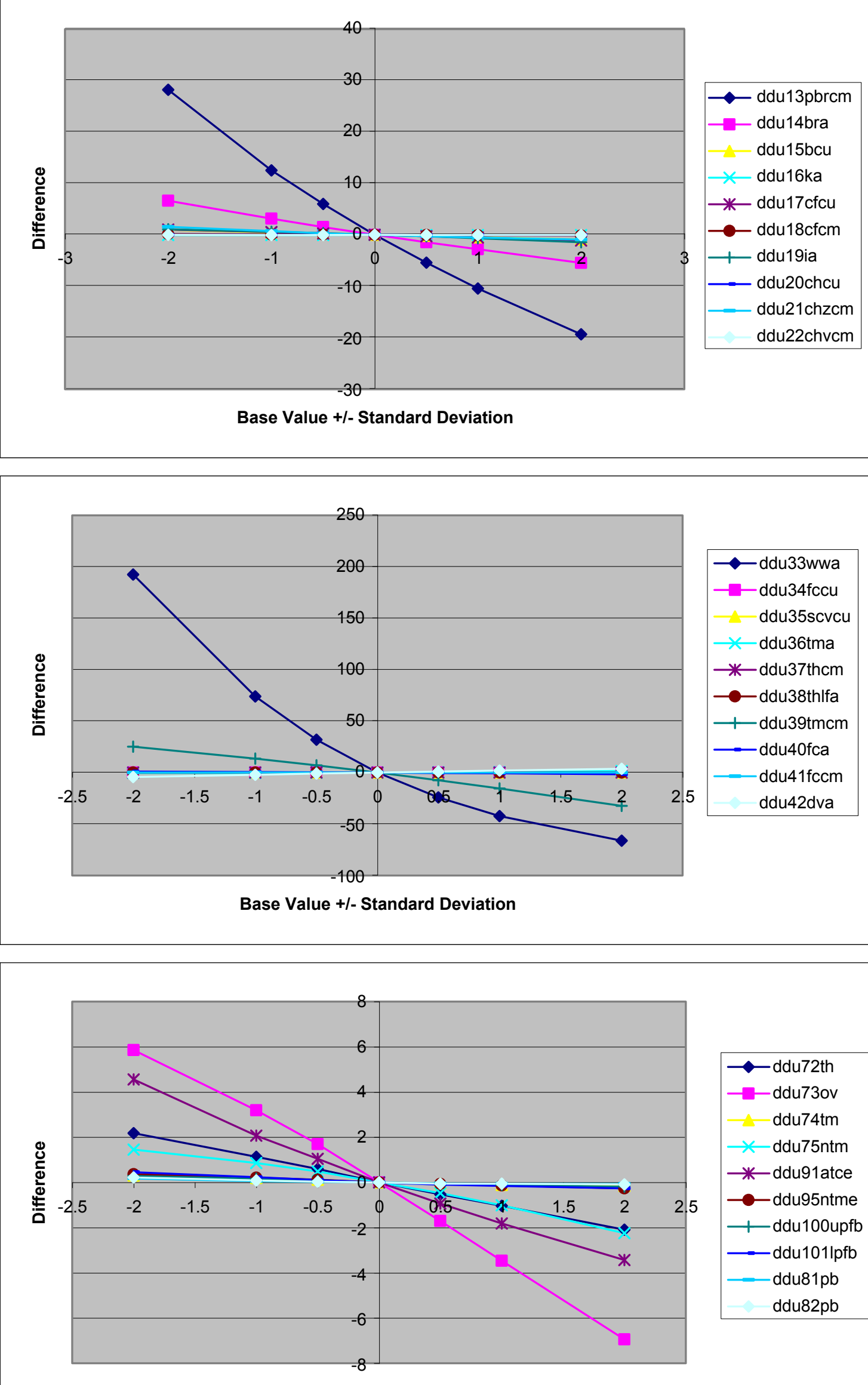

Base Value + I. Standard Deviation
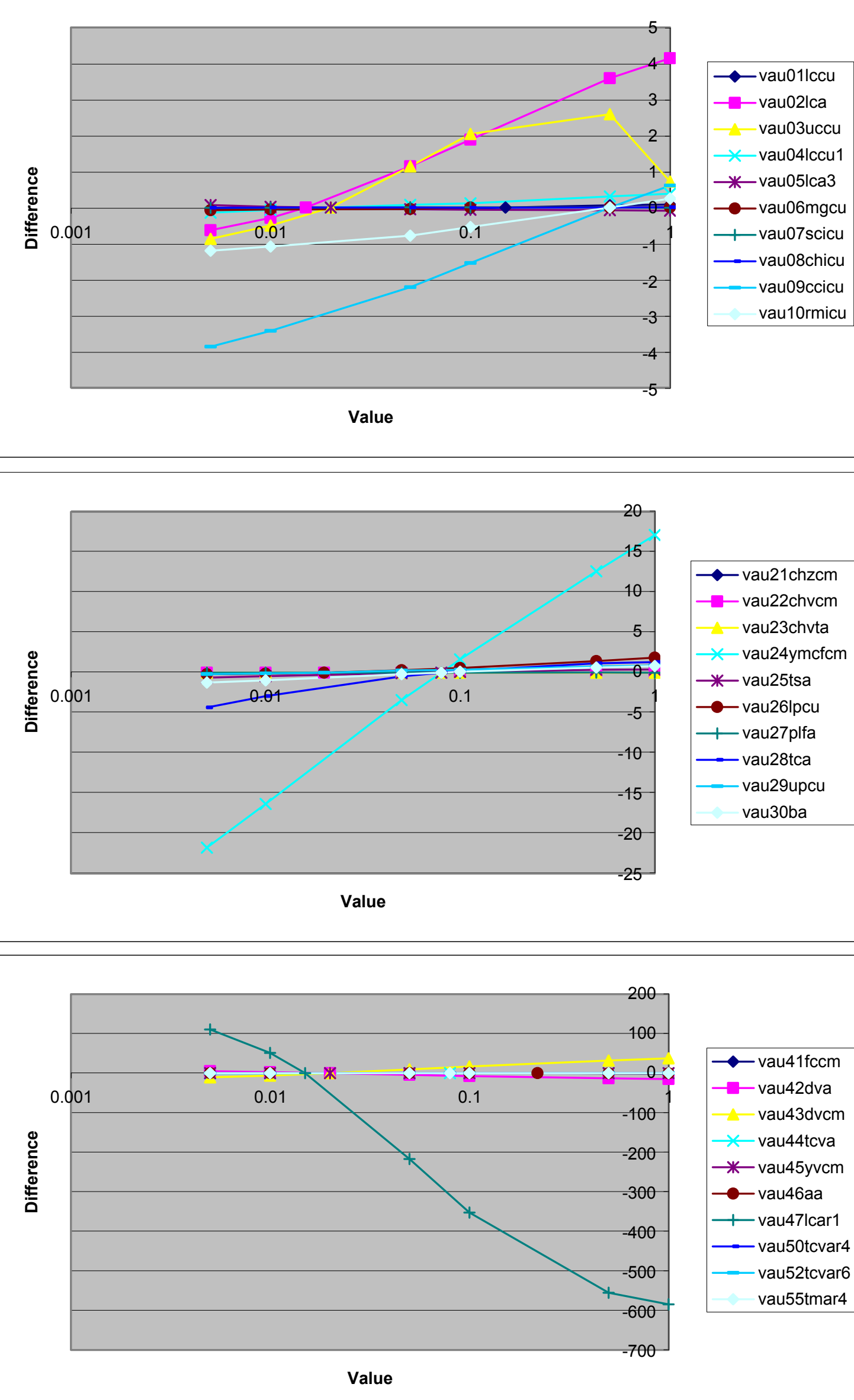

Value

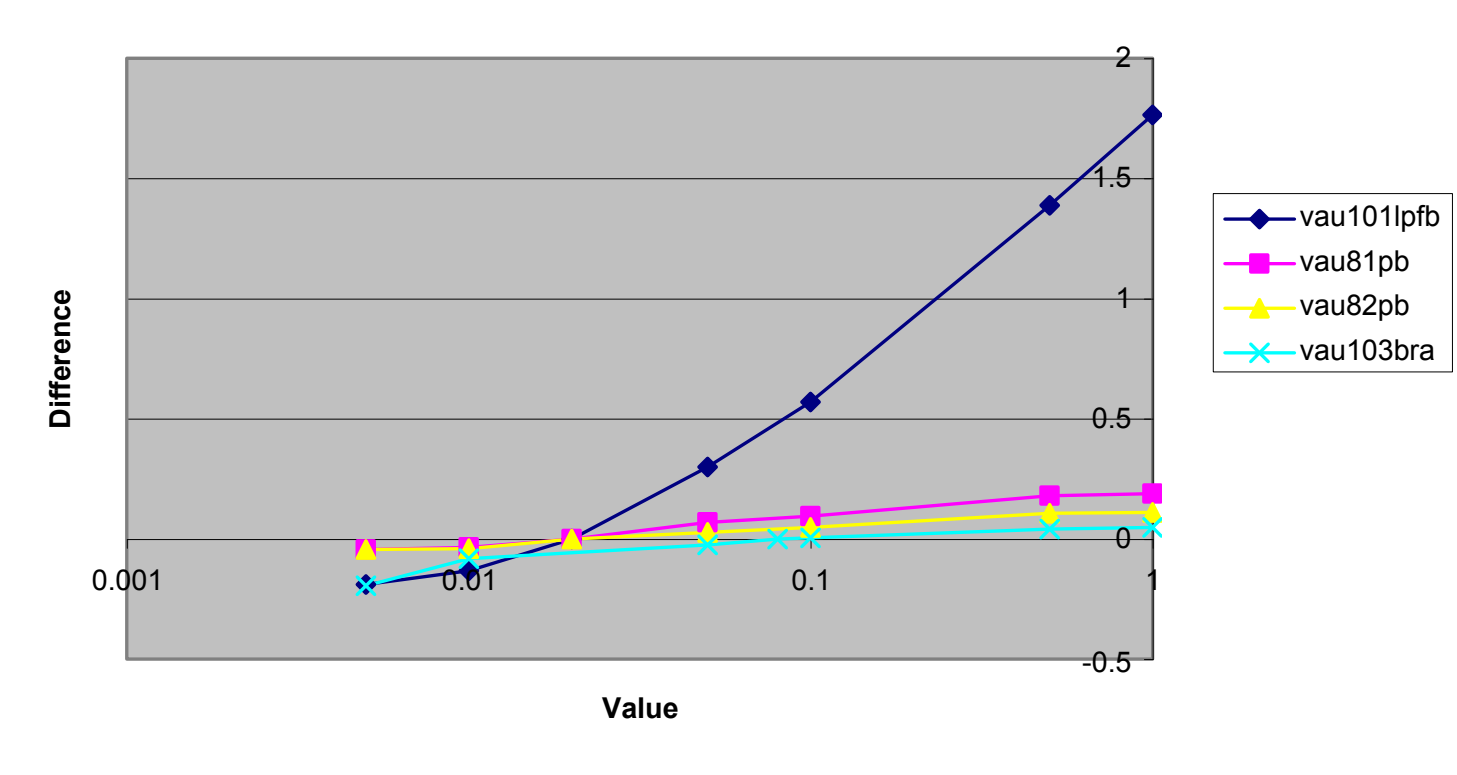




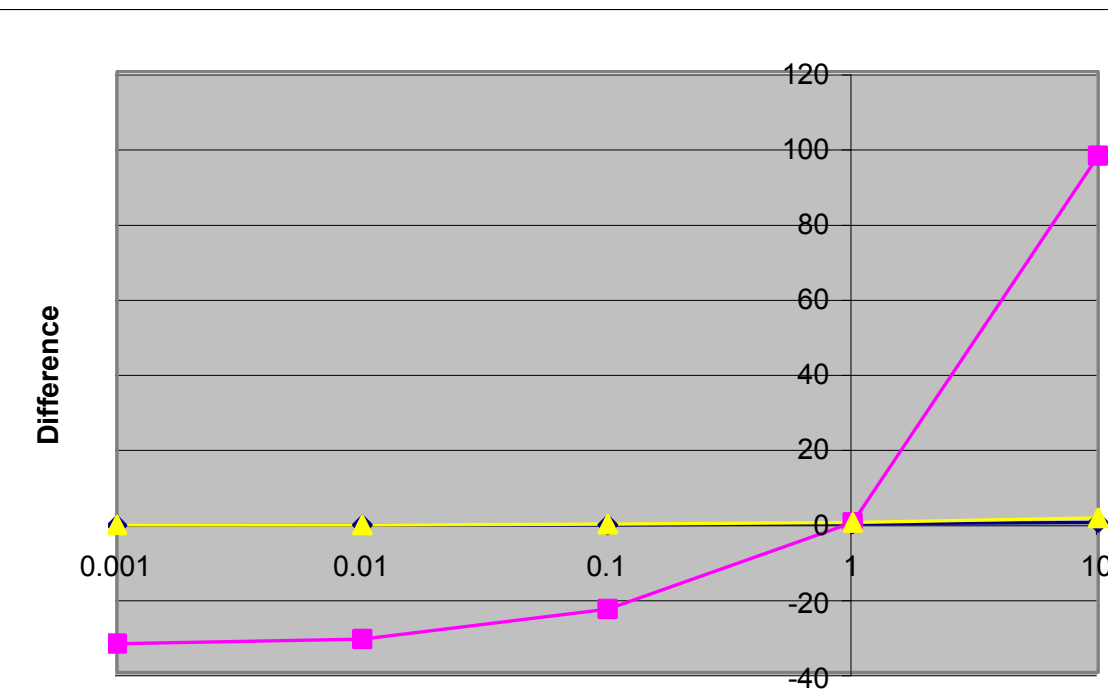

$\longrightarrow-01$ almendro
$\rightarrow-02$ baremtnf $\rightarrow \quad 03 \_b m c s m w d f$

Value
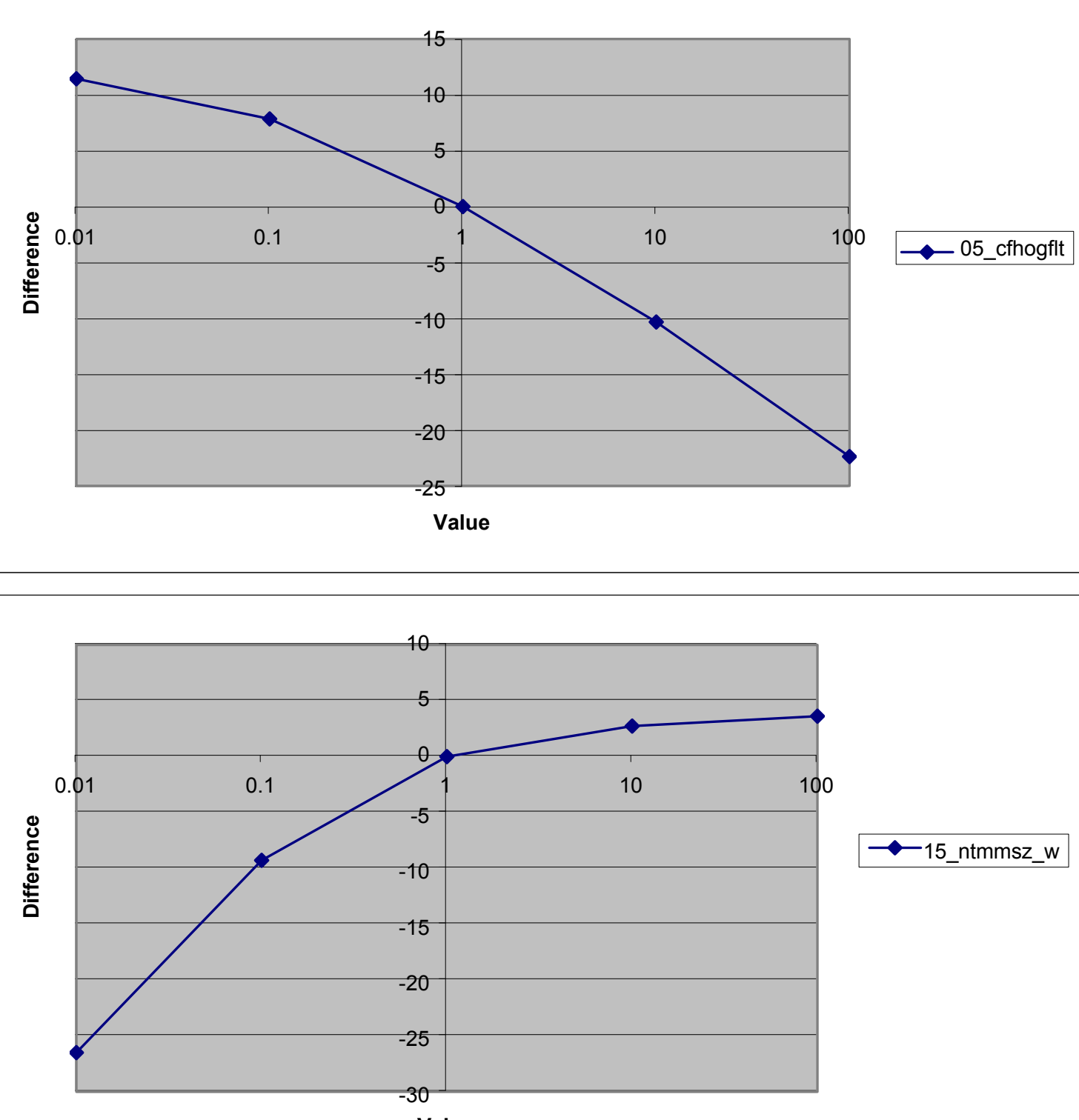

$\rightarrow-15$ ntmmsz_w
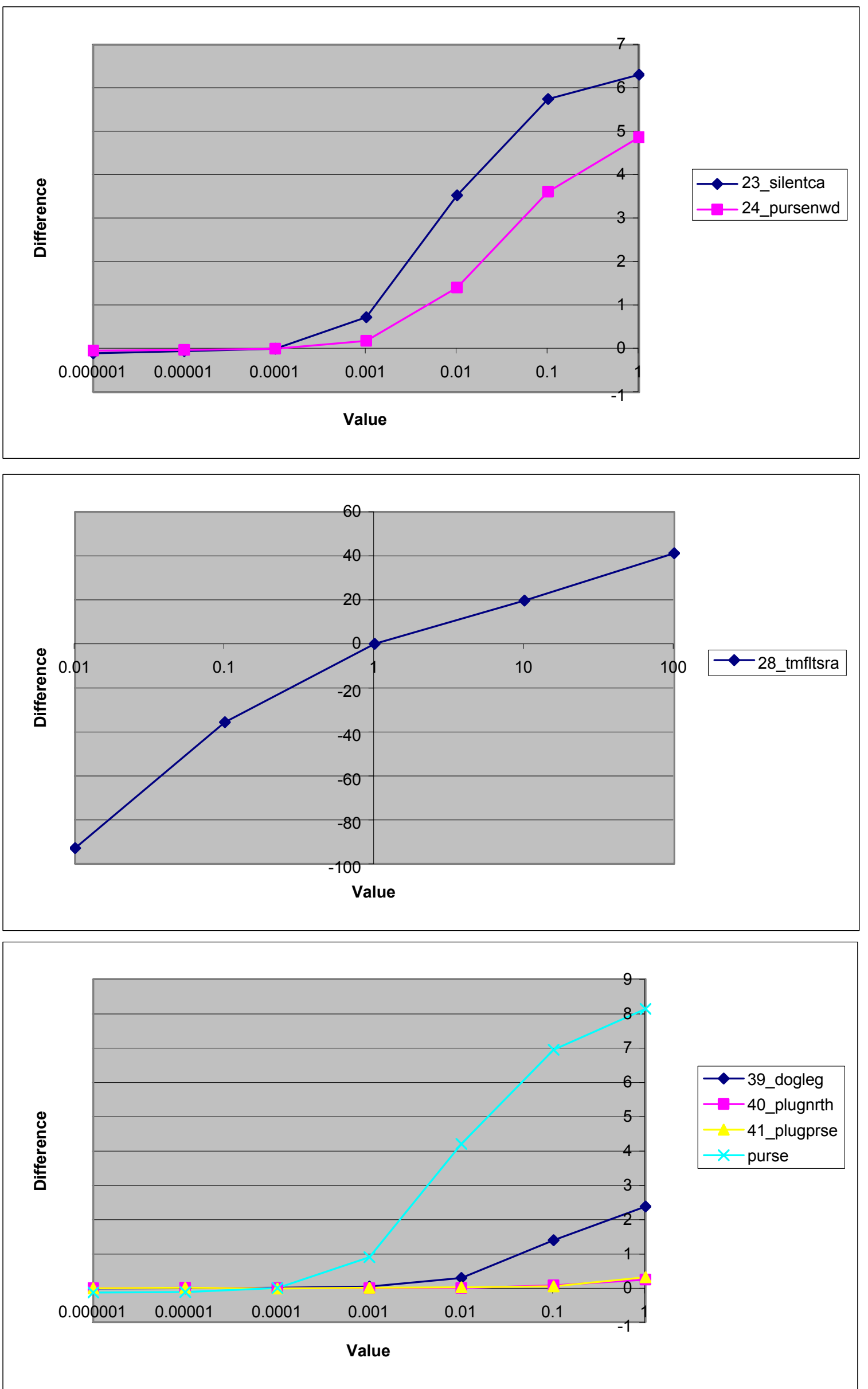

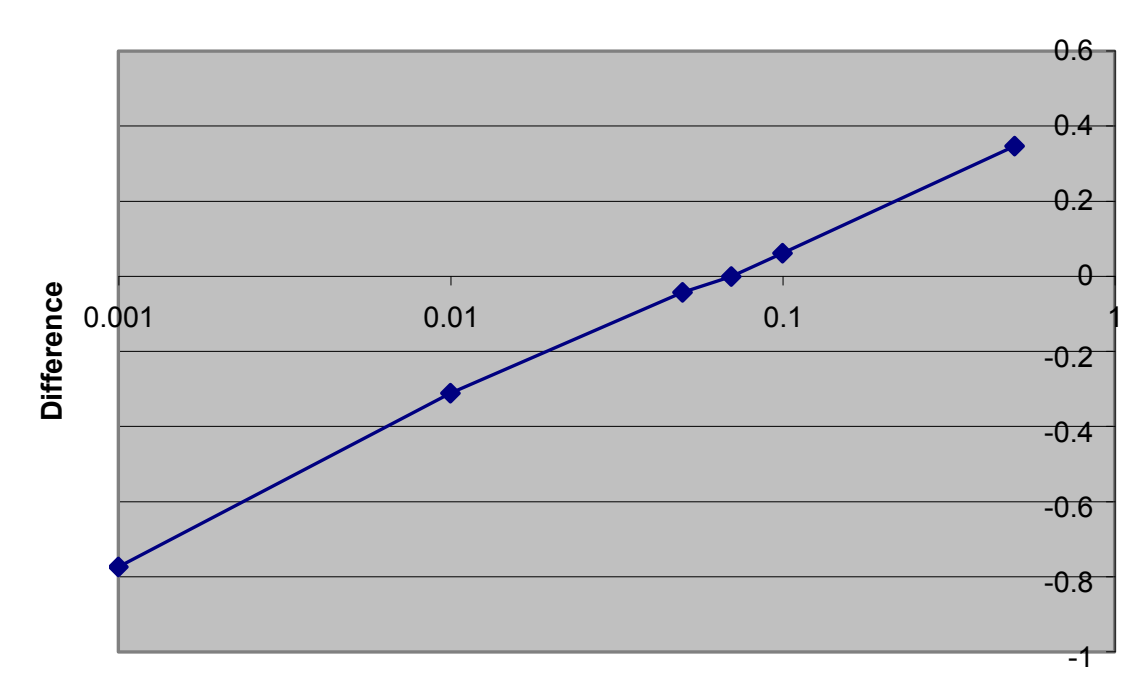

$\multimap$-04_boxcar_w

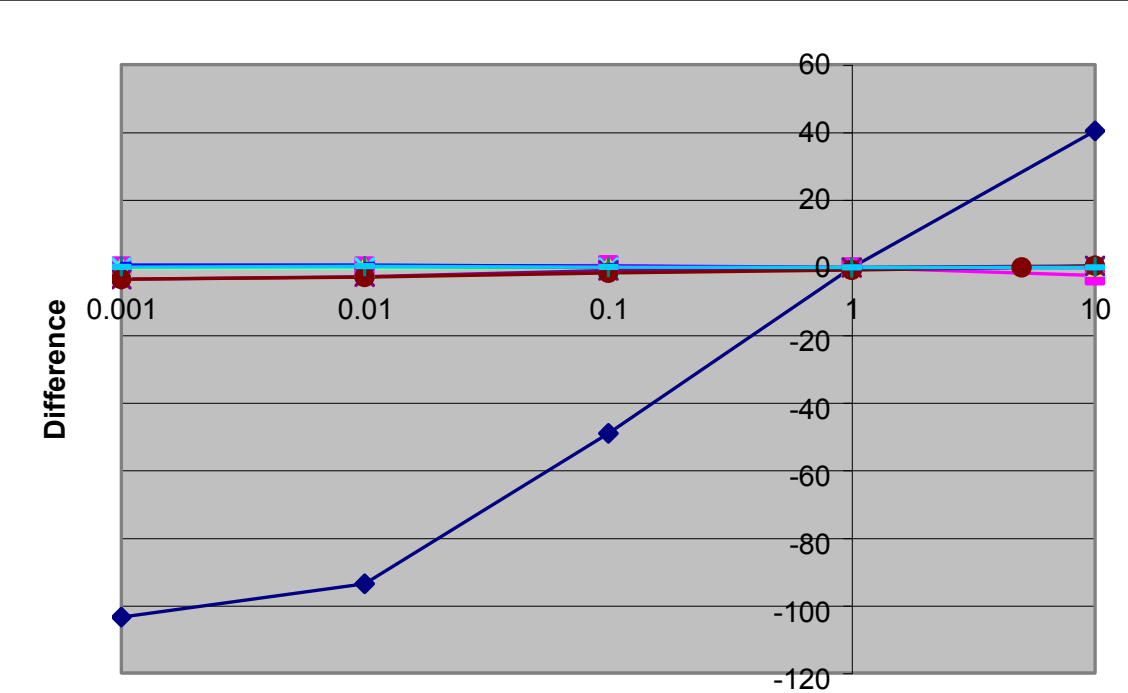

Value

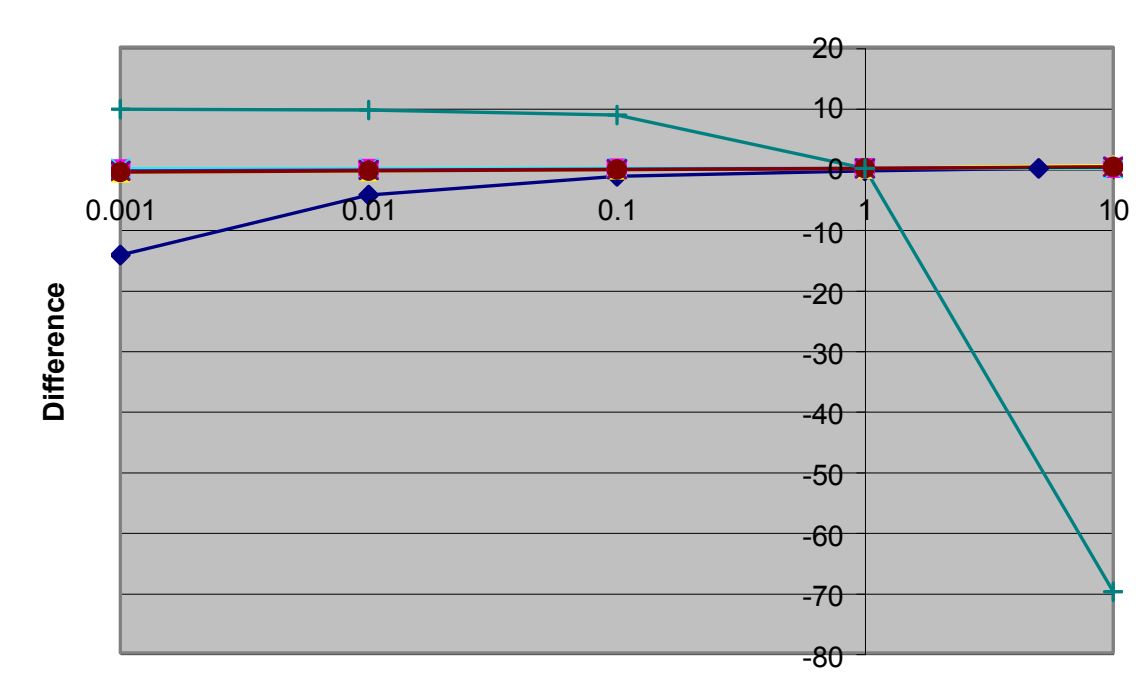

Value

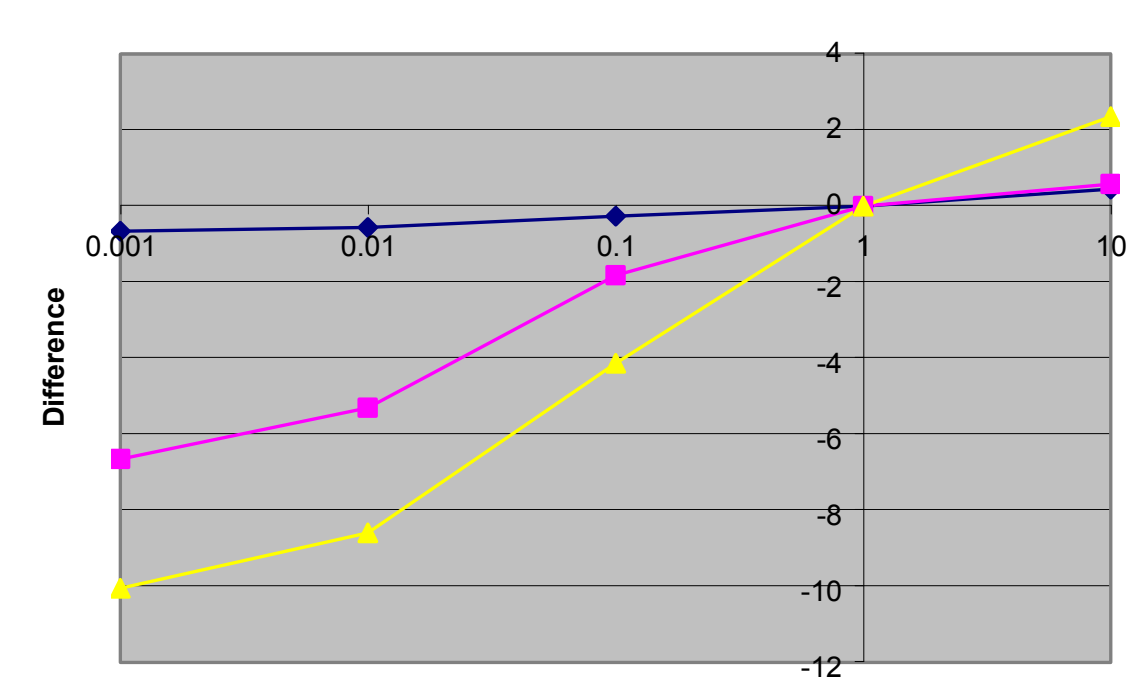

Value

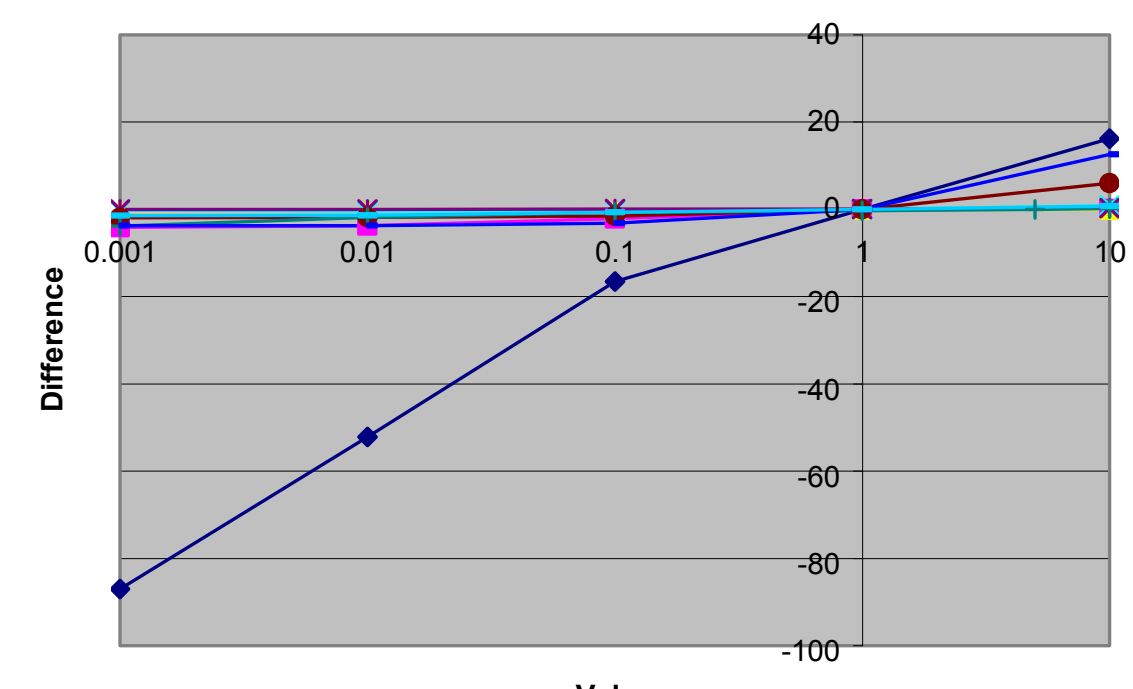

Value

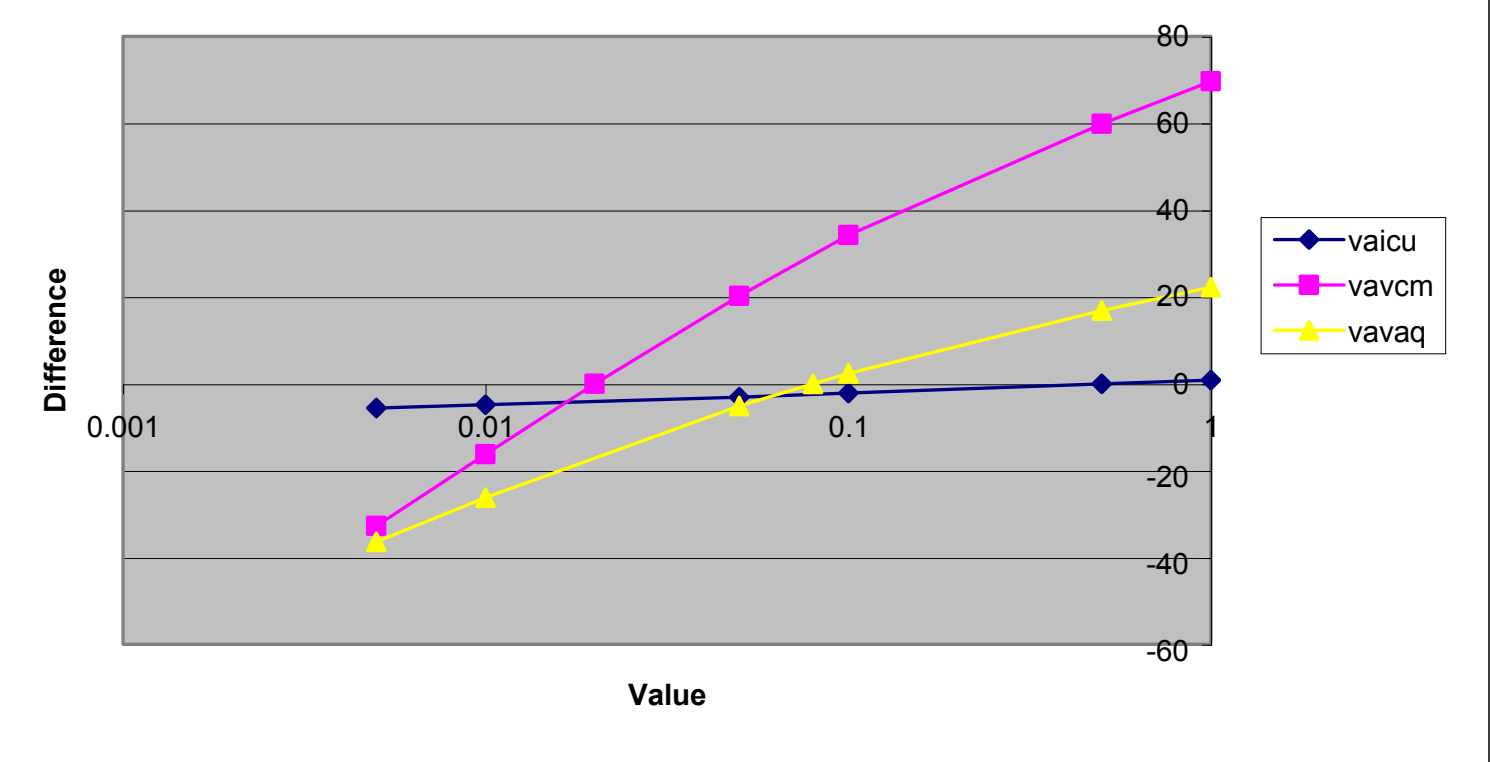



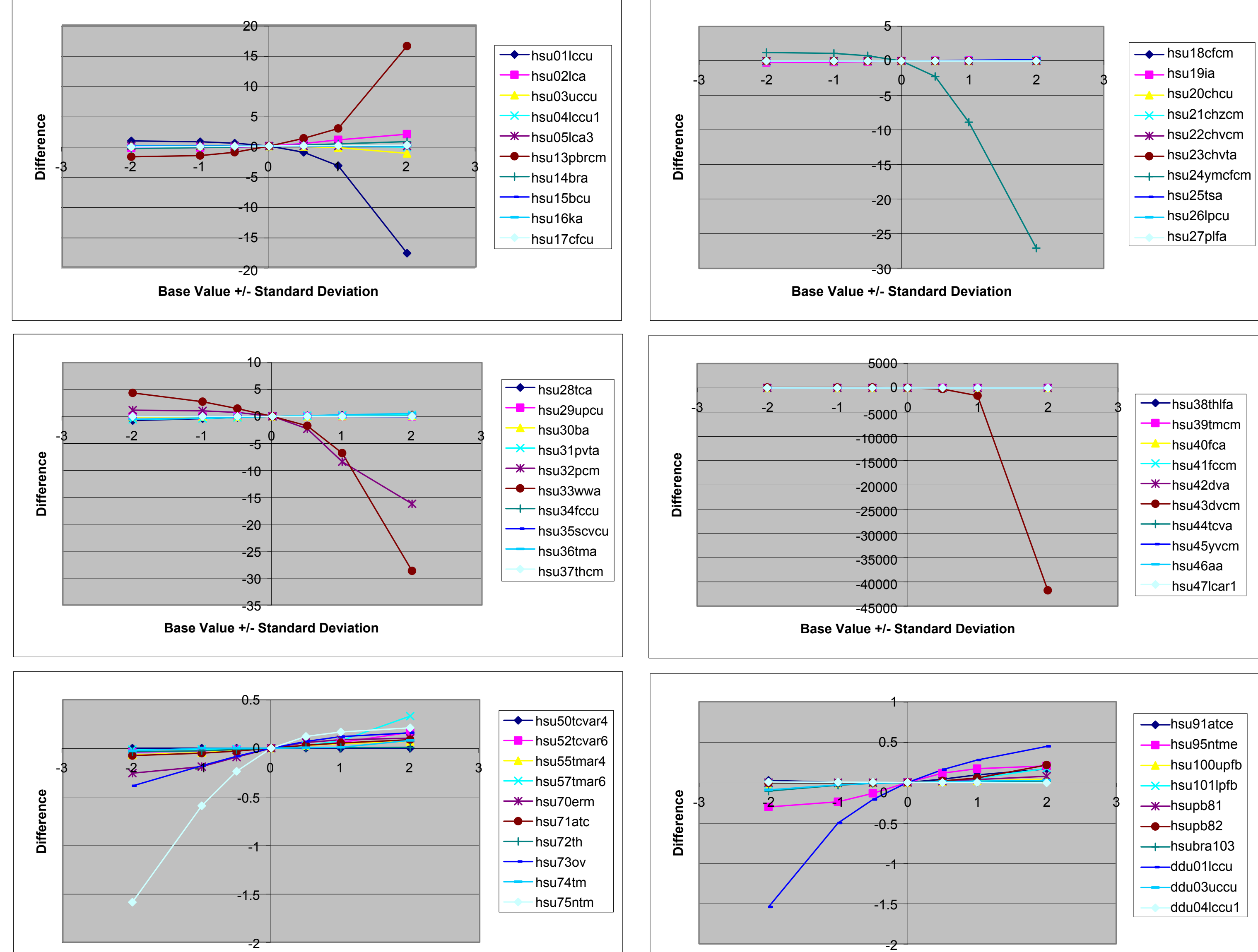

Base Value +1-Standard Deviation
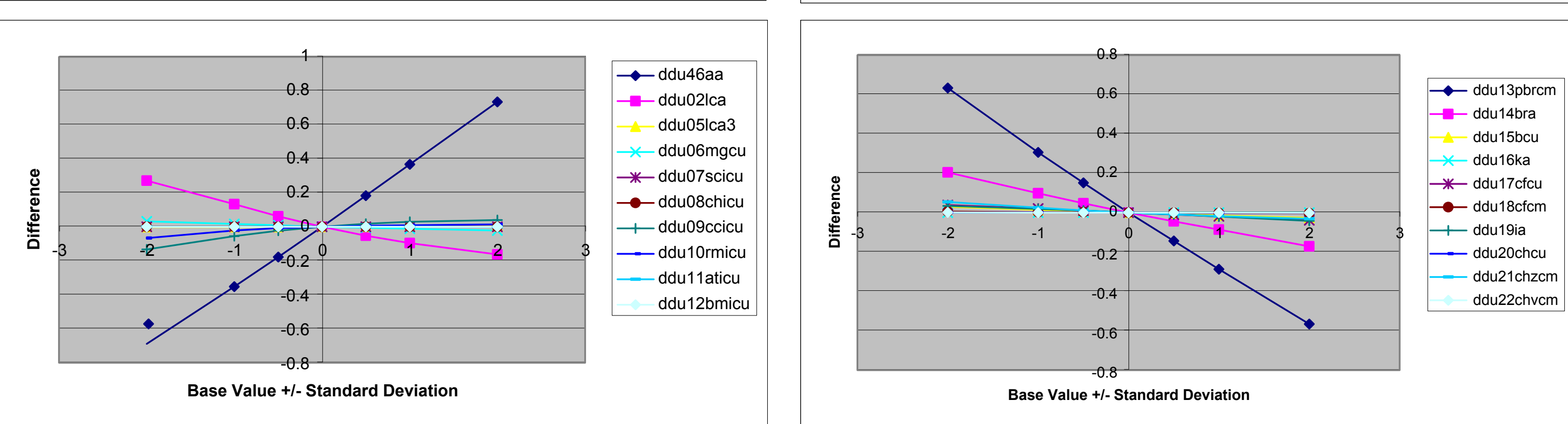

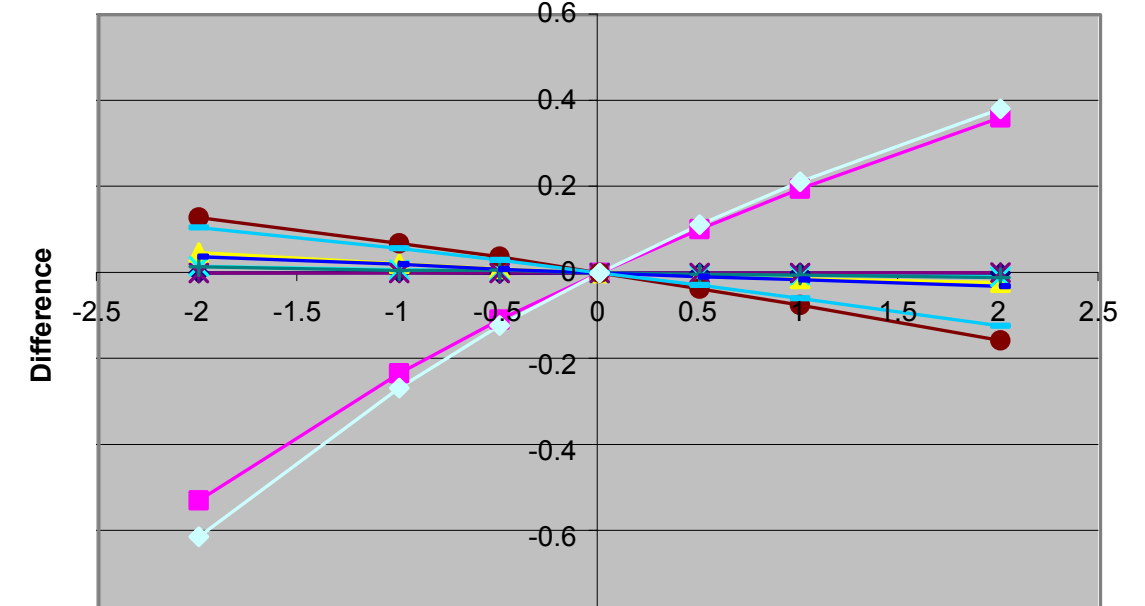

Base Value ++.8 -Standard Deviation

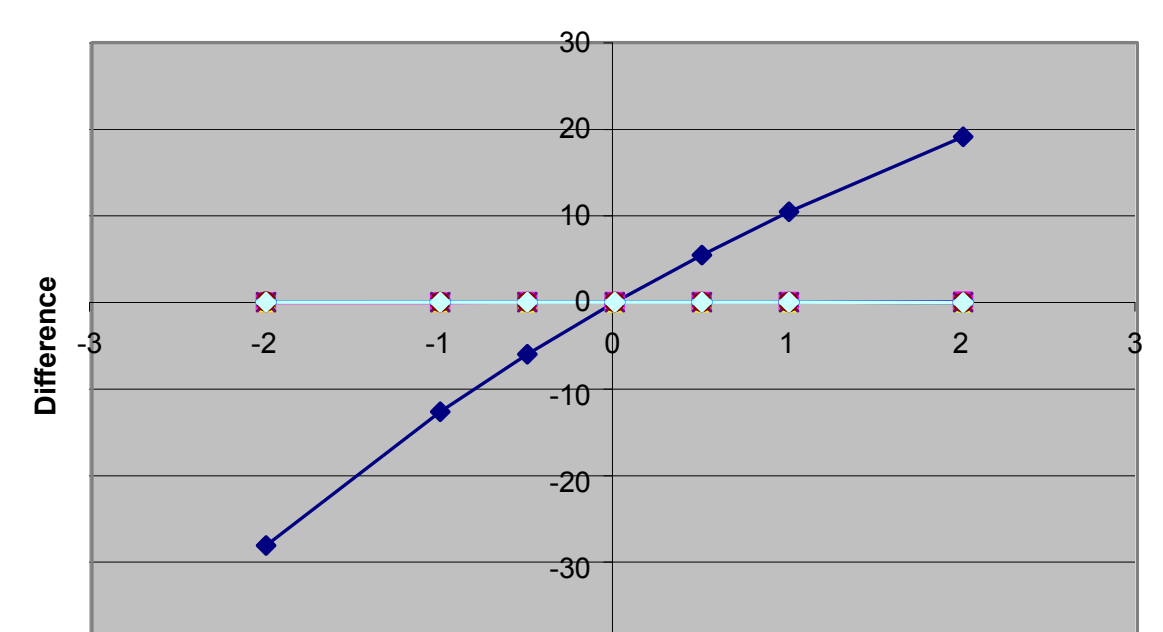

Base Value +40 - Standard Deviation
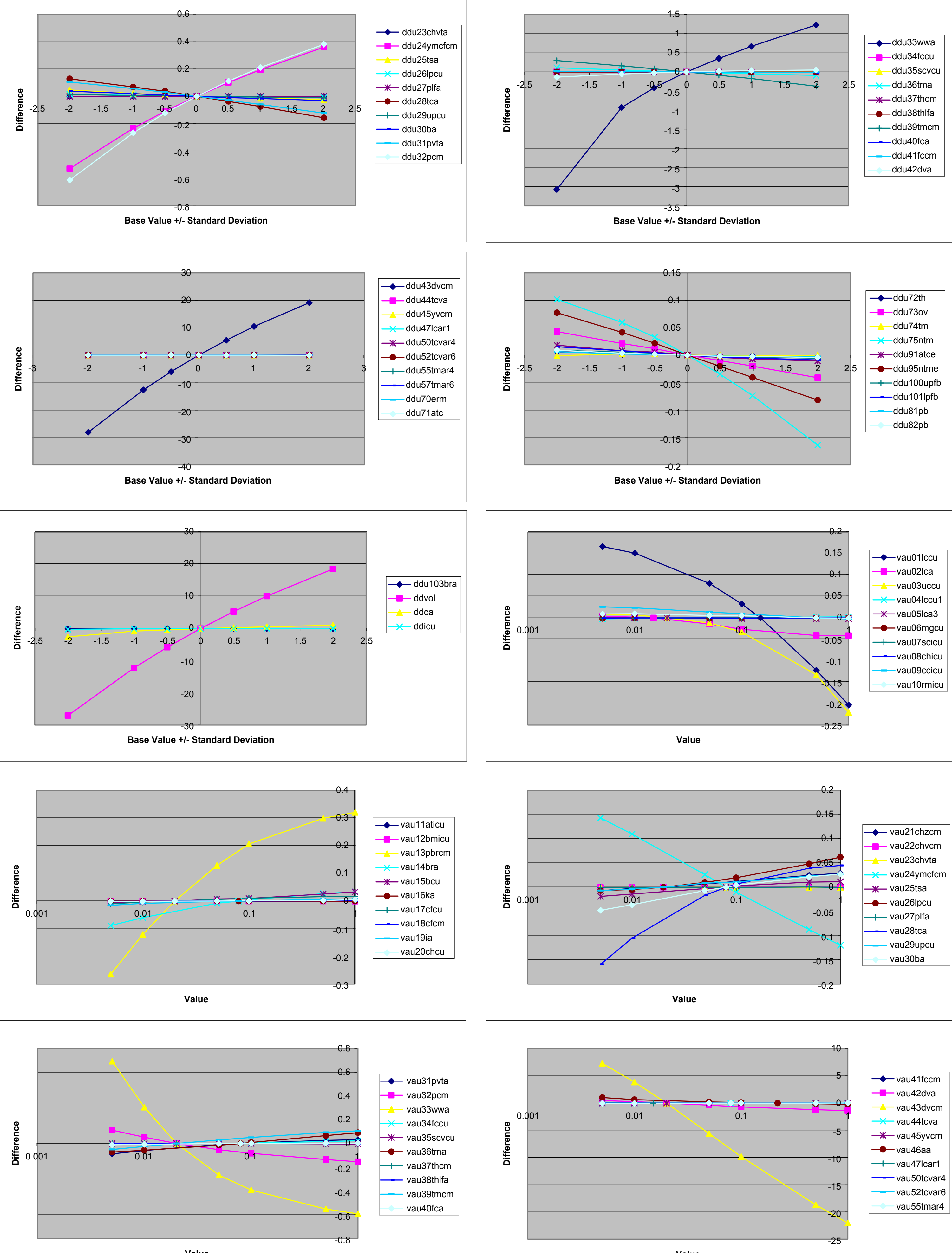

Base Value + + + Standard Deviation

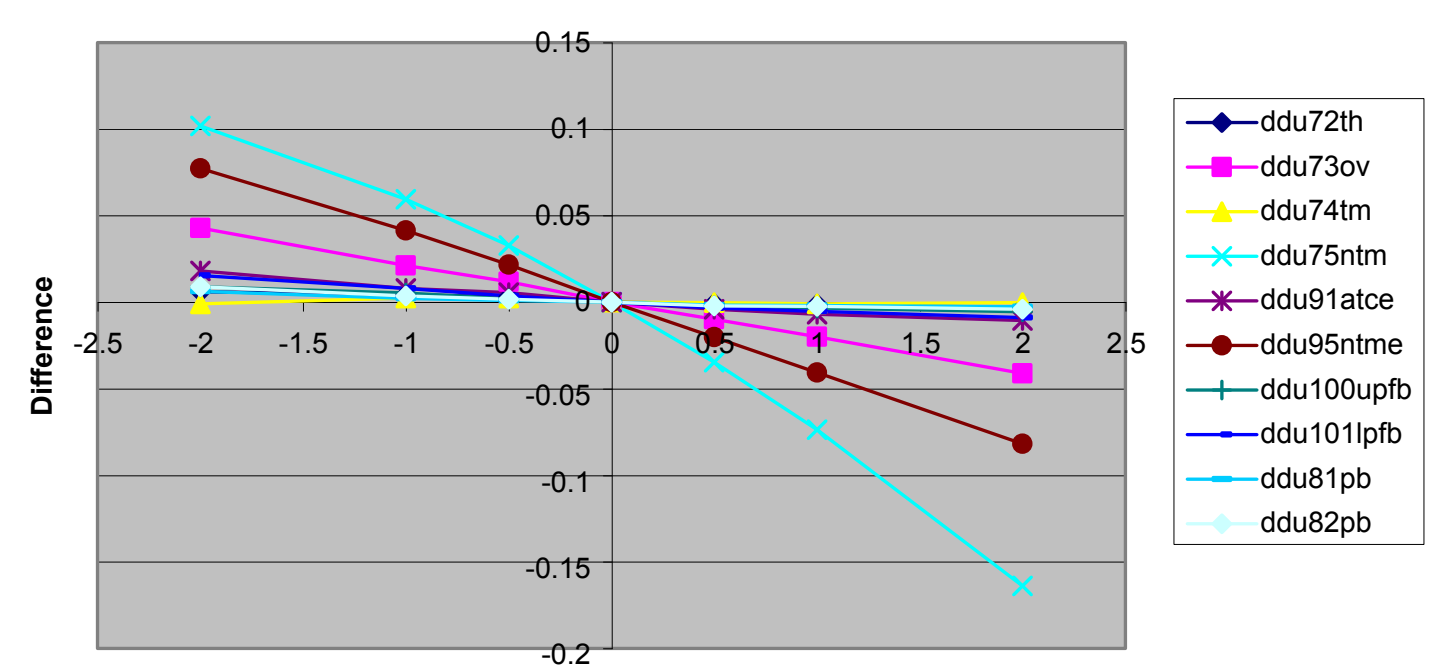

Base Value.$+ / 2$ Standard Deviation
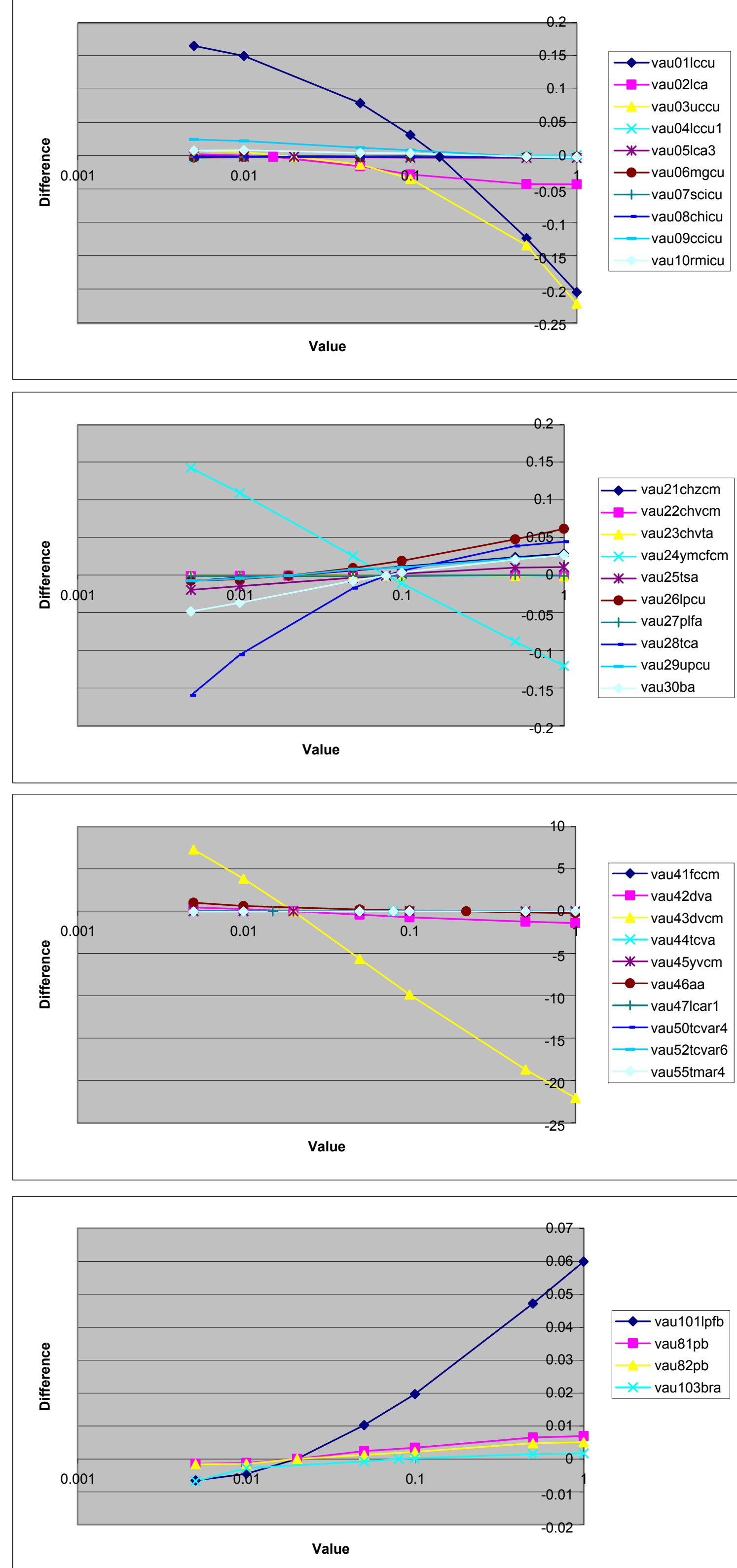

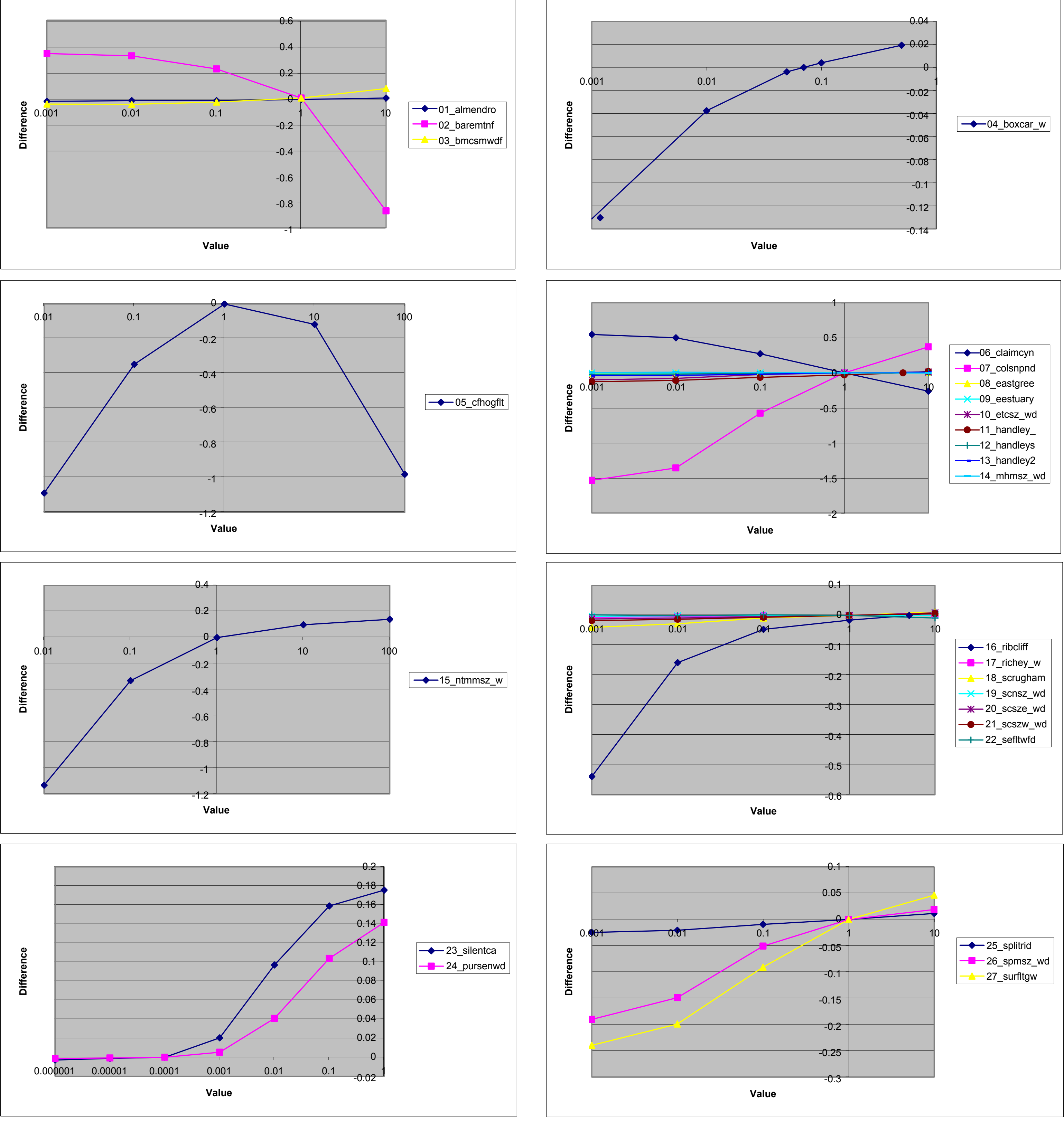

$\bullet-25$ splitrid
--26 sspmsz_wd

27_surfltgw
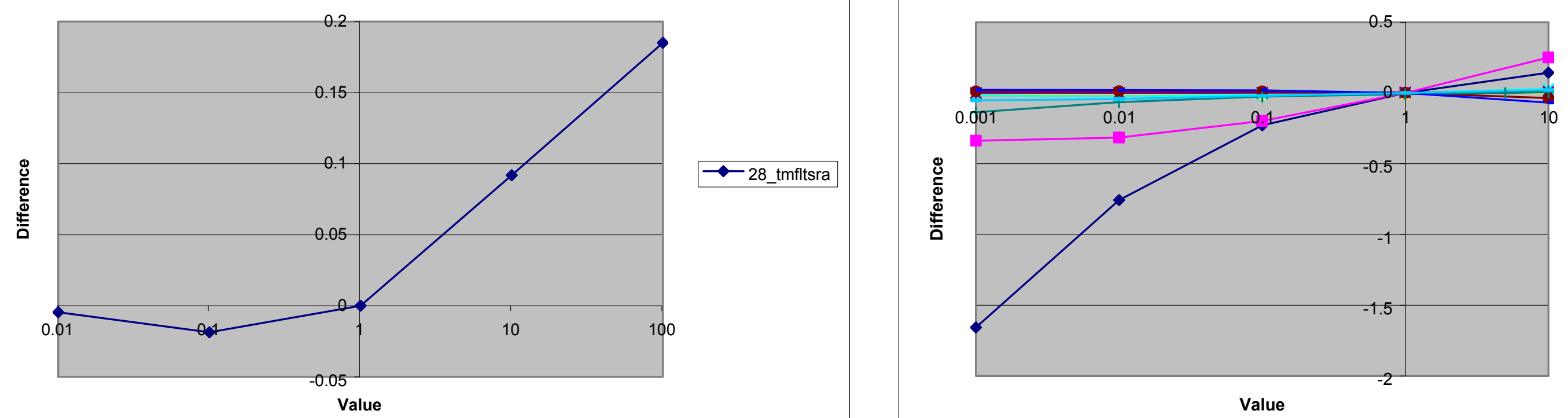

$\longrightarrow-29$ tmfltstm $\rightarrow$-30_tmext2ho 31 walmendr $\times$ 33_westgree * 34 westuary - 35_windywas — 36_wscsz_wd - 37_paintbrs - 38 _silentca

Value
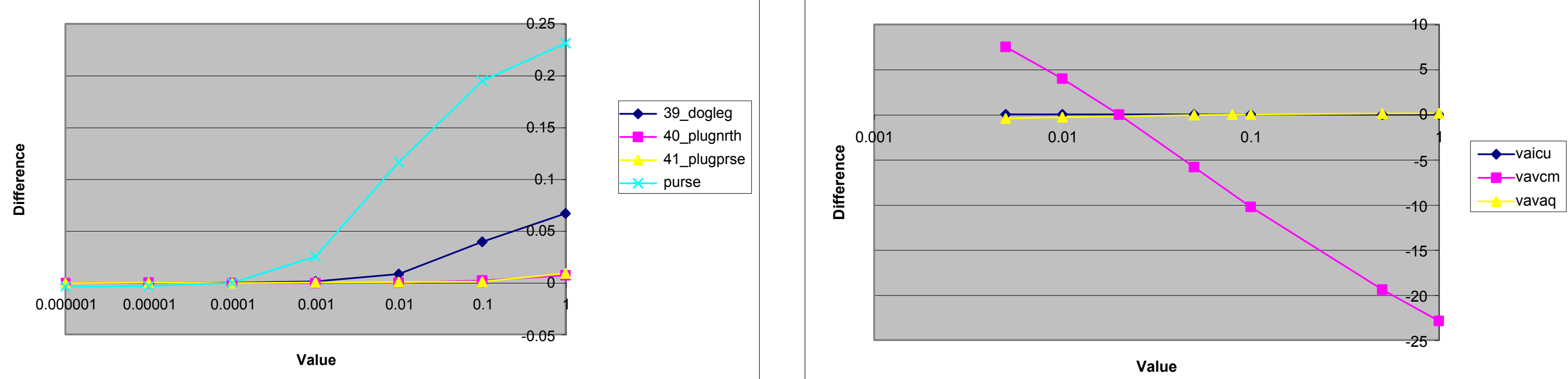

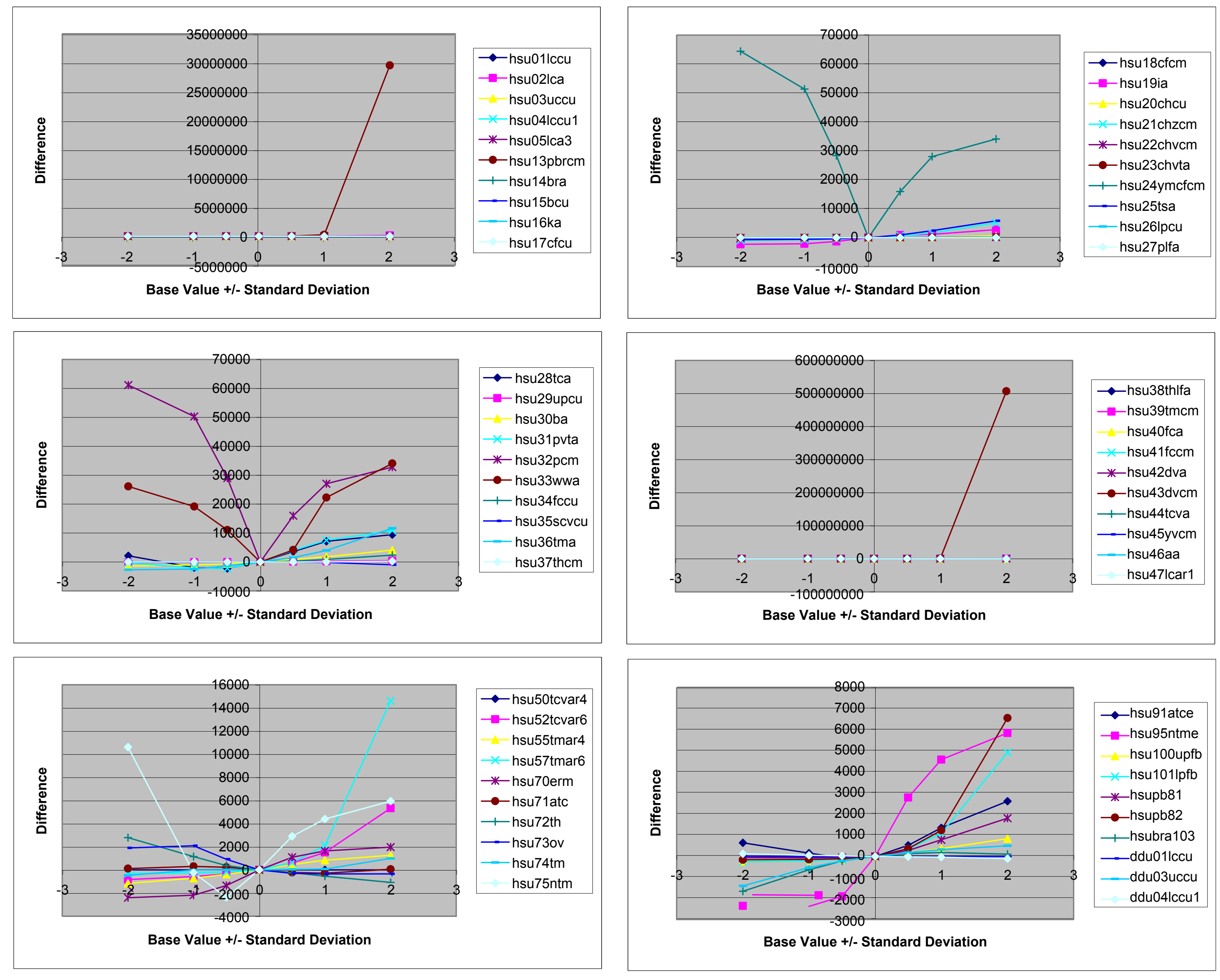

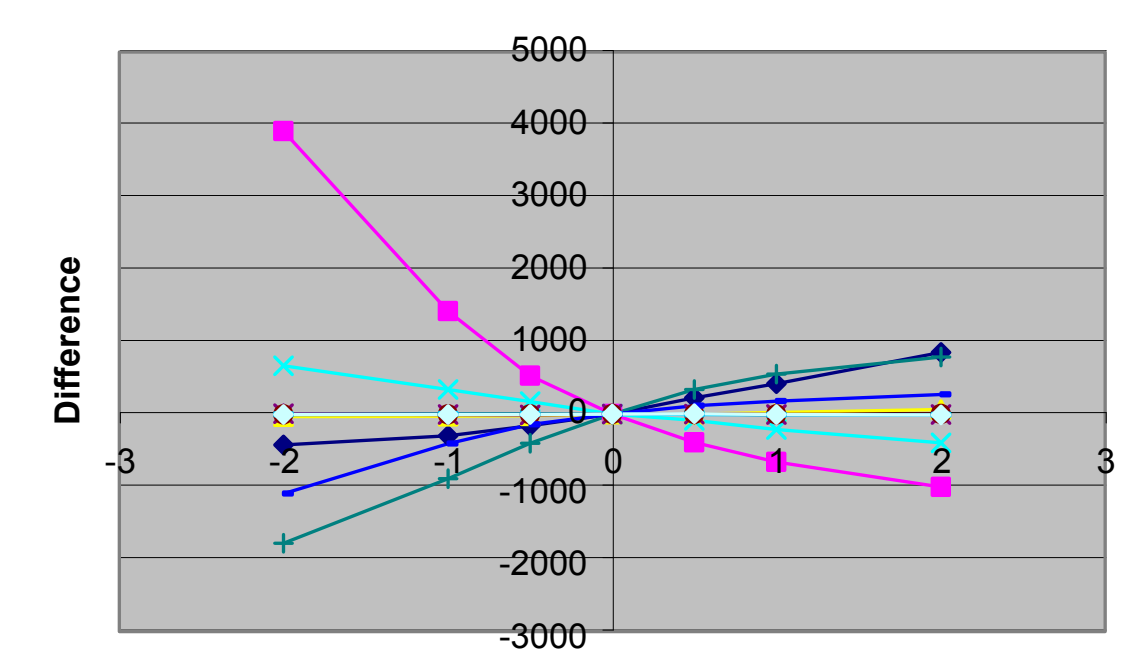

Base Value + / Standard Deviation

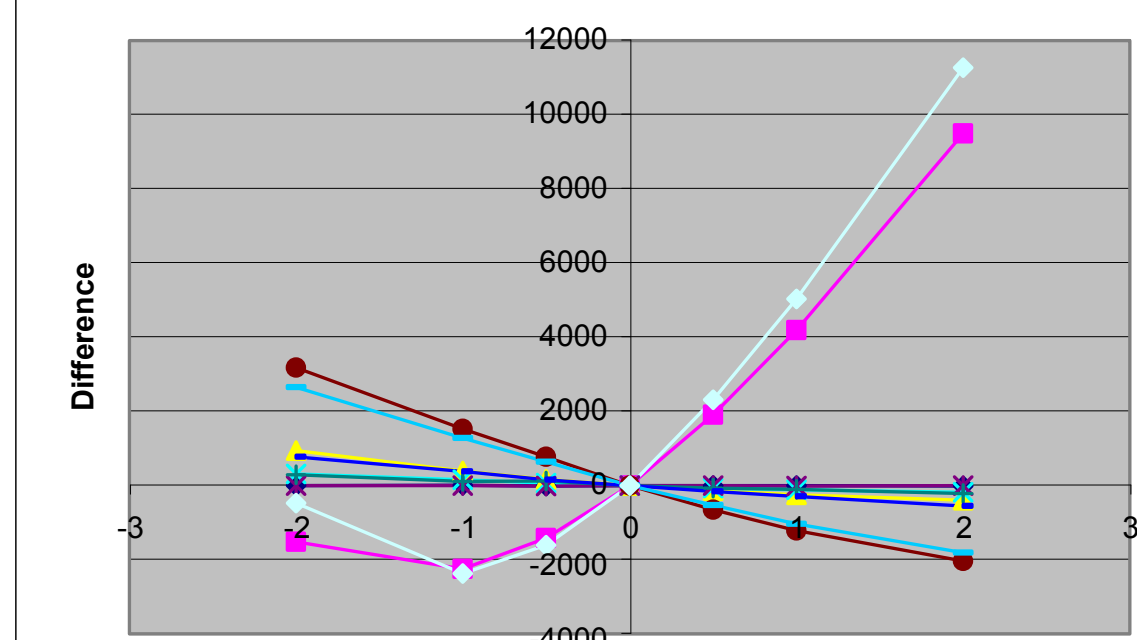

Base Value +1/ Standard Deviation

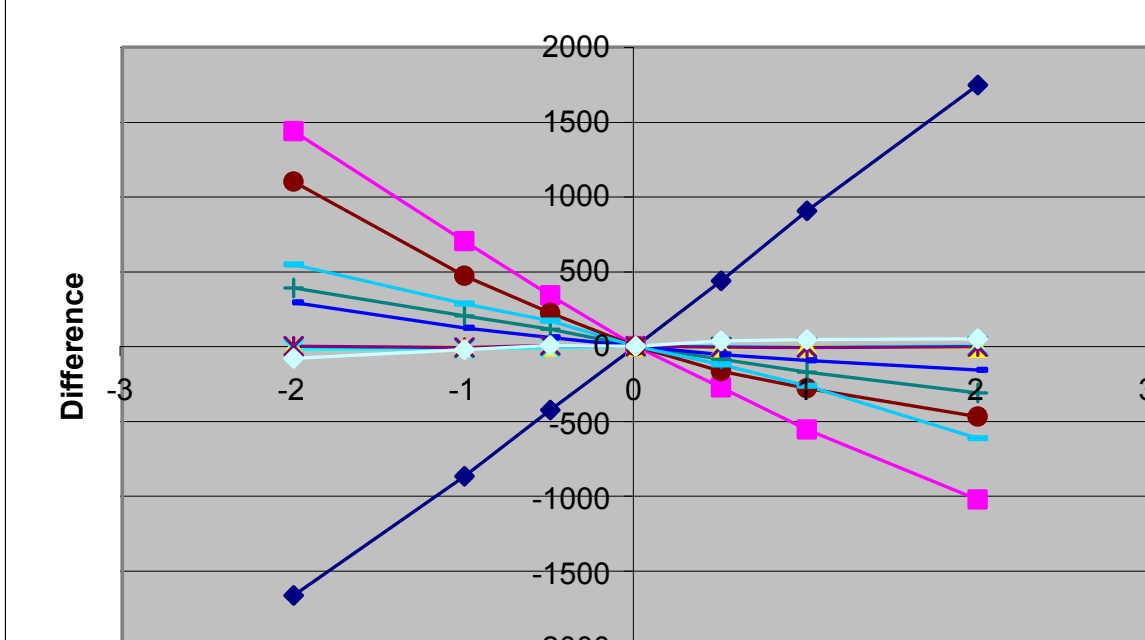

Base Value +1/-Standard Deviation
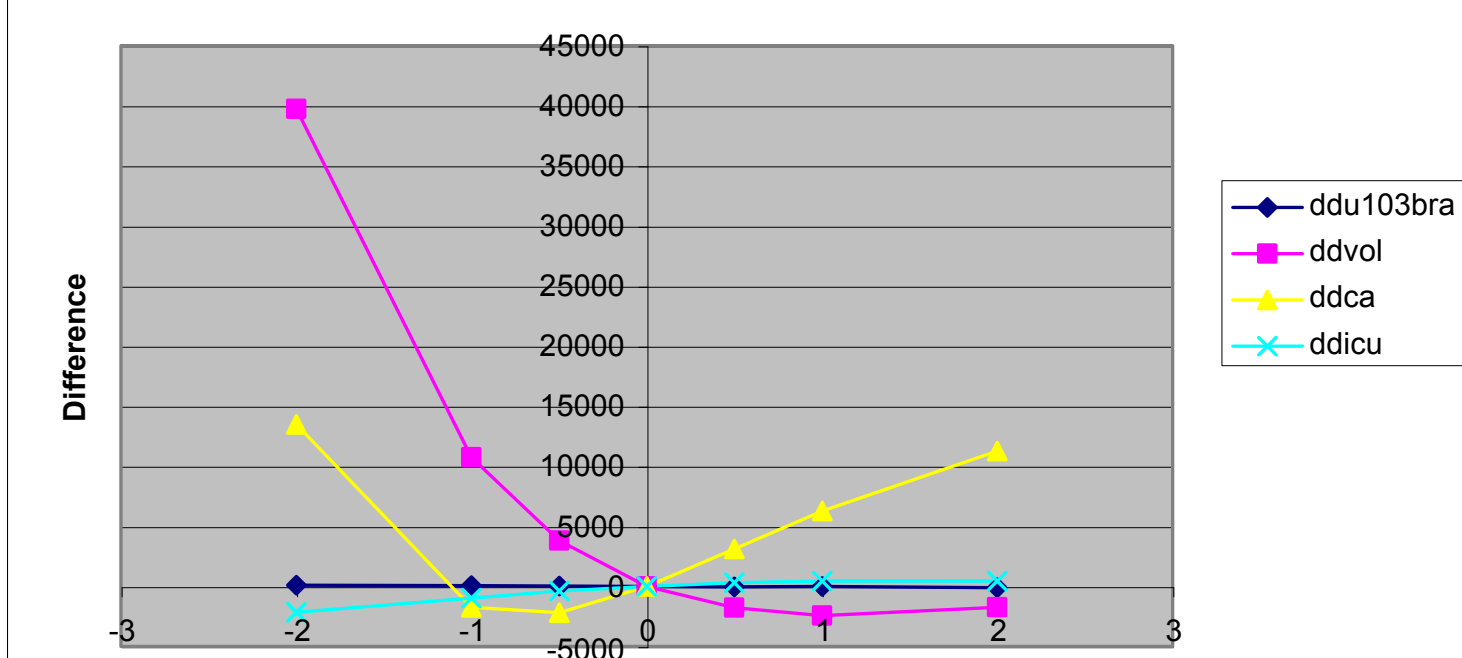

Base Value +l/-Standard Deviation

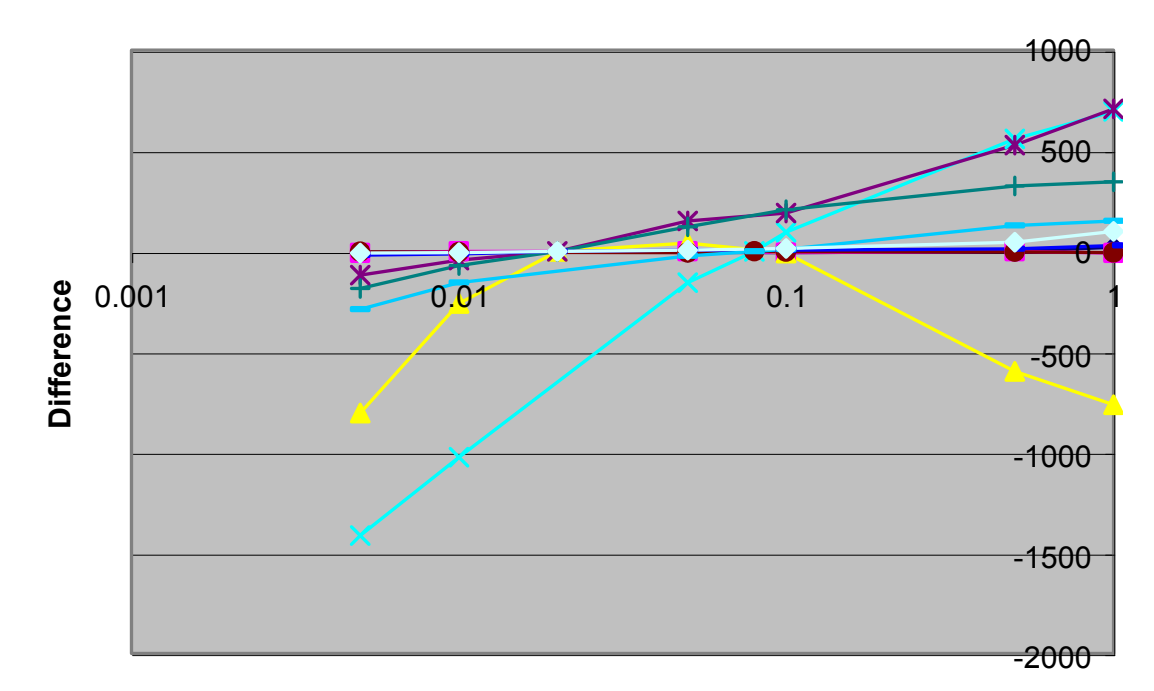

value

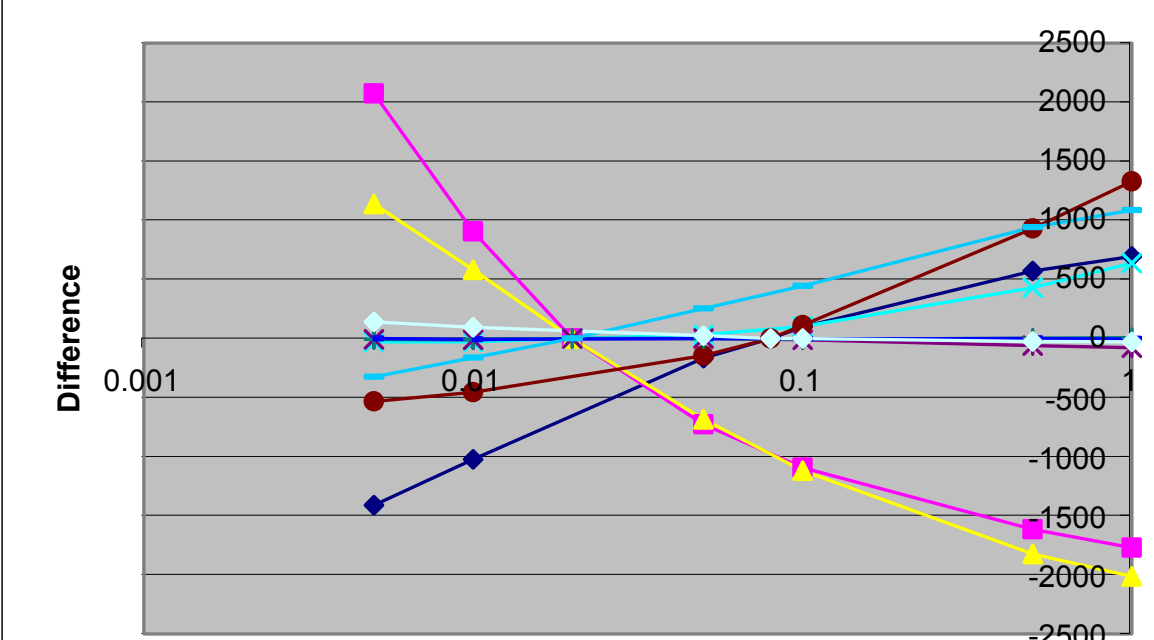

value
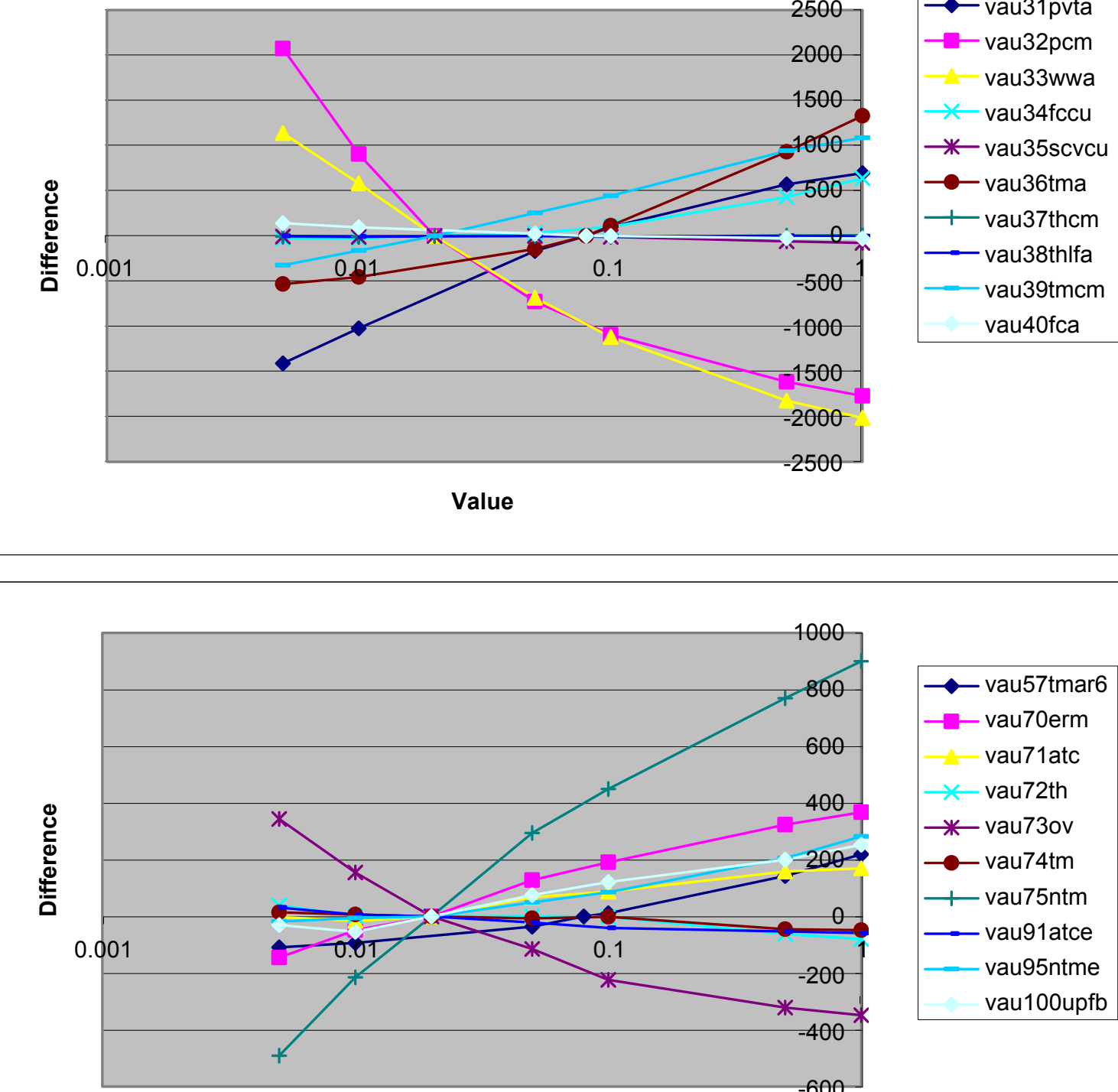
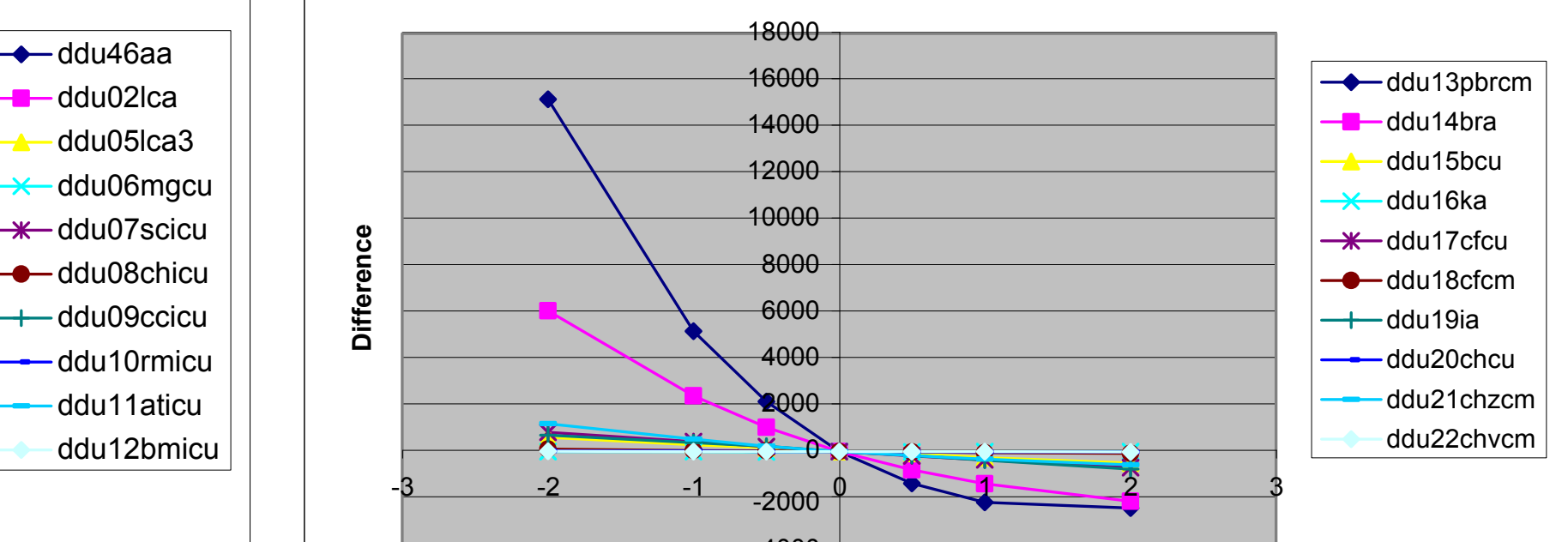

Base Value +/- Standard Deviation
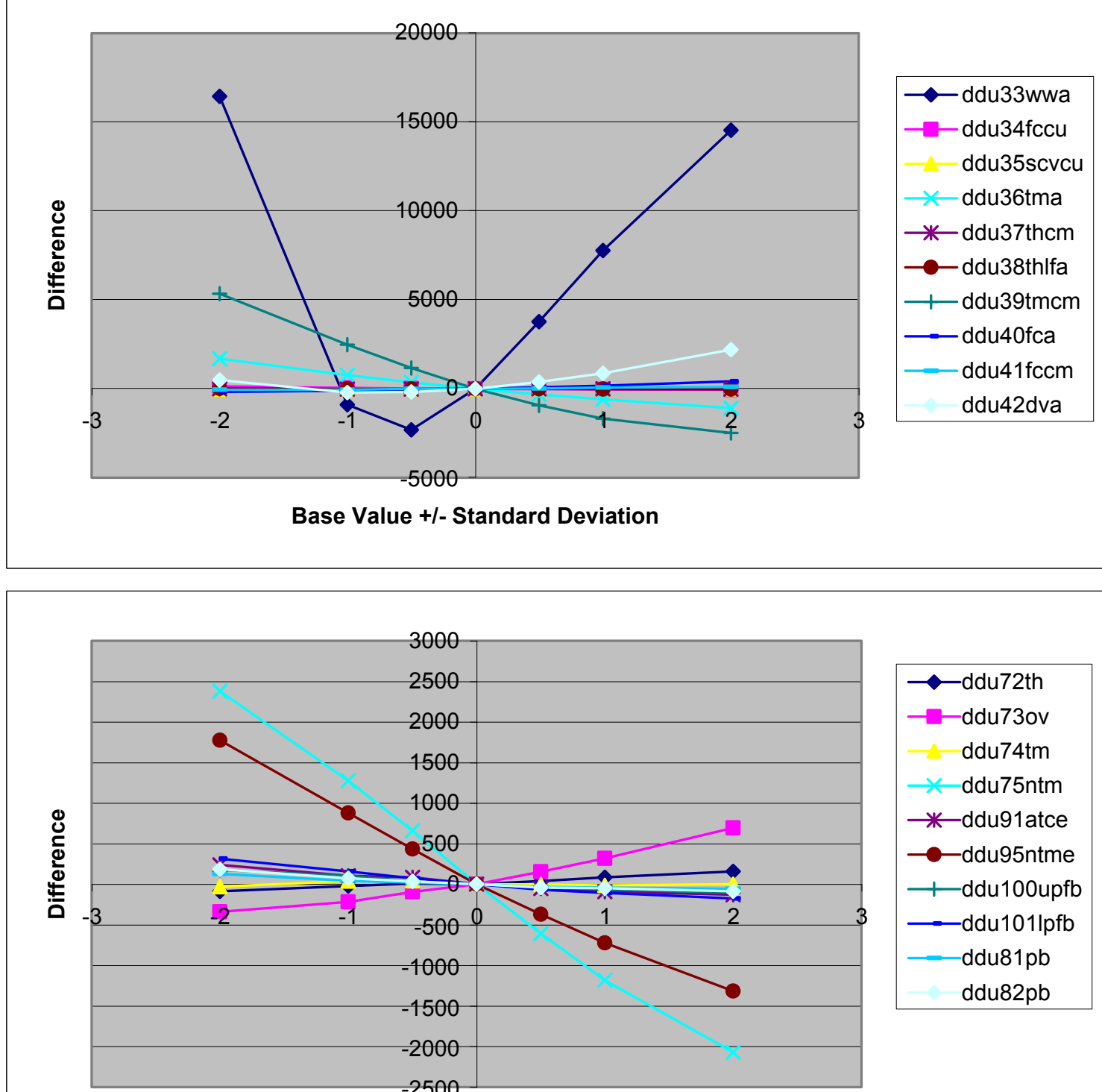

Base Value +1/-Standard Deviation

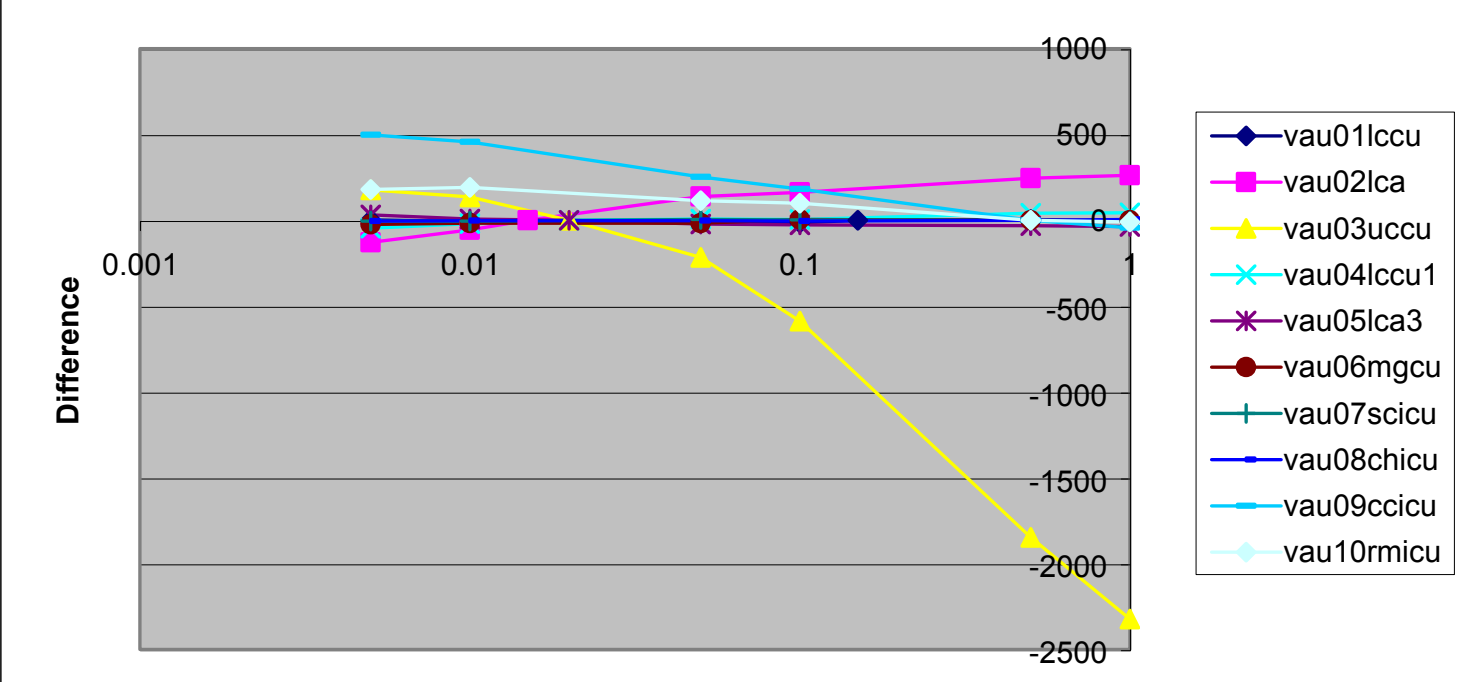

value

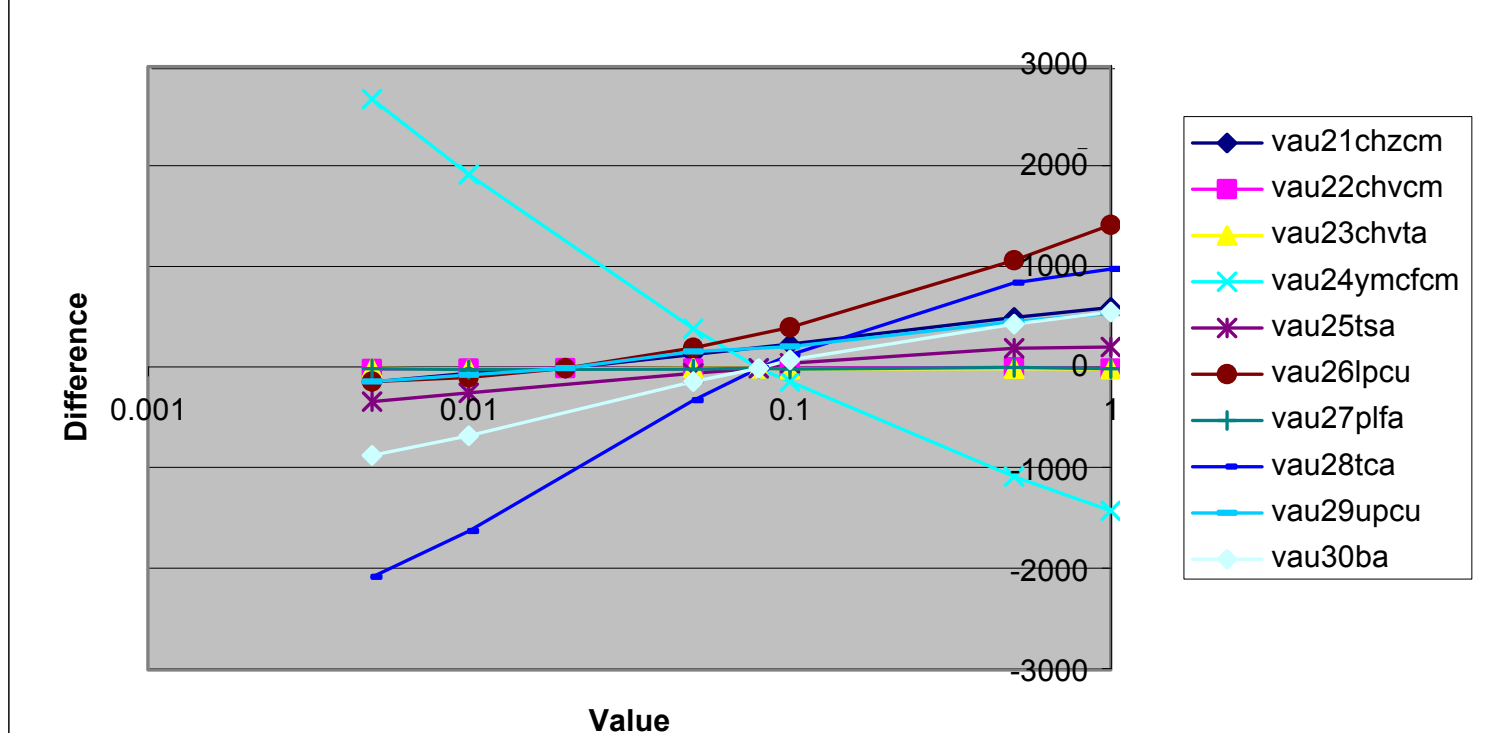

value
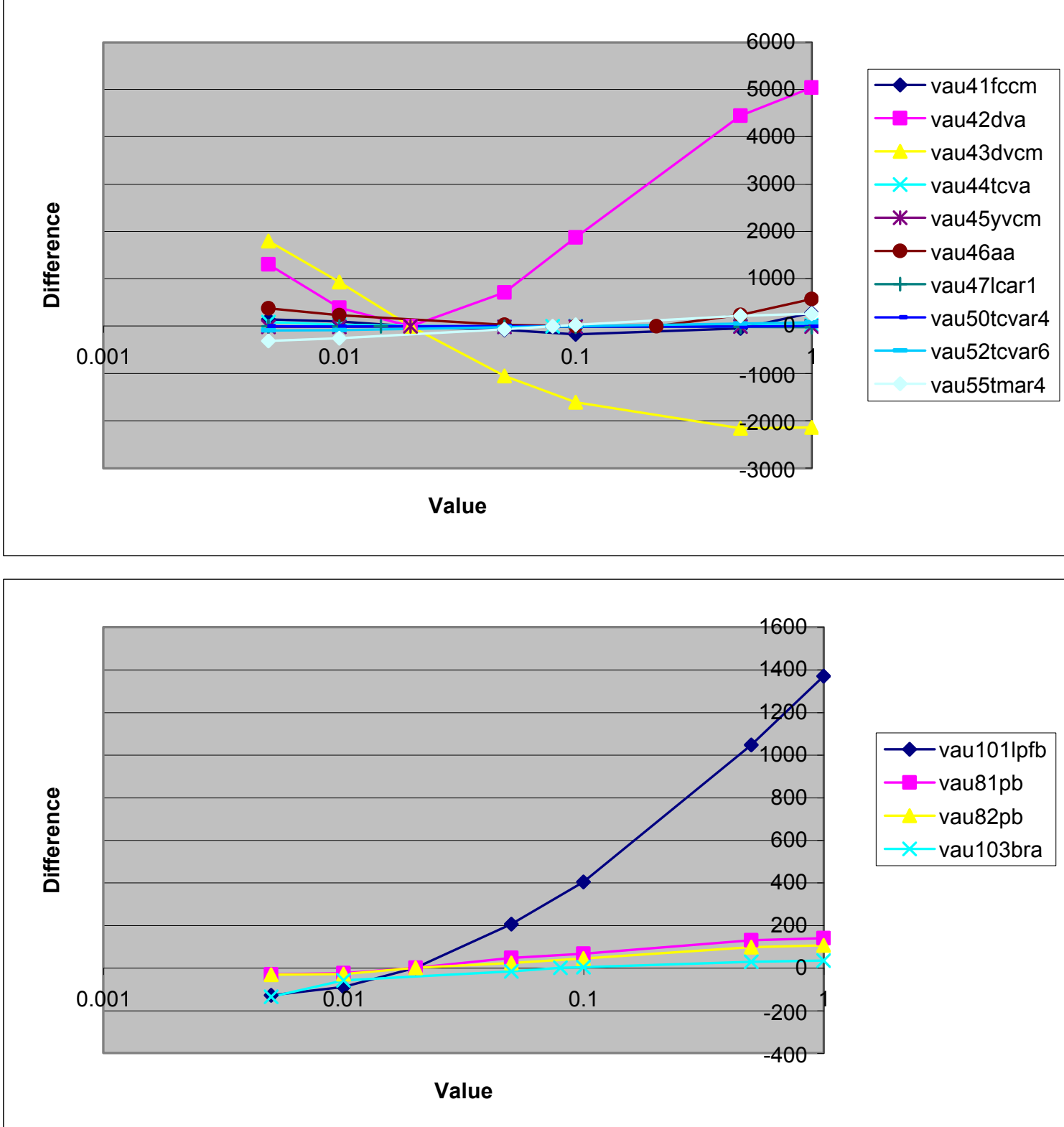

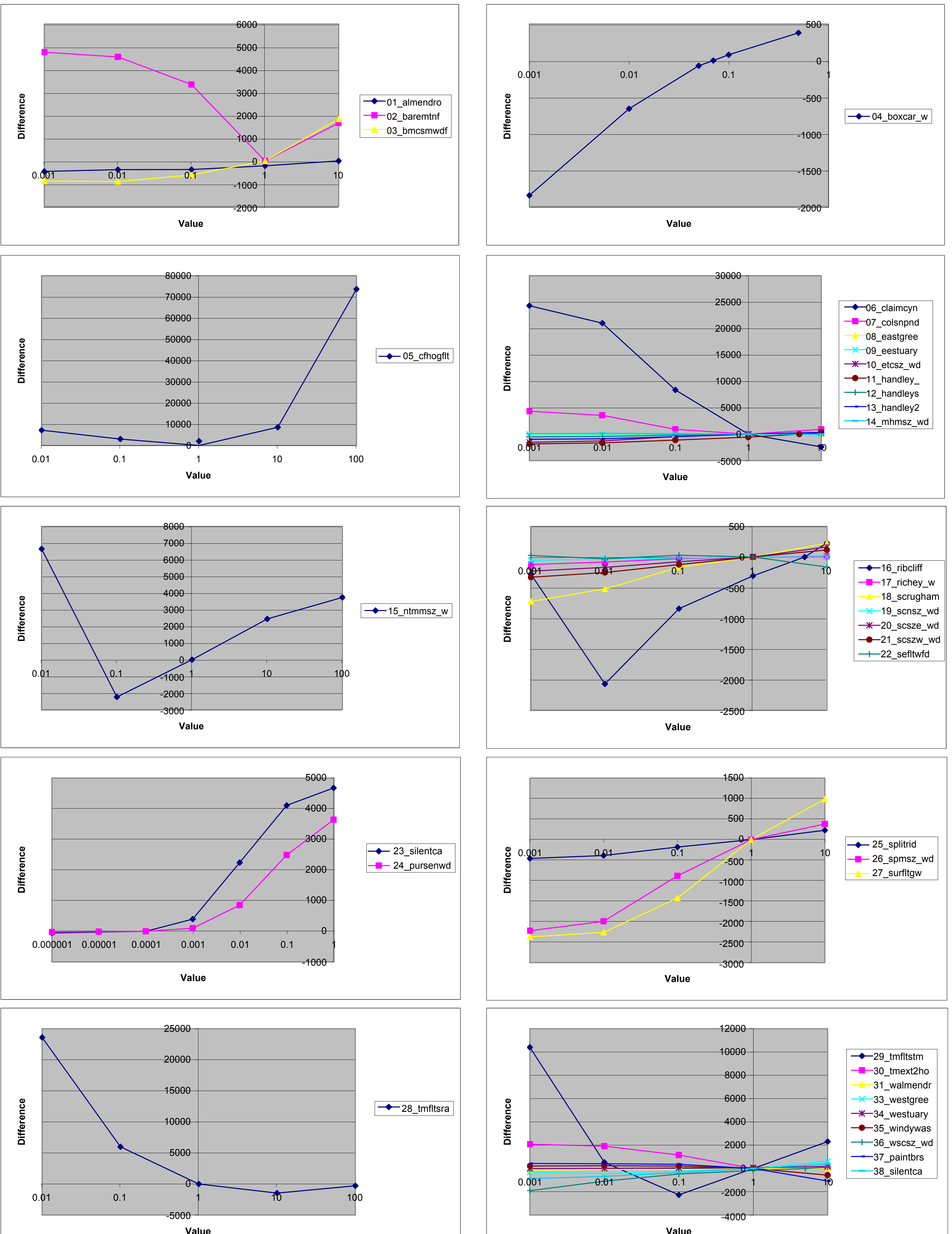

Value
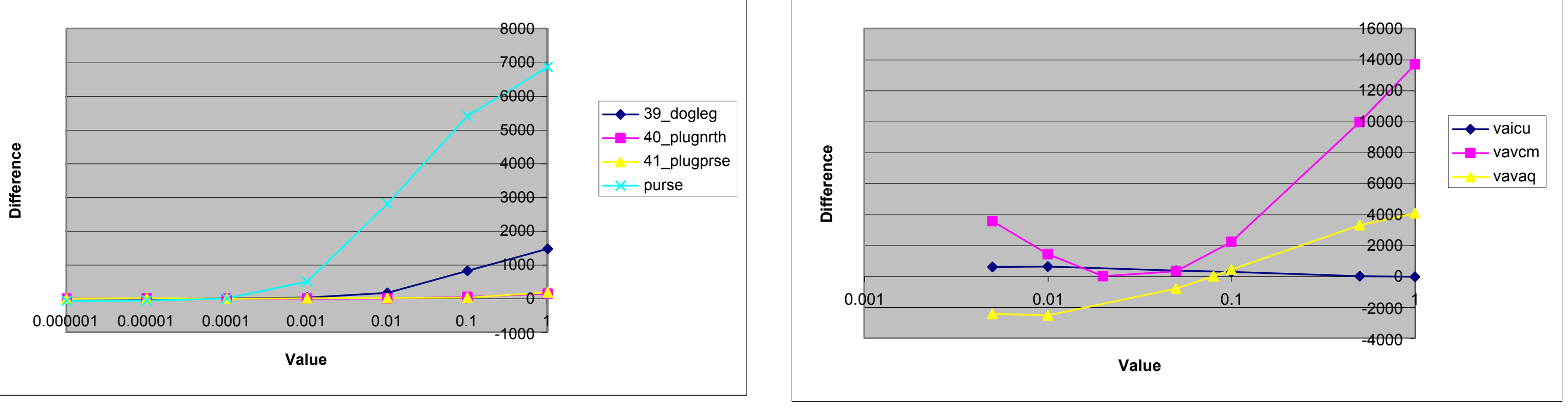

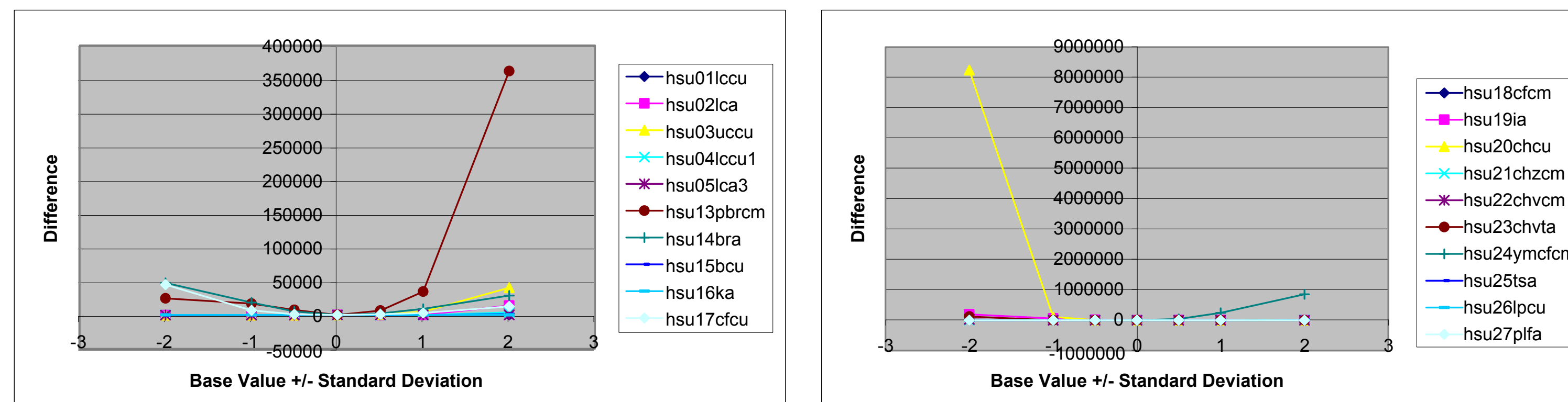

Base Value +1 -

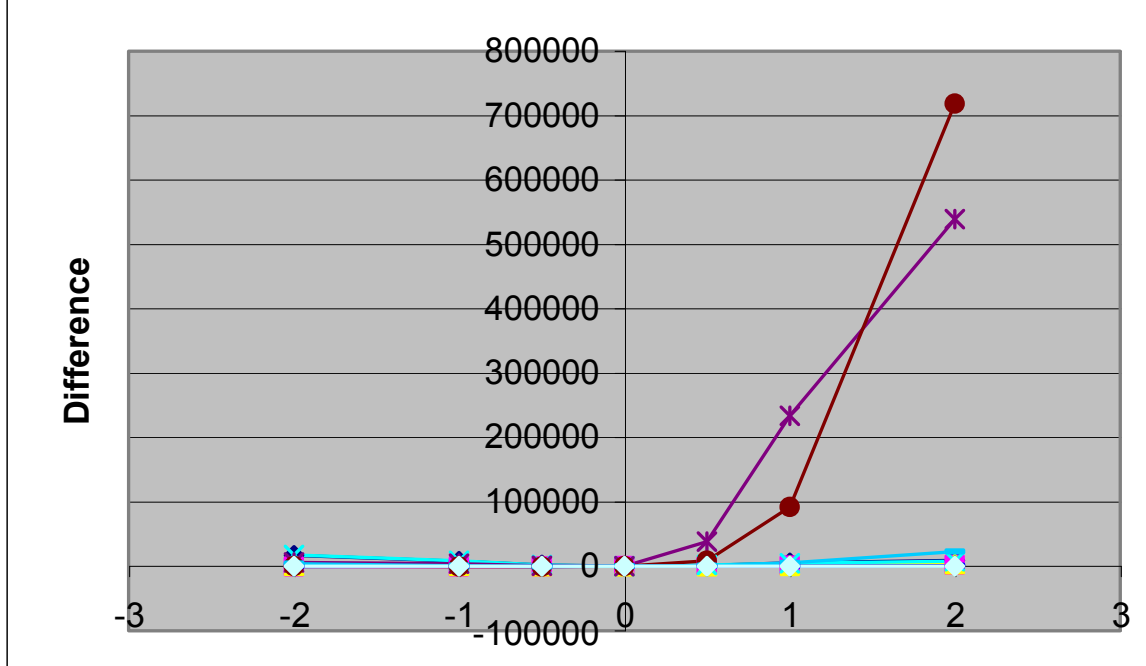

Base Value +/-Standard Deviation
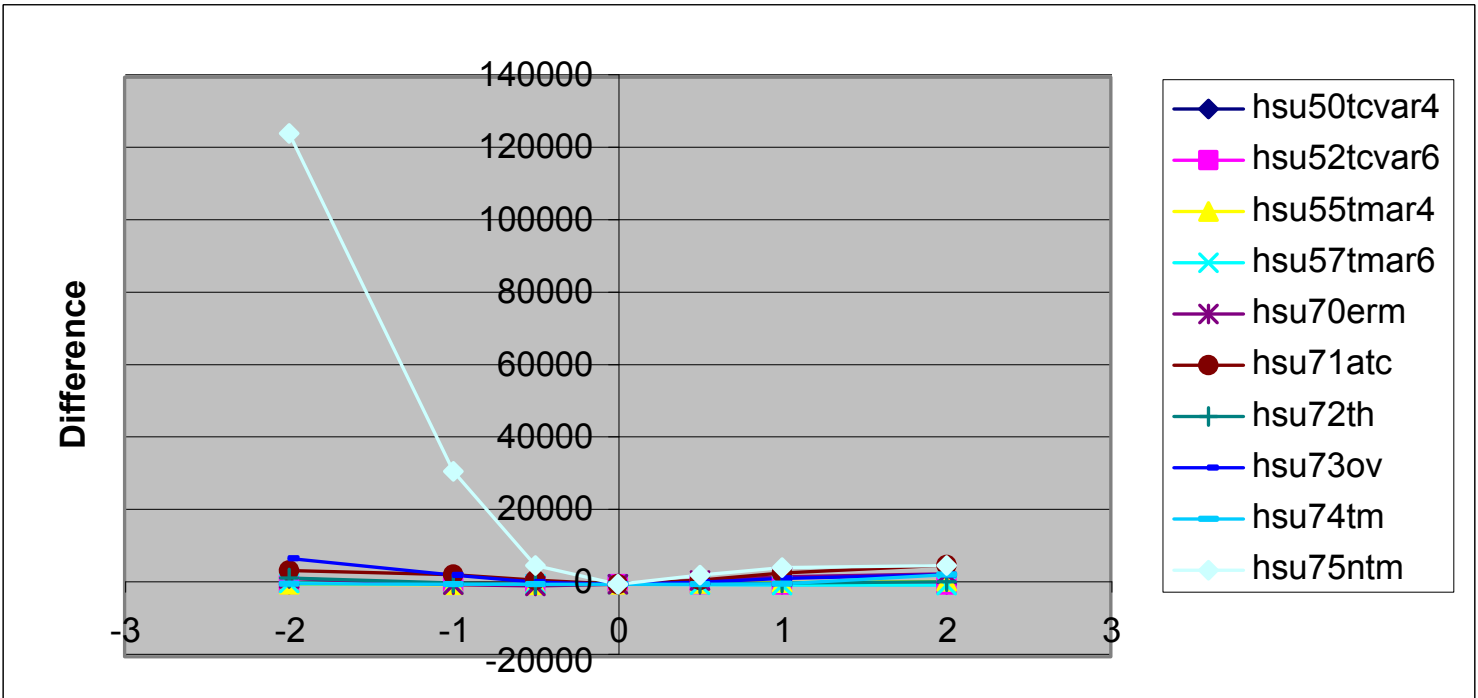

Base Value + - Standard Deviation
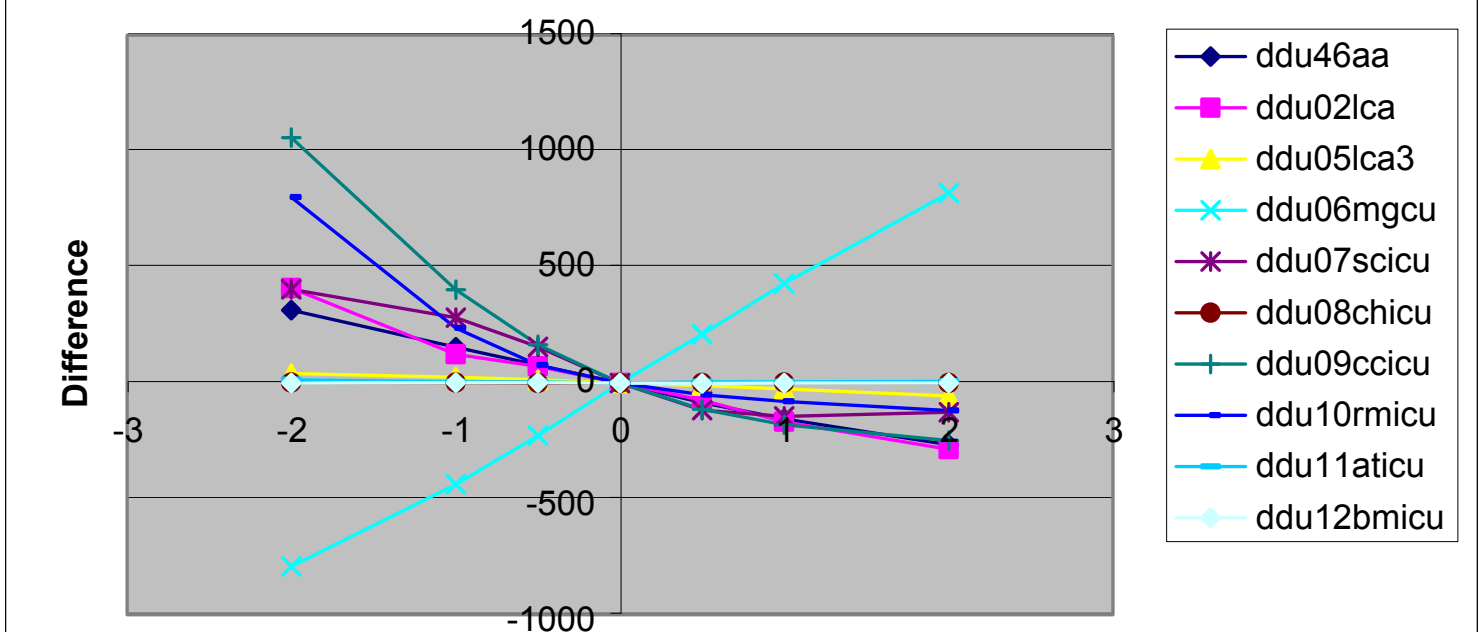

Base Value +/-Standard Deviation
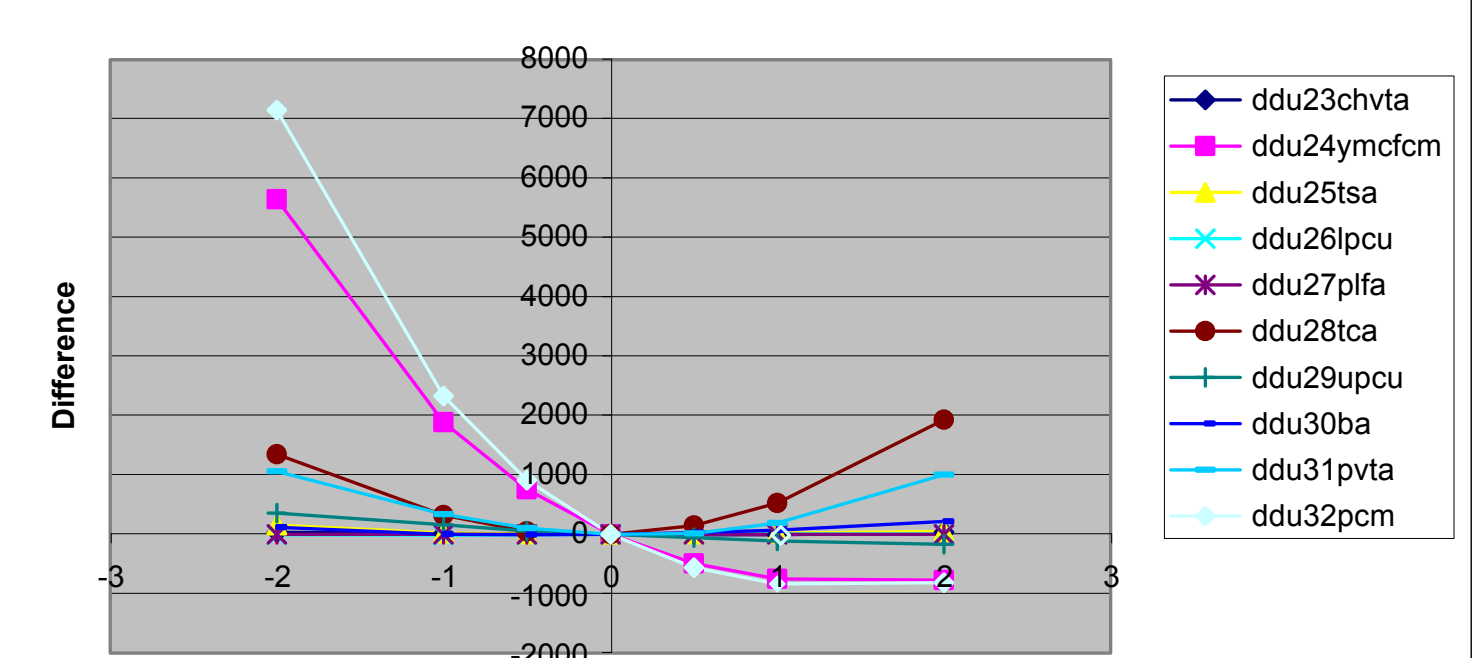

Base Value + - Standard Deviation
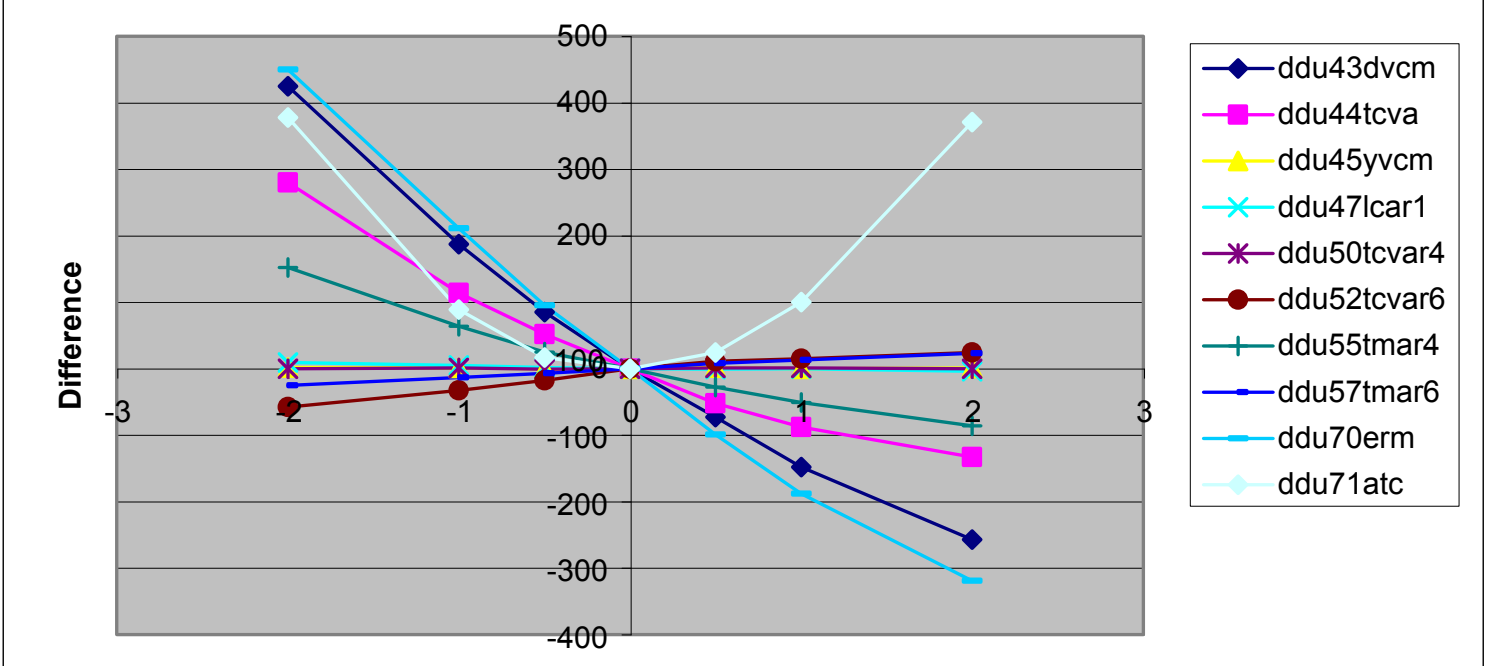

Base Value + t/ Standard Deviation

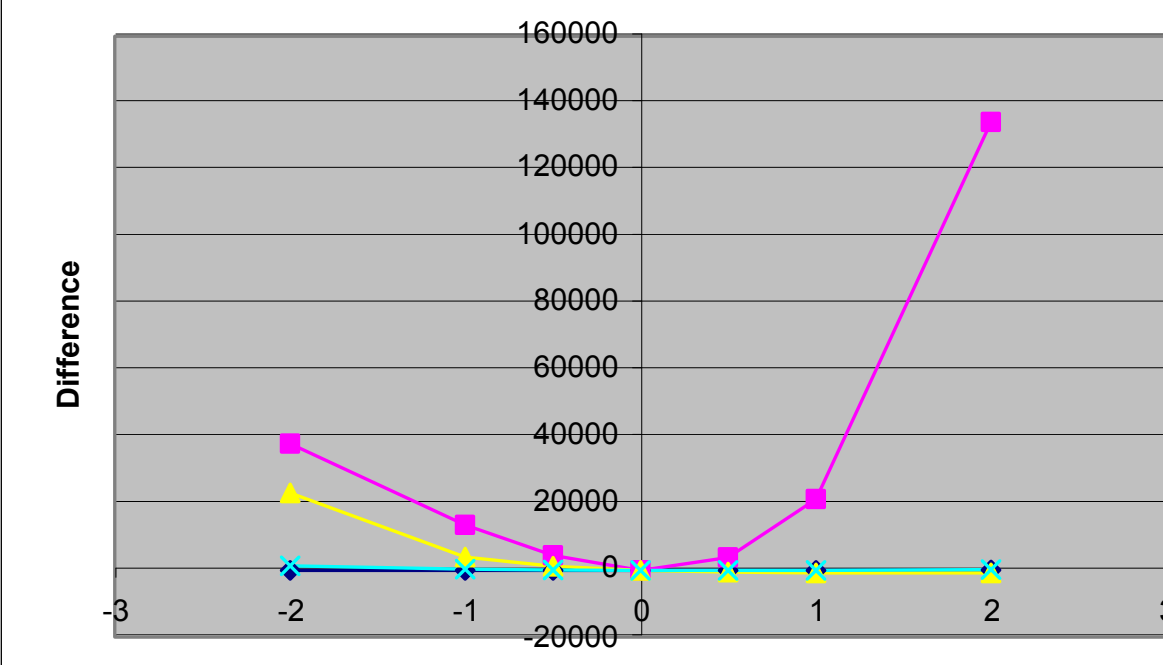

Base Value + - $/$ Standard Deviation

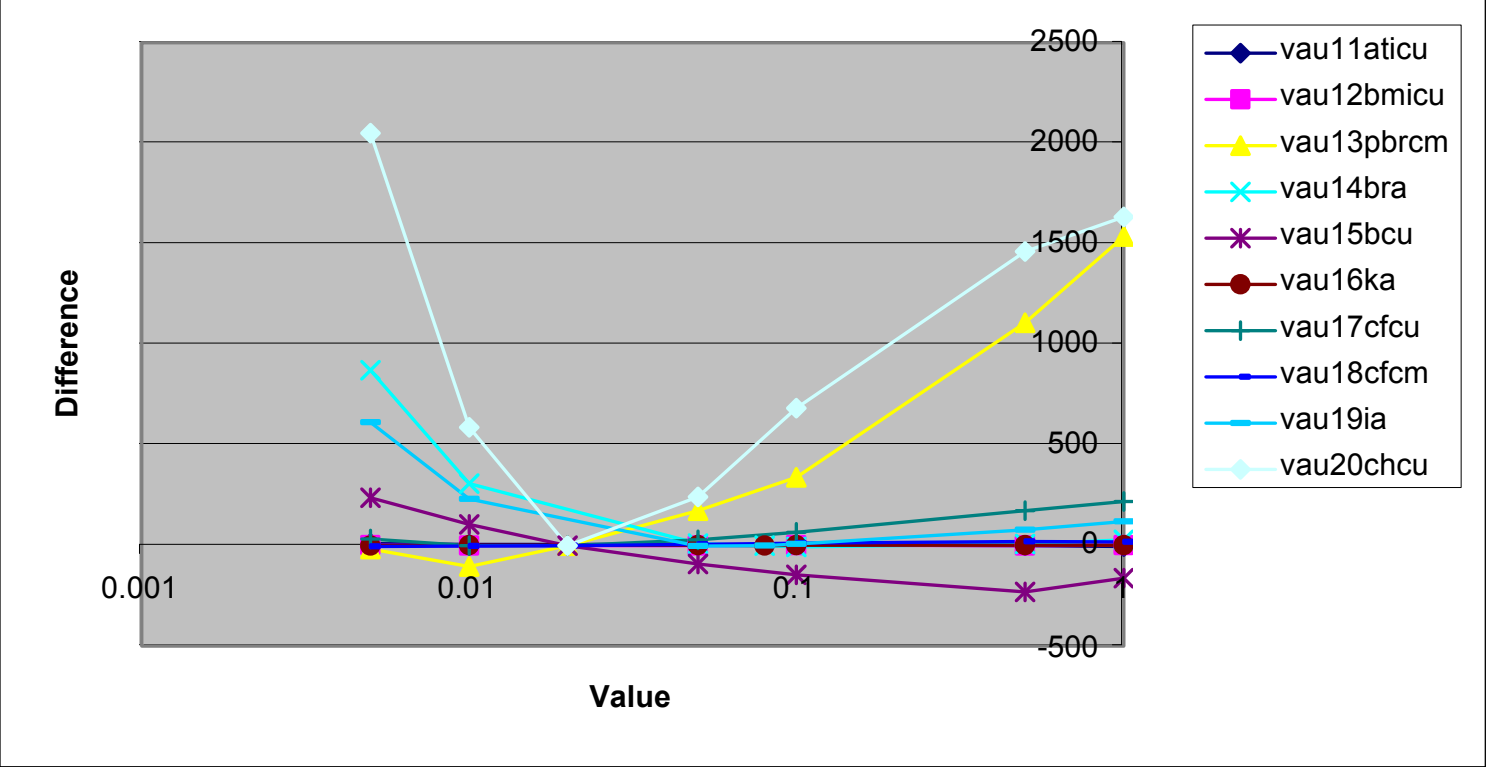

Value
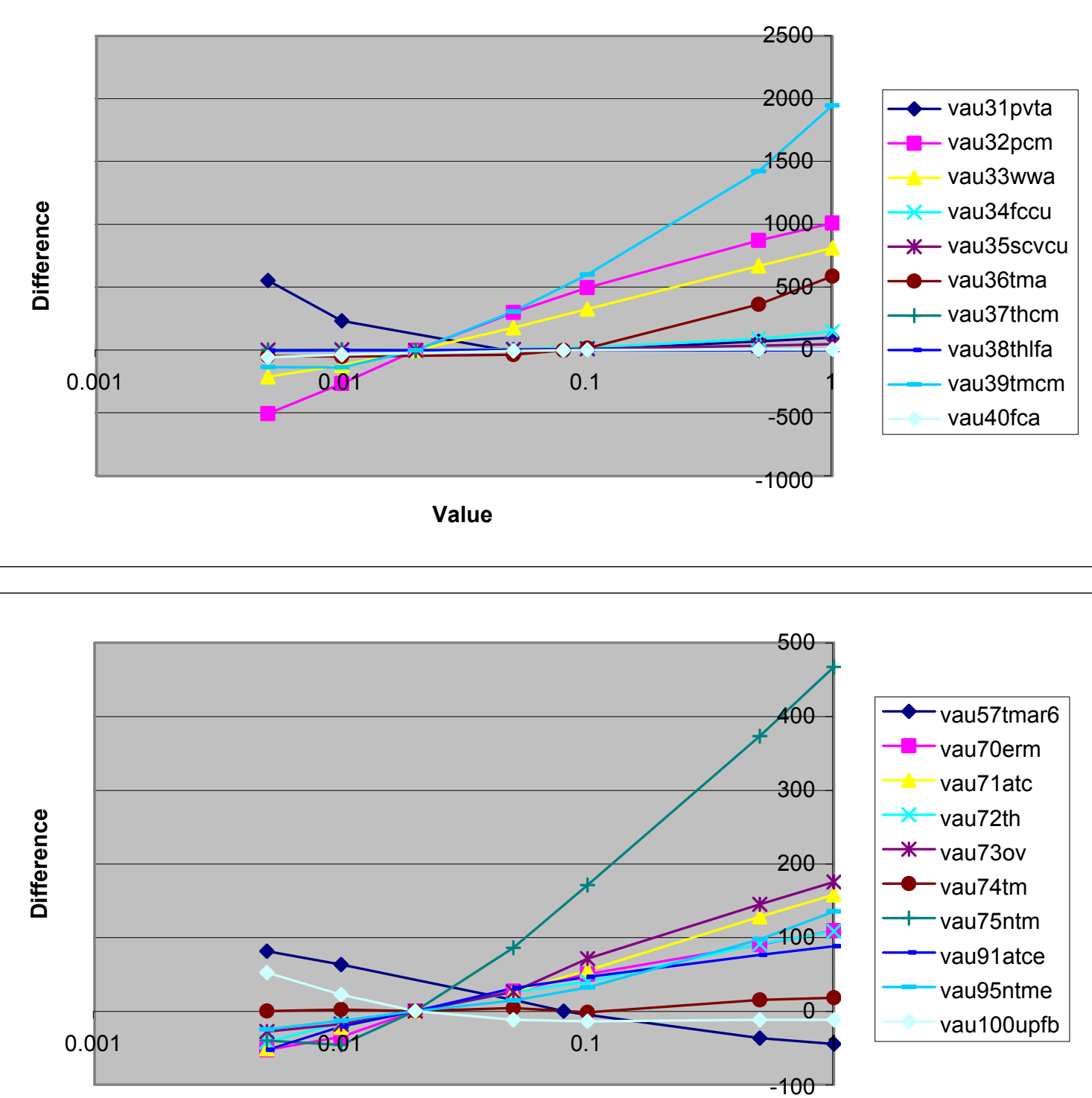

I-ddd0103bra
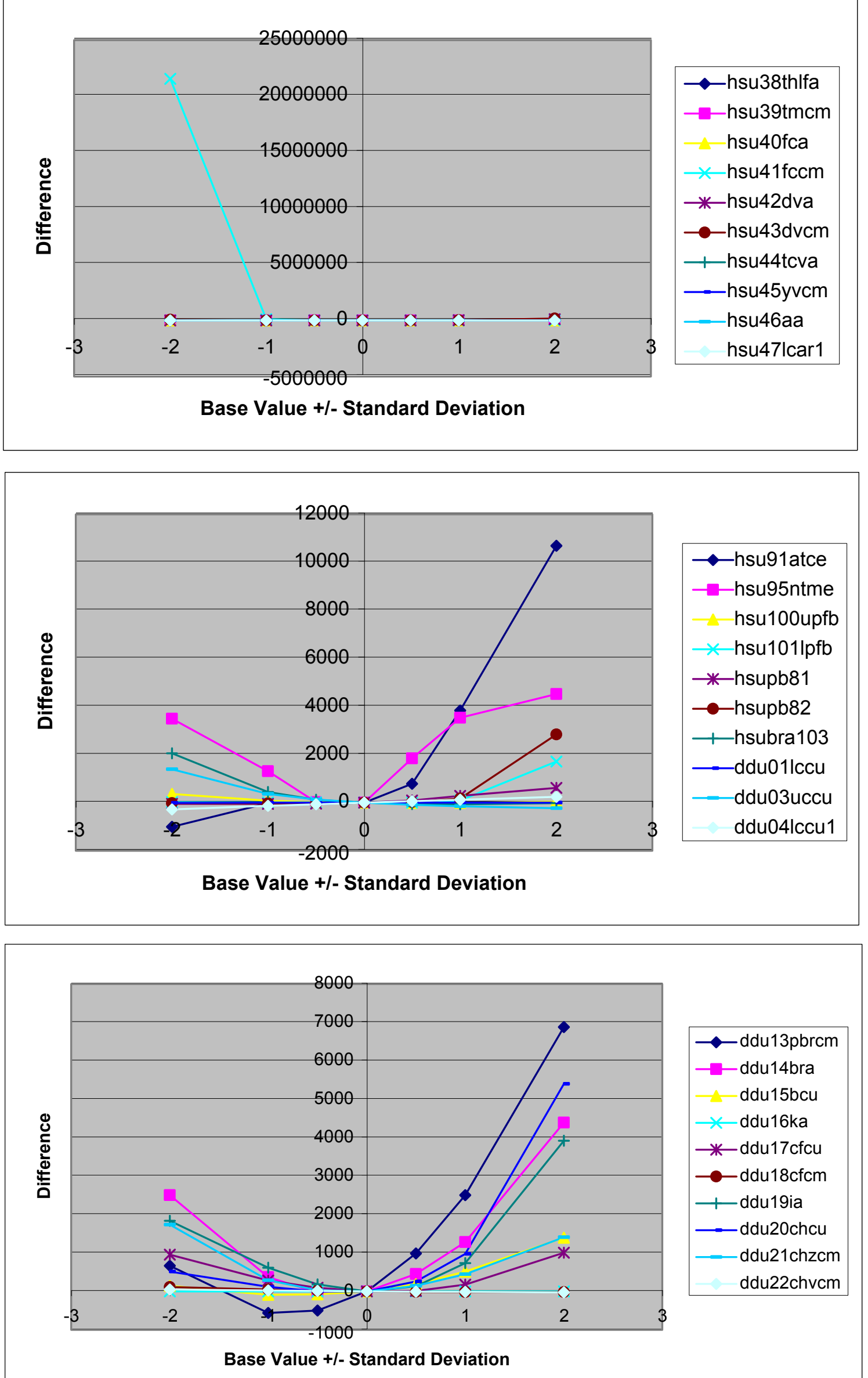

Base value + - Standard Deviation
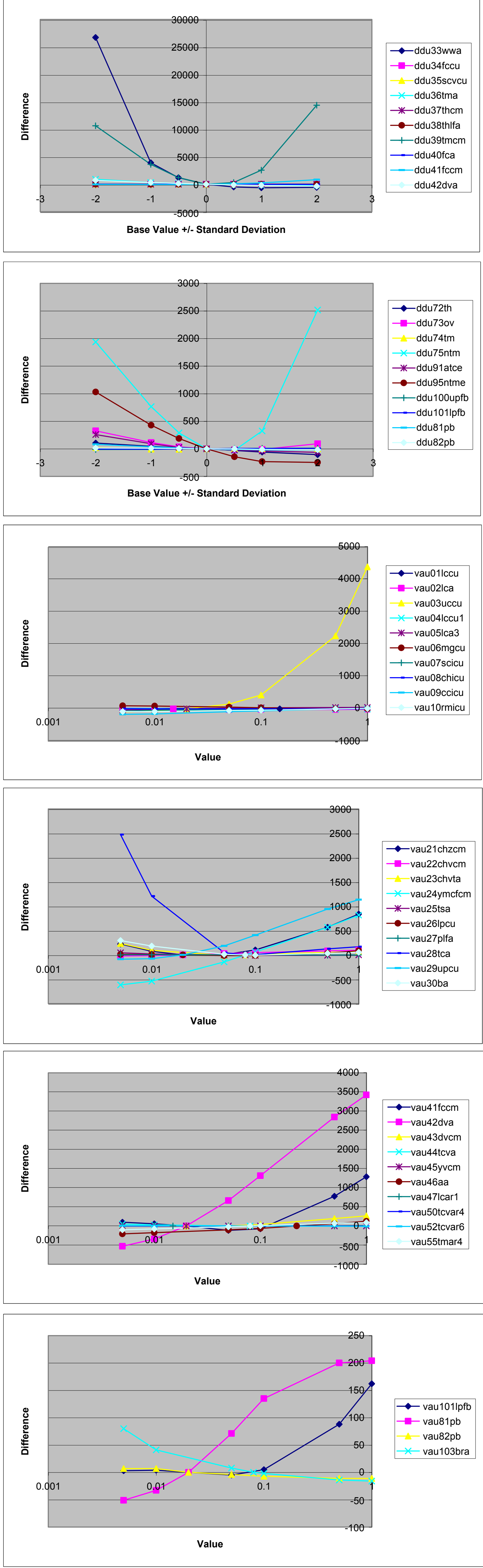

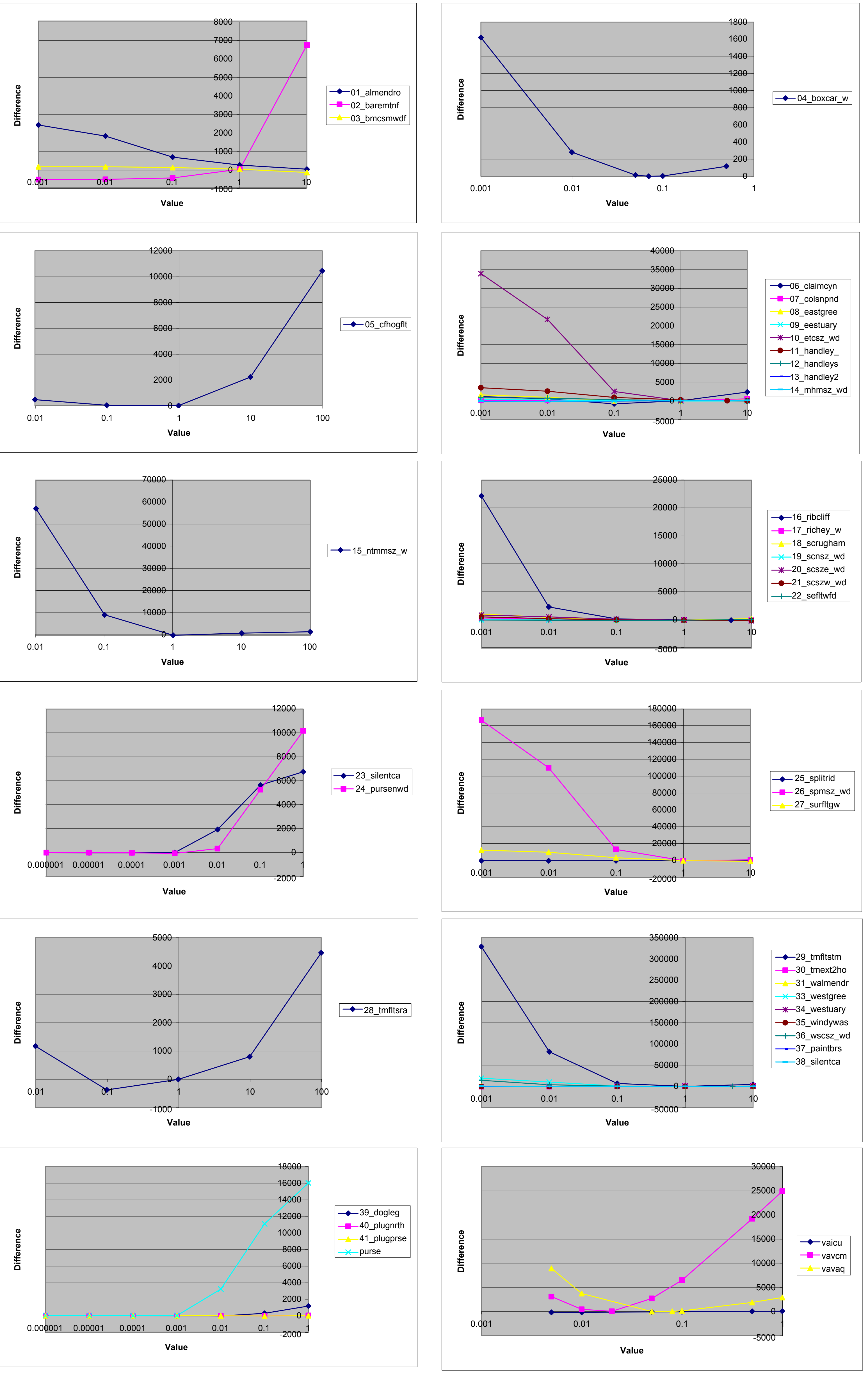


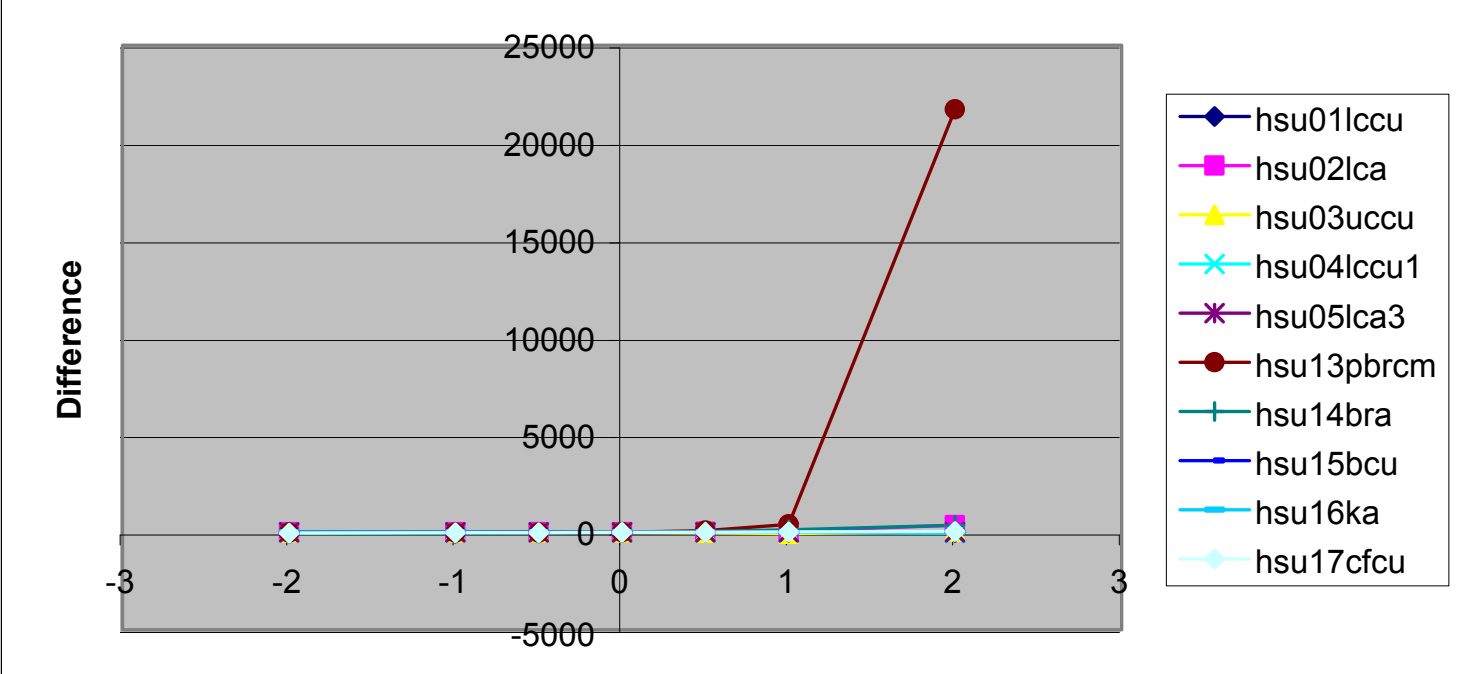

Base Value + -l Standard Deviation

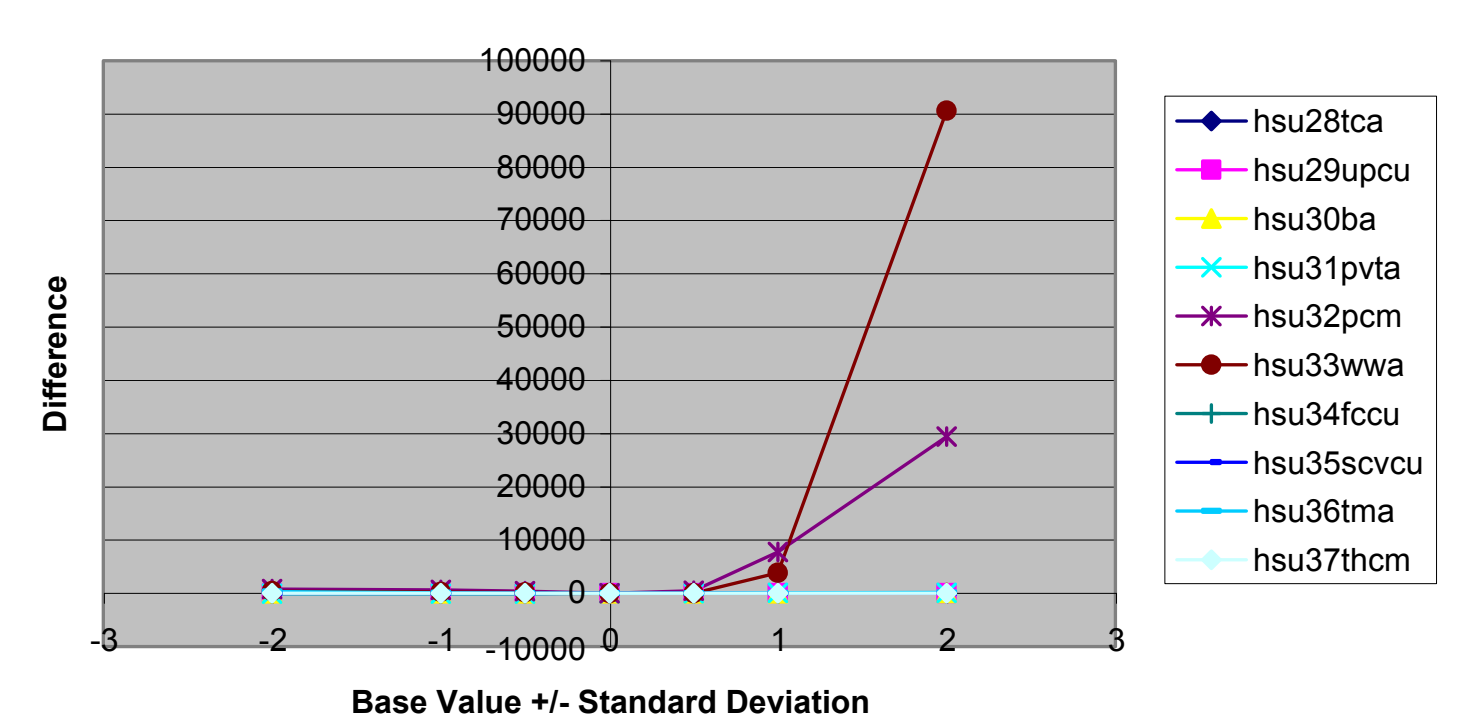

Base Value + / Standard Deviation
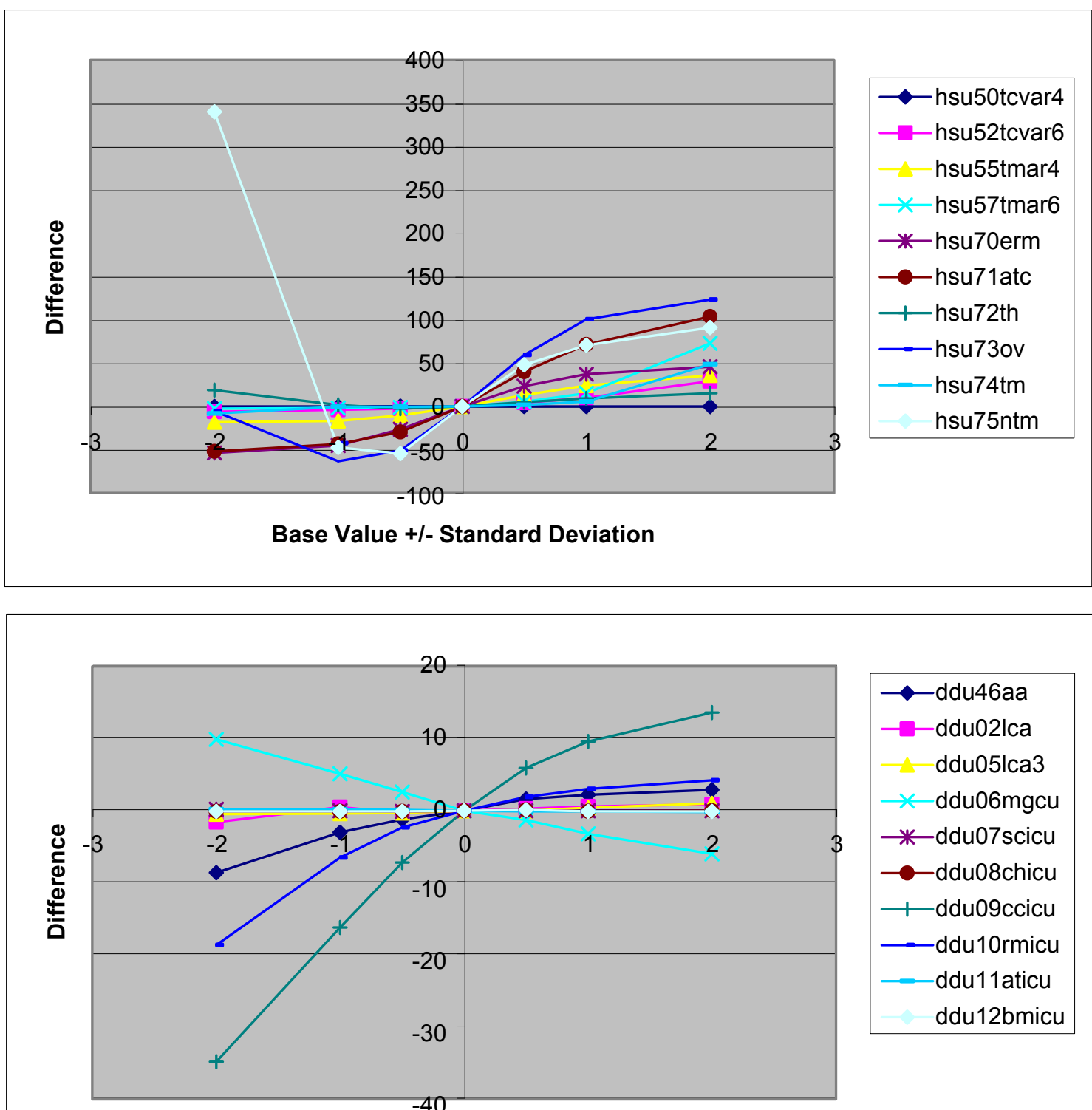

Base Value + +l-Standard Deviation

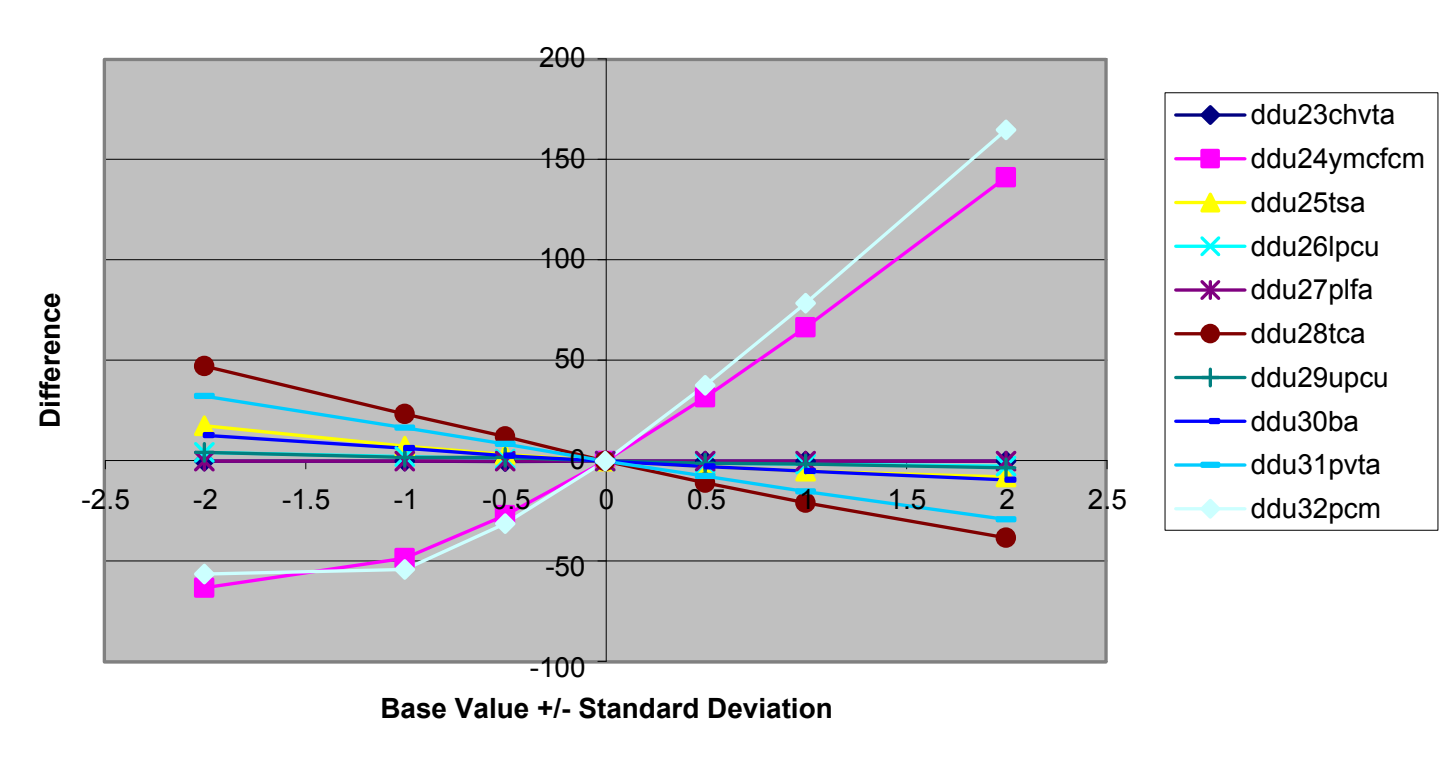

Base Value $+/$ - Standard Deviation
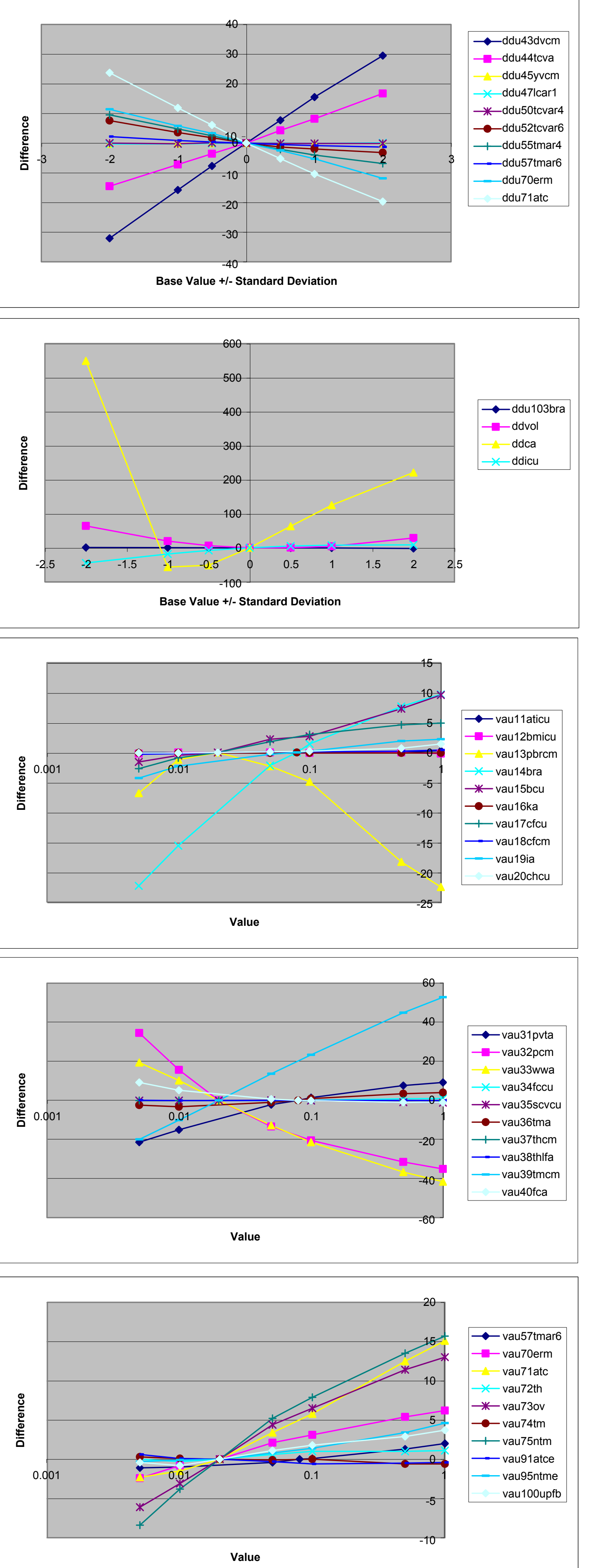

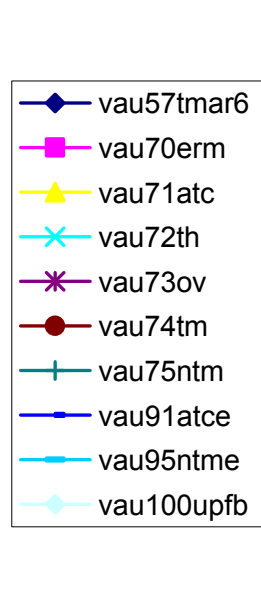
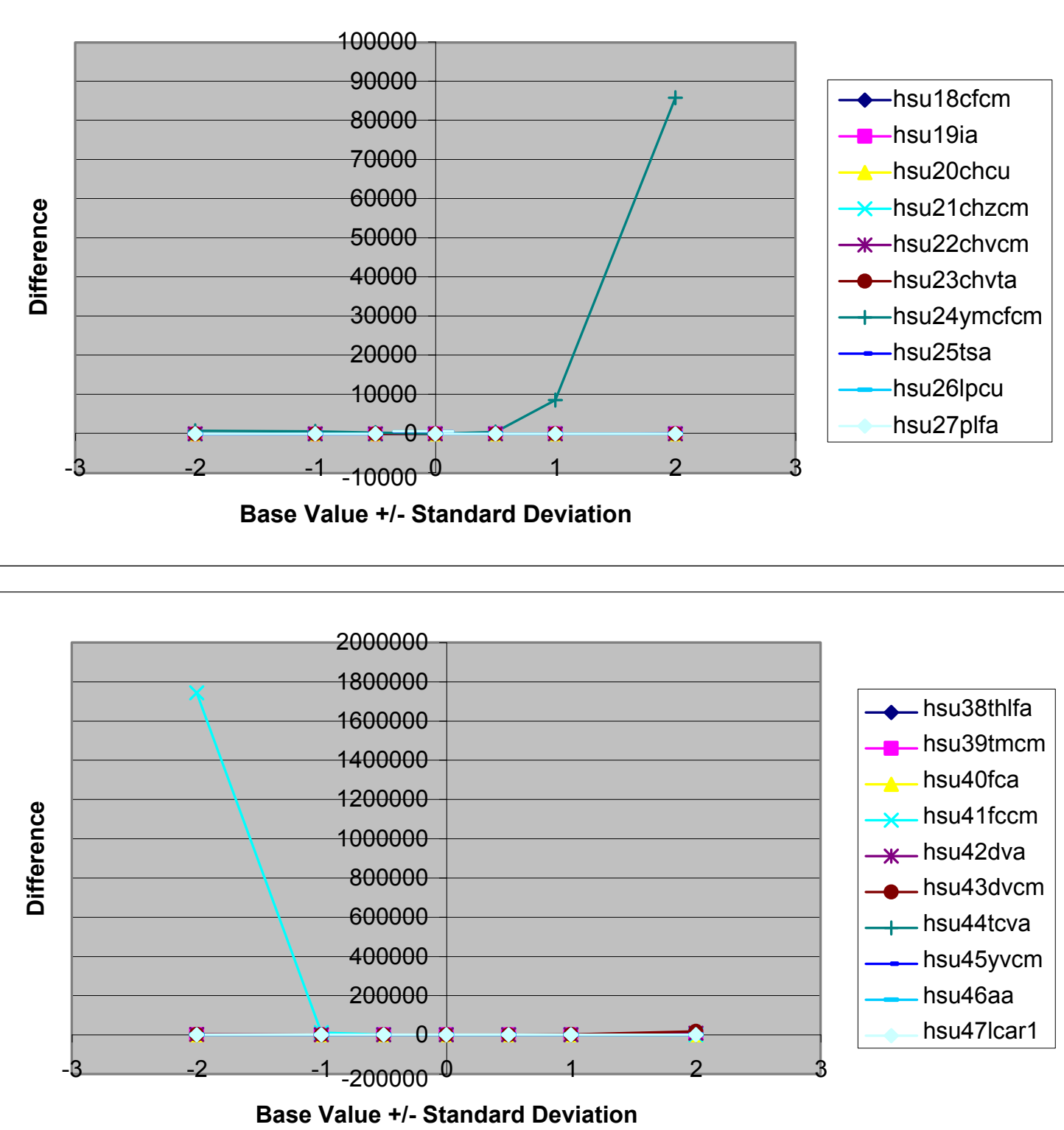

Base Value +/-Standard Deviation
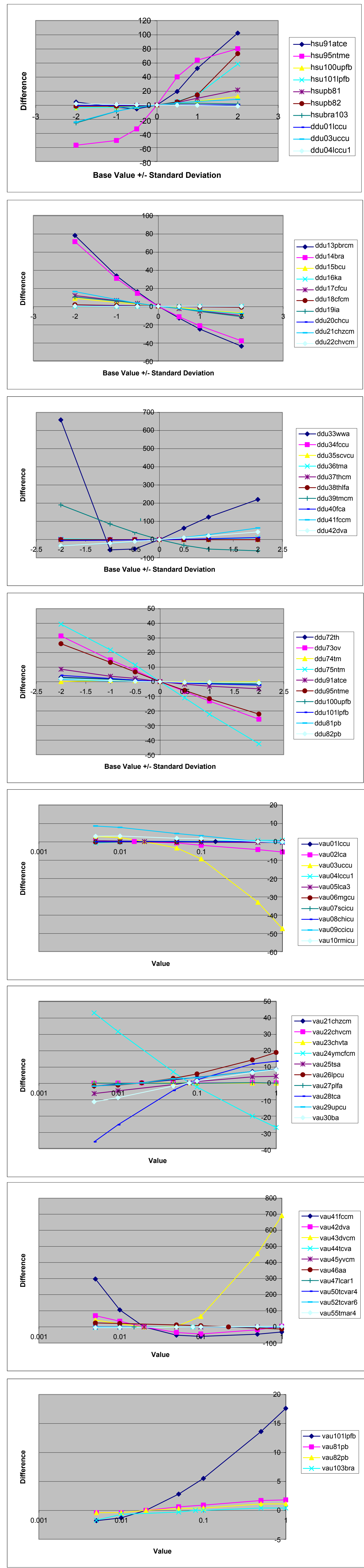


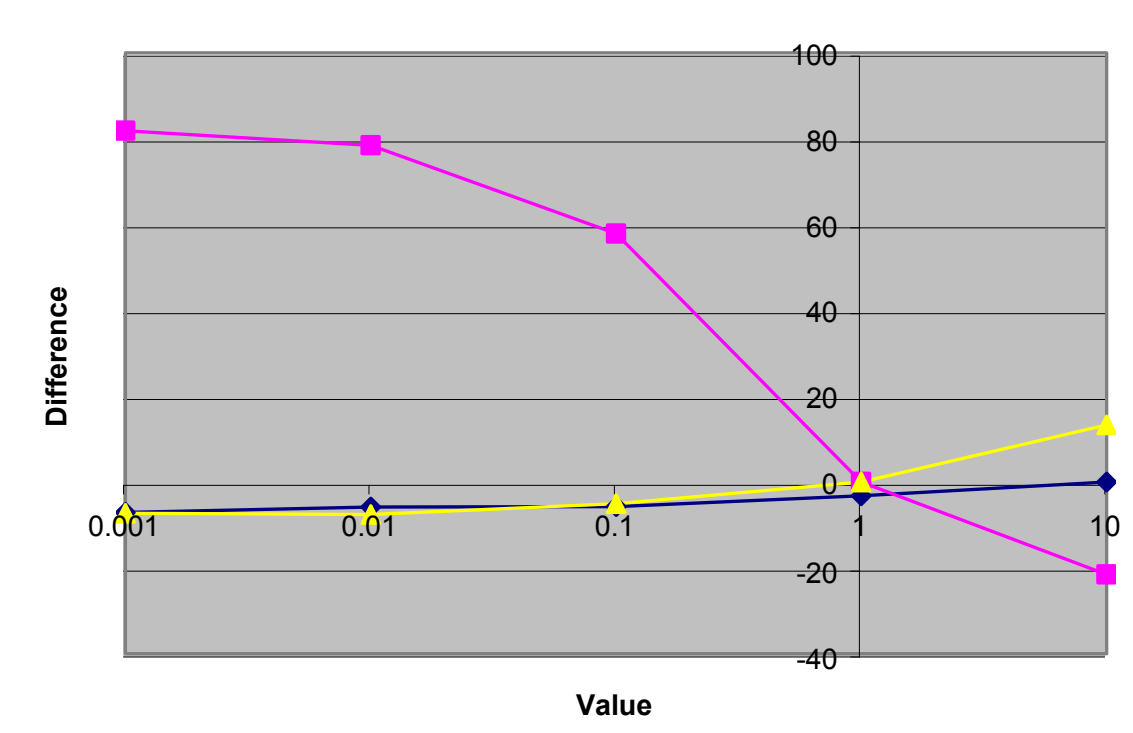

- 01_almendro $-03 \_b m c s m w d f$
-
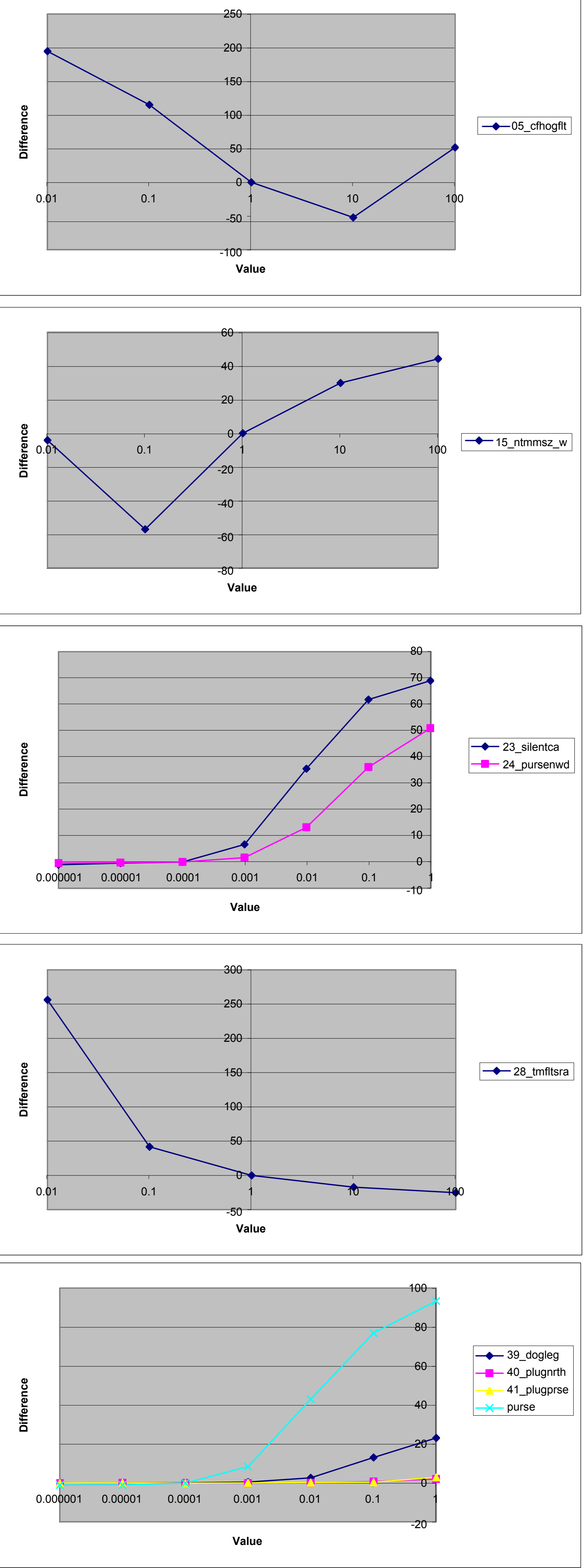
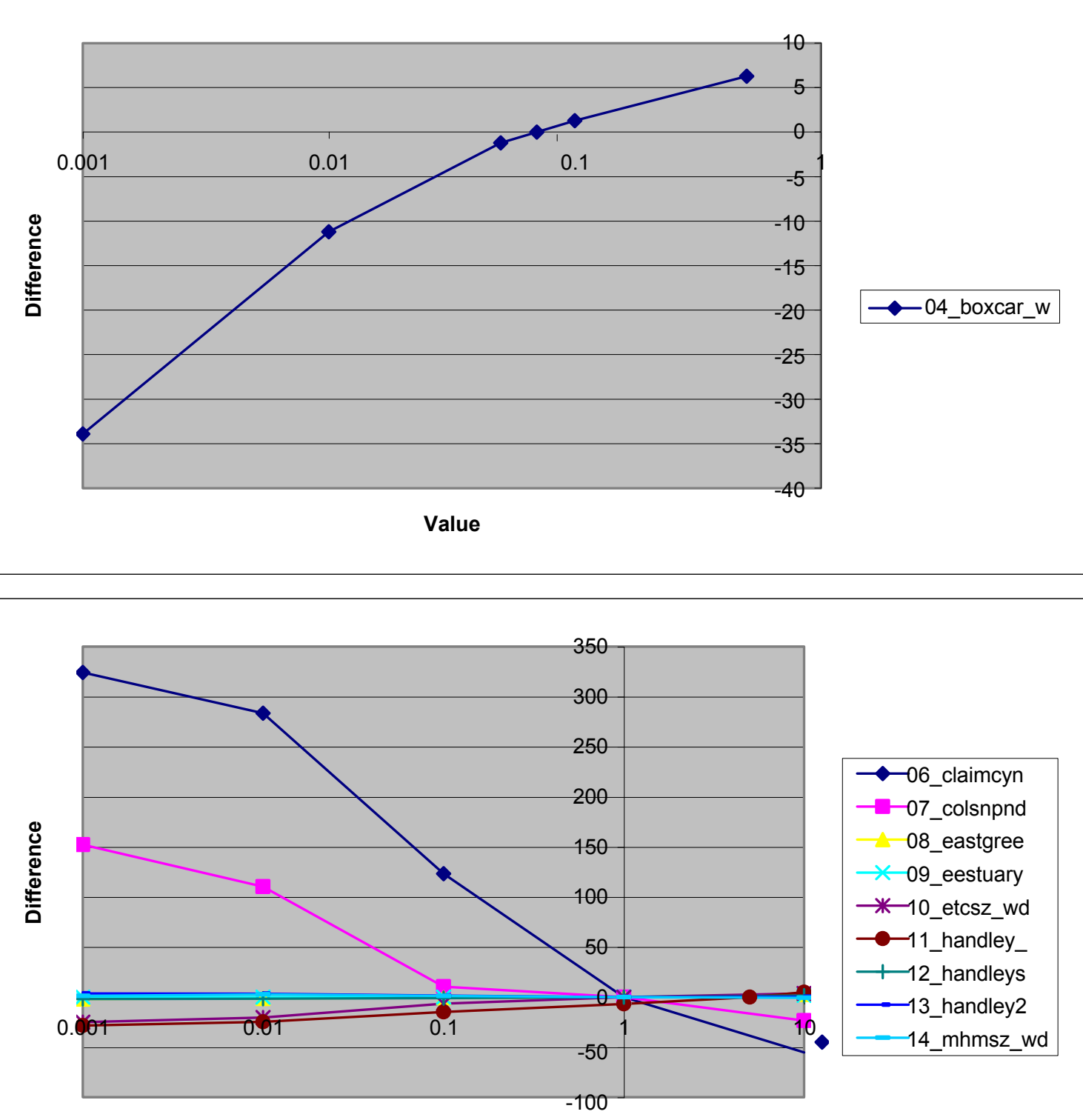

Value

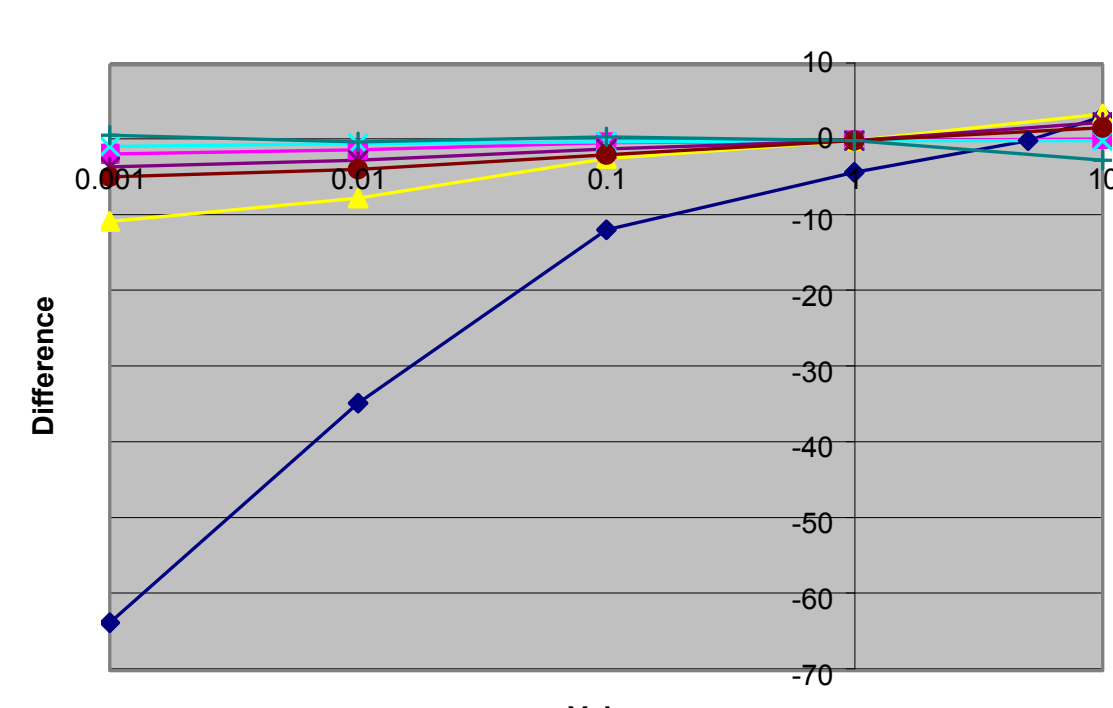

$\longrightarrow$-16_ribcliff

-17_richey_w

18_scrugham

-19_scnsz_wd

*-20_scsze_wd

-21_scszw_wd

—-22_sefttwfd

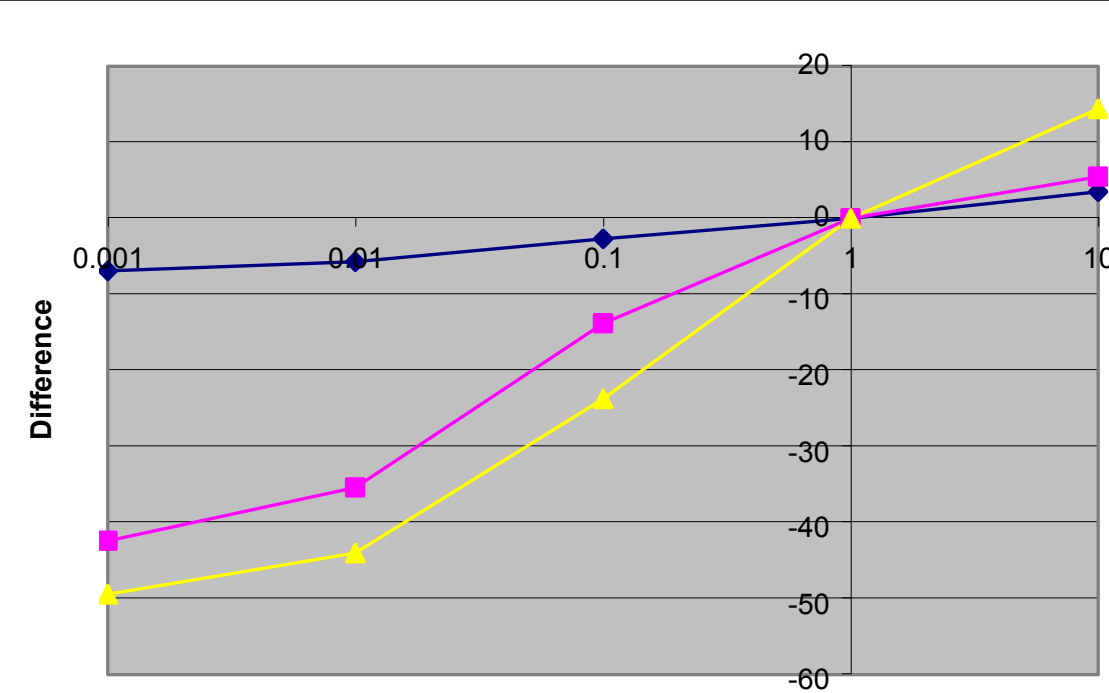

Value

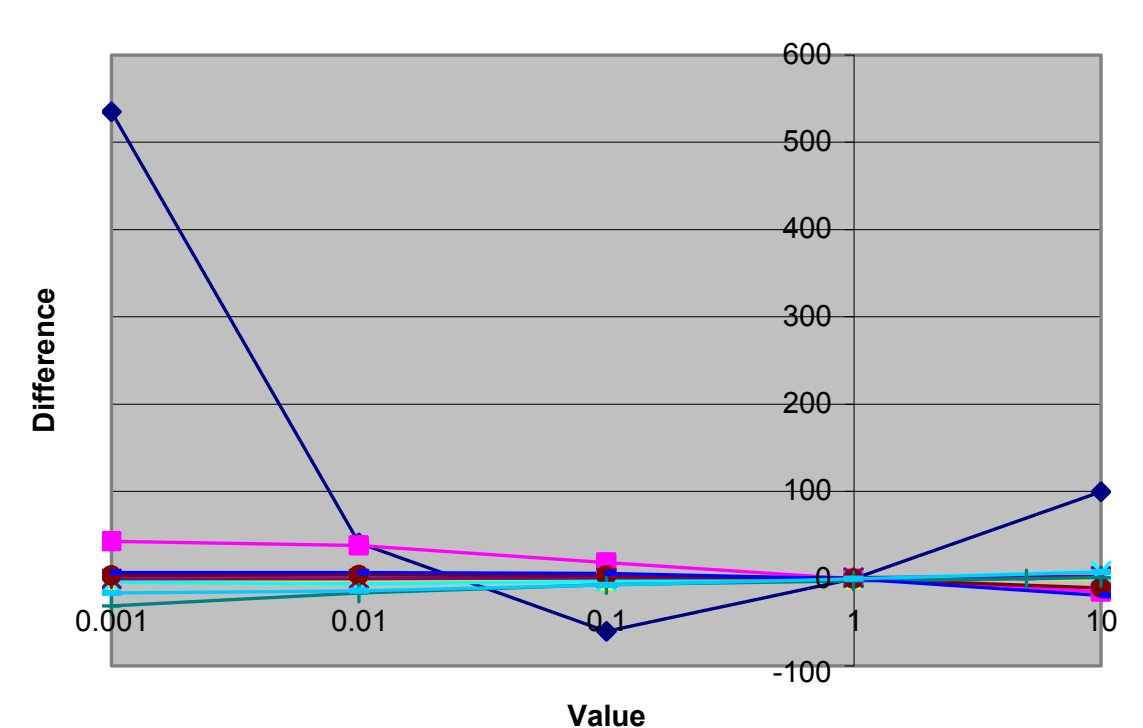

$\bullet-29 \_$tmfltstm

- 30_tmext2ho 31_walmendr -33_westgree

* 34_westuary

- 35_windywas

— 36_wscsz_wd

- 37_paintbrs - 38 _silentca

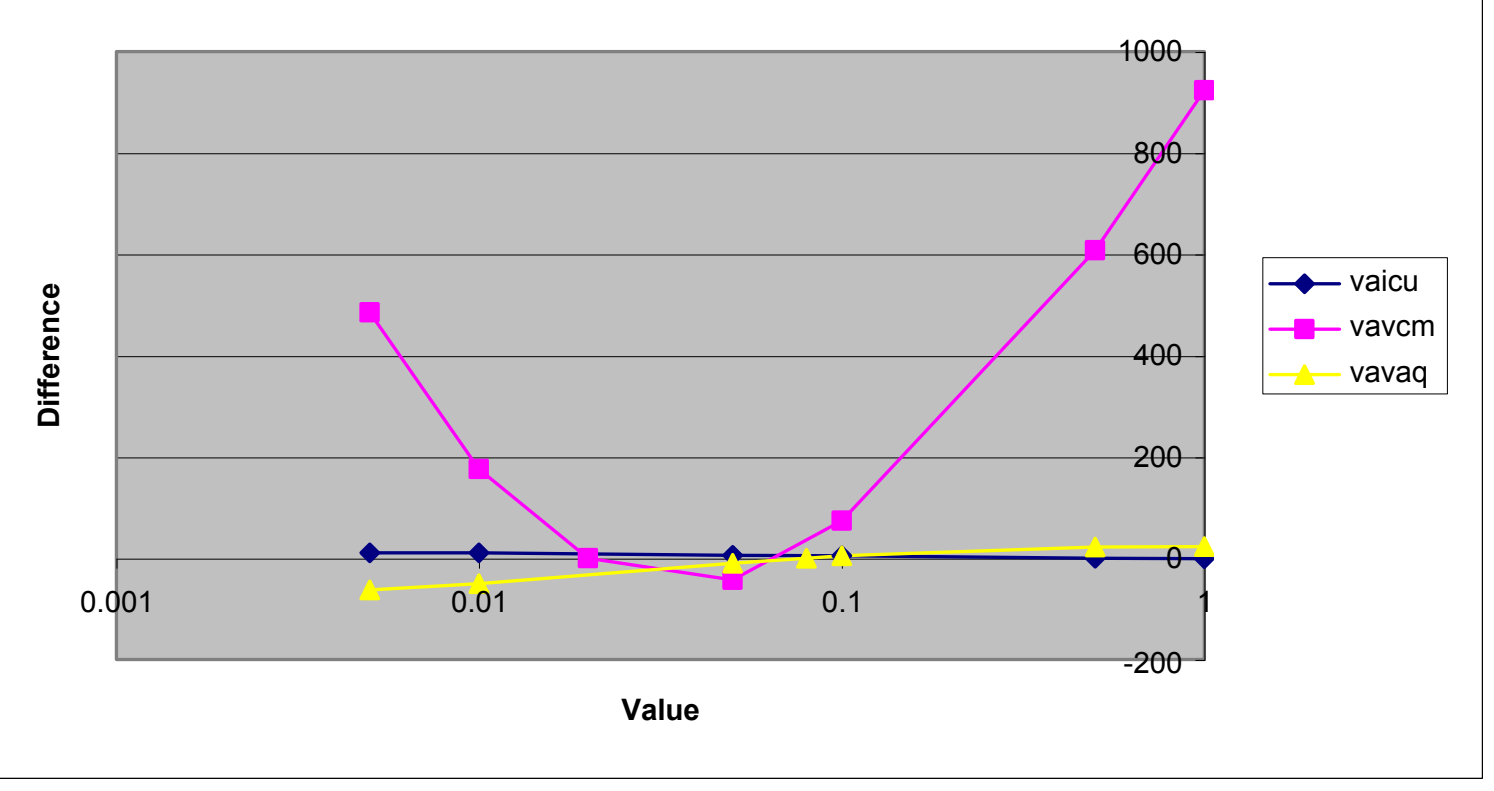




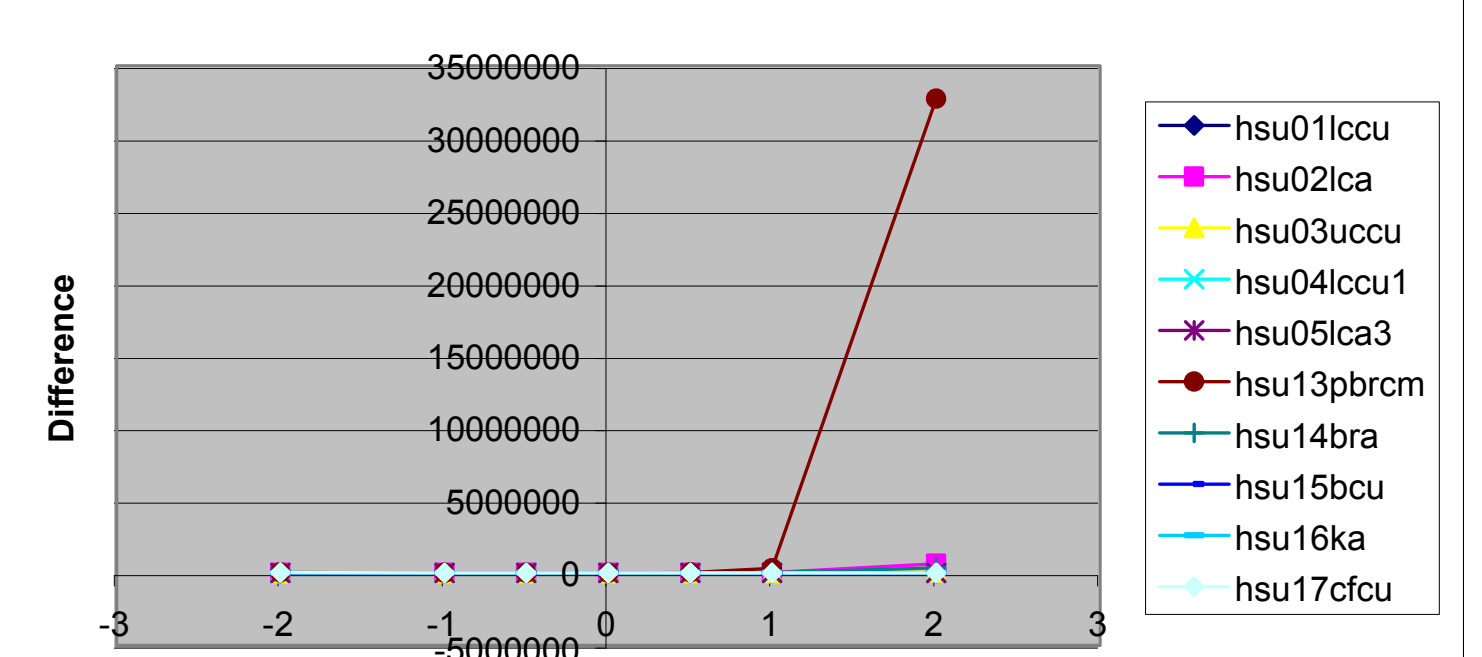
Base Value +/-Standard Deviation
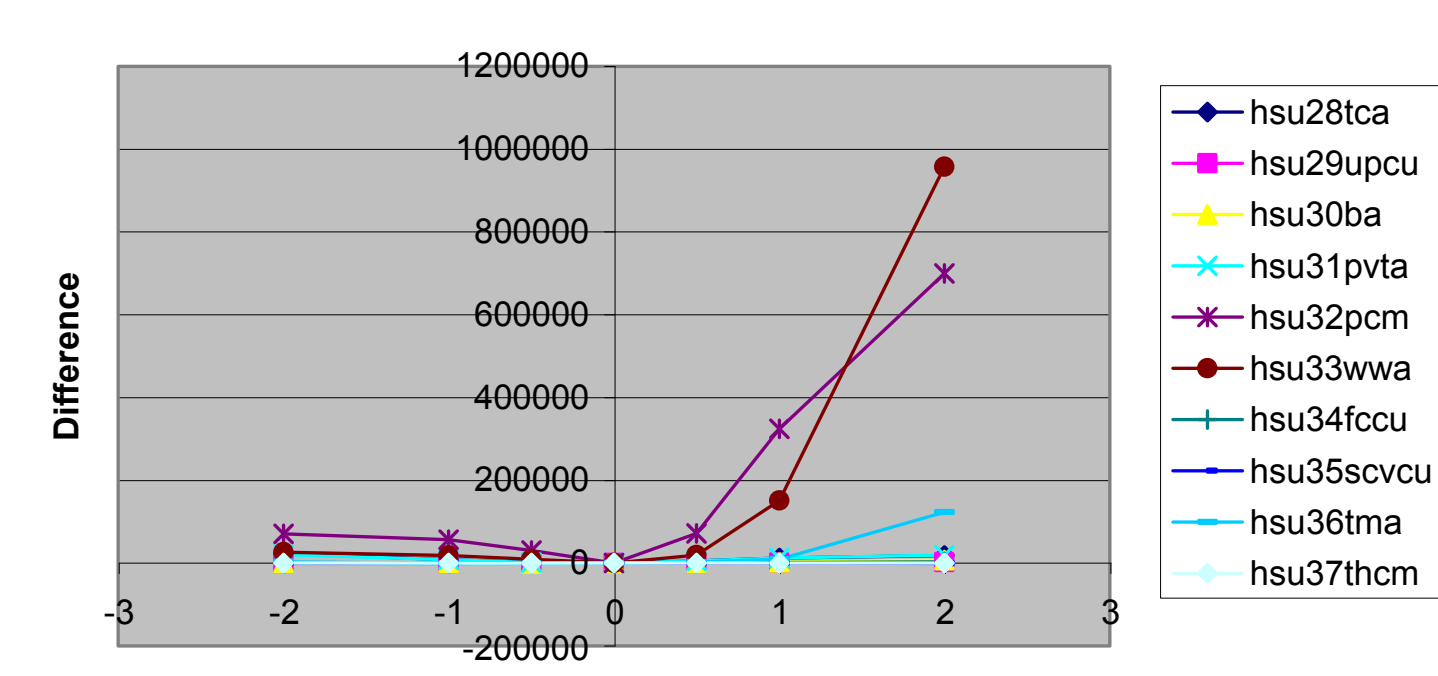

Base Value +/- Standard Deviation
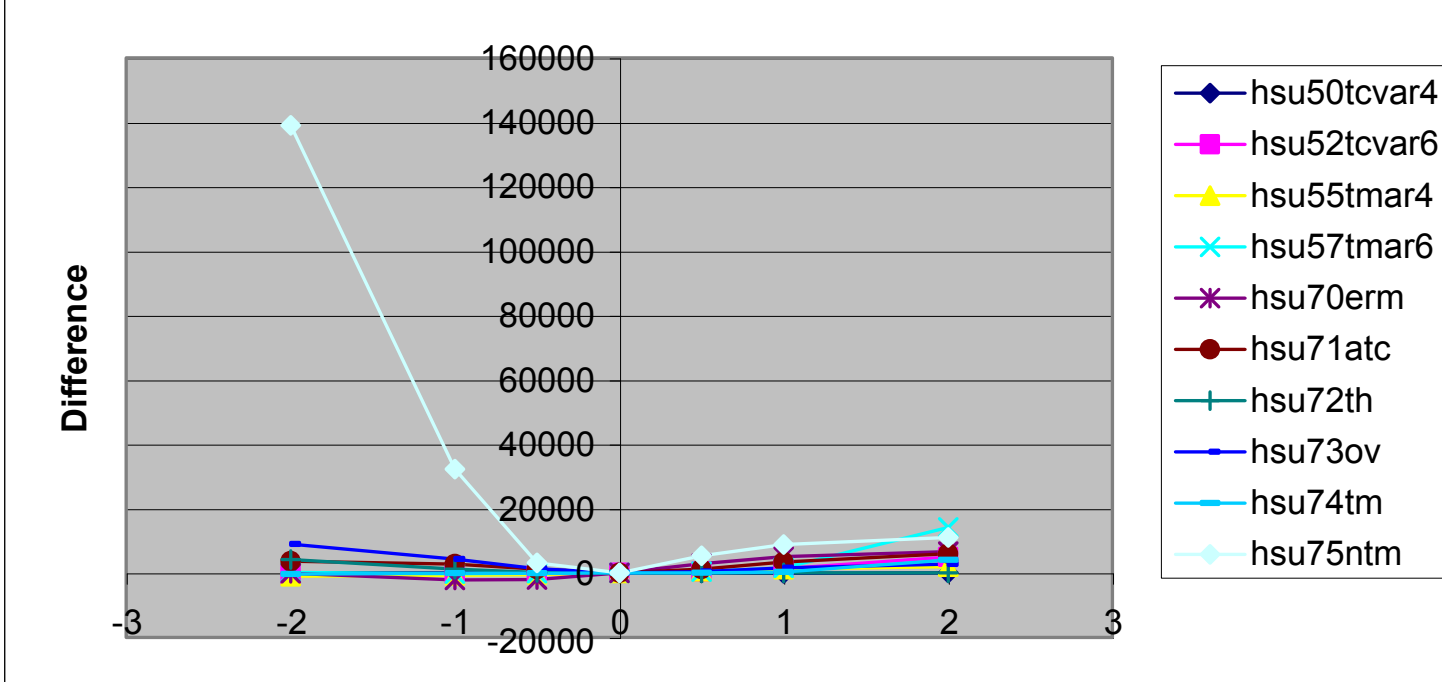

ase Value + - Standard Deviatio
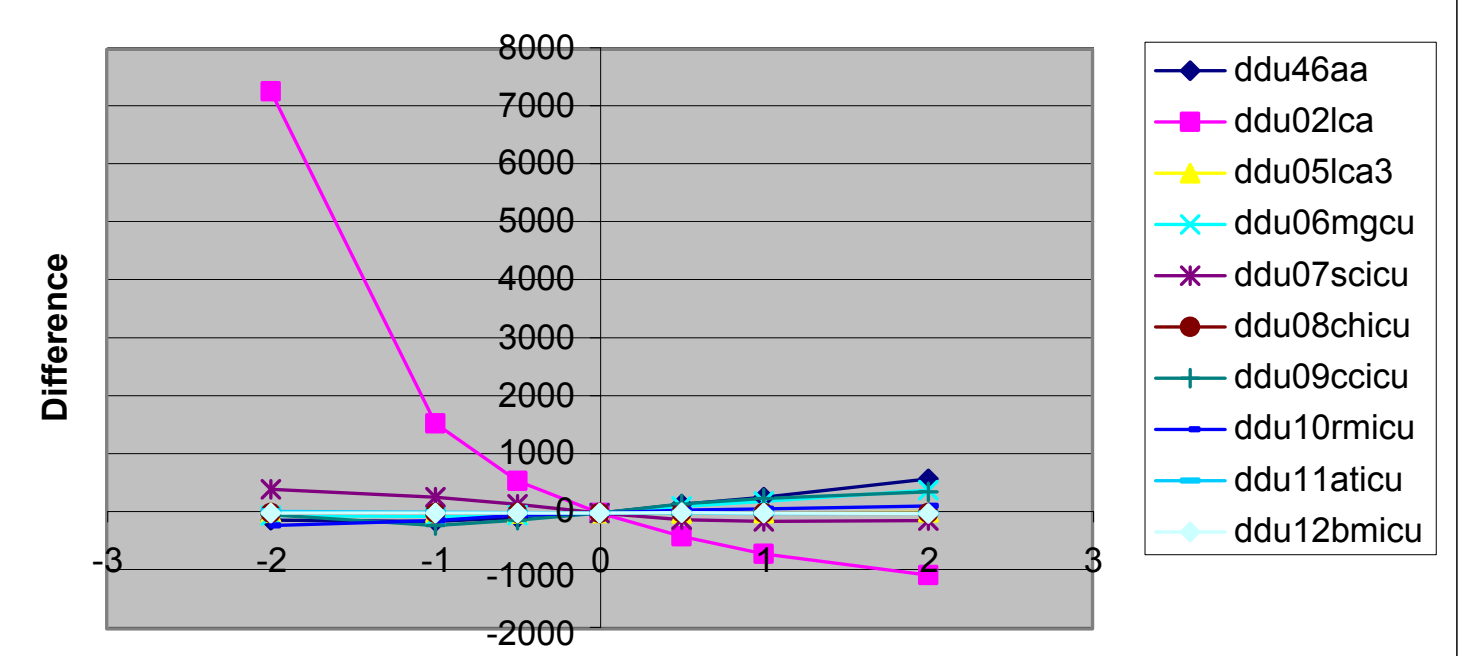

Base Value +1-Standard Deviation
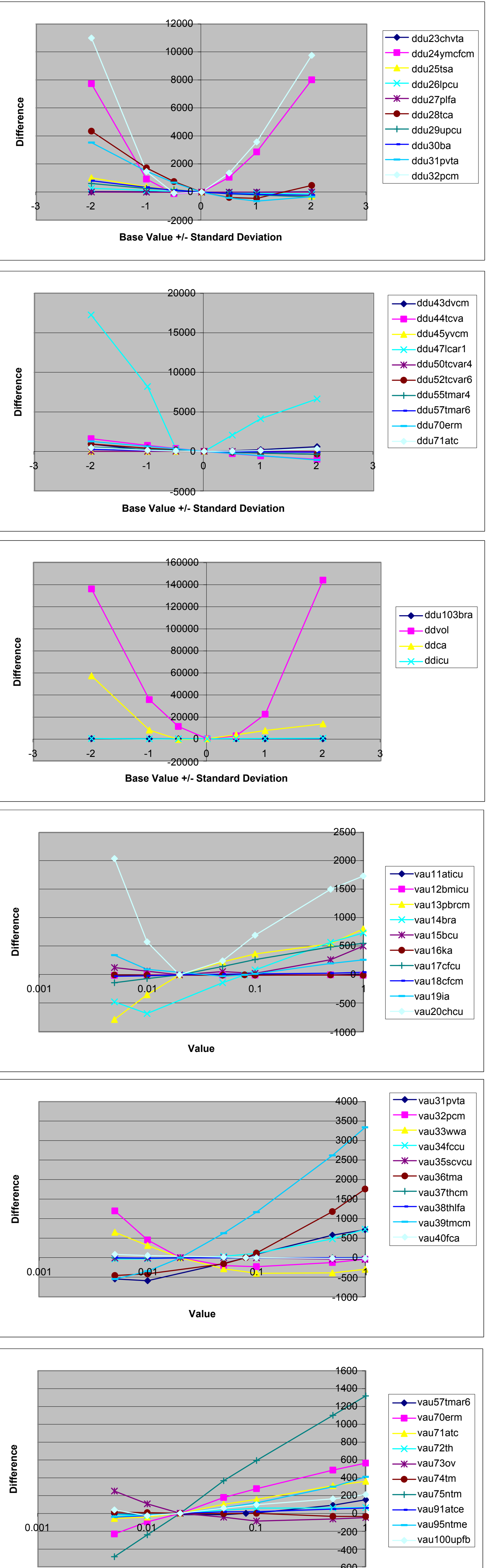

value
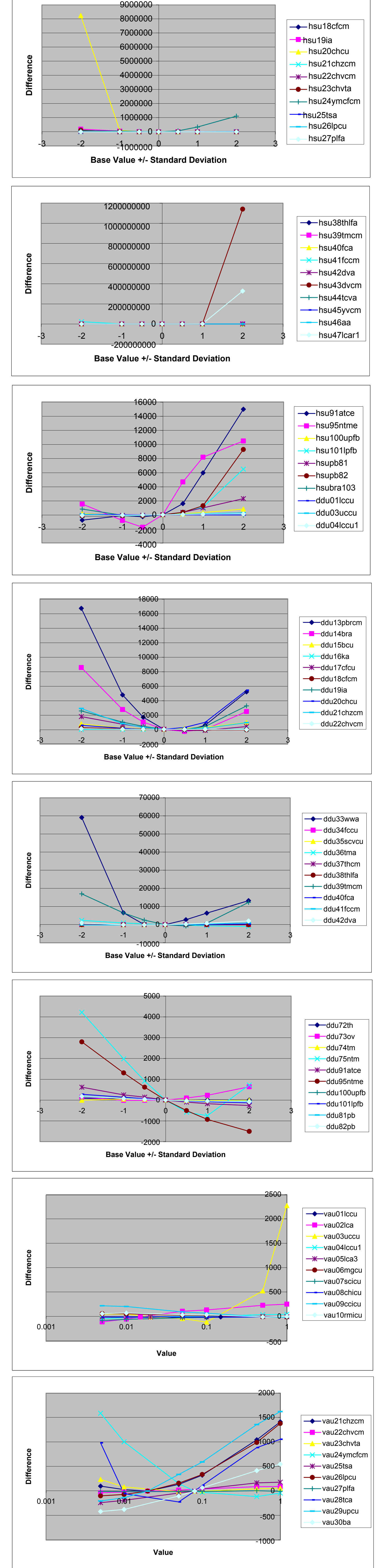

Base Value +/-Standard Deviation
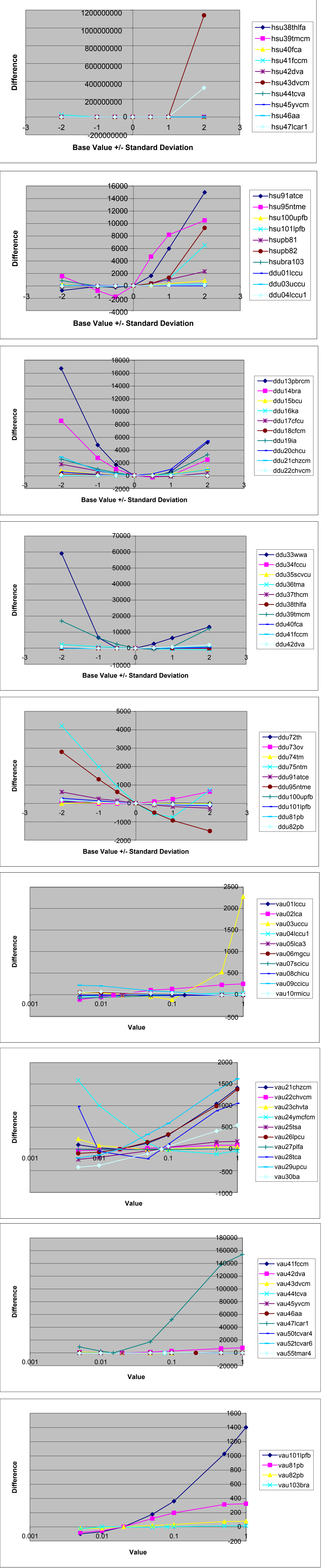

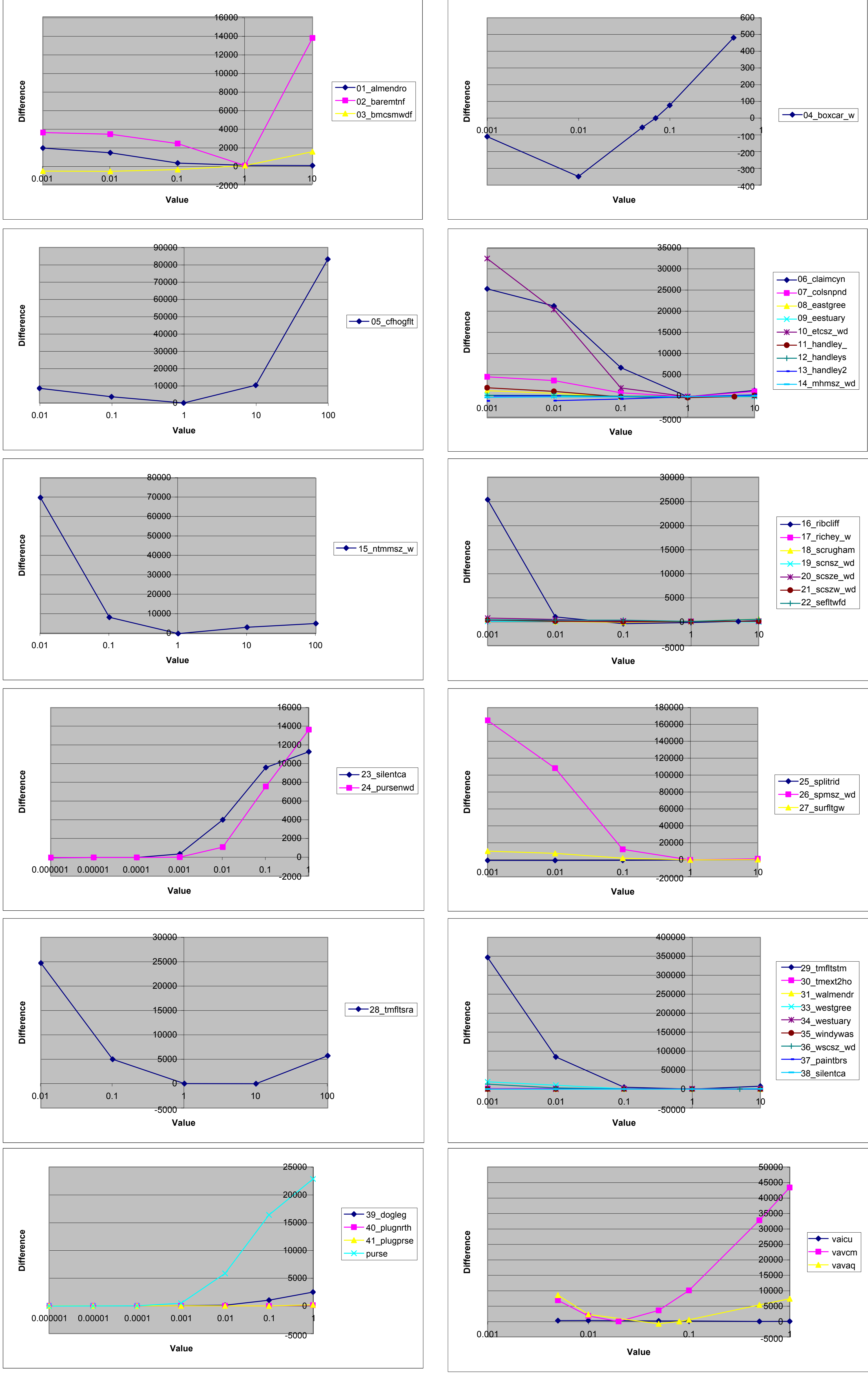
D.3.2 


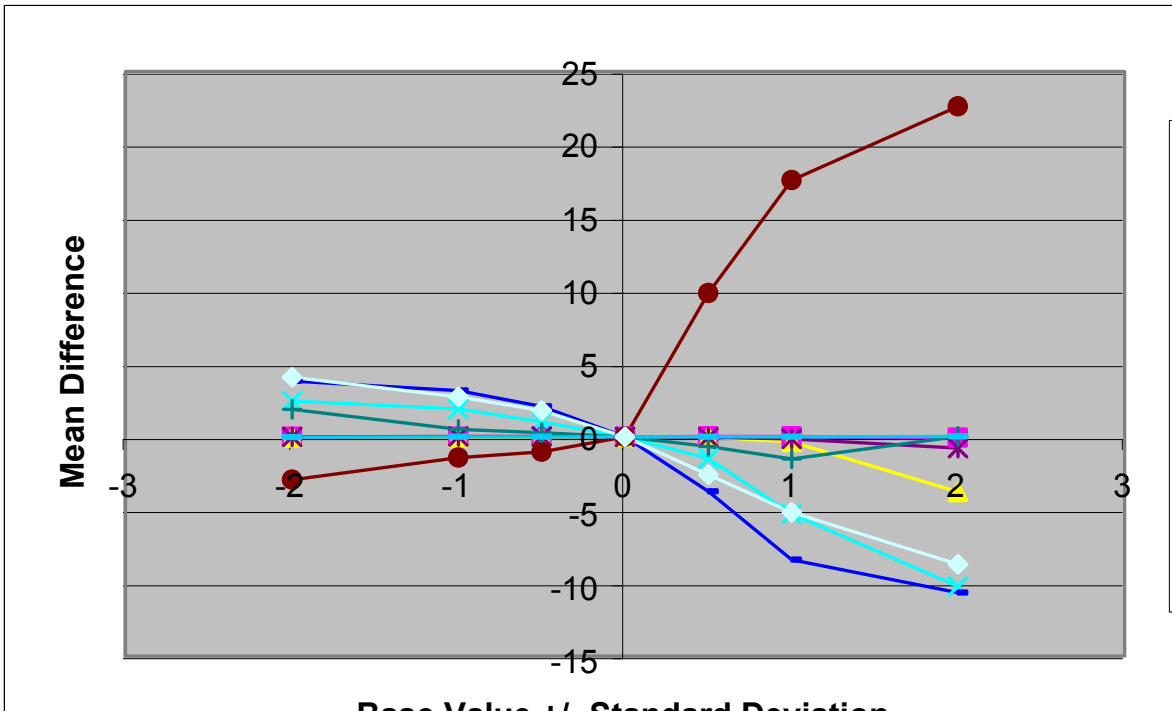

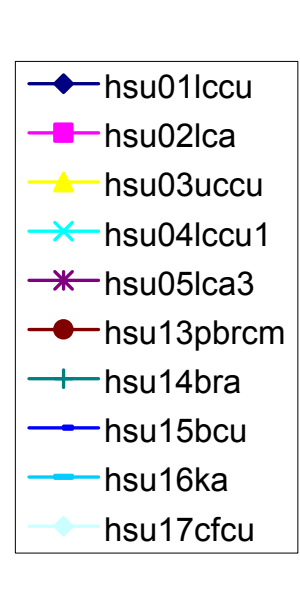

Base Value +/-Standard Deviation
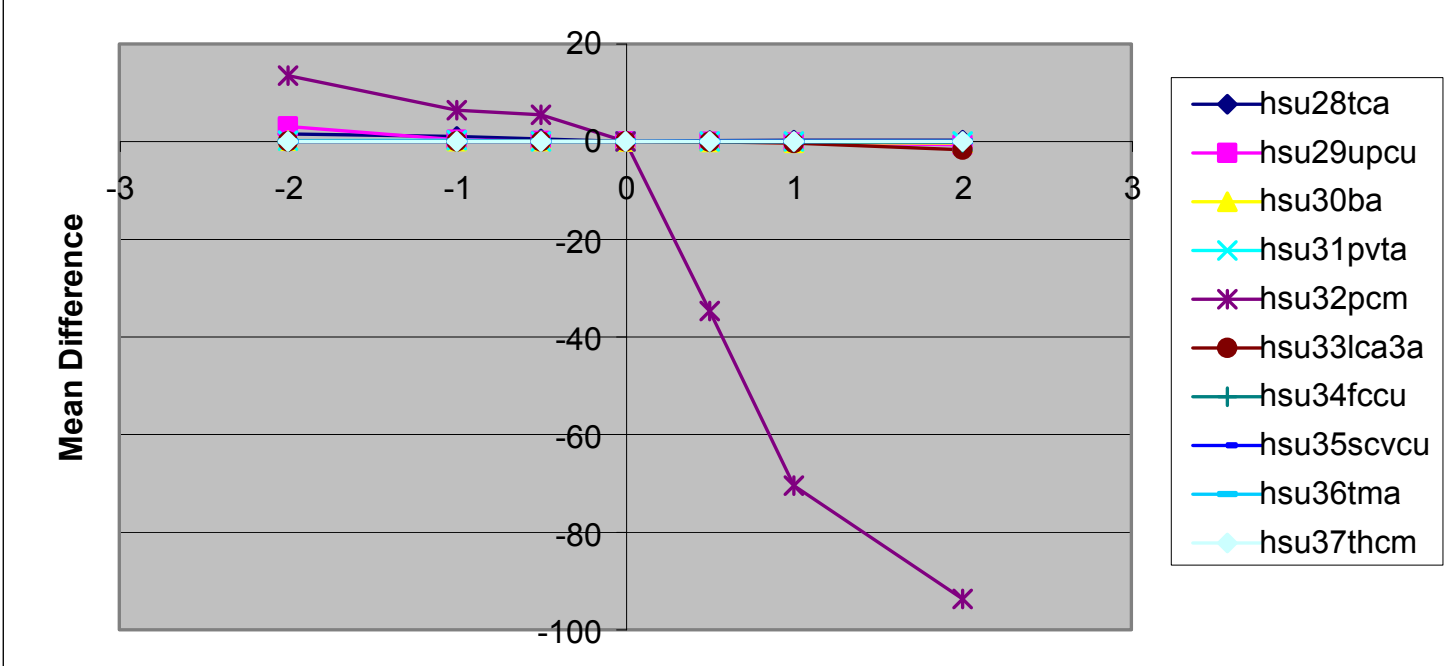

Base Value +/-Standard Deviatio
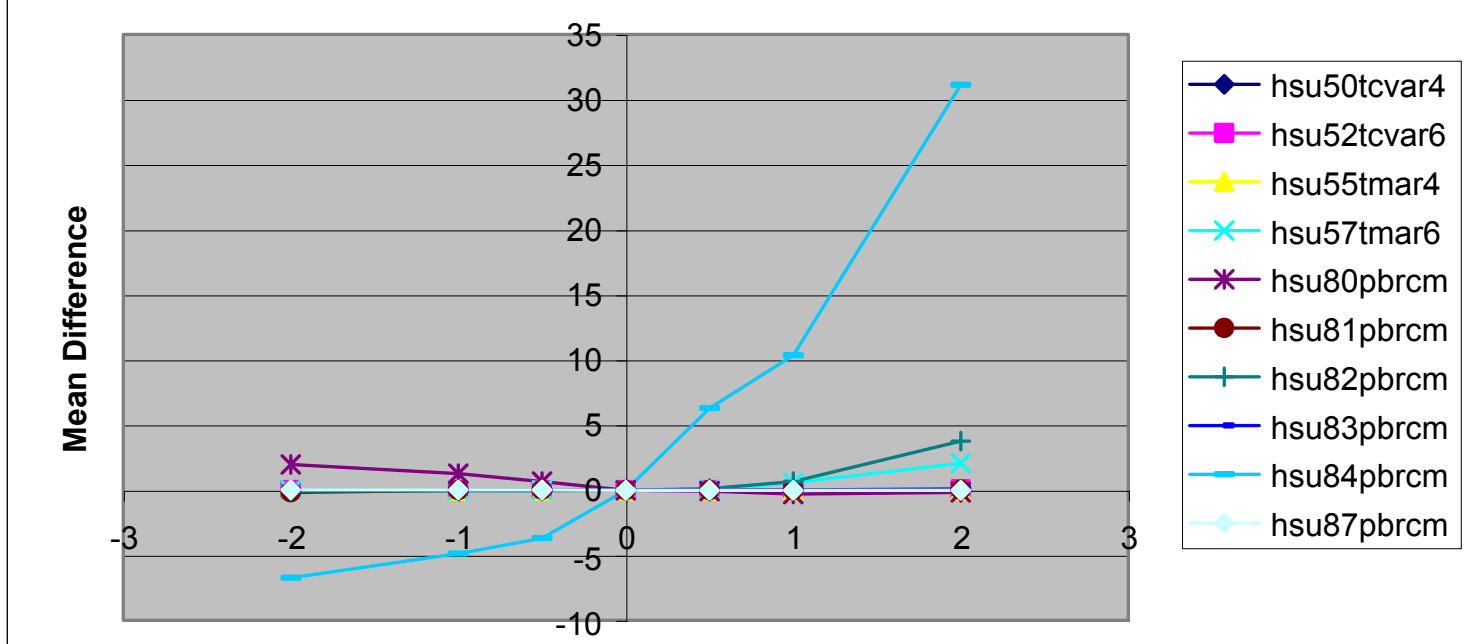

Base Value +/- Standard Deviatio
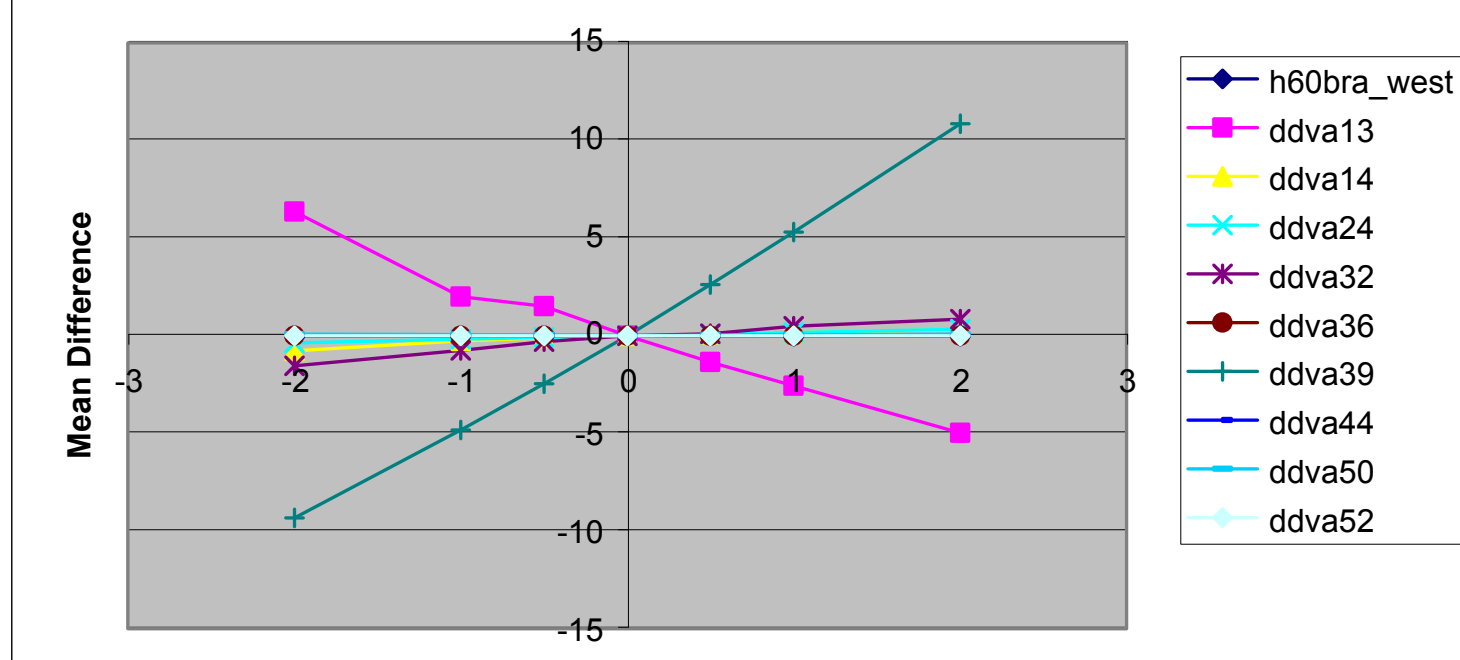

Base Value +/- Standard Deviatio
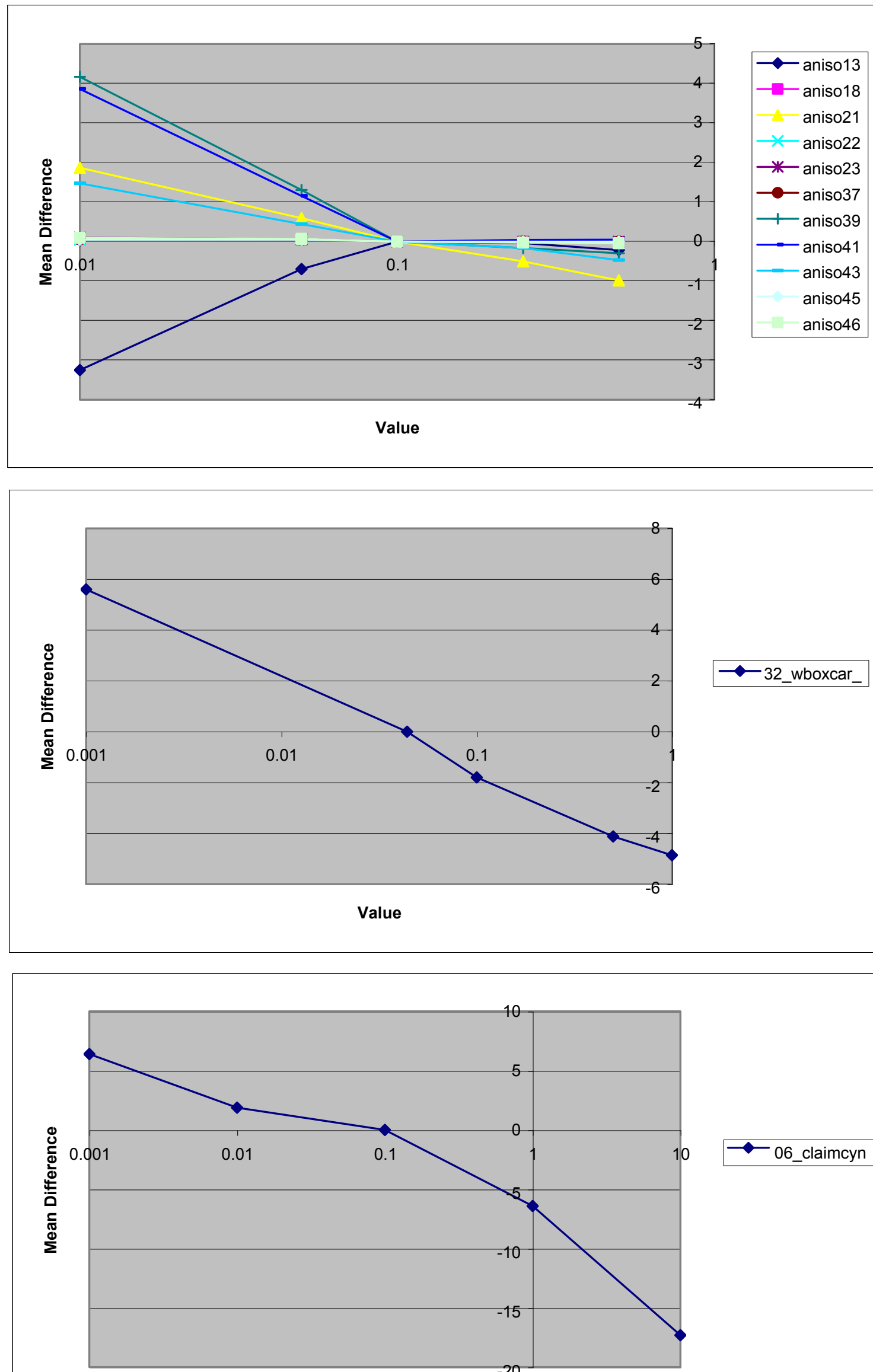

Value

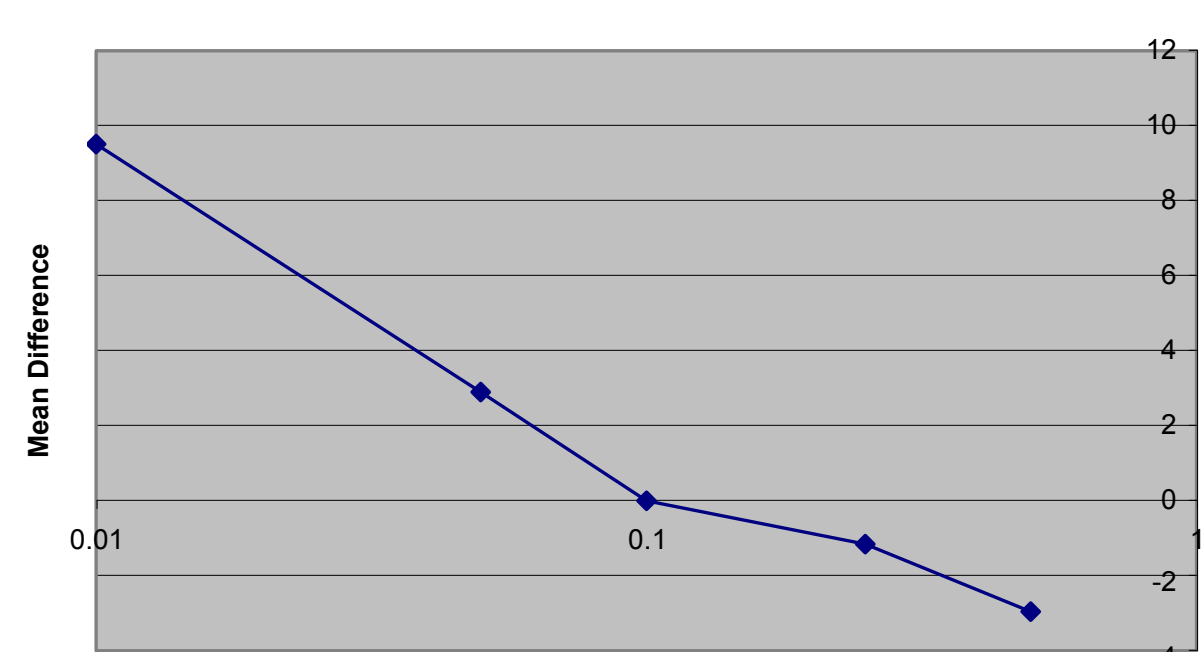

value

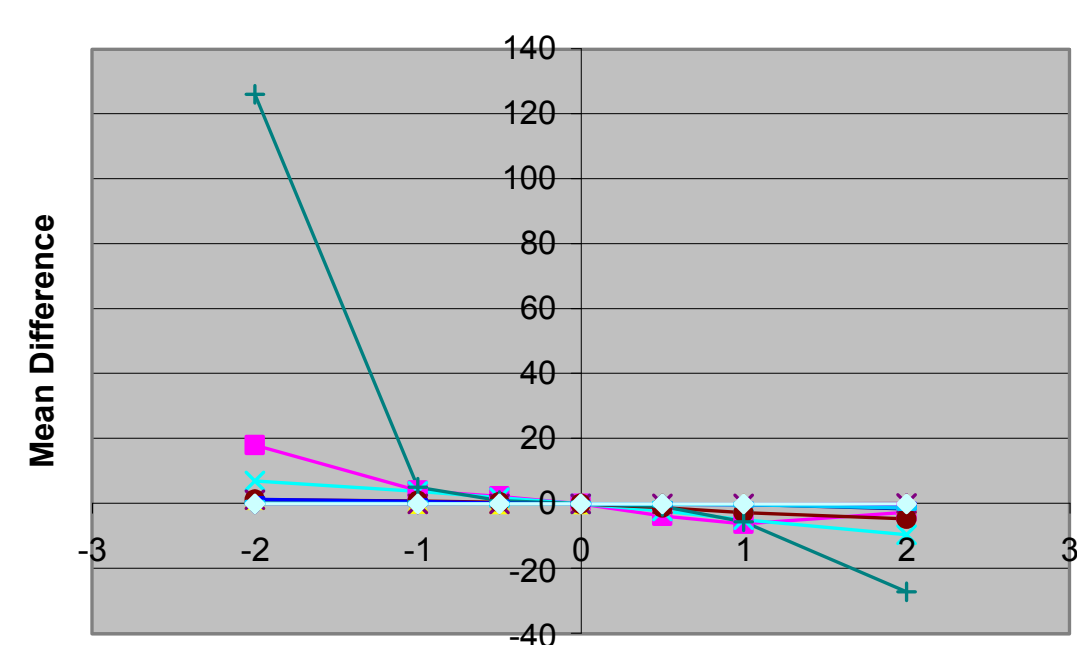

$\rightarrow$ hsu18cfcm
$\rightarrow$ hsu19ia hsu20chcu $*$ hsu21chzcm
$*$ - hsu22chvcm - hsu23chvta
— hsu24ymcfor - nsu25tsa
- nsu26lpcu hsu27pffa

Base Value +/-Standard Deviation

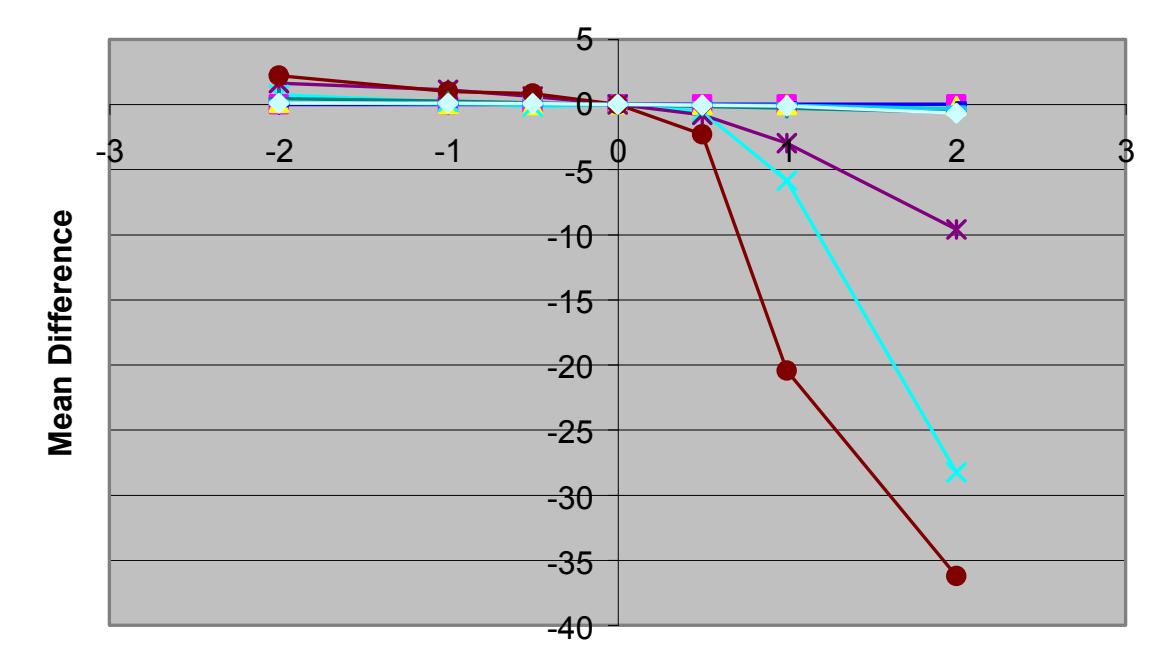

- hsu3909tmcm 4- hsu4fofca * hsu42dva - hsu43dvcm - hsu45yvcm

Base Value + /-Standard Deviation

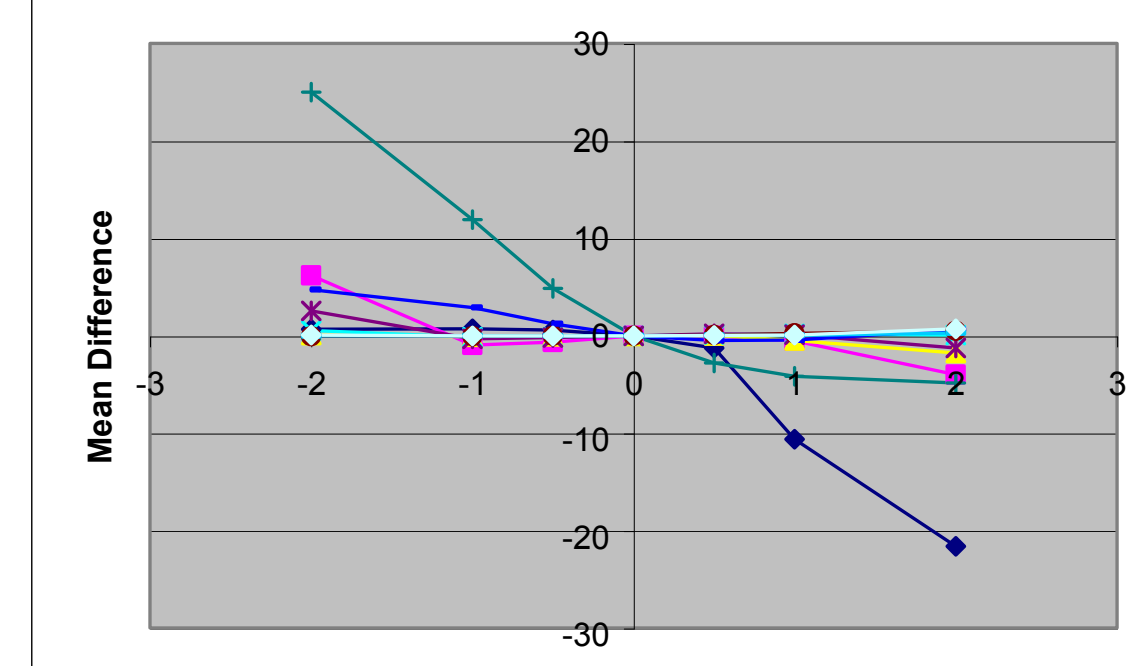

- h70tmomerm h71 tmamatcw - h91mcmatce *-n73tmomov + $\mathrm{h} 75 \mathrm{tmcmntmw}$ - h581pcu_fbu

Base Value +/-Standard Deviatio

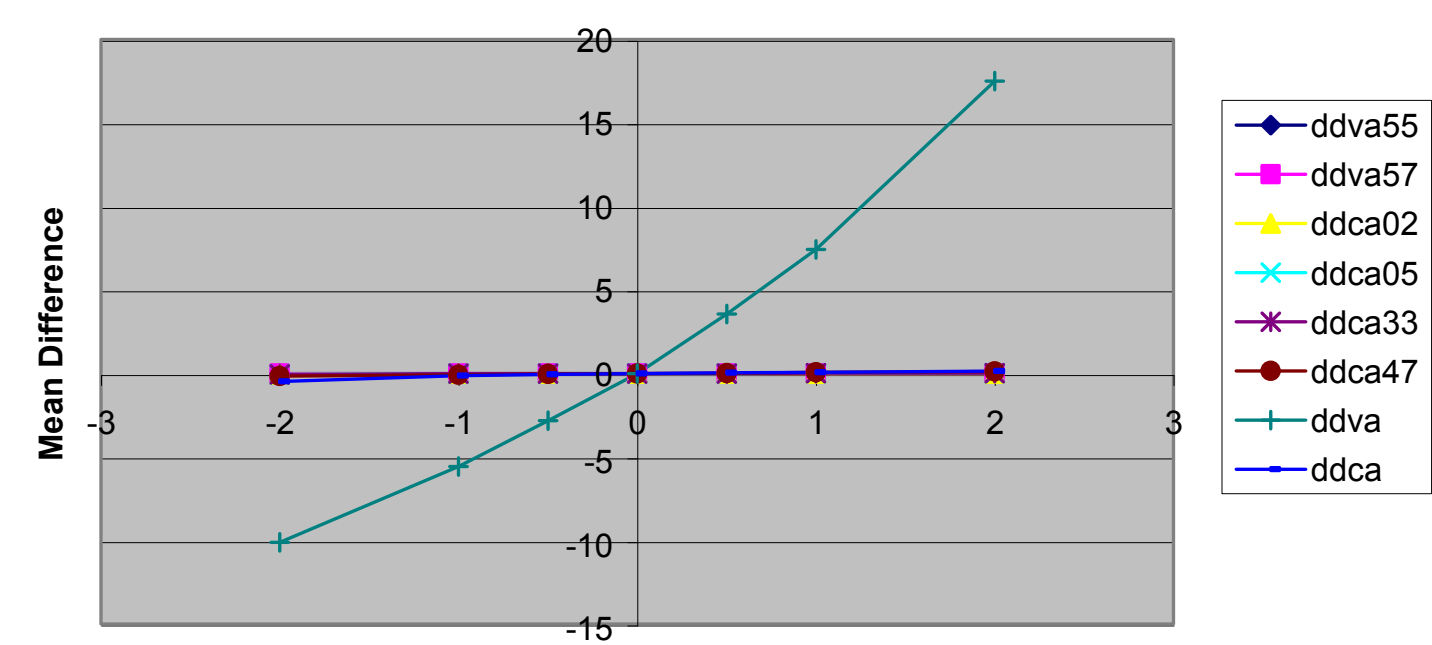

Base Value +/-Standard Deviatio
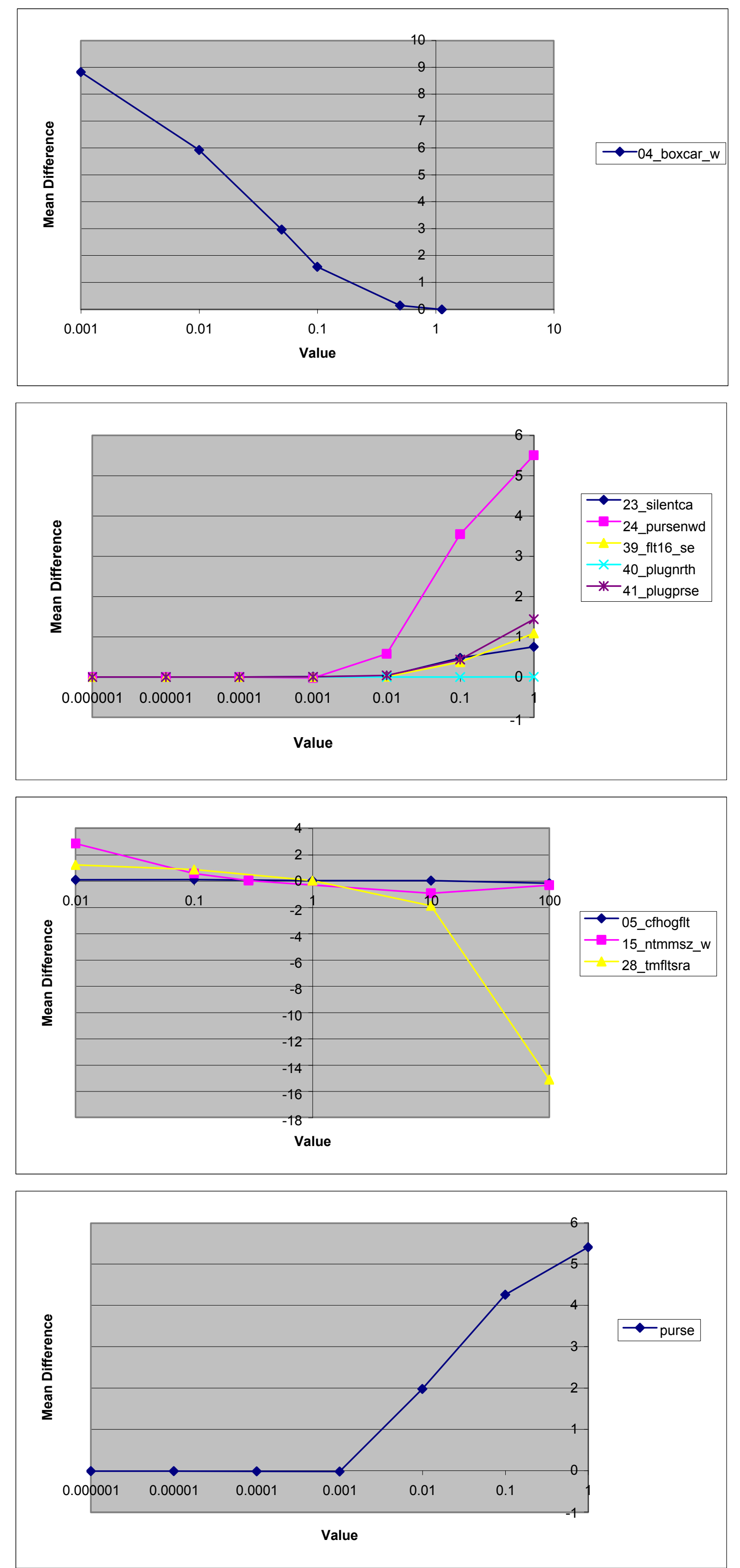

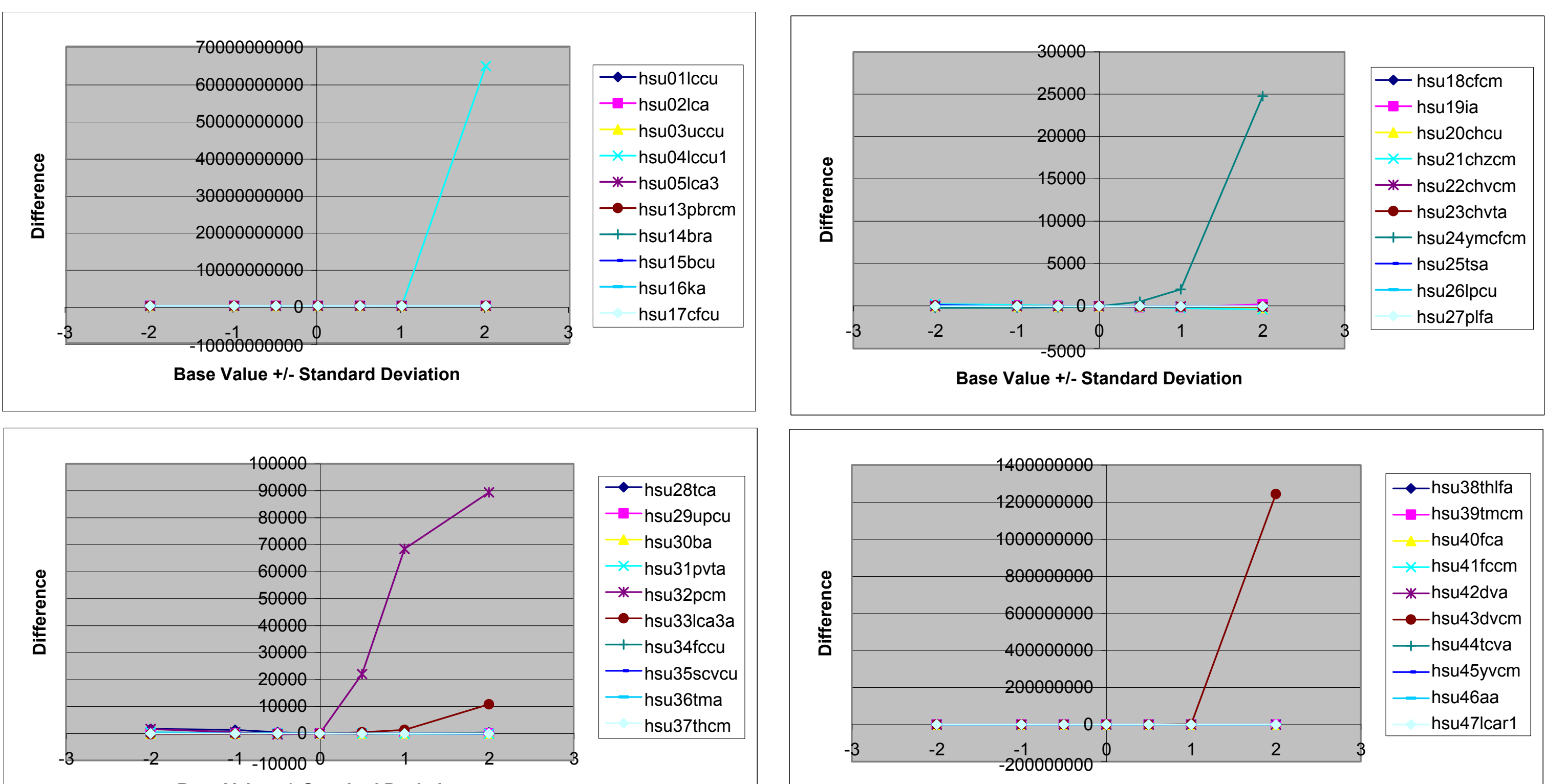

$\rightarrow$-hsu38thlfa - -hsu39tmcm
hsu40fca $*$ hsu41fccm *-hsu42dva - - hsu43dvcm + -hsu44tcva - hsu45yvcm - hsu46aa
hsu47lcar1 Base Value +/- Standard Deviatio

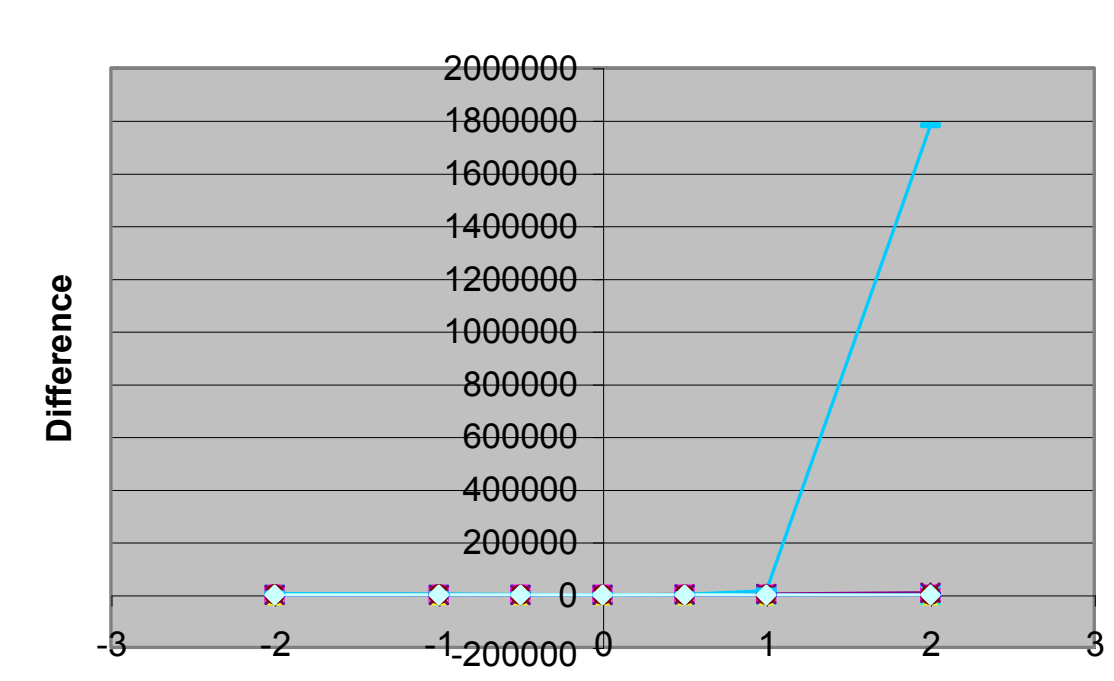

Base Value + + -Standard Deviation
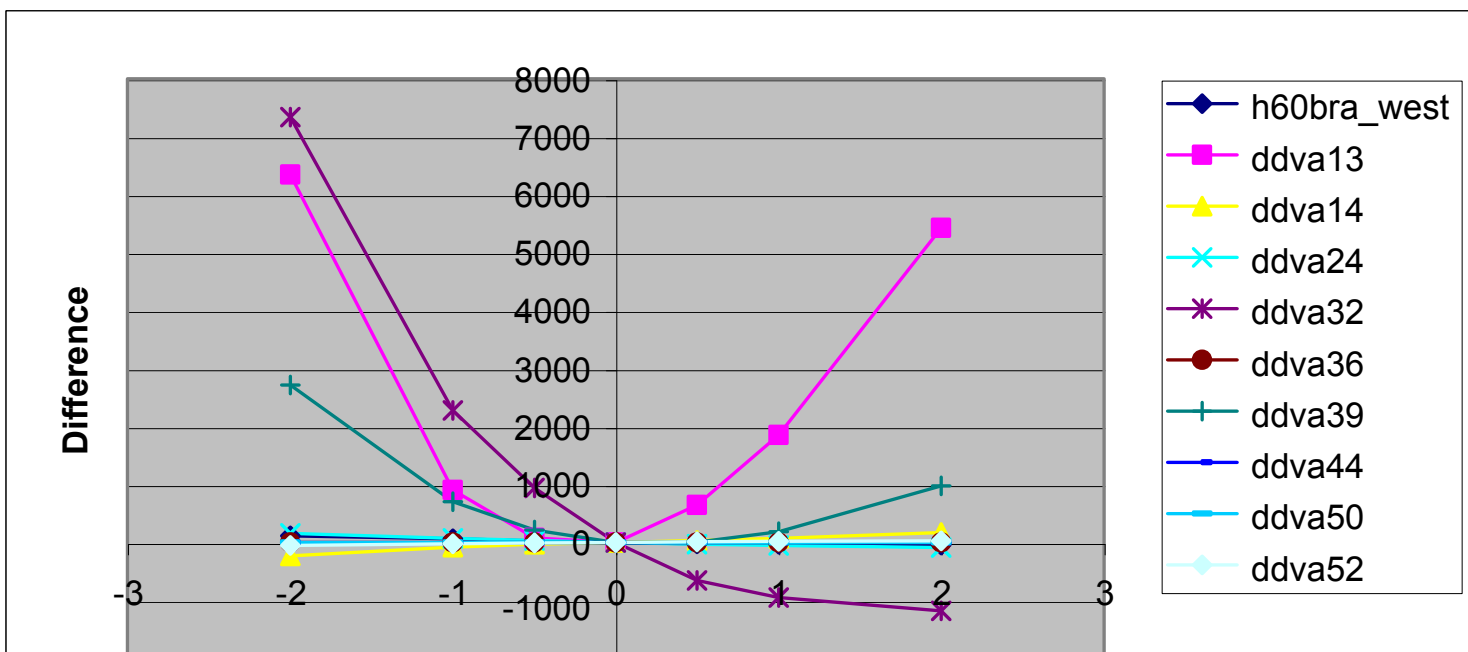

Base Value + +- Standard Deviatio
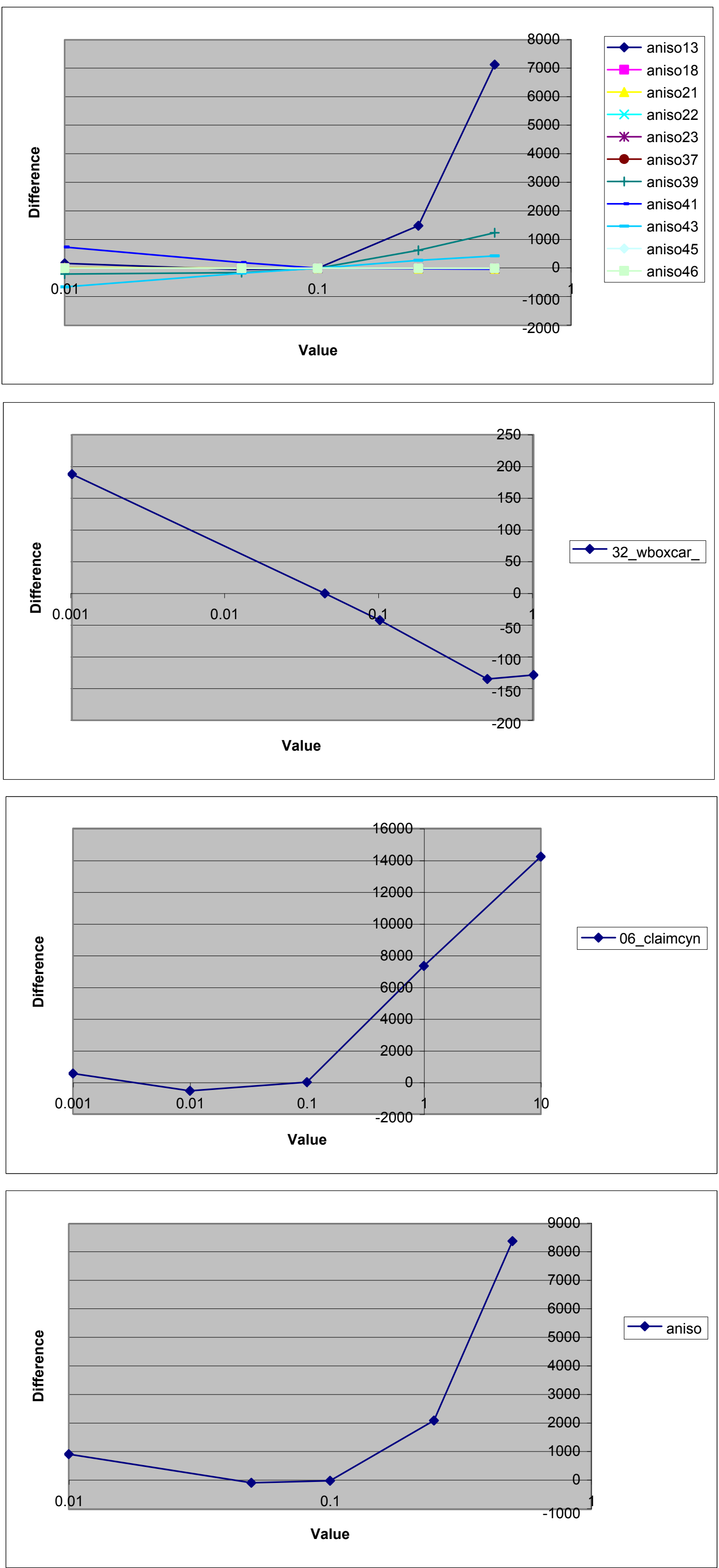
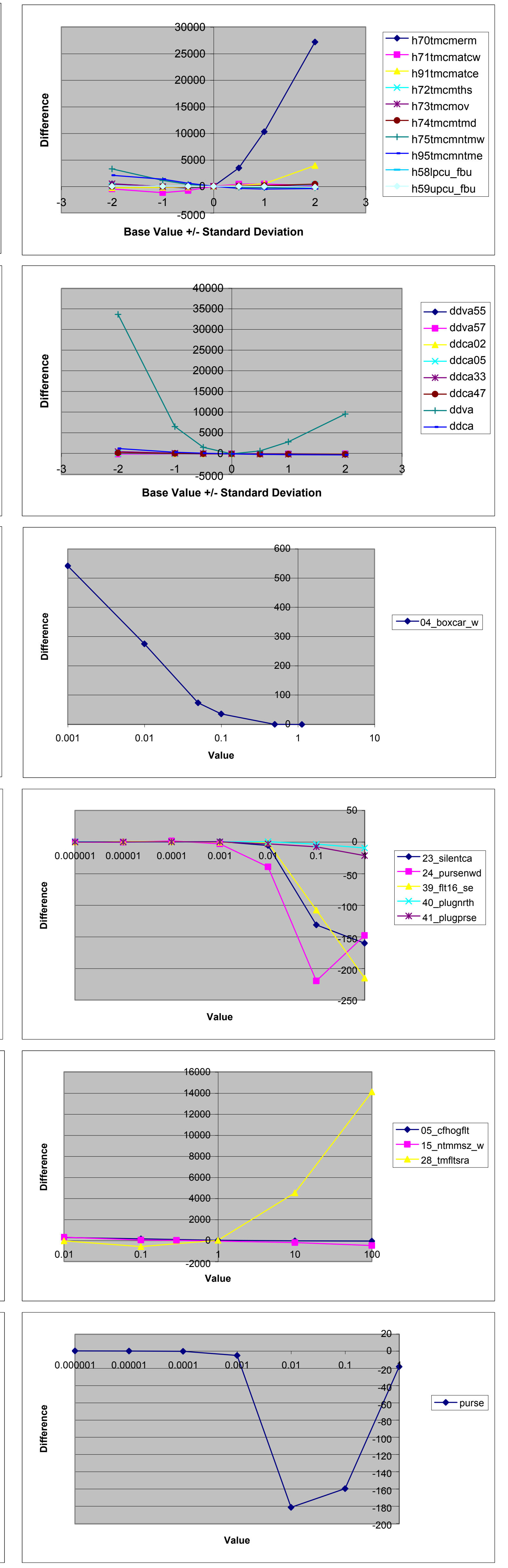

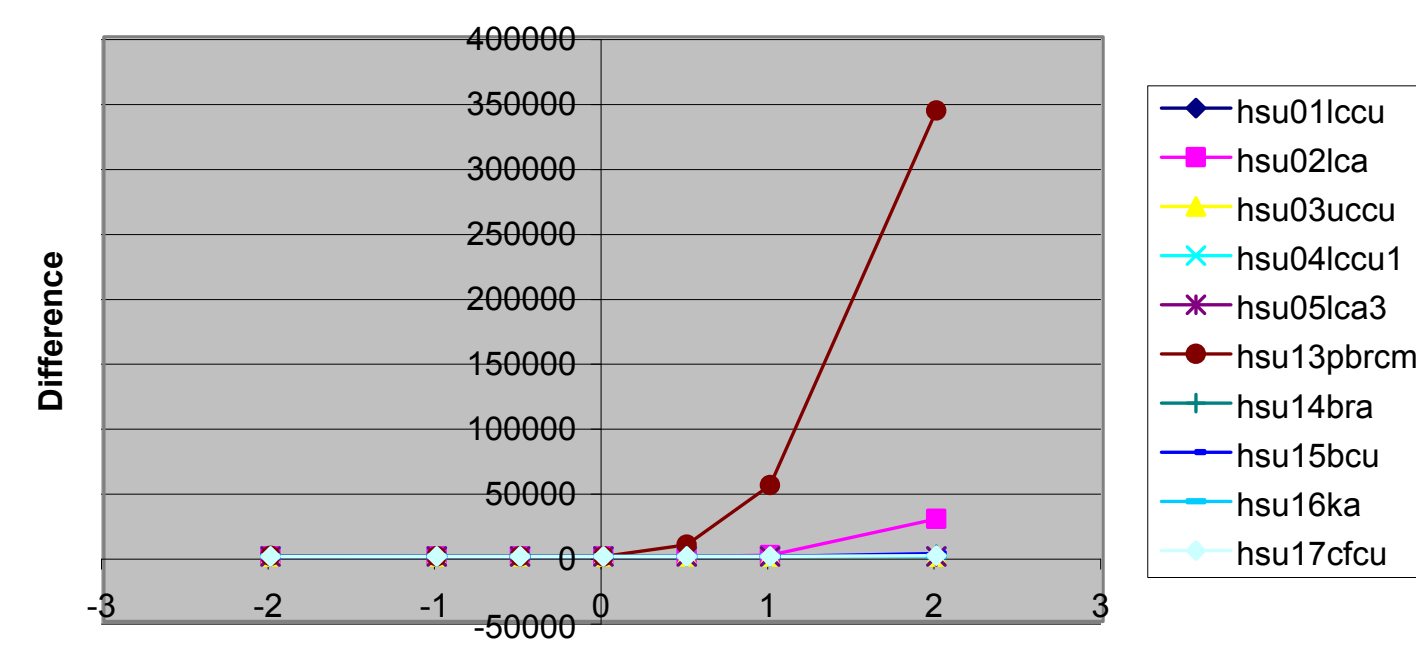

Base Value +/-Standard Deviation
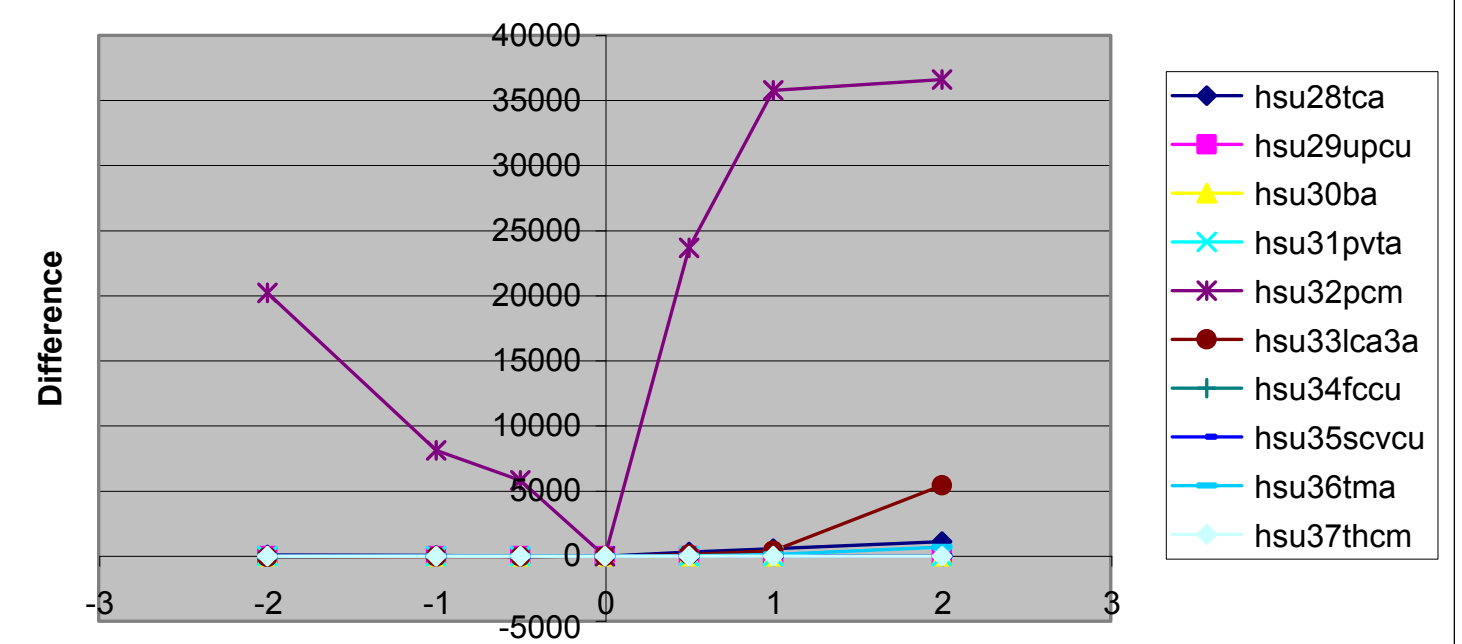

Base Value + + - Standard Deviation
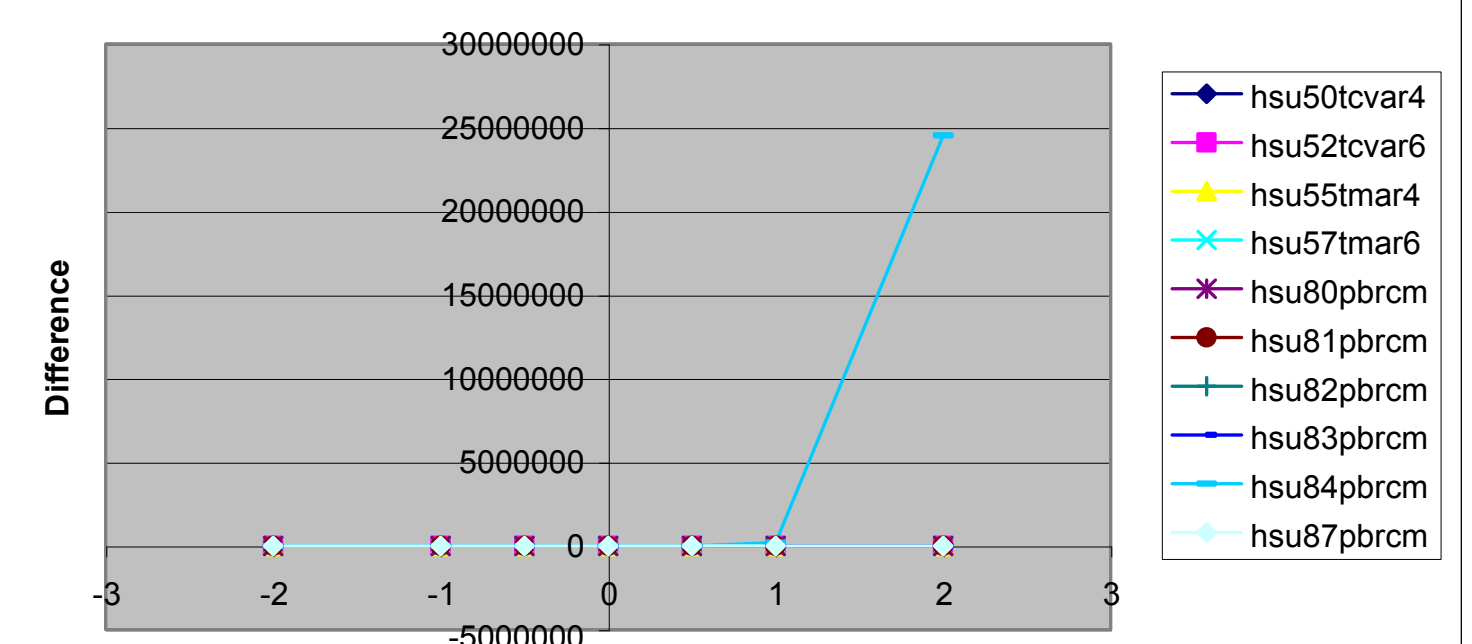

Base Value +t-Standard Deviation
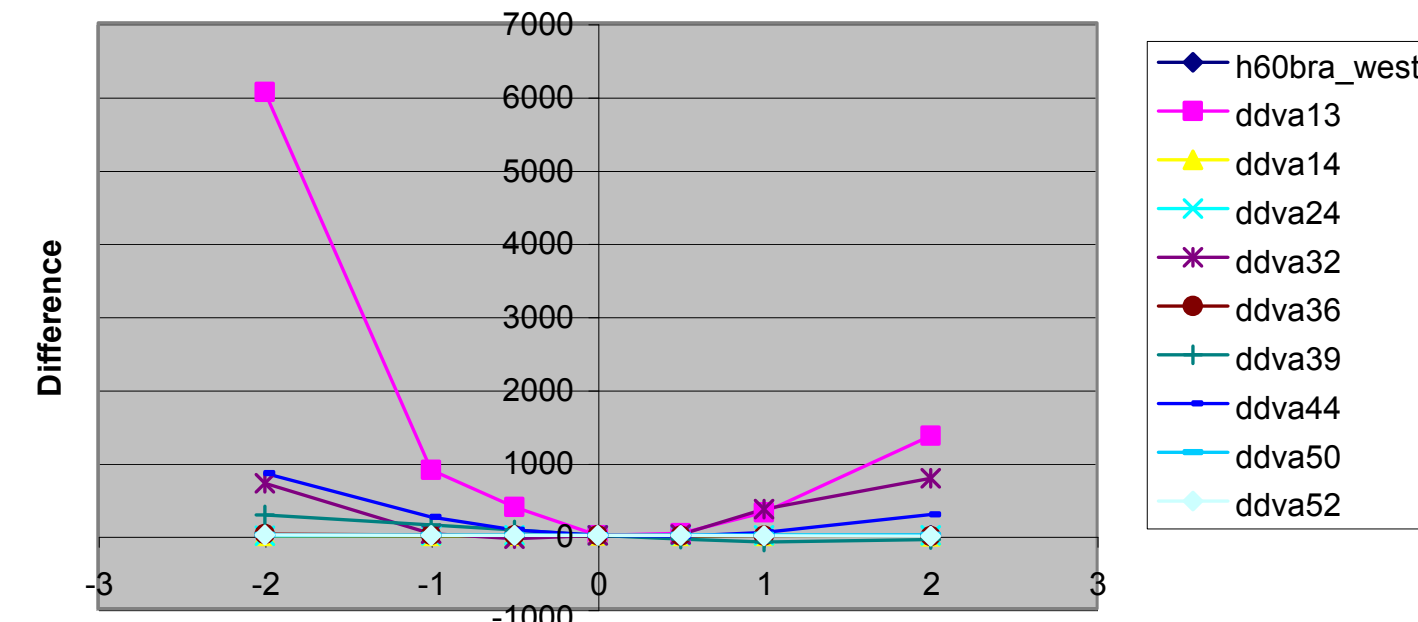

Base Value +/-Standard Deviation
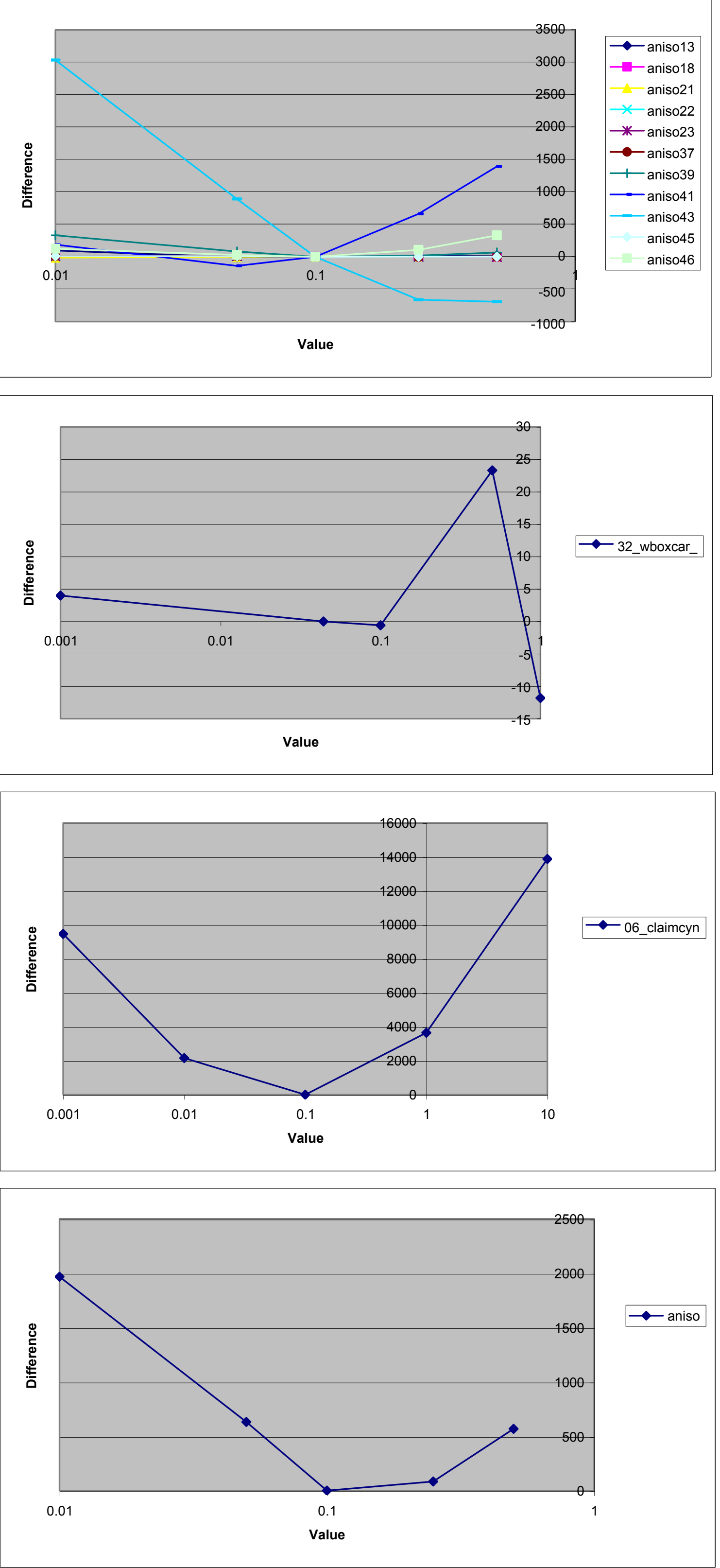

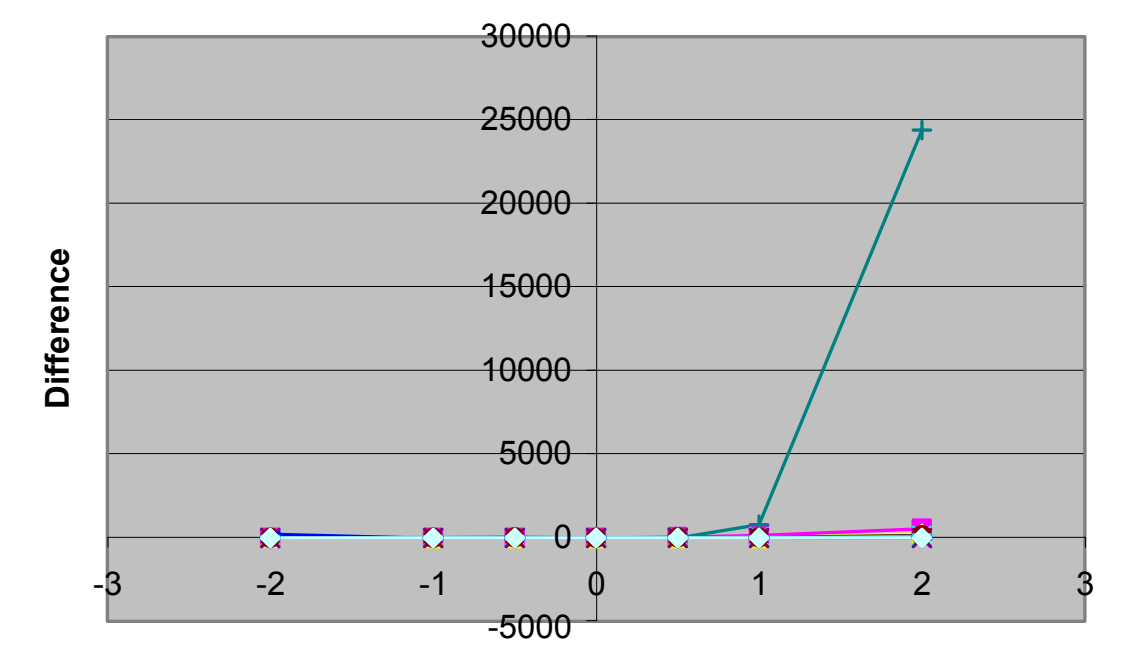

$\rightarrow$ hsu $18 \mathrm{cfcm}$

- hsu20chcu

$*$ hsu21chzcm
$*$ - hsu22chvcm

$\rightarrow$ - hsu23chvia

- hsu25tsa

hsu261pcu
hsu27plfa

Base Value +/-Standard Deviation

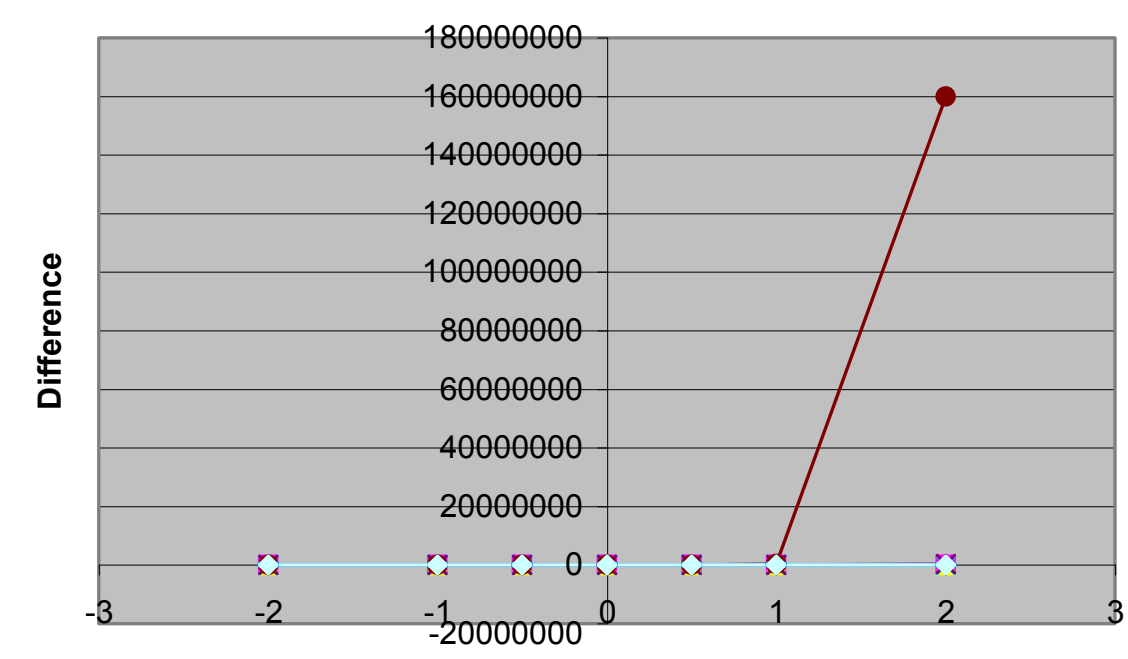

$\rightarrow$-hsu38thfifa

- hsu39tmcm

$-\leftarrow$ hsu $41 \mathrm{fccm}$

* hsu41fccm
$*$ - hsu42dva
- - hsu43dycm - - hsu43dvam
+ $\mathrm{hs} 444 \mathrm{tcva}$ - hsu45yvcm
- hsu46aa -hsu46aa
hsu47lcar1

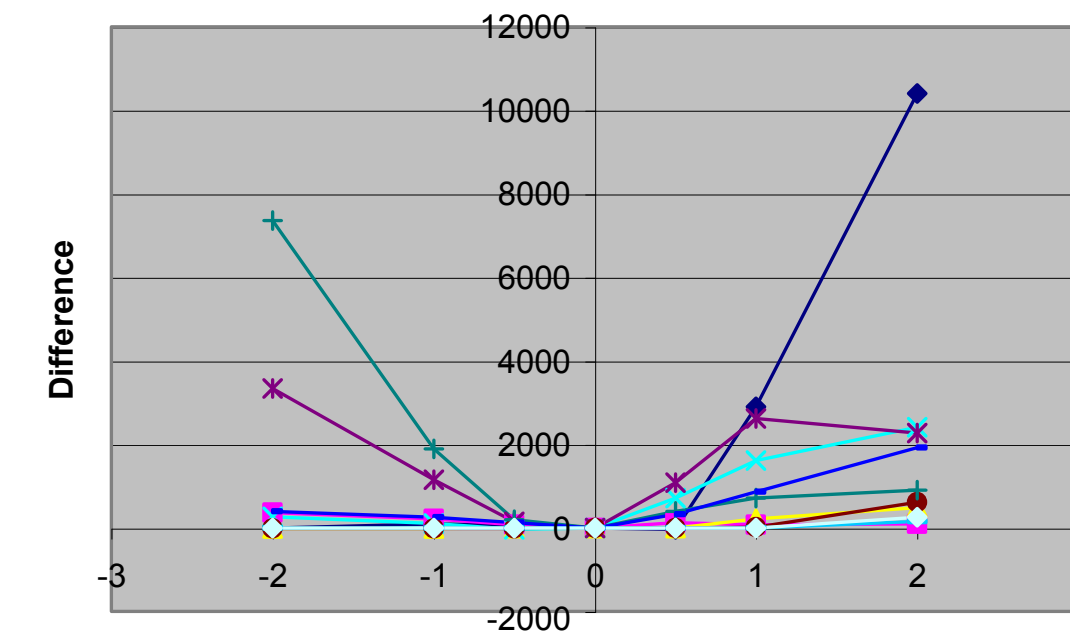
- h70tmcmerm h91tmcmatce * h73tmcmov - - h74tmomtma + h75tmcmntmw - h55tmomntme Base Value + - Standard Deviation
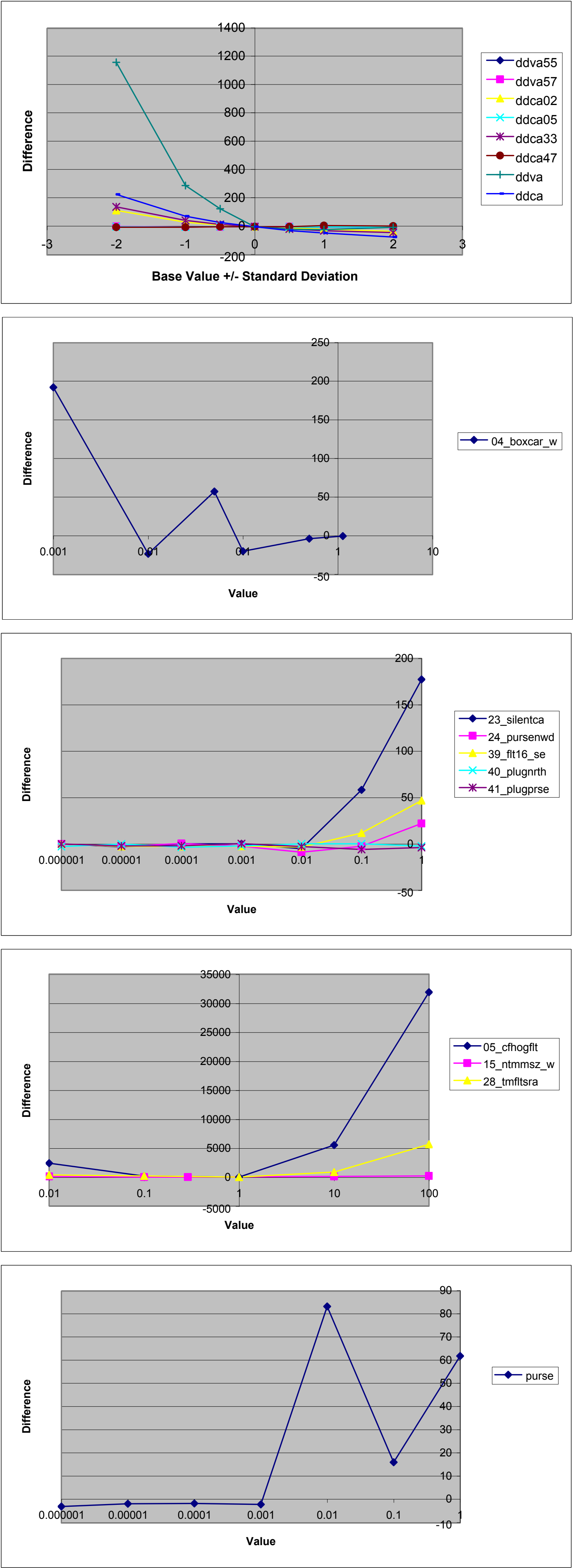

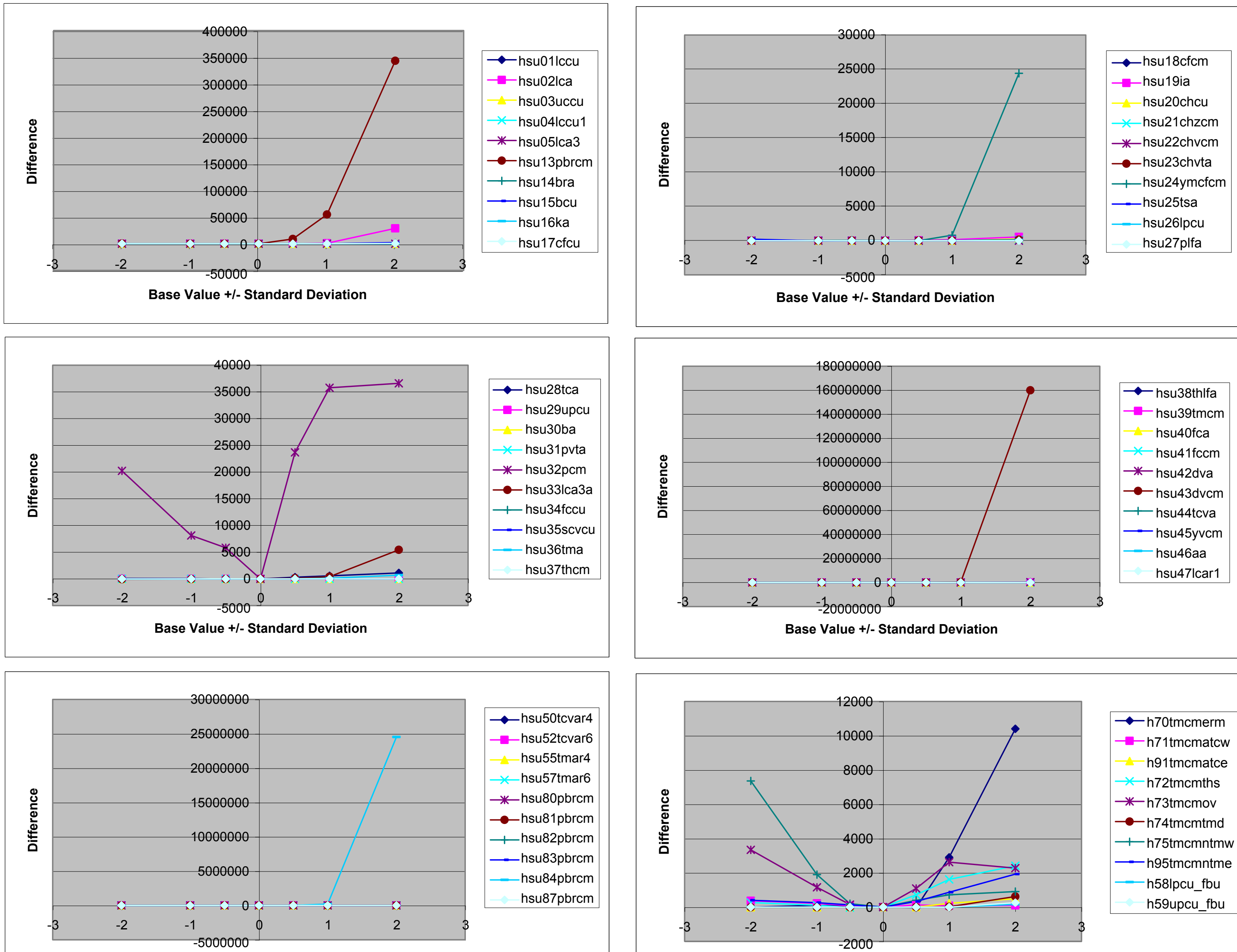

- -h70tmcmerm -h71 tmamatcw h91tmcmatce
-h72tmmiths *-h73tmcmor -h74tmcmtmd + h75tmcmntmw - h5stmcmntme

Base Value +/-Standard Deviation
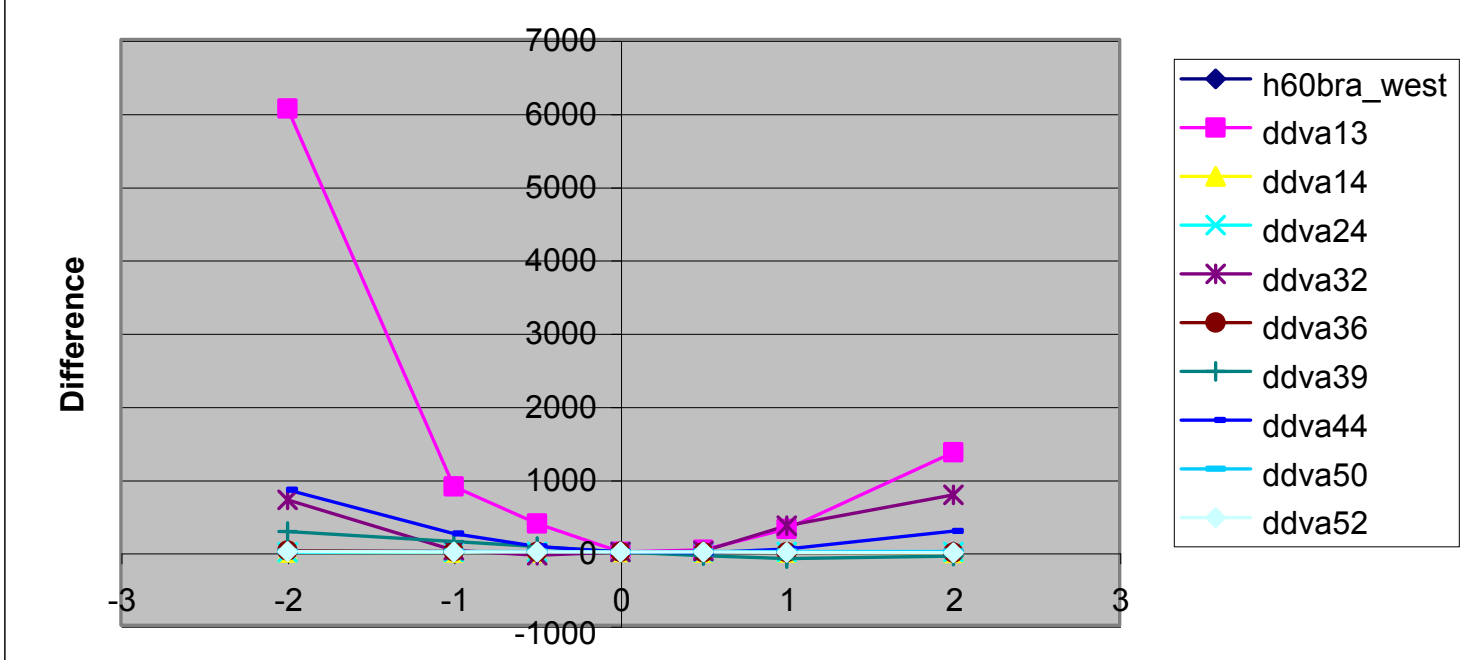

Base Value +/-Standard Deviation
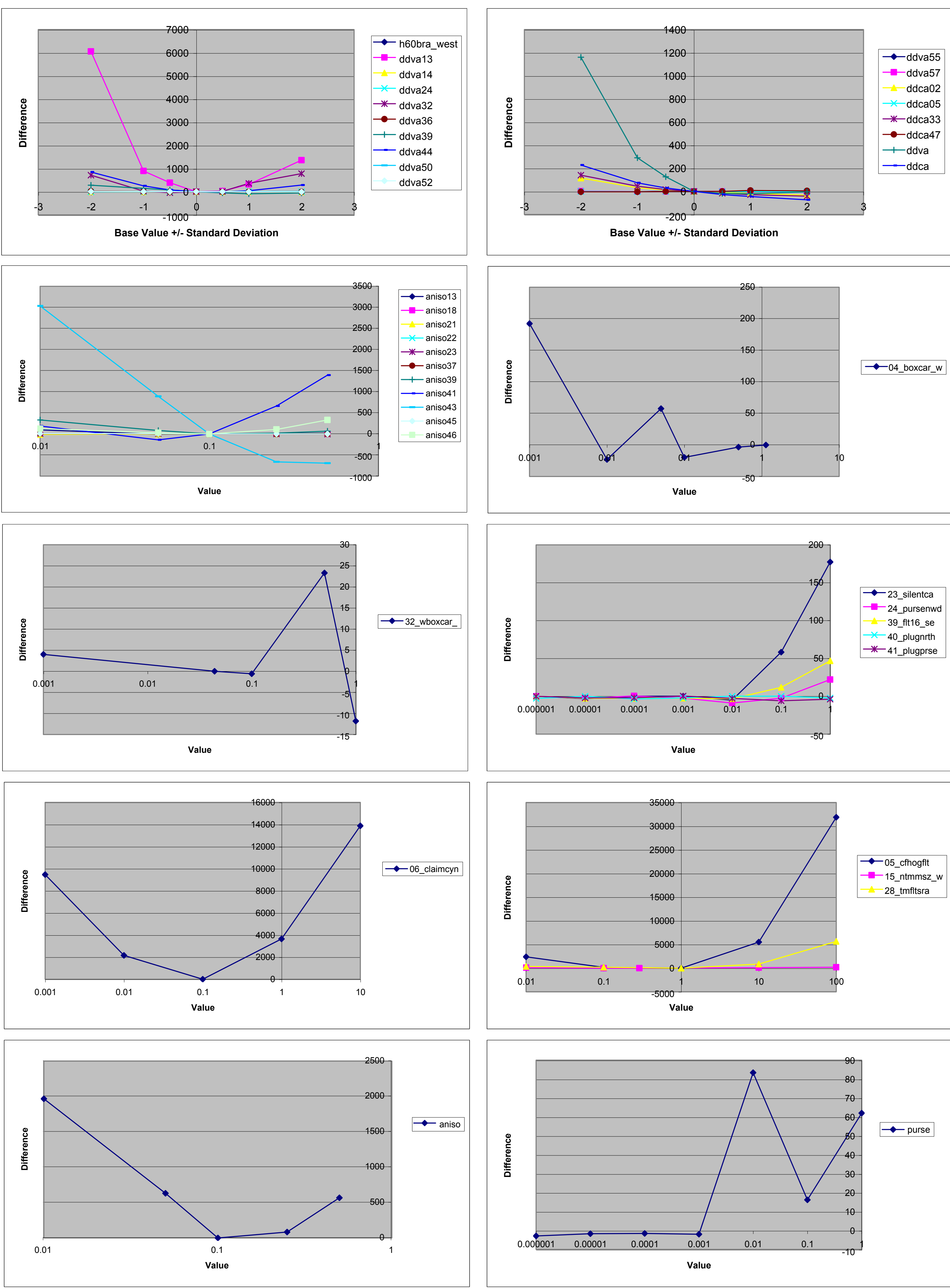


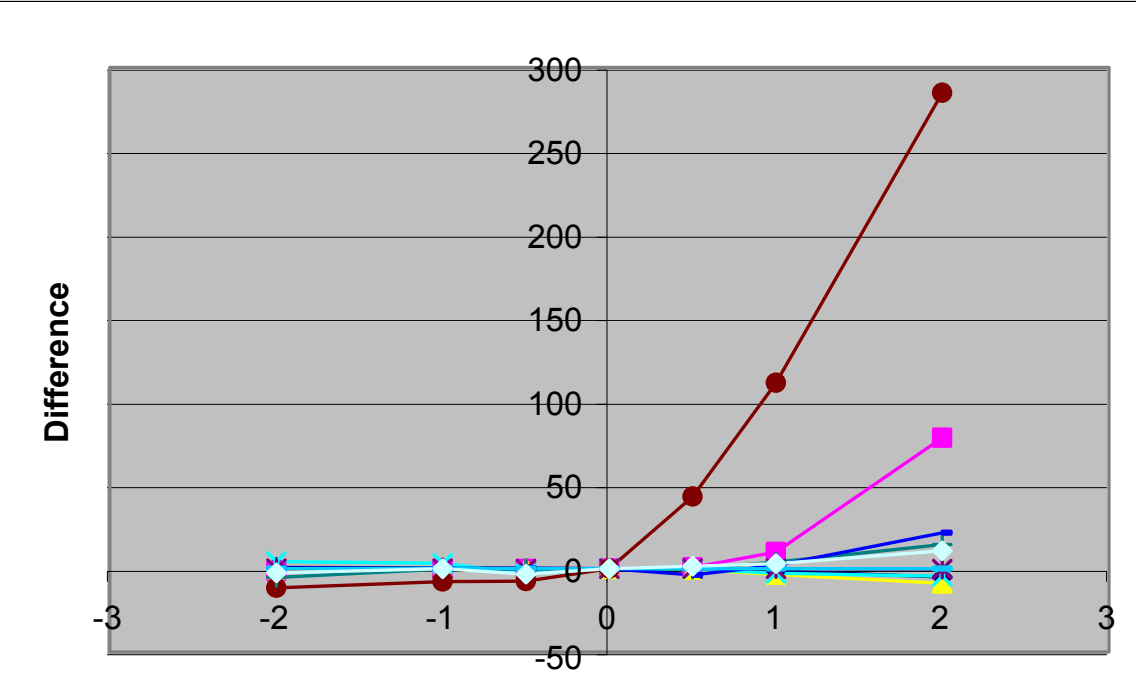

Base Value +/-Standard Deviation
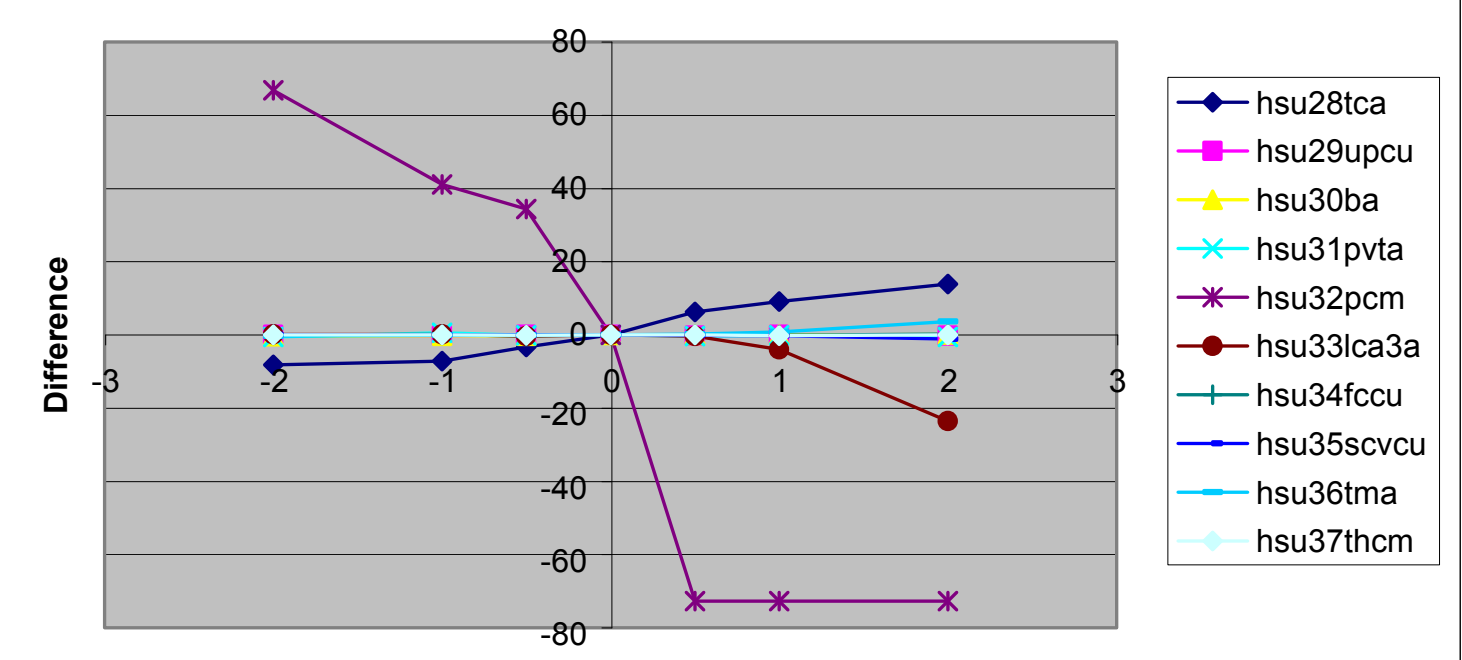

Base Value +/-Standard Deviation
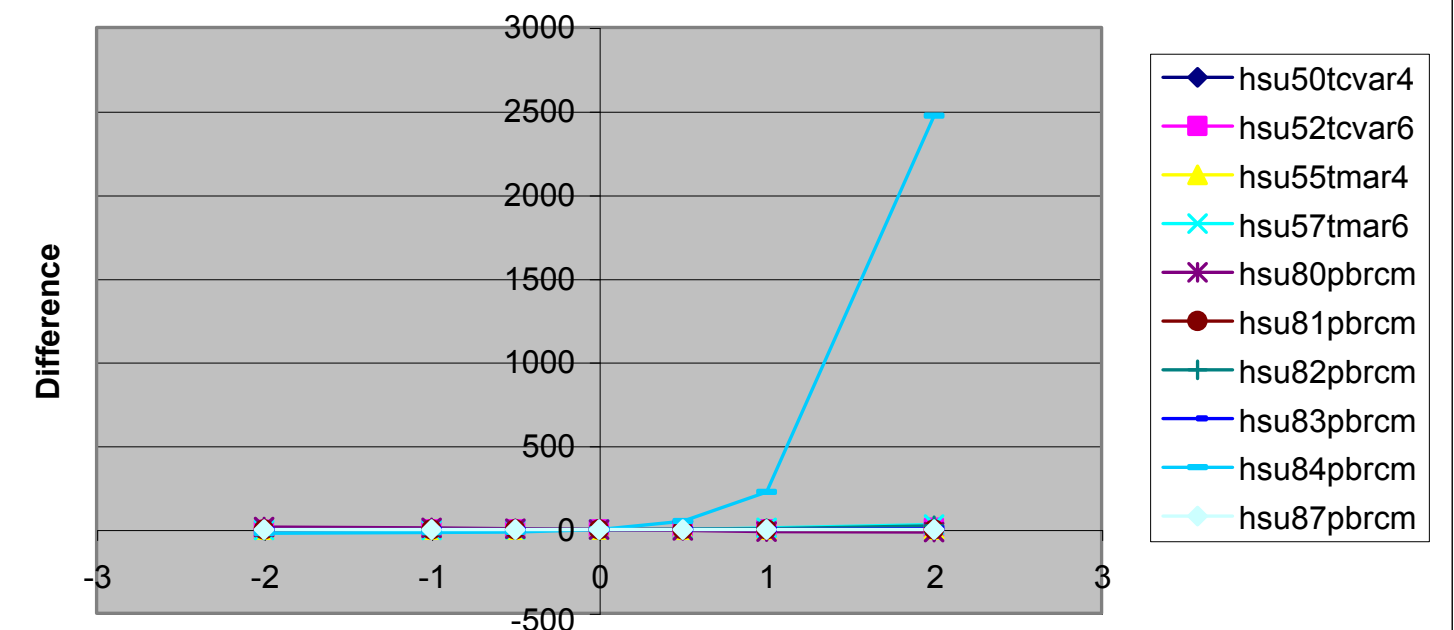

Base Value +l- Standard Deviation
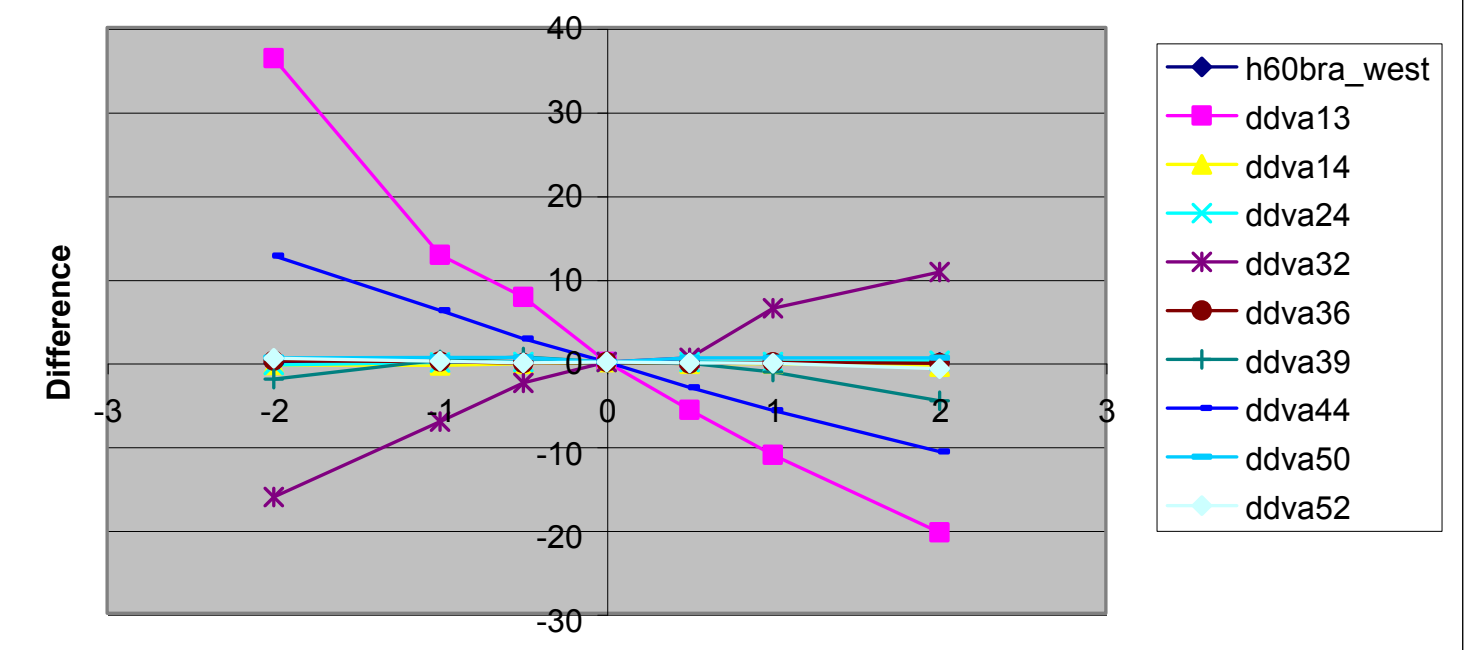

Base Value +/- Standard Deviation
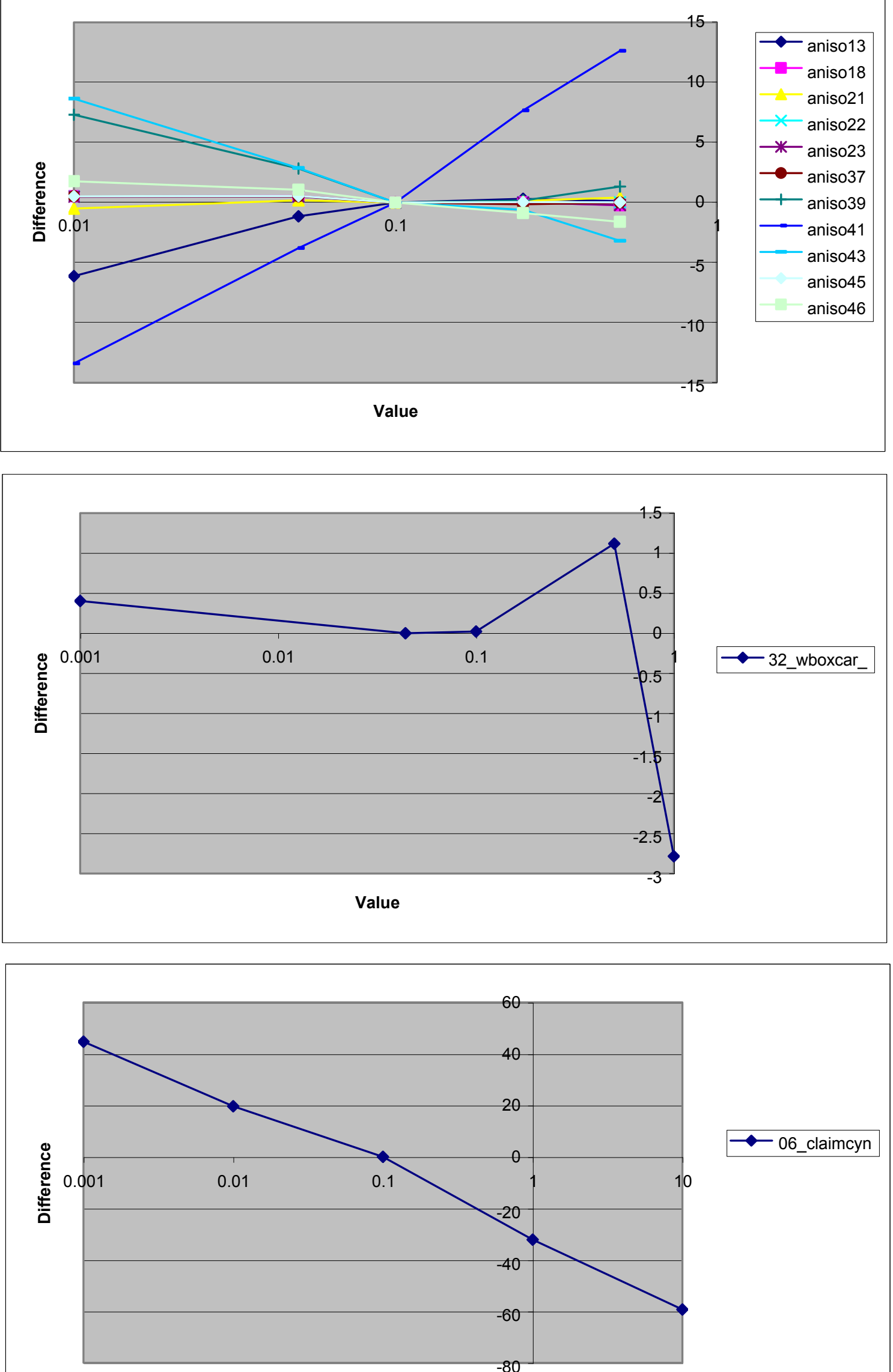

value

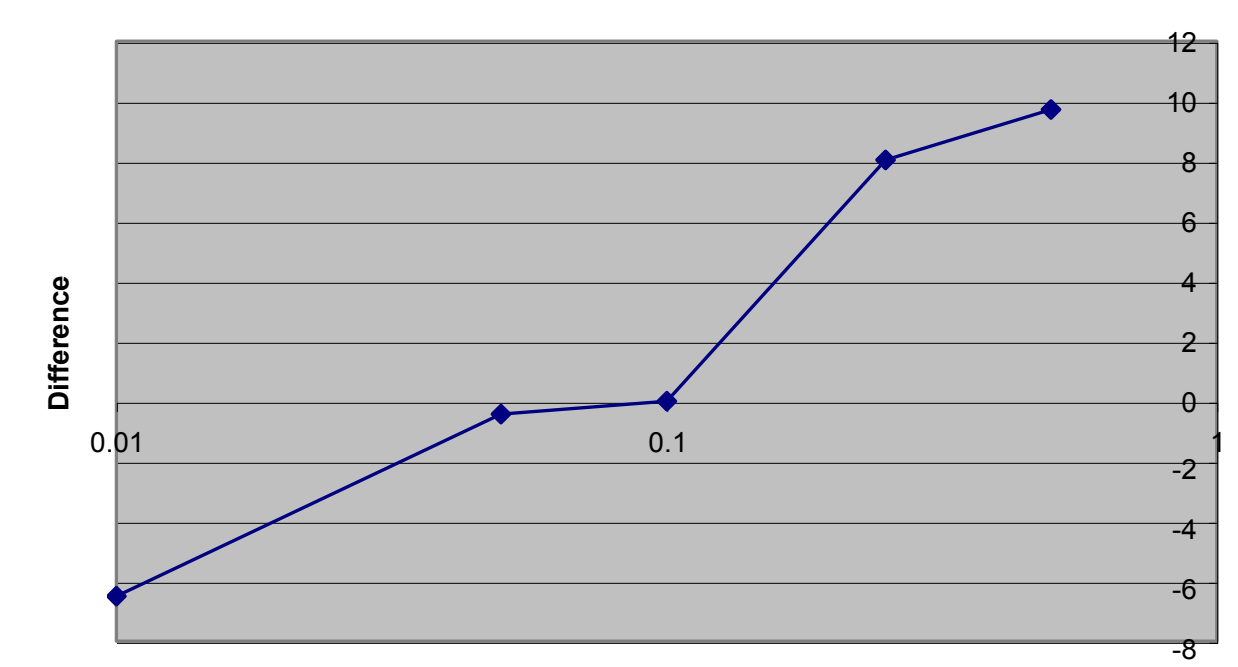

value

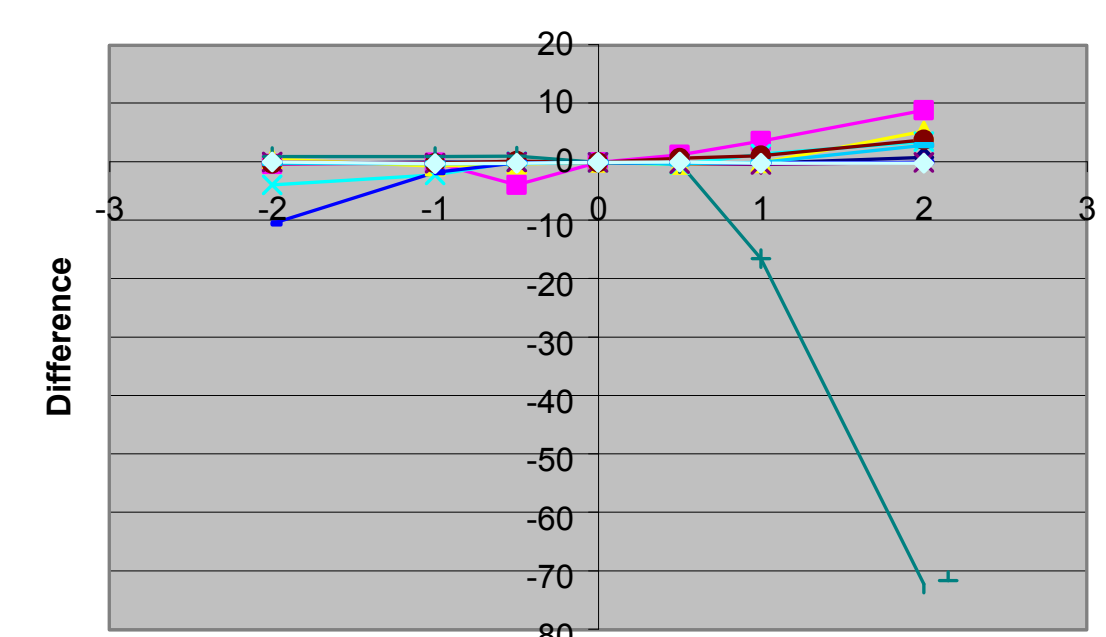

- hsu18ctcm

A- hsu20chcu

$\rightarrow$ hsu21chzcm

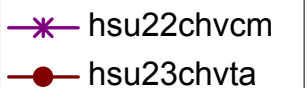

$\rightarrow$ - hsu24ymofom

- hsu25tsa

hsu27plfa

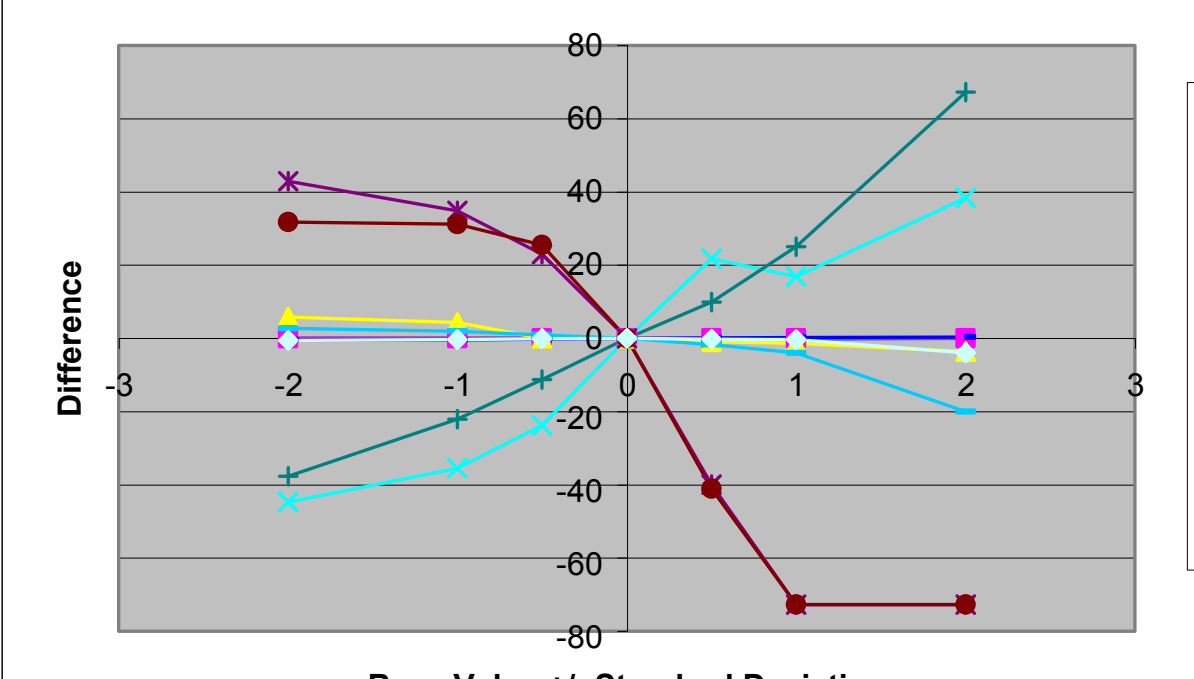

-hsu3sthfia - hsu39tmcm
hsu40fca

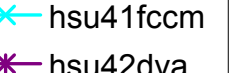
- nsu43dvem + hsu44tcva \begin{tabular}{l} 
- hsu45yvem \\
- hsu46aa \\
\hline
\end{tabular} hsu47lcar1

Base Value +/-Standard Deviation

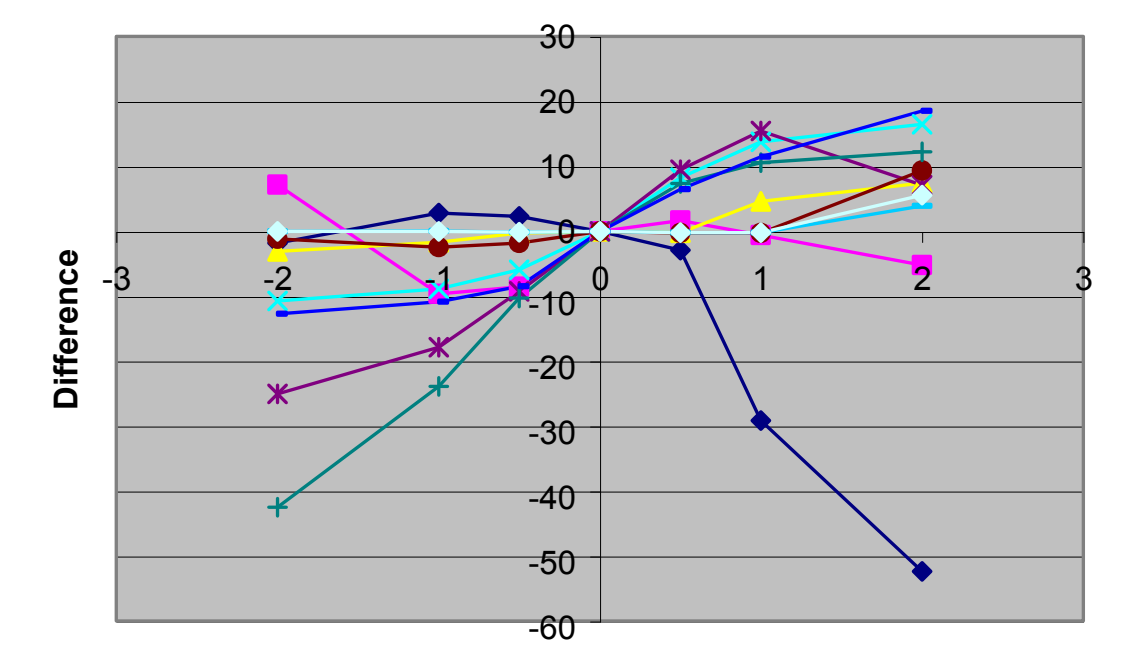

$\rightarrow-$ h70tmomerm -h71tmamatcw $-h 91$ momatce
- h72tmcmths -h73tmcmov - h74tmemtma -h75tmcmntmw

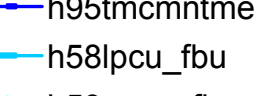
Base Value +/-Standard Deviation
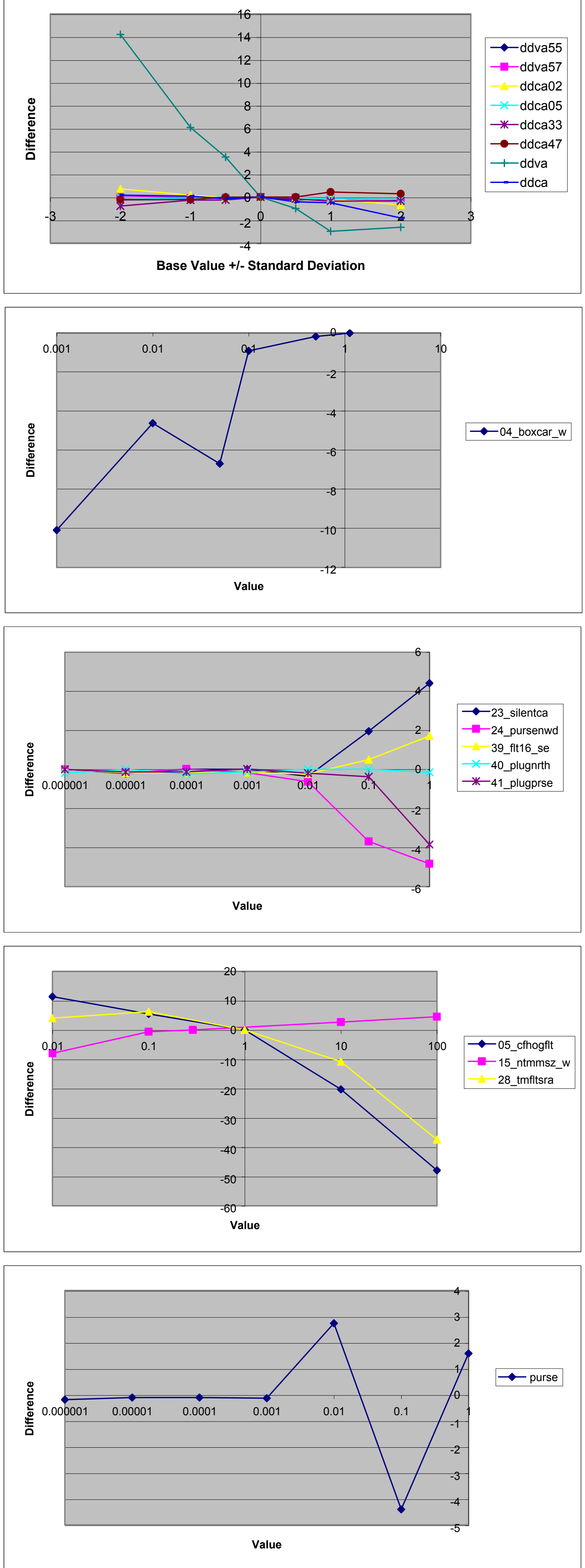

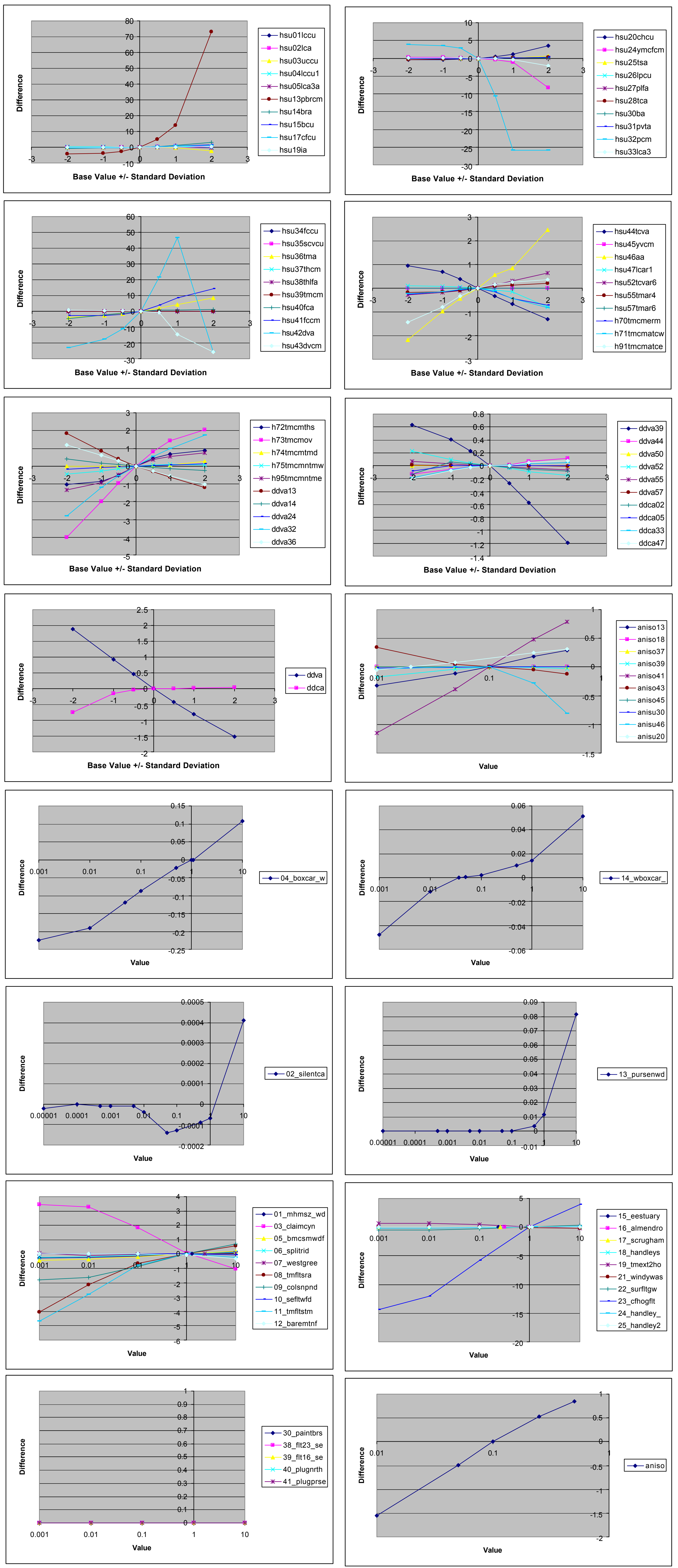


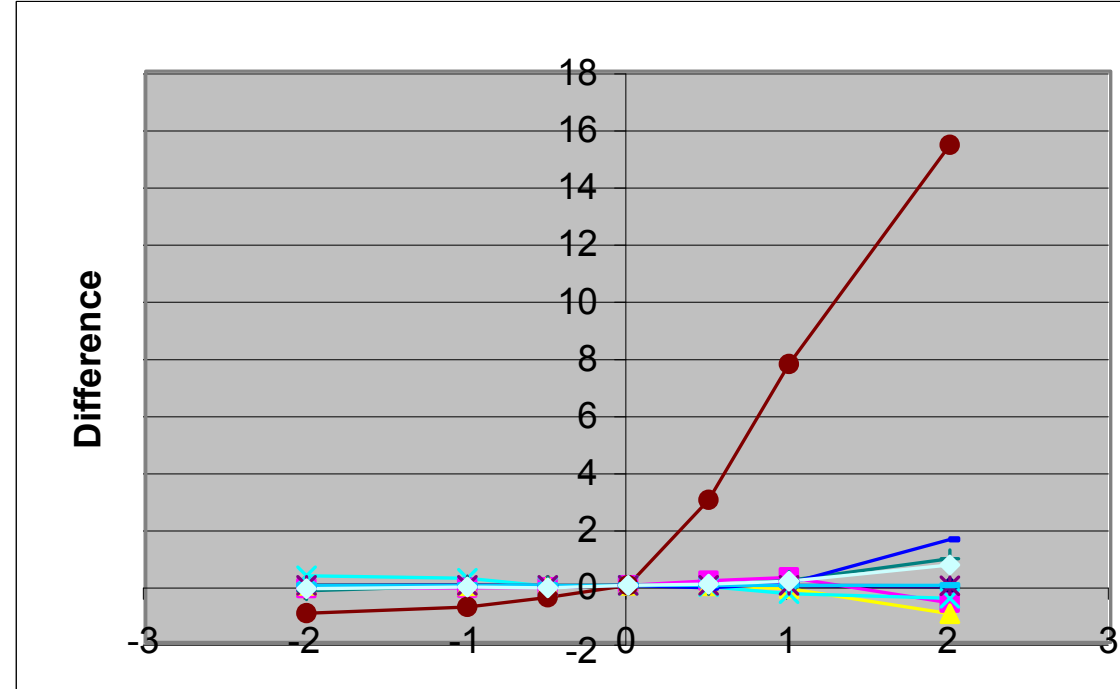

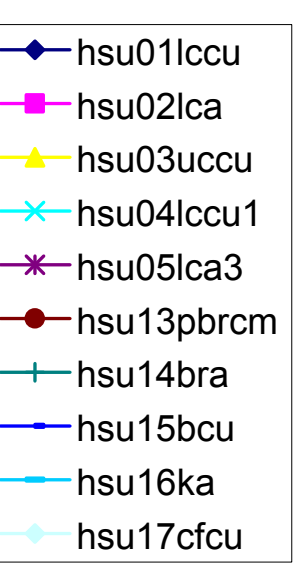

Base Value + /- Standard Deviation

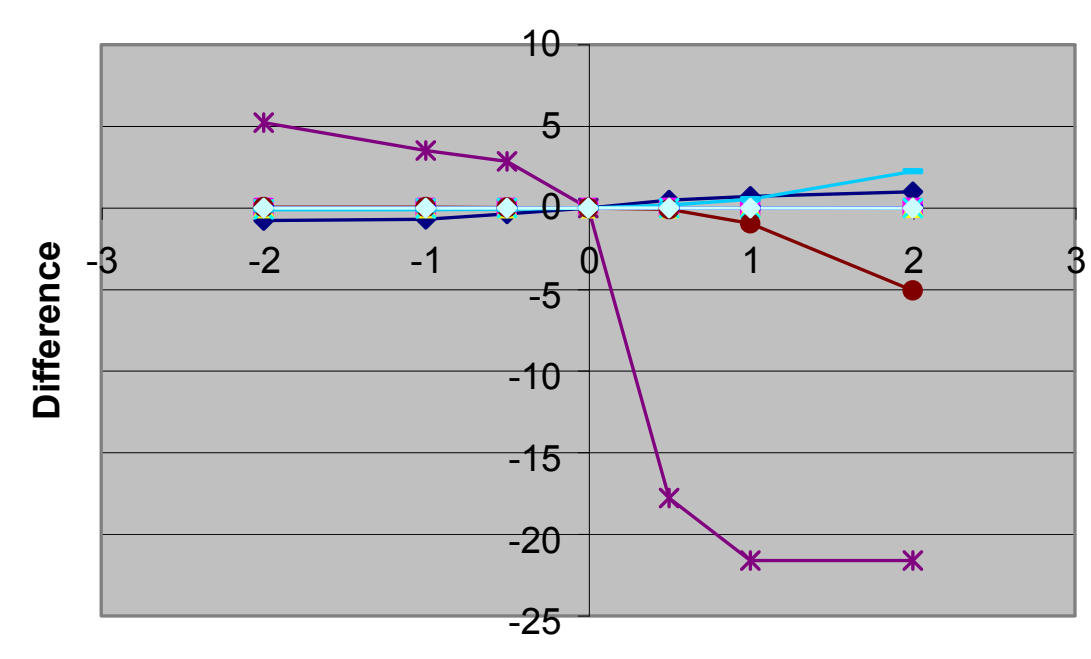

- - hsu28tca -hsu29upcu $\leftarrow$ hsu31pvta
*-hsu32pcm -hsu33lcaza - - hsu34ffccu - hsu35scvcu - hsu36tma hsu37thcm

Base Value +/- Standard Deviation

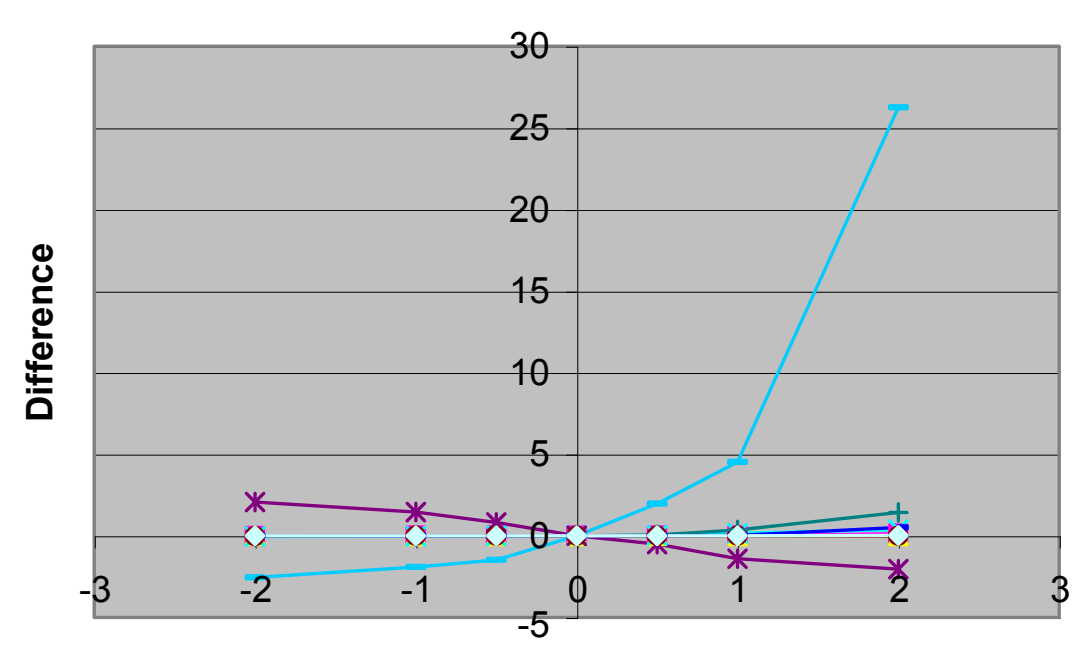

- - hsu50tcvar4 hsu55tmar4 - hsu5tmar4 *-hsu80pbrcm - hsu81pbrcm T-hsu82pbrcm - hsu83pbrcm - hsu84pbrcm
hsu87pbrcm Base Value +/- Standard Deviation

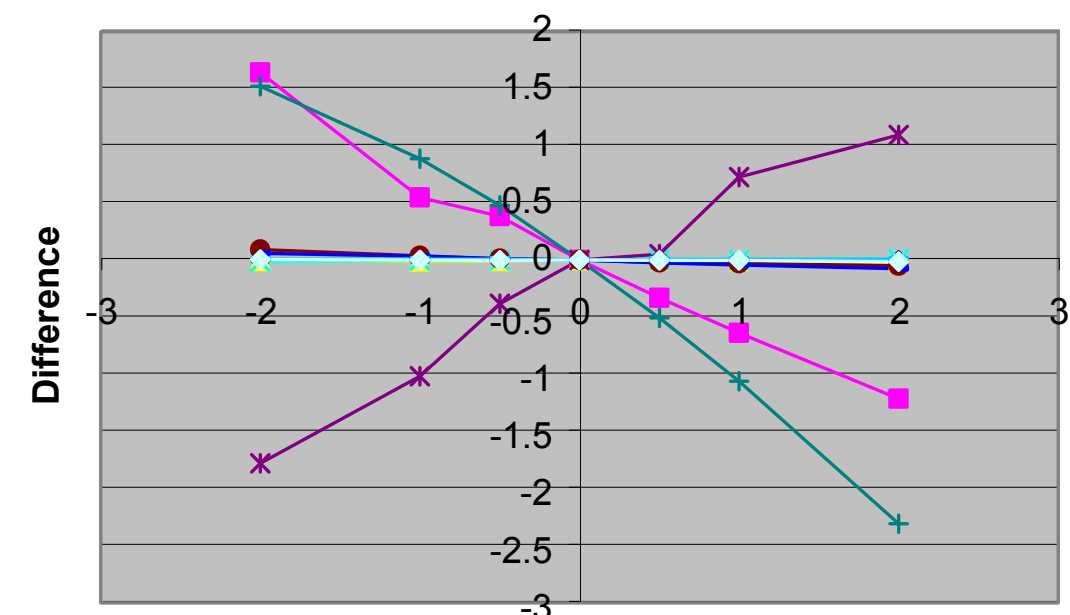
- h60bra_west $-\quad d v a 14$
$\times \quad d d v 24$
$*$ ddva24
$*$ ddva32 $\stackrel{*}{*}$-ddva32 $\rightarrow$ ddva36 千-ddva39 ddva50

\section{Base Value +/-Standard Deviation}
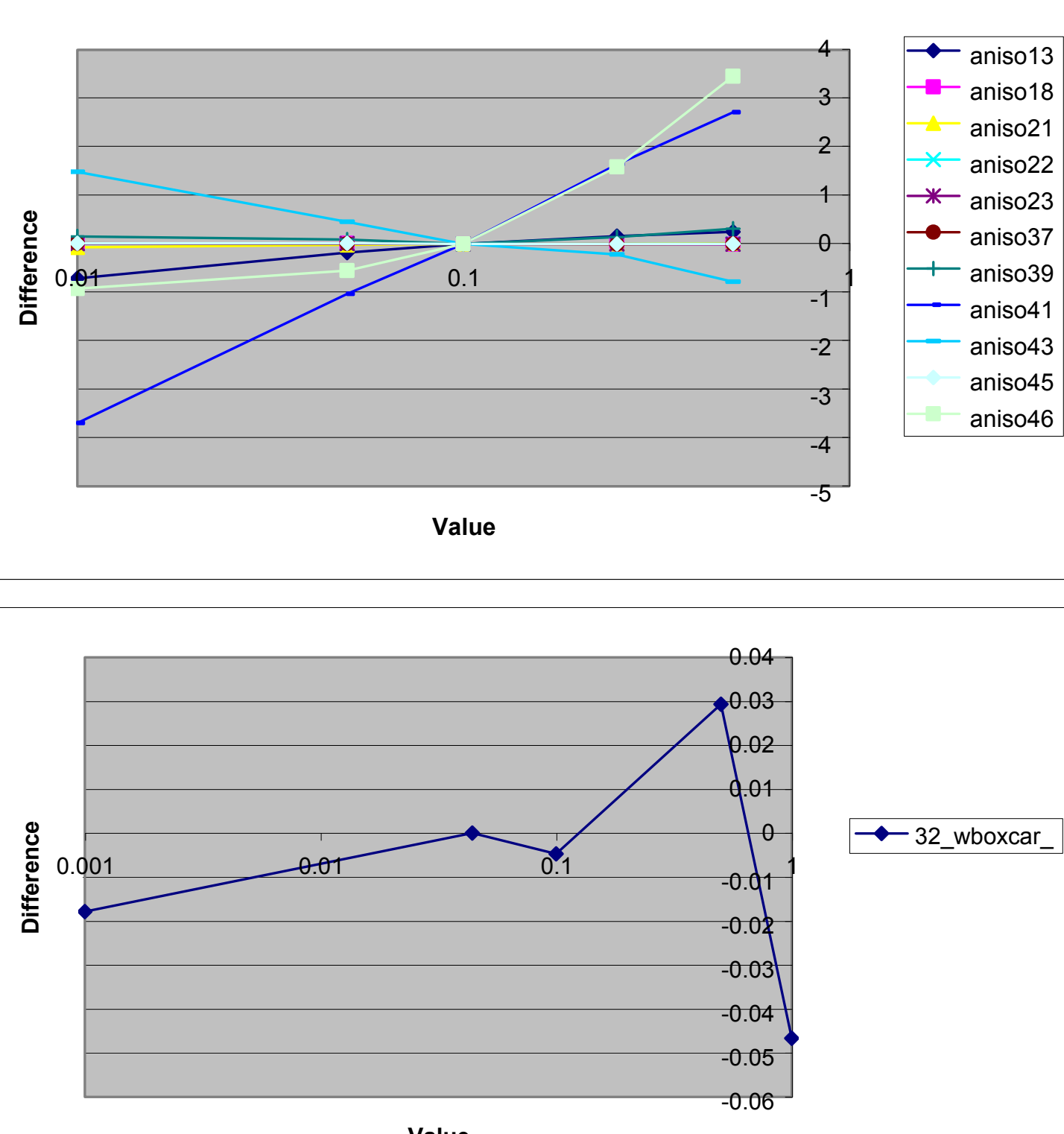

$\leftarrow$-32_wboxcar_

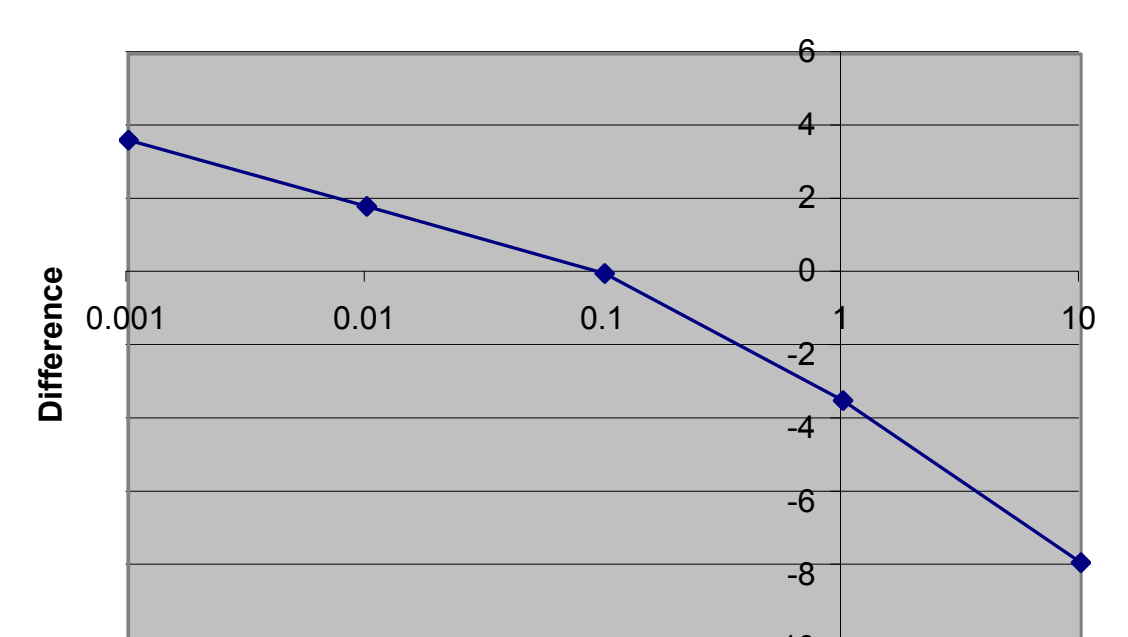

Value

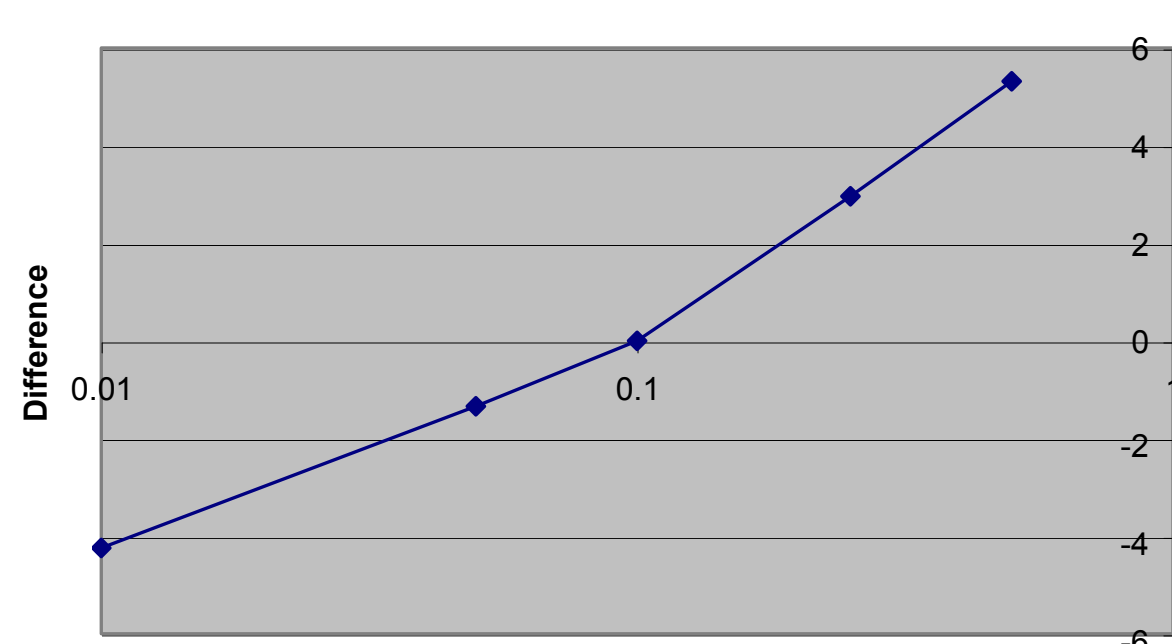

Value

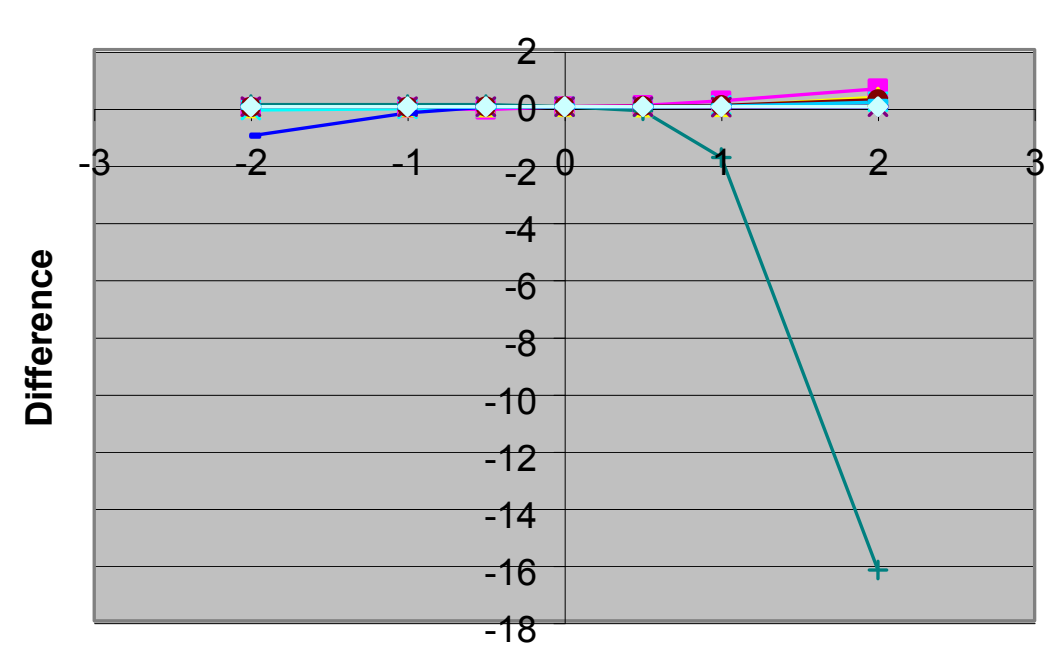

-hsu18cfom

-hsu20chcu

* hsu21chzcm

*-hsu22chvcm

- - hsu23chvta

- hsu24ymcfom

- hsu25tsa

hsu27plfa
hsu

Base Value +/-Standard Deviation

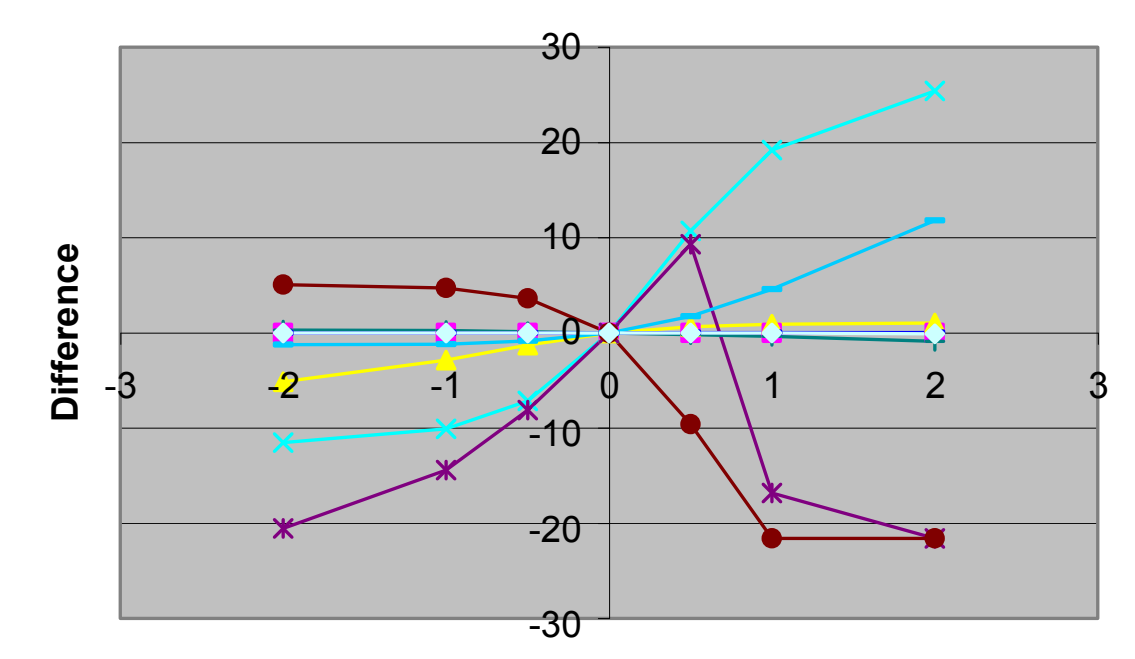

- hsu38thlfa

- hsu39tmcm

- hsu40fca
$*$ hsu41fccm

*- hsu42dva

- hsu43dvcm

- hsu45yvcm - hsu46aa

Base Value +/-Standard Deviation

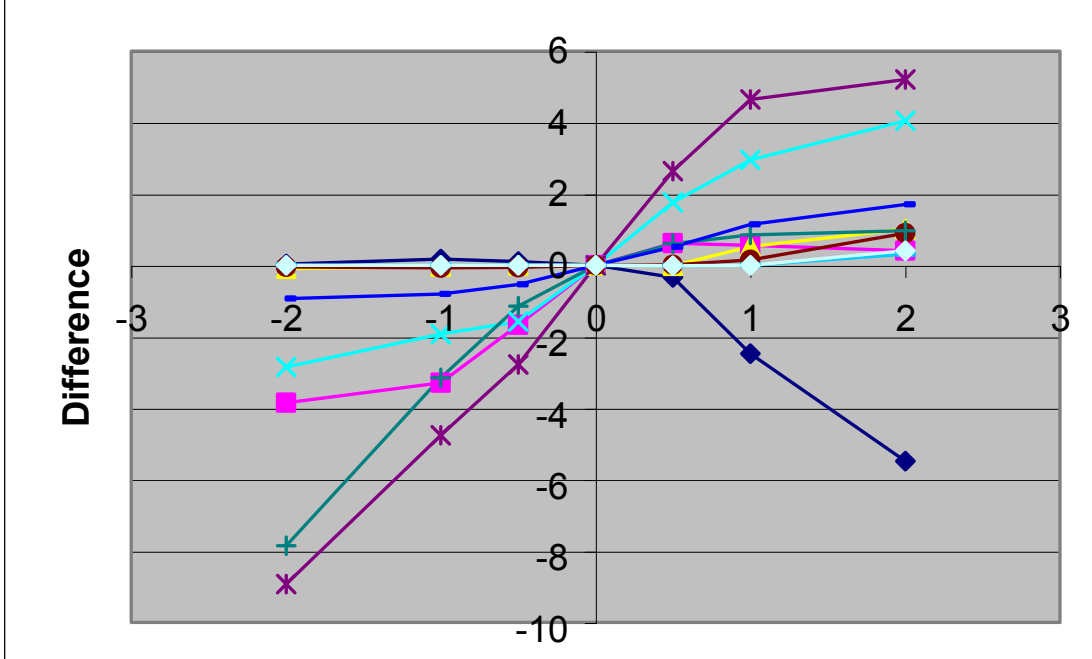

- h70tmcmerm

- h91tmcmatce

- h72tmcmths

- h73tmcmov

- h74tmcmtmd

+ h75tmcmntmw

- h95tmcmntme h59upcu_fbu

Base Value +/- Standard Deviation

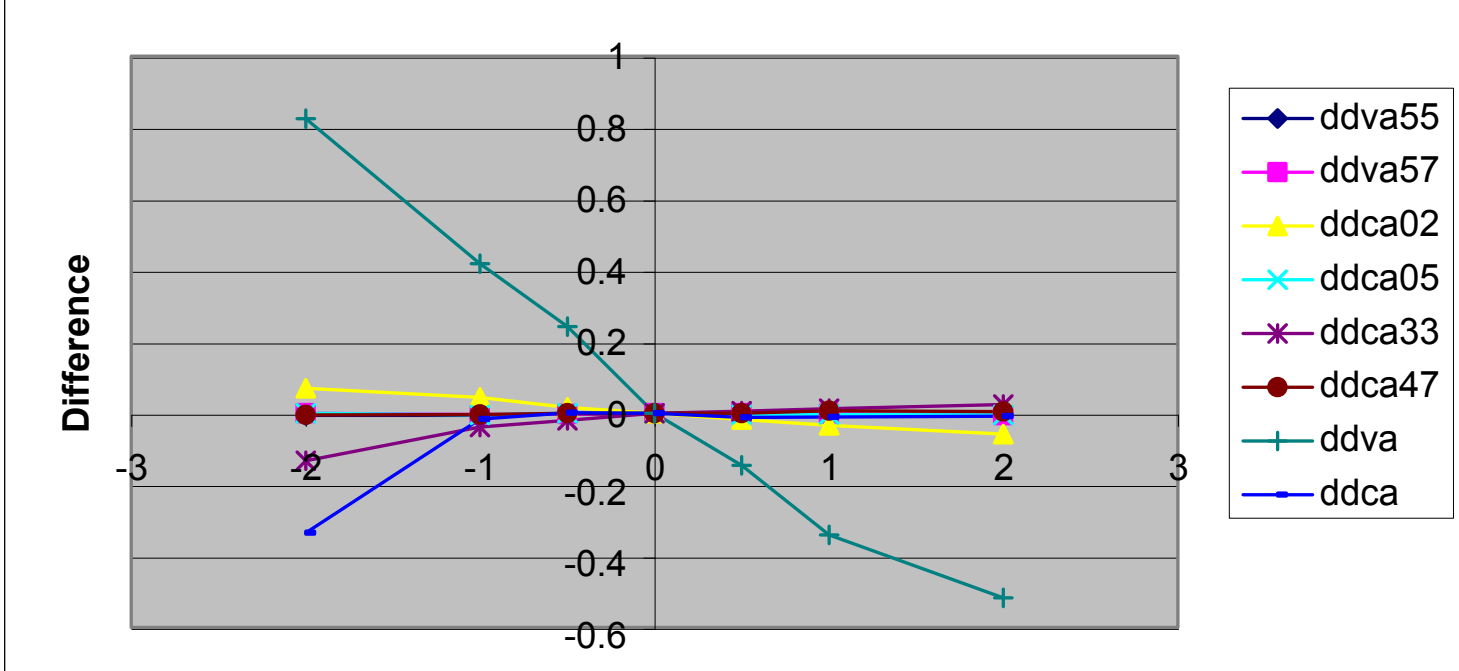

Base Value +/- Standard Deviation

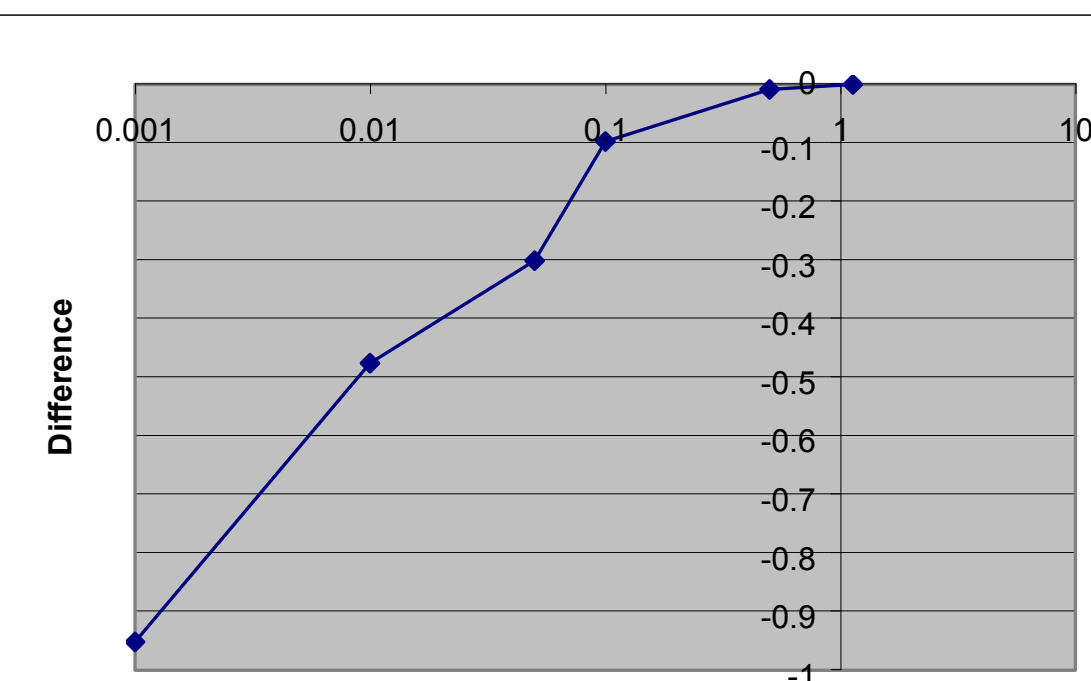

$\rightarrow$-04_boxcar_w
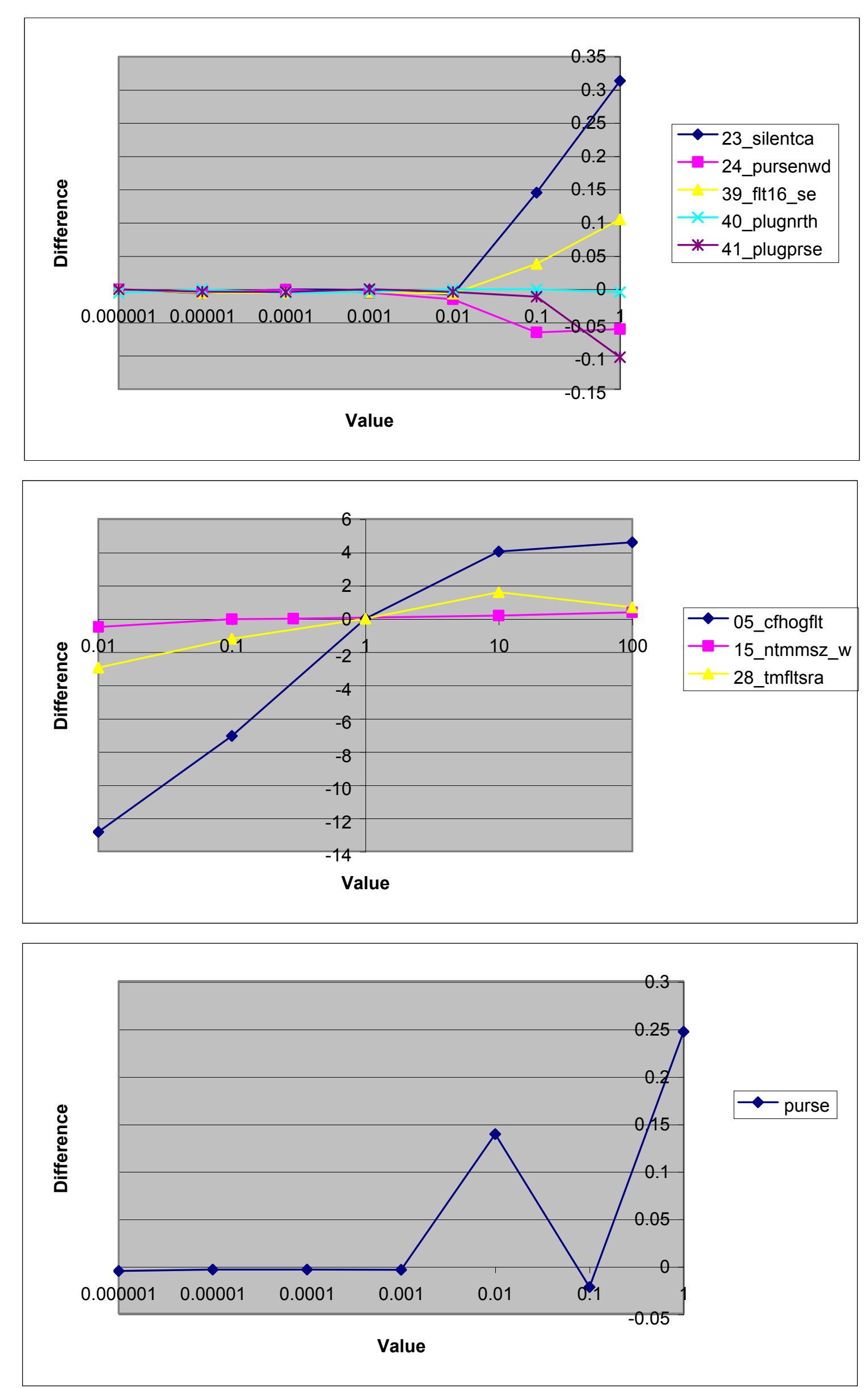


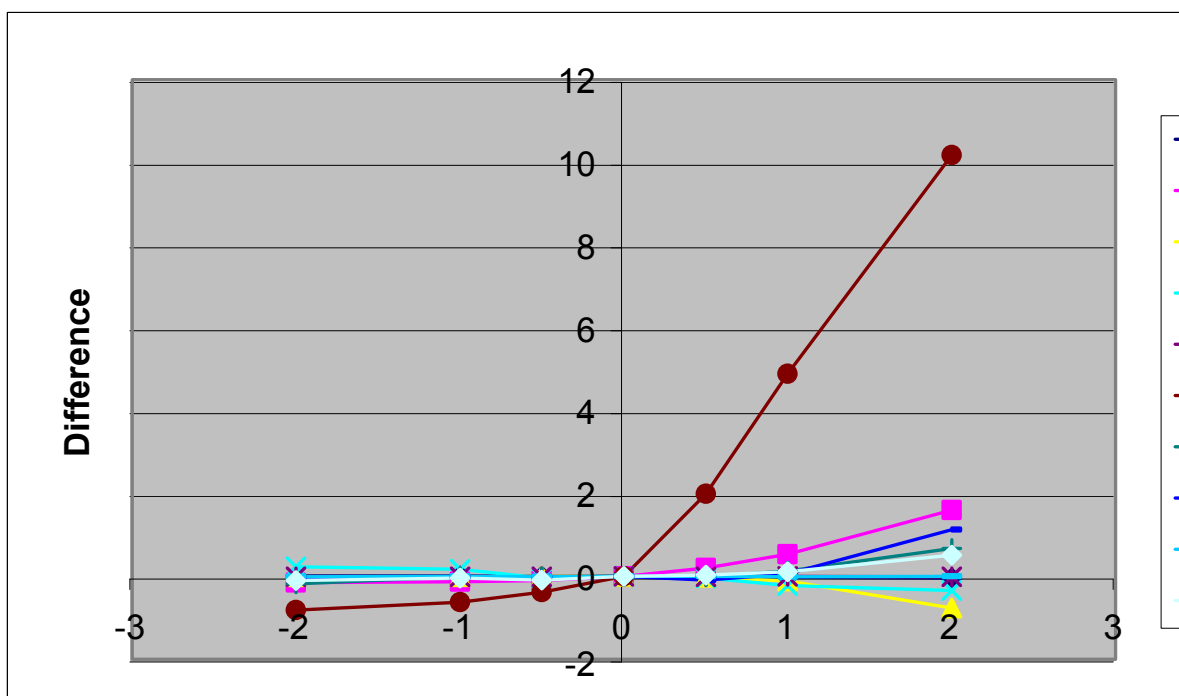

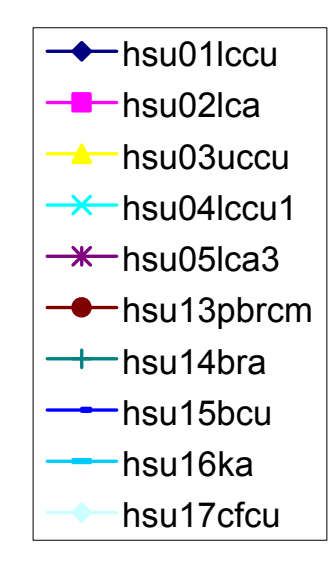

Base Value +/- Standard Deviation

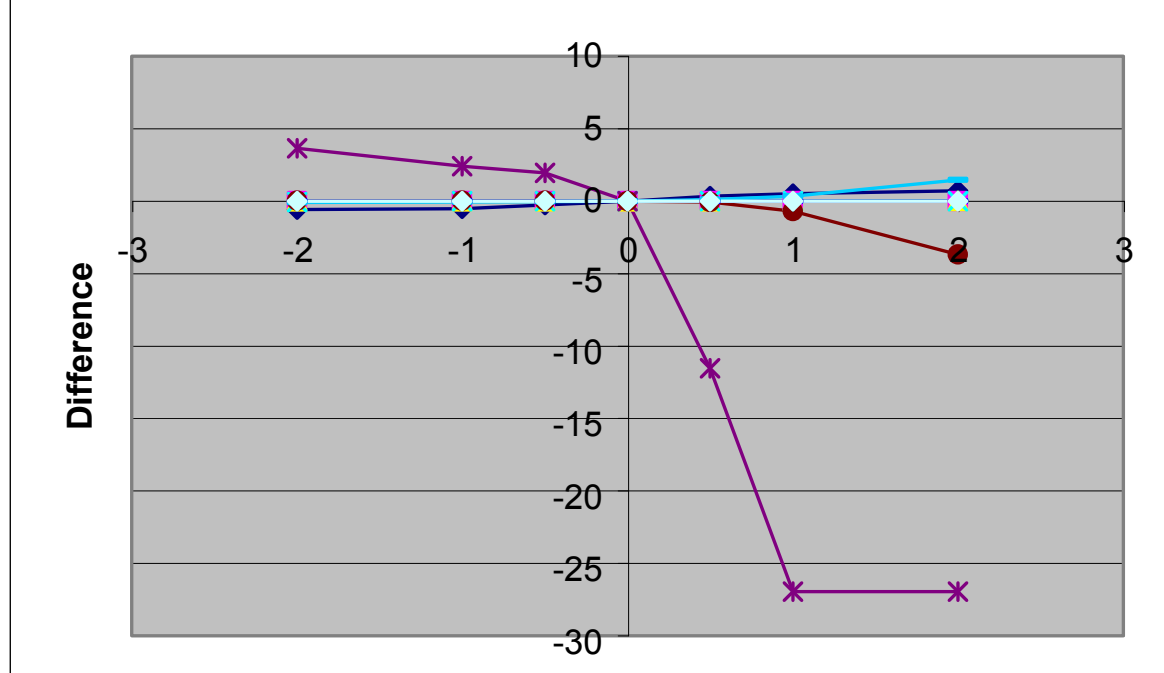

- hsu28tca - hsu29upcu - hsu31pvta - nsu33lcaza - hsu34fсcu - hsu35scrvcu - nsu36tma hsu37thcm

Base Value + / -Standard Deviation
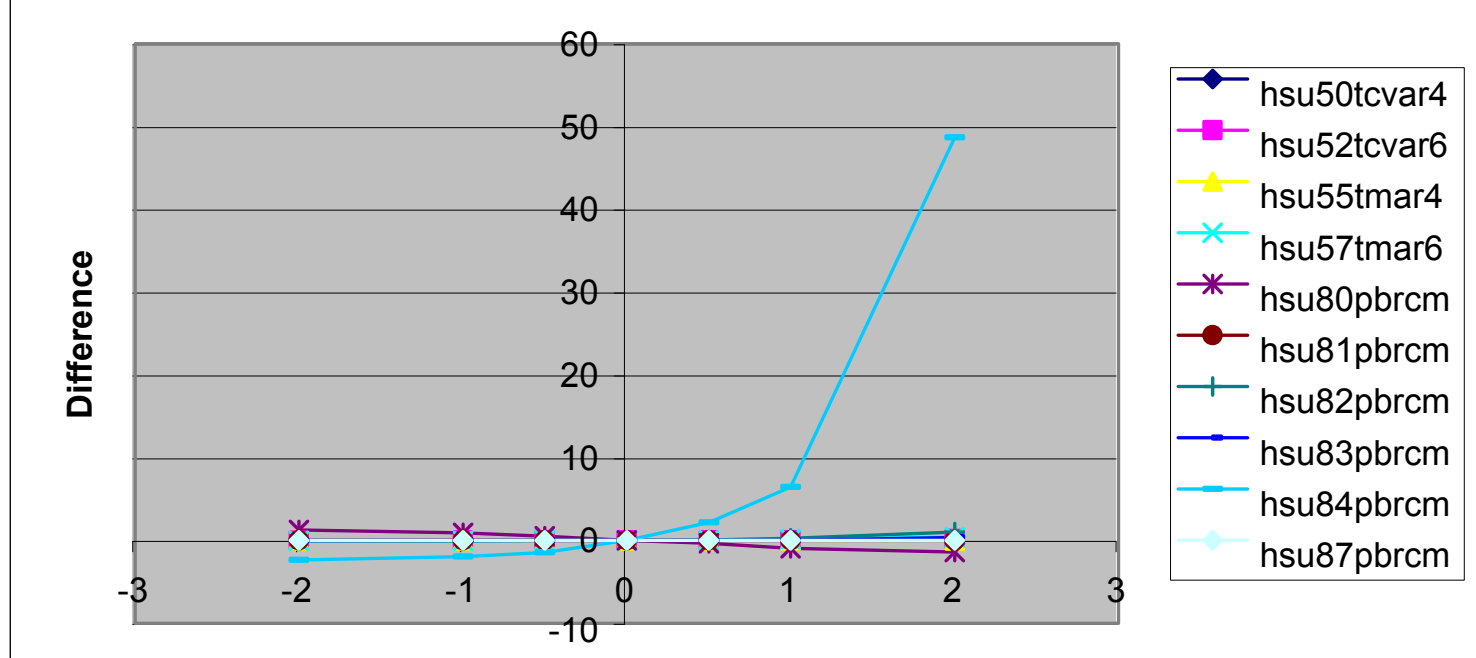

Base Value +/- Standard Deviation
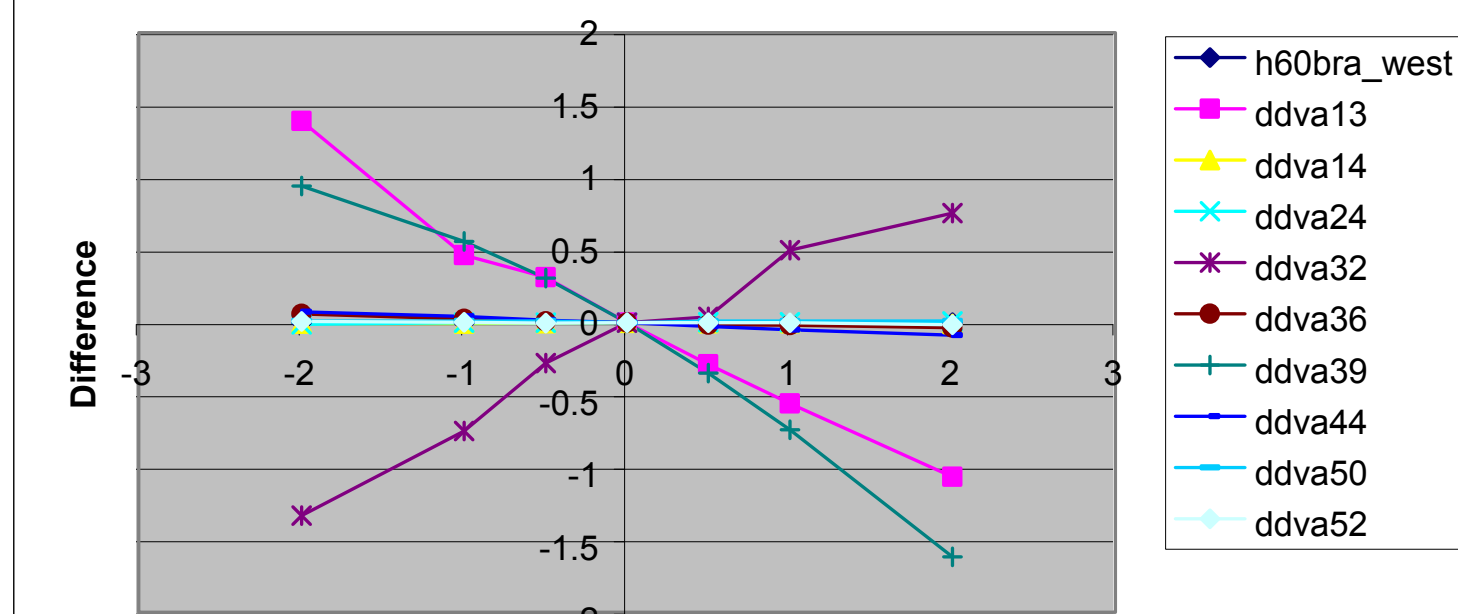

Base Value + +-Standard Deviation
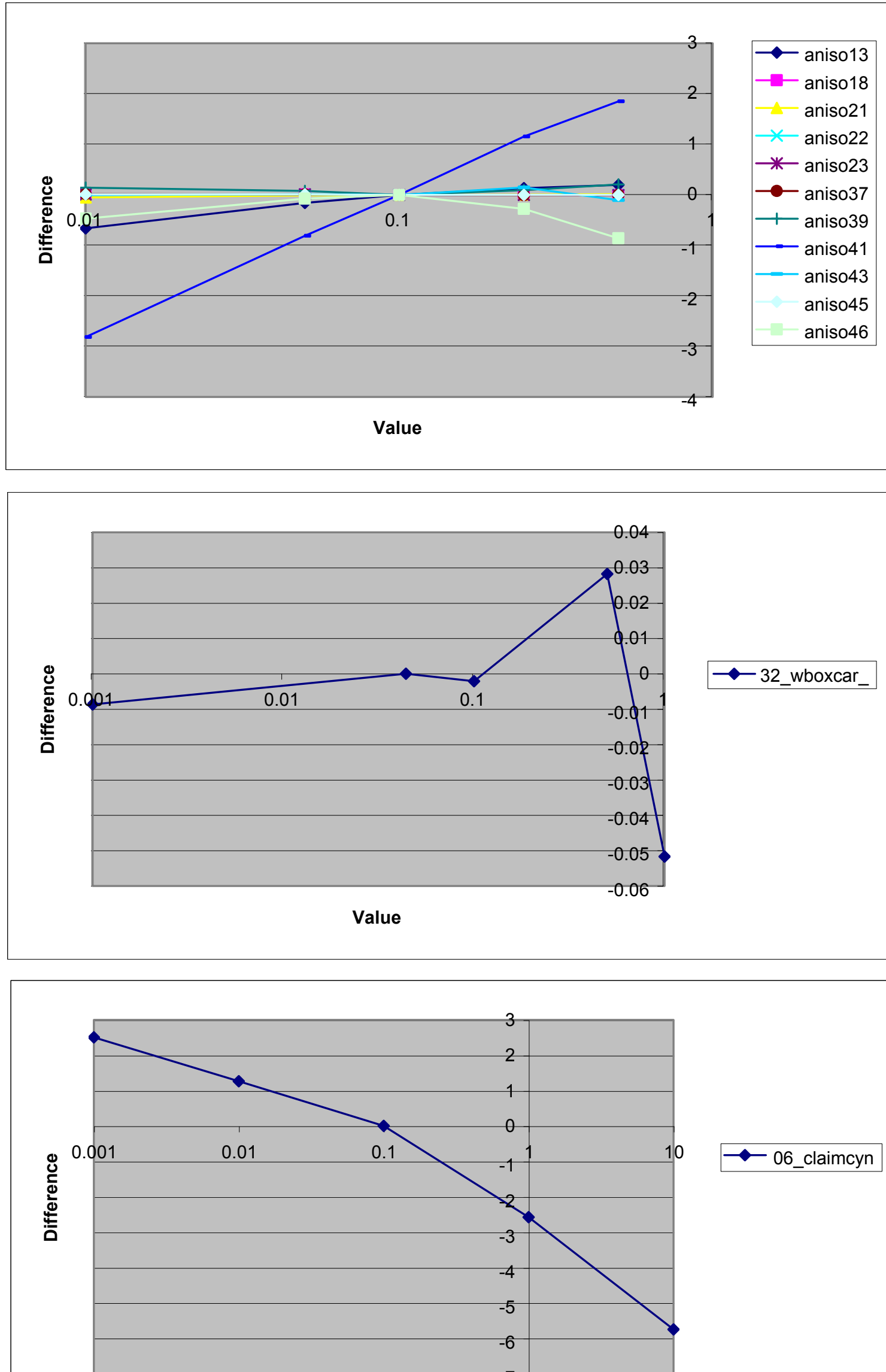

Value

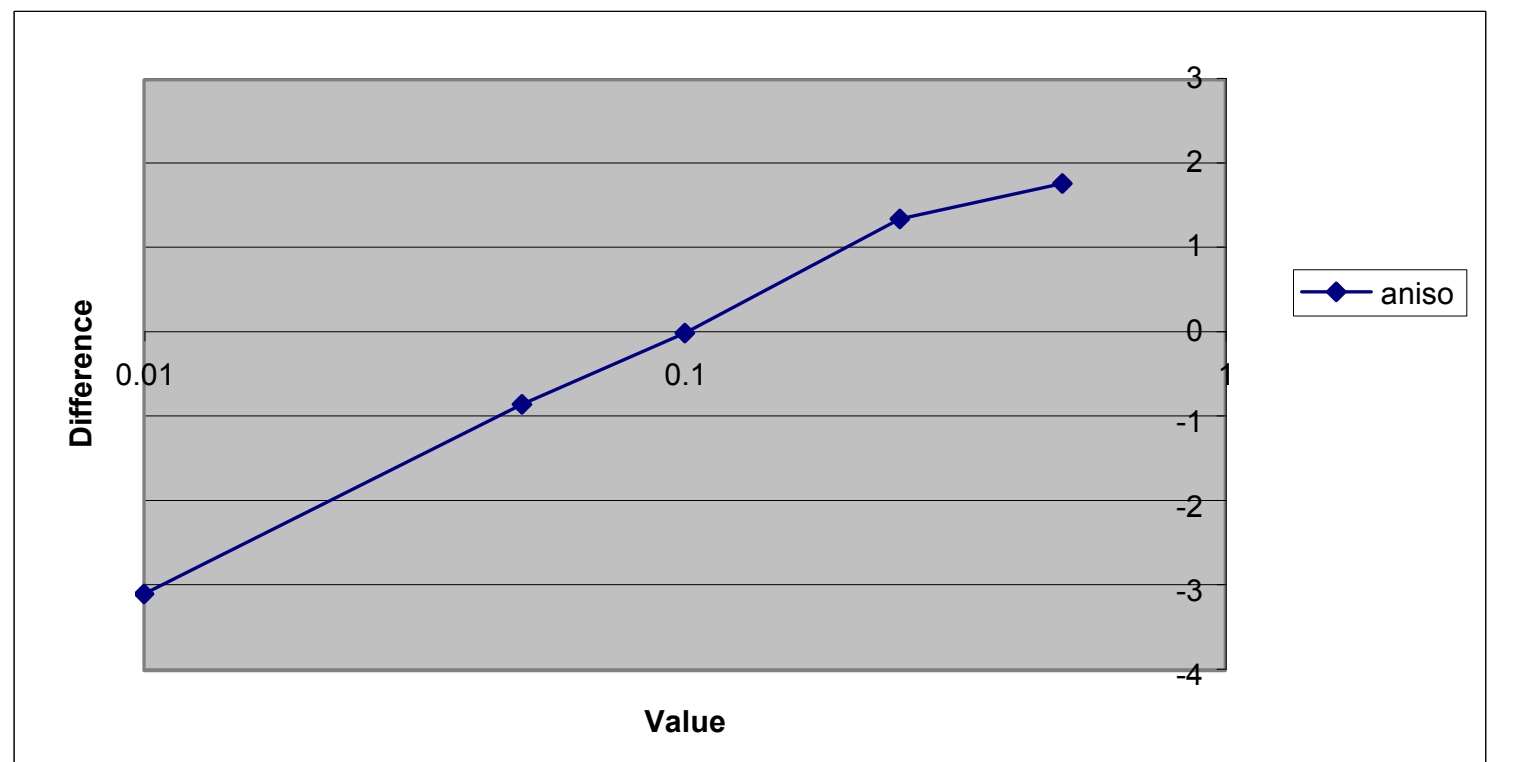

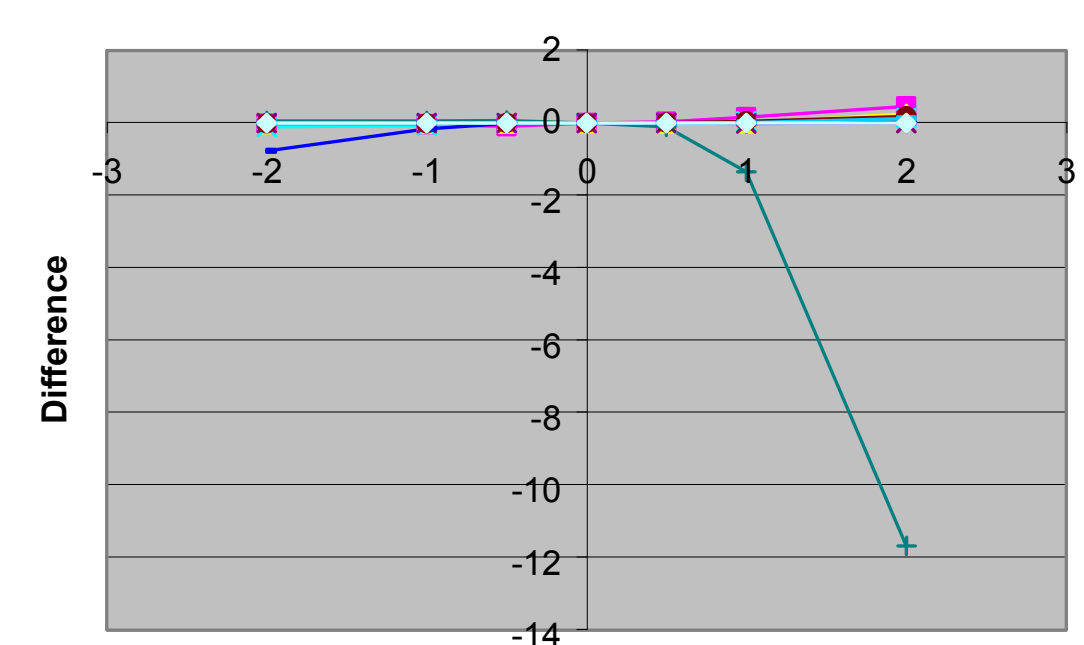

- hsu18cfom -hsu19ia $*$ hsu21chzcm * hsu22chvcm - hsu23chvta - hsu25tsa hsu27plfa
hsu2lpu

Base Value +/- Standard Deviation

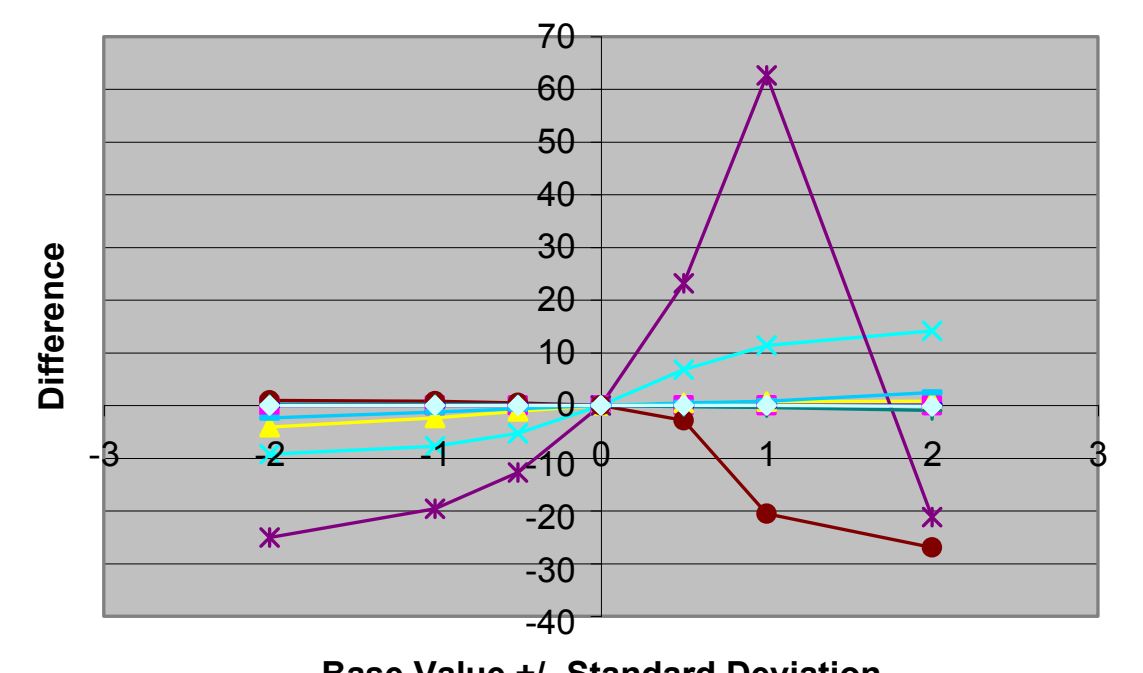

- hsu38thlfa
- hsu39tmcm - hsu39tmcm * hsu41fccm $\because$ * hsu42dva + hsu44tcva - hsu45yvcm hsu46aa
hsu47lcar1

Base Value +/-Standard Deviation

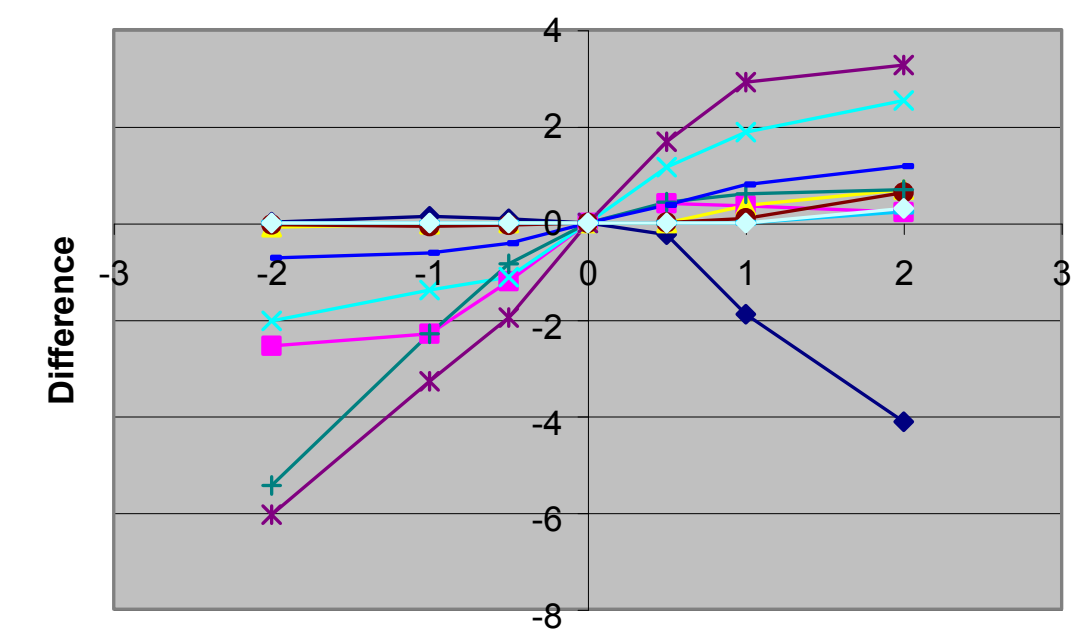

- - h70tmomerm

$-\mathrm{h} 71 \mathrm{tmcmatcw}$
$\mathrm{h} 91 \mathrm{tm}$ matce $x$ h72tmcmths *-h73tmcmor - - h74tmcmtmd + -h5581pcuntfbu h59upcu_fbu

Base Value +/- Standard Deviatio

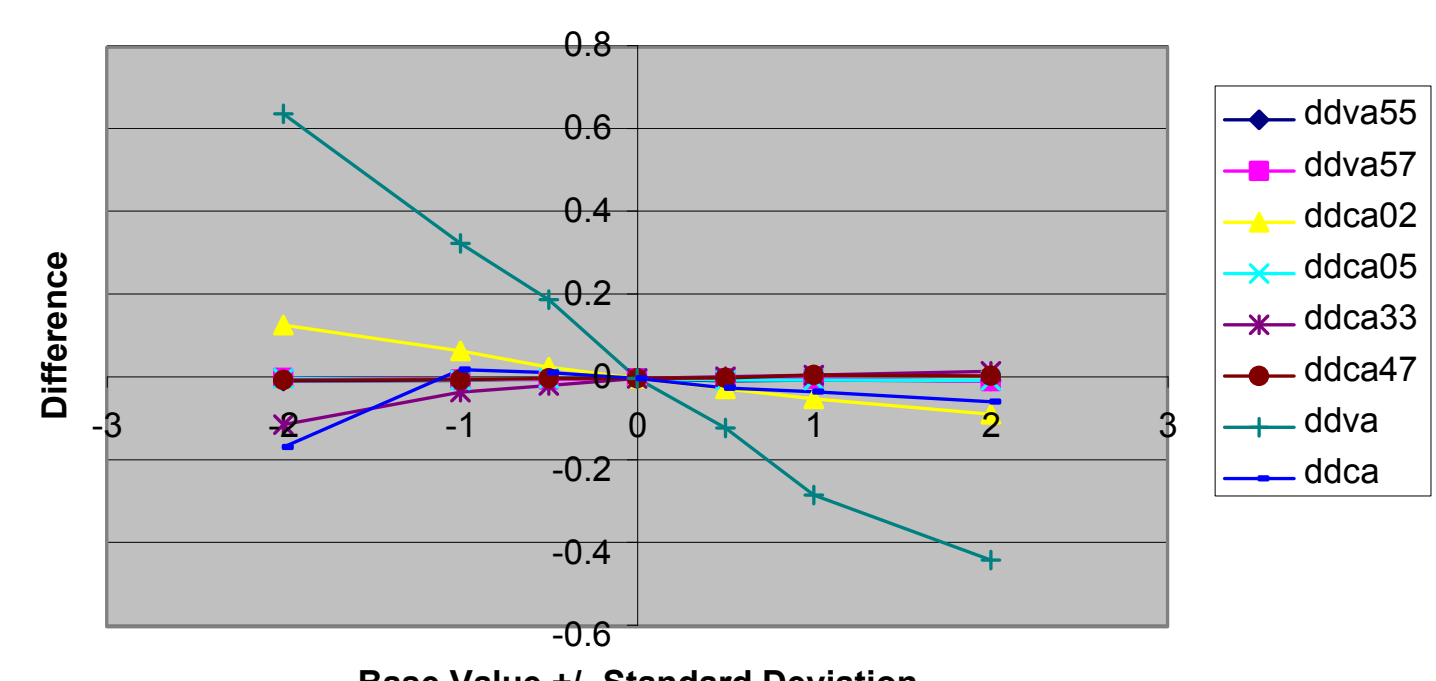

Base Value + +- Standard Deviatio
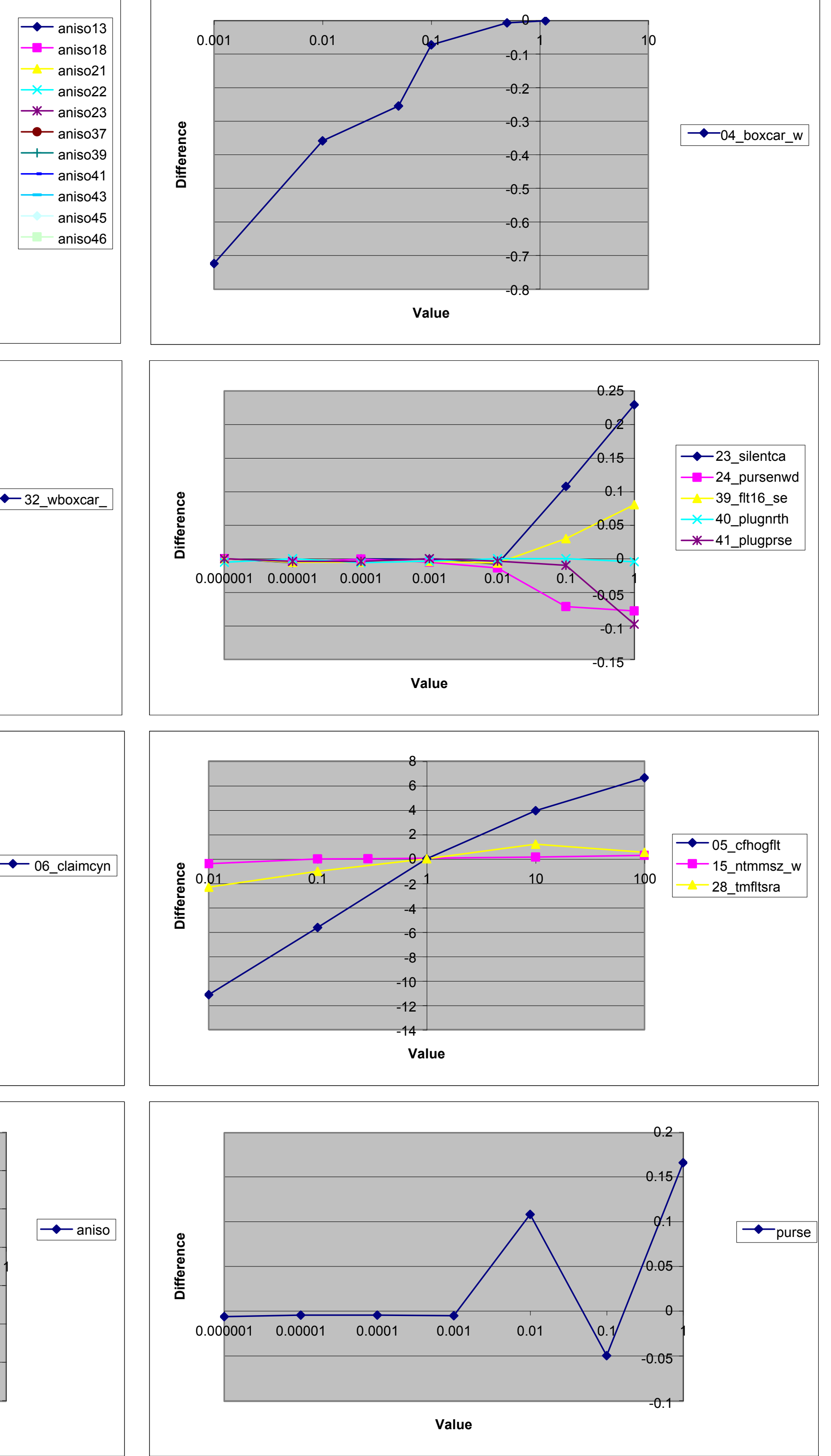


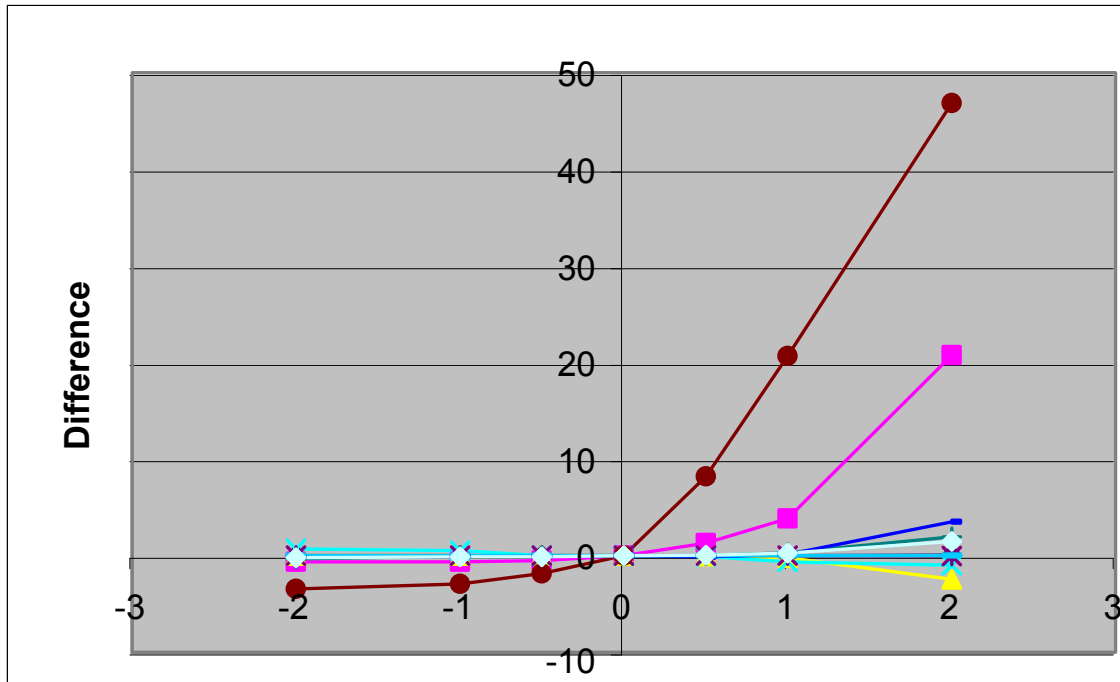

$\rightarrow-\mathrm{hsu011 \textrm {ccu }}$ - -hsu02lca $\begin{array}{r}\text { hsu03uccu } \\ \times \text { hsu04lccu1 } \\ \hline\end{array}$ *-hsu05lca3 - - hsu13pbrcm - hsu16ka Base Value +/-Standard Deviation

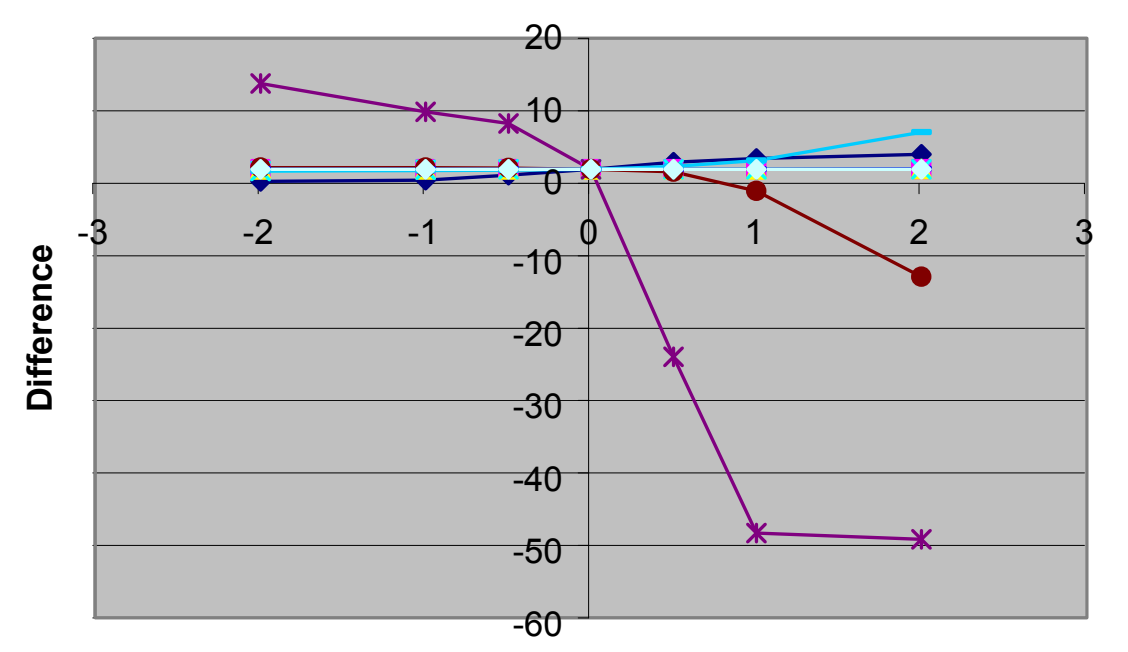

$\rightarrow$ - hsu28tca - hsu29upcu - hsu30ba * hsu32pcm - hsu34fccu - hsu35scvcu - hsu36tma Base Value +/-Standard Deviation

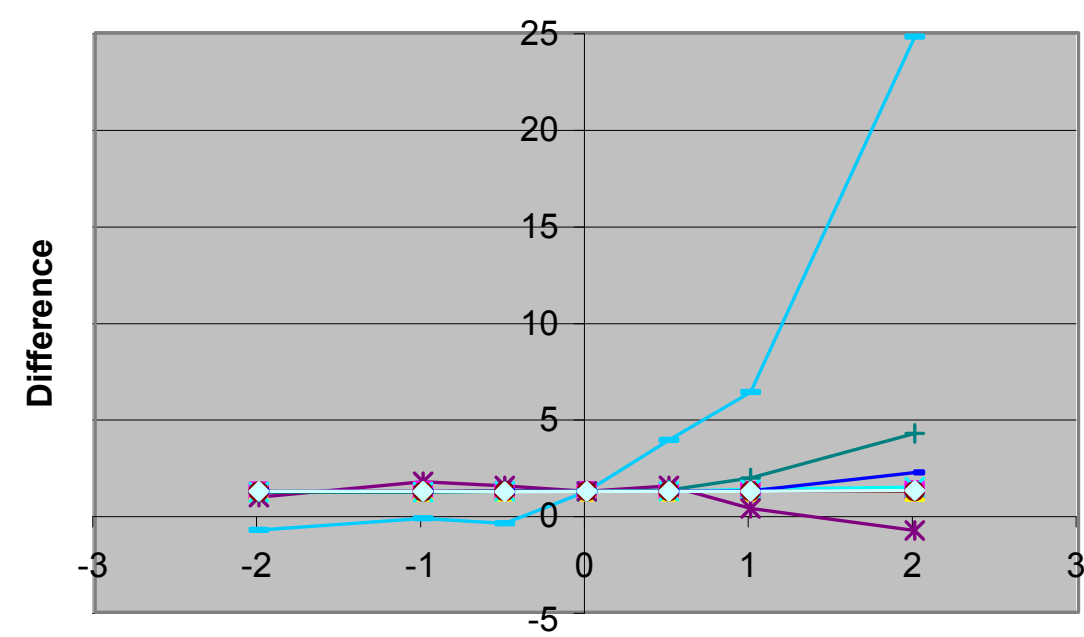

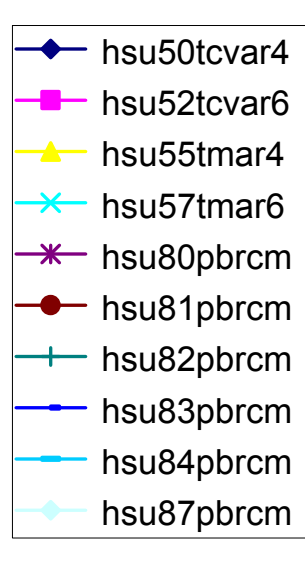
Base Value +/- Standard Deviation

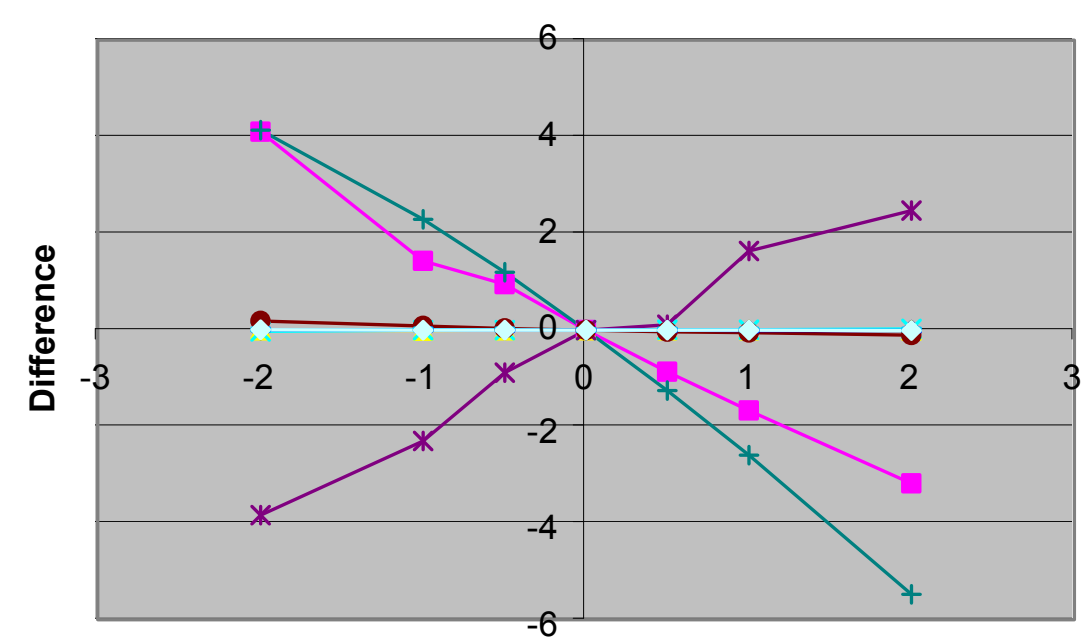
- h60bra_west -ddva14 $\star$ ddva24 *-ddva32 - - ddva36 ddva39
ddva44
ddva50 Base Value +/- Standard Deviation
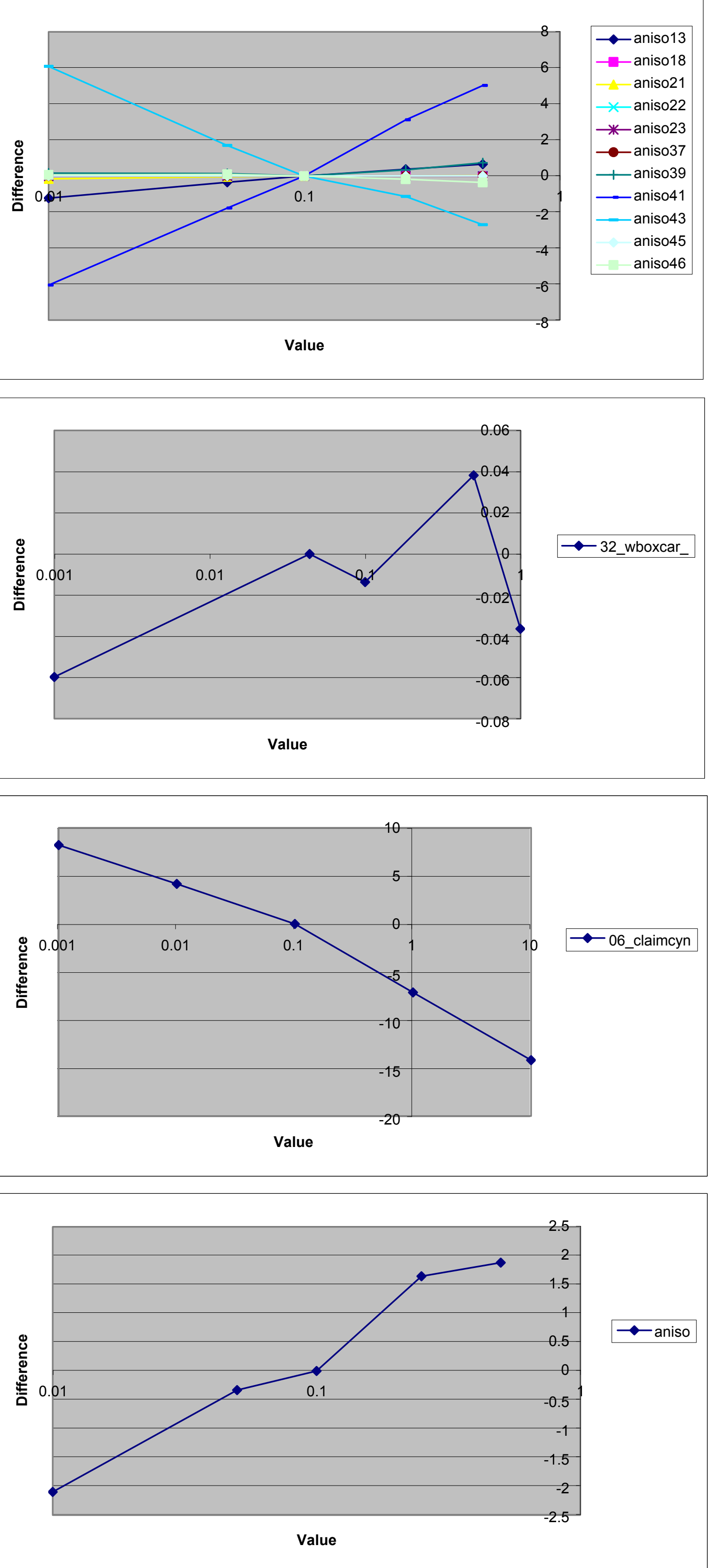

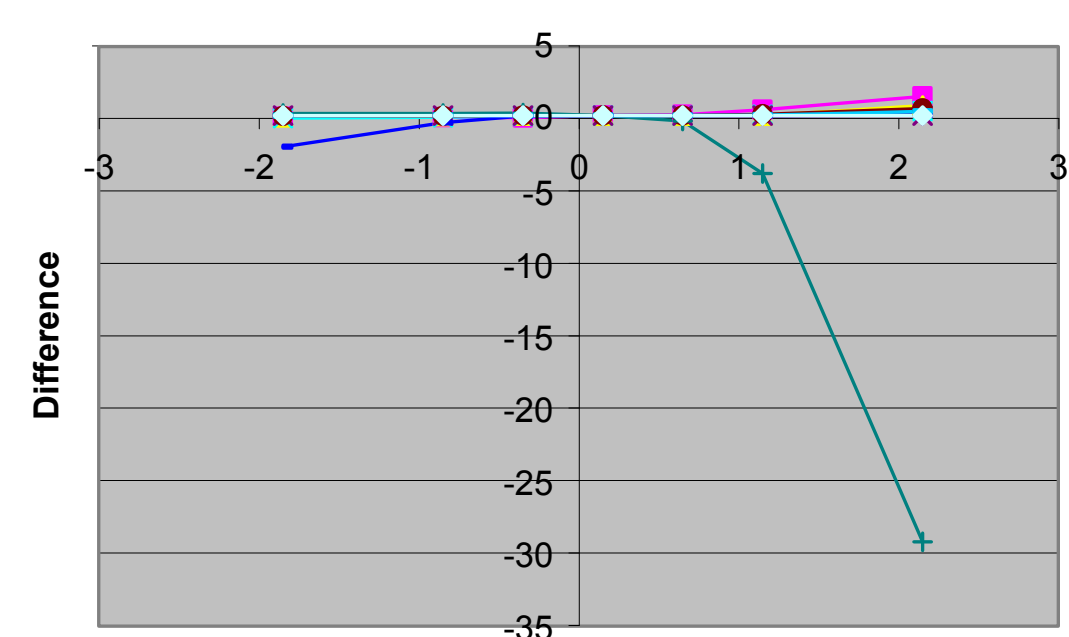

- hsu $18 \mathrm{cfcm}$
- -
- sul $9 \mathrm{ia}$ - nsu20chcu * hsu21chzcm *- hsu22chvcm
-
- hsu23chvta + hsu24ymafom - hsu25tsa - hsu26lpcu
hsu27plfa

Base Value +/- Standard Deviation

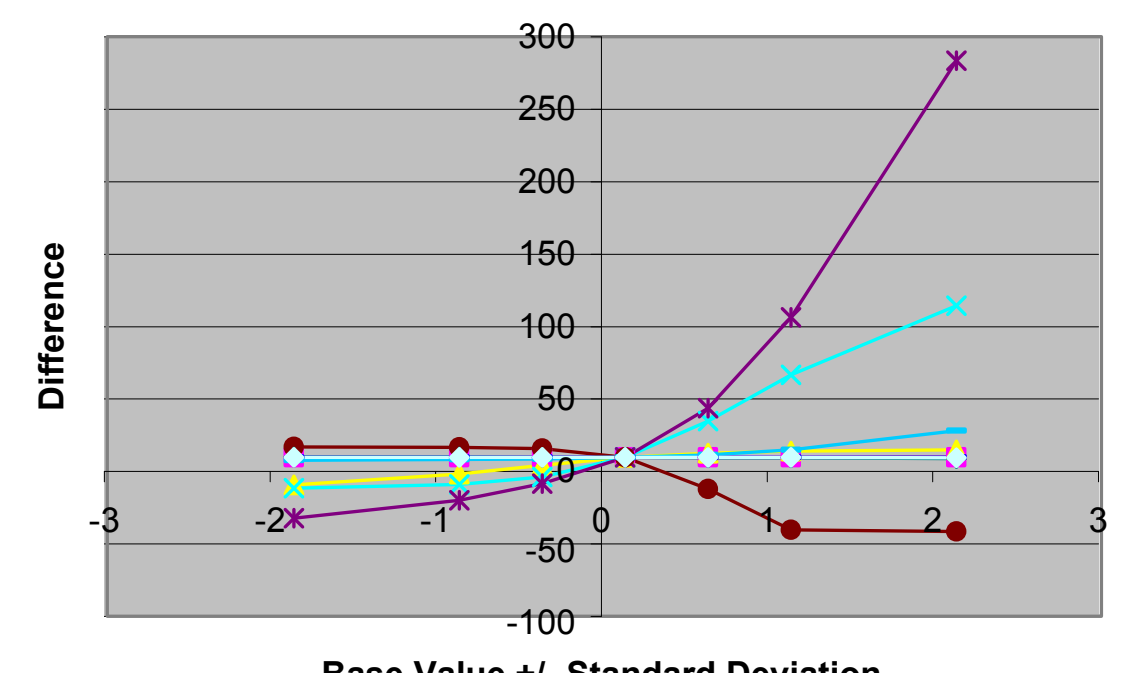

$\rightarrow$ hsu38thlfa - hsu39tmcm - hsu41fccm - hsu43dram - hsu44tcva - hsu45yvcm - hsu46aa

Base Value +/-Standard Deviation

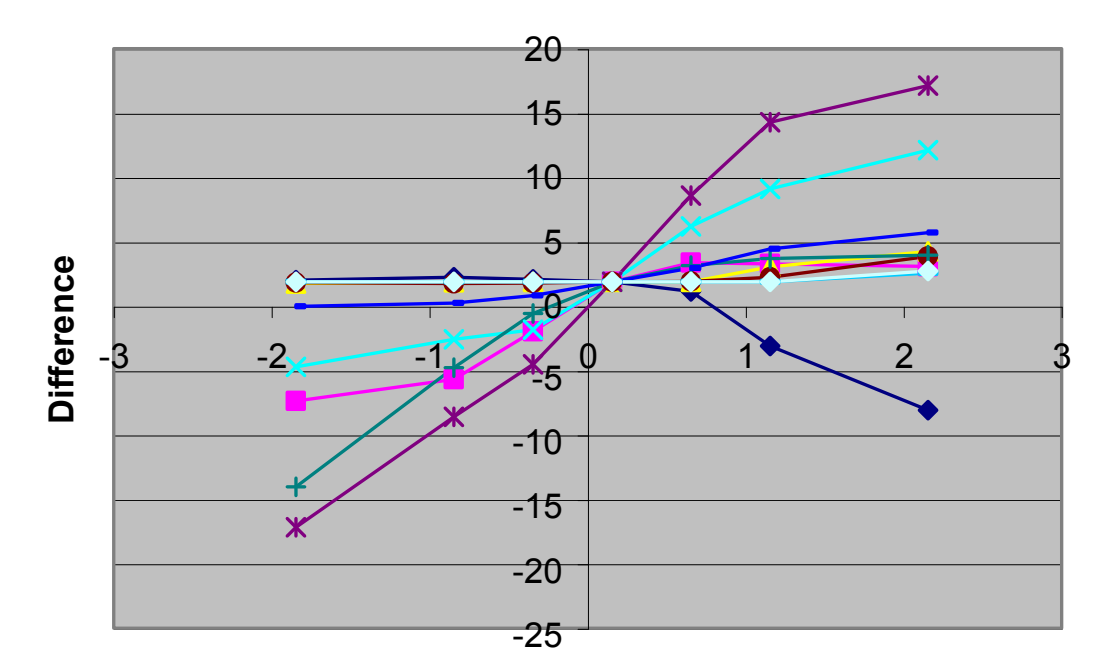
- h70tmcmerm $\leftarrow$ h72tmcmths * h73tmamov - h74tmomtmd - h75tmcmntmw - h95tmcmntme - h581pcu_fbu h59upcu_fbu

Base Value + +/ Standard Deviatio

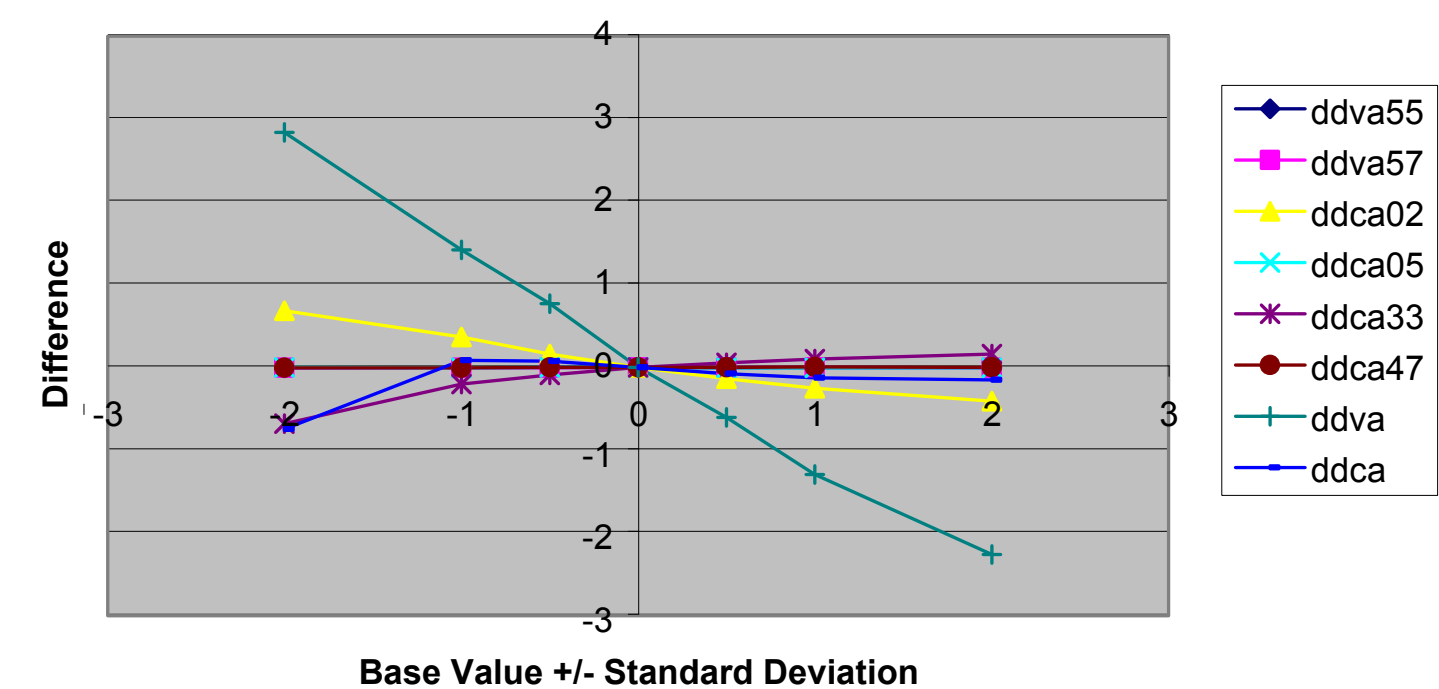

Base Value +/-Standard Deviatio
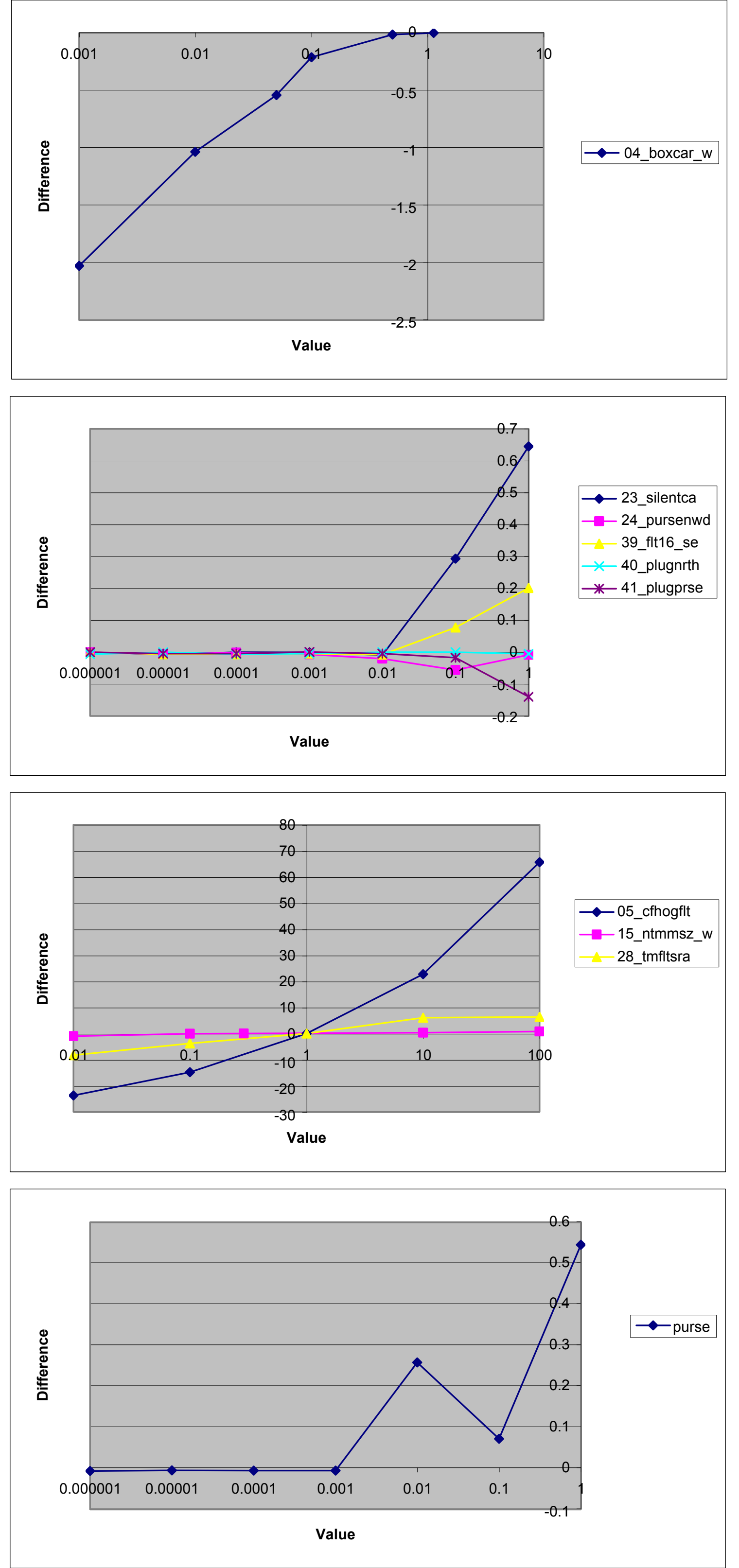

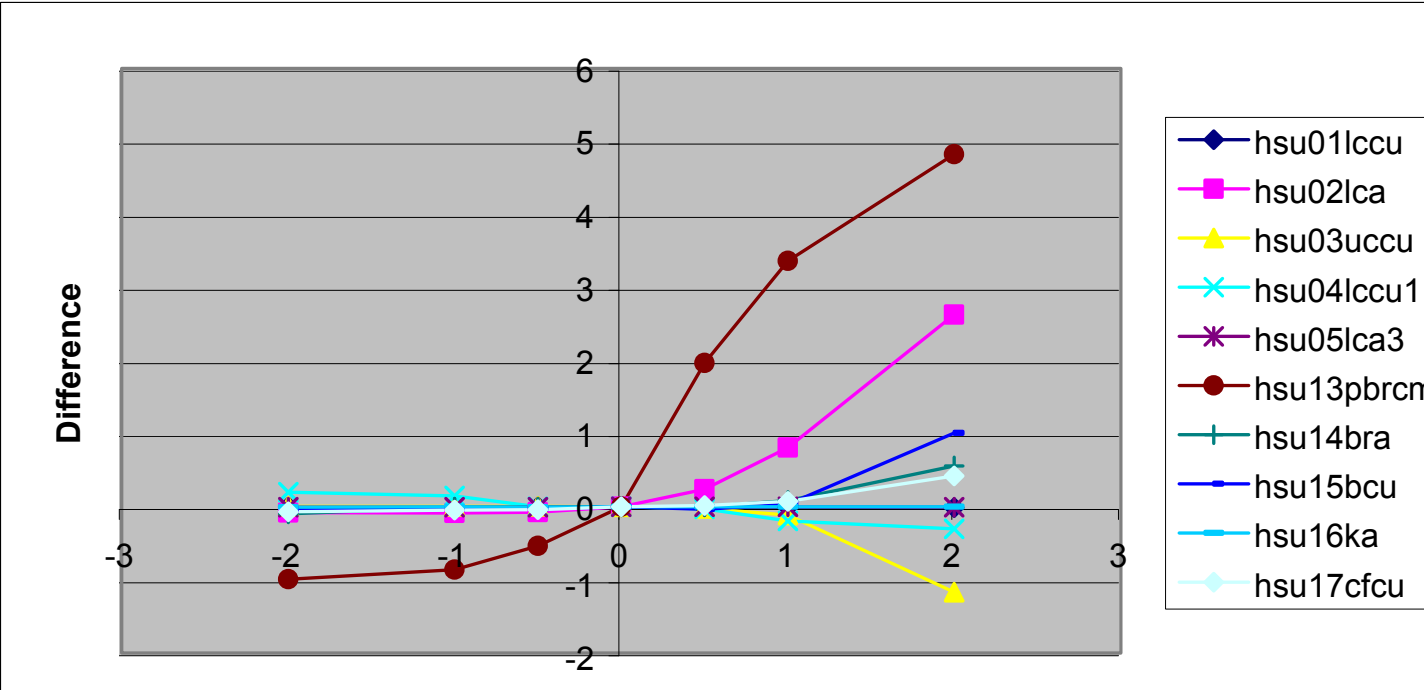

Base Value +/- Standard Deviation

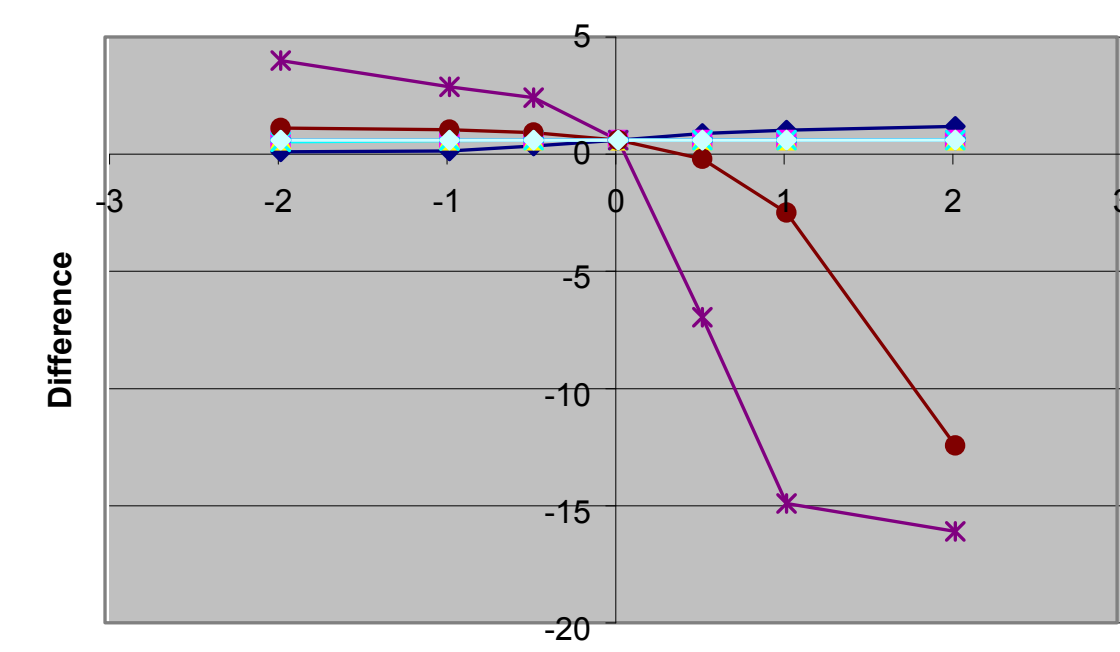

- - hsu28tca
$\rightarrow$ hsu29upcu

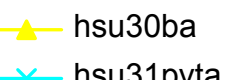
*- hsu32pcm - - hsu33lca3a
+ hsu34ffccu
- hsu35scrcu
- hsu36tma
- hsu36tma
hsu37thom

Base Value + + -Standard Deviation

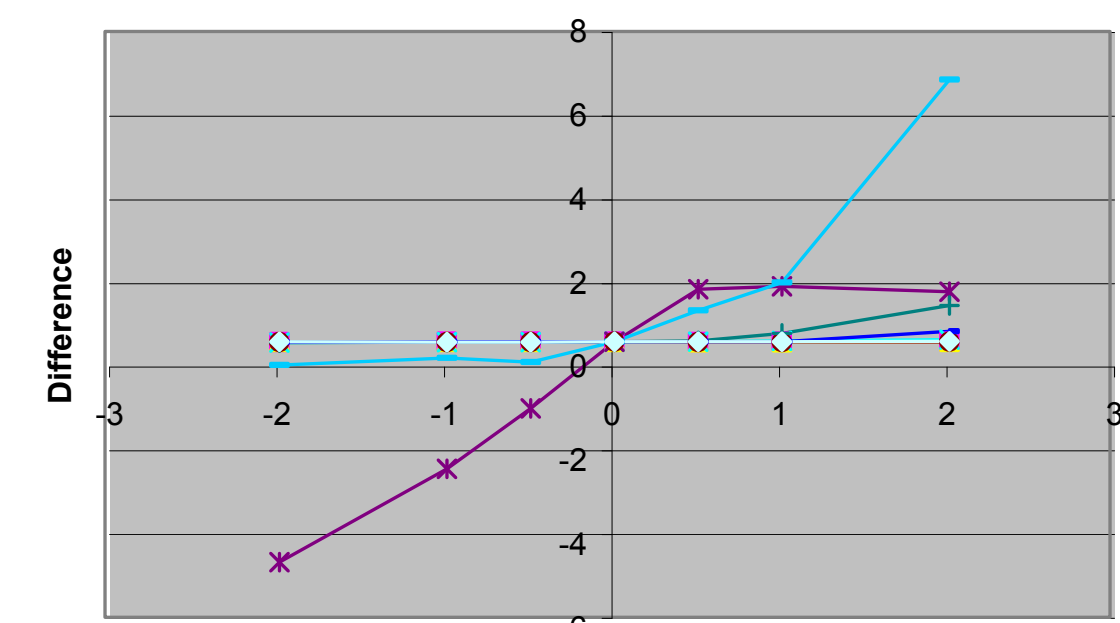

$\rightarrow$ - hsu50tcvar4 - hsu52tcvar6 - hsustmar6 * hsu80pbrcm
- hsu81 pbrcm - hsu81pbrcm
+ hsu82pbrcm - hsu82pbrcm - hsu84pbrcm
hsu87pbrcm

Base Value +/- Standard Deviation

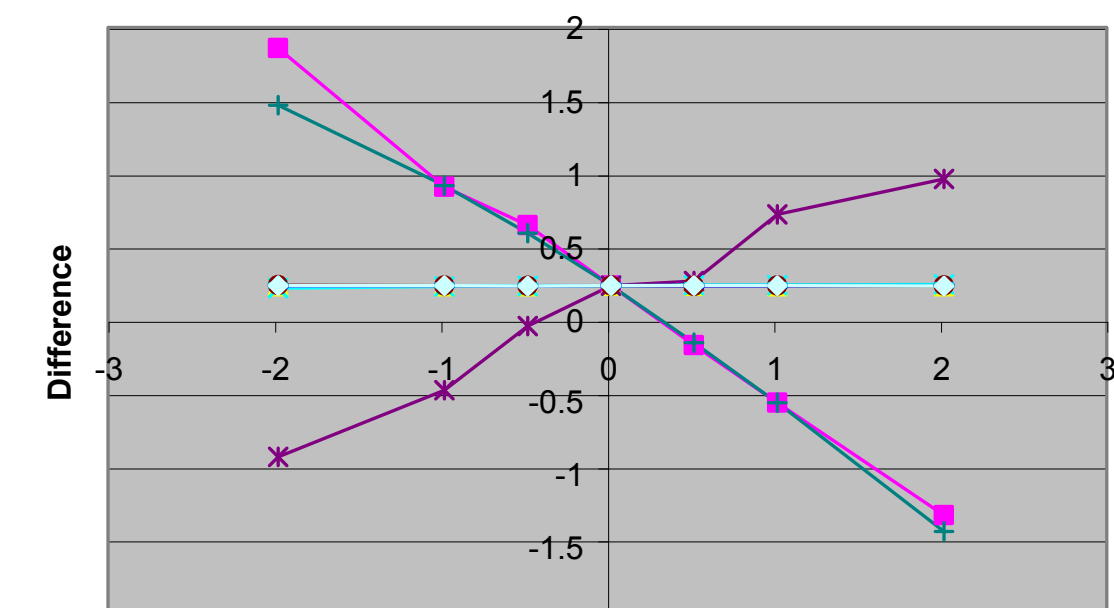

Base Value +/-Standard Deviatio
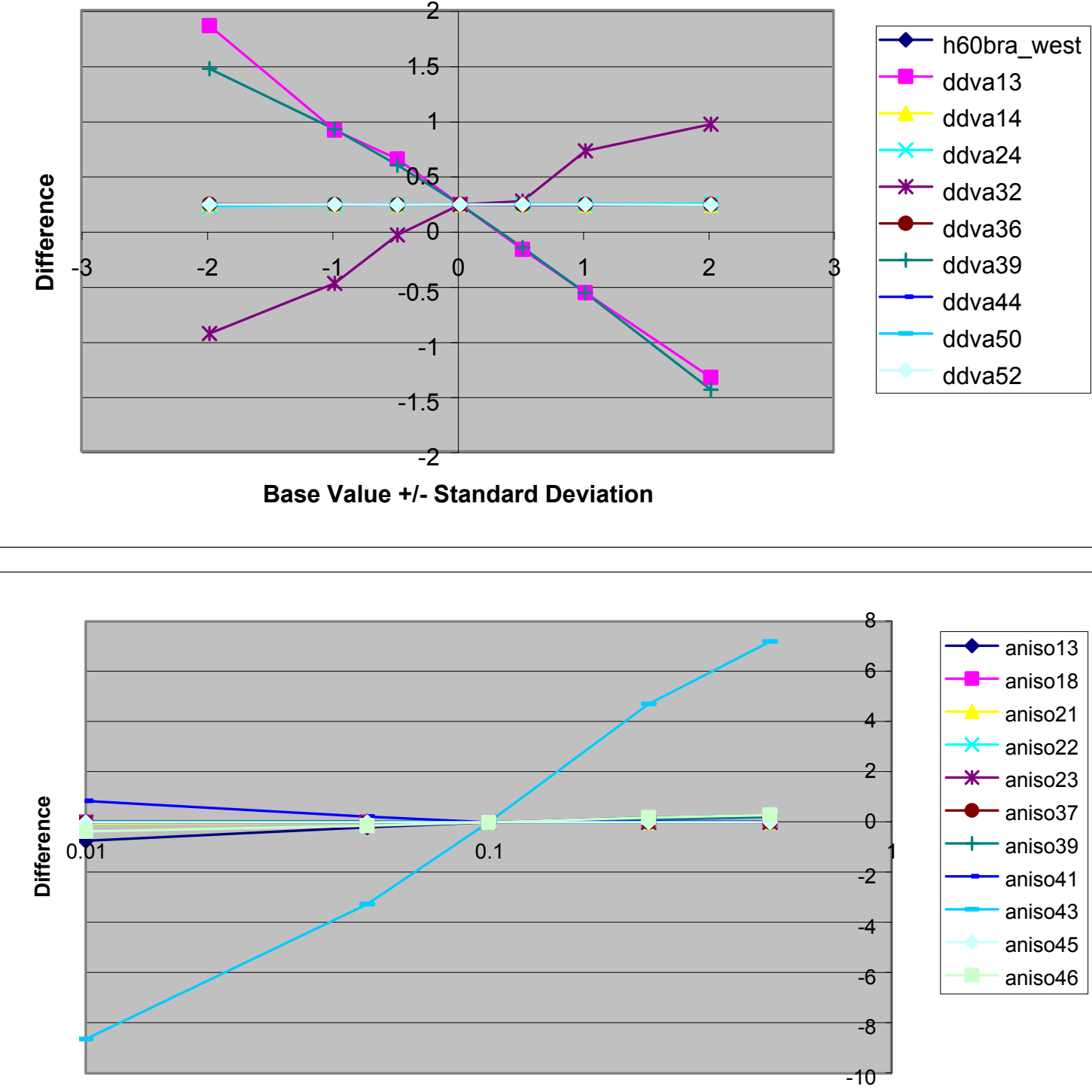

ddva50
ddva52
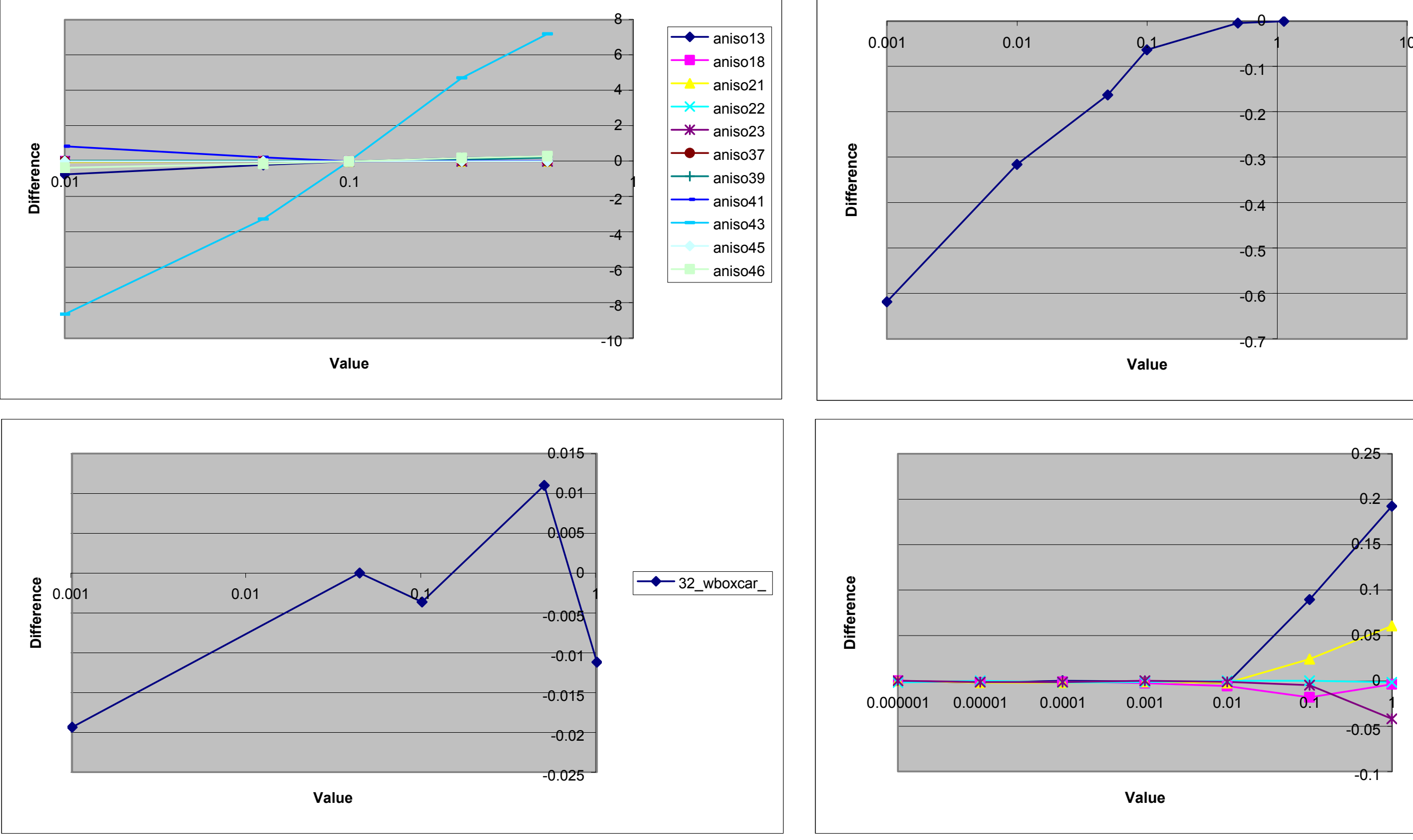

$\rightarrow$-04_boxcar_w
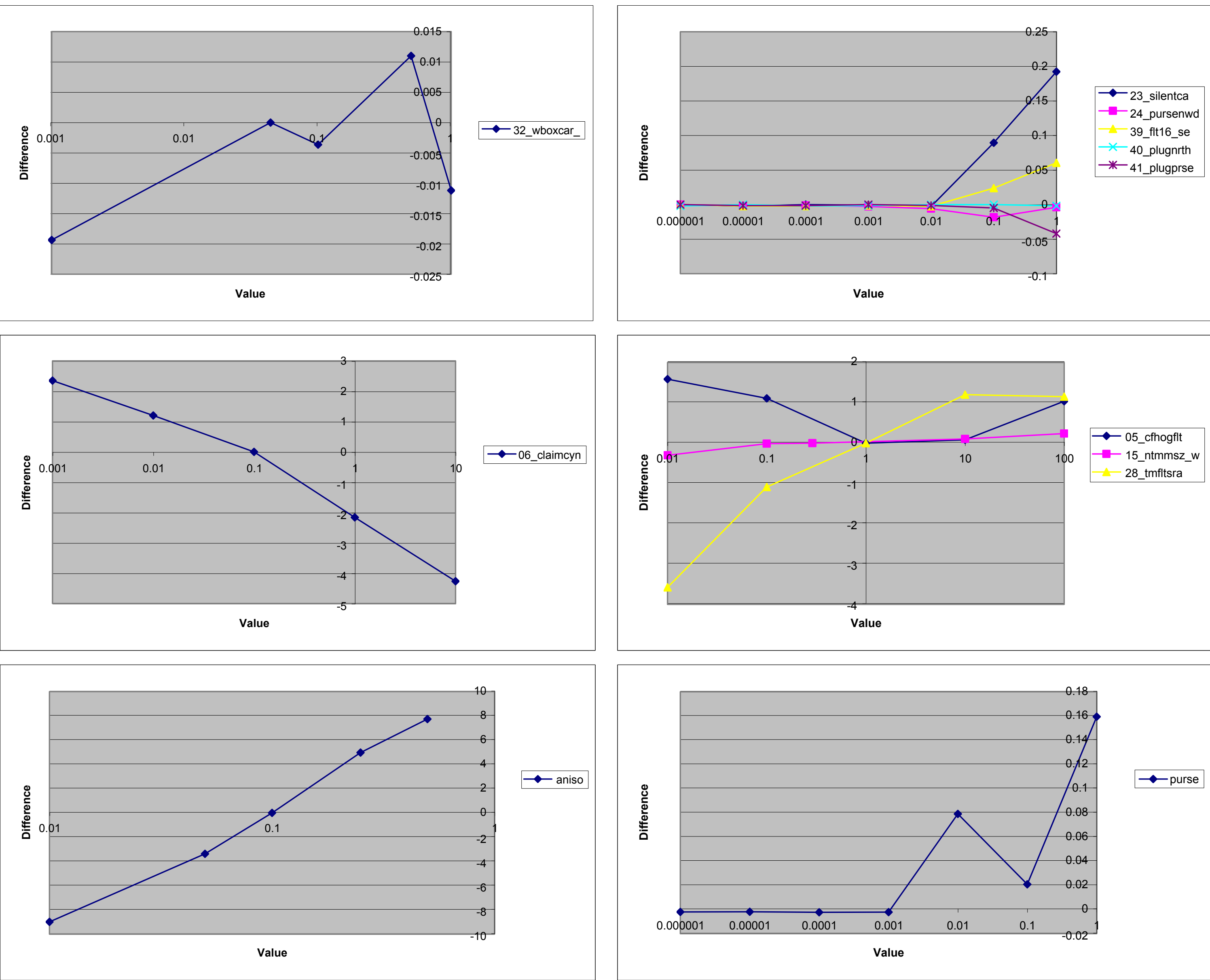

- hsu20chcu
$-\times$ hsu21chzcm

* hsu22chvcm - hsu23chvta - hsu24ymcicm
- hsu25tsa
- hsu26lpcu - hsu26lpcu
hsu27plfa

Base Value +/- Standard Deviatio

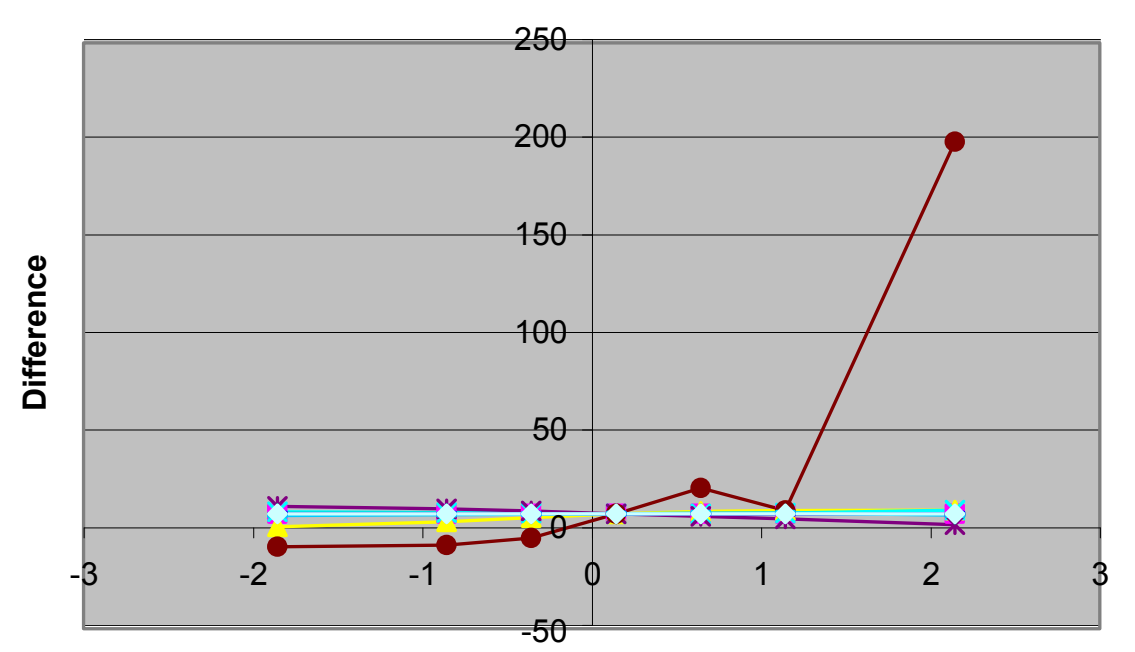

- hsu38sthfia 2- hsu4fora *- hsu42dva
- hsu43dvcm + hsu4titva - hsu46aa hsu47lcar1
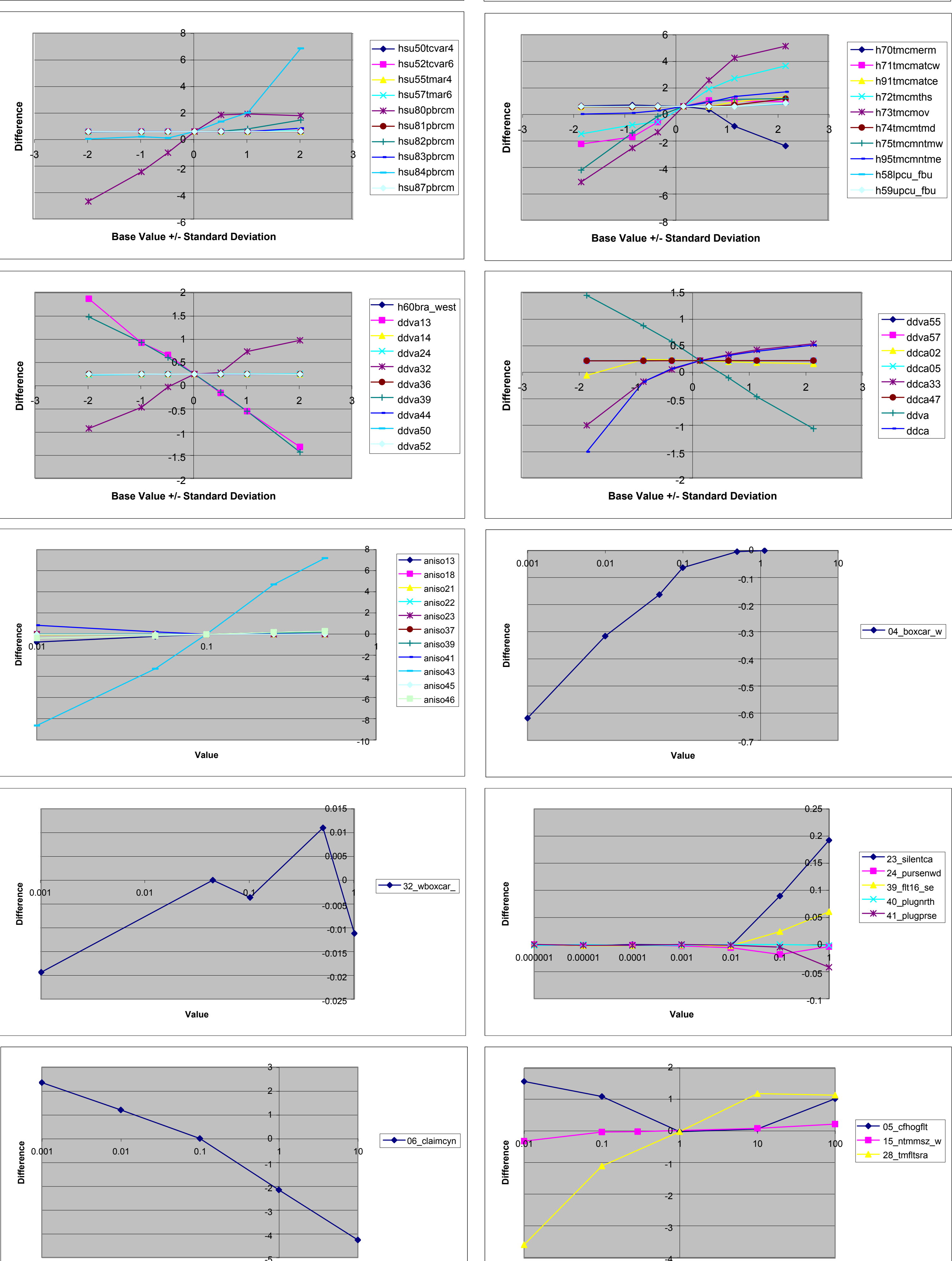

$\rightarrow$-06_claimcyn

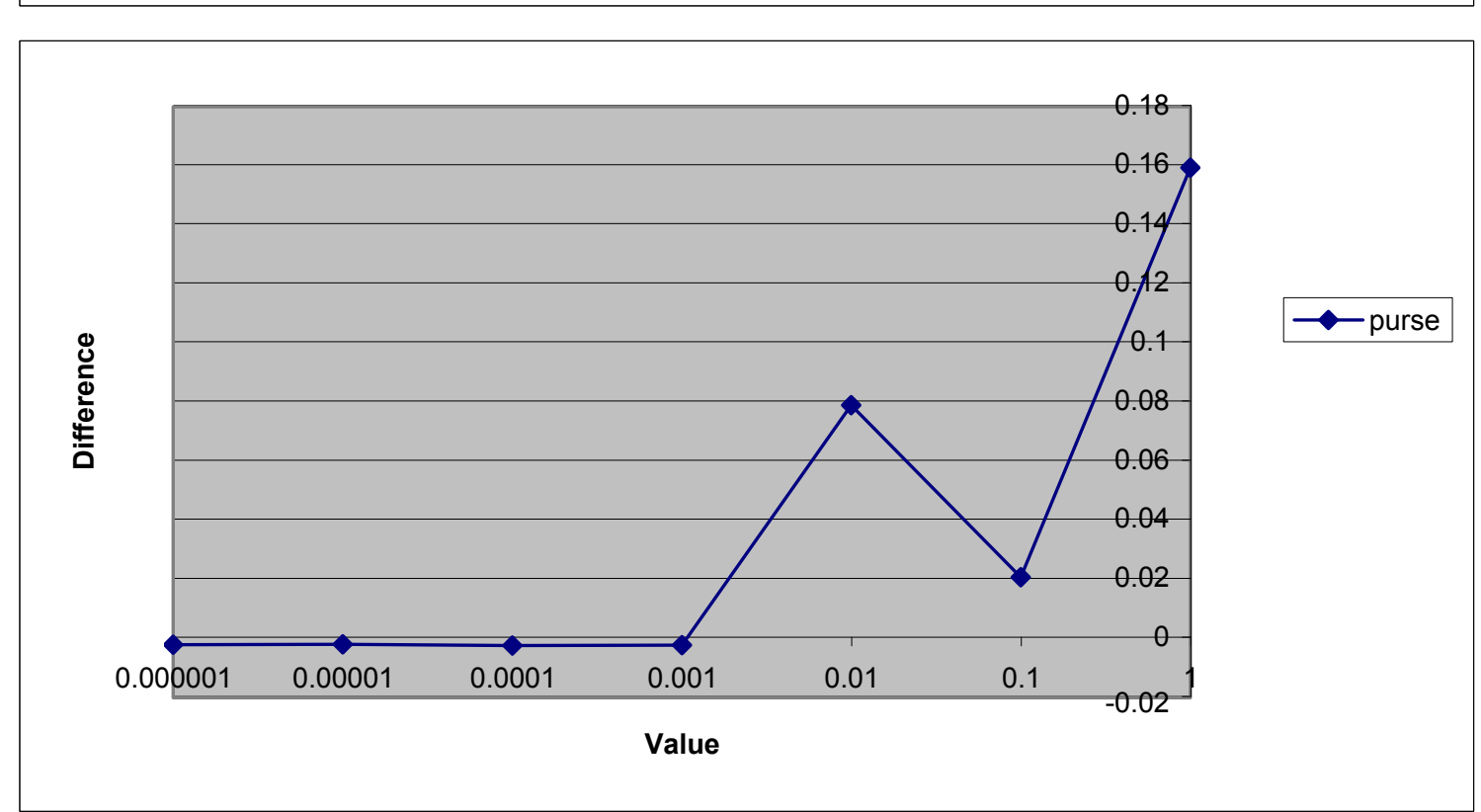



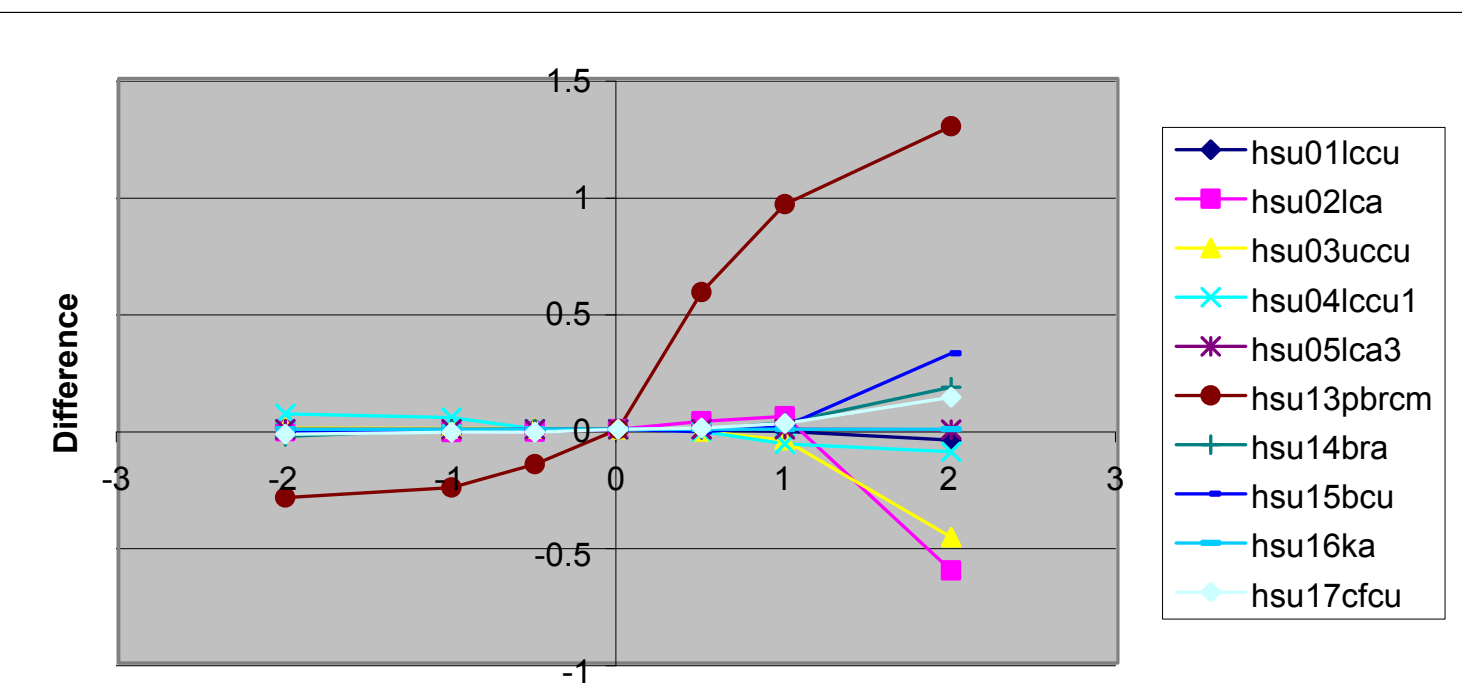

Base Value +/- Standard Deviation
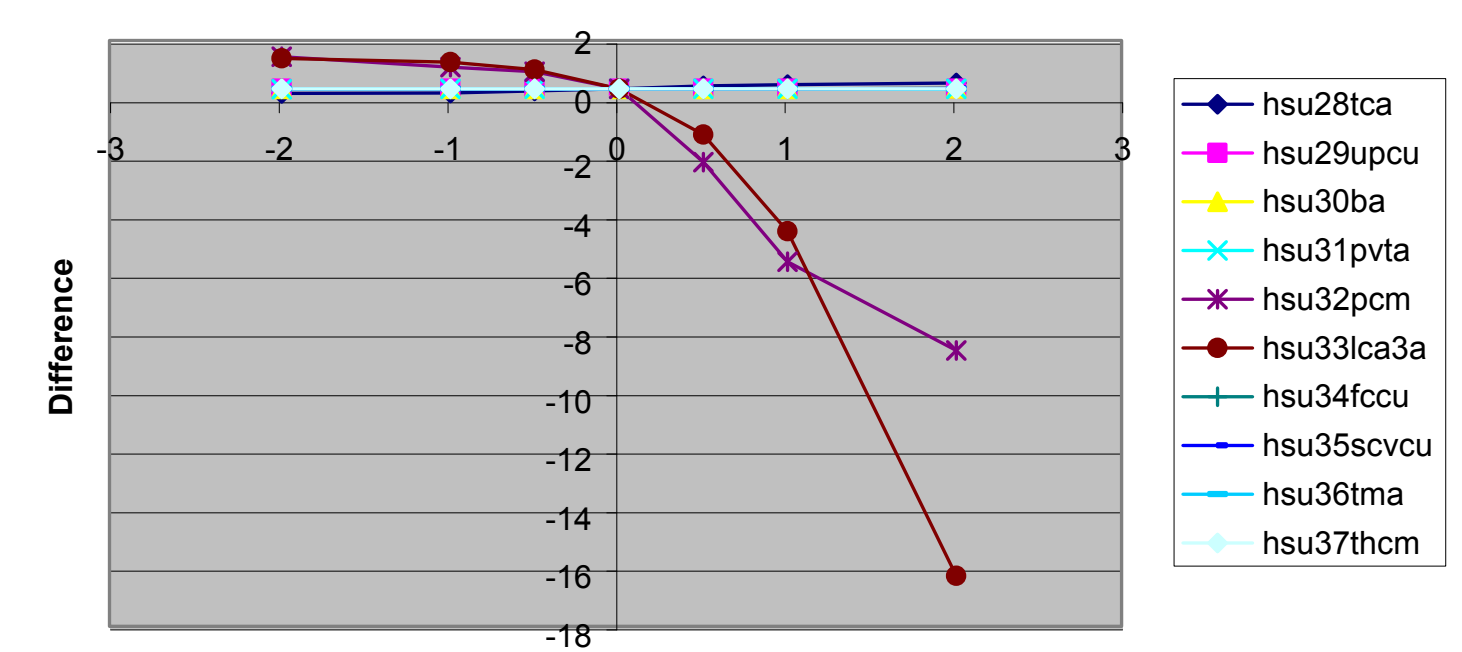

Base Value +/- Standard Deviation
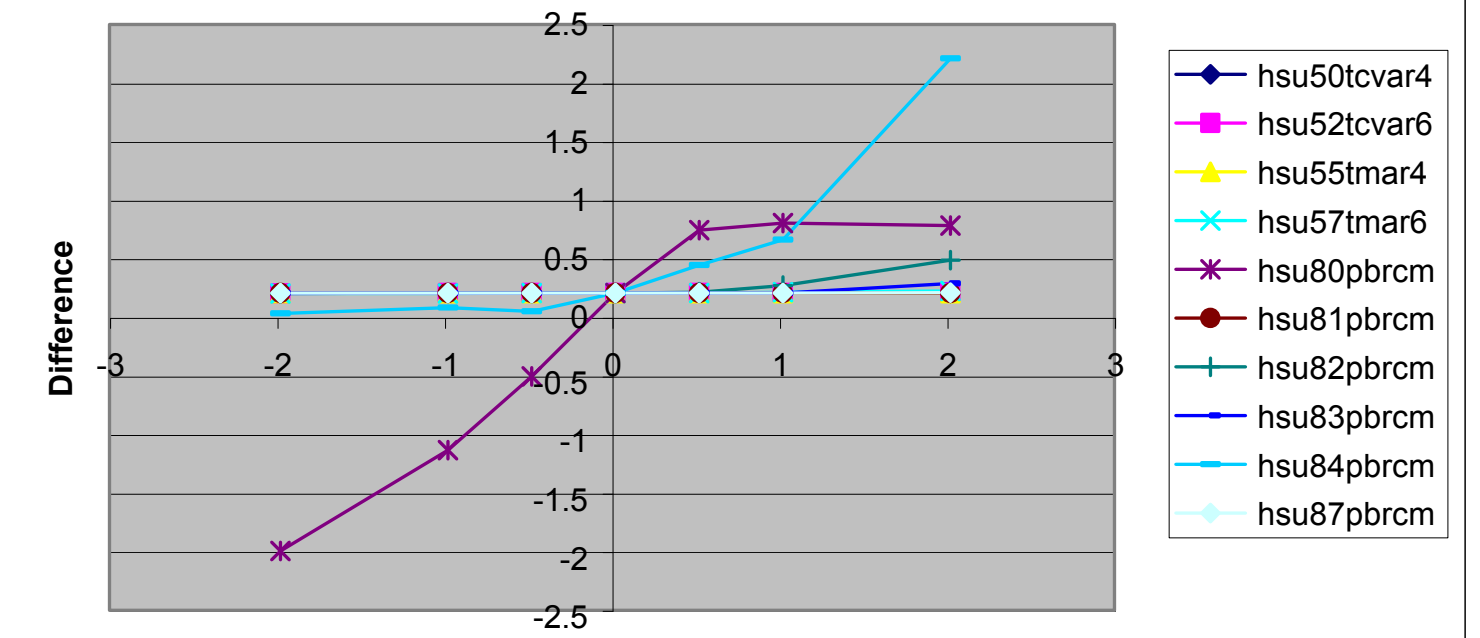

Base Value + /-Standard Deviation
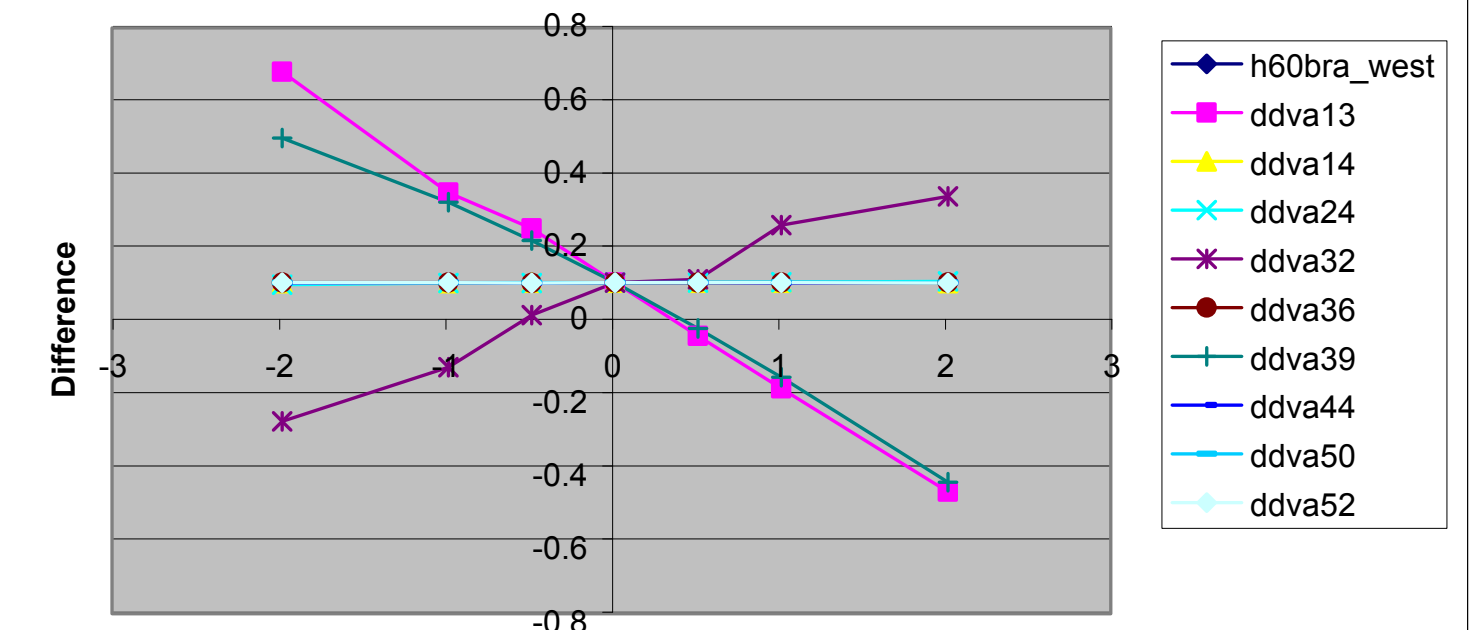

Base Value +/-Standard Deviatio
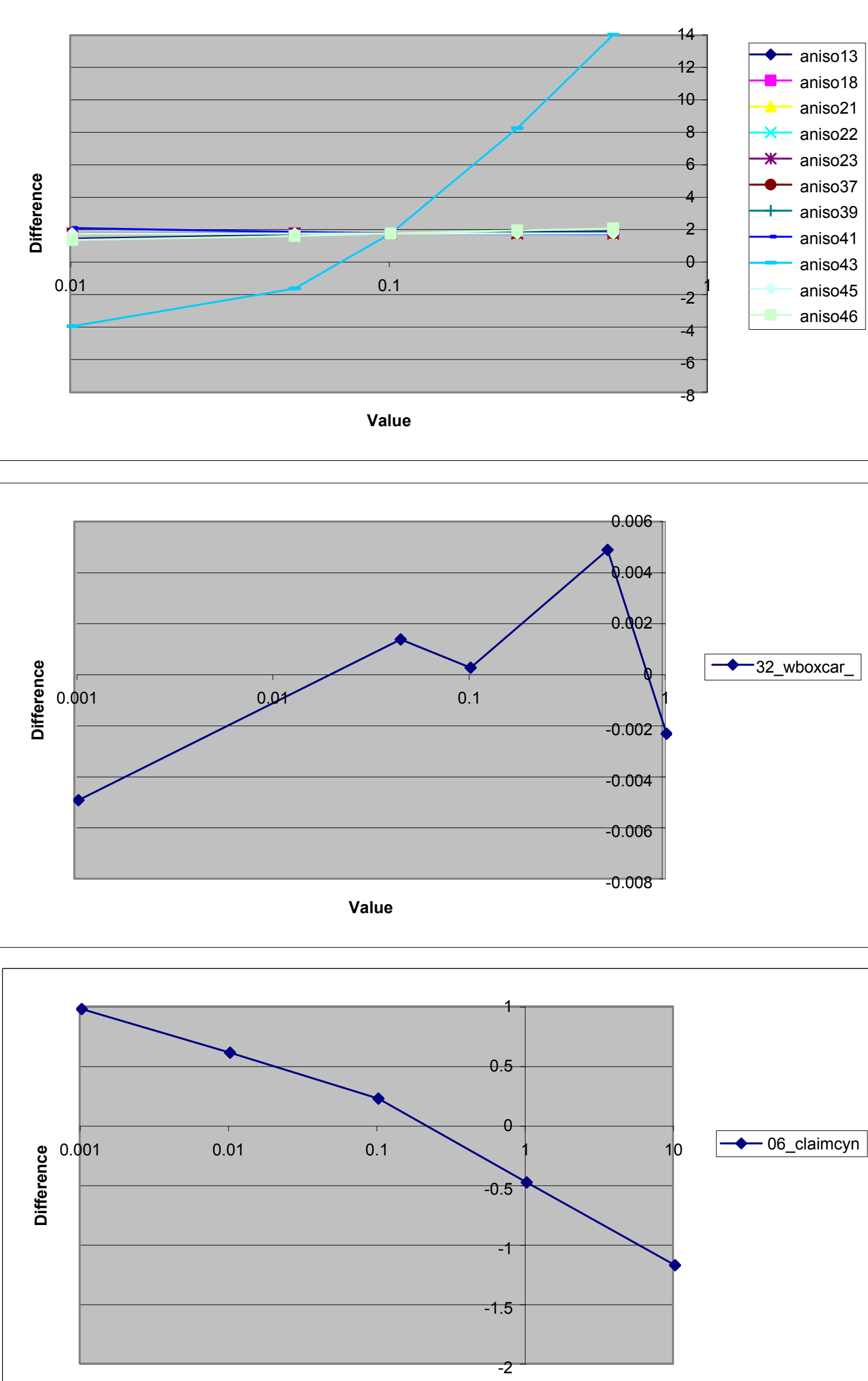

value

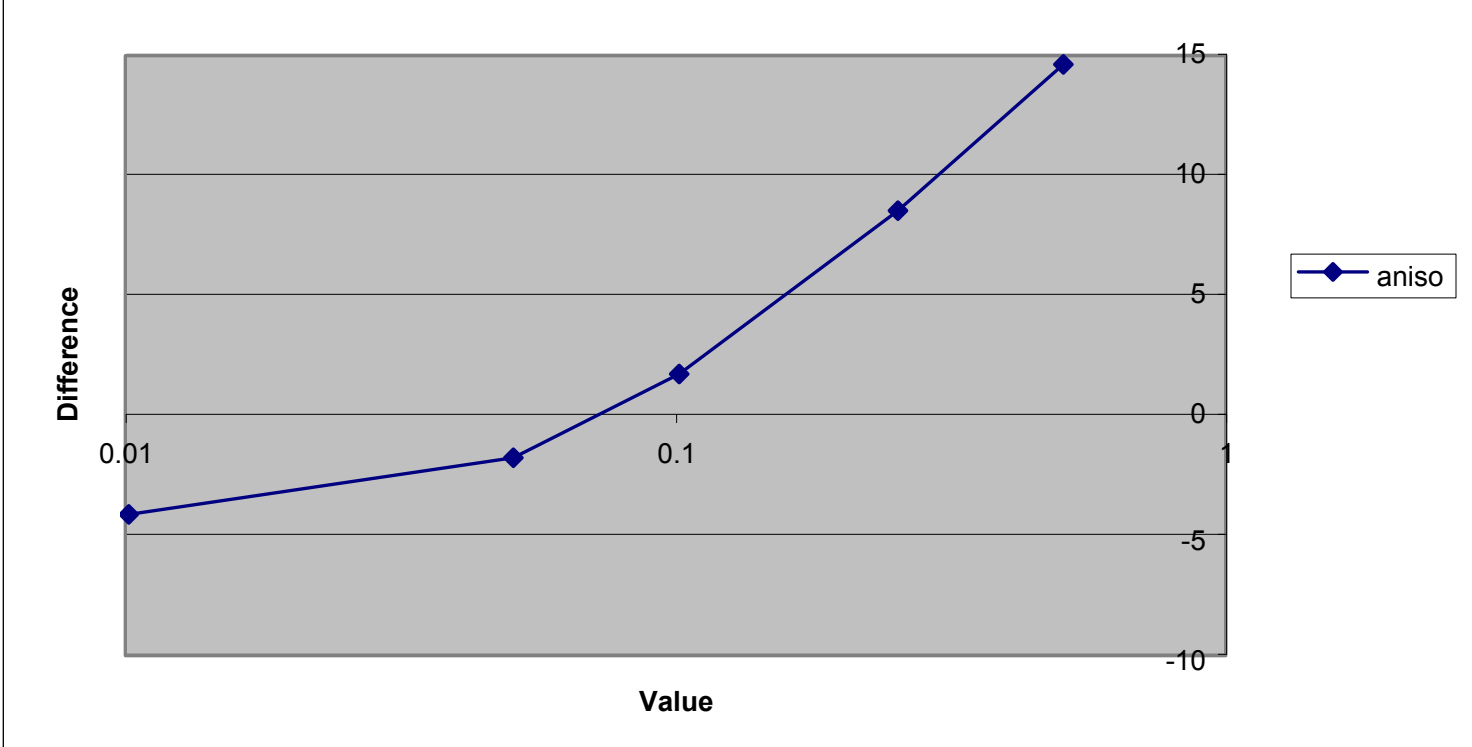

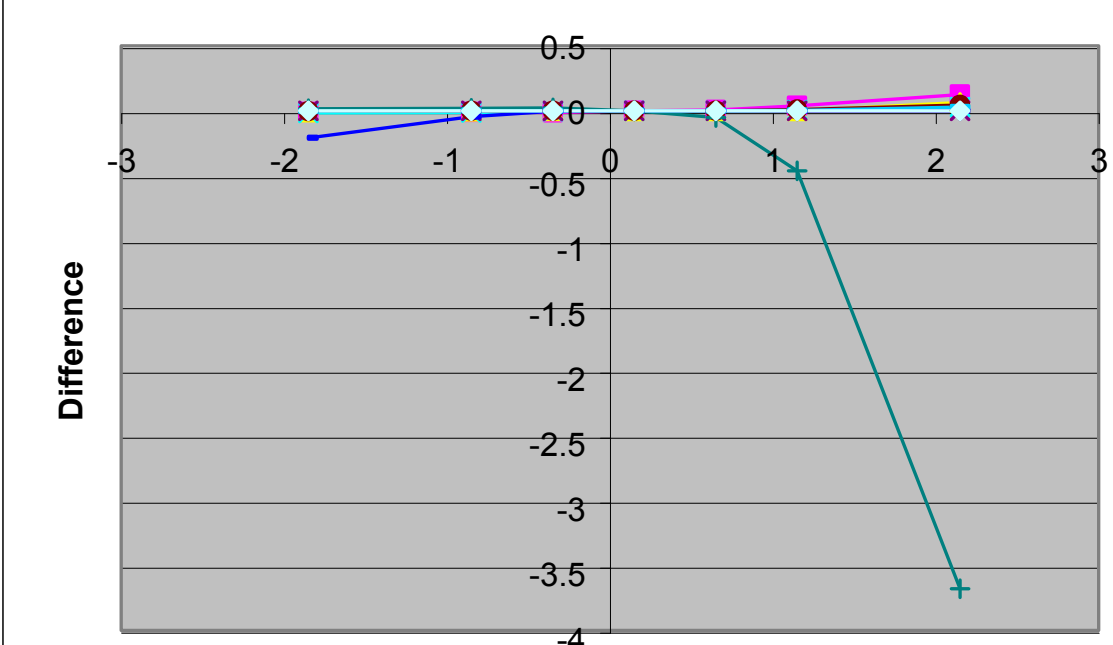

$\rightarrow-$ hsu18cfom - hsu19ia L- hsu20chcu
$*$ hsu21
$*$ hzcm *- hsu22chvcm + hsu24ymcfom - hsu25tsa -hsu261pcu

Base Value + +/-Stand

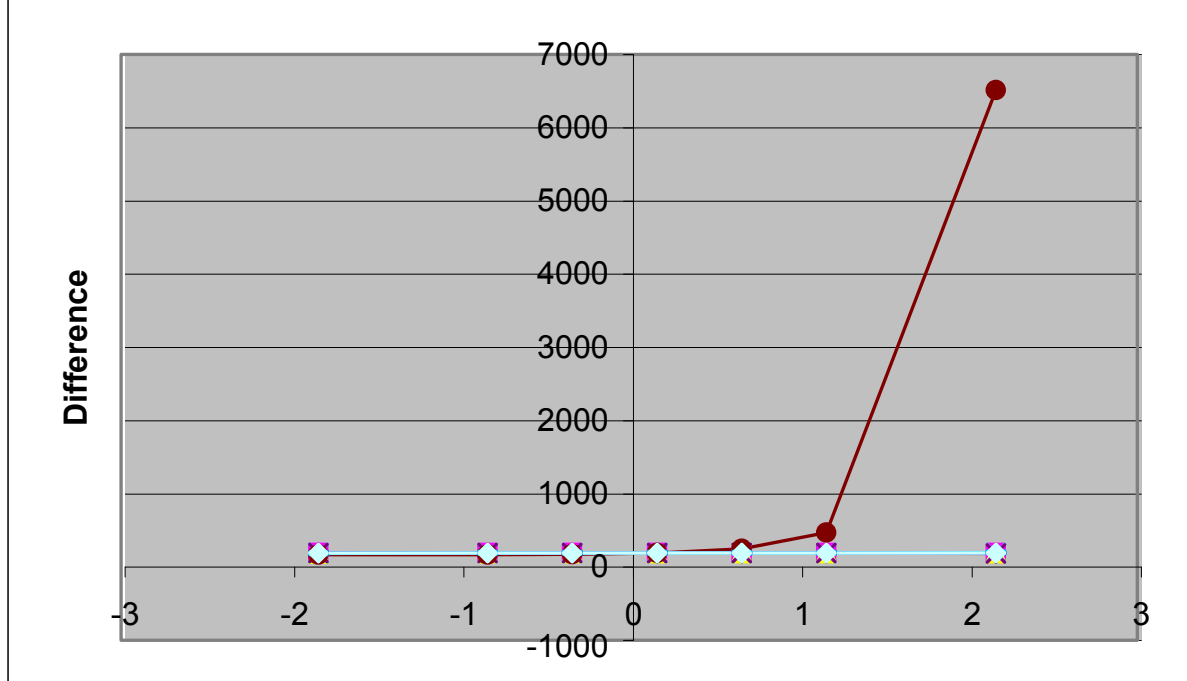

- hsu38thlfa - hsu39tmcm $*$ hsu4tfccm *- hsut2dva
$\rightarrow-$ hsu43dvem + hsu4titcra - hsu45yvam hsu47lcar1

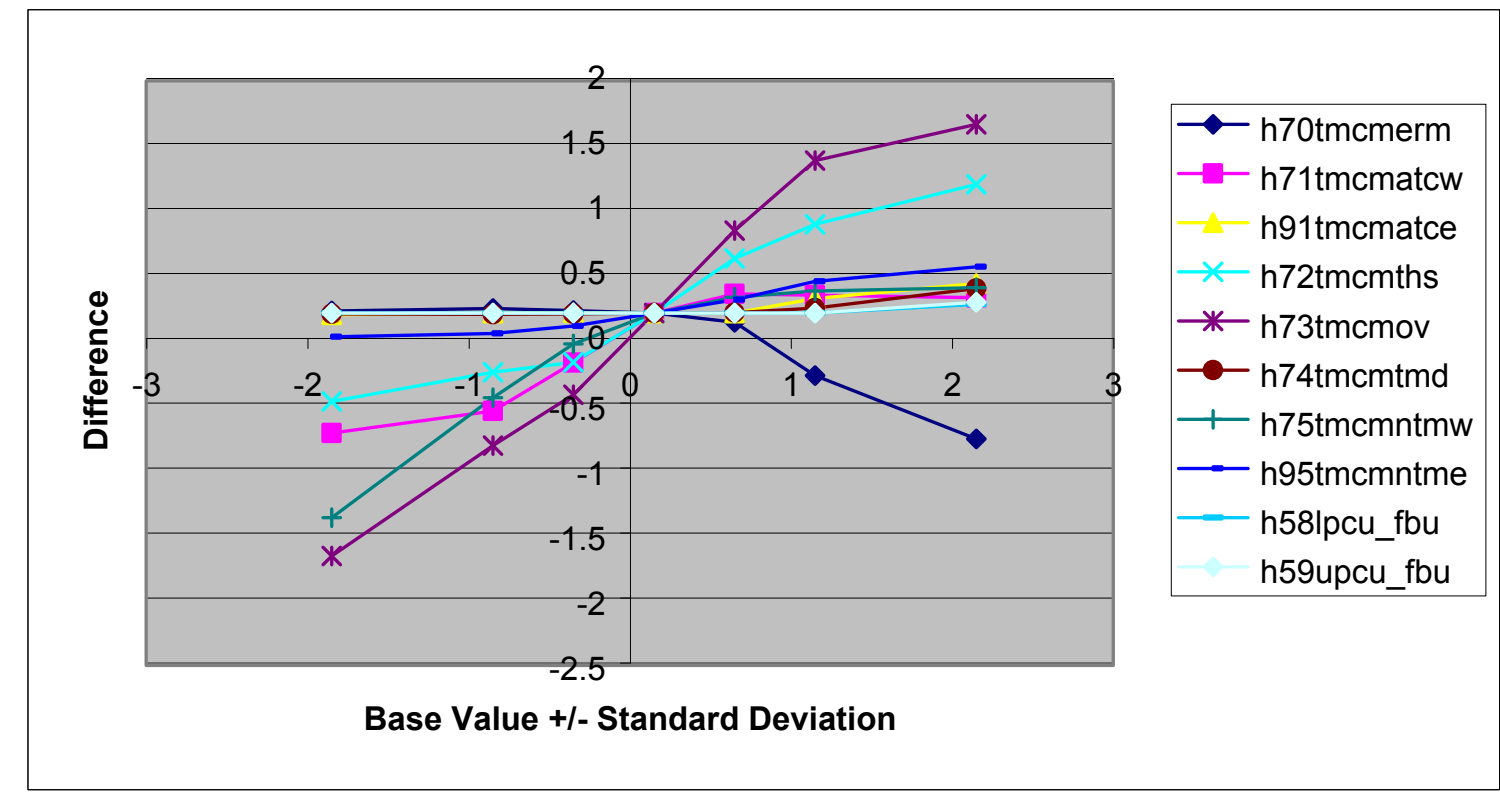

Base Value +/- Standard Deviation

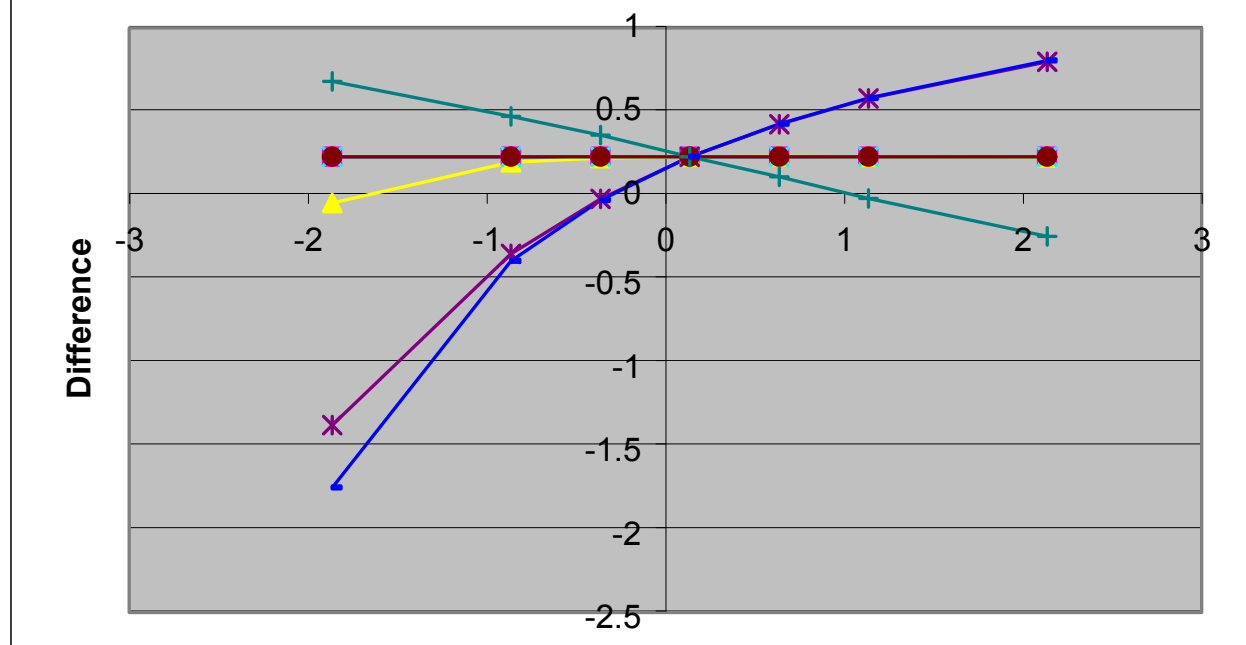

$\rightarrow$ ddva55 Lddca02 * ddca33 - ddca47
+ ddva
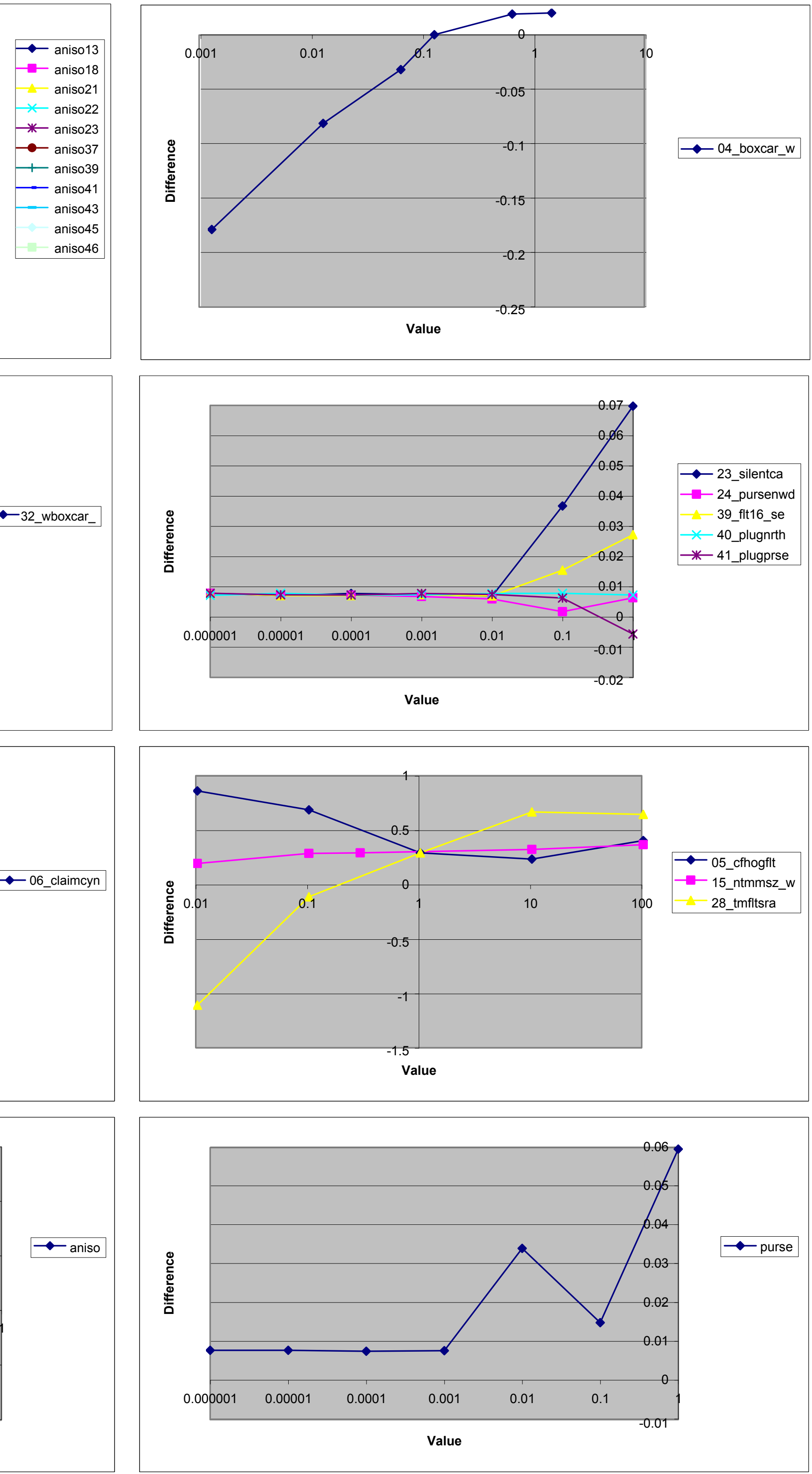

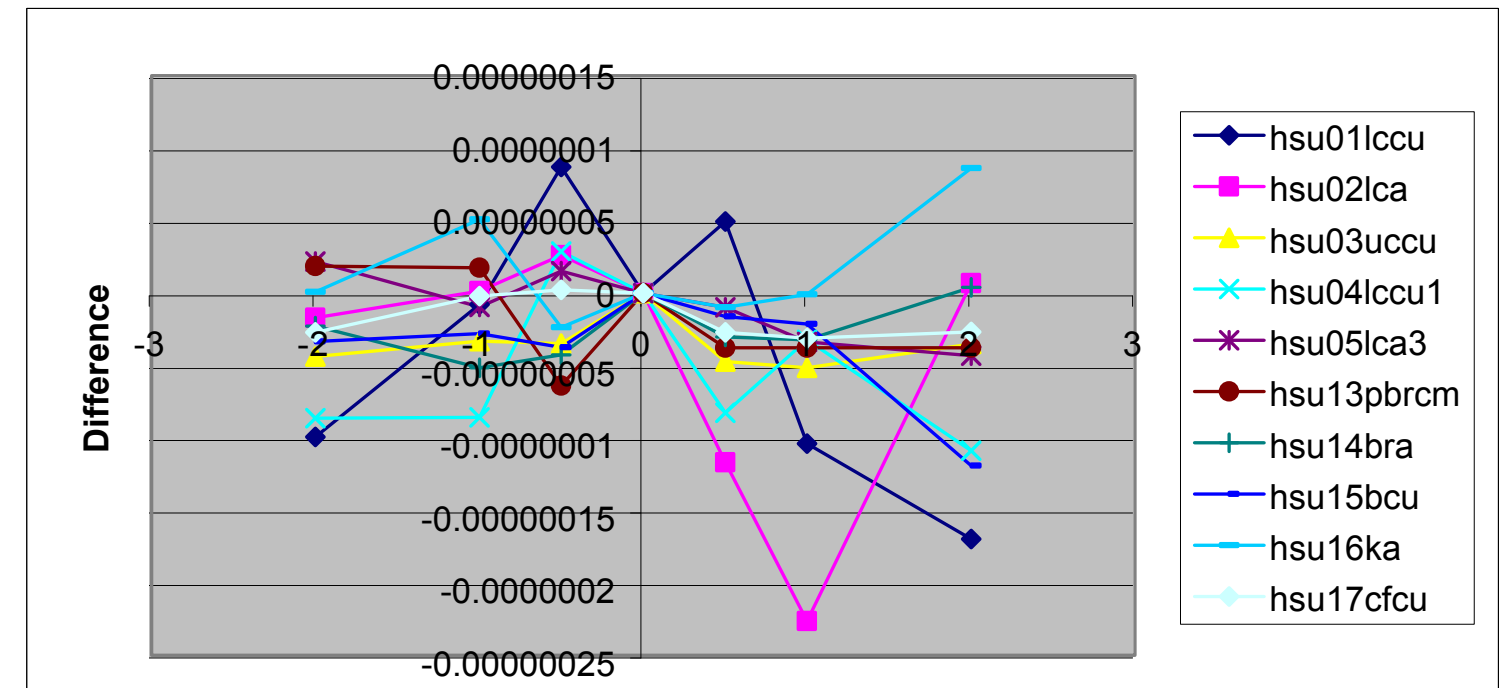

Base Value + + - Standard Deviation

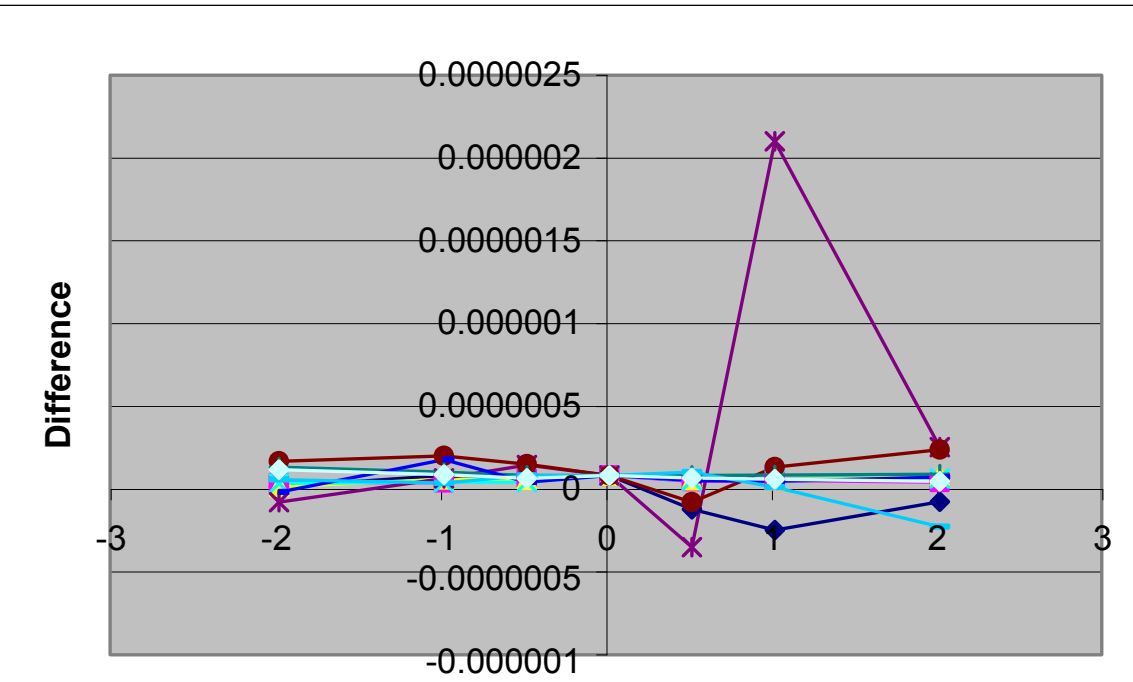

$\rightarrow-$ hsu28tca $\rightarrow$-hsu29upcu - hsu30ba
- - hsu31pvta *-hsu32pcm $\because-$ hsu33lca3a +
+- $\mathrm{nsu} 34 \mathrm{ffccu}$
$+\mathrm{nsu} 35 \mathrm{sccvcu}$ -
- hsu35scvcu
- hsu36tma hsu36tma
hsu37thcm

Base Value +/-Standard Deviation
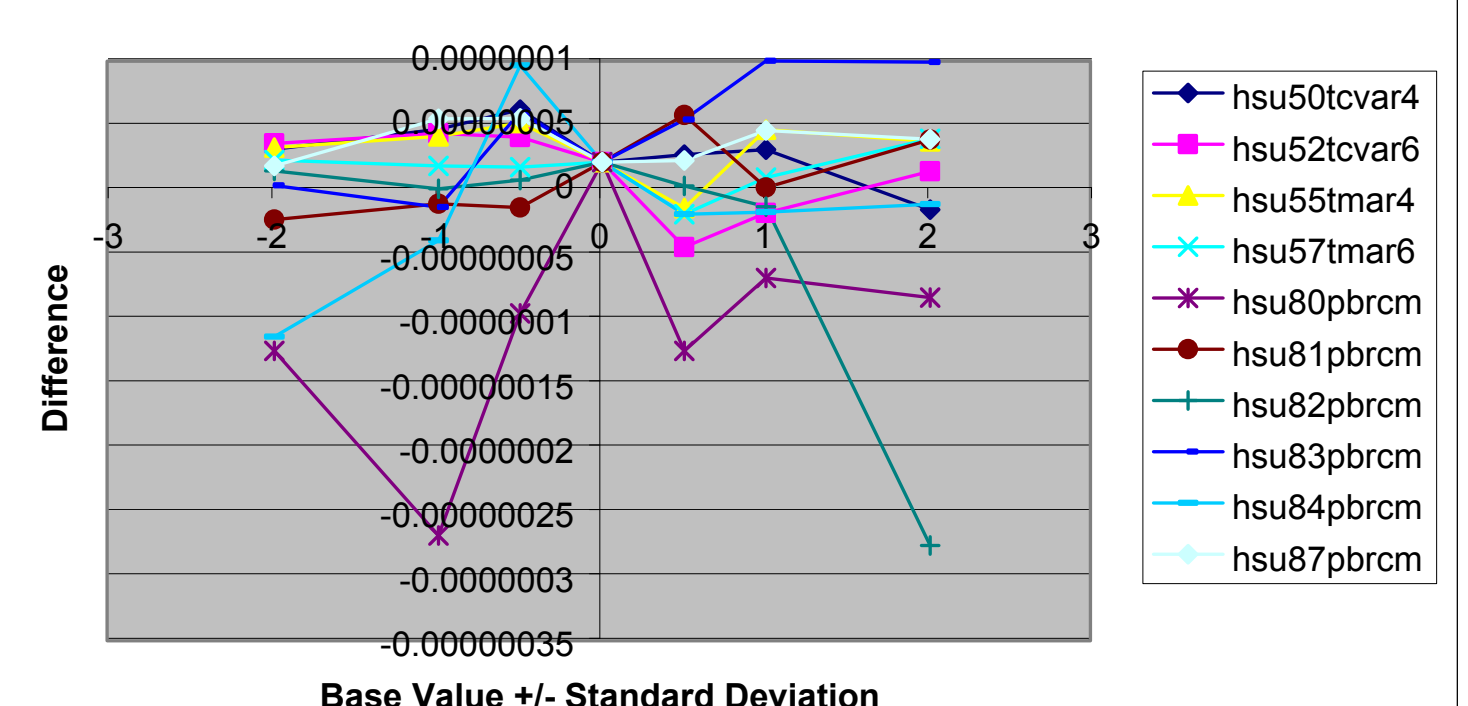

Base Value +/-Standard Deviation

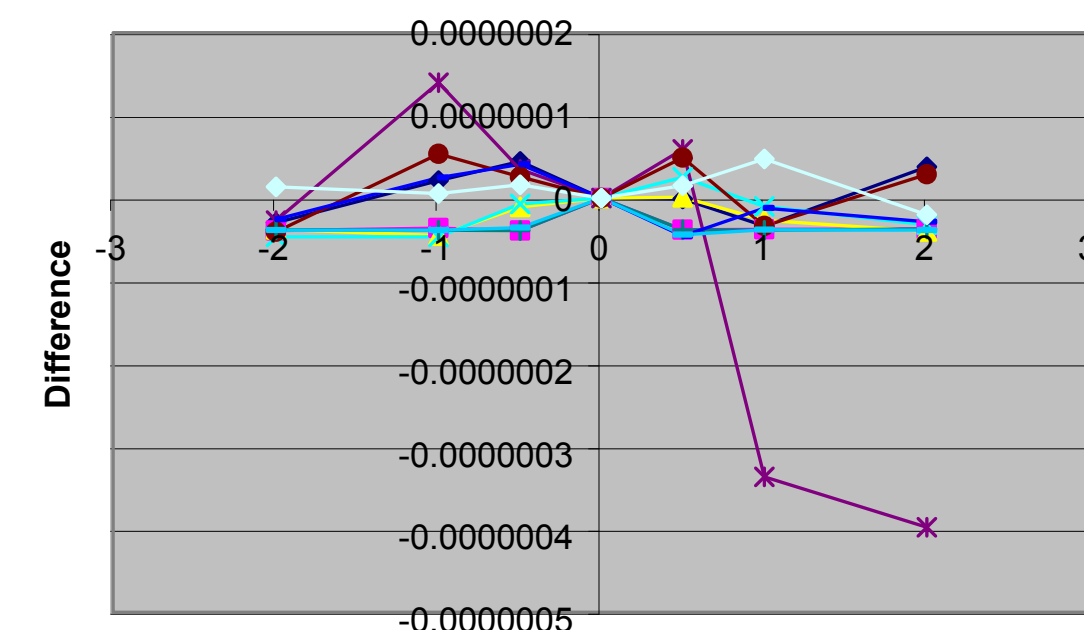

$\rightarrow$ - h60bra_west - d60bra_w -ddva14

*-ddva24 $\rightarrow$ ddva36 -ddva39 - ddva44
- ddva50
ddva52

Base Value +/- Standard Deviation
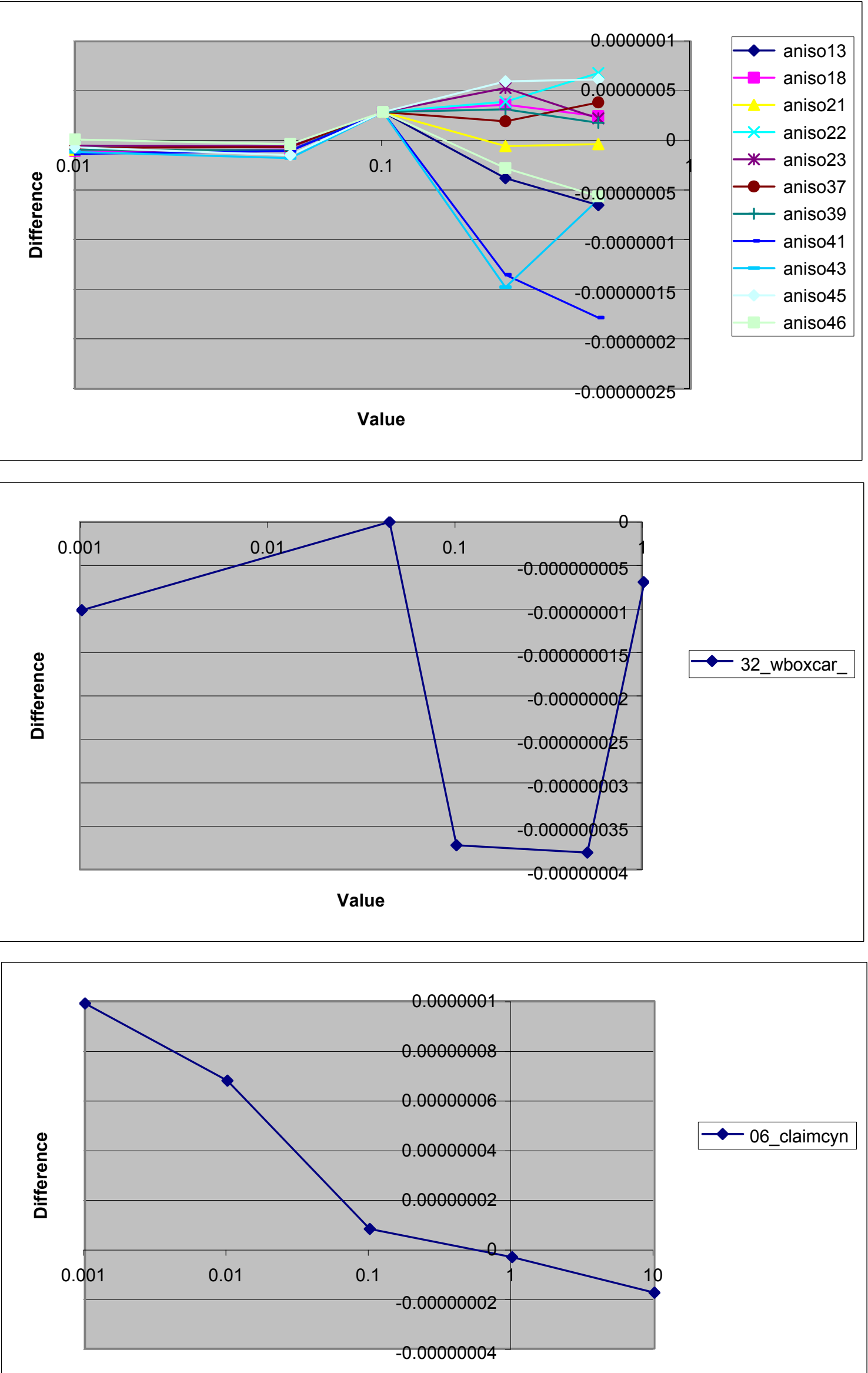

value

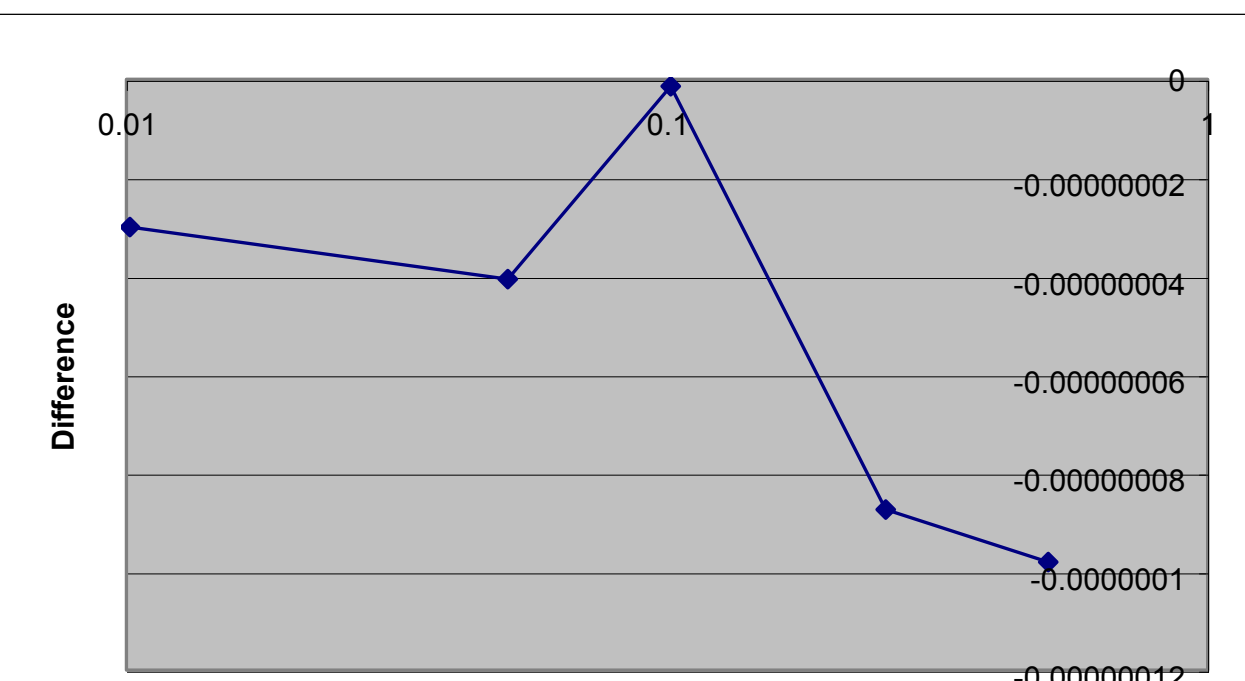

value

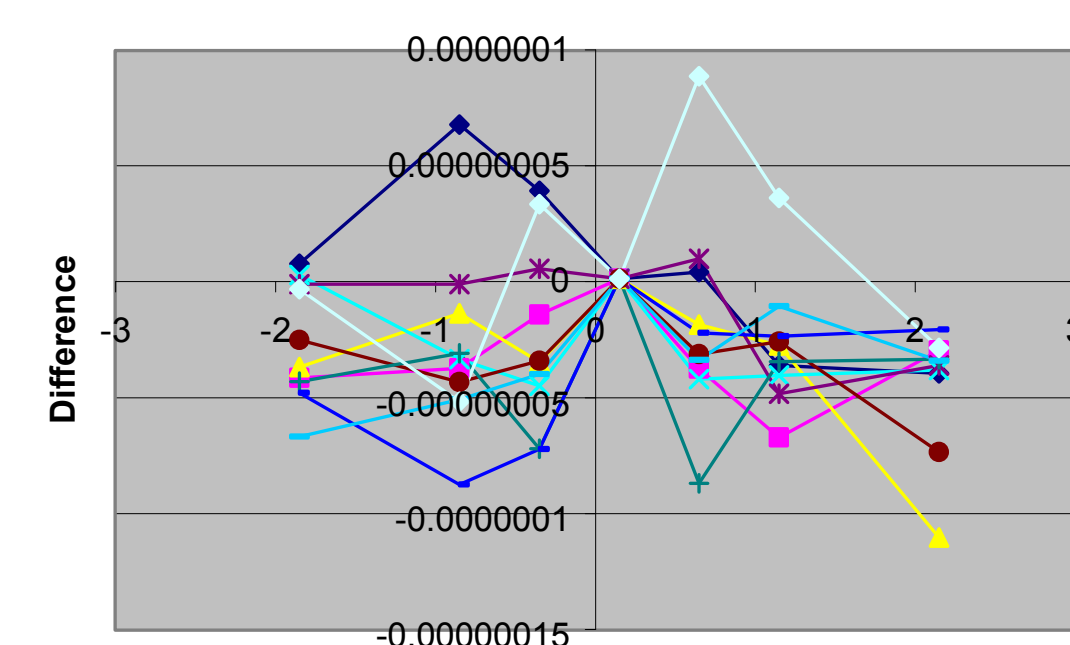

$\rightarrow$ hsu18cfom - hsu19ia hsu20chcu
$\times$ hsu21chzom * hsu22chvom $\rightarrow-$ hsu23chvta
+ - hsu24ymcfom - hsu25tsa hsu26lpcu
hsu27plfa

Base Value +/-Standard Deviation

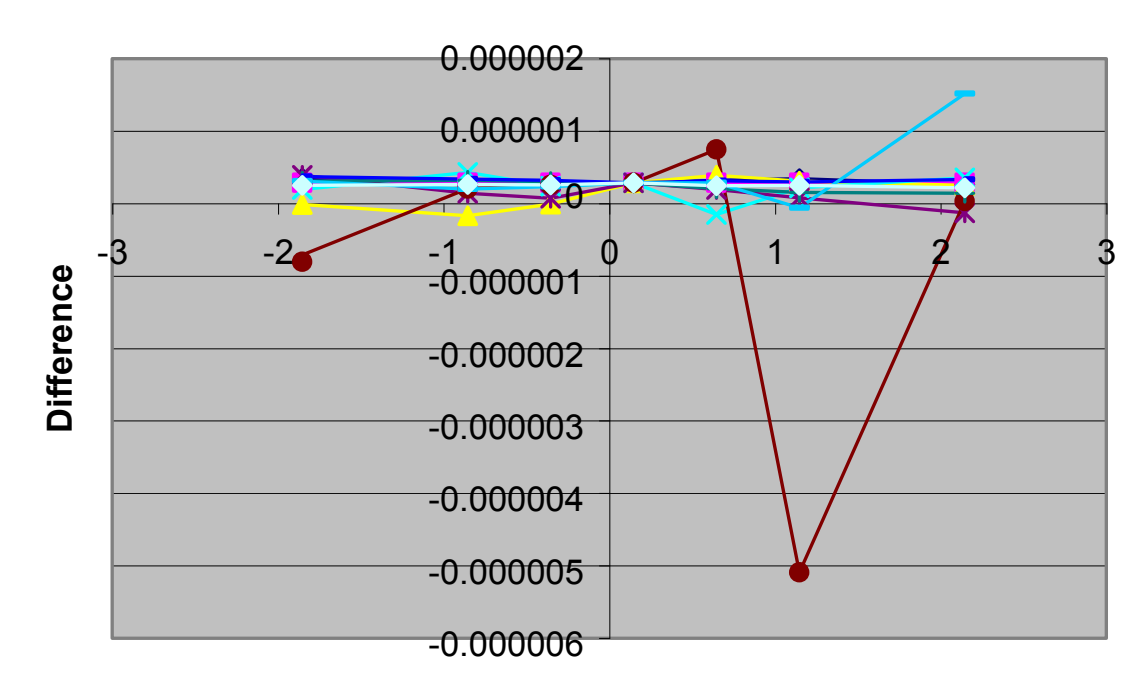

$\rightarrow$ hsu38thffa - hsu39tmcm - hsu40fca *
- - hsu42dva
- hsu43dvcm 千 hsu44tcva - hsu45yvcm - hsu46aa
hsu47lcar1

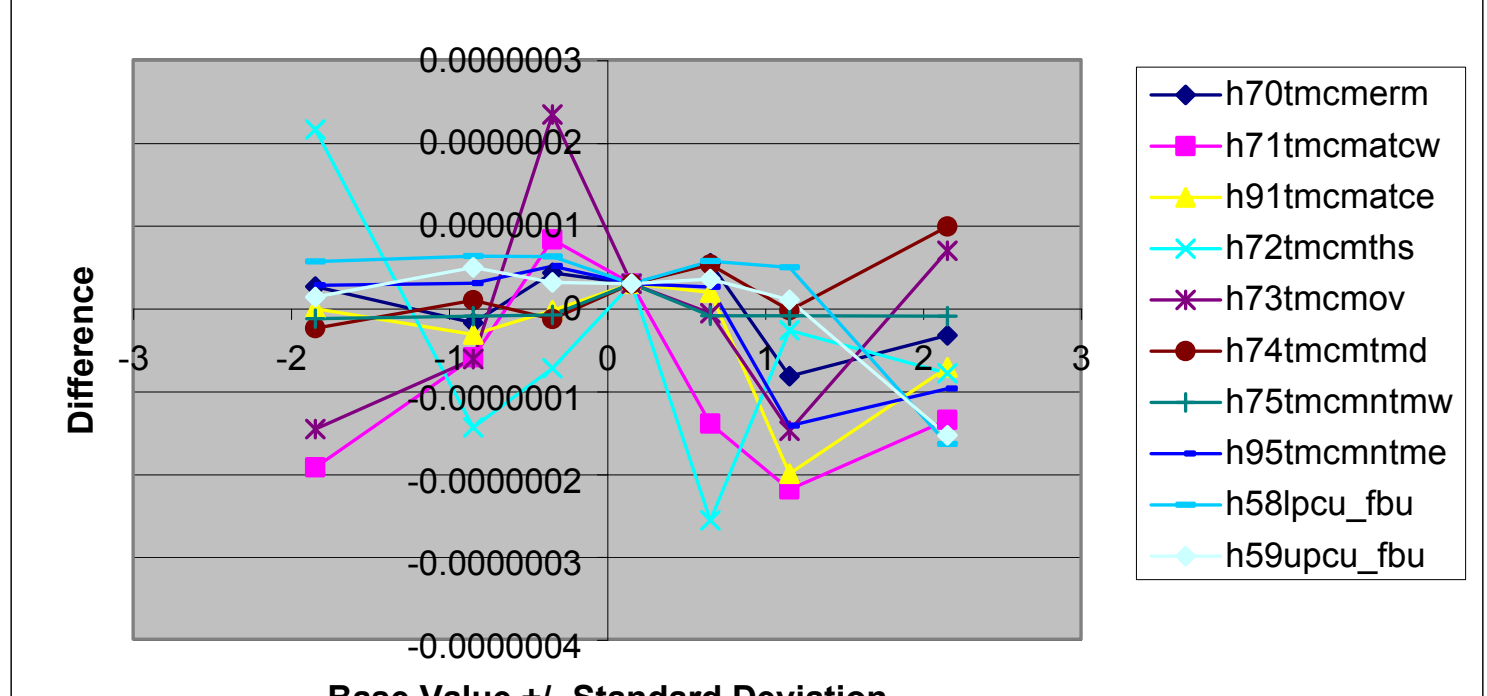

Base Value +/- Standard Deviation

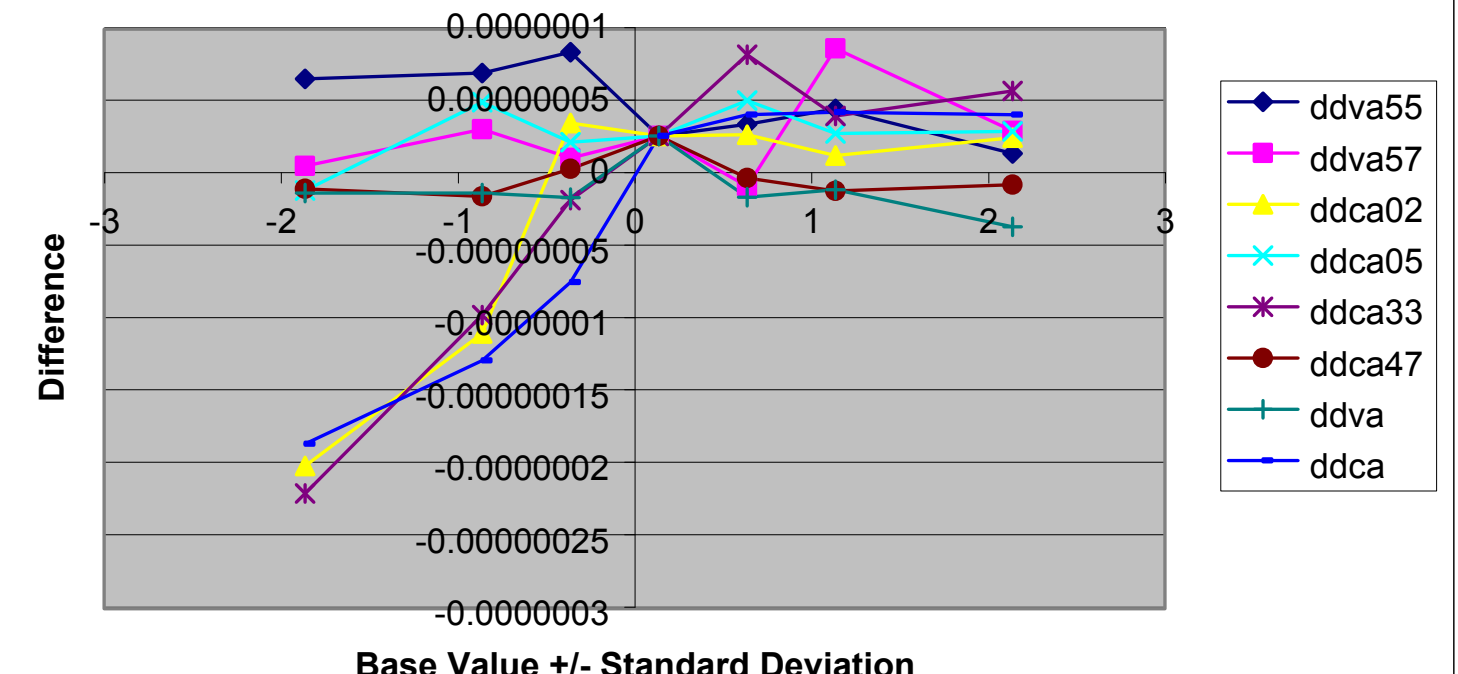

Base Value +/-Standard Deviation
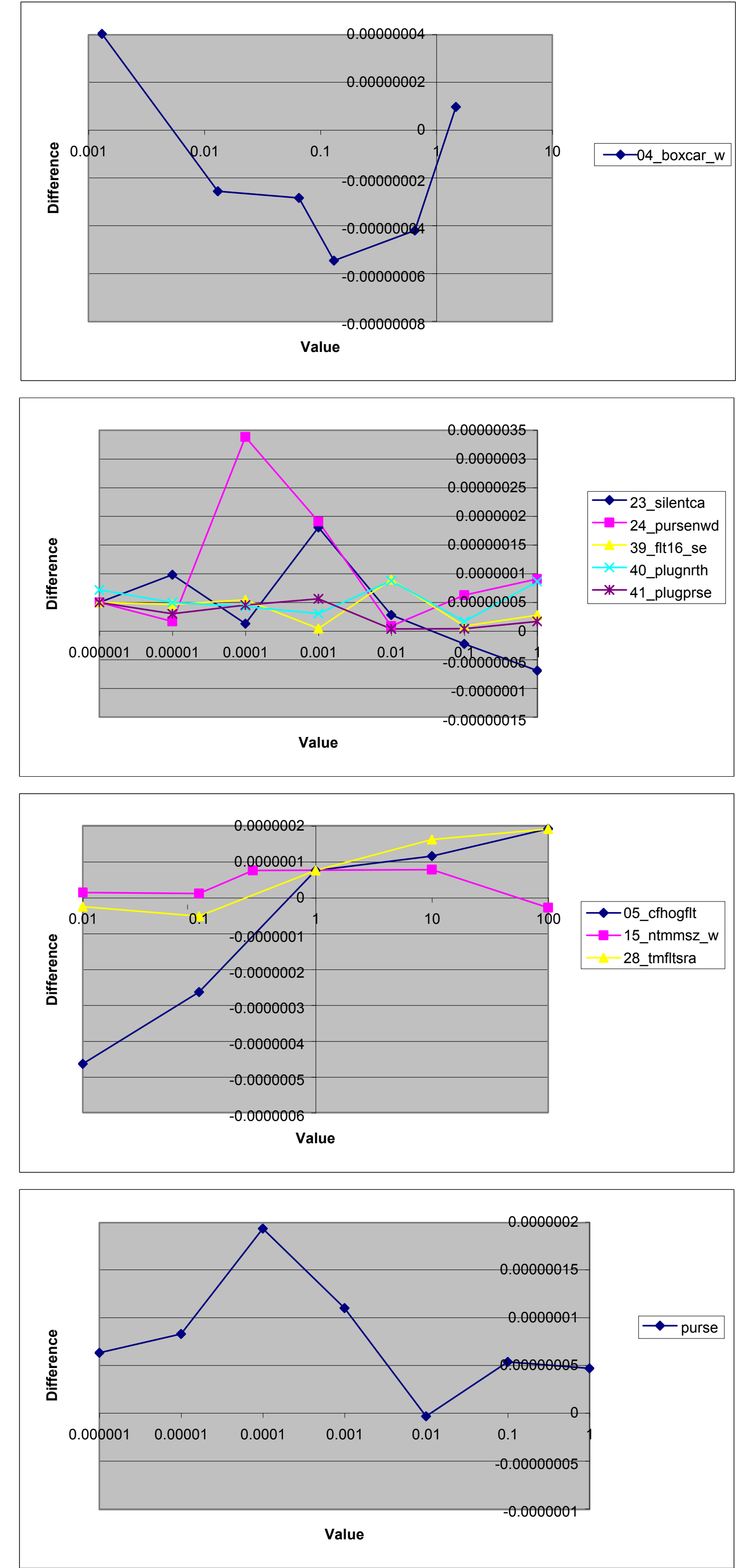

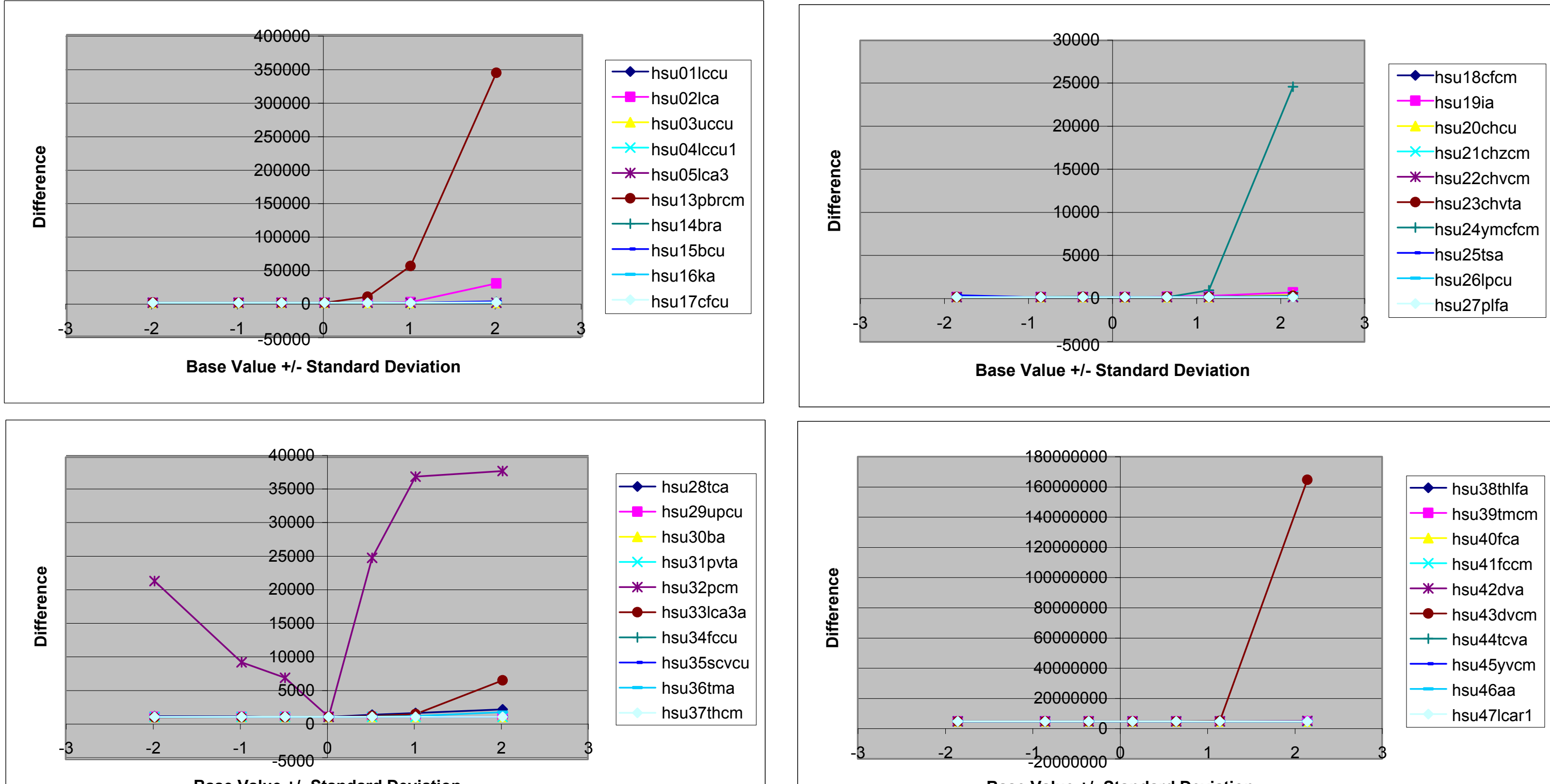

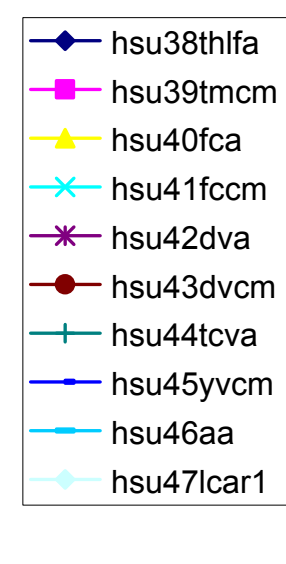

Base Value +/- Standard Deviatio
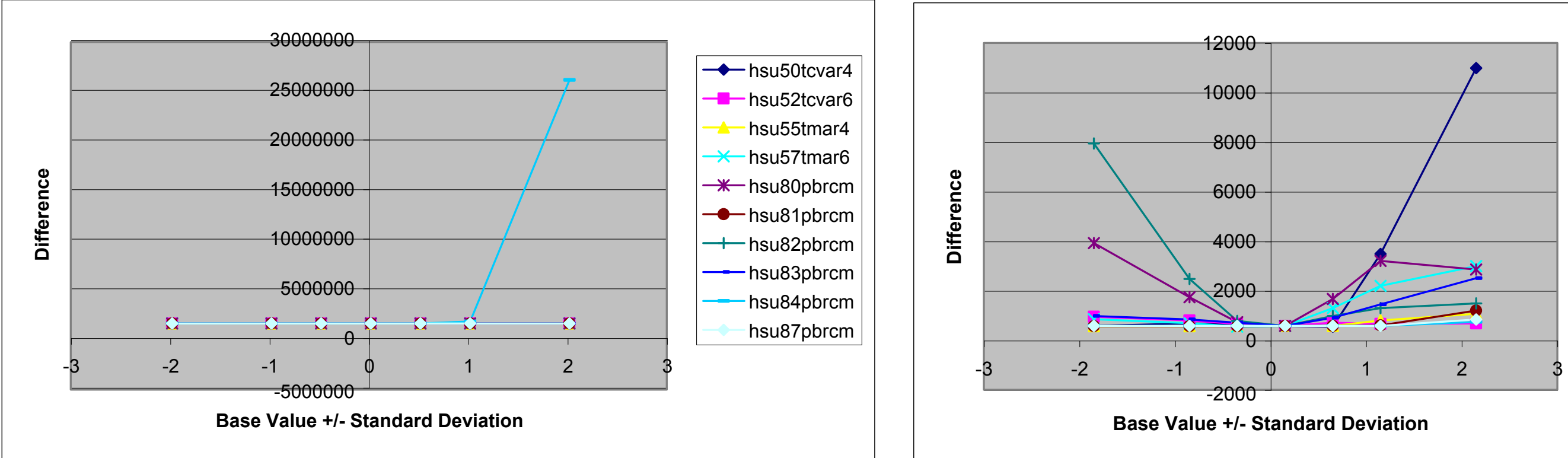

- h70tmcmerm - h71 1mmatcm * h72tmemths * h73tmcmov - n74tmcmtmd —- h75tmcmntmw - h581pcu_fbu

Base Value +/-Standard Deviation
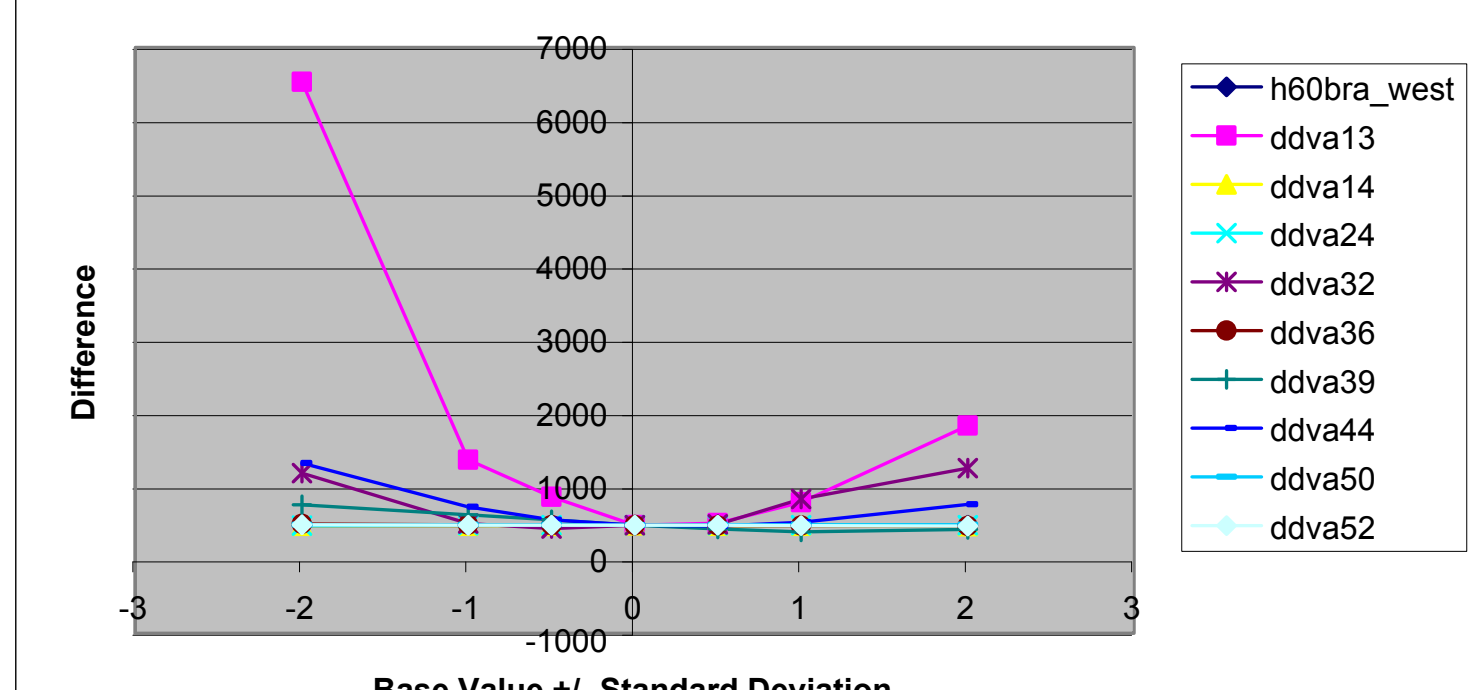

Base Value +/-Standard Deviatio
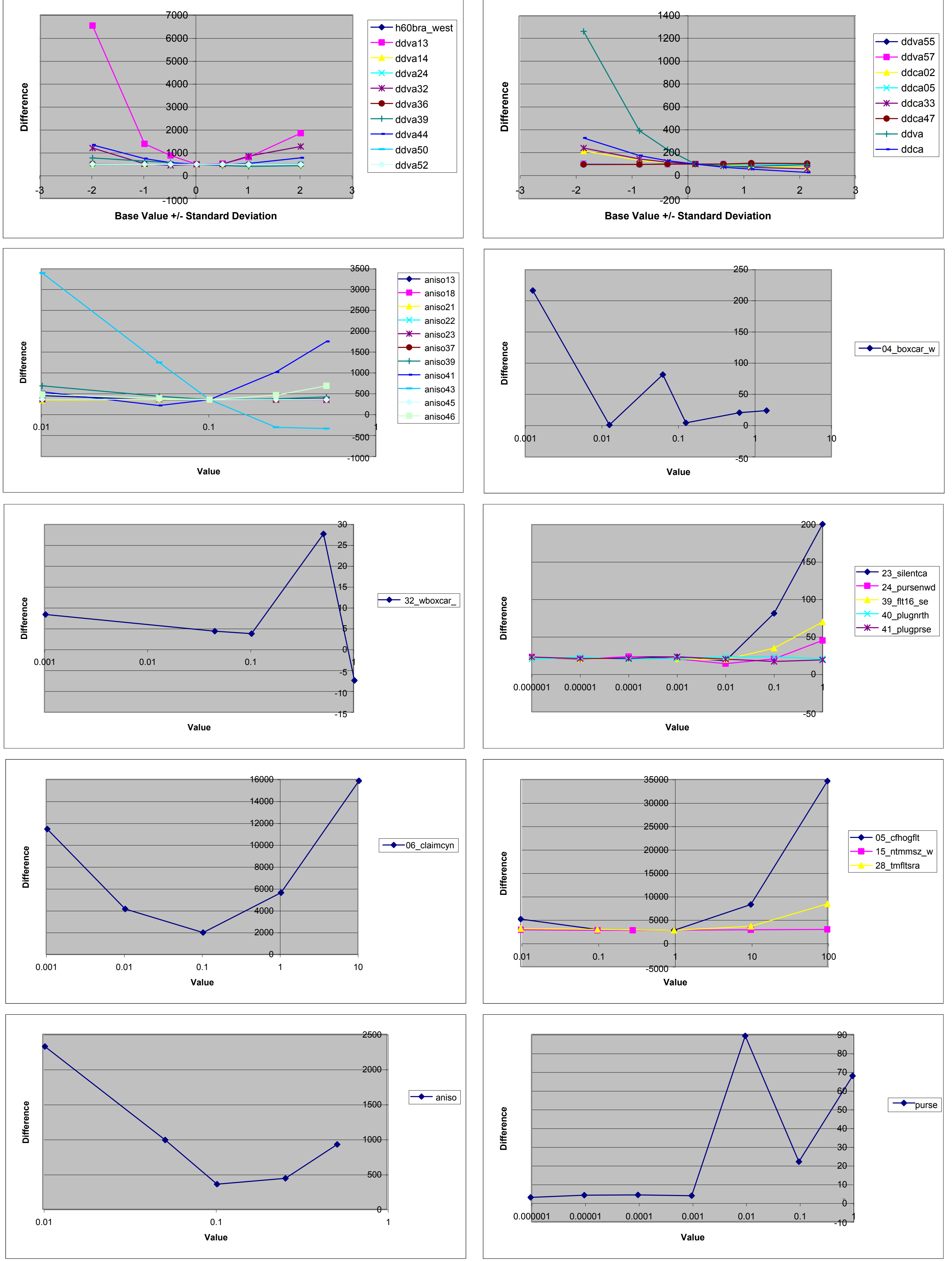

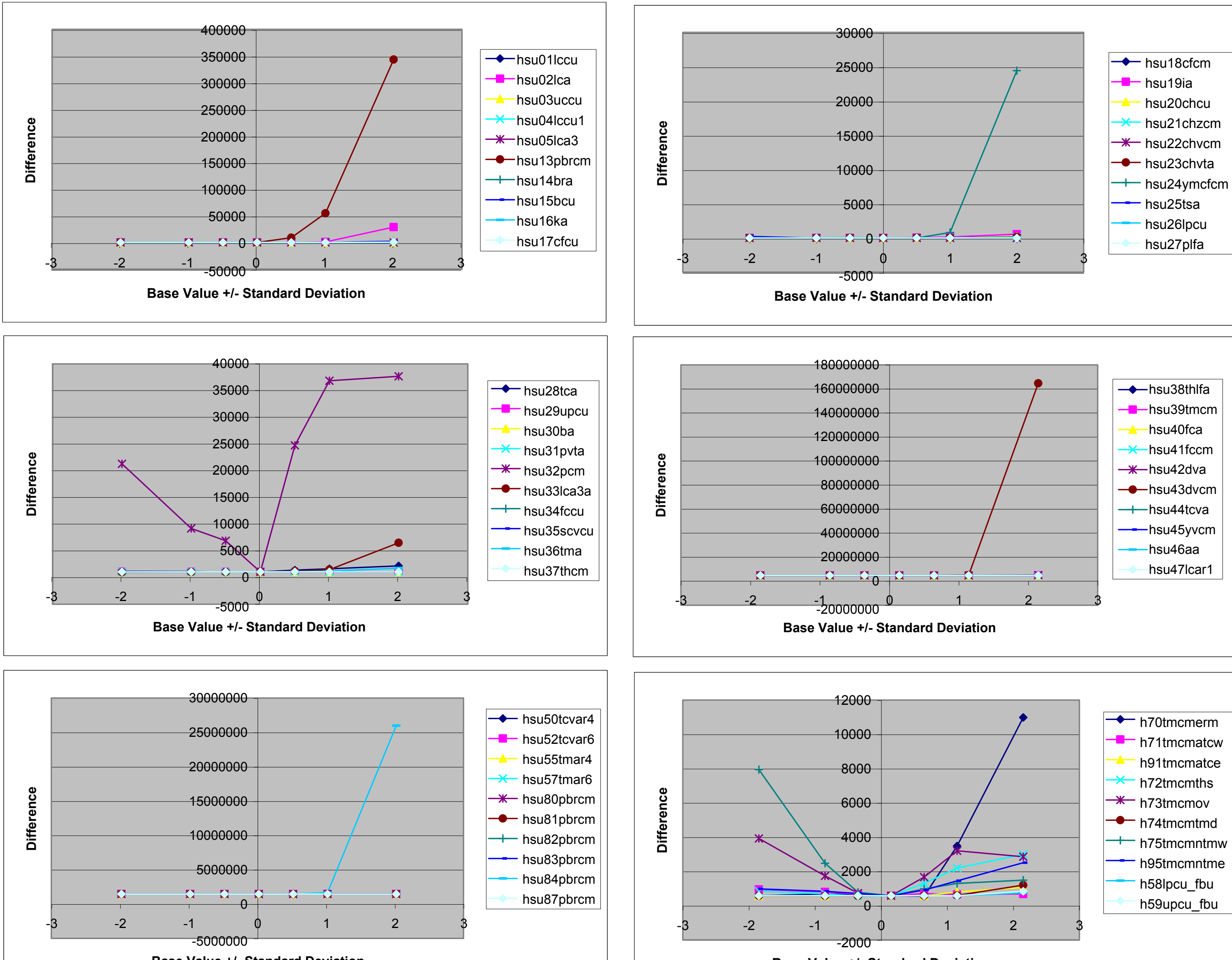

Base Value +/-Standard Deviatio
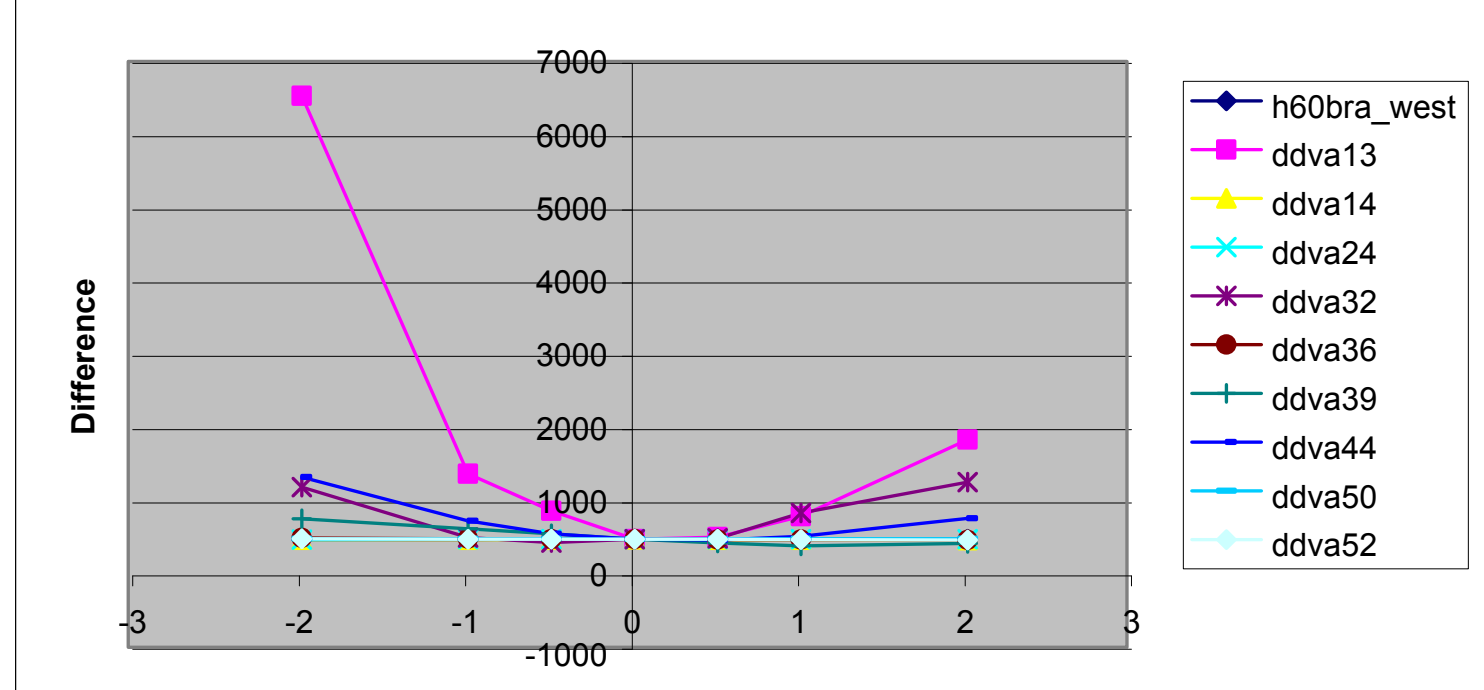

Base Value +// Standard Deviation
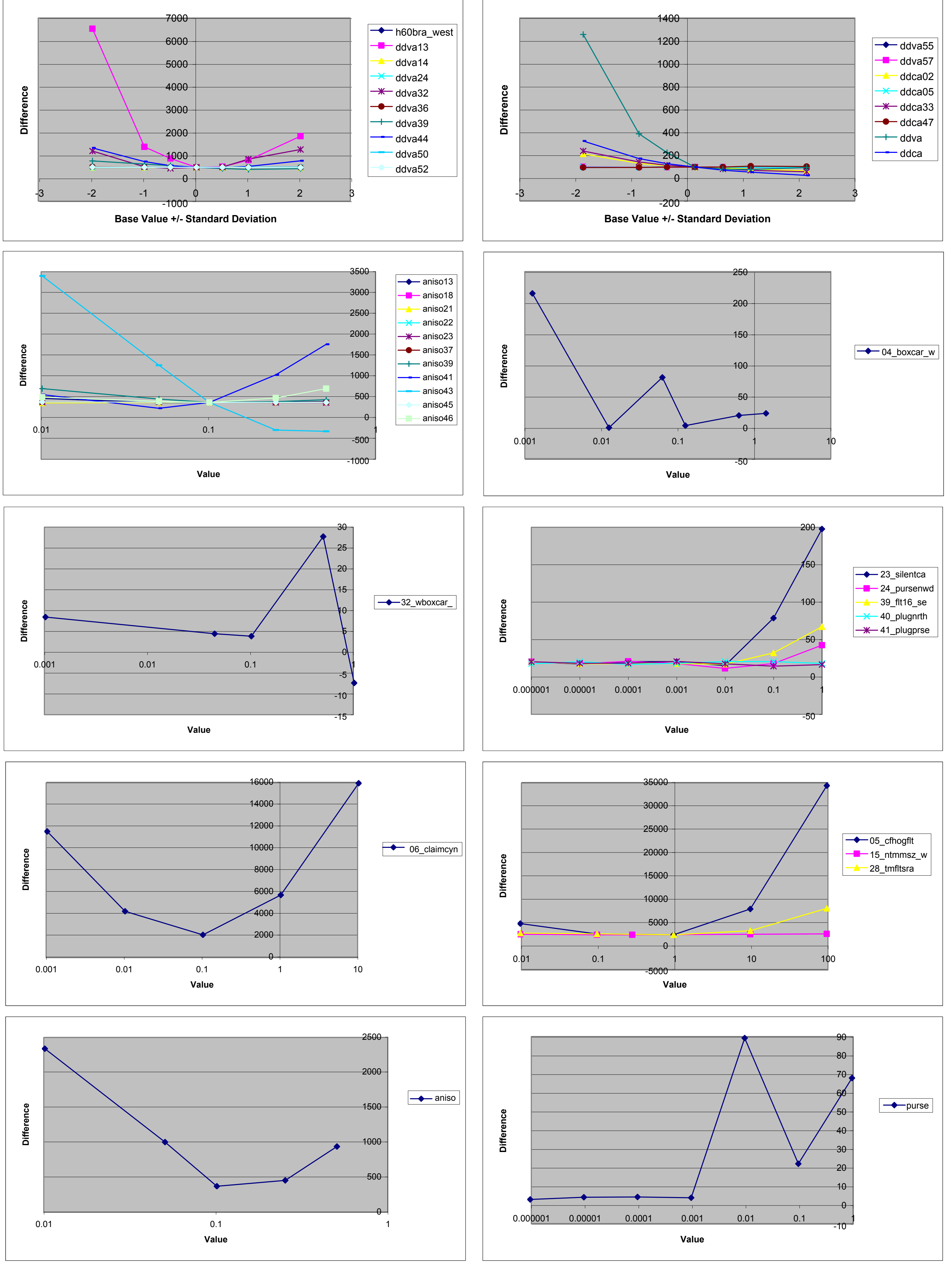

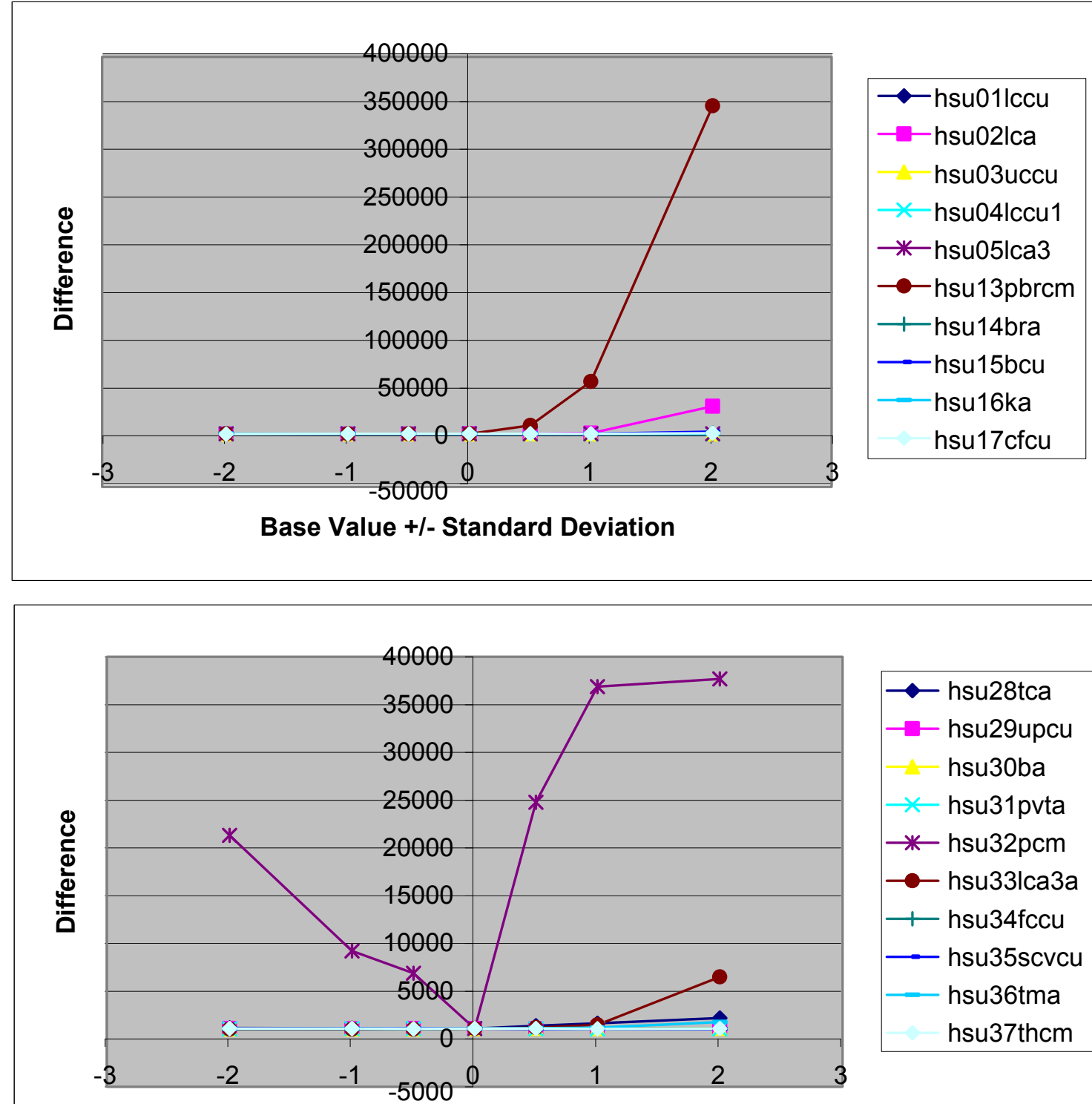

- hsu28tca - hsu29upcu * hsu31pvta + hsu34fccu - hsu35scrveu - hsu36tma hsu37thcm Base Value +/- Standard Deviation
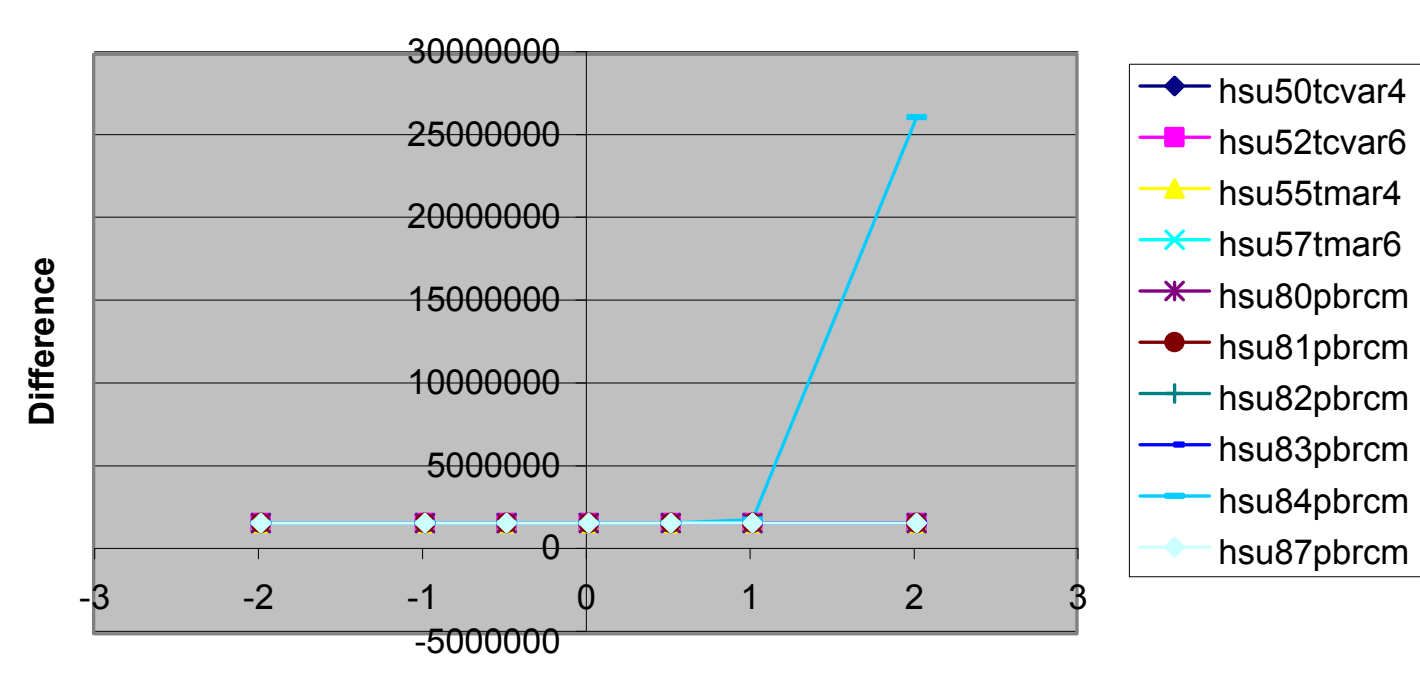

Base Value +/- Standard Deviation

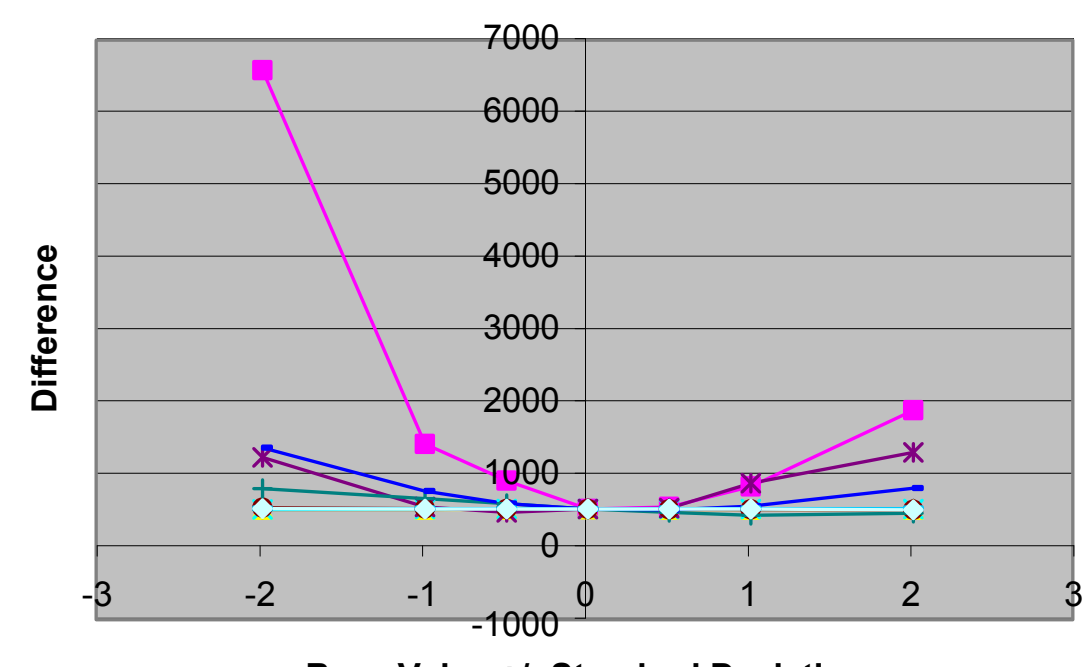
- h60bra_west - ddva14 $*$-ddva24
$*$ - ddva32 *-ddva32
$\multimap-$ ddva36 — ddva39 - ddva50 Base Value +/-Standard Deviation
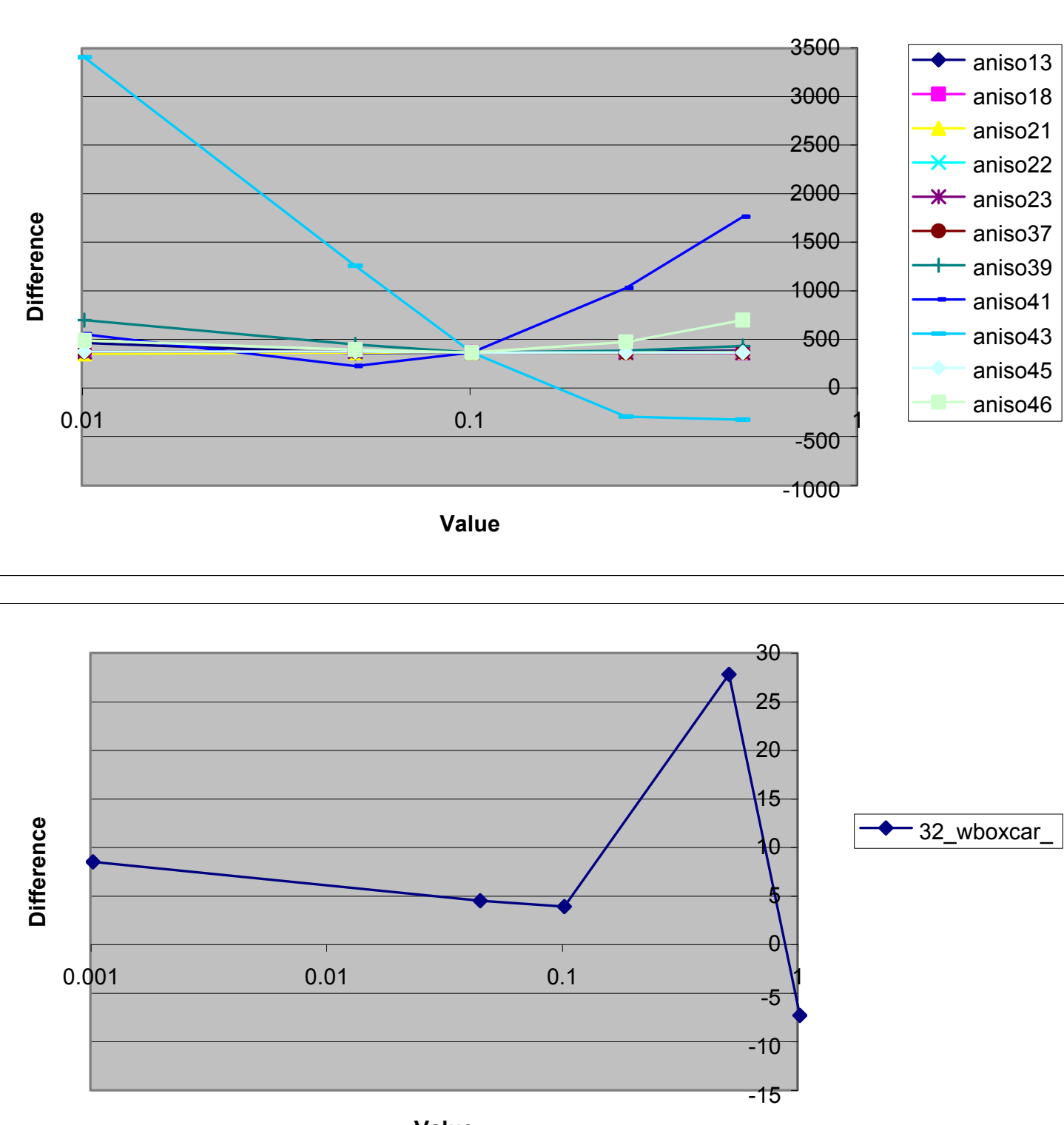

- 32_wboxcar_
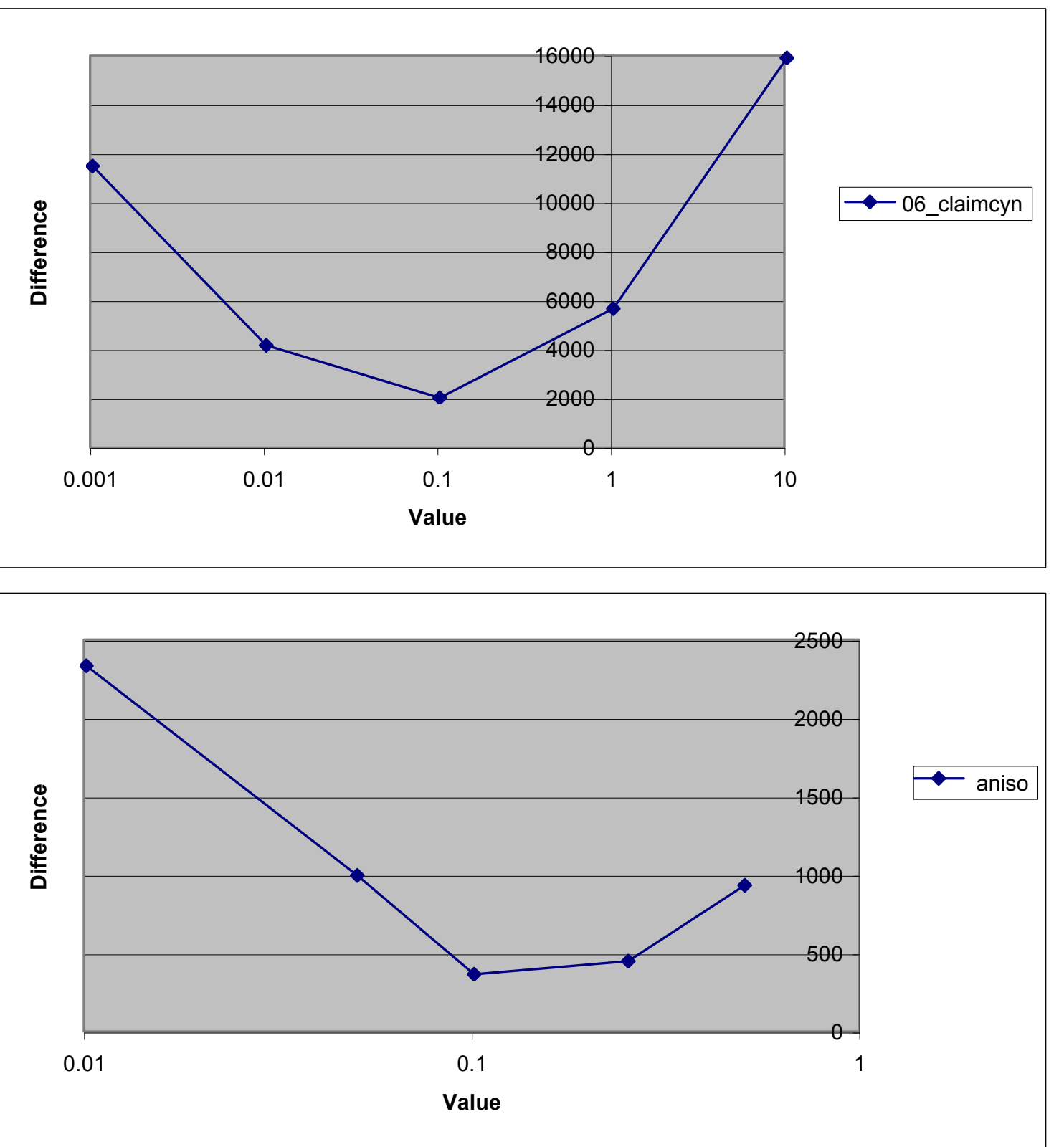

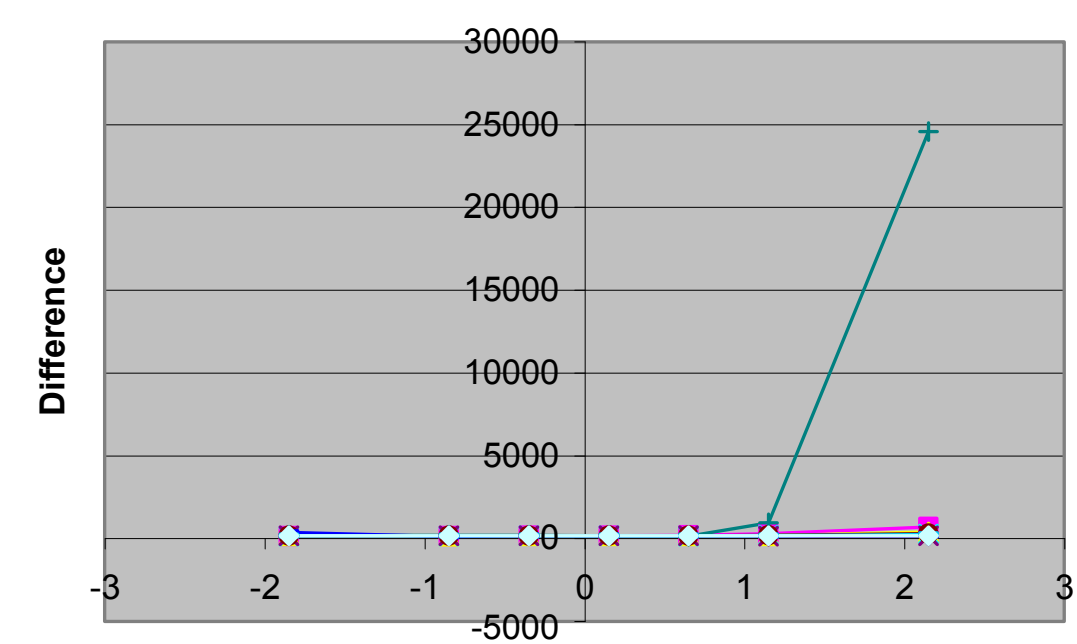

$\rightarrow-$ hsu18cfom - hsuroche $*$ hsu21chzcm
$*$-hsu22chvcm - - nsu23chvta - hsu24yma - hsu25tsa - hsu2lipcu
hsu27plfa

Base Value +/- Standard Deviation

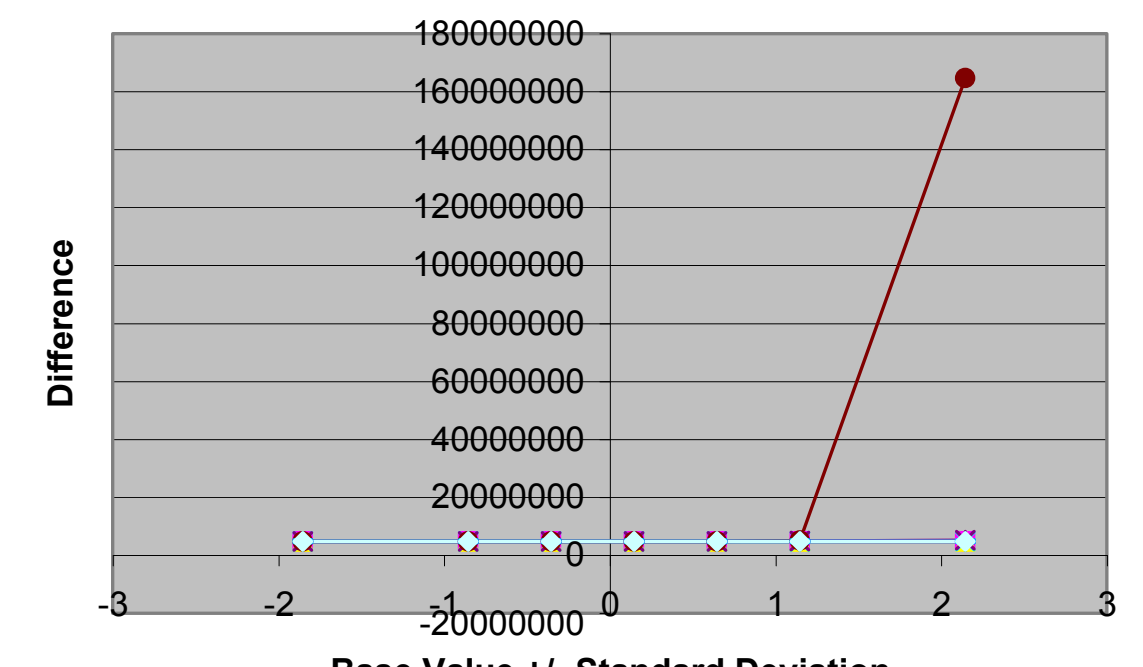

$\rightarrow$-hsu38thlfa $\rightarrow$-hsu39tmcm - hsu40fca
$x$-hsu4 1 fccm
*-hsu42dva $\because-$ hsu43dvcm + - hsu4ticva - hsu45yvcm hsu47lcar1 Base Value +/-Standard Deviation
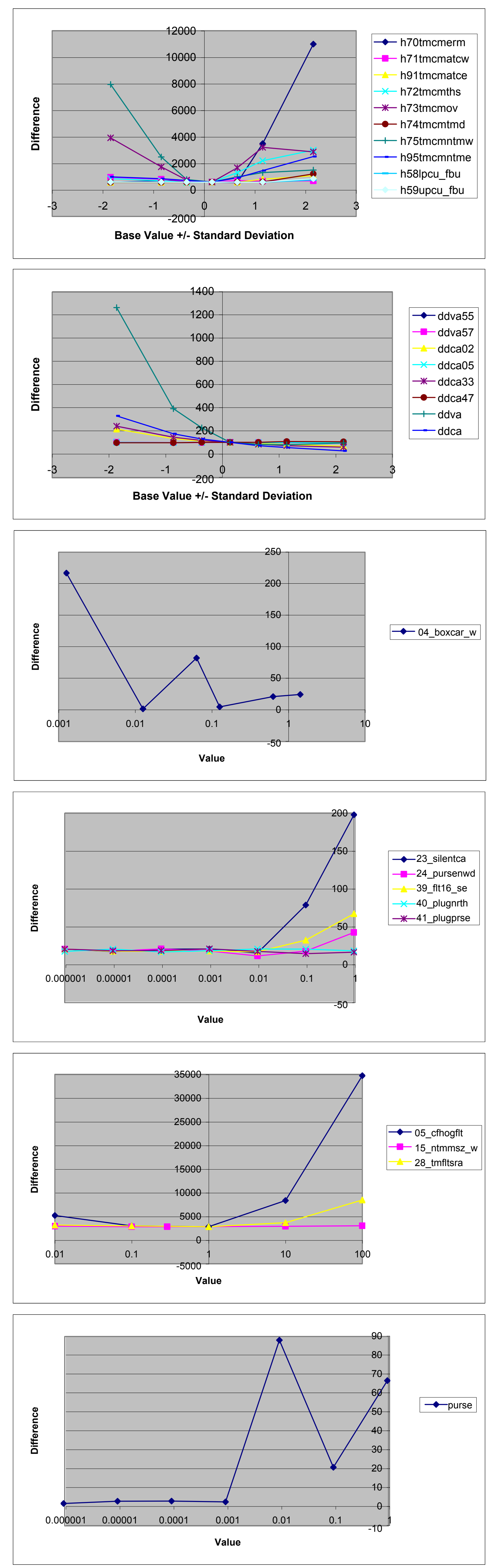

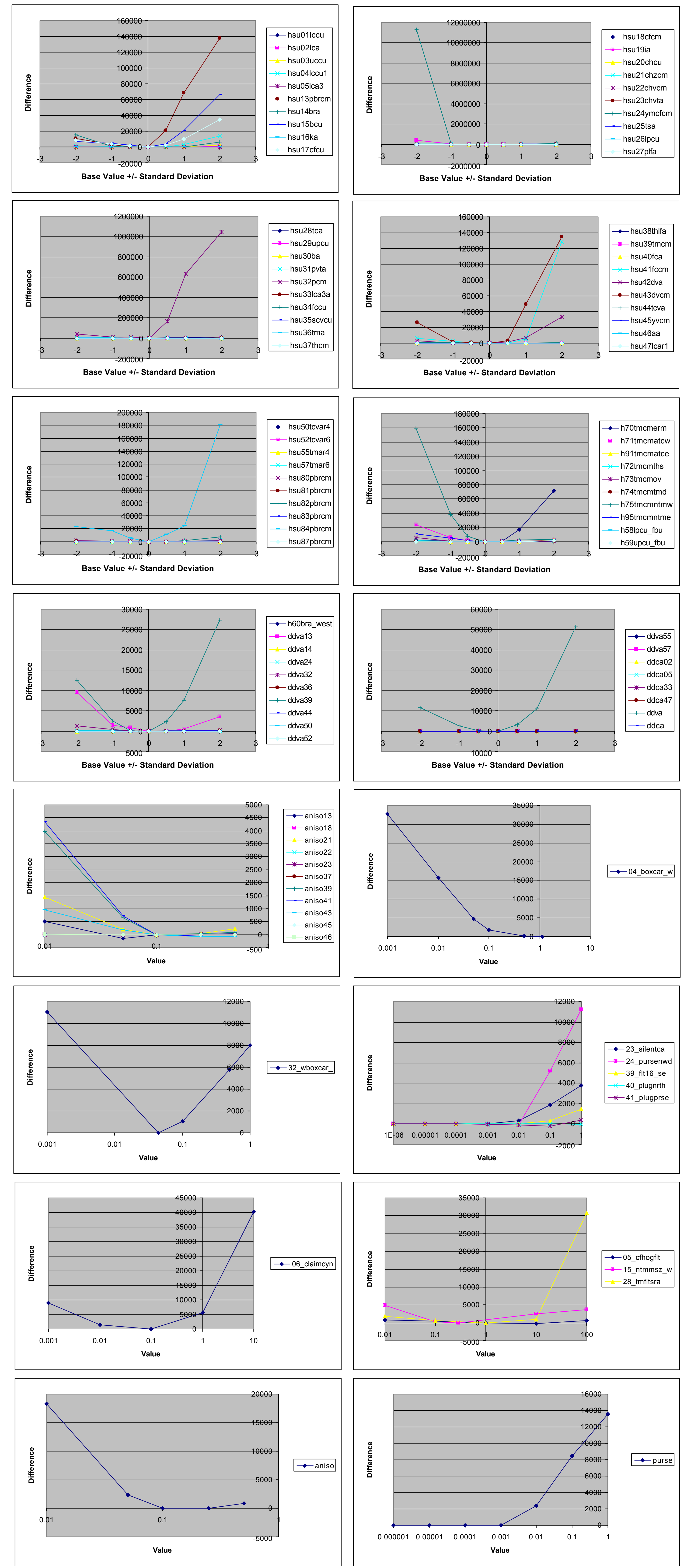

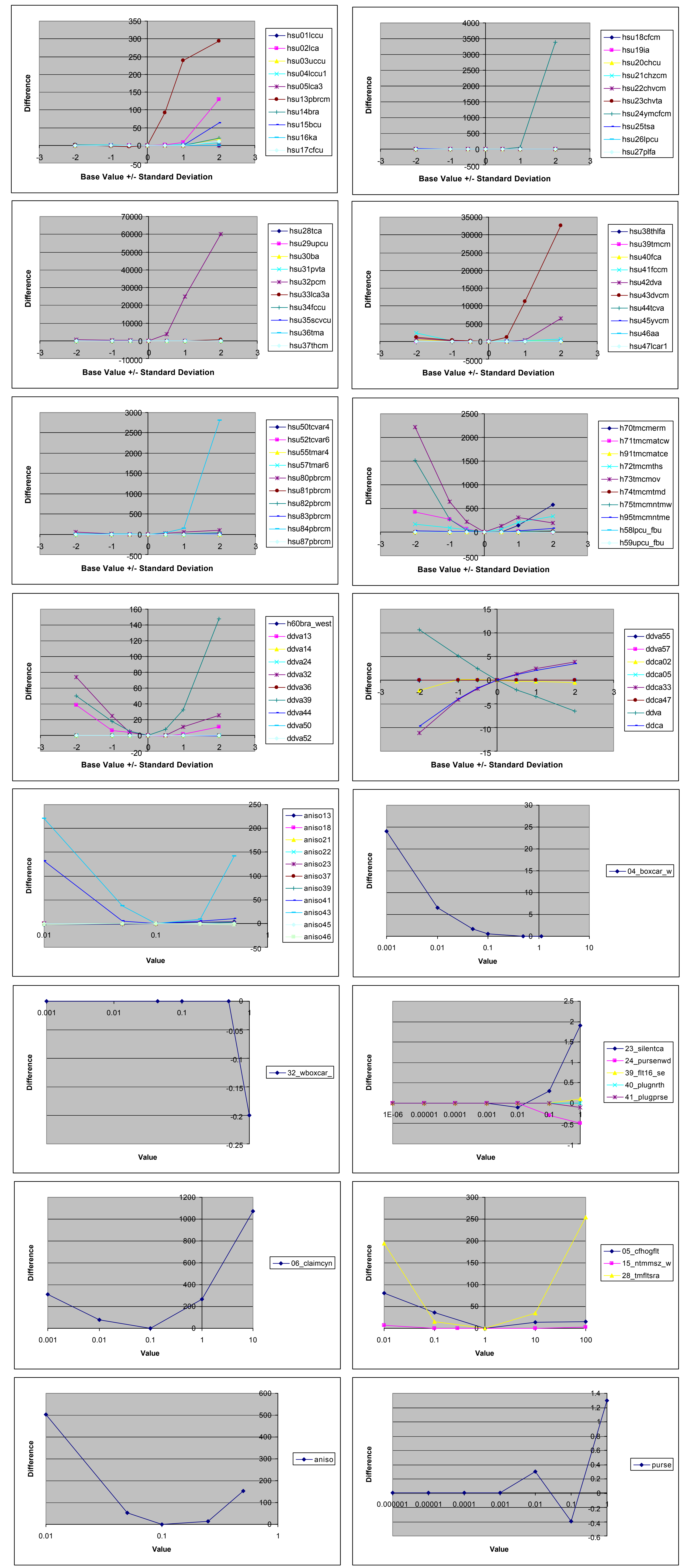


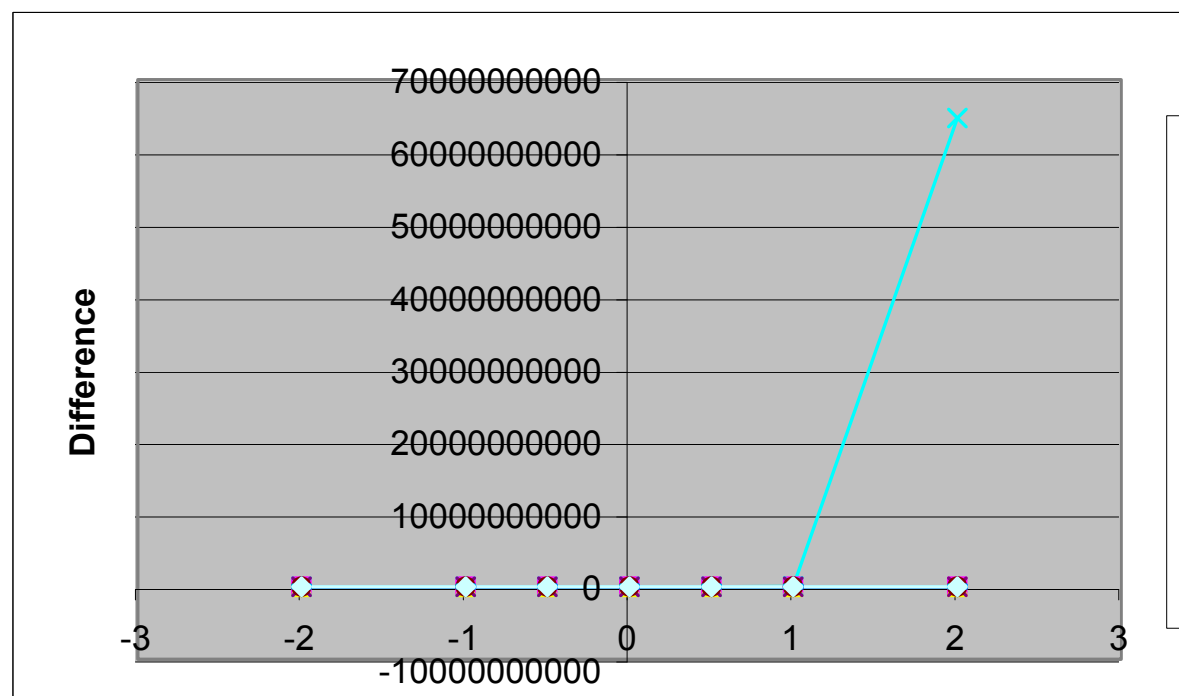

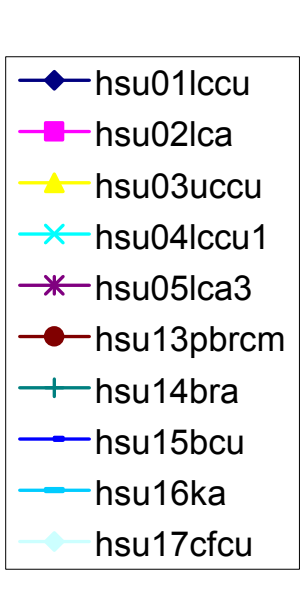

Base Value +/- Standard Deviation

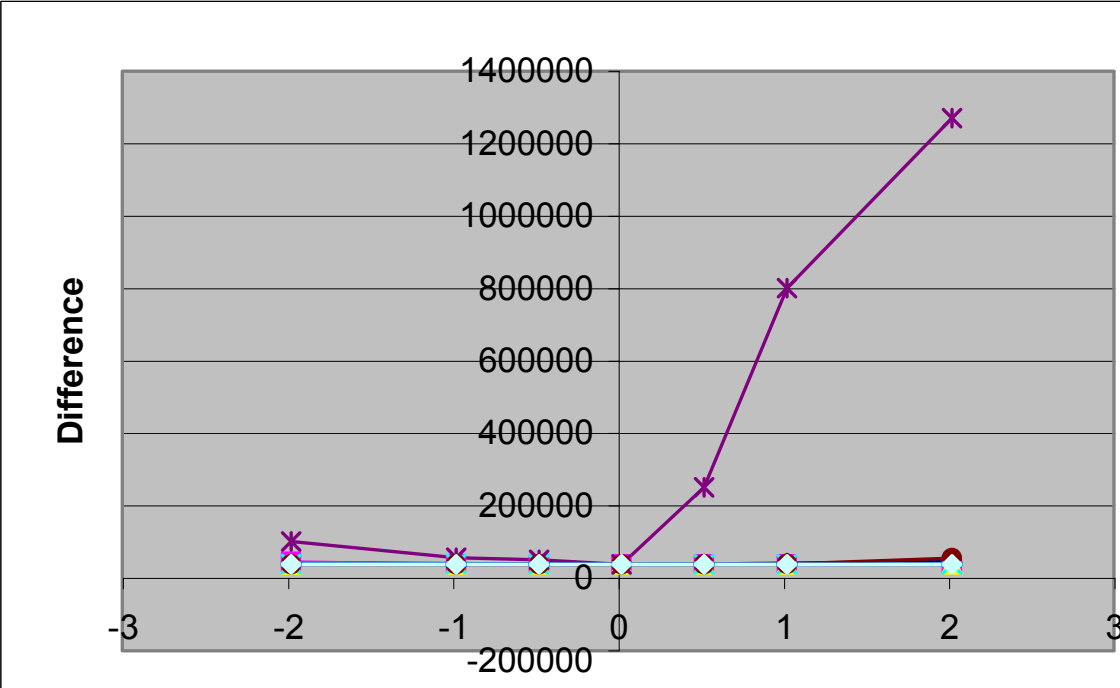

$\rightarrow$ - hsu28tca - - hsu29upcu - hsu30ba
- - hsu31pvta $\rightarrow$ - hsu331ca3a - hsu36tma Base Value +/-Standard Deviation

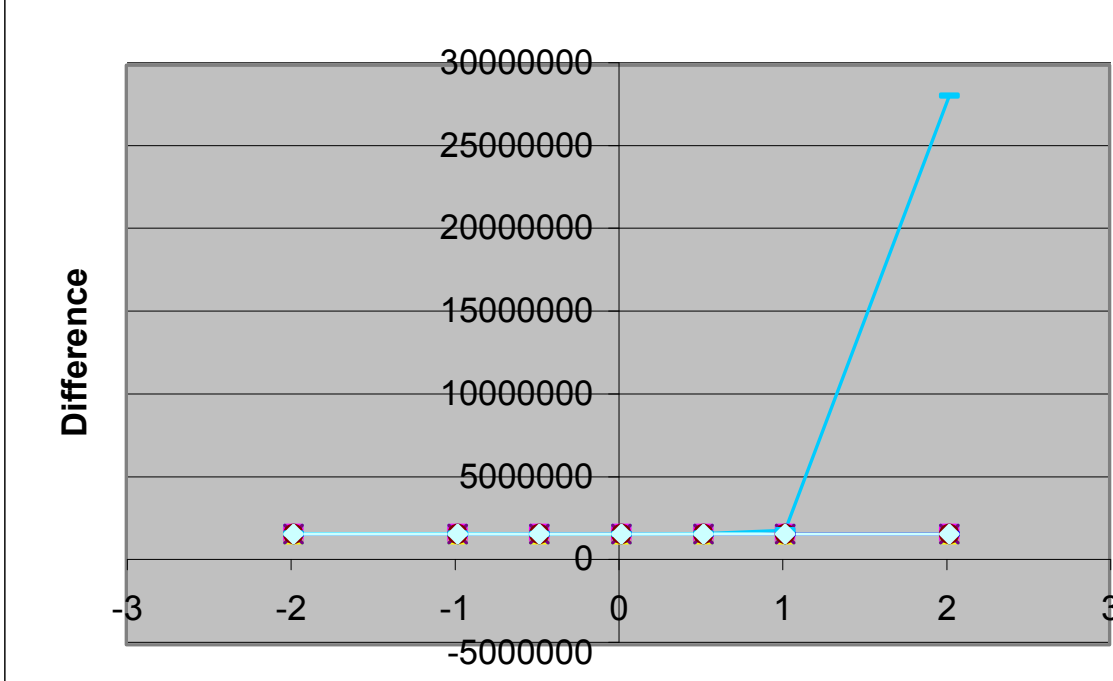

$\rightarrow$ - hsu50tcvar4 - hsu52tcvar6 < hsu57tmar6 * nsu80pbrcm - - hsu81pbrcm + hsu82pbrcm - hsu83pbrcm hsus4pbrcm

Base Value +1-Standard Deviation

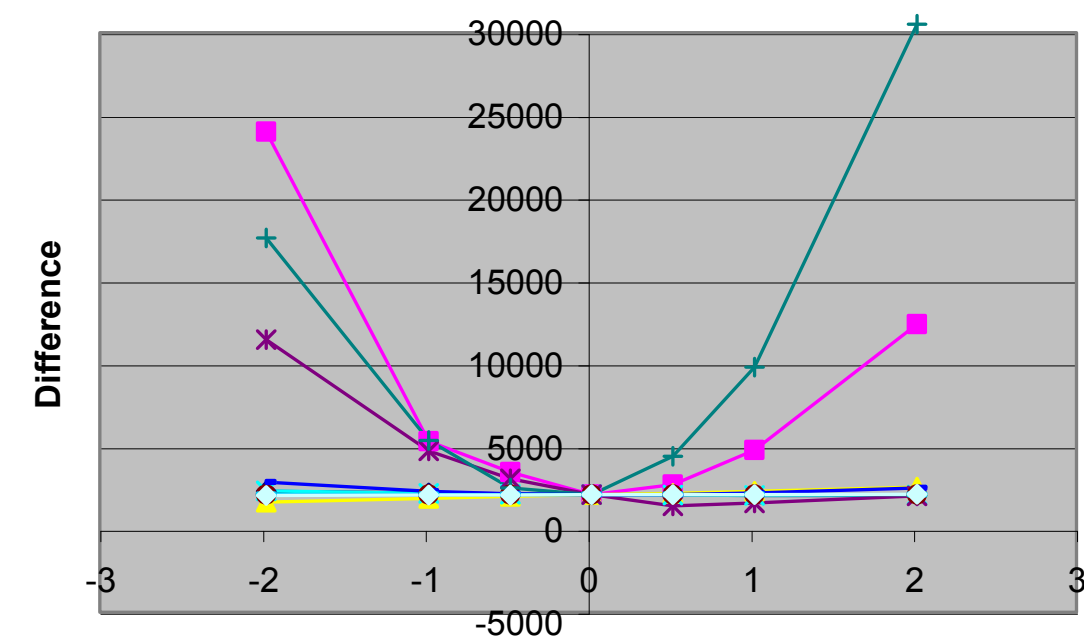

- h60bra_west - ddva13

$\times$ ddva24

*-ddva32 - - ddva36 —ddva39 - ddva44

Base Value +/-Standard Deviation
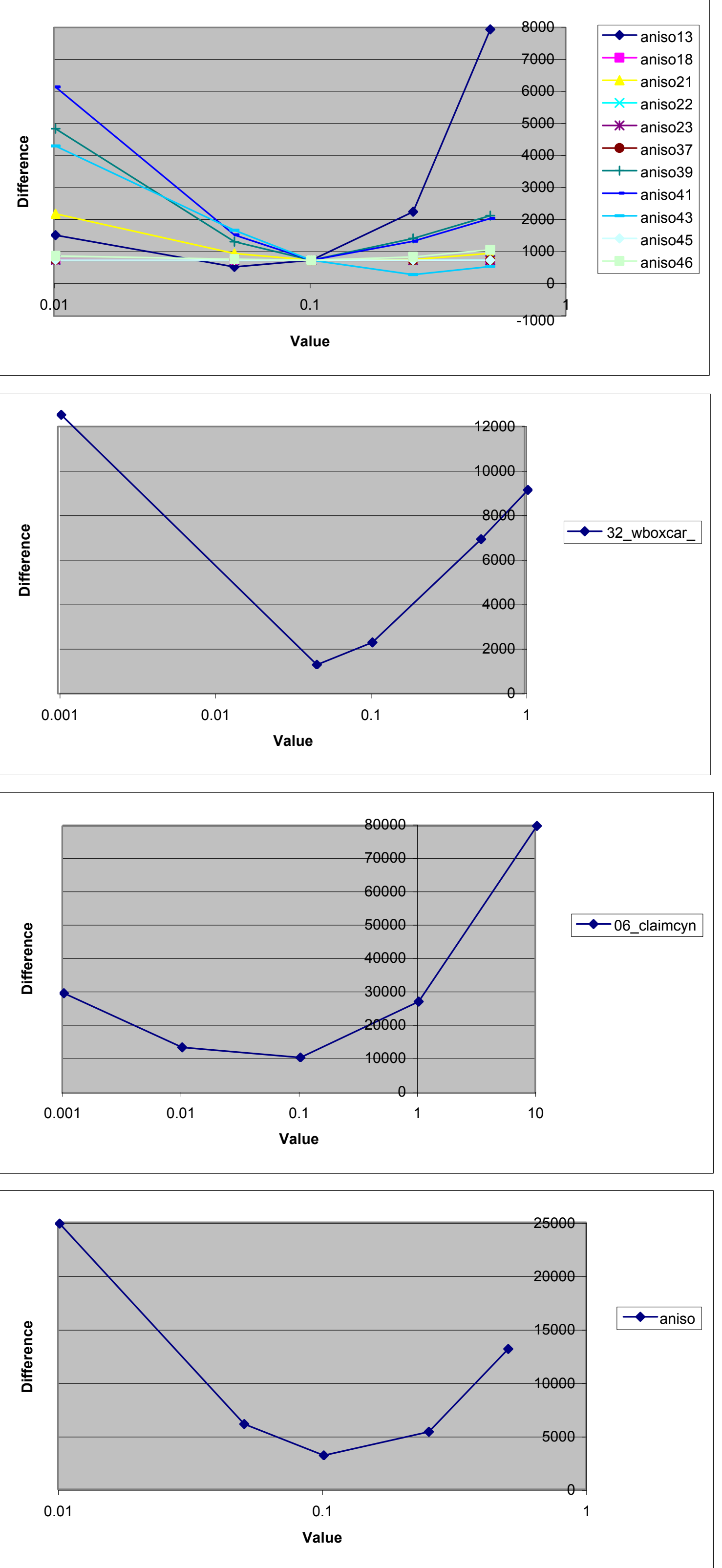

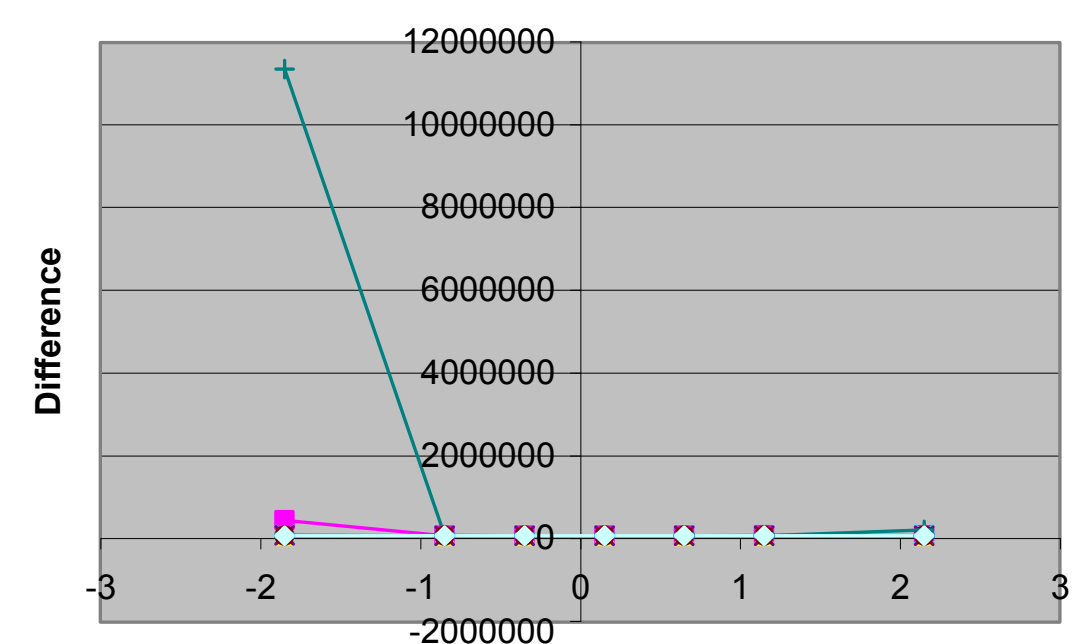

- $\mathrm{hsu18cfcm}$ - hsu19ia
- hsu20chcu * hsu21chzcm *-hsu22chvcm $\rightarrow$ - hsu23chvta - hsu26ipcu - hsu26lpcu
hsu27plfa

Base Value +/-Standard Deviation
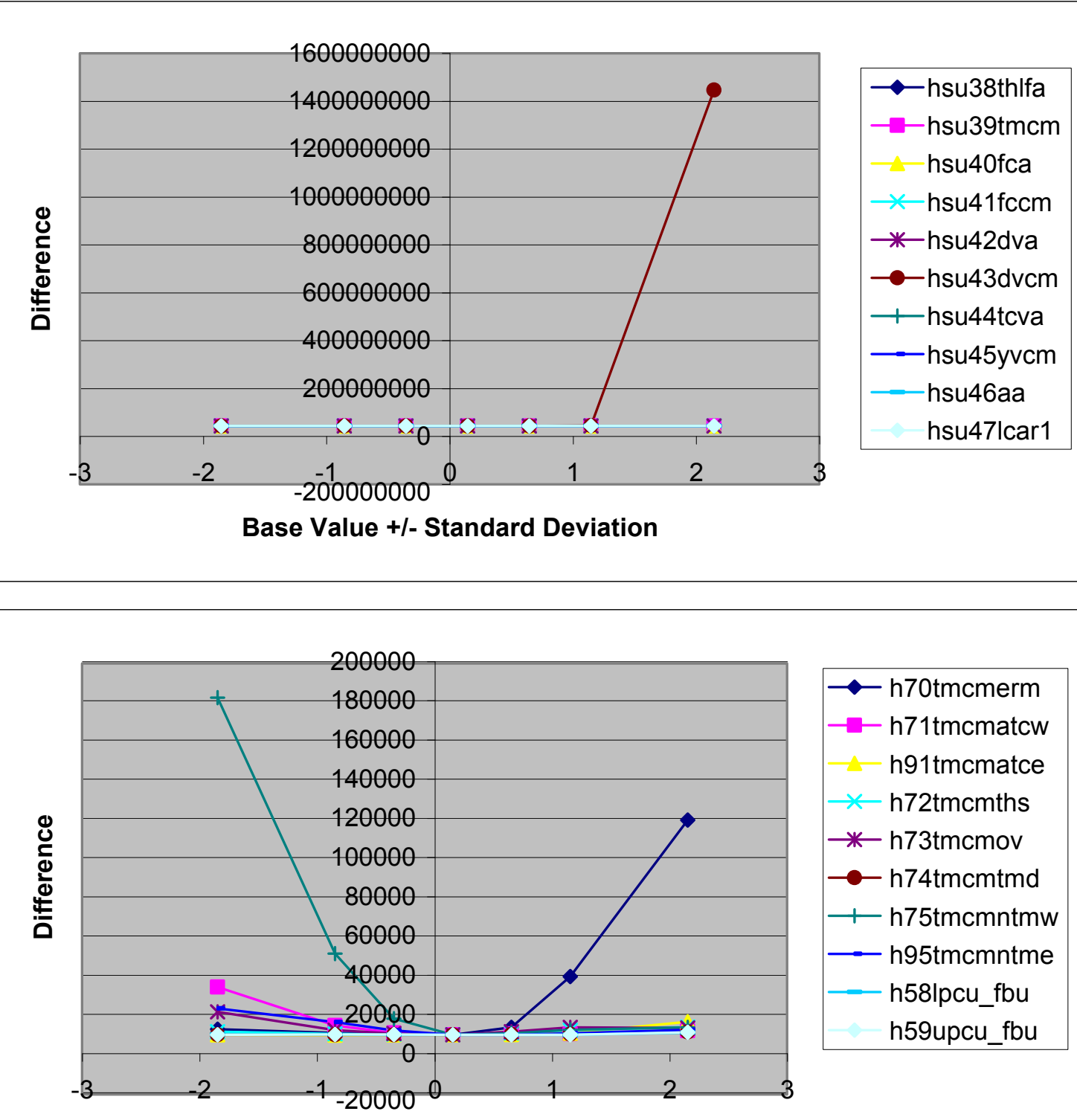

- h70tmcmerm - h71tmcmatcw $-\mathrm{h} 91$ tmmatce
$*$ - h72tmcmths - h73tmcmov - h74tmcmtmd - h75tmcmntmw - h95tmcmntme
- h581pcu fbu
has h581pcu_fbu
h59upcu_fbu Base Value + - Standard Deviation
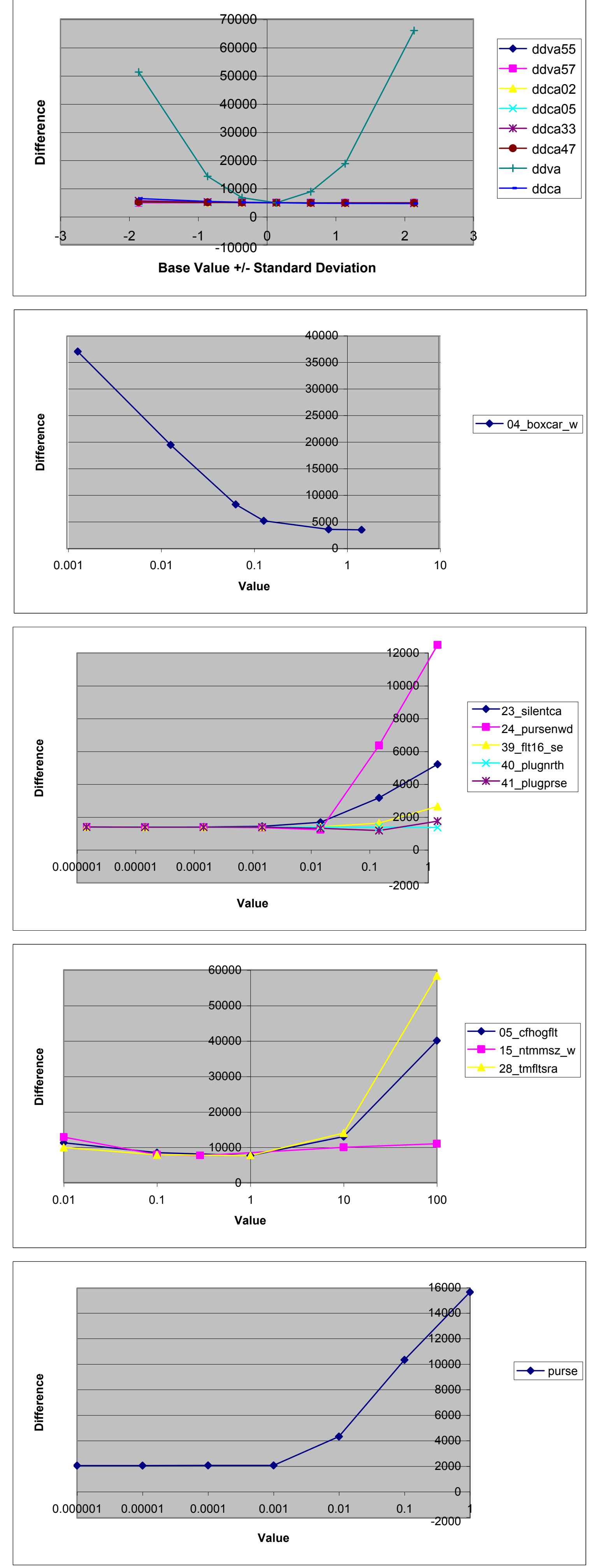
D.3.3 

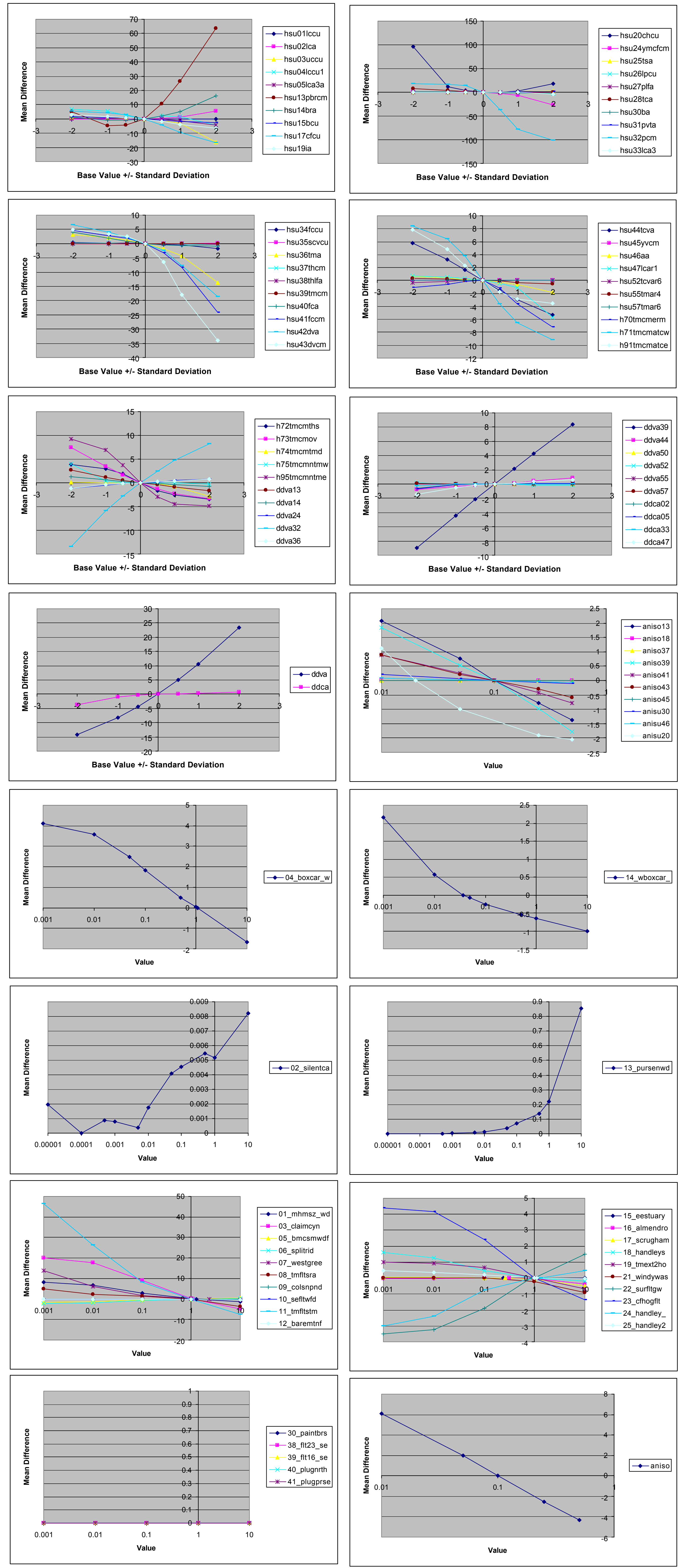

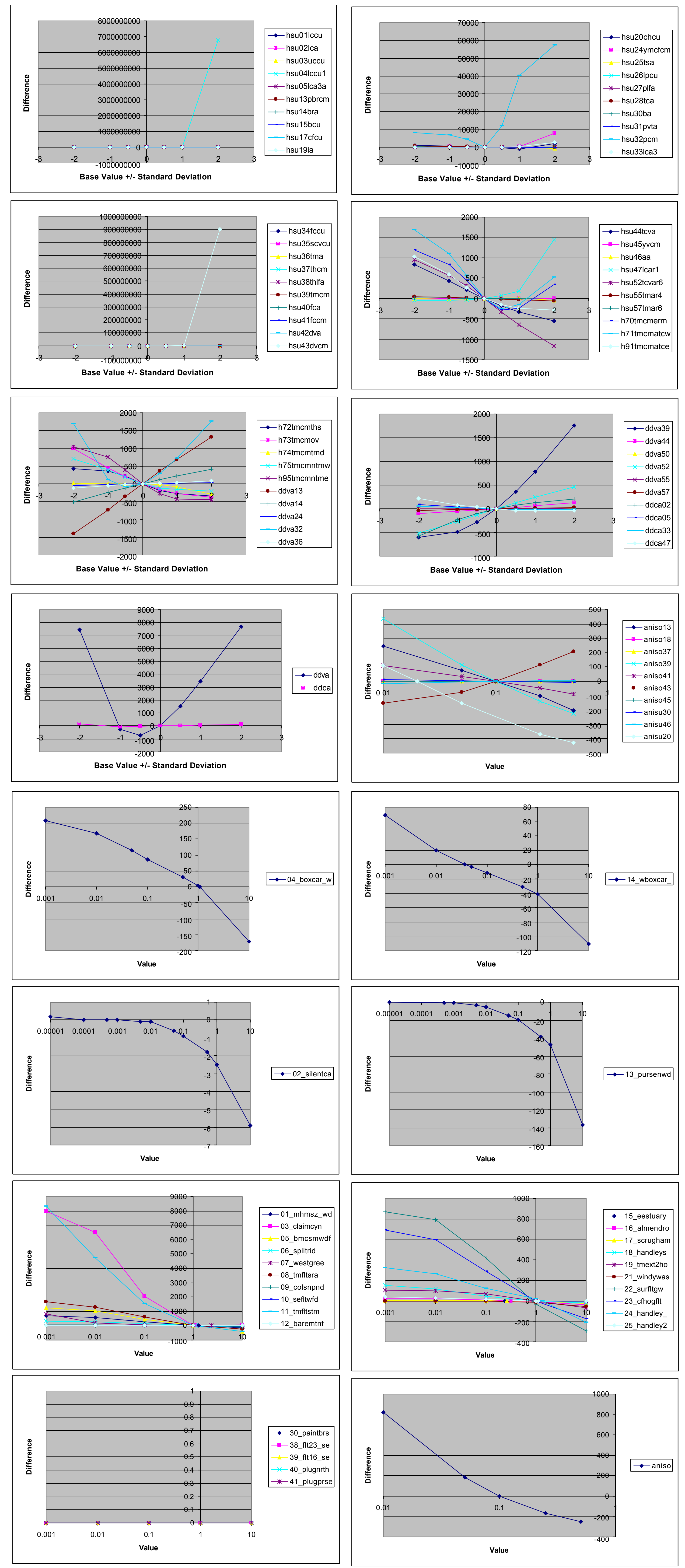

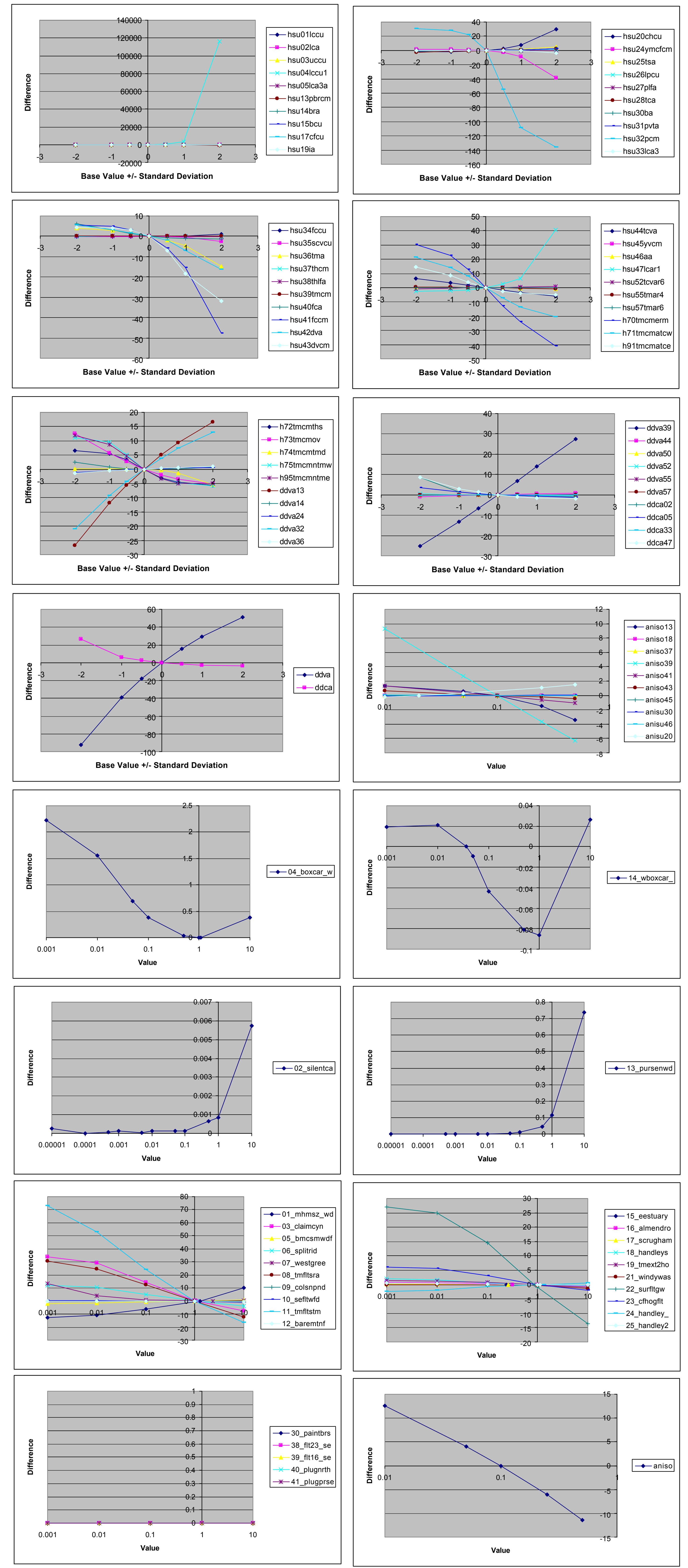

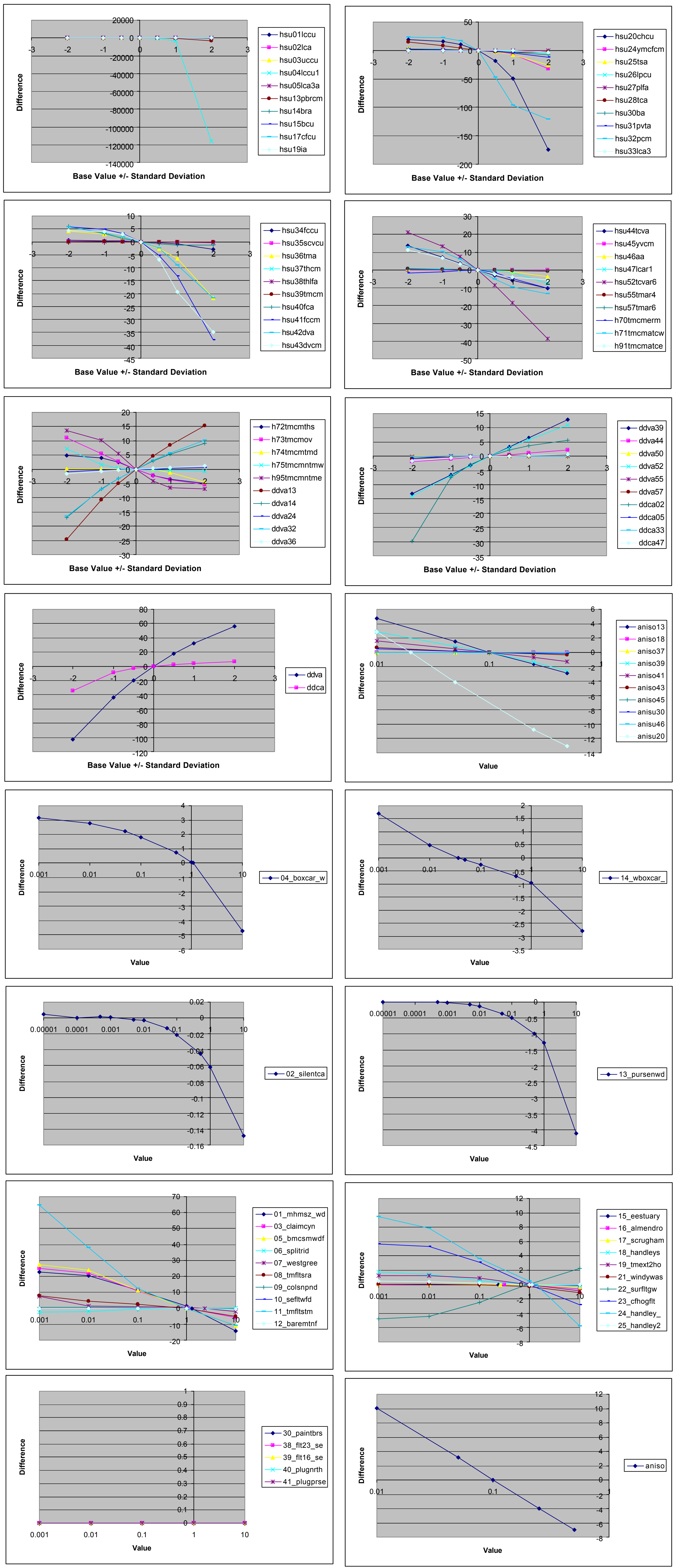

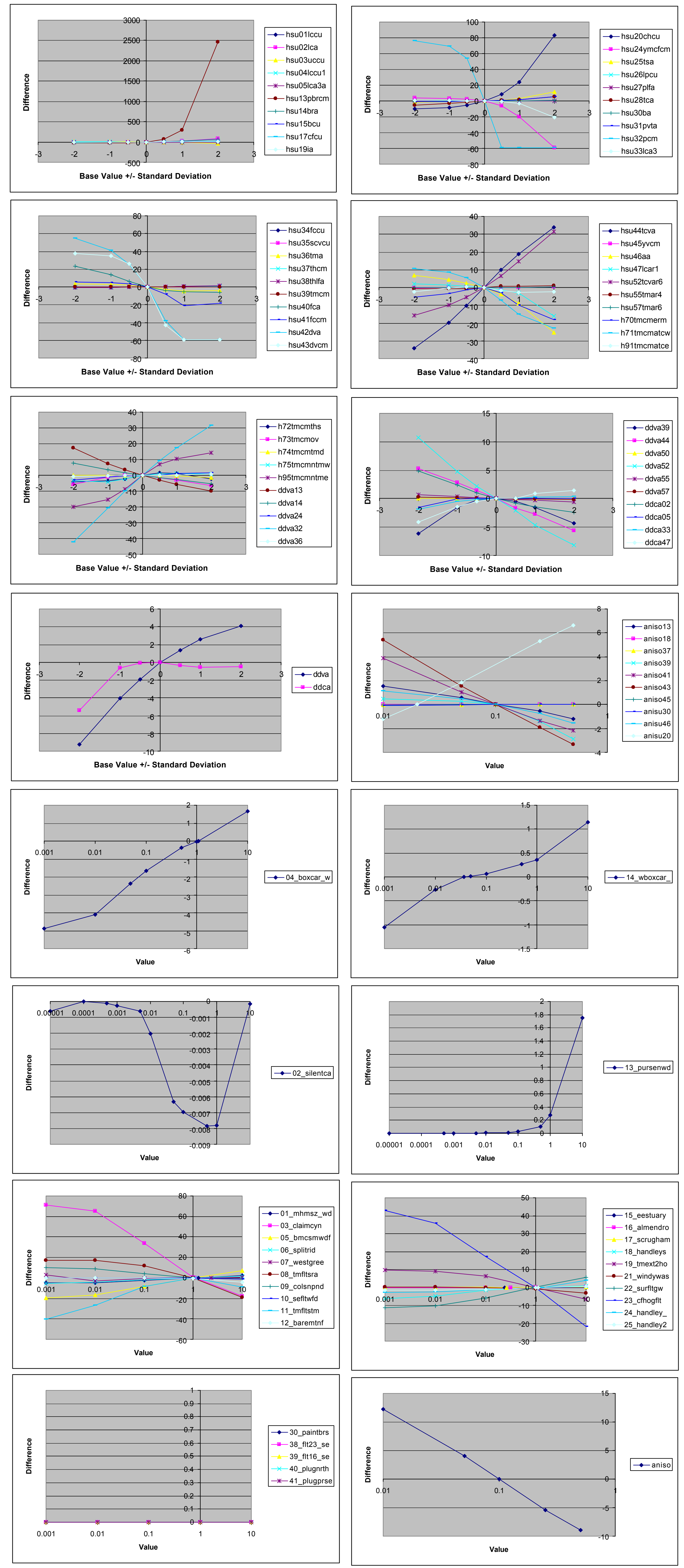

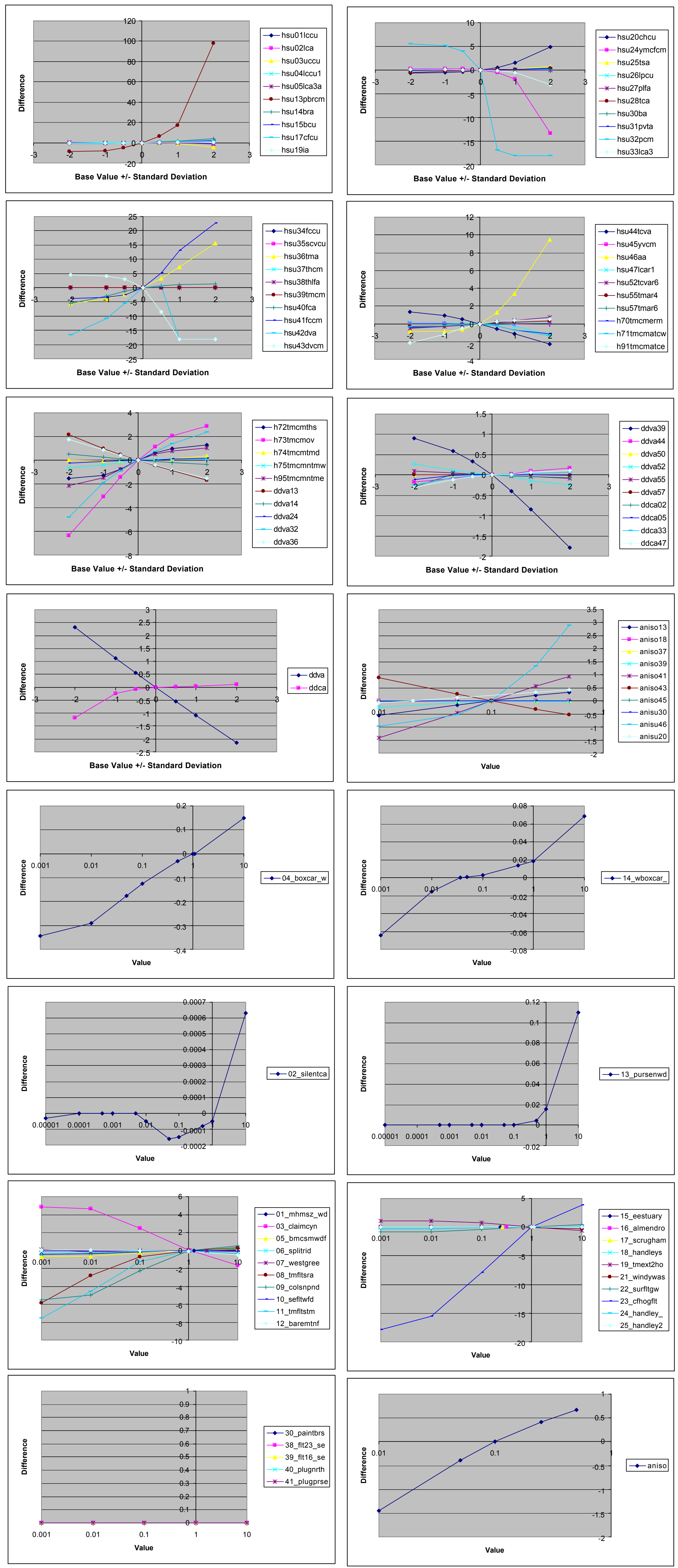

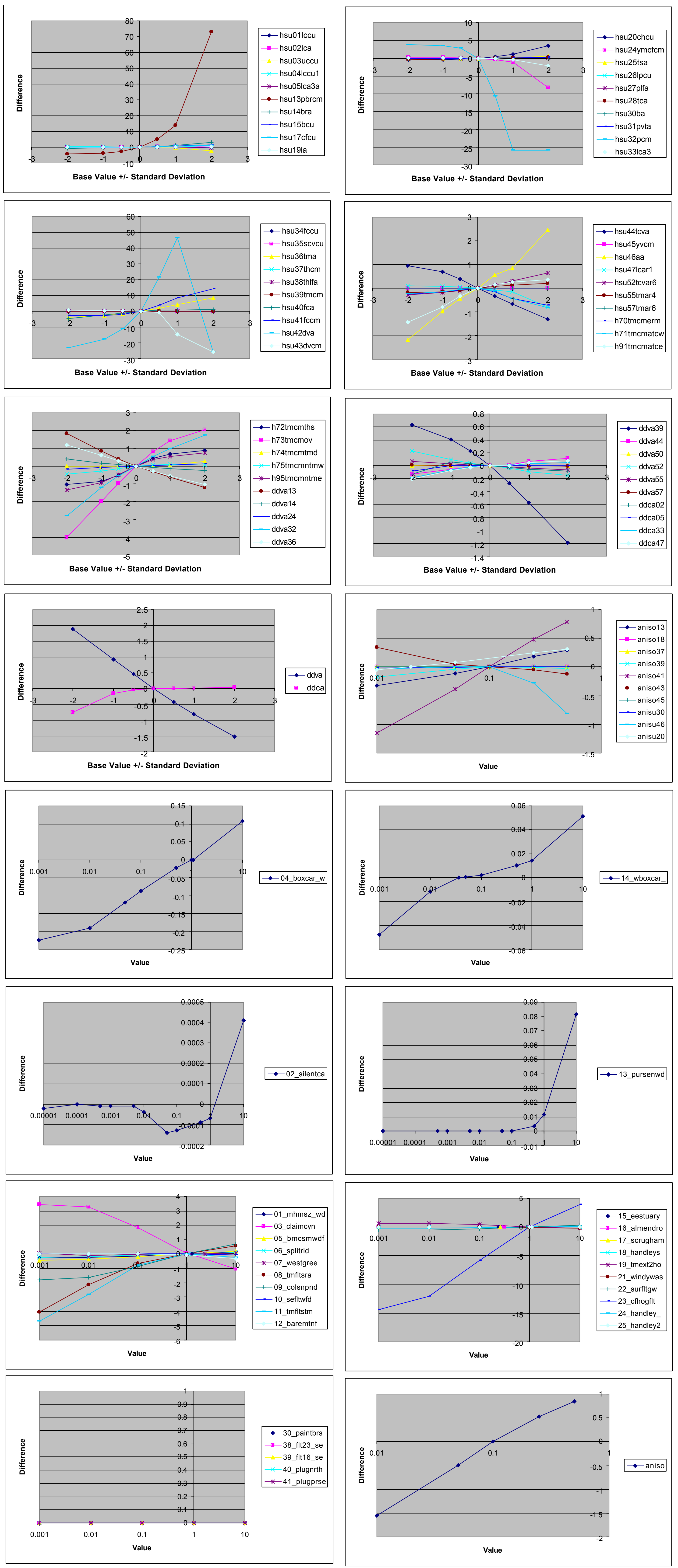

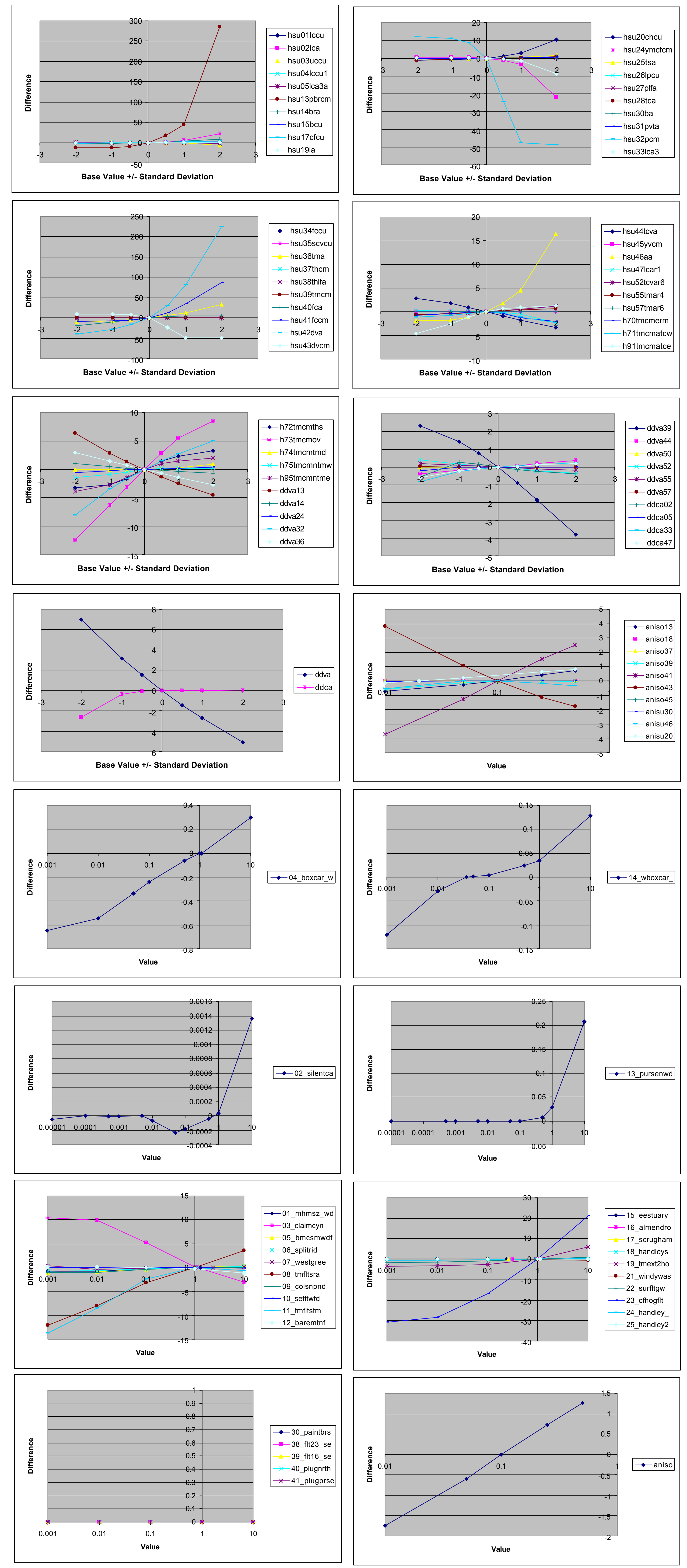

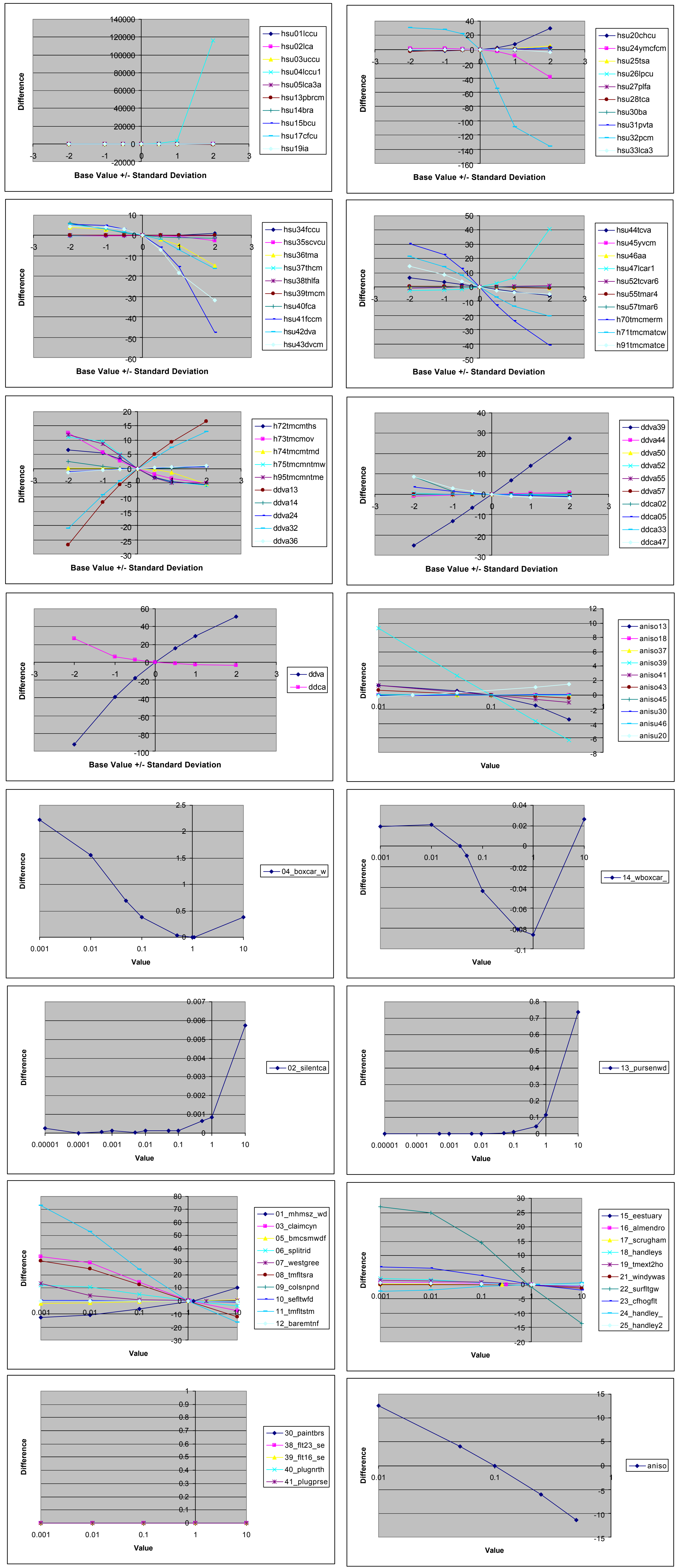

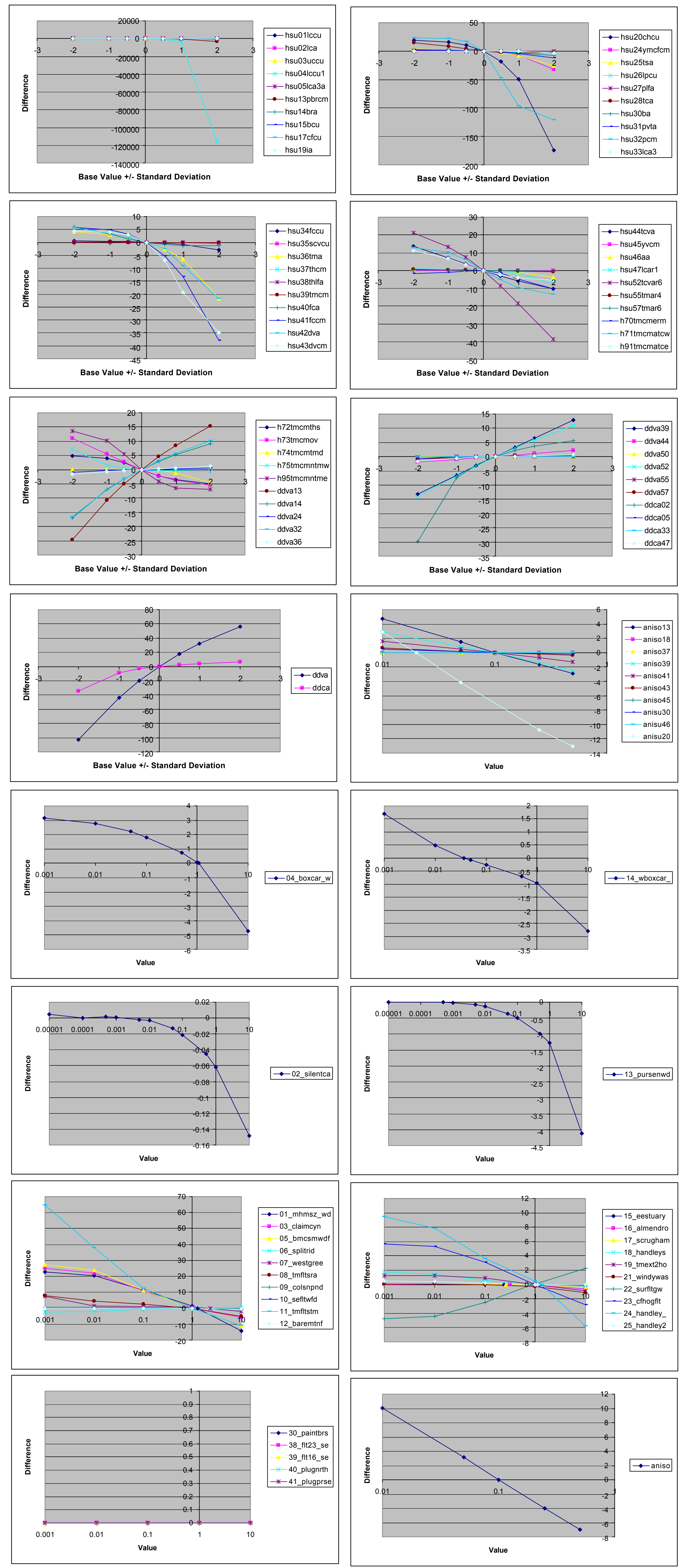

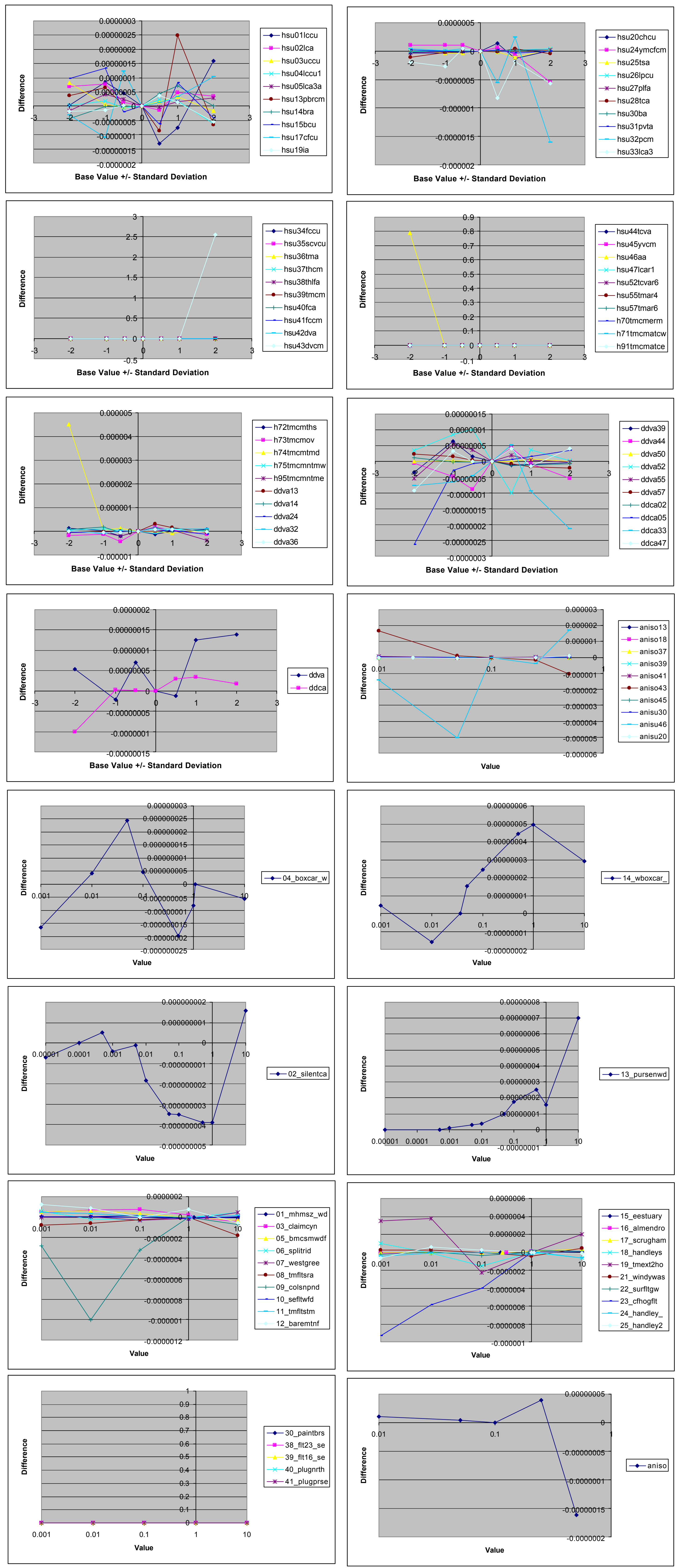

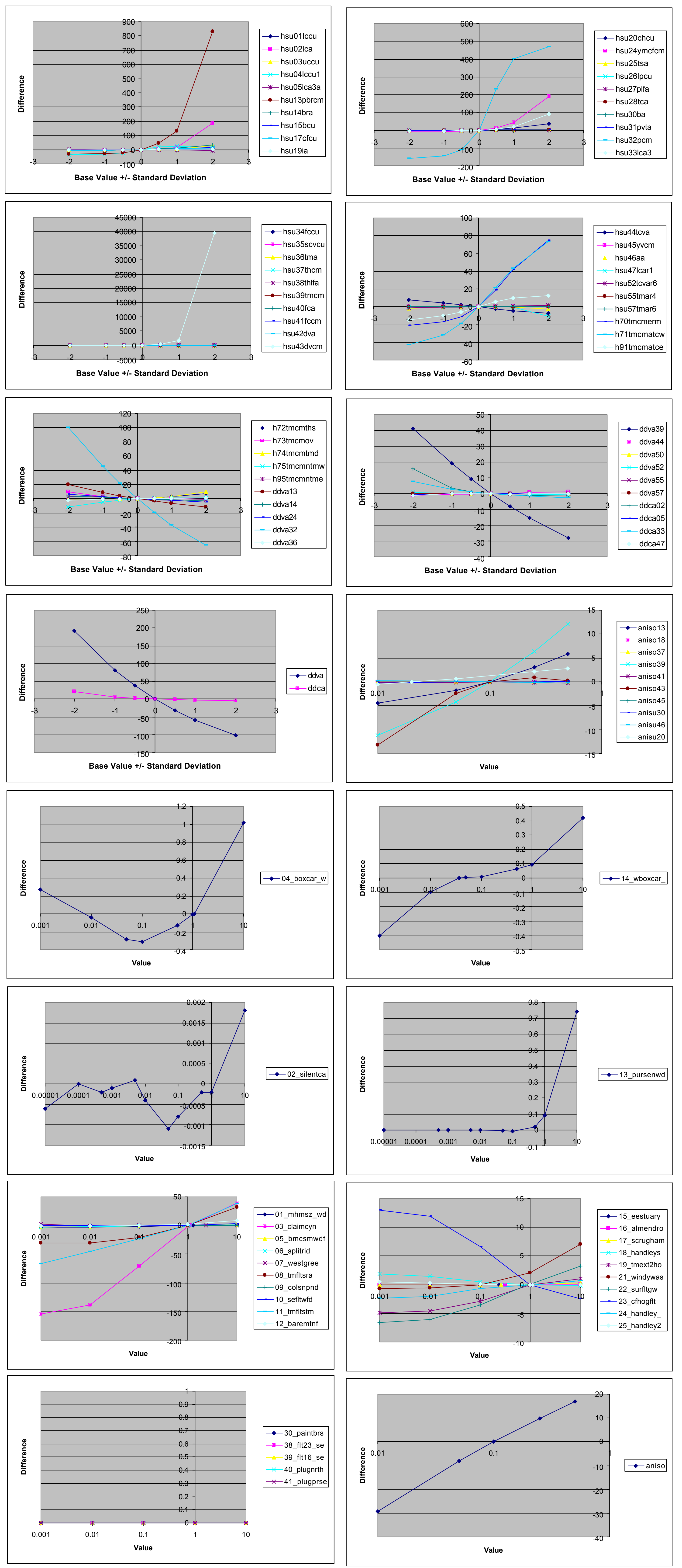

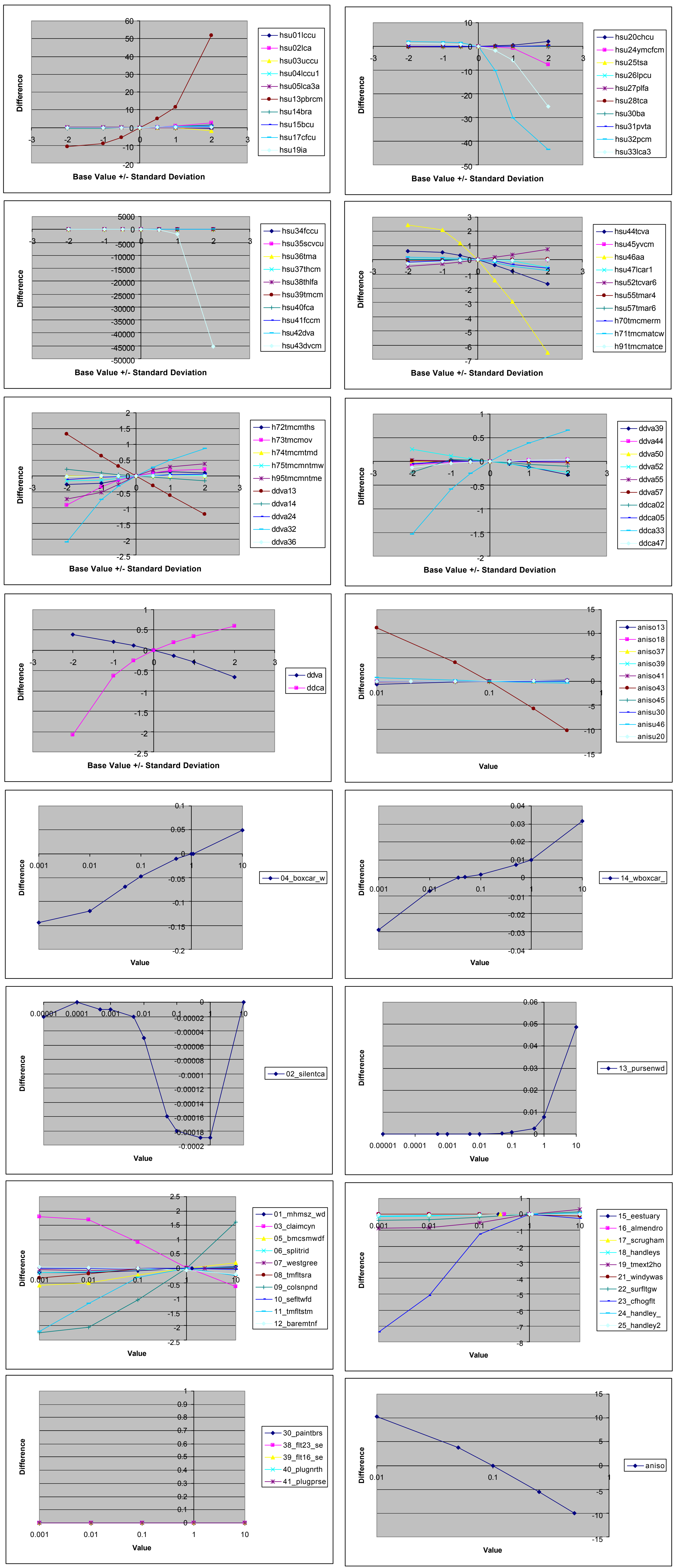

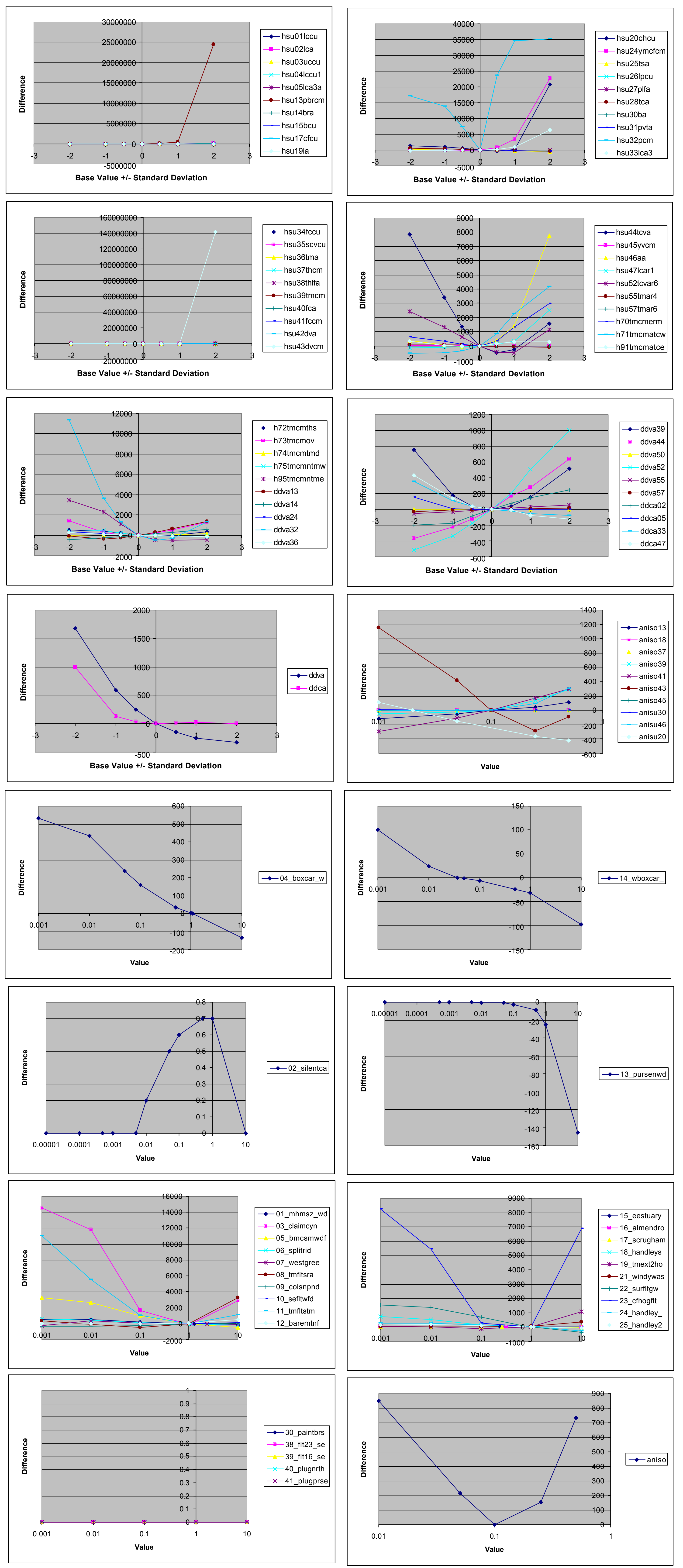

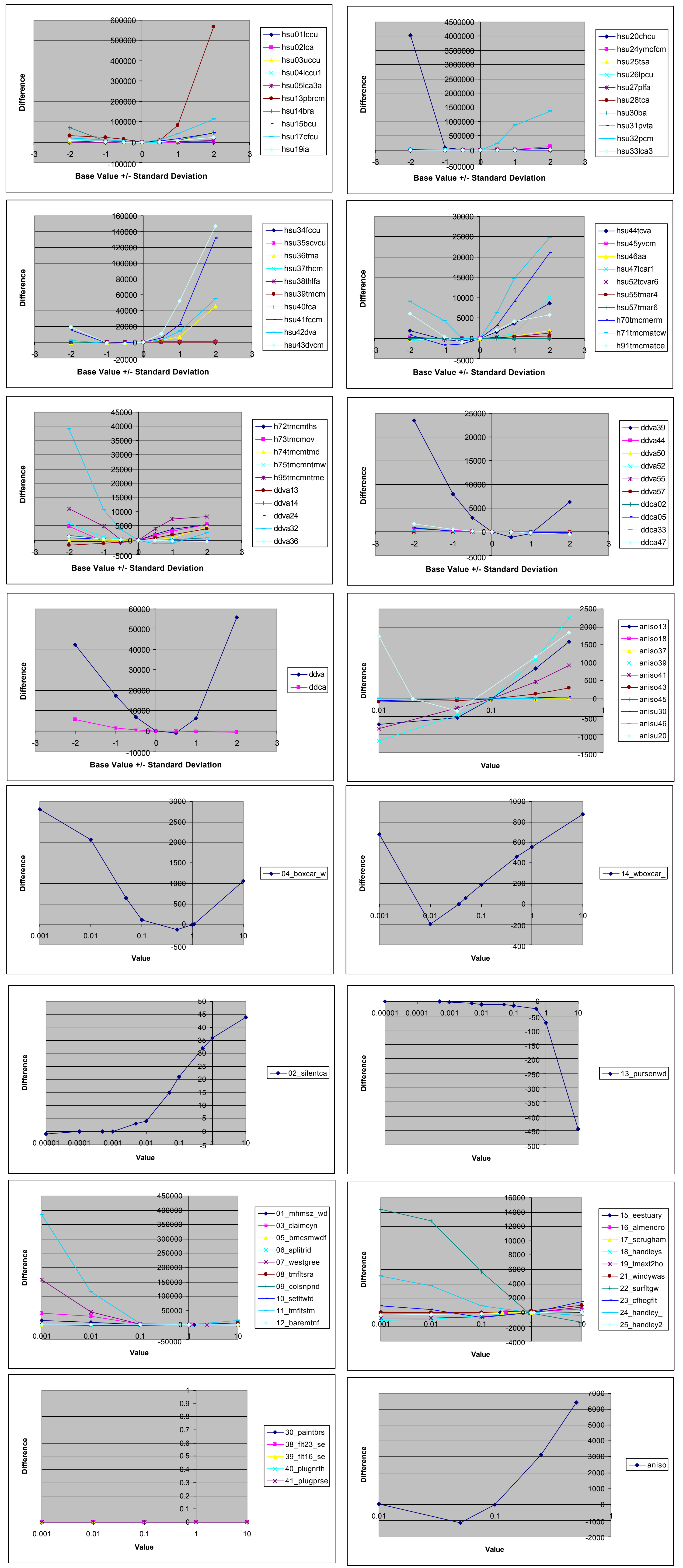

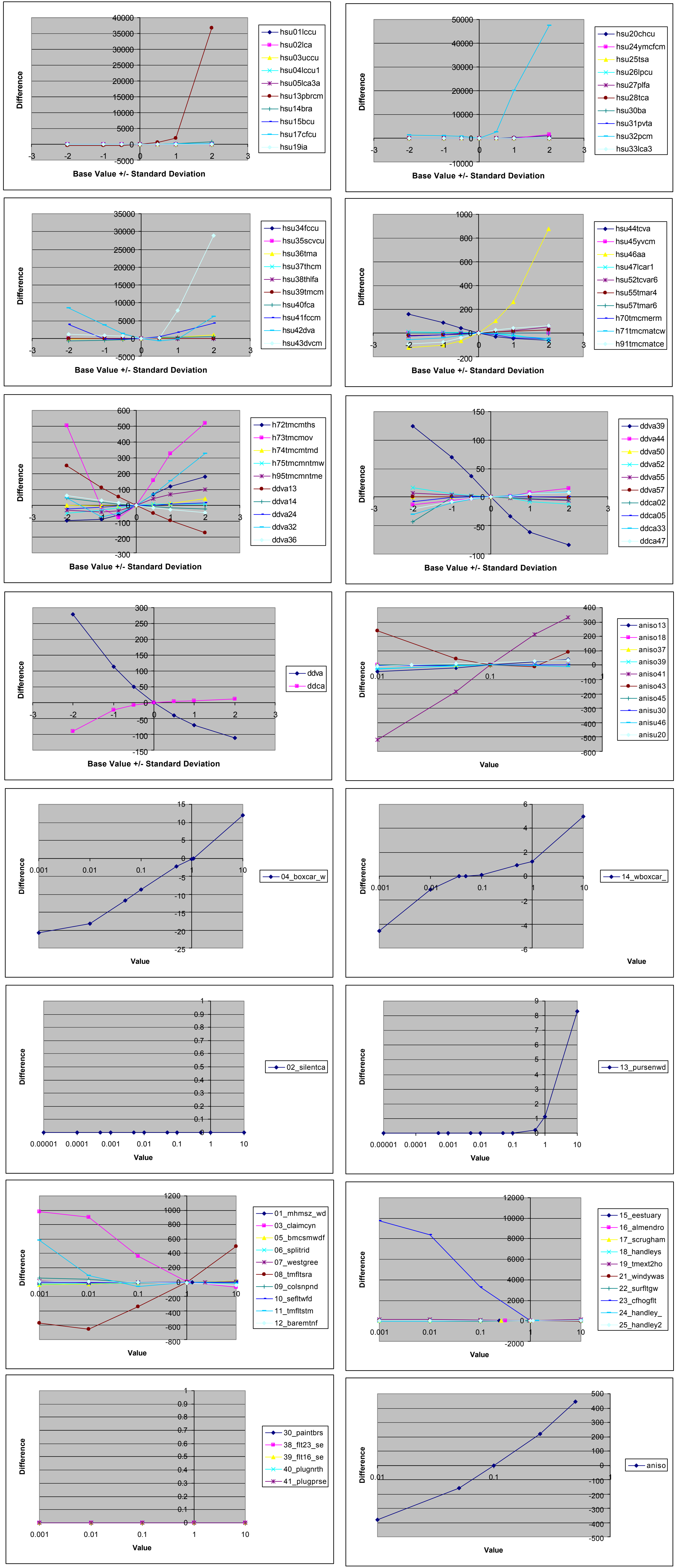

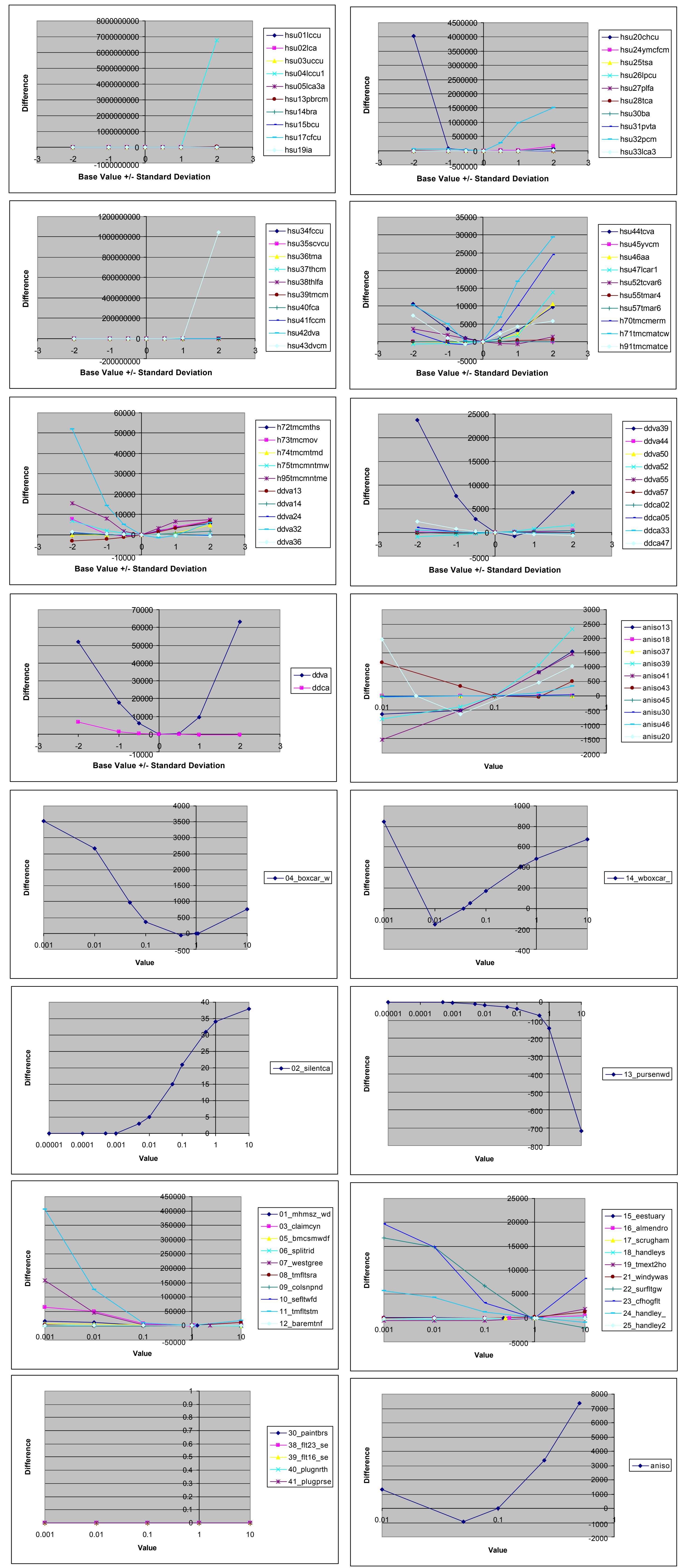
Plates 


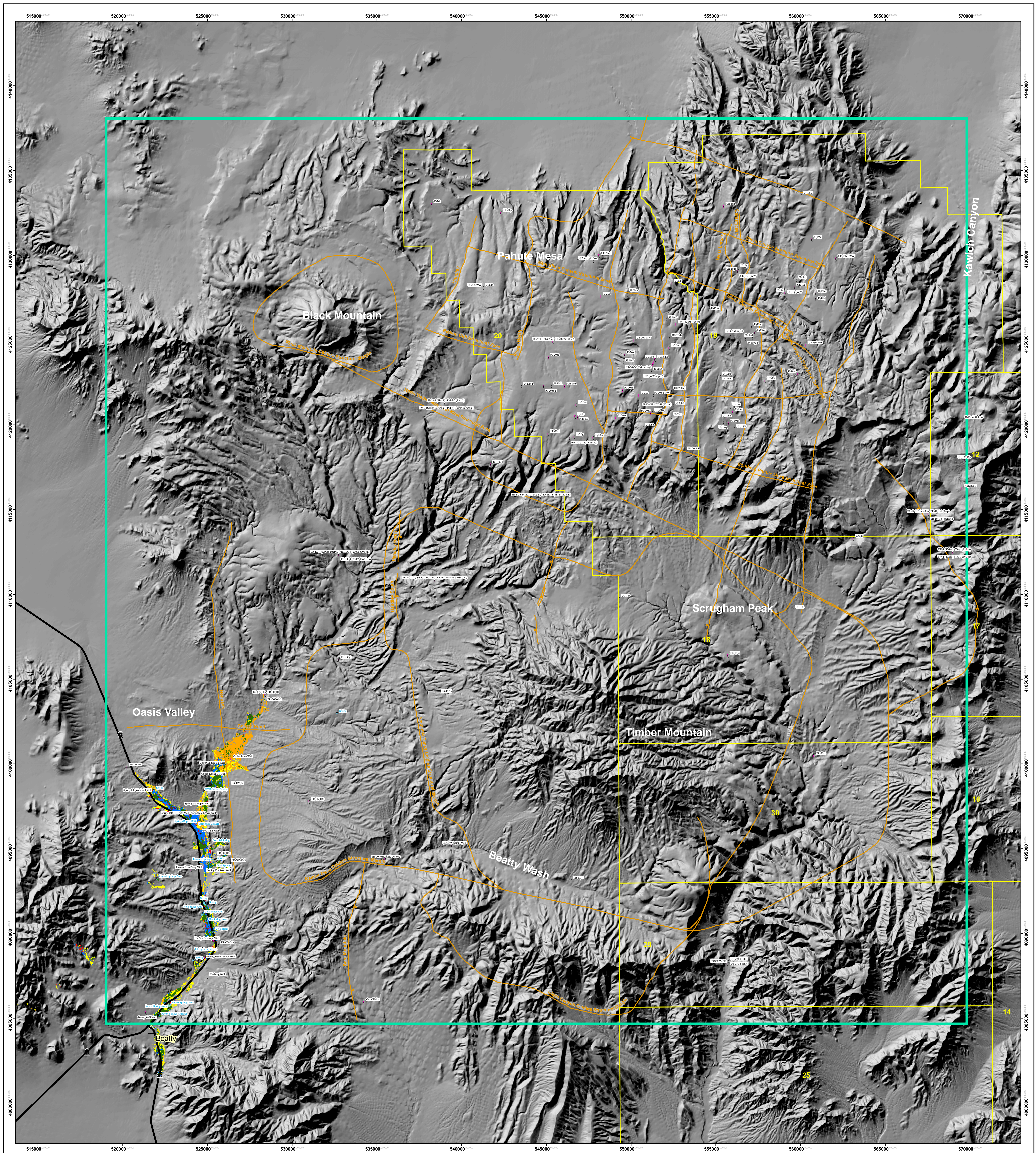

Plate 1 - Pahute Mesa Model Area Showing Topography, Selected Geographic Features,

EXPLANATION and Wells and Springs Used in Calibration of the Flow Model

Oasis Valley ET Unit (area in acres)

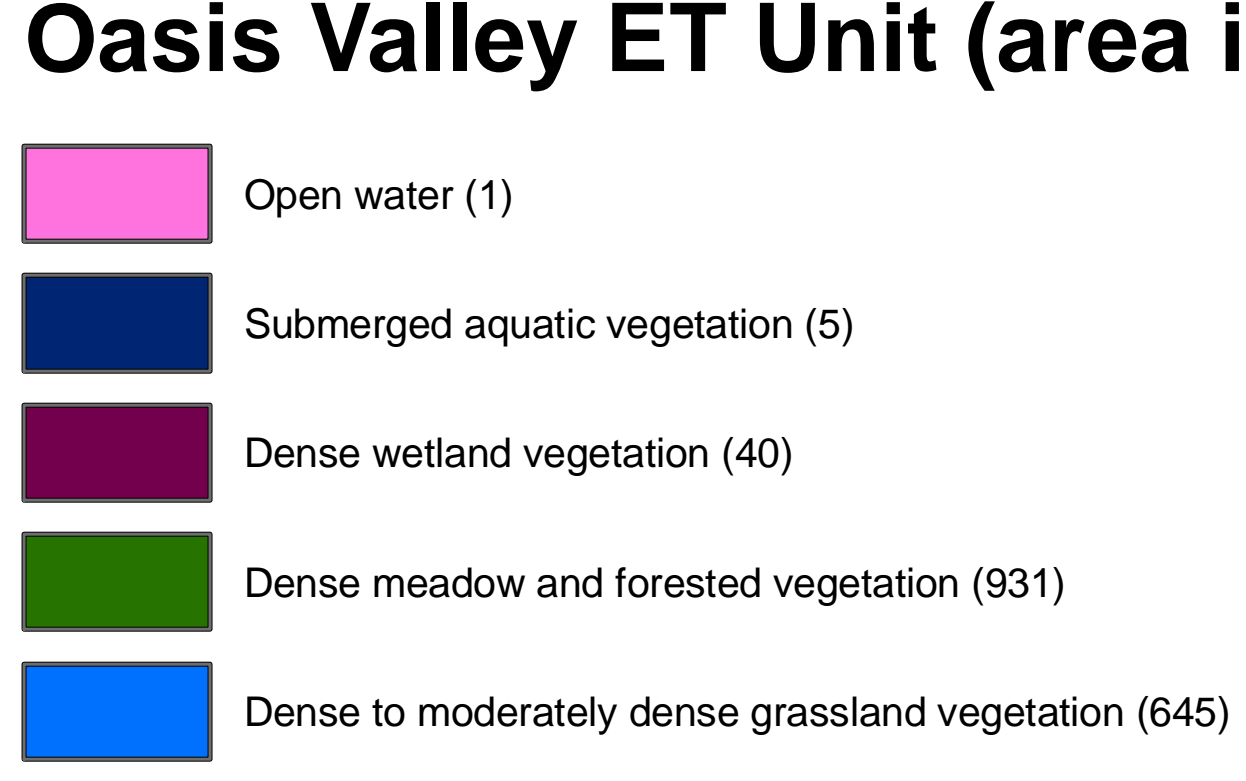

